Universidad Politécnica de Madrid

Escuela Técnica Superior de Arquitectura

ASPECTOS FORMALES Y CONSTRUCTIVOS EN LA OBRA DE GUILLEM SAGRERA: EL USO DE LAS PLANTILLAS

Tesis doctoral

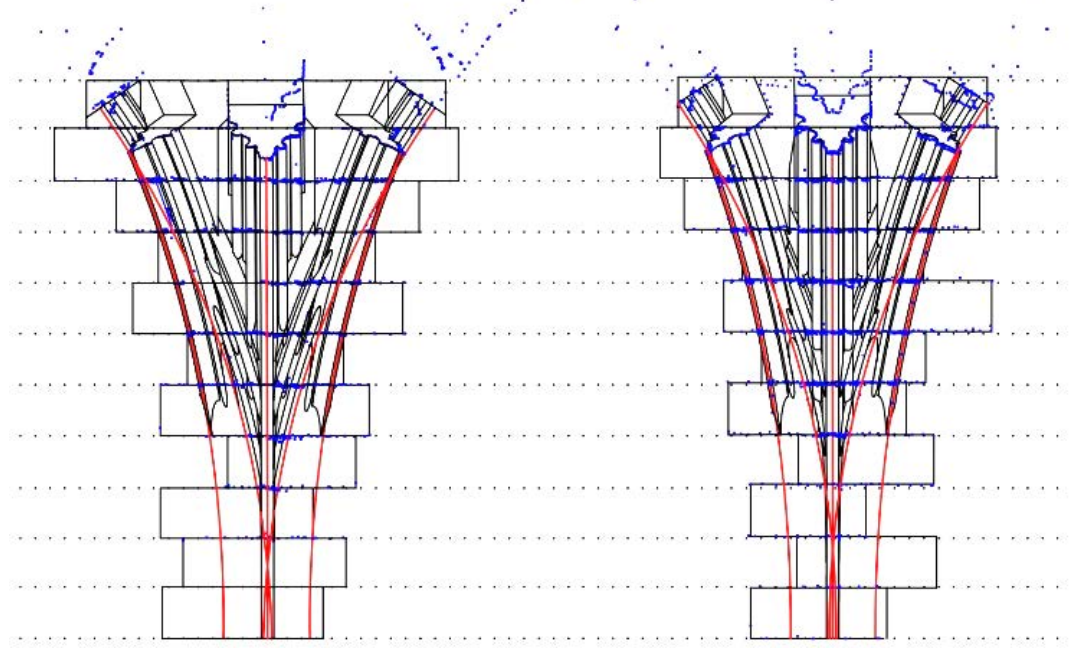

Carmen Pérez de los Ríos arquitecta 

Departamento de Construcción y Tecnología Arquitectónicas

Escuela Técnica Superior de Arquitectura de Madrid

ASPECTOS FORMALES Y CONSTRUCTIVOS EN LA OBRA DE GUILLEM SAGRERA: EL USO DE LAS PLANTILLAS

Tesis doctoral

Carmen Pérez de los Ríos

arquitecta

Director

Enrique Rabasa Díaz

Doctor arquitecto 

Tribunal nombrado por el Sr. Rector Magfco. de la Universidad Politécnica de Madrid, el día. de $20 \ldots$

Presidente:

Vocal

Vocal:

Vocal:

Secretario:

Suplente:

Suplente:

Realizado el acto de defensa y lectura de la Tesis el día de de $20 \ldots$ en la E.T.S.I. /Facultad.

Calificación

EL PRESIDENTE

LOS VOCALES

EL SECRETARIO 


Los caminos se hacen al andar y para ello son necesarios buenos compañeros de viaje que te apoyen, ayuden, guíen y faciliten visitas o mediciones. Y con los que, por supuesto, se pueda discutir acerca de las ideas que se van desarrollando, con la confianza de poderte recordar lo obstinado que puedes llegar a ser en ocasiones.

A Pedro Rabassa Sansalini le agradezco haber gestionado amablemente mi primera visita y toma de datos en la Lonja de Palma, así como al Gabinete de presidencia del Govern de les Illes Balears, especialmente Javier Fons y Catalina Comas. Francisco Cifuentes, quien también se encuentra realizando una investigación sobre la Lonja, me acompañó en esa visita compartiendo su entusiasmo por el edificio. Miguel Alonso Rodríguez me enseñó a medir con la estación total durante el desarrollo de este trabajo y me ayudó durante la toma de datos.

Agradezco a la Secretaria del Cabildo Catedral de Mallorca, especialmente Jeroni Segui Coll, haber gestionado mi visita a la Seu y la toma de datos en la Sala Capitular. Especialmente a Cati Mas Andreu haberme guiado por ella. Gracias a Santiago Huerta tuve acceso a las cubiertas.

La familia Caldentey, especialmente Sebastian padre y Sebastian hijo, me mostraron su cantera de piedra de Santanyí y me guiaron con pasión por ella, así como por su taller de cantería. Mi conocimiento del material se lo debo a ellos, así como el amor a esa piedra.

Jean Marc Huertas, jefe del servicio territorial de arquitectura y patrimonio de Pyrénées-Orientales, y Frack Velay facilitaron mi trabajo en la sala capitular de la catedral de San Juan el Nuevo en Perpinán. Laurent Barrenechea nos permitió visitar la sala con antelación y nos ayudó con los permisos, siempre dispuesto a ofrecernos su ayuda. Santiago Huerta y Paula Fuentes me salvaron la vida al prestarme una estación total para 
medir allí. Rosa Senent me facilitó imágenes de la sala antes de ser restaurada, fundamentales para el trabajo.

Agradezco al Servizio Patrimonio Artistico e Museale Comune di Napoli, especialmente a la dirigente Dott.ssa Silvana Dello Russo y Gian Carlo de Simone, habernos atendido tan amablemente en Castelnuovo. En especial, a los guardias de seguridad de la fortaleza habernos dejado entrar en lugares impensables idescubrimos una vis de Saint Gilles! Gracias por brindarme vuestra confianza. Agradezco también a mis compañeros Ana López Mozo y Miguel Alonso Rodríguez haberme facilitado su levantamiento de la Sala dei Baroni para unirlo al mío ahorrándome muchas horas de trabajo. También a Ana López y Santiago Huerta su ayuda con el análisis de la sección de la bóveda.

Dominique Vingtain, Conservateur en chef du Palais des Papes, y Julien Gallon me permitieron llevar a cabo el trabajo en la Sala de Teología del Palacio de los Papas en Aviñón.

Hélène Echaniz, Chargée de l'accueil des publics dans les Monuments et Musées en Narbona, nos facilitó a Rosa Senent y a mí llevar a cabo toma de datos en el claustro de la catedral.

El Ayuntamiento de Altura me facilitó la medición en la cartuja de Valdecristo y la Fundación Jaume $\|$ el Just en el refectorio del Real Monasterio de Santa María de la Valldigna. Agradezco también a las monjas clarisas del Real Monasterio de la Santísima Trinidad en Valencia haberme permitido quebrantar su tranquilidad y silencio para realizar la toma de datos del claustro. Especialmente a la madre Inmaculada, por su amabilidad y compañía. Y por un café con galletas que no olvidaré. Por supuesto, a Arturo Zaragozá Catalán, quien ha sido un apoyo fundamental durante estos años. Sin él el trabajo en estos ejemplos valencianos no hubiera existido. Él me los mostró, me ayudó con la gestión de las visitas y me acompañó durante las mediciones contagiándome de su entusiasmo por la arquitectura levantina. Ha sido un privilegio haber contado con su confianza y ayuda.

El cabildo de la catedral de Burgos me permitió medir la bóveda de la capilla del Condestable. Agradezco especialmente a mi compañero Tomás Gil que se encargara de todas las gestiones y se animara a venir conmigo a Burgos casi nevando para medir la bóveda. José Antonio Gárate, cara amiga al entrar a la catedral, gracias por tu amabilidad y por hacernos las cosas fáciles.

Francisco Pinto Puerto, quien siempre ha estado dispuesto a resolver cualquiera de mis dudas con respecto a la arquitectura sevillana, nos gestionó la posibilidad de medir la bóveda de la capilla de La Antigua y nos permitió ver los enjarjes desde la plataforma superior. 
Ginés Ampudia de la catedral de Palencia me permitió realizar un levantamiento topográfico de la bóveda de la capilla de la Inmaculada y Javier Salazar, de la iglesia de los Santos Justo y Pastor de Toledo, de la bóveda en la tumba de Juan Guas. Alfredo, el párroco de Santa María del Campo me posibilitó medir una bóveda de la iglesia, también el de Santa María la Real en Sasamón. No puedo olvidar la compañía y ayuda de Thomas Bremen -cantero, arquitecto y amigo- en la medición y toma de datos de las bóvedas.

Gracias al departamento de patrimonio de la catedral primada de Toledo pude tomar imágenes en la capilla de Álvaro de Luna, así como a la Fundación Casa Ducal de Medinaceli en la Casa de Pilatos de Sevilla.

El Patronato del consulado de la Lonja de la Seda de Valencia me posibilitó la medición de las bóvedas. Especialmente agradezco a mi compañero Pau Natividad Vivó haberse encargado de gestionar la visita y de parte de la toma de datos.

Estoy especialmente agradecida a la Universidad Politécnica de Madrid por haberme financiado este trabajo durante cuatro años, facilitándome realizar estancias en el extranjero y dándome la oportunidad de llevar a cabo labores docentes. También al proyecto del Ministerio de Ciencia e Innovación "Construcción en piedra de cantería en los ámbitos mediterráneo y atlántico. Análisis de ejemplos construidos" haber financiado los viajes para la medición de las bóvedas o la asistencia a congresos.

Agradezco el consejo, ayuda y palabras de ánimo de Licinia Aliberti, Begoña Alonso, María Aranda Alonso, Nicolas Burette, Fabienne Feraud, Paula Fuentes, Javier Gómez Martínez, Étienne Hamon, Javier Ibañez, Benjamín Ibarra, Federico Iborra, Virginia Jansen, Rafael Marín Sánchez, Jorge Portal Liaño, Juan Clemente Rodríguez, etc. También a Elena Paulino Montero haber compartido generosamente conmigo parte de su tesis antes de defenderla.

A todos los profesores que durante la carrera me hicieron amar la construcción. En especial a Santiago Huerta, que me contó por primera vez qué es esto de la Historia de la Construcción y lo hizo con tanta pasión y emoción que no he tenido más remedio que acabar escribiendo una tesis sobre ello. Y a José Carlos Palacios, quien me ayudó e impulsó a ir a mi primer congreso.

El Dr. -Ing David Wendland me brindó la posibilidad de realizar una estancia de tres meses en la TU Dresden, facilitándome la visita a edificios relevantes para mi investigación. 
A Norbert Nußbaum le debo mucho en los dos últimos años. Le agradezco haberme acogido en el Kunsthistorisches Institut de la Universität zu Köln en dos ocasiones, facilitándome entre otras cosas la visita a los talleres de cantería de la catedral de Colonia, de St. Viktor en Xanten y de St. Maria zur Wiese Soest. Le agradezco su tiempo, tener siempre tiempo para mí, para discutir aspectos de la tesis que me han permitido encajar ideas. Y su generosa ayuda y consejo. Agradezco a los miembros del instituto haberme tratado con tanto cariño y haber participado de los debates, en especial a Nicolás Menéndez González, Heike Lehmann y Julian Jachmann. Y a la Universität zu Köln, que siempre me ha hecho las cosas fáciles. Ha sido un honor trabajar en el despacho de al lado del profesor Binding.

Ich habe Herrn Nußbaum für alles zu danken, was er in den letzten zwei Jahren für mich getan hat. Er hat mich im Kunsthistorisches Institut der Universität zu Köln zweimal willkommen geheißen und mir die Möglichkeit eröffnet, die Kölner Dombauhütte sowie die Bauhütten in Xanten und Soest zu besuchen. Er hatte immer Zeit für mich und war immer bereit, meine Doktorarbeit zu diskutieren. Seine großzügige Hilfe und Rat waren sehr wichtig für mich. Ich danke ebenso Nicolás Menéndez González, Heike Lehmann und Julian Jachmann und allen anderen im Institut, die ich kennenlernen durfte. Sie alle sind immer sehr freundlich und liebevoll zu mir gewesen. Es war mir eine große Ehre, im Büro neben Herrn Prof. Binding zu arbeiten.

Agradezco al taller de cantería de la catedral de Colonia (Kölner DomBauhütte) haberme permitido la visita; así como al de St. Maria zur Wiese en Soest, especialmente al Dombaumeister Herr Prigl y al Steinmetz Stefan Stubenhofer; y al de St. Viktor en Xanten, especialmente al Dombaumeister Herr Schubert y al Steintechniker Herr Knapp.

A mis compañeros Ana López Mozo, Miguel Ángel Alonso Rodríguez, Alberto Sanjurjo Álvarez, Elena Pliego de Andrés, Rafael Marín Talaverano, José Calvo López y Pau Natividad Vivó les estoy agradecida por su inestimable ayuda, consejo y apoyo durante el trascurso de la investigación. Por muchos viajes y experiencias compartidas.

A Miguel Sobrino González y a César Cabeza les debo todo lo que sé sobre cantería. Pacientemente me han enseñado y me han guiado a lo largo de la investigación en lo referente a la talla de la piedra. Muchas páginas de esta tesis son también de ellos.

A mis alumnos del taller de cantería les agradezco la ilusión y el entusiasmo con que emprendieron la talla de cada una de las piezas. De vosotros he aprendido mucho: María Vaquero, Eva, Laura Cuellas, Alfonso, Alba, Nereida Fernández, Alba de Luis, Irene Casado, Soraya Moreno, Jerónimo Guerrrero, Ana Sánchez, Paloma Almajano, Helena 
Bueno, Eva García, Javi, Cristina Martínez, Laura Martín-Borregón, Gonzalo Sánchez, Alzbeta Bruhova, Andrea, Marisol Gallego, Carlos García, Ana, Inma Gallego, Beatriz Fernández, Miguel de la Ossa, Ignacio López, David García, Beatriz Madrigal, Sara Peñalver, Irene Redondo, Francisco Tapia, Nuria Casal, María Jesús Álvarez, Mercedes Laborda, Javier Feijoo, Daniel Rodriguez, María del Mar Ramos Mateos, Irene Álvarez-Sostres González, Raquel Serna de la Fuente, José Manuel Ormeño Cruz, Javier Ortiz Temprado, Pablo Vaquero Ramírez, Iván Cosgaya Noriega, Ana Bermejo González, Mirella García Martín, Rebeca Gómez-Gordo Villa, Javier Vázquez Renedo, Sara Martín Montes, Ester Corral Martínez, César Bedoya Donoso, Marta Galeano García, Ignacio Rejos Urbina, Cristina Román Díaz, Mónica García Koewandhono, Sara Gil Garcés, César Nohales Aragonés, José Adrián Rico Blanco, Begoña Coluerga Torreblanca, Paola Liza Hernández, Kevin Malca Vargas, Gonzalo López Hernández, Sara Cebrián García, Irene Jimeno Guadalix, Andrés Ávalos Robles, Julia Seewald Blohm, Mercedes Álvarez de Sotomayor Ortega, María de la Paz Vargas López, Paula de Cruz Bernal, Paula Sánchez García, J. Alberto Benitez Fornell, Rubén Rodríguez Ramos, Ana Cortina González, Victor Ingmo, María Moure Rosende, Carmen Ruf Equilios, Paloma Nistal González, Arturo Romo Pérez, Clara González Fernández, Ángel L. Sánchez Martín, Sonia Moral Rodríguez, Érika Sánchez Pascual, Clara Murillo Blasco, Linda Pierozzi, Carla Frieling, Vincent Weipert, Montse Cicuendez Maroto, Raúl Valencia Moreno, Miriam Rodríguez, Bea Riber López, Irene Alcocer Amores, Borja Ramírez Méndez, María Ballesteros Díaz, Patricia Cavestany García-Matres, Mónica Esteban González, Abel Fernández Villegas, Carmen González Bellón, Carlota Le Quinio de Corral, Gabriela Marco Martínez, David Ortega Moro, Omar Alonso Barroso, Ana M. Sánchez Sáez, Fabianna Ottavi, Etienne Gravisse, Vanesa Vera Kaminskas, Laura Corrales Pérez, Elia Legaz Acitores, Domitille Chaigne, Adrián Agudo Naranjo, Álvaro Bajo Fernández, Ernesto Martínez Rivera, Rafael Clemente Sánchez, Andrés Augugliaro González, Carlos de Arquer Fernández, Sara Petrelli, Mercedes Oliveira, Juan Miguel Labrador Martín, etc.

A Robert Bork le estoy especialmente agradecida por su ayuda con muchos de los trazados geométricos a los que me he enfrentado.

Enrique Rabasa Díaz, mi director de tesis, me presentó a Guillem Sagrera y compartió conmigo sus intereses. Muchas gracias por tu ayuda, aliento y paciencia durante estos cuatro años.

Rosa Senent empezó siendo mi compañera y acabó siendo mi amiga. Gracias por tantas cosas compartidas. Por tu ayuda desde el principio cuando estaba tan perdida y tu apoyo en este final de tesis tan agotador. También a Juanmi, por animarme siempre en este camino, por recorrerlo juntos. 
A Nico, por muchas horas góticas y por compartir conmigo importantes tonterías. Por cuidarme. iAndo a la espera de escribir cosas juntos!

A mi querido amigo Alberto Calderón González. Él sabe que sería imposible enumerar todo lo que le debe esta tesis, así como todo lo que yo le debo. Muchas de estas páginas también son de él. Gracias por estar siempre a mi lado, por haber leído cada una de las páginas, por tus correcciones, traducciones, apuntes y ayuda.

A Ramón Cuevas Ramírez, por muchos años compartidos, por ser mi apoyo durante mucho tiempo.

Agradezco especialmente el aliento y cariño de mi familia, de mi hermana Miriam y de Stefano, de mis padres -Lourdes y Faustino-, de Mercedes y Jose, y, en especial, de mis abuelos, quienes no entenderán -o hubieran entendido- mucho de lo que hago. Gracias a ellos he tenido la oportunidad de haber estudiado arquitectura y haber escrito una tesis.

Aparte de mi Lebensgefährte, Alexander Kobe ha sido mi guía en muchas partes de este trabajo y mi apoyo en los momentos de flaqueza. Es fantástico tener a un historiador del arte siempre a mi lado, pero es aún mejor tenerte a ti. 
A mis abuelos, por su ejemplo 
1. Definición de enjarje

1.1. Terminología 15

1.2. La reunión de los nervios en el arranque de la bóveda................... 16

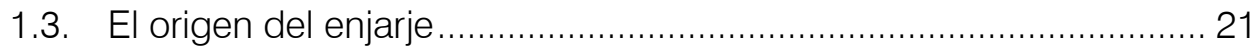

1.4. Clasificación de enjarjes. Una nueva definición................................. 22

1.4.1. Según el contacto de los nervios con el muro....................... 23

1.4.2. Según la junta de su última pieza con el nervio.................... 26

1.4.3. Según la relación entre los ejes de los nervios entre sí y con el muro

2. Tecnología

2.1. Diseño: el dibujo como herramienta de proyecto .........................47

2.1.1. El dibujo de arquitectura (a escala reducida) ..................... 48

2.1.2. Manuscritos y tratados medievales ..................................... 54

2.1.3. Dibujos a escala 1:1, las también llamadas monteas o dibujos constructivos......................................... 62

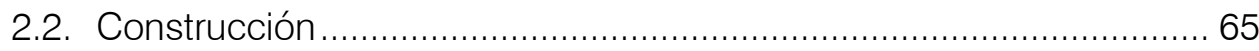

2.2.1. Evidencias arqueológicas y su relación con la montea ........66 66

2.2.2. Otras propuestas relativas al trazado................................ 75

2.2.3. La utilización de plantillas en enjarjes ................................. 78

2.2.4. La talla y el control del trabajo ......................................... 86

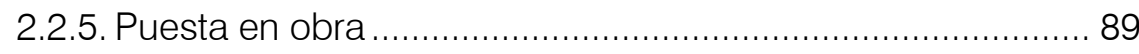

3. Proyecto

3.1. Dying mouldings, interpenetraciones, intersecciones y maclas ........ 93

3.1.1. Dying mouldings............................................................ 94

3.1.2. Intersecciones: molduras que desaparecen y aparecen ...... 104

3.1.3. Interpenetraciones y maclas .............................................. 111 
3.2. Análisis de algunos casos

3.2.1. Enjarjes parecidos con diseños diferentes: el caso

Valenciano

3.2.2. Variaciones sobre el trabajo con plantillas en uno de los primeros cruzamientos de molduras; la Sala de Teología del Palacio de los Papas en Aviñón

3.2.3. El enjarje como experimentación: tres diseños diferentes para una panda en el claustro de la catedral de Narbona 150

3.2.4. La bóveda traza el enjarje: la capilla del Condestable de la catedral de Burgos 153

4. Arqueología experimental

4.1. Experiencias de construcción de enjarjes de Enrique

Rabasa Díaz 179

4.2. Experiencias en el taller de cantería de la ETSAM 181

4.2.1. Enjarje similar a uno en el claustro de la catedral de Narbona

4.2.2. Enjarje de la Lonja de Palma de Mallorca ............................ 193

4.2.3. Enjarje de la capilla del Condestable ..................................202

4.2.4. Enjarje bajo la escalera de la Sala dei Baroni .......................212

4.2.5. Trabajo con plantillas deformadas y no deformadas............218

\section{Guillem Sagrera}

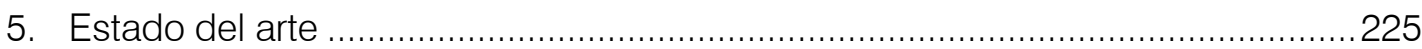

5.1. Primeros trabajos: de Mallorca al continente ...................................227

5.2. Sagrera en Gerona .................................................................... 230

5.3. Maestro mayor de la catedral de San Juan en

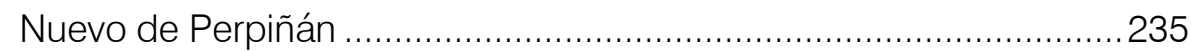

5.4. Mallorca: la catedral y la Lonja ....................................................237

La catedral de Palma ............................................................ 237

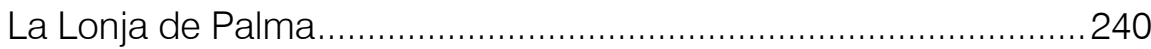

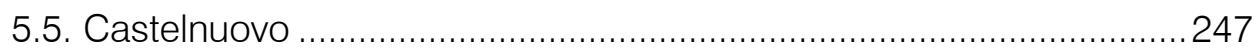

6. Análisis de la obra

6.1. La Sala Capitular de Perpiñán. El desorden ordenado....................251

6.2. La Lonja de Palma. Una idea única, una única idea ........................293

6.3. La gran sala de Castelnuovo. La caja de las sorpresas ....................337

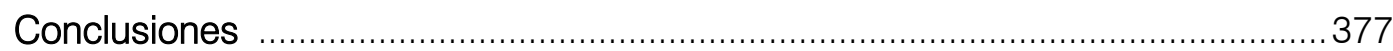

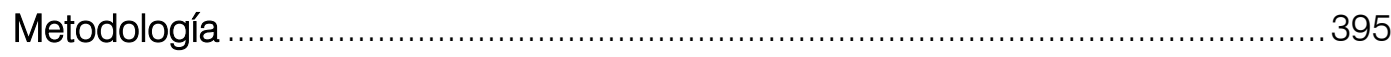

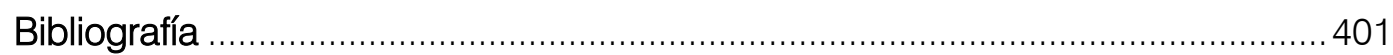

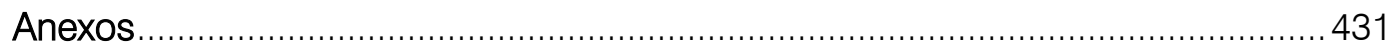





\section{INTRODUCCIÓN}

Los enjarjes, jarjas o jarjamentos conforman el comienzo de la bóveda de crucería, el lugar en el que todos los nervios nacen reunidos. Permiten la transición entre el muro y las dovelas que conforman nervios, resolviendo un encuentro de gran importancia constructiva y estructural. No son sillares, pero siguen siendo piezas de piedra de lechos horizontales -a diferencia de las dovelas de los nervios cuyos lechos son radiales- y en muchas ocasiones su tamaño y peso son más que considerables.

Los enjarjes se construyen a la vez que el muro y antes que el resto de la bóveda, por lo que se podría decir que son los encargados de portar su ADN: en ellos queda registrado el número de nervios que tendrá la bóveda, su curvatura, desde qué altura arrancará cada uno, su perfil, etc.

El objetivo de este trabajo se centra en estudio de los enjarjes en la obra de Guillem Sagrera abordando su dimensión tecnológica, constructiva y de diseño. Dos características los distinguen de otras soluciones y justifican su interés: los nervios surgen directamente del muro, sin la intermediación de capiteles, ménsulas o pilastras; y se diseñan con la intención de facilitar la aparición de intersecciones entre las molduras de sus perfiles, en algunos casos mediante el cruce de los ejes de los nervios.

Sagrera nos acerca a una innovación arquitectónica en la que el esfuerzo no se centra en realizar bóvedas con muchos nervios o con trazados en planta complejos, sino en la cuidada resolución de esta unión de nervios en la que se adivina el trabajo minucioso con las plantillas que controlan el trazado del contorno de los lechos de las piezas y la hábil mano de los canteros que son capaces de tallar intersecciones de gran complejidad. 
Guillem Sagrera es el primer arquitecto que convierte esta nueva forma de diseñar y construir enjarjes en el motivo diferenciador de su arquitectura, en su marca personal.

Pocas veces se encuentra una vida tan sobresaliente, apasionante y llena de nuevos retos como la suya. El maestro mallorquín que nació a finales del siglo XIV en el seno de una familia de canteros dedicada a la extracción de piedra en Santanyí llegó a convertirse en el arquitecto de cabecera del rey Alfonso el Magnánimo en Nápoles.

Su obra, como Gabriel Alomar sugiere, podría ser resumida en tres actos. El primero transcurre en el sur de Francia, donde aparece como maestro mayor de la catedral de Perpiñán. Parece ser que allí lleva a cabo la construcción de la sala capitular, un proyecto complejo en el que tiene que cubrir mediante bóvedas de crucería un espacio preexistente y con un contorno especialmente irregular.

El segundo acto se desarrolla en Mallorca, en el momento central de su vida, donde trabaja como maestro mayor de la Seu y construye la Lonja de Palma, un ambicioso proyecto de arquitectura civil que le permite llevar a cabo un diseño unitario, claro y controlado.

Finalmente acaba sus días en Nápoles, a cargo de la remodelación de la fortaleza del Castelnuovo bajo las órdenes del rey Alfonso V. En Italia cambia de escala y de temática, pues ha de combinar la arquitectura fortificada con la palatina sobre los restos de una fortaleza anterior. Allí, además, cubre el extraordinario espacio de la Sala dei Baroni mediante la bóveda con mayor luz del gótico. En resumen, en cada etapa se enfrenta a un proyecto único y de difícil comparación en un conjunto, dando respuesta en cada caso a muy diversos requerimientos.

A pesar de que estas divergencias puedan conducir a imaginar un conjunto arquitectónico inconexo, la obra del mallorquín es fácilmente reconocible. Debe su carácter unitario a la utilización sistemática de un modo determinado de resolver los arranques de los nervios de las bóvedas.

Para acercarnos a la comprensión de las estrategias de diseño que permiten el proyecto de estos enjarjes y los procedimientos técnicos y constructivos necesarios para su ejecución nos vimos en la necesidad de adentrarnos en la problemática de los enjarjes de la bóveda de crucería. De este modo, lo que empezó siendo una introducción para poder contextualizar la obra del mallorquín acabó convirtiéndose en la primera parte de la tesis, cuyo volumen prácticamente equipara a la segunda.

Decidimos no denominarla "estado del arte" porque estimamos que queda suficientemente clara la autoría de cada una de las contribuciones y porque, así como seguramente en otros temas la bibliografía es extensa y en muchos casos inabarcable, en el caso de los enjarjes es escasa, 
dispersa y, en ocasiones, repetitiva; lo que habría conducido a un texto deshilvanado y difícil de articular.

Esta primera parte, a su vez, se divide en cuatro. En ellas hemos incidido en las cuestiones que consideramos necesarias para poder llevar a cabo el estudio sobre Sagrera: ¿qué es un enjarje?, ¿por qué surgen y cuál es su función?, ¿son todos iguales?, ¿cómo se diseñan y se trazan?, ¿cómo se tallan y construyen?, etc.

Comienza, por tanto, la investigación abordando tanto la definición de enjarje desde el punto de vista terminológico como los motivos que propiciaron su aparición y las consecuencias derivadas de su uso. Así mismo proponemos una clasificación que pueda contener todas las particularidades advertidas en los ejemplos que hemos recopilado en el trascurso de este trabajo. Hay diferentes soluciones de enjarjes según sea la relación del contacto de los nervios con el soporte, según como se ejecute la junta inclinada de la última pieza o según como se relacionen los ejes de los nervios entre sí y con los soportes. La casuística es realmente variada.

A continuación nos centramos en su dimensión tecnológica. En primer lugar, en el dibujo como herramienta de proyecto y diseño de enjarjes, con tres vertientes diferenciadas: el dibujo de arquitectura (a escala reducida), los manuscritos y tratados medievales y los dibujos a escala 1:1, las también llamadas monteas o dibujos constructivos. Se han analizado los dibujos que han llegado hasta nosotros de enjarjes representados a escala reducida, que son pocos. También en manuscritos de la época, siendo reseñable el dibujo contenido en el manuscrito atribuido a Rodrigo Gil de Hontañón en Simón García o, a pesar de ser posterior, el del tratado de Alonso de Vandelvira. También mostramos la única montea original de un enjarje que conocemos, situada en una iglesia de Polonia.

En segundo lugar se ha prestado atención a la construcción de enjarjes, analizando las evidencias arqueológicas que han sido documentadas en piezas desmontadas y su relación con los dibujos de montea. De este modo podemos entender cómo se diseña y construye un enjarje y cuáles son los procedimientos necesarios en todo este proceso. Como consecuencia se ha abordado el papel del trabajo con plantillas en los lechos de las piezas para definir el contorno que ha de ser tallado y la pertinencia o no de su alargamiento, pues los cortes del perfil del nervio en las piezas del enjarje se realizan por planos horizontales y no radiales. También se ha incidido en el proceso y problemática de su talla, el control del trabajo y la puesta en obra de las piezas.

A continuación tratamos el proyecto o diseño de enjarjes. Se ha realizado un repaso de los primeros experimentos relativos al modo de relacionarse los nervios entre sí para ilustrar el contexto y origen de las soluciones 
realizadas por Guillem Sagrera. Mostraremos que ante ciertas dificultades fruto de la reunión de nervios los constructores fueron capaces de desarrollar nuevas soluciones mediante la experimentación con un sistema constructivo que conocían y manejaban con destreza.

La sintaxis gótica permite una libertad y flexibilidad que, desde etapas muy tempranas, favorece la aparición de pruebas y variaciones en diferentes localizaciones, asociadas, en un primer momento, a la necesidad de resolver un problema constructivo y que acaban por convertirse en motivos formales específicos de un modo de entender la modernidad del momento.

Y la estudiaremos especialmente en relación a la obra de Sagrera ya que supone una gran novedad en términos de lugar y tiempo, especialmente si la ponemos en relación con el gran desarrollo que tendrán este tipo de soluciones posteriormente en Centroeuropa. En España, encontrar enjarjes de este tipo es difícil, por no decir imposible. Destacan tres ejemplos en Valencia y sus alrededores que hemos analizado y en los que hemos podido comprobar como tres enjarjes que a primera vista son muy similares responden, sin embargo, a tres diseños diferentes.

Que Sagrera haga uso de estas soluciones tecnológicas con gran habilidad y maestría sin referencias claras ha despertado el interés de los historiadores, quienes no han dudado en ir en búsqueda de su origen. Entre otros, se apunta que Sagrera pudo viajar a Dijon, lo que explicaría la relación entre su supuesta obra escultórica y la de Claus Sluter. Joan Domenge i Mesquida ha localizado ejemplos de enjarjes anteriores a Sagrera y que comparten ciertas características con él en el sur de Francia; entre otros, en el Palacio de los Papas de Aviñón o en el claustro de la catedral de Narbona, los cuales hemos medido y analizado con motivo de esta investigación. En Aviñón, el comienzo de los enjarjes revela variaciones sobre el trabajo con plantillas en los lechos de las piezas en uno de los primeros ejemplos de cruzamientos de molduras, mientras que en Narbona somos testigos de una de las primeras pruebas de experimentación con enjarjes, con tres soluciones consecutivas y diferentes que no son fruto de irregularidades en planta.

Planteamos la búsqueda de referentes en el entorno de Sagrera, pues si se estudian con atención los enjarjes de la catedral de Palma, la de Gerona, Narbona, Rodez, etc., se puede atisbar este nuevo modo de proyectar ya en este ámbito del sur de Francia, Cataluña y Mallorca.

Hemos incluido la capilla del Condestable de la catedral de Burgos en el trabajo con motivo de ampliar los casos estudiados en relación al diseño de enjarjes, pues representan uno de los pocos ejemplos en España en los que los nervios se cruzan. Nos enfrentamos en este caso, además, a una bóveda con un trazado más complejo que los estudiados previamente en Valencia, Aviñón y Narbona, en los que al tratarse de bóvedas cuatripartitas sencillas el esfuerzo recaía en el diseño de enjarjes. En el caso burgalés pudimos comprobar la estrategia inversa, en la que la compleja 
configuración de la bóveda resulta en unos enjarjes de nervios que nacen separados y se cruzan en su recorrido.

La cuarta parte se ha dedicado a la arqueología experimental. Contiene el proceso de diseño, trazado y talla de los cuatro enjarjes que hemos llevado a cabo en el taller de cantería de la ETSAM, en los que hemos podido experimentar de manera práctica todos los aspectos teóricos presentados en los apartados anteriores. Estos ensayos nos han permitido contrastar hipótesis y baremar la dificultad de ciertos procedimientos o procesos, así como acercarnos realmente al elemento constructivo. El trabajo práctico nos ha enseñado a no fiarnos siempre de las hipótesis que se desarrollan modelando con el ordenador o dibujando; a valorar el pensar con las manos.

Con los principios establecidos nos dispusimos al análisis de los enjarjes de la obra de Guillem Sagrera. Para ello hemos llevado a cabo un levantamiento topográfico mediante estación total de cada uno de los edificios, realizando una toma de datos más densa y detallada para los arranques de las bóvedas. Se han propuesto hipótesis de trazado en planta de los recintos, de las direcciones de los nervios de las bóvedas, de sus curvaturas y de sus molduras a partir del análisis de los puntos tomados. Se ha construido un modelo virtual de cada uno de los enjarjes a partir de estas premisas con el objetivo de cotejarlas con los puntos tomados en sus lechos y juntas. De este modo, y junto con la comparación con fotografías, hemos podido comprobar que el resultado de las intersecciones de molduras de los nervios fruto del modelado se correspondía con la realidad.

Gracias a este proceder hemos evidenciado la utilización de plantillas alargadas o no alargadas en lechos de piezas, la correspondencia de ciertos restos de molduras con el trabajo con plantillas en los lechos, el numeroso uso de ajustes y cambios en la trayectoria de los nervios, la modificación del resultado directo del trabajo con plantillas en favor de otra solución o la utilización de sólidos capaces, entre otros.

Para poder afrontar el estudio de cada enjarje era necesario llevar a cabo un análisis general de cada uno de los edificios. En Perpiñán, donde las bóvedas cubren un espacio tan irregular, planteamos estrategias de trazado de los nervios en planta y grupos que comparten curvatura, con objeto de permitir controlar el conjunto y dar respuesta a la gran variedad de soluciones de enjarjes existentes en la sala, donde no hay dos iguales.

En la Lonja de Palma el esfuerzo se puso en encontrar un proceso sencillo de trazado para los nervios en planta en el que se pudiera definir el lugar imaginario dentro del muro en el que confluyen sus ejes. También se pretendía establecer una hipótesis para el diseño de bóvedas y enjarjes que se correspondiera con la claridad y sencillez del proyecto general del edificio. 
En la Sala dei Baroni se ha trabajado sobre su geometría general, planteando nuevas hipótesis sobre su definición. Del mismo modo, se ha abordado la concepción y construcción de elementos singulares en relación a la sala, como un nudo de nervios con intersecciones de molduras bajo su escalera; o una vis de Saint Gilles.

Tras el estudio de la obra de Sagrera y otros enjarjes relacionados con ella o anteriores, la presente investigación realiza aportaciones al estudio del cambio proyectual y constructivo llevado a cabo en los arranques de las bóvedas entre los siglos XIII y XV, cuando los nervios comienzan a surgir directamente de los soportes y se dan los primeros cruzamientos. Mostramos que ya no solamente se construyen enjarjes fruto directo de la geometría general de la bóveda, sino que se llevan a cabo cambios deliberados en relación a su resultado en los que se advierten decisiones proyectuales que, por supuesto, no serían viables sin las posibilidades que ofrece el trabajo con plantillas. 
INTRODUCTION

The solid blocks commonly known as tas-de-charge (in Spanish enjarjes, jarjas or jarjamentos) constitute the beginning of the ribbed vault - the place from which all the ribs spring together. They facilitate a transition between the wall and the rib voussoirs, and thus solve a junction of utmost constructive and structural importance. They are not simple wall ashlars but they are still horizontal courses of stone blocks, in contrast to the rib voussoirs whose beds radiate from a point; and their size and weight are often more than considerable.

The tas-de-charge are built simultaneously with the wall and well before the remainder of the vault - thus, they arguably carry its 'DNA', since they register how many ribs the vault will have as well as their curvature, their springing height or their profile.

This work is focused on the study of the tas-de-charge in the works of Guillem Sagrera, and will address their technological, constructive and design aspects. Two characteristics set these apart from other solutions and justify their relevance: these are that the ribs spring directly from the wall without the mediation of capitals, corbels or pilasters; and that they are deliberately designed to force the intersection of their mouldings, in some cases by crossing the rib axes.

Sagrera's work tells a story of architectural innovation - one where the effort is not centred on creating vaults with numerous ribs or a sophisticated 
ground plan, but on carefully solving the rib unions, which evidence a meticulous use of templates to control the tracing of the pieces' profiles as well as the skill of the stonemasons, able to carve highly complex intersections. Guillem Sagrera would be the first architect to turn this new way of designing and building tas-de-charge into the hallmark of his architecture - his personal device.

Only rarely does such an outstanding and enticing life as Sagrera's take place, and one so full of new challenges. The Majorcan master, born in the late $14^{\text {th }}$ century to a family of stonemasons in charge of extracting stone from the Santanyí quarries, would rise to become the court architect of King Alfonso the Magnanimous in Naples.

His work, as suggested by Gabriel Alomar, could be summarised in three acts. The first took place in southern France, where he is noted as Master Mason of Perpignan Cathedral. It seems that it was he that carried out the construction of its Chapter House, a complex project in which ribbed vaults were used to cover a pre-existing space with a particularly irregular contour.

The second act took place in Majorca and was the central point of his life there, he worked as Master Mason of the Cathedral (Seu) and built the Merchants' Exchange (Llotja de/s Mercaders) in Palma, an ambitious secular project in which he was able to conceive and execute a unified, clear and controlled design.

Finally, he would end his days in Naples, where he was in charge of remodelling the Castelnuovo fortress under the orders of King Alfonso V. In Italy he would change both his scale and his subject, for he would have to combine fortified and palatial architecture over the remains of a previous fortification. His extraordinary Sala dei Baroni would become the largestspanning vault ever built in the Gothic system. In summary, at each stage he faced a different, equally unique project. This makes a comparison of the whole difficult to undertake due to the variety of the requirements met in each case.

While these differences would lead us to imagine a disconnected architectural corpus, Sagrera's work is easy to recognise. And the key to its unity is precisely the systematic use of a specific solution for the springing of the vault ribs.

In order to gain a better insight into the design strategies behind his tas-decharge and the technical and constructive procedures required for their execution, we found ourselves facing the need to address the general subject of tas-de-charge in ribbed vaults. This, which began as an introduction meant as context for Sagrera's work, took on a life of its own and became the first half of the thesis, with a volume practically equal to that of the second.

We have chosen not to write this section as a 'state of the art' due to our considering that the authorship of each contribution is sufficiently clear and that, while in other fields bibliographies can be extensive or even unfathomable, for the subject of tas-de-charge it is sparse, fragmentary and, in some cases, repetitive; and this would have led to a disconnected, disorganised text. 
This first half of the thesis is itself divided into four parts. In these we have emphasised the topics that we consider relevant to the study of Sagrera's work: what a tas-de-charge is, why they appeared and with what function, whether there are different types, their design and tracing or their carving and construction, among others.

Thus, our research will begin by addressing the definition of tas-de-charge as a word and by analysing the reasons behind their appearance and the consequences derived from their use. Additionally, constituting a new definition of tas-de-charge, we will propose a classification encompassing all the peculiarities found in the examples observed along our research. There are different types of tas-de-charge according to the encounter between the ribs and the supporting structure, to the execution of the tapered beds in the last course or to the relationship of the rib axes with each other and with the supporting structure. The variety of cases is noteworthy.

We will then discuss their technological dimension. This will first touch on drawing as a tool for tas-de-charge design, including three separate aspects: architectural (reduced scale) drawing, medieval manuscripts and treatises and full-scale construction drawings (monteas). We have also analysed the extant original scale drawings of tas-de-charge, which constitute a very small corpus. These include manuscripts, among which the drawing contained in the manuscript attributed to Rodrigo Gil de Hontañón in Simon García's text is of particular note, as is, although later, that in Alonso de Vandelvira's treatise. We will also show the only original full-scale drawing of a tas-de-charge known so far, located in a church in Poland.

Then, we will address the actual construction of the tas-de-charge, analysing the archaeological evidence gathered from disassembled elements and its relationship to original full-scale drawings. We will thus be able to understand how tas-de-charge were designed and constructed, and which procedures would be necessary for this. Consequently, the role of templates in defining the contour to be carved will be discussed, as will the pertinence, or lack thereof, of their deformation due to the mouldings in the tas-de-charge being cut horizontally - and thus obliquely - rather than radially. We will also look at the process and issues of carving, work control and the on-site placing of the pieces.

The next area to be addressed will be tas-de-charge design. An overview of the first experiments with rib relationships will illustrate the context and origin of Guillem Sagrera's solutions. We will show how, faced with difficulties arising from the convergence of ribs into the tas-de-charge, builders were able to develop new solutions by experimenting with a construction system that they were already familiar with and could control easily.

The language of Gothic architecture allows for a degree of freedom and flexibility that, from a very early stage, favoured experimentation and the appearance of variations in multiple locations. These, initially associated with the need to solve constructive issues, would ultimately become formal motifs inherent to the understanding of modernity in their time. 
This we will particularly discuss in relationship to Sagrera's work, since it was highly innovative for both his time and his place, and especially in light of the acceptance that this kind of solutions would later gain in Central Europe. In Spain it is all but impossible to find tas-de-charge of this kind. Three cases in the region around Valencia stand out, in which we have discovered that three apparently very similar solutions actually arise from very different designs.

Sagrera's great skill and mastery in executing these technological solutions without clear references has drawn the interest of historians, who have quickly sought to find their origins in the 'dark years' in which his whereabouts are not known. Some suggest that he might have reached Dijon, which would explain the relationship between his purported sculpture works and those of Claus Sluter. Joan Domenge I Mesquida has found cases of tas-de-charge in Southern France which predate Sagrera and share some characteristics with his work. These include the Papal Palace (Palais des Papes) in Avignon or the cloister of Narbonne Cathedral, which we have measured and analysed as part of our research. In Avignon, the beginning of the tas-de-charge reveals variations in the work with templates on the stone beds and shows one of the first cases of crossing mouldings, while in Narbonne we have witnessed one of the first instances of experimentation with the tas-de-charge in three consecutive, different solutions which do not arise from plan irregularities.

We set out to find references in Sagrera's environment - a careful study of the tas-de-charge in Palma and Gerona Cathedrals, Narbonne or Rodez shows glimpses of this new approach to design already appearing in Southern France, Catalonia or Majorca.

We have also included the Constable's Chapel (Capilla del Condestable) in Burgos Cathedral in order to broaden the scope of the cases studied, for it is one of the very few Spanish cases of crossing ribs. What is more, in this case the vault design is rather more complex than those already studied in Valencia, Avignon and Narbonne which, being simple quadripartite vaults, could concentrate all of the design effort in tas-de-charge design only. In the Burgos case we found the opposite strategy - the complex vault configuration is what led to a tas-de-charge in which the ribs spring separately and cross each other afterwards.

The fourth part we have devoted to experimental archaeology. It comprises the design, tracing and carving processes for the four tas-de-charge executed at the ETSAM Stonecutting Workshop, in which we have tested experimentally the theories set forth in the previous chapters. These tests have allowed us to contrast hypotheses, assess the difficulty of certain procedures or processes and understand the built element as a real entity. The practical work has taught us not to always trust the hypotheses proposed through computer modelling or drawing - and to recognise the importance of coordinating the hands and the mind.

Once we had established the principles, we set out to analyse the tas-decharge in Sagrera's work. To do this, we carried out a topographic measurement of each of the buildings using a total station theodolite (TST), gathering a denser, more detailed set of data for the vault springers. We have proposed ground plan tracing hypotheses for the spaces as well as 
for the ribs' axes, curvatures and mouldings from an analysis of the measured points. From these premises, a virtual model of each of the tasde-charge was drawn in order to contrast them with the points measured for their beds and joints. Thus, and with the additional aid of photographic evidence, we were able to confirm that the rib moulding intersections obtained in our modelling matched the real measurements.

With this strategy we have confirmed whether deformed or non-deformed templates were used for the tracing on stone beds, the correspondence of moulding remainders with the outcome of template work, the frequent use of adjustments and rib trajectory changes, the substitution of a different solution for the actual result of template work or the use of uncarved containing volumes, among others.

For the study of each tas-de-charge, a general analysis of the buildings was necessary. In Perpignan, where the vaults cover a very irregular space, we have proposed strategies for tracing the ground plan of the ribs and established groupings of ribs with common curvatures in order to be able to understand the ensemble and shed some light on the numerous tas-decharge present in the room, all of which are different from each other.

In the Palma Merchants' Exchange our efforts centred on finding a simple tracing process for the ground plan of the ribs, trying to define the imaginary point inside the wall in which their axes converge. We also sought to propose a hypothesis for the design of the vaults and the tas-de-charge in accordance with the clarity and simplicity of the building's general project.

For the Sala dei Baroni, the general geometry has been addressed and new hypotheses for its definition have been proposed. The inception and construction of singular elements related to the room, such as a rib crossing with moulding intersections under its staircase or a vis de Saint Gilles, have also been discussed.

After studying Sagrera's work and contrasting it with other related or previous tas-de-charge, our research will seek to make a contribution to the study of the shift in the design and construction of vault springers that took place between the $13^{\text {th }}$ and $14^{\text {th }}$ centuries, when ribs began to spring directly from their support and moulding crossings began to appear. We will show that, from then on, tas-de-charge would not only depend on the general vault geometry - deliberate modifications would be carried out in order to achieve the desired result. This reveals design decisions that would have been unworkable if not for the effective use of template strategies. 

ENJARJES GÓTICOS Y EL USO DE PLANTILLAS 



\section{DEFINICIÓN DE ENJARJE}

\subsection{Terminología}

Los investigadores españoles de la historia de la construcción, arquitectos e historiadores, hacen uso de diversos términos para referirse al arranque de los nervios en una bóveda. Es frecuente encontrar la palabra jarja, que aparece como xarxa en el Libro de las traças y cortes de piedra de Alonso de Vandelvira (1575-1580); ${ }^{1}$ así como el término jarjamento que se utiliza en el texto atribuido a Rodrigo Gil en Simón García. ${ }^{2}$ Sin embargo ambos no aparecen en el Diccionario de la lengua española. Allí, lo que se define en segunda acepción como enlace de varios nervios de una bóveda en el punto de arranque, es la palabra enjarje. ${ }^{3}$

Enjarje es un término que evoluciona del árabe clásico šarğ-colocación de ladrillos- al árabe hispano *iššarğ. Su primera acepción, curiosamente, nos remite a la palabra adarajas -también de raíz árabe- que alude a cada uno de los dentellones que se forman en la interrupción lateral de un muro para su trabazón al proseguirlo. ${ }^{4}$ Enjarje será el término principalmente utilizado durante la presente investigación, con la intención de precisarlo y clarificarlo para el caso de las bóvedas de crucería.

Quizás la palabra más utilizada para referirse a los enjarjes en la literatura de fuera de nuestras fronteras proviene del francés, tas-de-charge, y ha sido utilizada recurrentemente no sólo en los textos escritos en esa lengua, sino también en inglés, alemán o castellano. Robert Willis dice que el término parece haber sido utilizado por primera vez por Philibert de

\footnotetext{
${ }^{1}$ Alonso de Vandelvira, Libro de las traças y cortes de piedra, (1575-1580), fol. 94v: "E declarado hasta aquí las monteas de las capillas romanas de todas suertes lo más desmenuçadamente qu'e podido [...], y, agora, declarar de la manera que se an de traçar las xarxas, porque son necesarias de saber para todas suertes de capillas, así romanas como modernas."
}

2 Simón García, Compendio de architectura y simetría de los templos conforme a la medida del cuerpo humano, (Biblioteca Nacional de Madrid, 1681), fol. 23 v- fol. 24r. Accesible en Biblioteca Digital Hispánica: www.bne.es: "En las claves se an de entender los miembros que sustentan y los que son sustentados. Porque los que son sustentados se an de Restar de los que sustentan conoçese en que los que sustentan, naçen de los jarjamentos, Y los que son sustentados naszen de las claues".

${ }^{3}$ Real Academia Española, Diccionario de la lengua española (23a ed.), (2014), Consultado el 14 de abril de 2015 en http://www.rae.es. "Enjarje: (del ár. hisp. *iššarğ, y este del ár. clás. šarğ, colocación [de ladrillos]). 1. m. adarajas. 2. m. Enlace de varios nervios de una bóveda en el punto de arranque."

${ }^{4}$ Real Academia Española, s.v. "Adaraja: (del ár. hisp. addaráğa, y este del ár. clás. darağah).1. f. Constr. Cada uno de los dentellones que se forman en la interrupción lateral de un muro para su trabazón al proseguirlo. U. m. en pl."

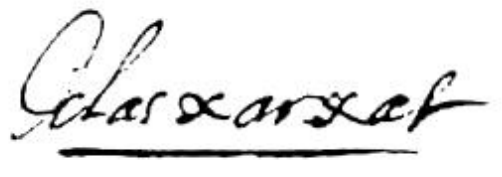

Fig. 1

"De las jarjas" (Vandelvira, 1575-1580, fol. 95r).

\section{larja mentos,}

Fig. 2

"Jarjamentos" (García, 1681, fol. 24v). 


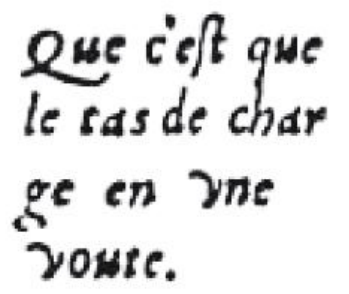

Fig. 3

"Que c'est que le tas de charge en une voute" (Philibert de L'Orme, 1567, fol 107r).

ON THE CONSTRUCTION or THE

VAULTS OF THE MIDDLE AGES

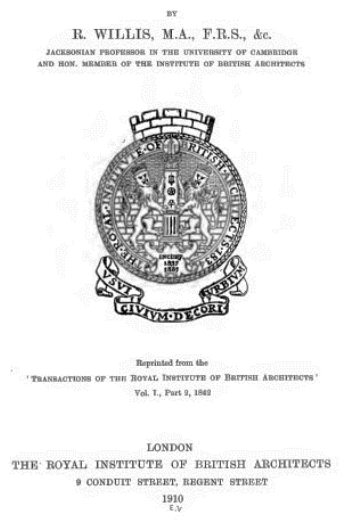

Fig. 4

Portada "On the construction of the vaults of the Middle Ages" (Willis, [1842] 1910).
$L^{\prime}$ Orme, ${ }^{5}$ quien señala que son las primeras piedras en las que se localiza el nacimiento de los diversos nervios. ${ }^{6}$ En inglés, Willis se refiere al enjarje también como block of masonry o solid block. ${ }^{7}$

Los alemanes Nußbaum y Lepsky en su estudio sobre la construcción de bóveda gótica definen en un glosario la palabra tas-de-charge como la construcción desarrollada por capas en la zona del arranque. ${ }^{8}$ A continuación nos remiten al término alemán Gewölbeanfänger, que aparece junto con Gewölbefuß; dícese, la parte inferior de la bóveda en la que, partiendo del arranque, los nervios se reúnen. Koepf y Binding en Bildwörterbuch también siguen la misma terminología. ${ }^{9}$

\subsection{La reunión de los nervios en el arranque de la bóveda}

En el artículo On the construction of the vaults of the Middle Ages, Robert Willis estudió la bóveda nervada medieval a través del análisis de edificios que había tenido la oportunidad de medir desde andamios o había podido observar con detenimiento y minuciosidad. Su intención era la de mostrar señales en las propias piedras o elementos constructivos que fuesen capaces de conformar una base objetiva sobre la que poder elaborar y desarrollar una investigación sobre la tecnología de la bóveda medieval. ${ }^{10}$

Al examinar los ejemplos pretendía dilucidar qué métodos y procedimientos geométricos fueron los utilizados en aquella época y cómo había ido evolucionando la necesidad de los mismos. Para él era imprescindible entender la construcción de cada elemento arquitectónico, pues de ella dependían tanto su forma como sus proporciones:

[...] unless we thoroughly understand these constructions, and the methods and resources which governed and limited

\footnotetext{
${ }^{5}$ Robert Willis, "On the construction of the vaults of the Middle Ages", Transactions of the Institute of British Architects, vol.1 (London: RIBA, [1842] 1910): 5, nota *.

${ }^{6}$ Philibert de L'Orme, Le premier tome de l'architecture, (Paris: Féderic More. Facsimil en París: Léonce Laget, 1988, y 1648 edición en Brusellas: Pierre Mardaga, 1981 [1567]), fol 107r. En una nota en el margen aparece la palabra tas-de-charge en una frase: "Que c'est que le tas de charge en une voute", acompañada por la explicación: "Ce sont les premières pierres que on voit sur les angles, et montrent le commencement et la naissance des branches, des ogives, tiercerons, formerets et arcs doubleaux."

${ }^{7}$ Robert Willis, "On the construction of the vaults of the Middle Ages", 5-7.

${ }^{8}$ Norbert Nußbaum y Sabine Lepsky, Das gotische Gewölbe. Eine Geschichte seiner Form und Konstruction, (Darmstadt: Wissenschaftliche Buchgesellschaft, 1999), 388: "Als mehrlagige Kragsteinkonstruktion ausgebildeter $\rightarrow$ Gewölbeanfänger; jede Lage besteht aus einem Werkstein. Die oberste Schicht hat zur Aufnahme des ersten Bogensteines ein schräges Oberlager." Es decir, cada capa se compone de una pieza, teniendo la última una superficie inclinada para recibir la dovela.

9 Hans Koepf y Günther Binding, Bildwörterbuch der Architektur, (Stuttgart: Alfred Kröner Verlag, 1999), 213.

10 Willis, "On the construction of the vaults of the Middle Ages".
} 
them, we shall never succeed in obtaining the master key to their principles, $[\ldots]^{11}$

Tras la introducción, Willis nos presenta la primera sección, titulada On the general construction of the vaults, donde tras dos breves párrafos en los que define de manera escueta qué es una bóveda nervada, nos sumerge en el tema que para él parece ser el primordial: la reunión de los nervios en los arranques, es decir, el enjarje. En este capítulo, que consta de siete páginas, explica qué es un enjarje, cuál es su origen, cómo se traza y ejecuta, etc., siempre presentando ejemplos medidos; cuidadosamente analizados y representados. ${ }^{12}$

Willis es el primero que trabaja sobre este tema, y su labor es encomiable. Su texto es sencillo de leer, didáctico y ante todo, brillante. Para todo el que se interese por la construcción de la bóveda nervada es una lectura indispensable donde también trata temas como la talla de claves, la geometría de las bóvedas o de manera monográfica las inglesas bóvedas de abanico. En cuanto a los enjarjes, poco han añadido tras de él los escasos investigadores que se han interesado sobre el tema, precisando quizás algunos aspectos o desarrollando alguna de sus ideas.

Los nervios de una bóveda nervada no presentan dificultad alguna en su trazado y en su talla. ${ }^{13}$ Se define la curvatura de cada uno de ellos en un dibujo a escala real y, con la moldura del plano que resulta de su corte radial que permite apoyar una en otra ${ }^{14}$, es decir, la plantilla que se extruye siguiendo la curvatura anteriormente definida, se tallan cada una de las piezas. ${ }^{15}$ Las dificultades aparecen en los puntos en los que estos nervios se encuentran, es decir, en las claves y en los enjarjes.

\footnotetext{
11 Willis, "On the construction of the vaults of the Middle Ages", 2.

12 Willis, "On the construction of the vaults of the Middle Ages", 2-9.

${ }^{13}$ Nos referimos a nervios con una única curvatura, pues el trazado y talla de los nervios de doble curvatura es significativamente más complejo. Sobre el tema ver: Thomas Bauer y Jörg Lauterbach, Die Schlingrippen der Gewölbe. Erasmuskapelle Berlin, Rotbergkapelle Basler Münster, Landhauskapelle Wien, Eleemosynariuskapelle Banska Bystrica, Ratssaal Bunzlau / Boleslawiec, Rathaus Löwenberg / Lwowek Slaski, (edición de los autores, 2011). Puede consultarse en www.schlingrippe.de; David Wendland, "Arches and Spirals - The Geometrical Concept of the Curvilinear Rib Vault in the Albrechtsburg at Meissen and Some Considerations on the Construction of Late Gothic Vaults with Double-Curved Ribs", Nuts \& Bolts of Construction History: Culture, Technology and Society, (Paris: Picard, 2012): 351357; David Wendland et al., "The Vault with Curvilinear Ribs in the "Hall of Arms" in the Albrechtsburg Meissen: Studies on the Concept, Design and Construction of a Complex Late Gothic Rib Vault", Proceedings of the First Conference of the Construction History Society, (Cambridge, 2014): 459-468.

${ }^{14}$ face moulds of the voussoir en: Willis, "On the construction of the vaults of the Middle Ages", 8

15 Utilizaremos durante toda la investigación el término extruir, utilizado en los programas de CAD para referirse a los polígonos que, siguiendo la dirección perpendicular a la tangente de la curva sobre la que se deslizan, conforman superficies. Pensamos que el mecanismo de extrusión ilustra de manera rápida y sencilla la conformación de las nervaduras. Es un
}

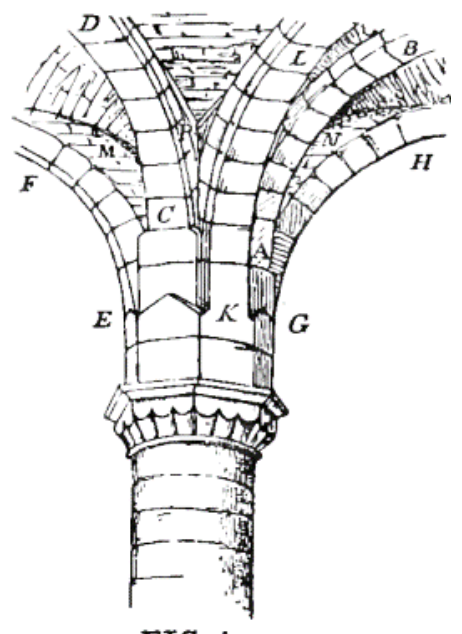

FIG.1.

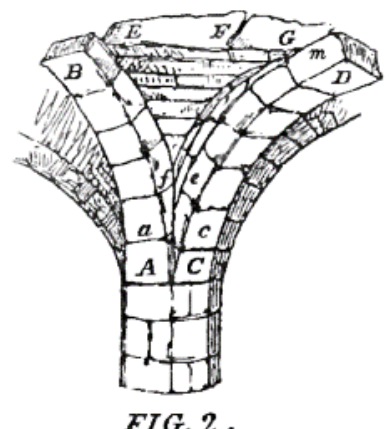

Fig. 5

Willis, [1842] 1910, 14. 


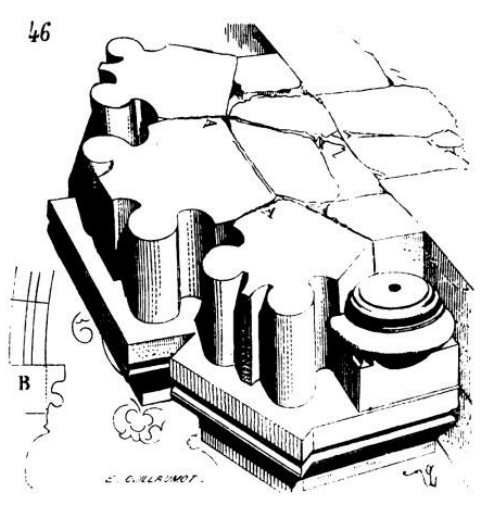

Fig. 6 Viollet-le-Duc, 1979, vol. 4: 86, fig. 46.

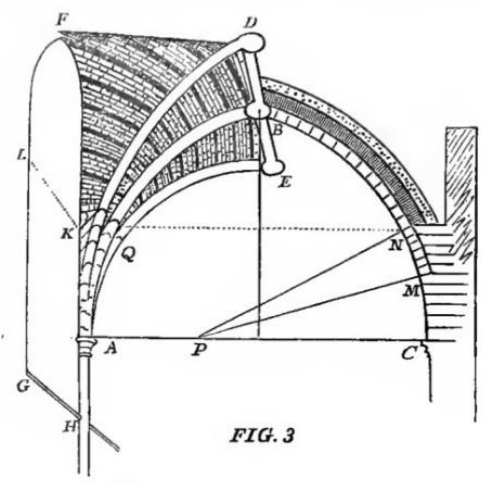

Fig. 7

Willis, [1842] 1910, 15.
En las primeras bóvedas nervadas las soluciones son, en cierto modo, ingenuas y fruto de la utilización del sistema de manera directa, es decir, los comienzos se conforman a partir de una serie de dovelas independientes. El problema era reunir una serie de nervios en un único lugar y eso mismo es lo que construían. Poco después, como explican Willis y Viollet-le-Duc, la solución constructiva fue evolucionando. ${ }^{16}$

Robert Willis ilustró la primera etapa de estas soluciones, en la que los nervios nacen separados. Cada nervio sale del pilar-del capitel, del ábaco, etc.- $\sin$ formar piezas solidarias con los demás. Dice que en la catedral de Peterborough se encuentran excelentes ejemplos de este sistema en los que incluso es necesario hacer uso de la mampostería para realizar ajustes entre diferentes nervios, o entre nervios y plementería debido al difícil control de las alturas. En la Fig. 5 (1 en Willis) se puede ver cómo los nervios ojivos salen a la misma altura mientras los perpiaños salen a diferentes cotas motivando la necesidad de hacer uso de unas superficies de mampostería verticales, que él designa con $\mathrm{M}$ en la imagen, tras el extradós de los nervios permitiendo la transición entre ellos. En la Fig. 5 (2 en Willis) se observa, igualmente, la dificultad de la reunión de los trasdoses de las dovelas en su encuentro provocando difíciles ajustes en los que parte de la piedra deberá ser eliminada para garantizar la reunión de las piezas.

Viollet-le-Duc muestra un dibujo al respecto en el que cada dovela es independiente y se ha tenido que descantillar para poder ajustarse con su correlativa en el arranque. Si el salmer del que parte no es lo suficientemente grande como para poder garantizar que todas las dovelas tengan donde apoyarse de manera estable, esta solución acarrea muchos problemas.

Parece ser que esta etapa no se extiende durante un gran periodo de tiempo y en seguida se produce un crucial avance en la construcción que, según Willis, una vez introducido, permanece con muy pocos cambios hasta los últimos periodos de construcción de bóvedas góticas: la aparición del enjarje. ${ }^{17}$

El enjarje es el comienzo de la bóveda, en el que las piezas tienen juntas horizontales y traban con el muro formando también parte de él. Willis señala que se produce un cambio a media altura de la bóveda, ilustrado en

término también utilizado en relación con la producción de ladrillos. Sin embargo en el diccionario de la Real Academia Española no aparece el término extruir, sino extrudir, s.v. "Extrudir:(del lat. extrudĕre).1. tr. Tecnol. Dar forma a una masa metálica, plástica, etc., haciéndola salir por una abertura especialmente dispuesta."

${ }^{16}$ Willis, "On the construction of the vaults of the Middle Ages": 3-5. Eugène Viollet-le-Duc, Dictionnaire raisonné de l'architecture française du XIe au XVle siècle, vol 9, (París: B. Bance, 1979), 7-12.

${ }^{17}$ Willis, "On the construction of the vaults of the Middle Ages", 4: "[...] it is remarkable that this new construction once introduced remains with very slight change to the very latest period of rib vaulting." 
la Fig. 7 (3 En Willis). La primera parte de la bóveda se conforma a base de una construcción maciza (AKQ) y la segunda de dovelas y plementería ligera. En el primer tramo, hay que diferenciar entre la zona del enjarje $(\mathrm{CM})$, en el que cada junta horizontal está compuesta normalmente por un único sillar y los niveles de sus lechos horizontales cortan oblicuamente a las molduras frontales; y su continuación hasta media altura (MN), donde las dovelas situadas a partir de la última junta inclinada del enjarje se trasdosan de mampostería para ser conectadas con el muro. Señala que esta parte se hace visible entre los nervios, con un aspecto similar al de la plementería ligera que encontramos a continuación.

El análisis de Willis se centra en la resolución de un problema constructivo, en la respuesta práctica a la necesidad creada por la reunión de los nervios que va perfeccionándose debido a una mejor compresión y utilización del sistema. Sin embargo, unos años más tarde, en el Dictionnaire raisonné de l'architecture française du Xle au XVle siècle, Viollet-le-Duc realiza un estudio de la evolución a través de una visión centrada en el funcionamiento estructural del elemento. ${ }^{18}$

La definición de enjarje de Viollet-le-Duc es escueta y abierta:

Assises de pierres à lits horizontaux que I'on place sur un point $d$ 'appui, sur une pile ou un angle de mur entre des arcs, pour recevoir des constructions supérieures. ${ }^{19}$

A Viollet-le-Duc le preocupa la trasmisión de la carga vertical a través de la reunión de los nervios hacia el pilar o el muro. A través de una serie de dibujos muestra su perfeccionamiento y la importancia estructural de juntar los nervios formando tas-de-charge..$^{20}$

En el primer dibujo de la Fig.8 señala que las juntas de las dovelas a no están preparadas para recibir la carga vertical $b$, por lo que registran problemas de deslizamiento o amontonamiento. A Viollet-le-Duc le preocupa que la carga recaiga sobre el trasdós de las dovelas pues puede ocasionar perjuicios a las construcciones. Añade que a los maestros románicos les acarreó problemas cuyo resultado es visible en algunos pilares arruinados de edificaciones de finales del siglo XII. Por ello, en B, cuando comienzan a entender el mal funcionamiento de la solución anterior, introducen entre el extradós de las dovelas unas piezas de lechos horizontales que se adaptan a la curvatura del arco.

\footnotetext{
${ }^{18}$ Eugène Viollet-le-Duc, Dictionnaire raisonné de l'architecture française du Xle au XVle siècle, vol 4 y vol 9 (París: B. Bance, 1979).

${ }^{19}$ Viollet-le-Duc, Dictionnaire raisonné de l'architecture française du Xle au XVIe siècle, vol 9: 7.

${ }^{20}$ Viollet-le-Duc, Dictionnaire raisonné de l'architecture française du XIe au XVIe siècle, vol 9: 8.
}

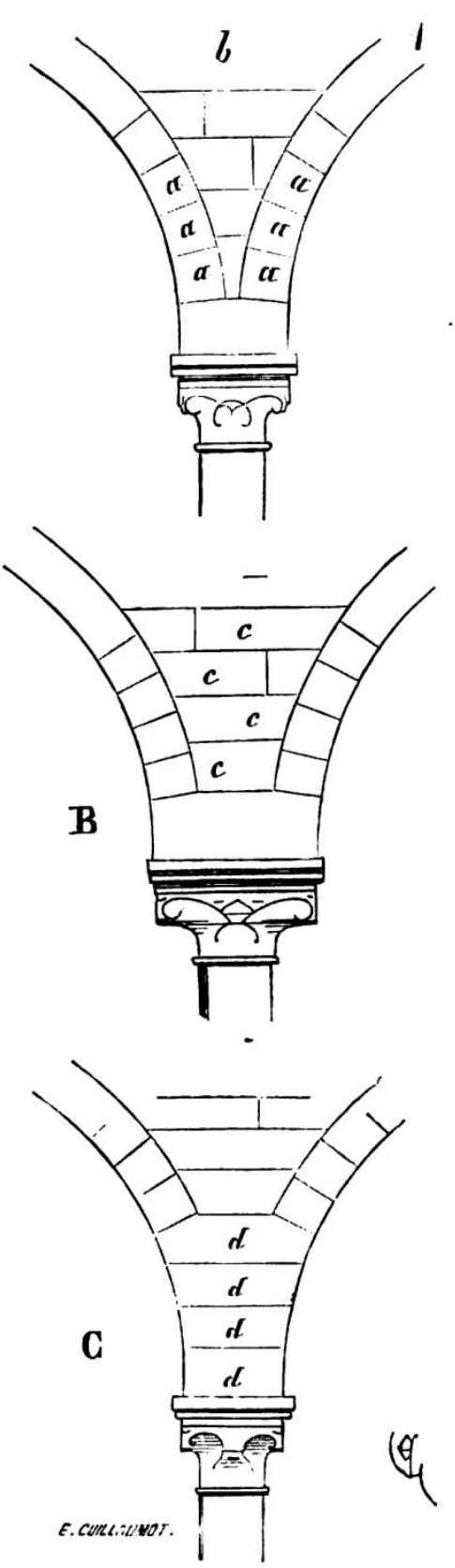

Fig. 8

Viollet-le-Duc, 1979, vol. 9: 8. 
Fig. 9

Choisy, 1899, tomo II, 294.
Como vemos en $\mathrm{C}$, implantan el lecho inclinado cuando no hay posibilidad de que la carga vertical entre en contacto con el extradós del nervio. Violletle-Duc-le-Duc sostiene que tiene muchas ventajas a la hora del contrarresto de las cargas y prevención de rupturas en la fábrica. Por ello, este tipo de construcción era utilizada por los maestros del XIV y el XV, constructores de gran conocimiento, que eran conscientes de la importancia de la construcción en tas-de-charge. ${ }^{21}$

Pocos años después, Auguste Choisy publica en el capítulo XVI de su Histoire de I'Architecture, titulado Architecture gothique, algunos párrafos dedicados al estudio del enjarje. ${ }^{22}$ Hace referencia al artículo de Robert Willis, que seguramente también conoció también Viollet-le-Duc a través de la traducción al francés realizada por César Daly. ${ }^{23}$

Choisy expone que, en un principio, los constructores pensaban en la columna como el apoyo real del nervio y por esa razón el capitel que permite su transición con los nervios guardaba un aspecto robusto. En la figura A se puede apreciar, además, que el arranque está compuesto por las dovelas de los nervios sin trabar con el muro.

\section{1}
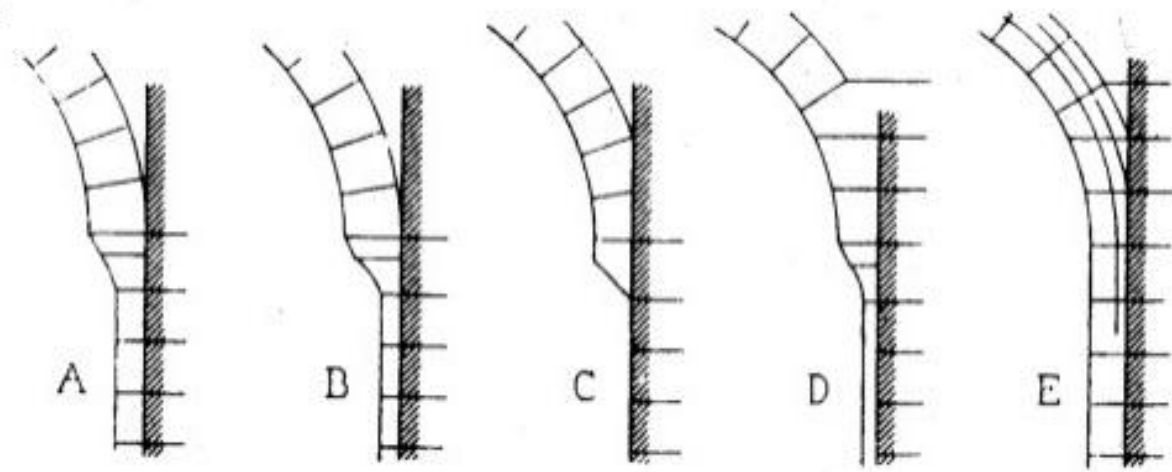

En los primeros años del XIII, se comprende que el rol de la columna como apoyo no es decisivo y comienzan a aparecer ejemplos resueltos con columnas de secciones más reducidas -figura B- o con ménsulas -figura C-. Con la introducción del enjarje, la ménsula deja de ser un elemento imprescindible para el soporte de los nervios y, tal y como se aprecia en la figura $\mathrm{D}$, las propias piezas del arranque que traban con el muro realizan esa función. Por ello, según Choisy, cualquier elemento que encontramos a partir de ese momento bajo el enjarje es mero ornamento.

También se resolverán enjarjes como el de la figura $E$ en los que las molduras de los nervios configuran la columnilla que se continúa hacia la

${ }^{21}$ Viollet-le-Duc, Dictionnaire raisonné de l'architecture française du Xle au XVle siècle, vol 9: 9.

${ }^{22}$ Auguste Choisy, Histoire de l'architecture, tomo II, (París: Gauthier-Villars, 1899), 294-295.

${ }^{23}$ Alejandra Albuerne Rodriguez, "Robert Willis y las bóvedas góticas inglesas: «on the construction of the vaults of the Middle Ages"', Actas del Quinto Congreso Nacional de Historia de la Construcción, (Madrid: Instituto Juan de Herrera, 2007): 18. 
bóveda directamente. Choisy apunta que los capiteles son de gran ayuda a la hora de realizar el replanteo del edificio o modificaciones en el proyecto, pues en esa junta se pueden absorber algunos cambios. ${ }^{24}$

\subsection{El origen del enjarje}

El origen de las formas, de las ideas o de las soluciones constructivas parece ser siempre un tema que despierta el interés de muchos autores. La aparición del enjarje no se ha visto libre de esta especulación, encontrándonos en diversos textos diferentes dataciones.

Al acercarnos a la Histoire de I'architecture de Choisy, si no nos limitamos simplemente al capítulo dedicado al gótico, encontraremos que en la arquitectura persa ya habla de la utilización del tas-de-chage, así como en el capítulo dedicado a la arquitectura románica. ${ }^{25}$ Choisy señala que el enjarje, que dibuja y rotula con $\mathrm{N}$, no formaba parte del repertorio tecnológico románico, a pesar de que la ilustración en la que lo presenta nos recuerda a la evolución del enjarje de Viollet-le-Duc. ${ }^{26}$

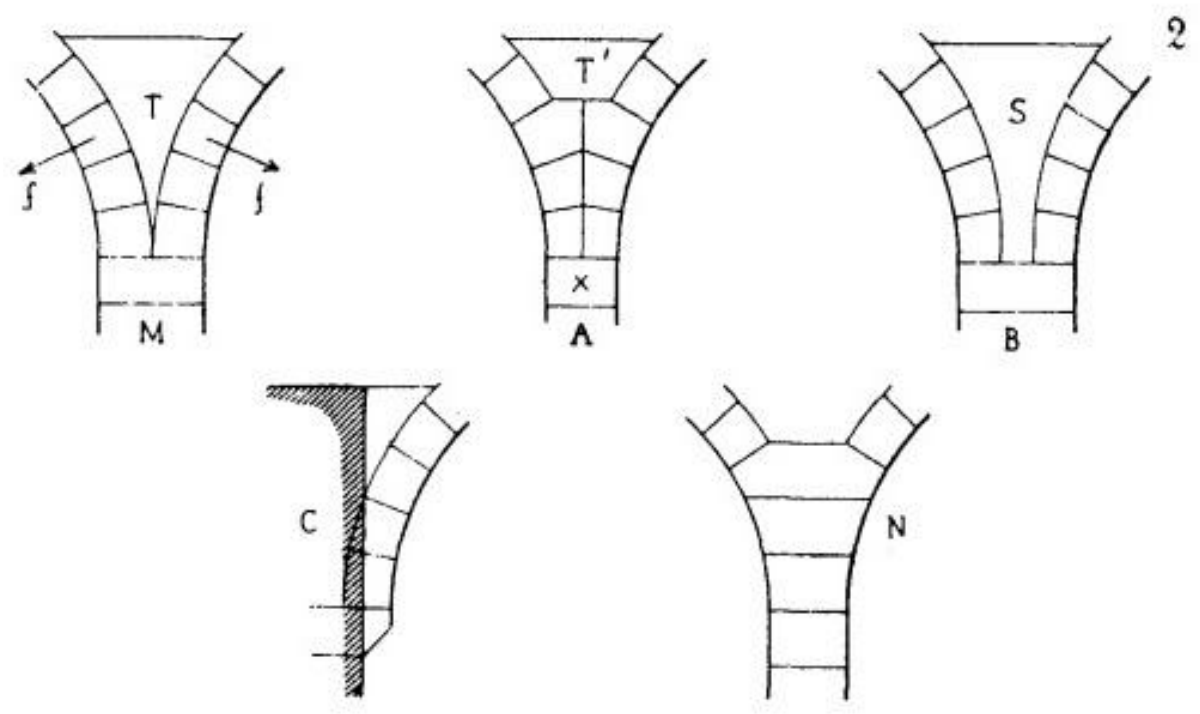

Fig. 10

Choisy, 1899, tomo II, 150.

No es de extrañar que en diferentes momentos de la historia de la arquitectura cuando los constructores se enfrentaban a la resolución del comienzo una bóveda hicieran uso de esta solución constructiva, por lo que no podemos afirmar que el enjarje sea exclusivamente medieval o incluso, gótico. Quizás, lo que sí ha variado a lo largo el tiempo no ha sido tanto el concepto, sino el problema a resolver, que es lo que puede acarrear mayor o menor dificultar. No es lo mismo ejecutar el enjarje de una bóveda de cañón que el de una bóveda en la que varios nervios se reúnen. Para la

\footnotetext{
${ }^{24}$ Choisy, Histoire de l'architecture, tomo II: 294-295.

${ }^{25}$ Choisy, Histoire de l'architecture, tomo II: 98 y 147.

${ }^{26}$ Choisy, Histoire de l'architecture, tomo II: 147.
} 


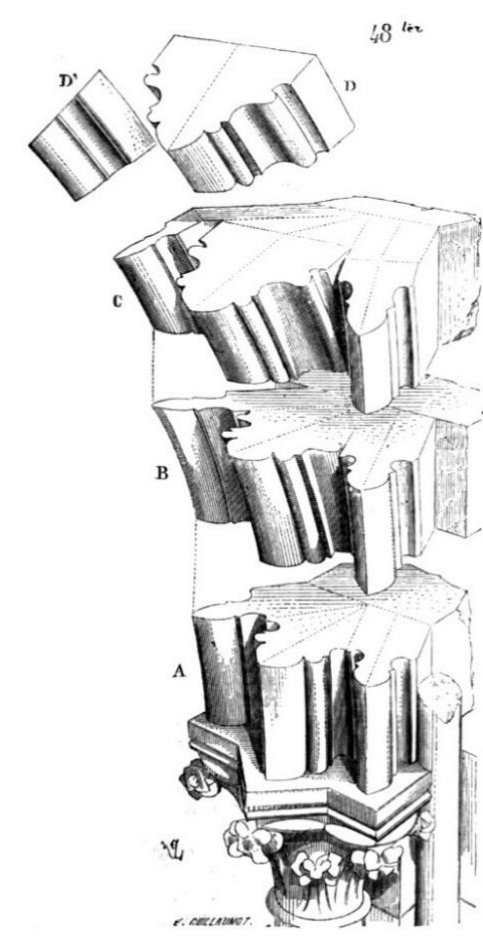

Fig. 11

Viollet-le-Duc, 1979, vol. 4: 93 fig. 48. primera bastará con el control de la curva cortada por planos horizontales en su alzado mientras que, para la segunda, será necesario un control en planta de esa confluencia de nervios donde, además del dominio en elevación de los cortes de cada uno, se deberán controlar también sus direcciones.

En cuanto a su utilización en la arquitectura nervada, Willis presenta en sus textos ejemplos ingleses bastante tempranos, incluso románicos, en los que las bóvedas poseen enjarjes. Parece que Viollet-le-Duc da muestras de su conocimiento del texto del inglés cuando dice a propósito del origen que ya en el siglo XIII en Inglaterra se habían realizado construcciones en tas-de-charge citando la parte románica de la catedral de Peterborough. Se asombra de la experiencia de los arquitectos normandos que en el siglo XII ya realizaban soluciones tan complejas y añade que, tiempo después, este sistema constructivo se dará también en Francia. ${ }^{27}$

Choisy señala que la catedral de Notre Dame de París, terminada alrededor de 1220, no tiene enjarjes mientras sí es una solución adoptaba desde un principio en Soissons, comenzada en esos momentos. ${ }^{28}$ Deneux vuelve a señalar esta última y también Reims como el origen. ${ }^{29}$

En textos posteriores se repite de manera constante que la aparición del enjarje se produce en el siglo XIII en Francia. Algunas construcciones anteriores permiten poner en duda esta afirmación, pues el comienzo en tas-de-charge era un recurso normal, como hemos mostrado anteriormente, para la solución del comienzo de las bóvedas. Lo que sí puede que ocurra a partir del siglo XIII es el empleo de esta solución en edificios de mayor entidad de modo sistemático, como es el caso de grandes catedrales.

\subsection{Clasificación de enjarjes. Una nueva definición}

La ilustración más conocida de un enjarje gótico aparece en el artículo sobre Construcción del Dictionnaire Raisonnée de I'Architecture de Violletle-Duc y ha sido utilizada repetidamente para describir cómo son las piezas que reúnen los nervios y de qué manera, al final del enjarje, aparece la pieza con los lechos inclinados para permitir el apoyo de las dovelas de los arcos. Es una imagen clásica, un enjarje idealizado que sintetiza las ideas que anteriormente expresamos en relación al avance tecnológico que supuso

\footnotetext{
${ }^{27}$ Viollet-le-Duc, Dictionnaire raisonné de l'architecture française du XIe au XVIe siècle, vol 4: 101.

${ }^{28}$ Choisy, Histoire de l'architecture, tomo II: 274.

${ }^{29}$ Henri Deneux, "De la construction en tas de charge et du point de butée des arcsboutants", Bulletin Monumental, (1944): 242.
} 
organizar los perfiles de los nervios en piezas únicas por hiladas horizontales. ${ }^{30}$

Tras el estudio de ejemplos de diferentes puntos de Europa pertenecientes a diversas fechas, nos parece pertinente presentar una nueva definición de enjarje en la que muchos modelos no recogidos hasta ahora y, en algunos casos, no del todo compatibles con las definiciones hasta ahora presentadas, puedan empezar a formar parte de nuestro vocabulario formal y técnico.

Durante el desarrollo de la investigación se hizo necesario poder establecer características que permitieran comparar los enjarjes que se iban recopilando, puesto que pronto se manifestaron diferencias y convergencias entre algunos de ellos que nos llevaron a conformar tipos que atendieran a diferentes respuestas proyectuales, formales 0 constructivas.

\subsubsection{Según el contacto de los nervios con el muro}

El contacto entre los nervios de la bóveda y el muro da lugar a diversas configuraciones de enjarjes. Robert Willis, en el capítulo III de Remarks on the Architecture of the Middle Ages señala la existencia de diferentes soluciones para la zona en la que se relacionan los pilares y los nervios, lo que denomina impost. ${ }^{31} \mathrm{~A}$ pesar de que no se centra en la dimensión constructiva del enjarje, como hemos visto otros escritos suyos, aquí presenta soluciones formales que llevan a problemáticas constructivas y ornamentales que han de ser resueltas. ${ }^{32}$

Establece en una tabla una clasificación para cinco casos:

Sin capitel:

1. Continuous. En este caso se produce continuidad entre las molduras del pilar y las de los nervios. Presenta un ejemplo en la figura 14, en la que advierte que se ha de obviar la parte en la que se entrelazan las molduras. ${ }^{33}$

\footnotetext{
30 Viollet-le-Duc, Dictionnaire raisonné de l'architecture française du Xle au XVIe siècle, vol. 4: 93.

31 Impost podría ser traducido al castellano por imposta, pero puede conducir a malentendidos, ya que imposta en este caso no se corresponde con la problemática que Willis quiere mostrar. Por tanto, hemos mantenido los nombres utilizados por Willis en inglés. Su comprensión es sencilla con aclaraciones y figuras explicativas.

${ }^{32}$ Robert Willis, Remarks on the Architecture of the Middle Ages, especially of Italy, (Cambridge: Pitt Press, 1835), capítulo III: 28-33.

${ }^{33}$ Willis, Remarks on the Architecture of the Middle Ages, especially of Italy, 28 y lamina III: fig.14.
}

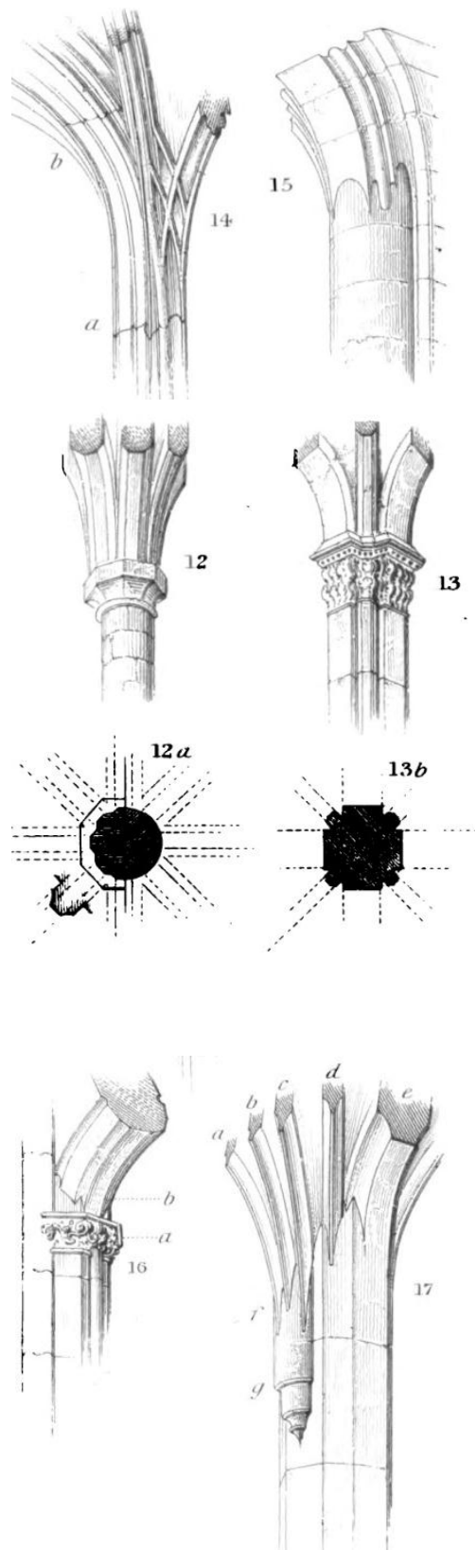

Fig. 12

Willis, 1835, lámina III. 
2. Discontinuous. Esta unión viene caracterizada por la muerte de un elemento en el otro y señala que este tipo de solución da lugar a gran cantidad de intersecciones. ${ }^{34}$

Con capitel:

3. Shafted. El capitel se sitúa en la separación entre el pilar y los nervios, teniendo ambos elementos molduras diferentes. ${ }^{35}$

4. Banded. En este caso, sin embargo, las molduras del pilar traspasan el capitel y continúan configurando los nervios. ${ }^{36}$

Con ménsula:

5. Corbel Impost. Ante la presencia de una ménsula, las diferenciaciones anteriores no son adecuadas, pues no hay presencia de elementos verticales.

Willis advierte la situación en la que se eleva un elemento prismático o cilíndrico desde el capitel o la ménsula para facilitar la intersección entre las molduras de los nervios que se reúnen. ${ }^{37}$ Este caso será tratado con más detalle en el capítulo dedicado a las dying mouldings, ${ }^{38}$ como han sido denominadas por Virginia Jansen. ${ }^{39}$

El dibujo de Choisy para la evolución del pilar gótico nos permite, prescindiendo de algunos casos y añadiendo otros, junto con las apreciaciones de Willis, presentar la casuística existente: ${ }^{40}$

Nervios que arrancan de un capitel que se apoya en un pilar o pilastra (1)

Estos enjarjes suelen ser más comunes en las primeras construcciones nervadas. Siguen de manera clara el sistema donde los nervios de la bóveda apoyan en un elemento vertical y para ello se introduce un capitel

\footnotetext{
${ }^{34}$ Willis, Remarks on the Architecture of the Middle Ages, especially of Italy, 31 y lamina III: fig. 15 y 17.

${ }^{35}$ Willis, Remarks on the Architecture of the Middle Ages, especially of Italy, 29 y lamina III: fig. 12.

${ }^{36}$ Willis, Remarks on the Architecture of the Middle Ages, especially of Italy, 29-30 y lamina III: fig.13.

${ }^{37}$ Willis, Remarks on the Architecture of the Middle Ages, especially of Italy, 32-33 y lamina III: fig.16.

38 Ver página 94.

39 Virginia Jansen, "Dying Mouldings, Vertical Springer Blocks, and Hollow Chamfers in Thirteenth- Century Architecture", Journal of the British Archaeological Association (1982), CXXXV, 35- 54.

${ }^{40}$ Choisy, Histoire de l'architecture, tomo II: 294.
} 
que permite esta transición. Cada elemento ha de tener correspondencia con sus contiguos y conformar una estructura ordenada.

Nervios que arrancan de una ménsula (2)

Se comienzan a utilizar también desde un primer momento combinándose en muchos casos con los enjarjes que se apoyan en pilares como, por ejemplo, en salas columnarias. Allí se recurre a este tipo de solución en los encuentros de los nervios con los muros. Choisy sostiene que su aparición guarda relación con la constatación del carácter no portante del pilar.

Nervios cuya moldura continúa el perfil del pilar con continuidad (3)

Este tipo de ejemplos se caracteriza por la utilización del contorno de los nervios en el arranque del enjarje para la definición del perfil del pilar. Es necesaria una coordinación en el proyecto del edificio desde el comienzo de su construcción hasta la ejecución del abovedamiento, pues se ha de asegurar que la molduración parezca fluir por el pilar de manera continua hasta separarse y configurar los nervios. Este procedimiento muestra que los maestros, desde el momento en el que concretaban la primera pieza del pilar, sabían exactamente qué configuración iba a tener la bóveda, puesto que este diseño del elemento sustentante es dependiente del diseño en planta del enjarje. Enrique Rabasa utilizó el término anticipaciones para definirlos, pues revelan cómo se prevé lo que sucederá en la parte superior. ${ }^{41}$

\section{Nervios que arrancan directamente del muro (4)}

Choisy explica que a partir del siglo XV los nervios se comienzan a cruzar por interpenetración permitiendo eliminar el capitel como accesorio inútil. Esta solución de nervios que salen directamente del muro no es exclusiva de los últimos siglos del gótico, pero sí podemos decir que su práctica se vuelve más extendida y frecuente en este periodo. Quizás la mayor comprensión del sistema, tanto a nivel proyectual como estático, favoreció este cambio de pensamiento en el que no era necesario que cada elemento tuviese su correspondencia.

Nervios que arrancan relacionándose con molduras del pilar que continúan verticalmente: los mal llamados arrepentimientos (5)

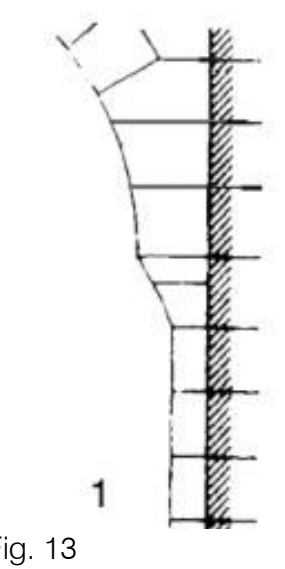

Choisy (tomo II: 294).

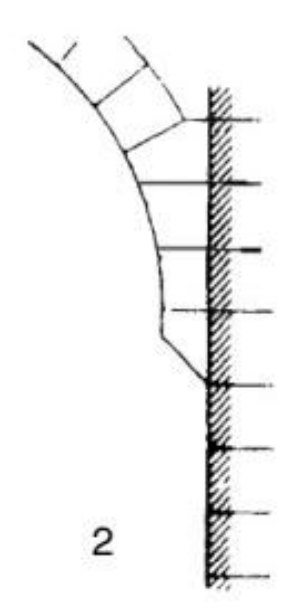

Fig. 14

Pérez de los Ríos sobre Choisy (tomo II: 294).

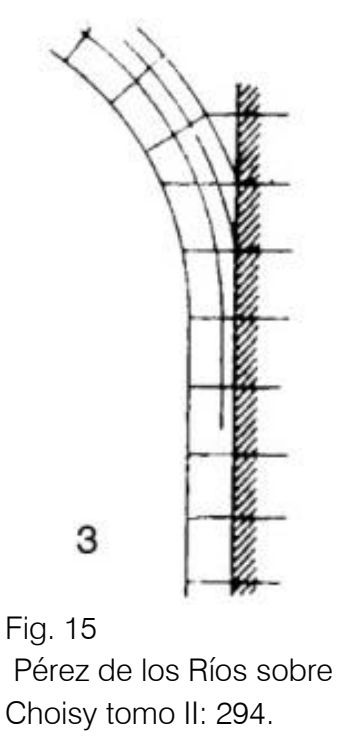

\footnotetext{
${ }^{41}$ Enrique Rabasa Díaz, "Plantillas y maclas", La arquitectura castellana entre Europa y América, (Madrid: Silex ediciones, 2011): 438.
} 


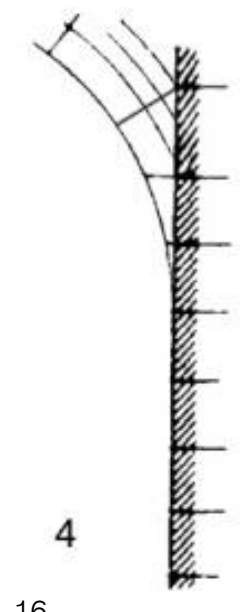

Fig. 16

Pérez de los Ríos sobre Choisy (tomo II: 294).

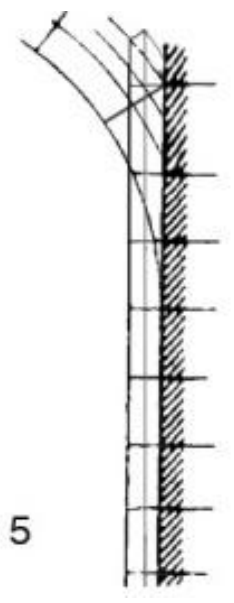

Fig. 17

Pérez de los Ríos sobre Choisy (tomo II: 294).

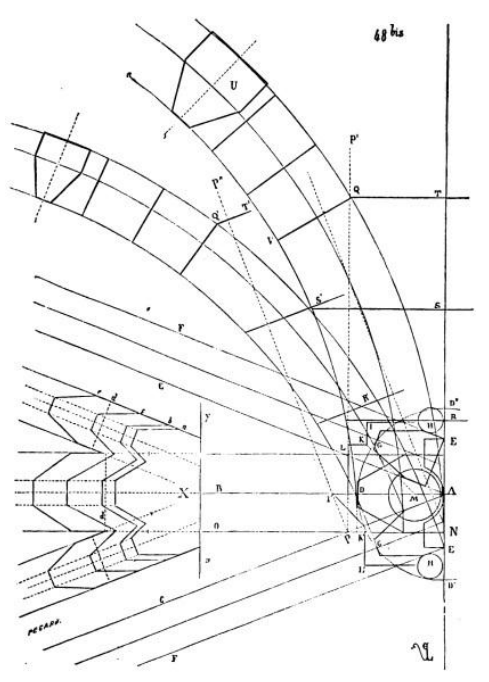

Fig. 18

Viollet-le-Duc, 1979, vol. 4: 91, fig. 48bis
Antonio Castro recoge el término arrepentimiento para explicar algunos casos en los que las maclas entre elementos no son deliberadas, refiriéndose a las discordancias entre las molduras del pilar y los nervios de la bóveda. ${ }^{42}$ En algunos casos sí que existe esta falta de previsión que deriva en desacuerdos entre las dos partes pero, bajo nuestro parecer, son los menos frecuentes. Es común encontrar molduras del pilar que mueren en el enjarje e, incluso, en parte de la plementería. En ocasiones, seguramente, son molduras pertenecientes a un proyecto anterior que se continúan para evitar separar el pilar de la bóveda mediante un capitel. Conscientemente, los maestros deciden que se relacionen los elementos verticales con los nervios.

En muchos casos, estas soluciones son proyectadas desde un primer momento. Por ejemplo, en la catedral de Sevilla, este recurso es manejado de manera sistemática, no siendo fruto de ninguna corrección o modificación. En este caso, los pilares son de una dimensión tal, que en su encuentro con los nervios de las bóvedas, aparecen huecos de gran calibre entre los nervios. Si los pilares no continuasen, estas superficies serían difíciles de ejecutar y su aspecto probablemente extraño. Por ello, entre los arranques de los nervios perpiaños y ojivos de estas bóvedas cuatripartitas se elevan elementos verticales continuación de los pilares hasta intersecar con la superficie que más adelante conformará la plementería, que nada tienen de arrepentimientos.

\subsubsection{Según la junta de su última pieza con el nervio}

La finalidad del enjarje es la de propiciar la cohesión entre el comienzo de la bóveda y el muro gracias a una serie de piezas horizontales. Además, en la parte superior, hay que garantizar la unión con los nervios, cuyas juntas son radiales. Este encuentro se puede resolver de varios modos:

\section{$\underline{\text { Solución general }}$}

El enjarje se ejecuta por lechos horizontales y, al llegar al encuentro entre la última junta horizontal y la línea de trasdós del nervio, se realiza el plano inclinado radial. En todas las descripciones de enjarjes que hemos manejado ha sido siempre la solución explicada y representada, encontrándola en Willis, Viollet-le-Duc, Choisy, Rabasa, etc.

Tiene la ventaja de ser una idea sencilla y clara que permite que la altura de las juntas horizontales en el enjarje pueda ser muy variable, que no se establezcan encuentros complejos con las dovelas y que además facilita el control de la última pieza en el momento de trazado y talla.

En el artículo Construcción, Viollet-le-Duc enseña cómo establecer el lugar en el que se debe decidir establecer la junta inclinada- cuyo procedimiento

\footnotetext{
${ }^{42}$ Antonio Castro Villalba, Historia de la Construcción Medieval. Aportaciones, (Barcelona: UPC, 1996).
} 
explicaremos en capítulos posteriores-, y que a partir de esa altura se dividirá el enjarje en hiladas. ${ }^{43}$

Asimismo, Viollet-le-Duc señaló que esas superficies inclinadas para recibir las dovelas pueden no estar en la misma pieza. En muchas ocasiones se localizan en la última, pero si los nervios arrancan a diferentes alturas o sus curvaturas son desiguales, es frecuente que, según el nervio, estas superficies de transición se den en diferentes piezas y a diferentes alturas.

Muestra el caso de un enjarje del que salen arcos con radios desiguales y a diferentes alturas. Explica cómo un arco puede separarse de los demás por el extradós y tener el corte oblicuo para recibir dovelas mientras el resto siguen su desarrollo en altura con lechos horizontales. Presenta una axonometría en la que de la primera pieza sale un nervio, de la segunda dos, de la tercera ninguno y de la cuarta los dos últimos. Además, incide en la existencia de refuerzos $R$ detrás de las dovelas libres.

Esta solución general es el modelo idealizado seguramente se acerca a la idea de tas-de-charge a nivel conceptual que podrían manejar los maestros medievales, pero debido a la gran cantidad de bóvedas con
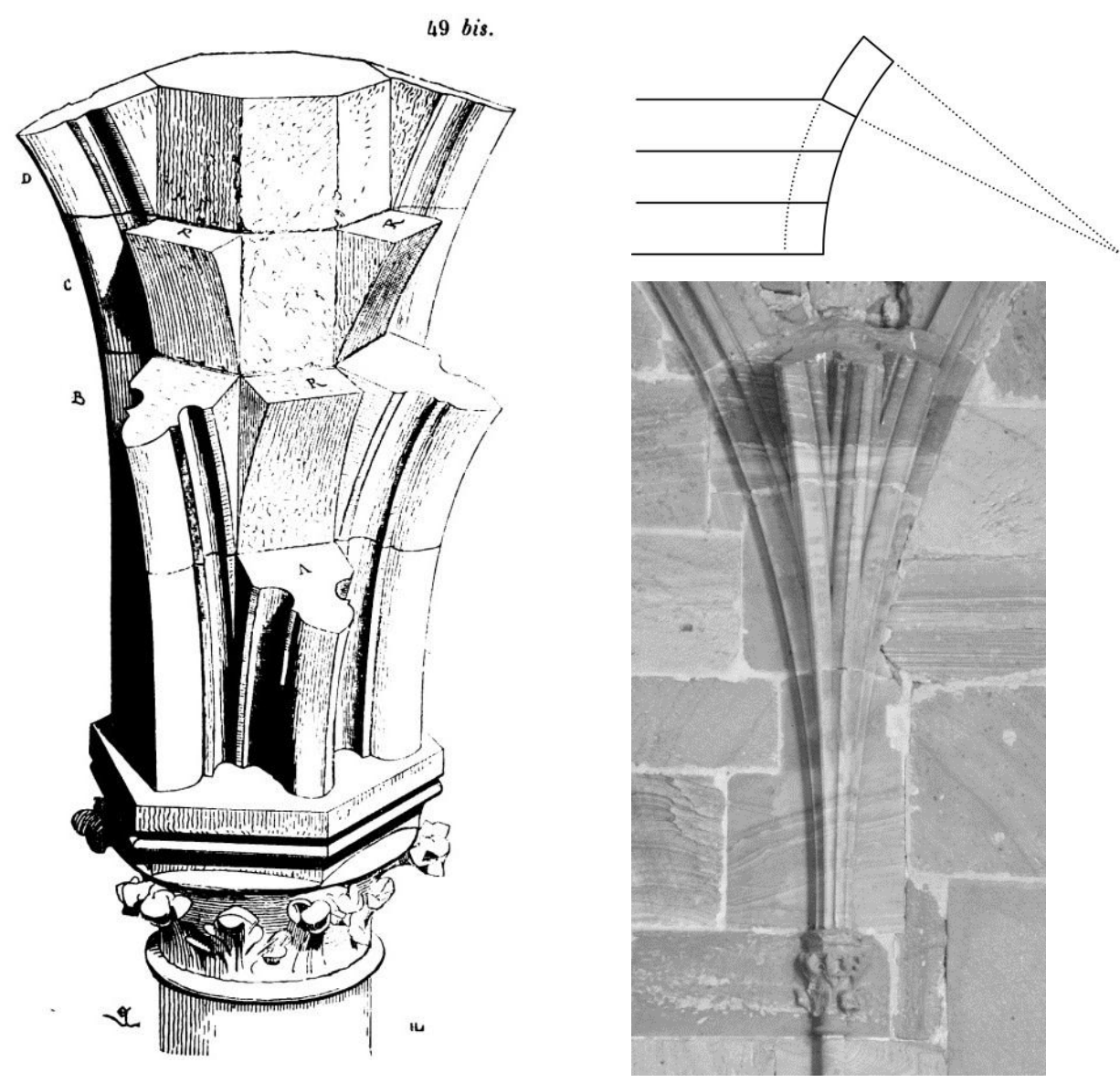

\footnotetext{
${ }^{43}$ Viollet-le-Duc, Dictionnaire raisonné de l'architecture française du Xle au XVIe siècle, vol 4:90-92. La imagen en la página 91.
}

Fig. 19

Viollet-le-Duc, 1979, vol. 4: 95, fig. 49bis.

Fig. 20

Solución general.

Ejemplo: claustro de Saint-Pierreet-Saint-Paul, Wissembourg 
particularidades tan dispares existen otras soluciones que no se ajustan a ella, a la que podríamos designar como canónica. ${ }^{44}$

\section{Solución simplificada}

Hemos tenido dudas a la hora de incluir este tipo de enjarje sin junta inclinada en la clasificación. En un primer momento pensamos que esta solución podría ser considerada una etapa anterior a la general, pero la hemos encontrado con cierta frecuencia en el siglo XIV en edificios de buena factura e incluso, como nos apunta Alberto Calderón, en edificios góticos del siglo XVII. ${ }^{45}$

Esta solución traslada el problema de la junta entre el enjarje y el arco a la primera dovela de cada uno de los arcos. Evita tener que resolver el problema geométrico de la ejecución de las juntas inclinadas al final del enjarje pero, por otro lado, la junta entre la dovela y la última pieza horizontal es susceptible de deslizamientos. Como ya es bien sabido tras los estudios

Fig. 21

Solución simplificada. Ejemplo:

Saint

Florentinus,

Niederhaslach.

Fig. 22

Tacón de Mallorca. Ejemplo: Lonja de Palma, Mallorca.
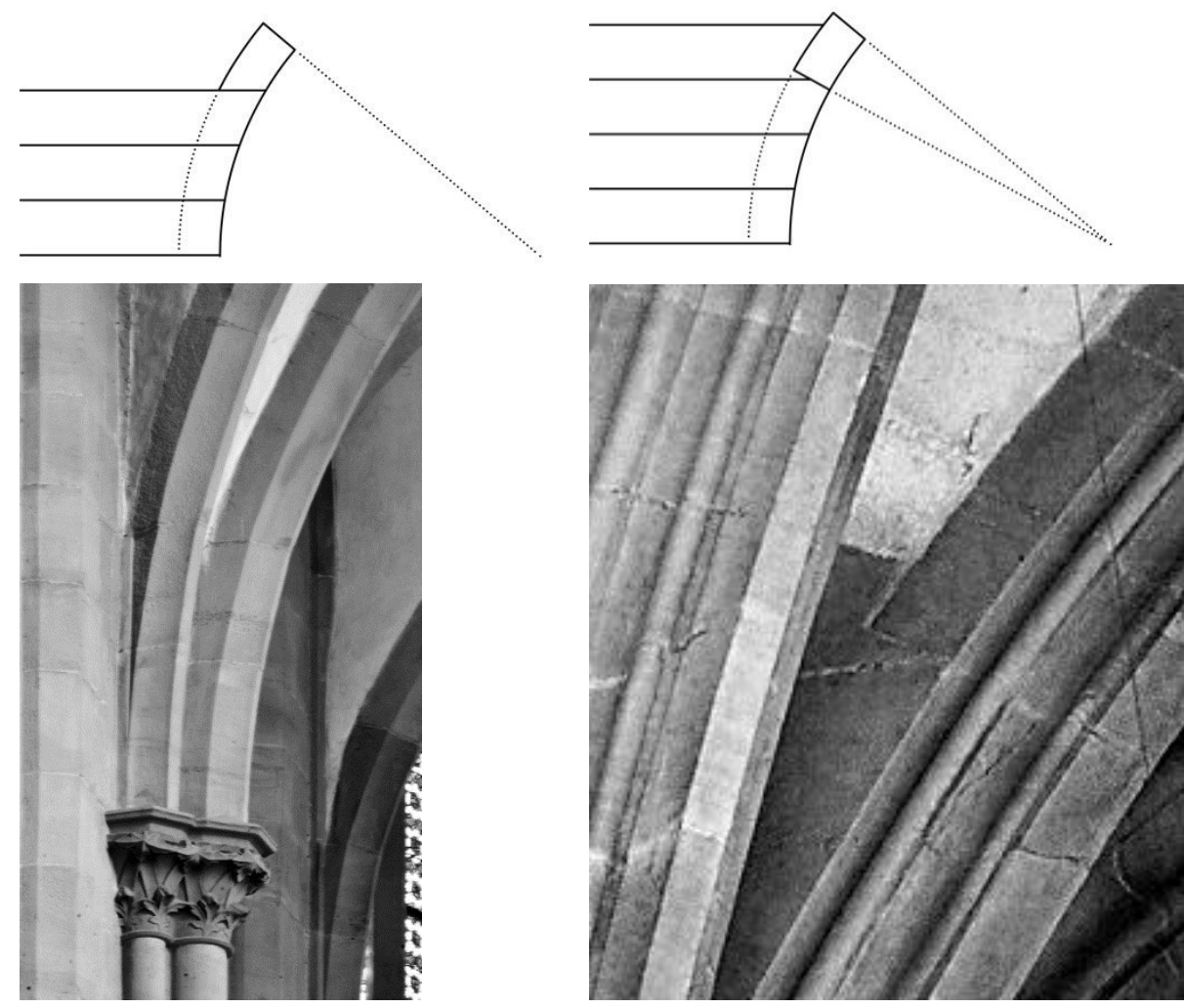

${ }^{44}$ Sobre lo canónico y no-canónico: Rosa Senent Domínguez, La deformación del tipo. Construcción de bóvedas no-canónicas en España (siglos XVI-XVIII), (Madrid: Escuela Técnica Superior de Arquitectura, UPM), tesis doctoral.

${ }^{45}$ Alberto Calderón está estudiando edificios de este periodo. Es especialmente relevante su investigación acerca de la convivencia de bóvedas de crucería gótica y bóvedas clásicas. Ha analizado la construcción conjunta de ambos elementos en los enjarjes de varias iglesias en el área burgalesa: Alberto Calderón González, "Strategies for the accord of Gothic and Classical stone construction systems in 16th -and 17th-century buildings in Northern Spain", Proceedings of the First Conference of the Construction History Society, (Cambridge, 2014). 

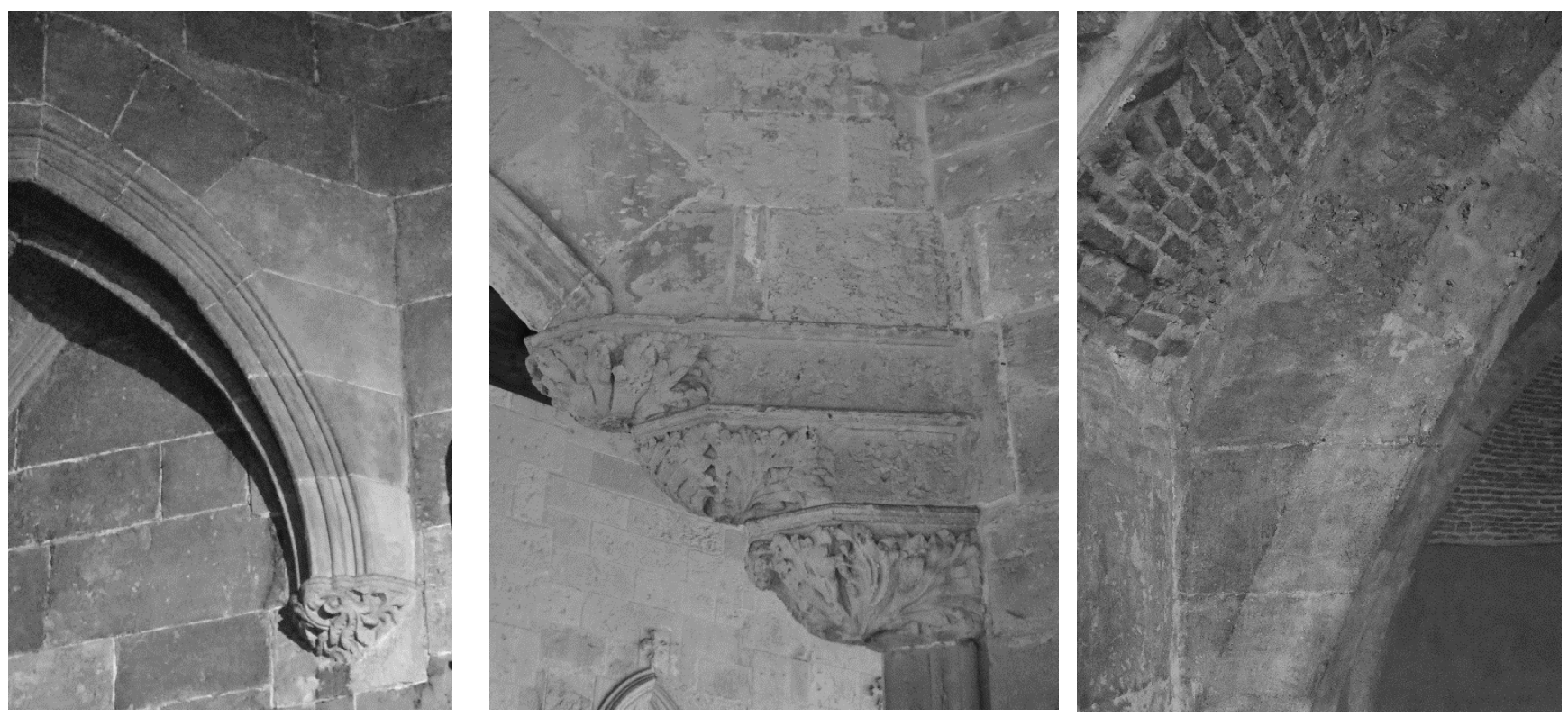

del profesor Jacques Heyman y el profesor Huerta Fernández, las fábricas no suelen presentar problemas estructurales relacionados con las tensiones, sino con la estabilidad y el equilibrio, por lo que este tipo de encuentros no es demasiado aconsejable. ${ }^{46}$

\section{$\underline{\text { Variaciones sobre el corte radial }}$}

Aparte de la solución general en la que el corte radial coincide con el punto en el que el último lecho horizontal y el extradós del nervio coinciden, es posible establecer otras fórmulas variando la situación de esa junta:

\section{El tacón de Mallorca}

Advertimos esta solución utilizada por primera vez de manera recurrente en Mallorca, entre otros, en algunos arcos en el claustro e iglesia de del convento de San Francisco o en los arcos perpiaños de las boveditas triangulares de los ábsides de la girola de la iglesia de la Santa Cruz. Sin embargo, en enjarjes, la vemos utilizada por primera vez en los de la lonja de Palma, donde aparecen unos pequeños picos que no son fáciles de percibir a primera vista. También en los enjarjes de la bóveda de la Sala dei Baroni en Castelnuovo. En Palma, todas las hiladas del edificio tienen la misma altura, probablemente debido a la utilización de la piedra de Santanyí, que es un material de características muy singulares. Su altura de bancada no es demasiado grande y la calidad del material sufre variaciones. La piedra utilizada para la Lonja se encuentra solamente en una capa con una altura de 1 metro. Por ello, seguramente se vieron condicionados a realizar sillares con la misma altura de hilada.

El problema constructivo en estos enjarjes viene dado por la relación entre esos cortes horizontales constantes y el espesor del nervio, pues si se

\footnotetext{
${ }^{46}$ Jacques Heyman, The Stone Skeleton, (Cambridge: Cambridge University Press, 1995); Santiago Huerta Fernández, Arcos, bóvedas y cúpulas. Geometría y equilibrio en el cálculo tradicional de estructuras de fábrica, (Madrid: Instituto Juan de Herrera, 2004).
}

Fig. 23

Izquierda: iglesia de la Santa Cruz, Palma. Centro: claustro del convento de San Francisco, Palma. Derecha: Torres de Quart, Valencia. 
realiza el corte inclinado como en el ejemplo general, el espesor del intradós del arco en la última pieza del enjarje sería demasiado pequeño y frágil. De esta manera, el corte no se lleva a cabo en relación al trasdós del nervio, sino más arriba, y la primera dovela apoya sólo parcialmente en la zona inclinada de la última pieza del enjarje, completando su soporte con una pieza especial a modo de tacón. En esa piedra de lechos horizontales se integran ese pico residual y una superficie que sigue el desarrollo del extradós del arco. ${ }^{47}$

Esta solución aparece con frecuencia en los capítulos dedicados a arcos en el manuscrito del mallorquín Josep Gelabert, lo que nos lleva a pensar que quizás este modo de solucionar los enjarjes pueda deberse a un gusto particularmente mallorquín o a la utilización de esta piedra local que fuerza altura de hilada constante. ${ }^{48}$

También encontramos ejemplos con esta solución en los arcos de las torres de Quart en Valencia o en los enjarjes de la sala capitular del monasterio de Santa María de la Valldigna en Tavernes.

Fig. 24

Acodado de Basilea. Ejemplo: claustro de la catedral de Basilea, Suiza.
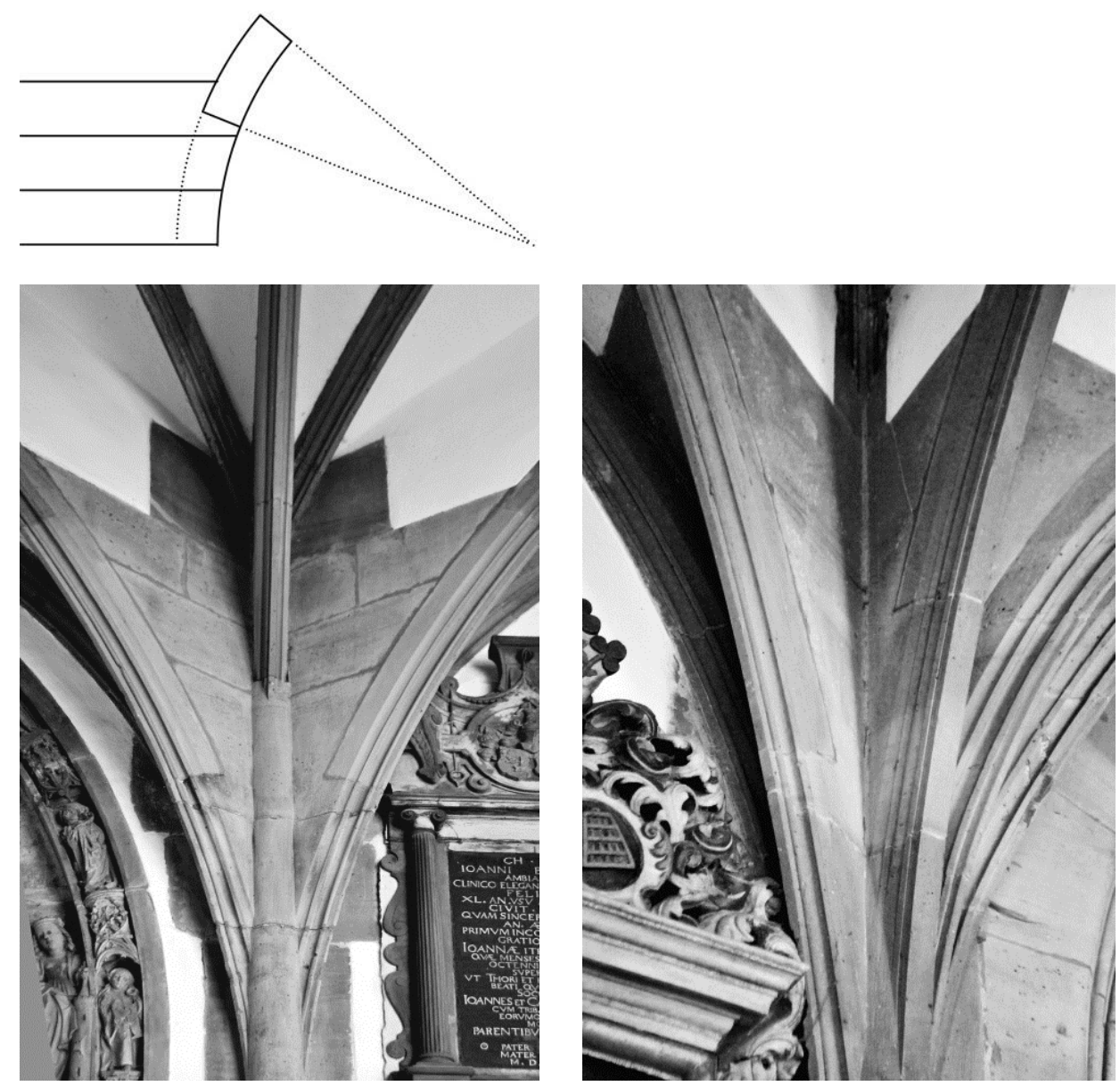

\footnotetext{
${ }^{47}$ Ver Lonja de Palma a partir de la página 240.

48 Josep Gelabert, Verdaderes traçes de l'Art de Picapedrer, (facsimil en Palma de Mallorca: Consell Insular de Mallorca, 1977 [1653]); Enrique Rabasa Díaz, El manuscrito de cantería de Joseph Gelabert, (Palma de Mallorca/Madrid: Collegi Oficial d'Arquitectes de les Illes Balears /Fundación Juanelo Turriano, 2011).
} 


\section{El acodado de Basilea}

En el claustro de la catedral de Basilea encontramos una variación sobre la solución anterior, en la que ese tacón aumenta de tamaño hasta conformar un pico que alcanza el intradós del nervio en la última pieza del enjarje, siendo sensible a la rotura debido a su pequeño espesor. Si el ejercicio anterior de Mallorca ofrecía dificultades para la talla, este es más complejo. La ejecución del plano en el que se apoya la dovela del nervio y la parte en la que entra en contacto con el extradós requieren un considerable esfuerzo de control geométrico y de habilidad en la talla. La dovela debe encajar correctamente garantizando una conexión satisfactoria entre las partes.

En los enjarjes de la panda oeste del claustro esta solución se repite de manera sistemática con piezas de bastante altura. Esto supone una mayor dificultad porque la superficie curva que ha de ajustarse al extradós del nervio tiene una dimensión considerable. En todas las bóvedas salen dos nervios a ambos lados del perpiaño, de manera simétrica y a igual cota, en los que las juntas son iguales. El perpiaño sale con cierto ángulo con respecto a la tangente desde una posición superior.

En la bóveda de la esquina noroeste la solución es especial porque entra en contacto con una capilla de diferente trazado. En el enjarje, los nervios salen a cotas similares pero, debido su diferente curvatura, los cortes se producen a alturas distintas. La ejecución de las bóvedas de Basilea demuestra gran destreza y habilidad; y denota un control técnico difícil de equiparar con obras coetáneas e incluso posteriores.

Este tipo de solución no es muy común probablemente debido a las dificultades que presenta su ejecución. Aun así la podemos encontrar en: Peterborough, ${ }^{49}$ la sacristía de St.-Annen-Kirche en Annaberg o las bóvedas de la escalera del castillo de Praga, que recientemente han estudiado Thomas Bauer, Jörg Lauterbach y Norbert Nußbaum. ${ }^{50}$

\section{La elongación de Reims}

La última solución hasta este momento detectada plantea la elongación del perfil del nervio a partir de la última pieza del enjarje, formando parte de ella, hasta configurar un plano inclinado en el que apoyar la primera dovela. A diferencia de las dos anteriores en las que se buscaba un cierto acodalamiento de esta primera pieza del arco, esta solución necesita piezas sobre el último bloque del enjarje que ayuden a reforzar la unión del trasdós de la dovela.

\footnotetext{
${ }^{49}$ Agradezco a Alberto Calderón González haberme mostrado este ejemplo y haberme facilitado imágenes.

50 Thomas Bauer et al., „Benedikt Rieds Schlingrippengewölbe auf der Prager Burg. Entwurf - Steintechnik - Kontext", INSITU, Jhrg.7, Heft 01/2015, (Worms: Wernersche Verlagsgesellschaft, 2015), $59-76$.
}

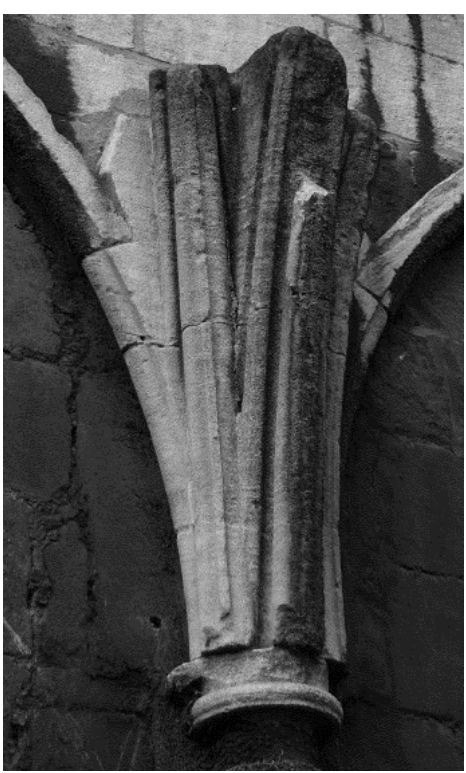

Fig. 25

Acodado en la catedral de Peterborough. Imagen: Alberto Calderón González. 

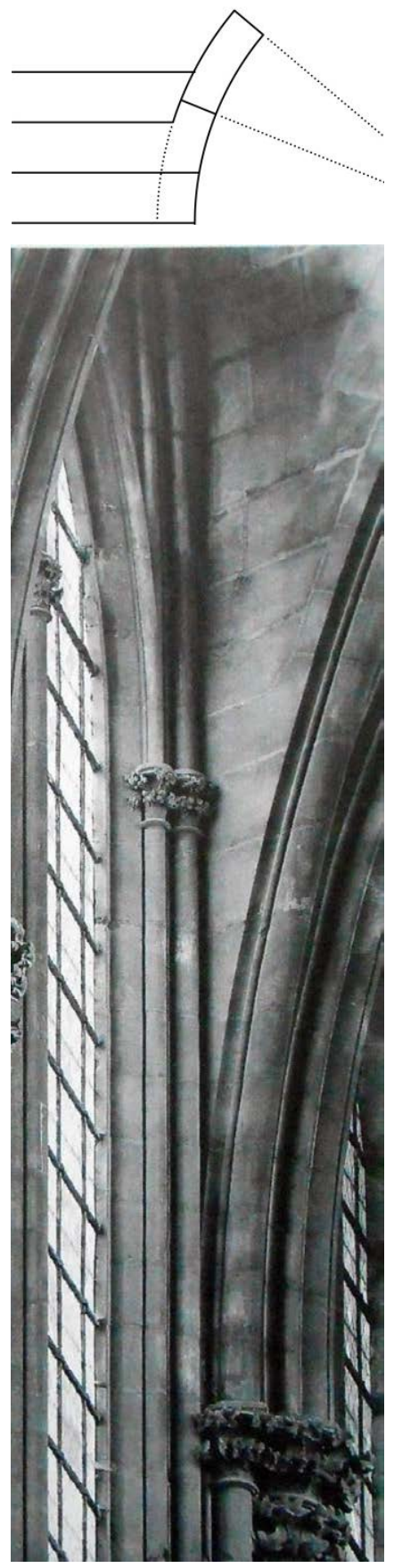

Fig. 26

La elongación de Reims. Imagen Nußbaum y Lepsky (1999, 75, fig. 61).
El primer ejemplo que conocemos se localiza en la catedral del Reims, donde, debido al peralte de los arcos formeros para propiciar la situación de los ventanales, la superficie por encima del enjarje de los ojivos y perpiaños continúa en vertical a base de piezas con juntas horizontales que se ajustan a la perfección al trasdós del nervio. Puede que en este caso, como nos señala Alberto Calderón, se decida alargar esta parte para que su intradós tenga el mismo tamaño que el del resto de piezas del enjarje, pues si se hubiere cortado por el procedimiento general, el intradós en esa hubiera sido muy estrecho.

Este tipo de solución técnica puede que sea utilizada con menor frecuencia aunque también está presente, por ejemplo, en la Abbatiale Saint-Pierre-etSaint-Paul de Wissembourg.

\subsubsection{Según la relación entre los ejes de los nervios entre sí y con el muro ${ }^{51}$}

Una vez definidas las posibilidades del encuentro de los nervios en la zona del enjarje con el muro y del propio enjarje con las primeras dovelas, el siguiente paso en este proceso de caracterización viene dado por el estudio de la relación de los propios nervios entre sí.

En los enjarjes los nervios se definen por su dimensión, su perfil, el número de ellos que se reúnen, la posición que adoptan, de qué cotas arrancan, etc.

Muchas veces las dificultades a la hora de describir un enjarje son motivadas por la incorrecta utilización del lenguaje o el vocabulario técnico; o porque hasta ahora la denominación "enjarjes de nervios cruzados" englobaba muchos casos cuyo principio no es el mismo. En muchas ocasiones se han designado así a enjarjes en los que no se cruzan los nervios propiamente dicho, sino simplemente parte de sus perfiles. Si entendemos que el nervio está determinado por su línea de intradós y su perfil, para que se crucen los nervios sus líneas de intradós deben cruzarse antes de su entrada en el muro. Si no, estaremos ante enjarjes de molduras cruzadas.

Una de las mayores preocupaciones durante el trascurso de la presente investigación ha sido la búsqueda de precisión en la caracterización de ejemplos que han de ser comparados y estudiados. Puede que en algunos casos la divergencia entre un grupo y otro sea difícil de poder ser establecida a primera vista, pero consideramos que son los menos. No hay que olvidar tampoco que la casuística es muy compleja, sobre todo si atendemos a enjarjes de finales del siglo XV o del siglo XVI, por lo que nuestra intención es dar una serie de pautas para su comprensión que puedan ser examinadas, ampliadas o puntualizadas dentro de la discusión científica.

\footnotetext{
${ }^{51}$ Agradezco a Alberto Calderón González su ayuda con los esquemas en planta de cada uno de los casos.
} 
Este enjarje podría ser considerado el clásico, general o canónico. Es quizás el más frecuente y el más utilizado desde un principio por su claridad de concepto, de trazado y por evitar intersecciones entre los nervios que hacen más complejo el proceso de talla.

A pesar de que en planta podríamos extender la dirección de los ejes de los nervios hasta que se encontrasen en un punto o en varios, este hecho no nos lleva a pensar que los nervios confluyen, solo lo hacen sus ejes. El recorrido de los nervios finaliza en su punto de arranque, es decir, donde se sitúa en intradós de los contornos de los nervios en su arranque.

\section{Enjarjes de nervios que convergen en un punto en el muro}

Esta solución podría ser la evolución directa de la anterior. Si llevamos los intradoses de esos nervios que salen separados hasta el punto en el que convergen sus direcciones y, además, lo hacemos coincidir con el muro, obtenemos enjarjes de nervios que emergen a modo de ramillete a partir de un punto del paramento.

Esta idea, que surge de manera sencilla si nos encontramos dibujando una bóveda en planta, parece ser una de las de las primeras soluciones de enjarjes de nervios que emergen directamente del muro que encontramos desde fechas muy tempranas. De este modo, localizamos ejemplos como en el claustro de Lincoln en 1290, ${ }^{52}$ el refectorio de la abadía de Bebenhausen en $1335,{ }^{53}$ la bóveda a los pies de la iglesia de Saint Florentinus en Niederhaslach (principios del XIV), ${ }^{54}$ el deambulatorio de la catedral de San Martín en Colmar (mediados del XIV), el claustro de la catedral de Narbona (finales del siglo XIV), la sala capitular de Perpiñán (principios del XV); o tres ejemplos del área valenciana: ${ }^{55}$ la cartuja de

\footnotetext{
52 Jenny Alexander, "Lincoln Cathedral Cloister", Journal of the British Archaeological Association, 159, (2006), 227

53 Jürgen Michler, „Studien zum Bebenhäuser Sommerrefektorium“, Jahrbuch der
Staatlichen Kunstsammlungen, n 35 , (1998), 44.

${ }^{54}$ Alexander Kobe nos ha facilitado esta fecha referente a la iglesia de Saint Florentius, sobre la que desarrolla su tesis doctoral. Alexander Kobe, Die Stiftskirche St. Florentinus in Niederhaslach im Kontext der Architektur und Skulptur des 14. Jahrhunderts am Oberrhein, (KöIn: Kunsthistorisches Institut-Philosophische Fakultät, Universität zu Köln), tesis doctoral inédita.
}

\footnotetext{
${ }^{55}$ Agradezco a Arturo Zaragozá Catalán haberme mostrado estos ejemplos. Carmen Pérez de los Ríos y Arturo Zaragozá Catalán, "Bóvedas de crucería con enjarjes de nervios convergentes que emergen del muro en el área valenciana, ss. XIV - XV", Octavo Congreso Nacional de Historia de la Construcción, vol. 2 (Madrid: Instituto Juan de Herrera, 2013): 833842; Arturo Zaragozá Catalán y Carmen Pérez de los Ríos, "Bóvedas de crucería con enjarjes de nervios convergentes que emergen del muro en el área valenciana. SS. XIV-XV", Bóvedas valencianas. Arquitecturas ideales, reales y virtuales en época medieval y moderna, (Valencia: Universidad Politécnica de Valencia, 2013). Ver "Enjarjes parecidos con diseños diferentes: el caso valenciano" a partir de la página 119.
}

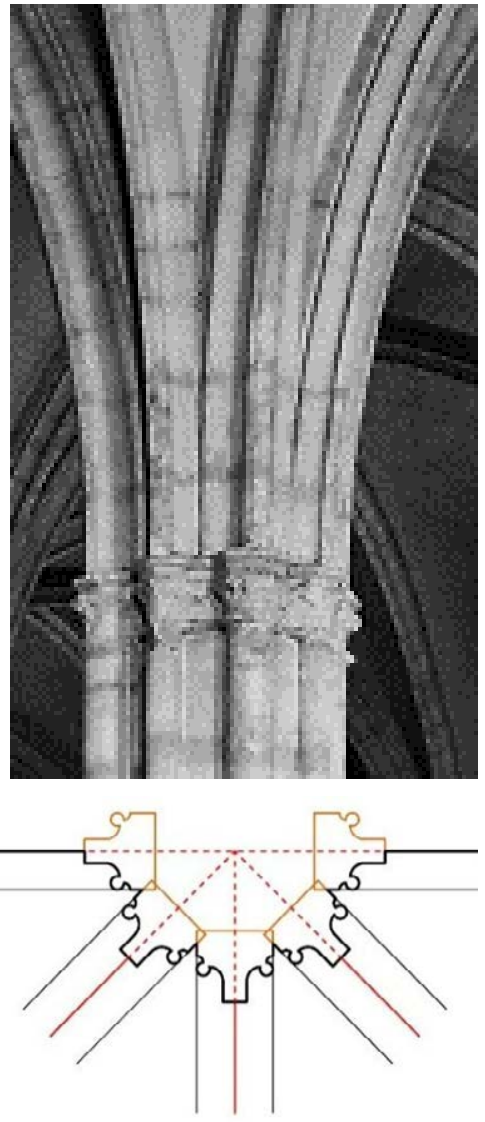

Fig. 27

Enjarjes de nervios independientes. Ejemplo: Sala de la Grand Audiencia en el Palacio de los Papas de Aviñón. 
Fig. 28

Enjarje de nervios que convergen en un punto. Ejemplo: Refectorio de la Abadía de Bebenhausen, Alemania.

Fig. 29

Enjarjes de nervios cruzados. Ejemplo: claustro de la catedral de Narbona.
Valdecristo (1385), el claustro del monasterio de la Trinidad (1445) y la sala capitular del monasterio de Santa María de la Valldigna (1448). Hemos seleccionado los ejemplos más tempranos que conocemos en Europa, así como los únicos que conocemos en el actual territorio español.
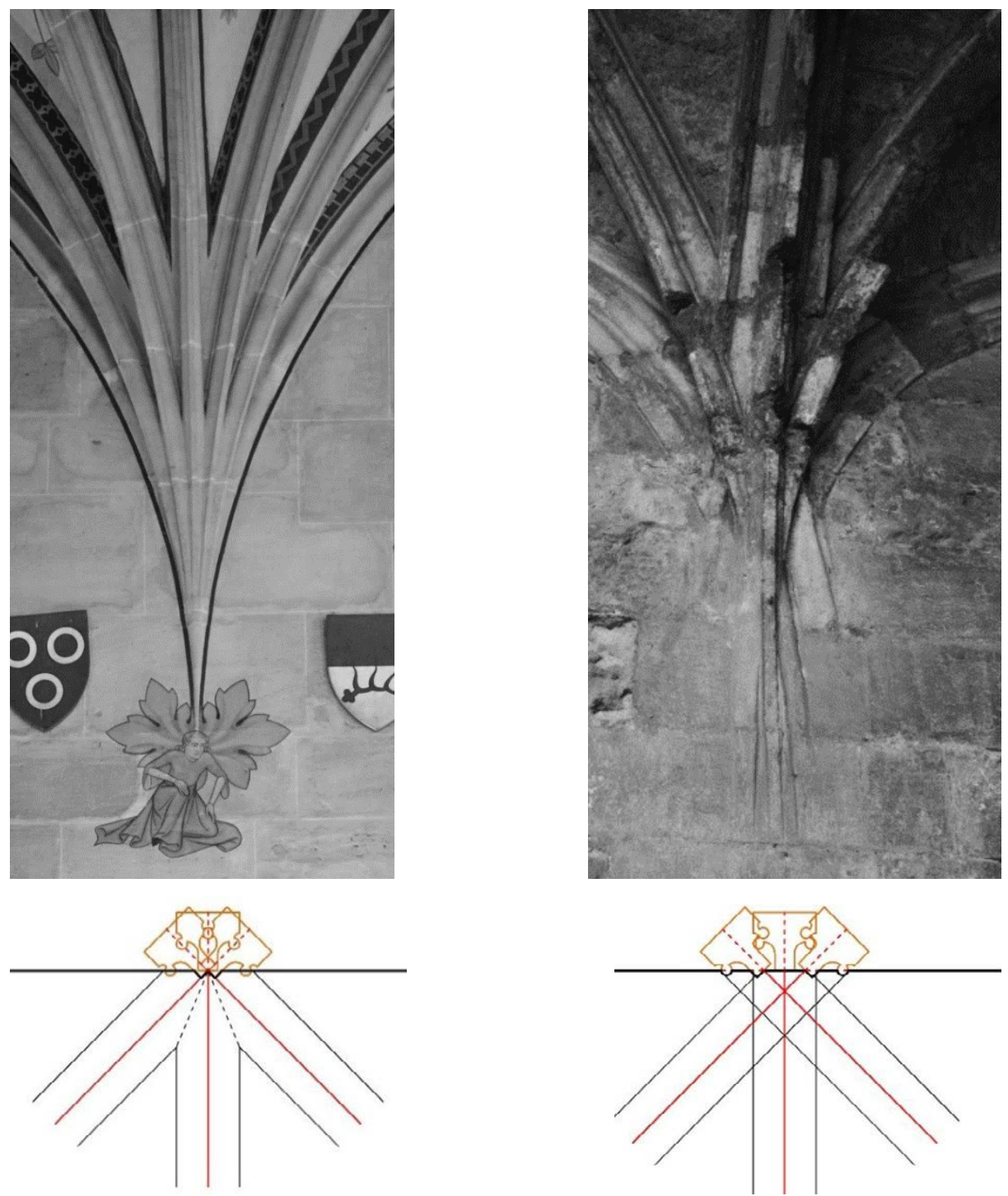

En la búsqueda, tan de actualidad, de la transferencia de formas, modelos o soluciones técnicas, estos enjarjes tan particulares ejemplifican perfectamente el hecho de que una idea puede surgir en diferentes lugares sin necesidad de conocer patrones previos. No nos parece acertado conjeturar que unos ejemplos inspirasen a otros o que esta idea viajase. Incluso, en el caso de Valencia, donde los tres enjarjes se encuentran relativamente cerca en la distancia y en el tiempo, como veremos más adelante, la solución técnica no es la misma.

\section{Enjarjes de nervios cruzados}

Se caracterizan por el cruce de los ejes y de los nervios en un punto alejado a cierta distancia del muro. Pueden darse cruces entre los ojivos o entre los ojivos con el nervio perpiaño. También pueden ser resultado del cruce del formero con el ojivo. A partir de ahí, muchas variaciones son posibles. Se 
generan mediante el movimiento del arranque del ojivo más allá del eje del perpiaño.

Los enjarjes de nervios que se cruzan no son tan comunes en los primeros estadios del gótico. Probablemente fueran considerados poco apropiados o demasiado arriesgados. Son fruto de la libertad que en cierto momento los constructores sintieron en el manejo de las reglas geométricas, compositivas y constructivas del gótico. Gracias a su mayor formación y maestría fueron capaces de proponer nuevas soluciones. ${ }^{56}$

El primer ejemplo lo encontramos en Beverley, Inglaterra, en el lateral de la nave de St. Mary de c. 1330-40. Aquí la solución aparece ligada a la necesidad de solucionar un encuentro complejo, no a la decisión premeditada de querer ejecutar un cruce de nervios. ${ }^{57}$ El primer enjarje que conocemos en el que este detalle se proyecta deliberadamente lo encontramos en la torre de Praga, bajo la factura de los Parler después de $1370 . .^{58}$
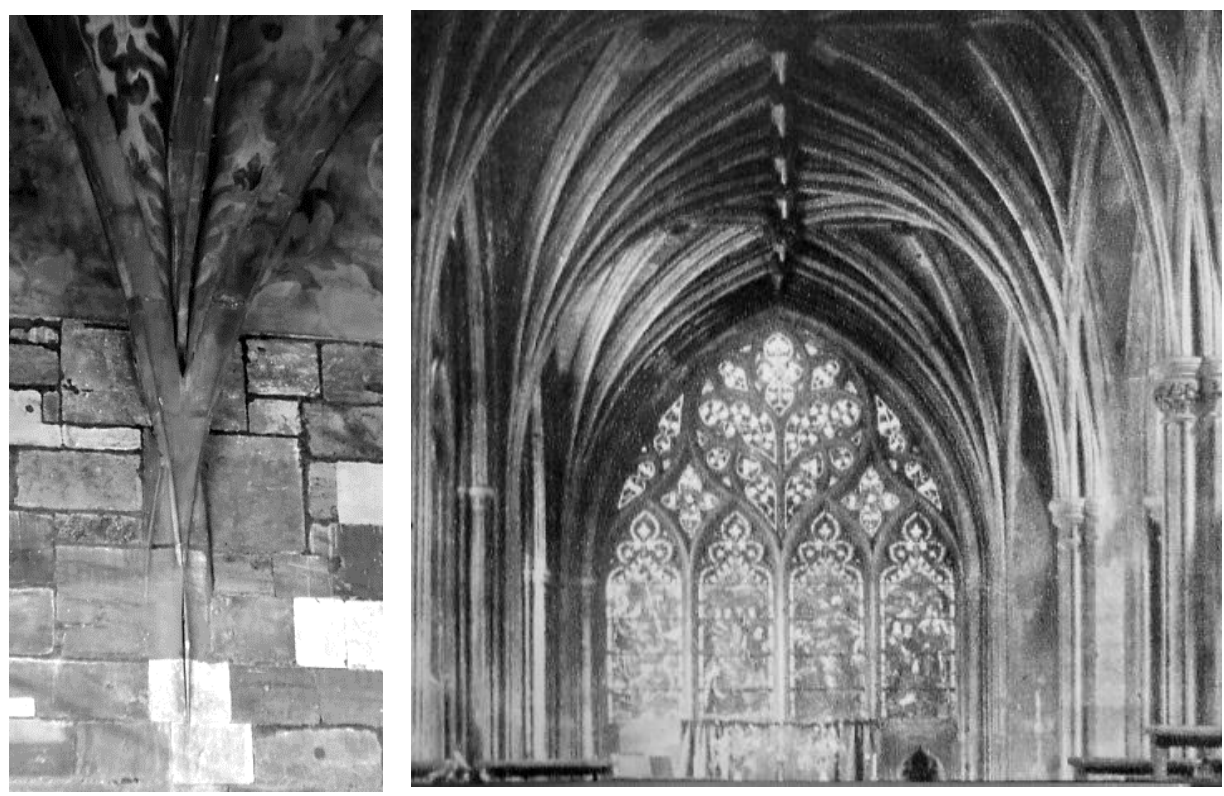

Fig. 30

A la derecha de la imagen se aprecian los cruces de nervios en la iglesia de St. Mary en Beverley. Imagen: Pevsner (1972, 182).

Fig. 31

A la izquierda: enjarje en la Torre de Praga.

De los ejemplos posteriores cabe citar las soluciones del claustro de la catedral de Narbona de finales del XIV, conformado principalmente por

\footnotetext{
${ }^{56}$ Enrique Rabasa Díaz y Carmen Pérez de los Ríos, "Late Gothic as an expression of procedure", Traces of making, Entwursfprinzipen von spätgotischen Gewölben. Shape, Design and Construction of Late Gothic Vaults, (Petersberg: Michael Imhof Verlag, 2014).

${ }^{57}$ Nikolaus Pevsner, The Buildings of England. Yorkshire: York and the East Riding, (London: William Clowes \& Sons, Limited, 1972), 182: "When the $\mathrm{N}$ arcade was built, three bays of the chancel aisle were made into a superb chapel with luscious tierceron-star vaulting. It means by the necessity of its supports that the corresponding arcade piers are totally different on their $\mathrm{N}$ and their $\mathrm{S}$ sides. The difficulty was partly solved by a brilliant intersecting of ribs, a device familiar in the C 15 and early C16 in Germany and France but here anticipated about 1330 or $1340 . "$

${ }^{58}$ Norbert Nußbaum y Sabine Lepsky, Das gotische Gewölbe. Eine Geschichte seiner Formund Konstruction, (Darmstadt: Wissenschaftliche Buchgesellschaft, 1999), 229.
} 

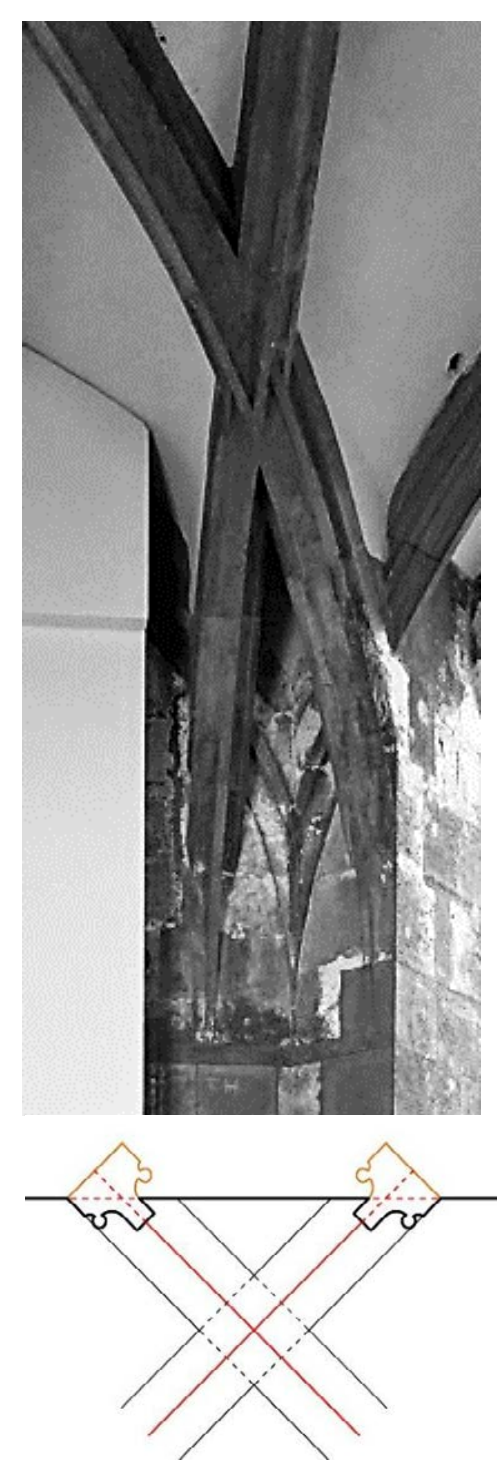

Fig. 32

Enjarje de nervios cruzados que nacen separados. Ejemplo: torre de la catedral de Viena. enjarjes donde los formeros se cruzan con los ojivos; a excepción de dos enjarjes: uno en el que los nervios convergen en un punto y otro en el que los ojivos se cruzan co n el perpiaño. Destacan también en la primera mitad del siglo XV la sala capitular de la catedral del San Juan el Nuevo de Perpiñán y la actuación de Guillem Sagrera en la Lonja de Palma de Mallorca o en la Sala dei Baroni en Castelnuovo en Nápoles. Estas soluciones de cruzamientos de nervios no se vuelven a adoptar de nuevo en el territorio peninsular, ${ }^{59}$ pero sí las encontramos frecuentemente en ejemplos franceses o alemanes, muchas veces en ejercicios de gran complejidad.

\section{Enjarjes de nervios cruzados que nacen separados}

En los enjarjes de nervios cruzados el cruce forma parte del enjarje, es decir, se resuelve en las piezas de lechos horizontales que traban con el muro. Sin embargo, hay un caso especial en el que los nervios salen separados del paramento y se cruzan a cierta distancia provocando, en ocasiones, que esta pieza de cruce deje de ser parte del enjarje y se convierta en una pieza contenedora del cruce de nervios. ${ }^{60}$

La mayoría de los ejemplos datan de finales de siglo XV o del XVI y se localizan principalmente en centroeuropa: Sajonia, Bavaria, BadenWurttemberg, Turingia, el valle del Rhin, Austria, etc.

Puede que los enjarjes de la torre sur de la catedral de San Esteban de Viena o los localizados en la torres de la catedral de Basilea en el primer tercio del siglo XV sean unos de los primeros ejemplos, a falta de un estudio más amplio sobre el tema. ${ }^{61}$ En Viena, la zona del cruce de los nervios ya no forma parte de las piezas de lechos horizontales que traban con el muro. Se localiza a continuación de una dovela que apoya en el enjarje, donde sí se cruzan las molduras de los nervios formeros. En Basilea, sin embargo, nos encontramos con un enjarje formado por una única pieza en la que se resuelve tanto la salida de los nervios como su cruce. Finaliza con un lecho horizontal en el que se ven los nervios separados tras su intersección.

\section{Enjarjes de nervios cruzados que nacen separados en España}

En España no existe un gran número de bóvedas en las que los nervios nazcan separados y después se intersequen, del mismo modo que los enjarjes con cruces de nervios son casi inexistentes con la excepción de los realizados por Guillem Sagrera. El primer ejemplo que ha llegado hasta

\footnotetext{
59 No tenemos noticia de más enjarjes de este tipo en España hasta el momento.

60 Es importante hablar de pieza de cruce de nervios influenciados por el término Rippenkreuzung del alemán, donde distinguen las claves que formalmente son nervios que se cruzan y las claves con cilindro para ocultar ese encuentro denominadas Schlubstein.

${ }^{61}$ Agradezco a Nicolás Menéndez González haberme mostrado estos ejemplos y su ayuda con la datación.
} 
nosotros de enjarjes con nervios separados que se cruzan lo encontramos en Burgos asociado la autoría del maestro Simón de Colonia, hijo de Juan de Colonia. ${ }^{62}$ Simón nace a mediados del siglo XV y se forma como cantero en la fábrica de la catedral de Burgos, donde trabaja con su padre. Tras la muerte de Juan, Simón se pone al frente de las obras que éste había dejado inconclusas, haciéndose cargo también de encargos propios. ${ }^{63}$

Parece ser que la primera obra documentada que ha llegado hasta nosotros de Simón con este tipo de enjarjes es esta de la capilla del Condestable en la catedral de Burgos ejecutada a finales del siglo XV. ${ }^{64} \mathrm{La}$ bóveda tiene planta ochavada, apoyándose la mitad de los nervios que salen del enjarje en ménsulas y la otra mitad en capiteles que descansan en pilastras. En ella los nervios nacen separados y se cruzan en su recorrido ascendente intersecándose uno con otro de manera simétrica dentro del propio enjarje. Al llegar estos nervios a las claves secundarias salen otros que configuran una estrella central resuelta con plementería calada.

La factura de los enjarjes de la capilla es de una calidad extraordinaria. La solución ejecutada no es sencilla de proyectar si no se tiene experiencia previa en el trabajo con este tipo de soluciones técnicas. La decisión de los cortes de las piezas y la destreza en la resolución de encuentros denota gran maestría, lo que nos podría llevar a imaginar la intervención de algún

\footnotetext{
62 Sobre Juan de Colonia, su llegada a Burgos y sus obras está en marcha la tesis: Nicolás Menéndez González, Zwischen dem Reich und Kastilien: Juan de Colonia und die spätgotische Architektur in Burgos 1440-1480 (Köln: Kunsthistorisches InstitutPhilosophische Fakultät, Universität zu Köln), tesis doctoral inédita.

${ }^{63}$ Sobre Simón de Colonia, entre otros: Leopoldo Torres Balbás, "Arquitectura gótica", Ars Hispanie, Vol 7, (Madrid: Plus Ultra, 1952); Rafael Domínguez Casas, Arte y etiqueta de los reyes católicos. Artistas, residencias, jardines y bosques, (Madrid: Alpuerto, 1993); Javier Gómez Martínez, El gótico español de la edad moderna: bóvedas de crucería, (Valladolid: Universidad de Valladolid, 1998); Javier Gómez Martínez, "El arte de la montea entre Juan y Simón de Colonia", Actas del Congreso Internacional sobre Gil de Siloé y la escultura de su época, (Burgos, 2001, 355-366); Begoña Alonso Ruiz, "Los tiempos y los nombres del tardogótico castellano", La arquitectura tardogótica castellana entre Europa y América, (Madrid: Silex ediciones, 2011).

${ }^{64}$ Especial interés tiene el capítulo dedicado a la Capilla de la Purificación, también llamada de los Condestables, en la tesis: Elena Paulino Montero, Patrocinio arquitectónico de los Velasco (1313-1512). Construcción y contexto de un linaje en la Corona de Castilla, (Madrid: Universidad Complutense, 2015), tesis doctoral, p. 360-431. Agradecemos a Elena habernos facilitado su texto antes de la lectura de su tesis, así como sus comentarios sobre la construcción de la capilla. Las obras se realizaron entre 1482 y 1494 según Domínguez Casas, Arte y etiqueta de los reyes católicos. Artistas, residencias, jardines y bosques, 52. Mientras tanto, Gómez Martínez sostiene que es en 1482 cuando el Condestable de Castilla junto con su esposa se reúnen para elegir el lugar de la construcción de la capilla y, a la muerte de éste, en 1492, la bóveda ya estaba cerrada. Ver Gómez Martínez, El gótico español de la edad moderna: bóvedas de crucería, 67.
} 
Fig. 33

Bóveda de la capilla del Condestable, catedral de Burgos.

Fig. 34

Rautenoktogon und Konsole, Wiener Sammlungen, $17.075 \mathrm{~V}$ (Böker, 2005, 392).
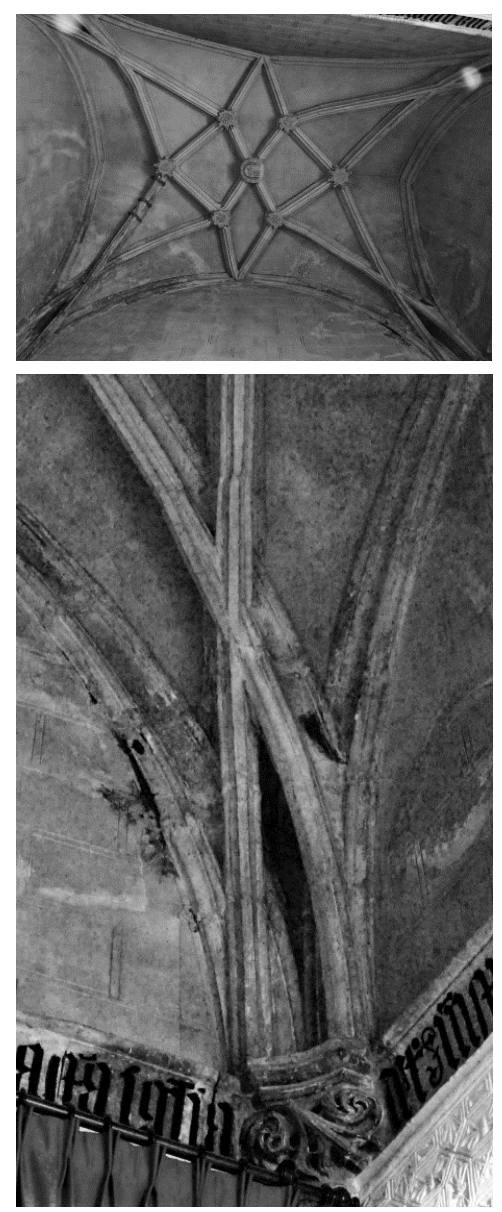

Fig. 35

Capilla funeraria de Juan Guas en la iglesia de los Santos Justo y Pastor, Toledo.
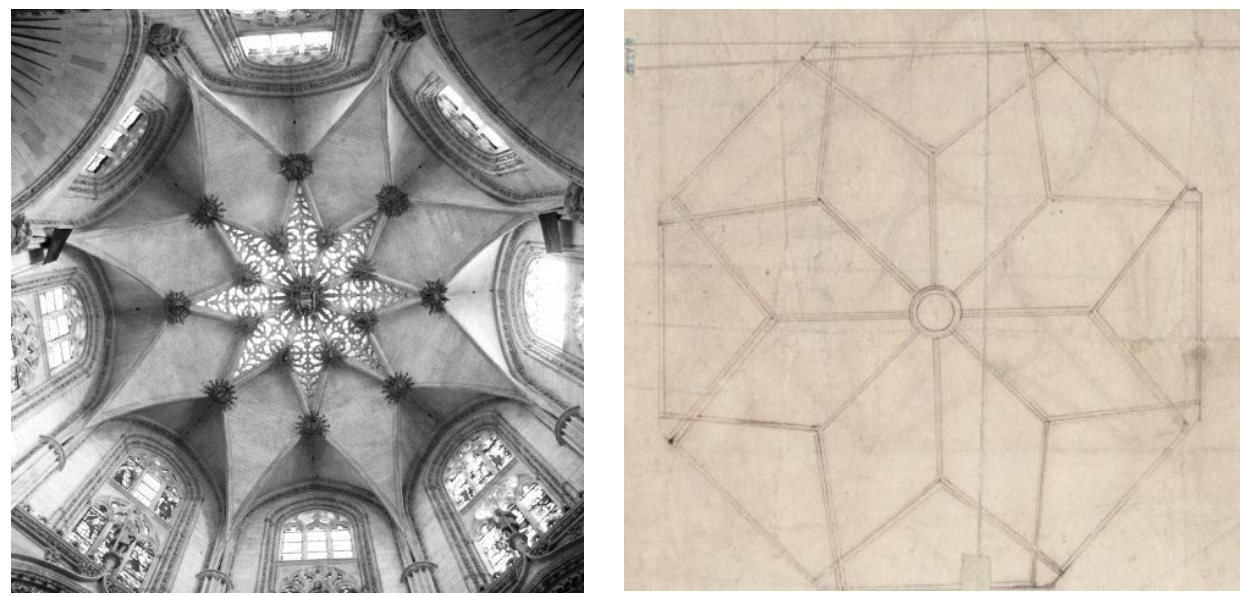

maestro de excepcionales conocimientos técnicos que seguramente habría llevado a cabo este tipo de soluciones con anterioridad. Se necesita experiencia para este diseño y ejecución.

No sabemos con qué repertorio técnico llegó Juan de Colonia a Burgos o cuáles eran los modelos que ya se conocían en la ciudad -tema del que se ocupa Nicolás Menéndez González- ni tampoco si la formación de Simón estaba exclusivamente basada en el repertorio de su padre y los maestros anteriores. Puede que incrementase sus conocimientos con algún viaje o se rodease de nuevos y expertos colaboradores. Lo único que podemos hacer al respecto es especular.

Encontramos este tipo de enjarjes con frecuencia en dibujos arquitectónicos centroeuropeos, siendo significativo uno de la colección de dibujos de Viena, conocida como Wiener Sammlungen. ${ }^{65}$ En el 17.075 v., Rautenoktogon und Konsole, y fechado c. $1515,{ }^{66}$ aparece la planta de una bóveda octogonal con un diseño en planta en que los enjarjes son similares a los del Condestable.

La actividad de Simón entre los años 1495 y 1500 presenta algunas sombras. Gómez Martínez sostiene que entre los años 1488 y 1497 trabaja en varias obras en Valladolid contratado por el obispo de Palencia. Parece ser que este le envía a Sevilla en 1495 para poner orden en la maestría mayor de la catedral y trazar la capilla de la Antigua, lo que permite a Gómez Martínez imaginar la posibilidad de que hiciera lo mismo en el caso de la catedral de Palencia. ${ }^{67}$ Domínguez Casas apunta que en 1495 parece ser que Simón estuvo en Toledo trabajando en el monasterio de San Juan

\footnotetext{
65 Johann Josef Böker, Architektur der Gotik. Gothic architecture. Bestandskatalog der weltgrößten Sammlung an gotischen Baurissen (Legat Franz Jäger) im Kupferstichkabinett der Akademie der Bildenden Künste Wien, (Salzburg: Pustet, 2005).

66 Böker, Architektur der Gotik. Gothic architecture. Bestandskatalog der weltgrößten Sammlung an gotischen Baurissen (Legat Franz Jäger) im Kupferstichkabinett der Akademie der Bildenden Künste Wien, 392.

67 Gómez Martínez, El gótico español de la edad moderna: bóvedas de crucería, 93; Domínguez Casas, Arte y etiqueta de los reyes católicos. Artistas, residencias, jardines y bosques, 54 .
} 
de los Reyes junto a Juan Guas y tasó las obras del claustro. Igualmente afirma que antes de que falleciera Juan Guas, en 1496, y de que Antón y Enrique Egas se hicieran con las obras de San Juan de los Reyes, Simón de Colonia ya había dado nuevas trazas para el cimborrio. ${ }^{68}$

Sobre la autoría y contribución de Simón de Colonia en ciertas bóvedas existen multitud de especulaciones, existiendo un vacío y una dispersión documental importante. Muchas atribuciones son fruto de afirmaciones repetidas en el tiempo.

En Toledo, por ejemplo, cubriendo la capilla funeraria de Juan Guas en la Iglesia de los Santos Justo y Pastor y con fecha de finalización de 1497 según la inscripción que recorre la capilla bajo la línea de imposta, se encuentra una bóveda con enjarjes de nervios que nacen separados y que posteriormente se cruzan y cuya autoría ha sido relacionada con el propio Simón. ${ }^{69}$ La bóveda es de planta rectangular, muy irregular y con un diseño sin nervios ojivos. ${ }^{70}$

El cruce entre los nervios se produce prácticamente a la mitad de la altura de la bóveda debido a su pequeña dimensión. Su factura es torpe, con cambios bruscos en la trayectoria de los nervios tras los enjarjes debido a la necesidad de ajustes o dificultades en la ejecución.

Ese mismo año de 1495, como señalamos anteriormente, parece ser que Simón es enviado a Sevilla. Allí realiza 3 ó 4 visitas a partir de esta fecha, prolongando su relación con la fábrica Sevillana hasta $1499 .{ }^{71}$ Se le atribuye la traza de la capilla de La Antigua, pues los autores ven probable su contribución por razones cronológicas. ${ }^{72}$ Aún es una incógnita el comienzo

${ }^{68}$ Domínguez Casas, Arte y etiqueta de los reyes católicos. Artistas, residencias, jardines y bosques, 53 .

${ }^{69}$ Gómez Martínez, El gótico español de la edad moderna: bóvedas de crucería, 141; Alonso Ruiz, "Los tiempos y los nombres del tardogótico castellano", 57.

${ }^{70}$ Sobre la capilla funeraria de Juan Guas, entre otros: Jose María Azcárate, Arquitectura gótica toledana del siglo XV, (Madrid: Instituto Diego Velázquez, del Consejo Superior de Investigaciones Científicas, 1958); Matilde Revuelta Tubino, Inventario artístico de Toledo, (Madrid: Centro Nacional de Información Artística, Arqueológica y Etnológica, 1983), 258266.

${ }^{71}$ Alfonso Jiménez Martín, Anatomía de la Catedral de Sevilla, (Sevilla: Diputación de Sevilla, Servicio de Archivo y Publicaciones, 2013), 125.

72 Sobre la capilla de la Antigua, entre otros: Torres Balbás, "Arquitectura gótica", 330; Domínguez Casas, Arte y etiqueta de los reyes católicos. Artistas, residencias, jardines y bosques; Gómez Martínez, El gótico español de la edad moderna: bóvedas de crucería, 48; Alfonso Jiménez Martínez et al, La catedral gótica de Sevilla: fundación y fábrica de la obra nueva, (Sevilla: Secretariado de Publicaciones Vicerrectorado de Investigación, 2006); Juan Clemente Rodríguez Estévez, "El Maestro Alonso Rodríguez", Los últimos arquitectos del gótico, (Madrid, 2010, 271-360); José Antonio Ruiz de la Rosa, Francisco Pinto Puerto y Juan Clemente Rodríguez Estévez, La prioral de El Puerto de Santa María. El proyecto gótico original, (Sevilla: Universidad de Sevilla, 2010), 93; Alfonso Jiménez Martín, Anatomía de la Catedral de Sevilla.

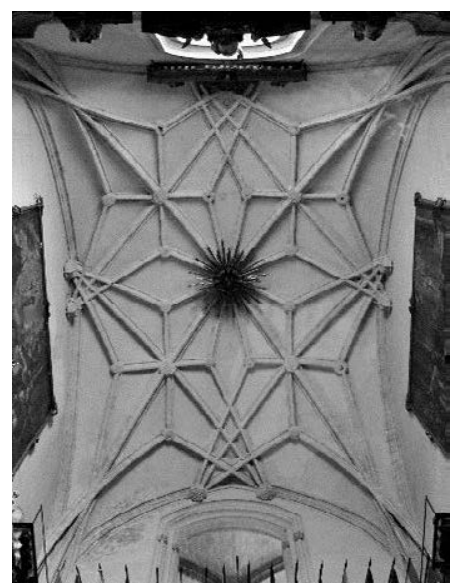

Fig. 36

Capilla de la Antigua en la catedral de Sevilla.

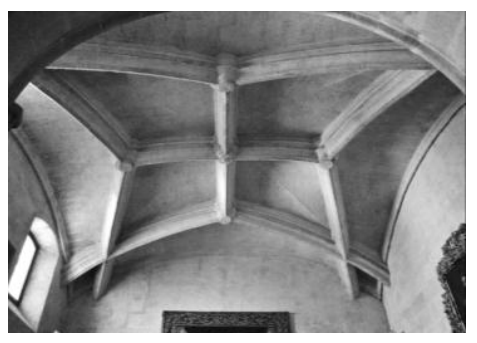

Fig. 37

Sacristía de la capilla de la Antigua en la catedral de Sevilla. 


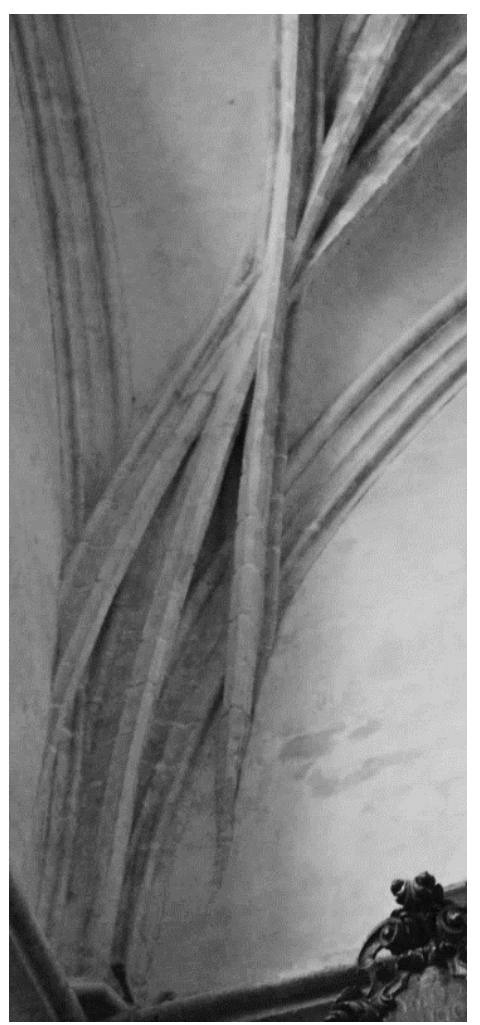

Fig. 38

Enjarje en la capilla de la Antigua en la catedral de Sevilla. de la obra. Sólo se han podido documentar unas obras de cantería y decoración entre 1496 y $1497 .^{73}$

Se ha señalado también que en algunas ocasiones Simón trazaba obras y no participaba en su construcción, sino que quedaban a cargo de otros maestros. ${ }^{74} \mathrm{El}$ caso de La Antigua nos plantea muchas dudas a este respecto, pues a pesar que podamos admitir que Simón de Colonia no la hubiera llevado a cabo, ${ }^{75}$ la dificultad técnica de la solución del enjarje debería haber recaído en alguien con experiencia en este problema específico. ¿Quizás alguien del equipo del maestro que permanece en Sevilla para guiar los trabajos? Dudamos que los maestros sevillanos del momento, que no habían ejecutado un enjarje de estas características, fuesen capaces de acometer tal ejercicio sin ayuda.

La bóveda, además, es de dimensiones importantes, 10,42 m por 13,80 y su trazado se basa en la repetición de 4 bóvedas de terceletes que, a diferencia de otros modelos existentes, se entrelazan entre sí dando lugar a un interesante trazado en planta. El análisis llevado a cabo por Martín Talaverano parece indicar que el control espacial de la bóveda se basa en la utilización de un arco sobre el que se definen las alturas de las claves. Una vez que esas alturas están definidas se procede al trazado de los arcos que las coordinan. ${ }^{76}$

Los enjarjes presentan la particularidad de introducir un nervio ojivo entre el cruce de los terceletes, no presente en las bóvedas anteriores y que además sale adelantado apoyándose en un elemento sobre la línea de imposta. Los terceletes salen directamente del muro. Tras una visita a la capilla hemos podido observar que las juntas horizontales, es decir las pertenecientes al enjarje, acaban antes de que se produzca el cruzamiento, por lo que probablemente sea una pieza de cruce de nervios, como ocurría en el caso de Viena. ${ }^{77}$

\footnotetext{
${ }^{73}$ Alfonso Jiménez Martín, Anatomía de la Catedral de Sevilla, 292-293.

${ }^{74}$ Gómez Martínez, "El arte de la montea entre Juan y Simón de Colonia", 358.

${ }^{75}$ Francisco Pinto Puerto atribuye su autoría a Alonso Rodríguez. Francisco Pinto Puerto, "Fábrica y forma del templo gótico", La catedral gótica de Sevilla: fundación y fábrica de la obra nueva, (Sevilla: Secretariado de Publicaciones Vicerrectorado de Investigación, 2006), 270.

${ }^{76}$ Rafael Martín Talaverano, Rosa Senent Domínguez y Carmen Pérez de los Ríos, "Late German Gothic Methods of Vault Design and Their Relationships with Spanish Ribbed Vaults", Nuts and Bolts of Construction History. Culture, Technology and Society, (Paris, 2012), 3:87-88.

${ }^{77}$ Agradezco a Francisco Pinto Puerto haberme facilitado ver el enjarje desde la pasarela superior de la bóveda y a Ana López Mozo haberlo fotografiado y hacerme llegar las imágenes en las que se pueden ver con claridad las juntas. Quedamos a la espera de poder realizar un análisis más exhaustivo del elemento tras una toma de datos con estación total para poder asegurar con total seguridad estas apreciaciones sobre el despiece del enjarje.
} 

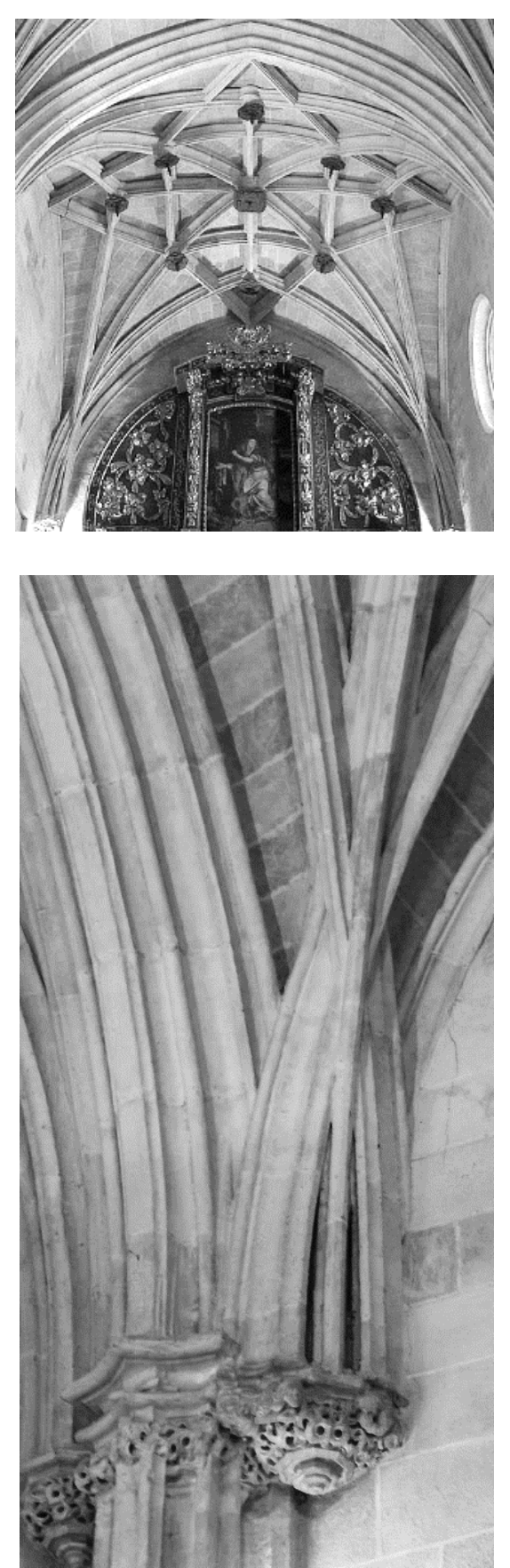
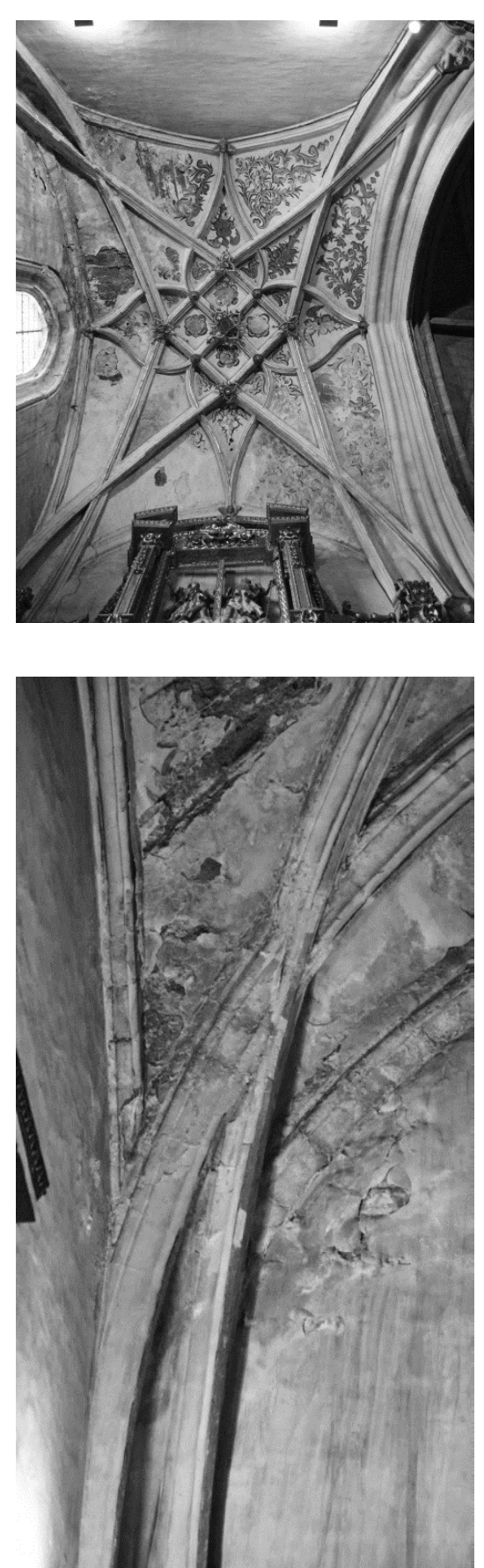

Fig. 39

Bóveda y enjarje en la bóveda en el Hospital de San Sebastián, Córdoba. Imagen: Enrique Rabasa Díaz.

Fig. 40

Bóveda y enjarje de la capilla de la Purísima Inmaculada en la catedral de Palencia.

También destaca en la bóveda de La Antigua el encuentro de los ojivos y terceletes de las 4 pequeñas bóvedas en la mitad del formero. Los nervios salen aparentemente de unas ménsulas colocadas un poco más abajo del nervio formero intersecándose como si se tratara de dos abanicos. Sin embargo los nervios mueren directamente en el muro, siendo las ménsulas simples elementos cuya función es ocultar un encuentro no deseado.

Junto a la capilla de La Antigua se localiza la sacristía de La Antigua, que también tiene una bóveda con dos terceletes que se cruzan. Se diferencia porque los nervios de la bóveda no salen tangentes al muro y el cruce no pertenece de ningún modo al enjarje, pues es una pieza de cruce de nervios que se sitúa a continuación de dos dovelas. Cabe destacar la 
configuración de la plementería, con aristas marcadas a modo de bóveda de arista, combinándose con la bóveda nervada.

Se ha querido atribuir a Simón de Colonia también la bóveda de la capilla del Hospital de San Sebastián en Córdoba, realizada entre 1513-1516. ${ }^{78}$ La planta es aparentemente cuadrada, cubierta por una bóveda de crucería con ojivos y terceletes. Hay un segundo orden de nervios que unen las claves de los formeros dibujando un cuadrado en planta y otros nervios que unen la intersección de los anteriores con los ojivos entre sí formando otro cuadrado girado.

Como en Sevilla, se vuelve a recurrir a la utilización de ojivos. Por lo tanto, el enjarje posee tres nervios que se intersecan aproximadamente en un punto, saliendo cada uno de diferente situación pero a la misma altura. Ningún nervio muere en el muro, sino que se apoyan en una ménsula. Además, el nervio ojivo sólo forma parte del despiece de los terceletes en la intersección. Por debajo y por encima, se labra con juntas horizontales independientemente de los otros.

Es también durante estos últimos años del siglo XV cuando se lleva a cabo otra bóveda que también ha sido atribuida a Simón de Colonia, la bóveda de la capilla de la Purísima Inmaculada en la catedral de Palencia. ${ }^{79}$ Situada en el lado norte de la catedral, junto al primer tramo de la nave lateral tras el transepto, es de planta rectangular, con dos terceletes saliendo desde cada una de las esquinas del rectángulo a un cuadrado central girado con respecto a la planta. De los medios lados del cuadrado y la clave ventral salen nervios combados que llegan a la clave de los formeros. El cruce de los nervios se localiza a bastante altura y ya no forma parte del enjarje, de

Fig. 41

Derecha: Enjarje en la iglesia de Santa María del Campo, Burgos. Izquierda: Enjarje en Santa María la Real en Sasamón, Burgos.
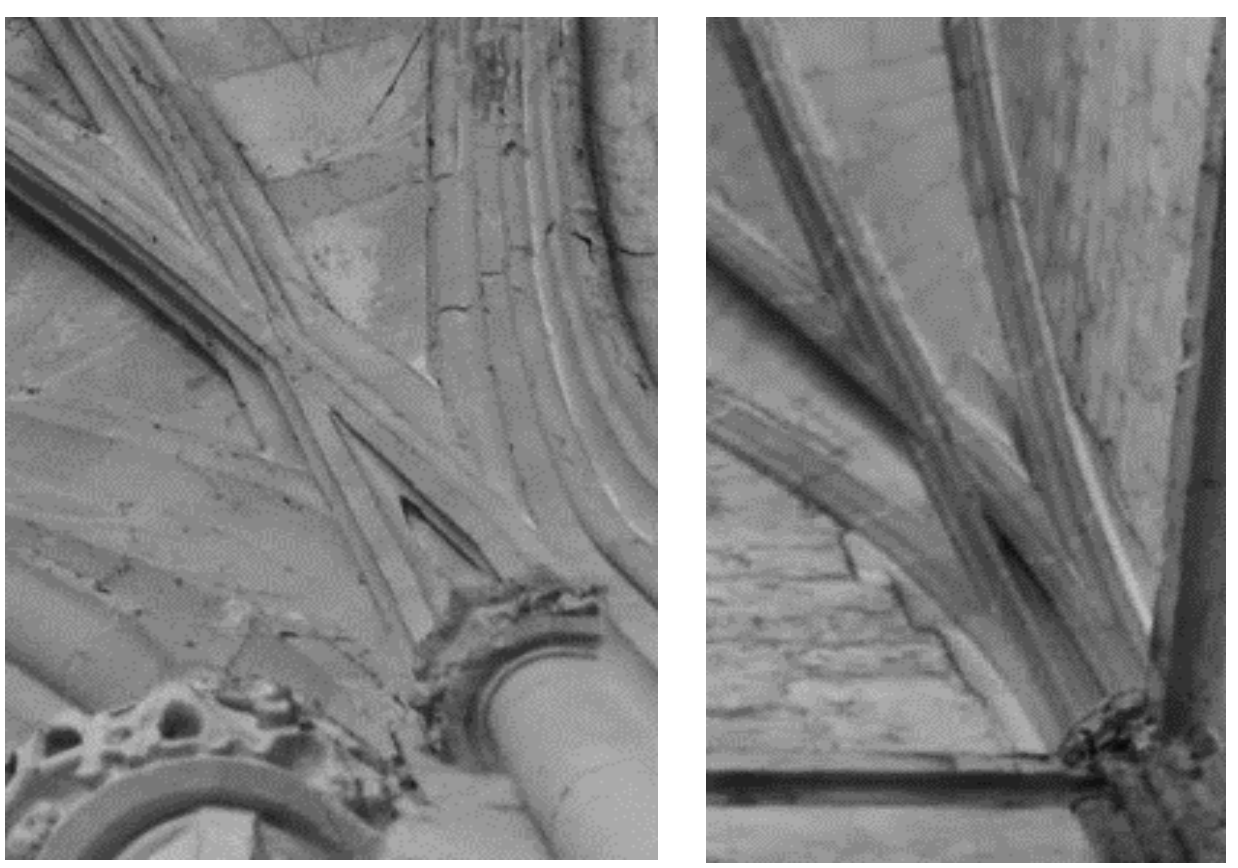

78 Gómez Martínez, El gótico español de la edad moderna: bóvedas de crucería, 142.

${ }^{79}$ Gómez Martínez, El gótico español de la edad moderna: bóvedas de crucería, 93; Begoña Alonso Ruiz, "Los tiempos y los nombres del tardogótico castellano", 57. 
las piezas horizontales que traban con el muro, sino que es una pieza de cruce de nervios como ocurría en La Antigua. Entre el enjarje y ella se sitúan algunas dovelas.

En los alrededores de Burgos, en Santa María del Campo y en Santa María la Real en Sasamón, hemos localizado también otros dos ejemplos con nervios que salen separados y se cruzan.

A finales del siglo XV se comienza a construir una nueva iglesia en Santa María del Campo sustituyendo la cabecera de la iglesia existente por una nueva. La obra no llegó a terminarse, pero entre las bóvedas que se acabaron hay una de planta rectangular que muestra un enjarje compuesto por dos terceletes que se cruzan. Es difícil entender el enjarje debido a que se encuentra pintado posiblemente con un despiece que no se corresponde con el real. ${ }^{80}$

Del mismo modo, en Santa María la Real de Sasamón, durante los trabajos de ampliación de la iglesia en su lado sur hacia 1500, se construyó una bóveda, hoy embebida en parte por la construcción de una torre posterior, que presenta una solución similar aunque más tímida. Los terceletes arrancan de los capiteles muy próximos y el cruce de los nervios no es tan marcado. ${ }^{81}$

\section{Enjarjes con cruces de molduras}

Los enjarjes en los que las directrices de los nervios, y por ello los propios nervios, no se cruzan pero sí sus molduras son numerosos. Su esquema en planta es similar al de los nervios independientes -en realidad lo sonpero sus perfiles en el arranque se intersecan debido a la proximidad de unos nervios con otros.

A pesar de poder haberlos incluido en el primer apartado Enjarjes de nervios independientes como un caso especial, hemos decidido desarrollar su problemática de manera individual debido a que son los enjarjes que acarrean mayores confusiones a la hora de ser descritos y estudiados. Muchos autores al ver entrecruzamientos los denominan enjarjes de nervios cruzados, cuando en realidad ningún nervio se cruza.

Encontramos enjarjes con cruces de molduras prácticamente desde un primer momento en que se empiezan a construir bóvedas nervadas. Los maestros proyectan la bóveda y el perfil de los nervios sin que para ellos suponga un inconveniente las intersecciones entre las molduras en el

\footnotetext{
${ }^{80}$ Sobre Santa María del Campo, entre otros: Salvador Andrés Ordax, "Castilla y León 1", La España gótica, (Madrid: Encuentro, 1989), 195-200; Javier Rivera, Catálogo monumental de Castilla y León: bienes inmuebles declarados, (Valladolid: Junta de Castilla y León, Consejería de Cultura y Turismo, 1995), 272-273.
}

81 Juan Ruiz Carcedo, Sasamón, (Burgos: Fundación Amaya, 2006), 41.
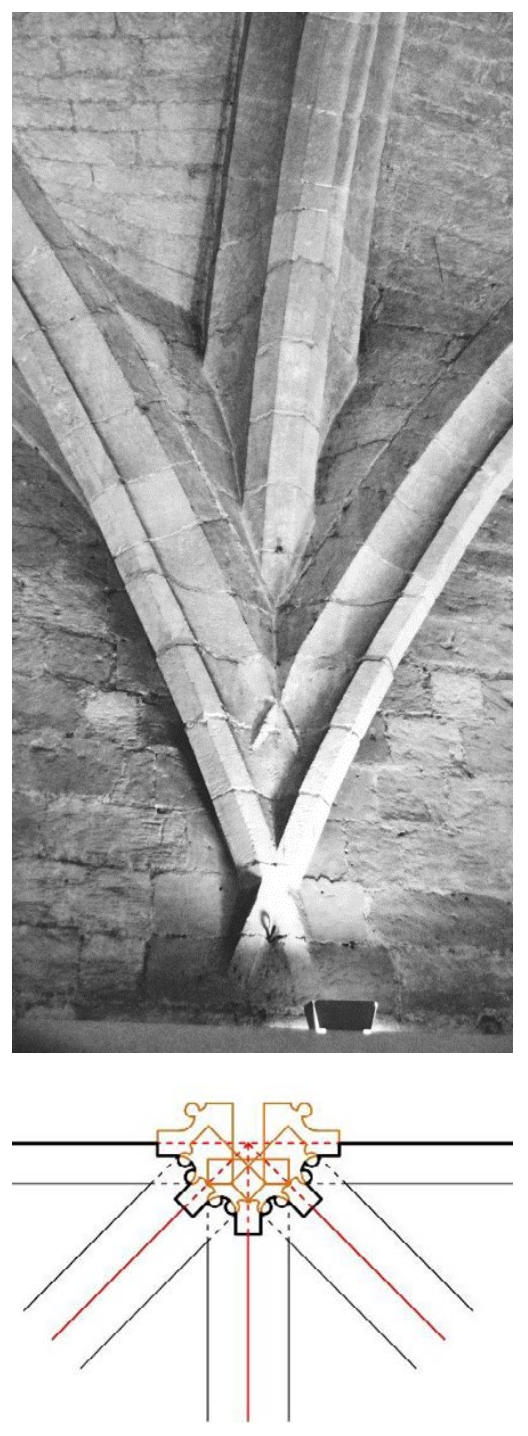

Fig. 42

Enjarjes con cruces de molduras. Ejemplo: Sala de teología en el Palacio de los Papas de Aviñón. 
Fig. 44

Nave de la iglesia de Saint Florentinus en Niederhaslach.

Fig. 43

Enjarje en la catedral de Saint Pierre en Montpellier. arranque debido a su proximidad. Este problema se soluciona de manera natural durante la ejecución de los trabajos en la piedra.
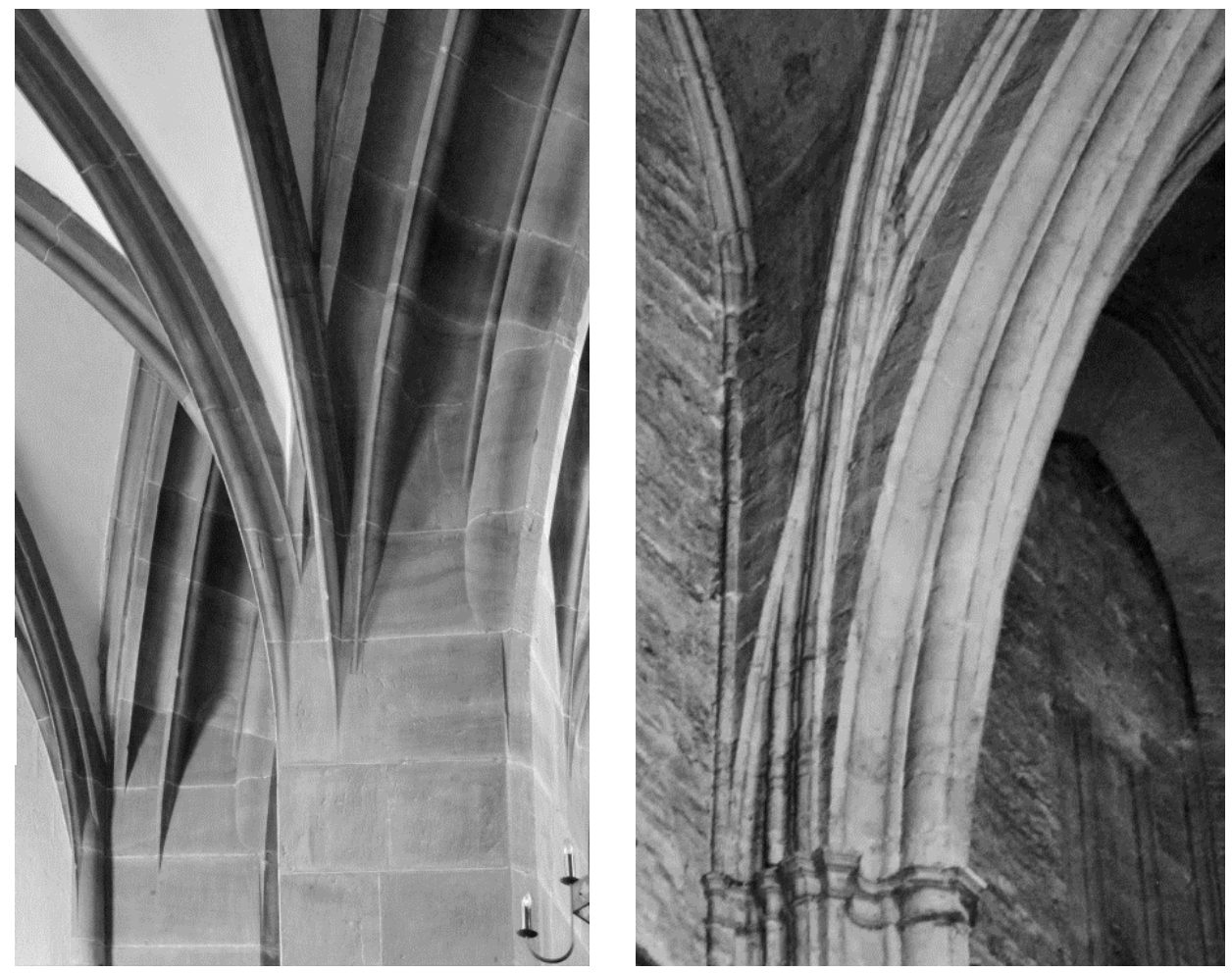

Por lo tanto, podríamos decir que, en muchos casos, estas intersecciones son fruto de la casualidad, es decir, aparecen como consecuencia de un determinado proyecto. No son pensadas desde un primer momento. Esto es lo que diferencia principalmente estos enjarjes de los de nervios cruzados. Cuando se cruzan nervios, la idea del proyecto de ese elemento es precisamente esa, cruzarles. La intersección se provoca y se busca, no se obtiene como mero resultado la reunión de nervios.

En Alsacia, por ejemplo, encontramos enjarjes de principios del XIV en la iglesia de Saint Florentinus de Niederhaslach ${ }^{82} y$, en las mismas fechas, pero más tímidamente en la Frauenkirche de Esslingen.

En Inglaterra hay soluciones muy tempranas como el cruzamiento de molduras de los arcos torales de la zona inferior del cimborrio de la catedral de Canterbury o los de la catedral de York. ${ }^{83}$

Joan Domenge i Mesquida ${ }^{84}$ ha localizado ejemplos de gran interés en el sur de Francia como los enjarjes de la nave y del pórtico de la fachada

\footnotetext{
82 Kobe, Die Stiftskirche St. Florentinus in Niederhaslach im Kontext der Architektur und Skulptur des 14. Jahrhunderts am Oberrhein.

${ }^{83}$ En el cimborrio de la catedral de Canterbury se cruzan las molduras de los arcos fajones. Su construcción comienza en 1378. En Peter Meyer, English Cathedrals, (London: Thames and Hudson, 1961), 17.

${ }^{84}$ Joan Domenge i Mesquida, Guillem Sagrera, Gli ultimi indipendenti. Architetti del gotico en el Mediterraneo tra XV e XVI secolo, (Palermo: Edizioni Caracol, 2007), p. 58-93; Joan
} 
oeste de Saint Pierre en Montpellier (1364-1372), ${ }^{85}$ la sala de teología del Palacio de los Papas de Aviñón o enjarjes en el claustro de la Chaise-Dieu de mediados del XIV. ${ }^{86}$ También hay ejemplos interesantes en el Mont Saint Michel a mediados del XV, ${ }^{87}$ o en la colégiale de Saint Didier en Aviñón. ${ }^{88}$

En España encontramos ejemplos de intersecciones de molduras en la iglesia románica de San Marcos en Salamanca o en el claustro viejo de la catedral de Burgos, donde se utiliza esta solución de manera premeditada en toda una panda. ${ }^{89}$

Es imposible realizar una compilación de todos los casos existentes pero seguramente es una solución adoptada con bastante frecuencia. En España encontramos significativos ejemplos a partir de la segunda mitad del XV como el de la capilla de Álvaro de Luna o de Santiago en la catedral de Toledo, la capilla Real de Granada; o los asociados al taller de Juan Guas. Por ejemplo, en el claustro de la catedral de Segovia, el claustro del monasterio de El Paular, San Juan de los Reyes en Toledo, etc.

En el Levante cabe destacar el claustro y la zona inferior de los arcos torales del cimborrio de la catedral de Barcelona, la sala capitular de la catedral de Palma, el monasterio de la Trinidad en Valencia, ${ }^{90}$ la Lonja de Valencia, etc.

Domenge i Mesquida, Guillem Sagrera et lo modern de son temps, Revue de I'art, $\mathrm{n}^{\circ} 166$ 4, (2009), 77-90.

${ }^{85}$ En abril de 1365 se traza el portal. Los trabajos en la catedral comienzan en 1364 y estaba terminada en 1372. François Robin, Midi Gothique. De Béziers à Avignon, (Paris: Picard, 1999), 323

${ }^{86}$ El 3 de mayo de 1344, Clemente VI, dos años antes de ser nombrado papa, anuncia la reconstrucción de la Chaise Dieu. En 1350 la obra está acabada: Anne Courtillé, Auvergne, Bourbonnais, Velay Gothiques. Les édifices religieux, (Paris: Picard, 2002), 155. Del claustro sólo queda la galería norte y oeste. Las claves de las bóvedas indican que la galería norte fue construida entre 1378-1420. La galería oeste, puede datarse entre 1390-1417: Courtillé, Auvergne, Bourbonnais, Velay Gothiques. Les édifices religieux, 174.

${ }^{87}$ La cripta se comienza en 1446 y es acabada en 1450. François Enaud, Le Mont SaintMichel, (Caisse Nationale des Monuments historiques, 1972).

88 Robin, Midi Gothique. De Béziers à Avignon, 155. La iglesia se consagra en 1359. Hay un cruce de molduras en el enjarje que recuerda al de la catedral de Montpellier.

${ }^{89}$ Agradezco a Alberto Calderón González haberme mostrado este enjarje. Para su datación: Henrik Karge, Die Kathedrale von Burgos und die Spanische Architektur des 13 Jahrhunderts: Granzosische Hochgotik in Kastilien und León, (Berlin: Gebr Mann, 1989), 177.

90 Arturo Zaragozá Catalán, "Real Monasterio de la Trinidad", Monumentos de la Comunidad Valenciana, T. X, (Valencia, 1995), p. 140-149; Mercedes Gómez Ferrer, "La cantería valenciana en la primera mitad del XV: El maestro Antoni Dalmau y sus vinculaciones con el área mediterránea", Anuario del Departamento de Historia y Teoría del Arte, Vols IX-X, (Madrid, 1997-1998), pp. 91-105; Arturo Zaragozá Catalán y Mercedes Gómez Ferrer, Pere Compte arquitecto, (Valencia: Ajuntament de València y Generalitat Valenciana, 2007); Mercedes Gómez Ferrer y Arturo Zaragozá Catalán, "Lenguajes, fábricas y oficios en la arquitectura valenciana del tránsito entre la Edad Media y la Edad Moderna. (1450-1550)", Artigrama, núm. 23, (2008), p. 149-184; Mercedes Gómez-Ferrer, El maestro de la catedral de Valencia Antoni Dalmau (act. 1435-1453), (s/f).

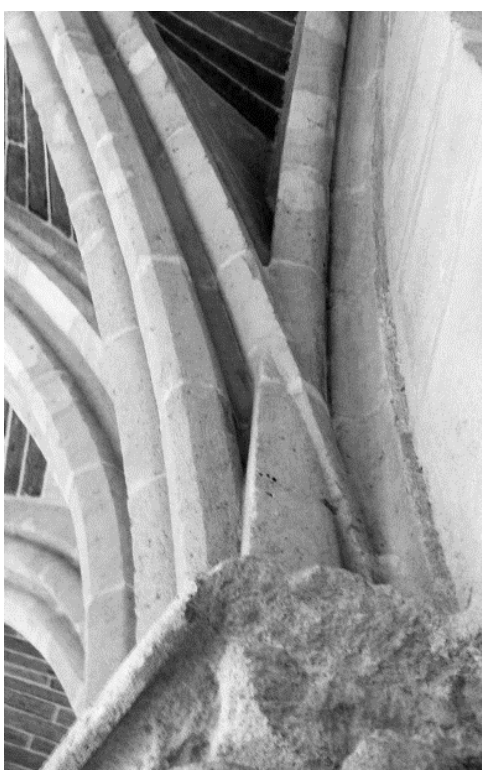

Fig. 45

Enjarje en el claustro de la catedral de Burgos. 
A partir de los últimos años del XV y el siglo XVI es imposible contabilizar estas soluciones debido a su gran difusión en Europa.

Fig. 46

De izquierda a derecha: Capilla de Álvaro de Luna en la catedral de Toledo, enjarje en la iglesia de San Juan de los Reyes en Toledo, enjarje en la bóveda bajo el coro de San Juan de los Reyes en Toledo, enjarje en el claustro de la catedral de Segovia y enjarje de la Lonja de Valencia.
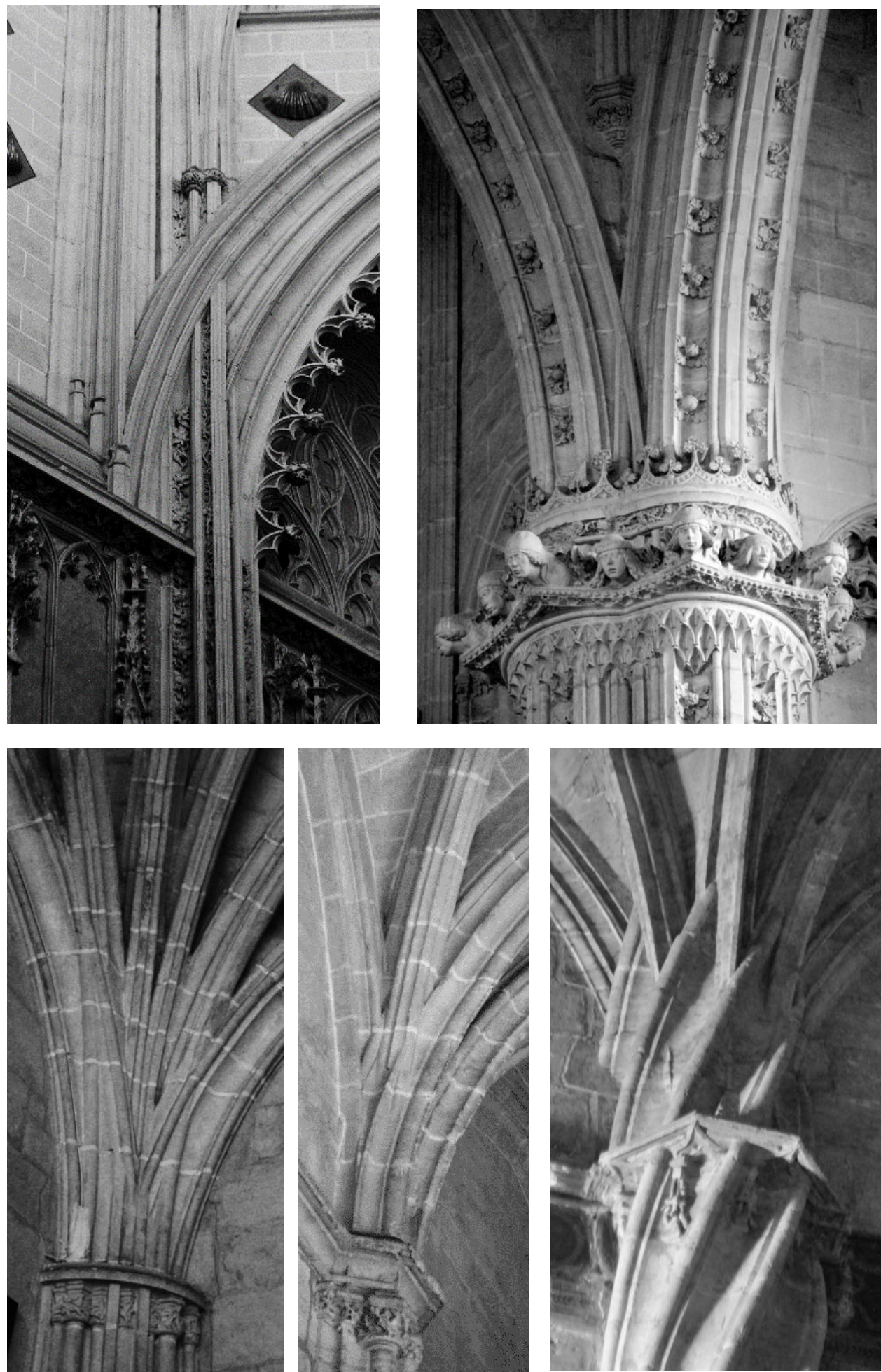


\section{TECNOLOGÍA}

\subsection{Diseño: el dibujo como herramienta del proyecto}

Para poder comprender los procedimientos que hacen posible el diseño y construcción en el medievo se han de valorar los recursos geométricos, gráficos y técnicos que suponemos manejaban los maestros. Si bien es cierto que el objeto de estudio de la presente investigación -los enjarjesno ha dado lugar a estudios monográficos, el análisis del repertorio existente puede ayudar a comprender y explicar su problemática.

Hemos realizado un recorrido por los dibujos medievales que hemos podido consultar centrado en la búsqueda de indicios relativos a los procedimientos gráficos que pudieron ser utilizados para el proyecto y diseño de enjarjes, los trazados concernientes a la información necesaria para su construcción, las indicaciones en manuscritos sobre su problemática, etc. De este modo pretendemos acercarnos al modo de pensamiento de los maestros góticos, a su sistema de representación, al conocimiento de las trazas que consideraban necesarias para la construcción, a su modo de trasmitir y explicar ideas, etc.

Para abordar la información disponible hemos establecido tres grupos de documentación gráfica, pues creemos que cada uno responde a una problemática y tiene una vocación diferente. En primer lugar, se hace pertinente estudiar los dibujos de arquitectura a escala reducida donde se representan generalmente los edificios en planta y alzado. En segundo lugar, los manuscritos y tratados medievales, que dan idea del conocimiento que se quiere explicar y trasmitir. Y finalmente, los dibujos a escala 1/1, las también llamadas monteas o dibujos constructivos que eran utilizados para la resolución del replanteo del objeto a construir y los problemas de su aparejo.

En cada caso haremos un recorrido partiendo de ejemplos tempranos, centrándonos en la búsqueda de dibujos e información referentes a enjarjes o elementos similares que nos ayuden en su comprensión. Si bien es cierto que en algunos casos las indicaciones son escasas o no demasiado representativas, pensamos que evidenciar también este hecho puede resultar relevante para futuros investigadores que se interesen por el tema.

Queremos dar testimonio de que hasta el momento son casi inexistentes los dibujos que hablen de procedimientos de diseño de enjarjes, tanteos en planta, etc. No obstante sí que hemos localizado y analizado la poca información gráfica referente a los mismos en dibujos de arquitectura, así como la documentación gráfica necesarias para su ejecución, como es el caso de una montea gótica en la que aparecen los trazados precisos para su talla. Apoyándonos en ella, en las evidencias arqueológicas presentes 
en enjarjes construidos, o en ruinas, y en investigaciones como la de Robert Willis o Luc Mojon ${ }^{91}$ pretendemos clarificar el procedimiento de trazado, talla y construcción del enjarje de la bóveda nervada.

\subsubsection{El dibujo de arquitectura (a escala reducida)}

El dibujo es una herramienta básica para el diseño, el pensamiento, la trasmisión de ideas o la resolución de problemas. Robert Branner sostiene que los constructores romanos y bizantinos ya utilizaban dibujos arquitectónicos que contenían la información necesaria para la construcción cuestionando, sin embargo, su utilización a comienzos de la Edad Media. De este primer periodo han llegado hasta nosotros dibujos programáticos como el plano de Saint-Gall -de alrededor del año 820- que no contiene ninguna información técnica, o dibujos a modo de perspectivas incluidos en manuscritos que eran elaborados una vez el edificio había sido acabado. ${ }^{92}$

También explica Branner que esta falta de documentación antes del siglo XIII es debida a que los maestros obraban mediante principios geométricos que permitían el trabajo a escala real basado en proporciones y reglas aritméticas. Con estacas de madera, cuerdas e instrumentos muy sencillos se podía realizar el replanteo y trazado de la planta. Además, dicha planta y su correspondiente alzado eran desarrollados en la mente por el arquitecto, quien dirigía los trabajos de manera continuada. Esto provocaba que su presencia en obra fuera indispensable y su abandono del lugar impidiera la continuación de la obra. ${ }^{93}$

Sin embargo, otros autores no comparten esta idea de que se prescindiera del dibujo arquitectónico antes del siglo XIII. Por ejemplo, Harvey señala que el dibujo es una herramienta tan necesaria para la trasmisión de ideas entre el diseñador y los trabajadores como en la música lo es la notación musical. Sin ella, los intérpretes no serían capaces de tocar lo que el compositor ha creado. Por supuesto, indica que no sería indispensable que cada dibujo estuviese contenido en un único soporte o que fuesen conservados una vez se hubieran acabado los trabajos y su uso dejase de ser necesario. El hecho de que no hayan llegado hasta nosotros no quiere

\footnotetext{
91 Robert Willis, "On the construction of the vaults of the Middle Ages", Transactions of the Institute of British Architects (London: RIBA, [1842] 1910), vol.1, 1-69. Luc Mojon, "Analyse eines spätgotischen Tas-de-charge", St. Johannsen Saint-Jean de Cerlier.Beiträge zum Bauwesen des Mittelalters aus den Bauforschungen in der ehemaligen Benediktinerabtei, 1961-1984, (Berna: Staatl. Lehrmittelverl, 1986).

92 Robert Branner, "Villard de Honnecourt, Reims and the origin of Gothic architectural drawing", Gazette des Beaux- Arts (1963), 129.

${ }^{93}$ Branner, "Villard de Honnecourt, Reims and the origin of Gothic architectural drawing", 129
} 
decir que no existiesen o no se utilizasen. ${ }^{94}$ Robert Bork también es partidario de la idea de que seguramente en los primeros estadios del gótico se realizasen dibujos, al menos para los proyectos más ambiciosos. ${ }^{95}$

Es a mediados del XIII cuando encontramos los primeros dibujos arquitectónicos a escala reducida, en el palimpsesto en el manuscrito G 661 de los archivos de Reims. Se trata de la representación de la fachada de la catedral de Reims inacabada. Branner sostiene que el dibujo tiene tal variedad de grosores e intersecciones entre curvas que parece poco viable que hubiese sido seguido como guía en la construcción. ${ }^{96}$ También de la segunda mitad del XIII se conservan los alzados A, B y D de la fachada de la catedral de Estrasburgo (sobre los años 1255-60, 1275 y 1285) y los dibujos de la catedral de Colonia de los maestros Arnold y Johannes (finales del XIII y principios del XIV). ${ }^{97}$

Wolfgang Schöller señala que la existencia de estos pocos ejemplos demuestra que este tipo de dibujos no eran muy comunes en ese momento, pues sólo podemos atestiguar su presencia en las obras de las catedrales más importantes. ${ }^{98}$ Harvey, sin embargo, sostiene que estos dibujos son de una calidad tal que parecen sugerir una larga tradición de dibujos anteriores personificando ellos el primer eslabón conocido. ${ }^{99}$ Schöller afirma que debido a su gran dimensión, seguramente fueran realizados para ser expuestos y no para el trabajo en el taller. ${ }^{100}$ Son en su mayoría diseños de fachadas sin vocación de mostrar indicaciones técnicas sobre despieces o juntas.

Durante los siglos XIV, XV y XVI se producen un gran abundante número de dibujos. Son remarcables los contenidos en los archivos de la catedral de Estrasburgo, la catedral de Viena, la catedral de Colonia, UIm, Praga y un

\footnotetext{
94 John Harvey, The Mediaeval Architect, (London: Wayland, 1972), 101-102.

${ }^{95}$ Robert Bork, The Geometry of Creation. Architectural Drawing and the Dynamics of Gothic Design, (Farnham: Ashgate, 2011), 30.

${ }^{96}$ Branner, "Villard de Honnecourt, Reims and the origin of Gothic architectural drawing", 131.

${ }_{97}$ Wolfgang Schöller, "Le dessin d'Architecture à L'époque Gothique", Les bâtisseurs des Cathedrales Gothique, (Estrasburgo: Editions les Musées de la Ville de Strasbourg, 1989, 232.

98 Schöller, "Le dessin d'Architecture à L'époque Gothique", 232.

99 Harvey, The Mediaeval Architect, 101.

100 Schöller, "Le dessin d'Architecture à L'époque Gothique", 233.
} 
gran número de iglesias en Suiza, Alemania y Bohemia. Algunos más hay en Francia, España o Italia, pero sin comparación con la profusión centroeuropea.

Johann Josef Böker ha realizado una fantástica labor junto a un equipo de investigadores reuniendo en tres libros editados en gran formato los dibujos de la colección del Kupferstichkabinett der Akademie der Bildenden Künste de Viena, los dibujos de Ulm y Donauraum; o los de Basel, Konstanz, Freiburg, Straßburg, Mainz, Frankfurt y Köln. ${ }^{101}$

La colección de Ulm y Donauraum contienen principalmente dibujos de alzados, plantas y Sakramentshäuser. También en el tomo dedicado a las ciudades del oeste de Alemania la prevalencia de alzados es abrumadora, principalmente de torres, con ejemplos tan representativos como los de la catedral de Friburgo.

Sin embargo, la colección vienesa, mucho más heterogénea, con dibujos fechados entre mediados del XIV y mediados del XVI, contiene gran variedad de plantas de bóvedas, elevaciones, alzados, esquemas de plantas de edificios, arbotantes, escaleras, púlpitos, gabletes, etc. Del mismo modo que el resto de dibujos estudiados hasta el momento no contienen ninguna referencia explícita a los enjarjes, entre los dibujos de Viena hemos localizado:

- 16.823. Sammelzeichnung. Dibujo del Santo Sepulcro de Wissembourg (Alsacia) ejecutado por Jodok Dotzinger en 1455. El dibujo debe de haber sido realizado a principio del siglo XVI. ${ }^{102}$ (Hemos girado la imagen del original). Aparece la planta asimétrica de la bóveda, junto a la que hay trazado un nervio de un espesor considerable. Se ve cómo éste arranca tangente a un plano vertical y es cortado por una línea radial que se continúa en horizontal a partir de su trasdós hacia el plano vertical del muro.

\footnotetext{
101 Johann Josef Böker, Architektur der Gotik. Gothic architecture. Bestandskatalog der weltgrößten Sammlung an gotischen Baurissen (Legat Franz Jäger) im Kupferstichkabinett der Akademie der Bildenden Künste Wien, (Salzburg: Pustet, 2005). Johann Josef Böker et al., Architektur der Gotik. Ulm und Donauraum, (Salzburg: Müry Salzmann, 2011). Johann Josef Böker et al., Architektur der Gotik - Rheinlande. Ein Bestandskatalog der mittelalterlichen Architekturzeichnungen. Basel, Konstanz, Freiburg, Straßburg, Mainz, Frankfurt, Köln, (Salzburg: Müry Salzmann, 2013).
}

102 Böker, Architektur der Gotik. Gothic architecture, 85-86. 

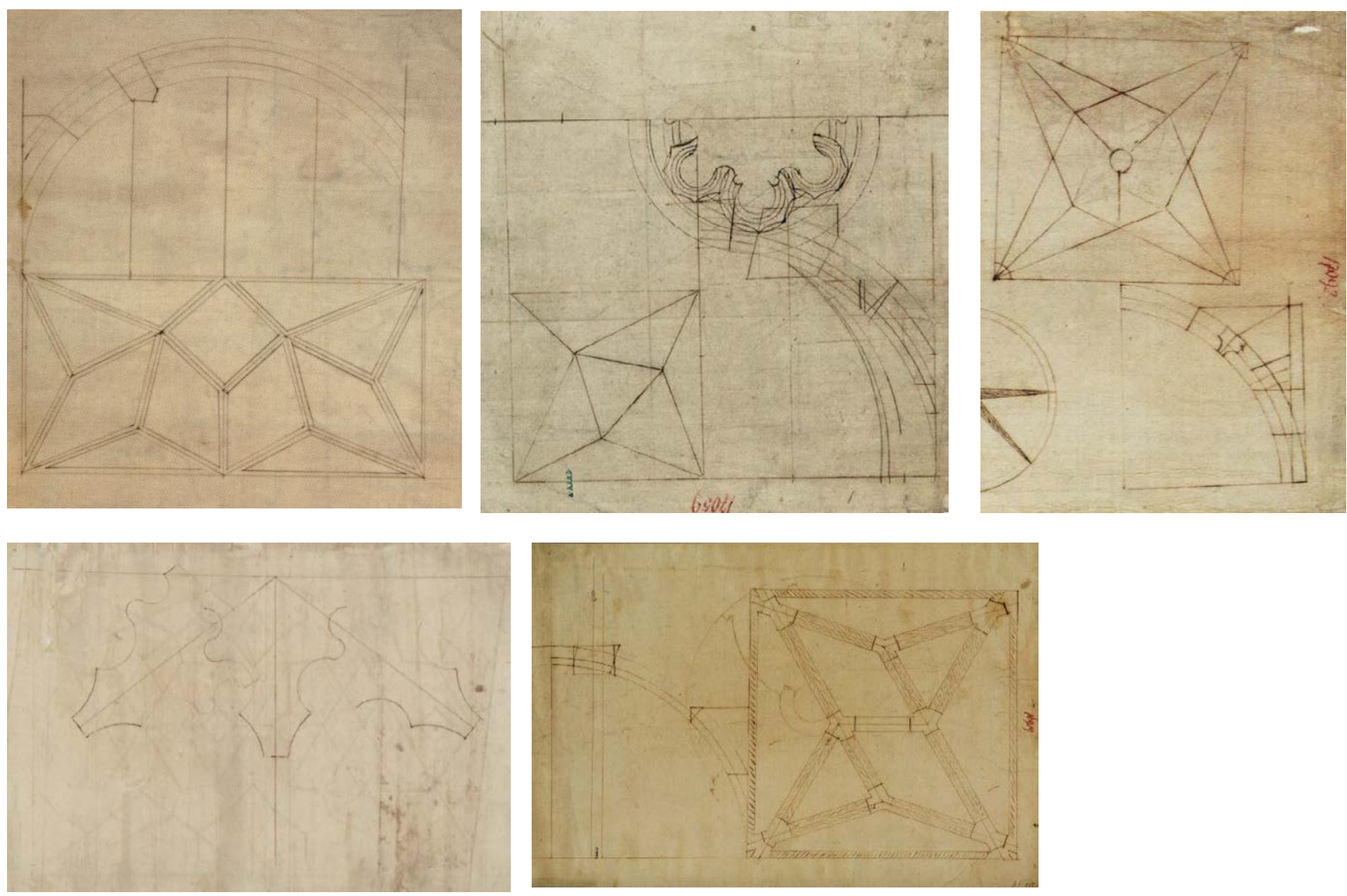

- 16.919. Grundrisszeichnung und Bogenaustragung eines asymetrischen Sterngewölbes. C. $1500 .{ }^{103}$ De nuevo volvemos a encontrarnos con una bóveda asimétrica a partir de la cual se representa un nervio que sale tangente del muro con cierto espesor. Esta vez se realizan dos cortes, uno horizontal en el punto en el que su trasdós interseca el muro y otro de igual al anterior, conteniendo el corte inclinado radial en la zona del nervio.

- 16.955 v. Rippenprofile. Corresponde a los perfiles de las bóvedas en Spišský Štvrtok en Eslovaquia de c. $1505 .{ }^{104}$ En el dibujo aparecen tres rectas, que representan las direcciones de los nervios que, además, convergen en un punto en una recta que podría ser la representación de un muro. En cada una de ellas vemos trazada la plantilla de un nervio.

- 17.059. Gewölbevorlage asymetrisches Gewölbefeld und Bogenaustragung. ${ }^{105}$ (Se ha girado la imagen). Este dibujo es ciertamente interesante al encontrarse el nervio, que sale tangente al muro, conformando varias piezas en el enjarje. La segunda y tercera hiladas son la mitad que la primera. La definición de la última

${ }^{103}$ Böker, Architektur der Gotik. Gothic architecture, 237-238.

${ }^{104}$ Böker, Architektur der Gotik. Gothic architecture, 268-269.

105 Böker, Architektur der Gotik. Gothic architecture, 373.

Fig. 47

De arriba abajo y de izquierda a derecha: 16.823 (Böker, 2005, 85-86), 17.059 (Böker, 2005,373), 17.092 (Böker, 2005, 402, 405), 16.955 v. ((Böker, 2005, 268-269), 16.919 (Böker, 2005, 237-238) 


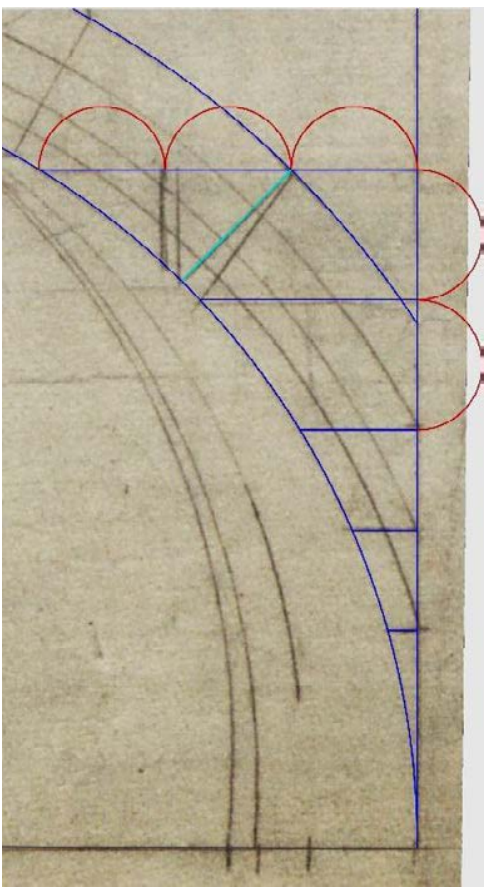

Fig. 48

Trazado de hipótesis sobre 17.059 (Böker, 2005,373), junta horizontal puede haber sido trazada, como explicaremos más adelante, mediante una serie de reglas.

17.092. Sammelzeichnung. Entre ellos, el dibujo de una bóveda estrellada de c. $1505 .{ }^{106}$ Se representa un enjarje en el que se ve que el nervio no sale tangente al muro y que su último corte horizontal se produce tan alto que casi completa la altura del arco. En la zona en la que el extradós del nervio se separa del muro aparecen unas líneas paralelas inclinadas a las que no encontramos explicación. Quizás se trate de una indicación relativa a la plementería, pero esto es mera especulación. Es interesante el hecho de que aparezca el perfil del nervio ajustándose a su espesor y colocado de manera radial.

Hemos querido ver en uno de ellos una indicación para el diseño de la última junta del enjarje al enfrentarnos a la comprensión de una serie de rectas que aparecen en el dibujo y para las que en un primer momento no encontramos explicación.

Las tres primeras piezas del enjarje del dibujo 17.059 son sencillas de delimitar, como hemos explicado anteriormente. Sin embargo, decidir la altura de la cuarta y quinta no es algo que resulte directo. Por ello, pensamos que quizás se podría haber decidido un lugar para realizar el último corte horizontal y luego se podría haber dividido esta altura en dos para determinar la altura de ambas piezas.

Al analizar este último corte horizontal advertimos que la recta llega hasta el intradós del nervio y que hay una extraña recta vertical bastante remarcada que se sitúa aproximadamente a mitad de distancia entre la intersección con el trasdós y ese punto. Efectivamente es así pero, además, la mitad de esa longitud se corresponde con la distancia del trasdós del nervio al muro.

Por lo tanto, puede que se buscara mediante este procedimiento una regla para determinar la localización de este último corte mediante la correspondencia entre la distancia a la que se encontraba el trasdós del nervio con respecto al muro y la distancia en el corte horizontal entre el intradós y trasdós, favoreciendo una relación proporcional entre ambas.

En todos los estos dibujos que hemos mostrado de la colección de Viena aparecen representados enjarjes de bóvedas en relación a sus plantas, en su gran mayoría asimétricas. Se representan los nervios de la bóveda en

\footnotetext{
106 Böker, Architektur der Gotik. Gothic architecture, 402 y 405.
} 
elevación, con su correspondiente espesor, cortados por juntas horizontales y una junta final inclinada.

Sin embargo, pese al gran número de dibujos de arquitectura existente, los relativos a enjarjes son muy escasos y corresponden a un periodo muy tardío. Gracias a ellos podemos saber, simplemente, que los maestros representaban el comienzo de la bóveda mediante la elevación del nervio en relación a la planta con una serie de juntas horizontales y una última junta inclinada.

No obstante, en estas representaciones se indican despieces de enjarjes que no pueden ser utilizados de manera general, puesto que la decisión de dichos cortes depende de muchas variables, como por ejemplo, la dimensión de la bóveda o la disponibilidad de unos bloques de piedra u otros para la talla de las piezas. Este tipo de información técnica no se puede esquematizar ni generalizar, por lo que el estudio de estos ejemplos se ha de realizar con cautela. Cada configuración de enjarje responde a un problema técnico y constructivo determinado.

Norbert Nußbaum ha señalado, en este sentido, que la cultura arquitectónica gótica ha de ser entendida como una red profesional que permitía la trasmisión de conocimiento a larga distancia sobre soluciones formales utilizando como medio el dibujo, mientras que para las soluciones constructivas se dependía de la presencia de los maestros. Cuando está tan de actualidad la atribución de ciertos detalles o elementos a talleres o artistas concretos, deberíamos ser más cautelosos y establecer relaciones solamente en los casos en los que no sólo la solución formal converge, sino también la técnica. La trasferencia de ideas artísticas se realiza mediante estos dibujos arquitectónicos, la información sobre técnicas constructivas no. Ésta es tan específica en cada caso, como ocurre con los enjarjes, que no puede ser generalizada y sólo los maestros, enfrentándose a cada situación, pueden dar la respuesta técnica adecuada. ${ }^{107}$

Las formas viajan. Los maestros también. Por ello las ideas y las soluciones se mueven y comparten. Era habitual que los arquitectos realizasen viajes para adquirir ideas o para formarse. ${ }^{108}$ Por ejemplo, en la Ordenanza de

\footnotetext{
107 Norbert Nußbaum, "Planning and Building without Writing: Questions of Communication in Gothic Masons' Lodges“, Architecture, Liturgy and Identity: Liber Amicorum Paul Crossley (Turnhout: Brepols, 2011), 145.

108 Harvey, The Mediaeval Architect, 105. Harvey muestra algunos ejemplos de arquitectos que realizaron viajes, como William Humberville, maestro de la biblioteca de Merton College quien, a finales del XIV, viajó a Sherbone, Salisbury, Winchester y Londres "with the purpose of viewing the library of the Preaching Friars" para tomar ideas; o Pedro Balaguer, autor del Miguelete de Valencia, que fue enviado a Lérida y a Narbona para estudiar torres a principios del $X V$, etc.
} 
Regensbourg de 1459, que supone una articulación e institucionalización de los talleres de cantería alemanes, se habla de la constitución del proceso de aprendizaje de los canteros estableciendo talleres que debían visitar o en los que tenían que trabajar para su formación. ${ }^{109}$ También en el Levante, en Valencia y Palma de Mallorca existía una organización corporativa legal. La primera en crearse fue la de la isla, a finales del siglo XIV, mientras que la de Valencia se estableció poco antes de comenzar la Lonja para controlar, mediante un examen, las capacidades de los maestros. ${ }^{110}$

Nos hubiera gustado haber encontrado en alguno de estos dibujos arquitectónicos alguna referencia a procedimientos de diseño en planta de enjarjes o tanteos de posibles configuraciones, pero parece ser que esta información no era factible de ser codificada del mismo modo que se puede mostrar el trazado en planta de una bóveda. Quizás no se trataba de un conocimiento que los maestros deseasen compartir.

\subsubsection{Manuscritos y tratados medievales}

El manuscrito medieval más antiguo conocido es el Álbum de Villard de Honnecourt, de cerca de 1235, ${ }^{111}$ cuyos dibujos difieren mucho de los anteriormente estudiados. El Álbum de Villard está compuesto por un grupo heterogéneo de dibujos y temáticas, agrupando dibujos de animales, figuras humanas, figuras religiosas, máquinas de construcción, elementos vegetales, representaciones de tumbas, relojes, plantas esquemáticas, tabernáculos, rosetones, pilares, cubiertas de madera, herramientas, plantillas, instrucciones, alzados y elevaciones de catedrales, secciones, etc.

En el caso de los ejemplos que se refieren a edificios reales Bork ha señalado que los dibujos difieren mucho de los objetos existentes, llevándonos a veces a malentendidos. ${ }^{112}$ Por ello, muchos autores dudan acerca de la profesión de Villard de Honnecourt, cuestionando si era arquitecto o un artista itinerante interesado en la arquitectura. ${ }^{113}$ Santiago

\footnotetext{
109 Nußbaum, "Planning and Building without Writing: Questions of Communication in Gothic Masons' Lodges", 145.

110 Javier Gómez Martínez, El gótico español de la edad moderna: bóvedas de crucería (Valladolid: Universidad de Valladolid, 1998), 41.

${ }^{111}$ Villard de Honnecourt, Carnet de Villard de Honnecourt: d'après le manuscrit conservé à la Bibliothèque nationale de Paris, $n^{\circ}$ 19093. Presentado y comentado por Alain ErlandeBrandenburg, Régine Pernoud, Jean Gimpel y Roland Bechmann, (Paris: Stock, 1986).

112 Bork, The Geometry of Creation. Architectural Drawing and the Dynamics of Gothic Design, 2.
}

${ }^{113}$ Carl F Barnes, "Le « probleme » Villard de Honnecourt", Les bâtisseurs des Cathédrales Gothiques, (Estrasburgo: Editions les Musées de la Ville de Strasbourg, 1989), 209-223. Carl 
Huerta llama la atención además del hecho de que entre los numerosos diseños contenidos en el álbum no parezca ningún dibujo sobre la construcción de una bóveda de crucería gótica. ${ }^{114}$

No es hasta finales del XV cuando comienzan a aparecer un gran número de tratados en Centroeuropa. ${ }^{115}$ Cabe destacar la labor de Matthäus Roritzer, maestro mayor de la catedral de Regensbourg, quien escribió en 1486 Buchlein von der Fialen Gerechtigkeit centrado en el diseño de pináculos y gabletes. ${ }^{116}$ Poco después, Geometria deutsch, cuya primera parte se centra en explicar cómo generar figuras geométricas simples, mientras la segunda en cómo resolver problemas geométricos sencillos. ${ }^{117}$

También Hans Schuttermayer, c. 1489, con su Fialenbüchlein se interesa por el diseño de pináculos y gabletes. ${ }^{118}$ Sus ejemplos han sido estudiados por diversos autores en relación con los del tratado de Roritzer, pues ambos parten del cuadrado para el diseño de la planta de los pináculos inscribiendo cuadrados girados sobre ella consecutivamente. La altura del elemento la determinan mediante la adición de módulos que vienen marcados por la medida de la planta. ${ }^{119}$

Tres décadas después del tratado de Roritzer, aparece además Unterweisungen, un compendio de instrucciones y consejos escritos por el maestro Lorenz Lechler para su hijo Moritz. Está compuesto por una serie de reglas basadas en simples relaciones aritméticas, entre las que se

F Barnes, The portfolio of Villard de Honnecourt (Paris, Bibliothèque nationale de France, MS Fr 19093), a new critical edition and color facsimile, (Burlington: Ashgate, 2009), 25.

114 Santiago Huerta Fernández, Arcos, bóvedas y cúpulas. Geometría y equilibrio en el cálculo tradicional de estructuras de fábrica, (Madrid: Instituto Juan de Herrera, 2004), 141.

${ }^{115}$ Roland Retch, "Les « traites pratiques » d'Architecture Gothique", Les bâtisseurs des Cathédrales Gothiques, (Estrasburgo: Editions les Musées de la Ville de Strasbourg, 1989), 279-285. Recht hace un recorrido por todos los tratados medievales desde Villard de Honnecourt hasta los alemanes y españoles.

${ }^{116}$ Matthäus Roriczer, Das Büchlein von der Fialen Gerechtigkeit, (Crier: Druck und Verlag [1486] 1845).

117 Se pueden consultar la trascripción de Das Büchlein von der Fialen Gerechtigkeit y Geometria deutsch en la web de la Bibliotheca Augustana: www.hsaugsburg.de/ harsch/germanica/Chronologie/15Jh/Roriczer/ror_intr.html

118 Hans Schuttermayer, Fialenbüchlein, (Nuremberg: Georg Stuchs ca. 1489).

119 Lon R. Shelby, "The Geometrical Knowledge of Mediaeval Master Masons", Speculum, Vol. 47, no 3, 395-421 (1972). Roland Retch, "Les «traites pratiques » d'Architecture Gothique", Les bâtisseurs des Cathédrales Gothiques, (Estrasburgo: Editions les Musées de la Ville de Strasbourg, 1989), 279-285. 
explica, por ejemplo, cómo, mediante combinaciones de figuras aritméticas, se pueden generar molduras. ${ }^{120}$

Otros tratados como el Steinmetzbuch WG $1572^{121}$ o el Codex Miniatus 3 de la Biblioteca Nacional de Viena (1540-1567)- también conocido como The Dresden Sketchbook contienen información gráfica de gran interés. ${ }^{122}$ Por ejemplo, en el tratado del maestro WG se recogen gran número de diseños de bóvedas en planta y 23 esquemas de proyección. Con todo, Roland Recht advierte que no se debe perder de vista la parte debida al renacimiento en estos ejemplos, pues con estos últimos tratados nos encontramos en un periodo realmente tardío del gótico. ${ }^{123}$

Mediante este acercamiento al estudio de la información gráfica recogida en estos tratados medievales pretendemos entender el modo de pensamiento de los maestros, qué recursos gráficos empleaban para la generación de elementos, de qué manera transmitían su conocimiento, etc. Como bien señala Robert Bork, es un tema complejo, pues tanto estos autores medievales como otros que intentaron dar una visión comprensible de la práctica del diseño gótica se encontraron con un problema fundamental: la lógica geométrica de la arquitectura gótica es difícil de explicar con palabras. ${ }^{124}$

En este sentido, los tratados nos dejan entrever de qué modo se enfrentaban los maestros a la generación de elementos y cuál era su método de trasmisión del conocimiento. Shelby ha explicado en varias ocasiones que tanto Roriczer como Lechler no intentan explicar principios fundamentales de diseño o procesos de construcción, sino que estos tratados funcionan a modo prescripciones de cómo hacer algo. En los textos se dirigen al lector de manera directa diciéndole: "si quieres resolver

120 Trascrito el original en Ulrich Coenen, Die spätgotischen Werkmeisterbücher in Deutschland. Untersuchung und Edition der Lehrschriften für Entwurf und Ausführung von Sakralbauten, (Munich: Scaneg, 1990).

121 Se puede consultar en la recopilación realizada François Bucher, Architector. The Lodge Books and Sketchbooks of Medieval Architects, (Nueva York: Abaris Books, 1979).

122 François Bucher, "The Dresden Sketchbook of Vault Projection", Actes du XII Congrès International d'Histoire de l'Art (Budapest, 1969). Évolution Générale et Développement Régionaux en Histoire de l'Art. Budapest, (1972), 527-537.

${ }^{123}$ Retch, "Les « traites pratiques » d'Architecture Gothique", 282.

${ }^{124}$ Bork, The Geometry of Creation. Architectural Drawing and the Dynamics of Gothic Design, 7: "Because Gothic design conventions govern the rules of the process more than the shape of the final product, the spatial relationships between building components varied far more widely in Gothic tan in classical architecture. This, in turn, means that precision can be achieved only with explicit description, rather than with allusions to venerated prototypes." 
este problema, sigue estos pasos". ${ }^{125}$ Esta es la gran diferencia entre los textos matemáticos que intentan demostrar el porqué de un procedimiento y estos tratados medievales en los que lo que se presenta es un proceso para abordar la solución de un problema. ${ }^{126}$

Shelby define, en este sentido, el término geometría constructiva, el procedimiento mediante la cual se manipulan las formas geométricas para la elaboración de plantas, alzados, etc. ${ }^{127}$ Consistía en una serie de pasos que había que seguir cuidadosamente y que los maestros aprendían. Sostiene que en todos los periodos se trabajó más o menos dentro de estas fórmulas, eso sí, siendo los menos los que se limitaban solamente a seguir mecánicamente estas reglas. Los mejores maestros eran capaces de adaptar esta geometría constructiva en la resolución de problemas concretos, manipulando las formas de manera hábil y creativa:

The nature of that geometry suggests that these canons, when recovered, will not be universal laws which will at last provide the key to mediaeval architecture; rather, they will be particular procedures used by particular master masons at particular times and places. ${ }^{128}$

Aunque pueda parecer sorprendente, ninguno de estos tratado alemanes contienen indicaciones de cómo se proyecta o ejecuta una bóveda de crucería, mientras sí lo encontramos en España, en la copia del tratado atribuido a Rodrigo Gil de Hontañón contenido en el Compendio escrito por Simón García en $1681 .{ }^{129}$ Los autores no se ponen de acuerdo, pero parece ser que el texto debió ser escrito después de 1550, sin duda un momento muy tardío en el que la construcción de bóvedas de crucería y la construcción clásica se solapaban en la península.

Santiago Huerta ha estudiado los dibujos y el texto de Simón García, haciéndonos comprensibles sus indicaciones sobre nervios, claves o la construcción de la bóveda de crucería. Señala la relevancia de un dibujo de una bóveda en el que se combina la representación de su planta y su

\footnotetext{
125 Shelby, "The Geometrical Knowledge of Mediaeval Master Masons", 414.

${ }^{126}$ Shelby, "The Geometrical Knowledge of Mediaeval Master Masons", 416

127 Shelby, "The Geometrical Knowledge of Mediaeval Master Masons", 411.

${ }^{128}$ Shelby, "The Geometrical Knowledge of Mediaeval Master Masons", 421.

129 Simón García, Compendio de architectura y simetría de los templos conforme a la medida del cuerpo humano, por Simón García, architecto natural de Salamanca. Año 1681. Ms. 8884, (Biblioteca Nacional de Madrid, 1681)
} 
elevación; y que viene acompañada de una explicación en la que se enumeran y explican las tareas más significativas de su proceso de ejecución. Entre ellas se hace referencia a los enjarjes o jarjamentos. ${ }^{130}$

Fig. 49

Dibujo sobre la construcción de una bóveda de crucería (García, 1681, fol. 25 r).

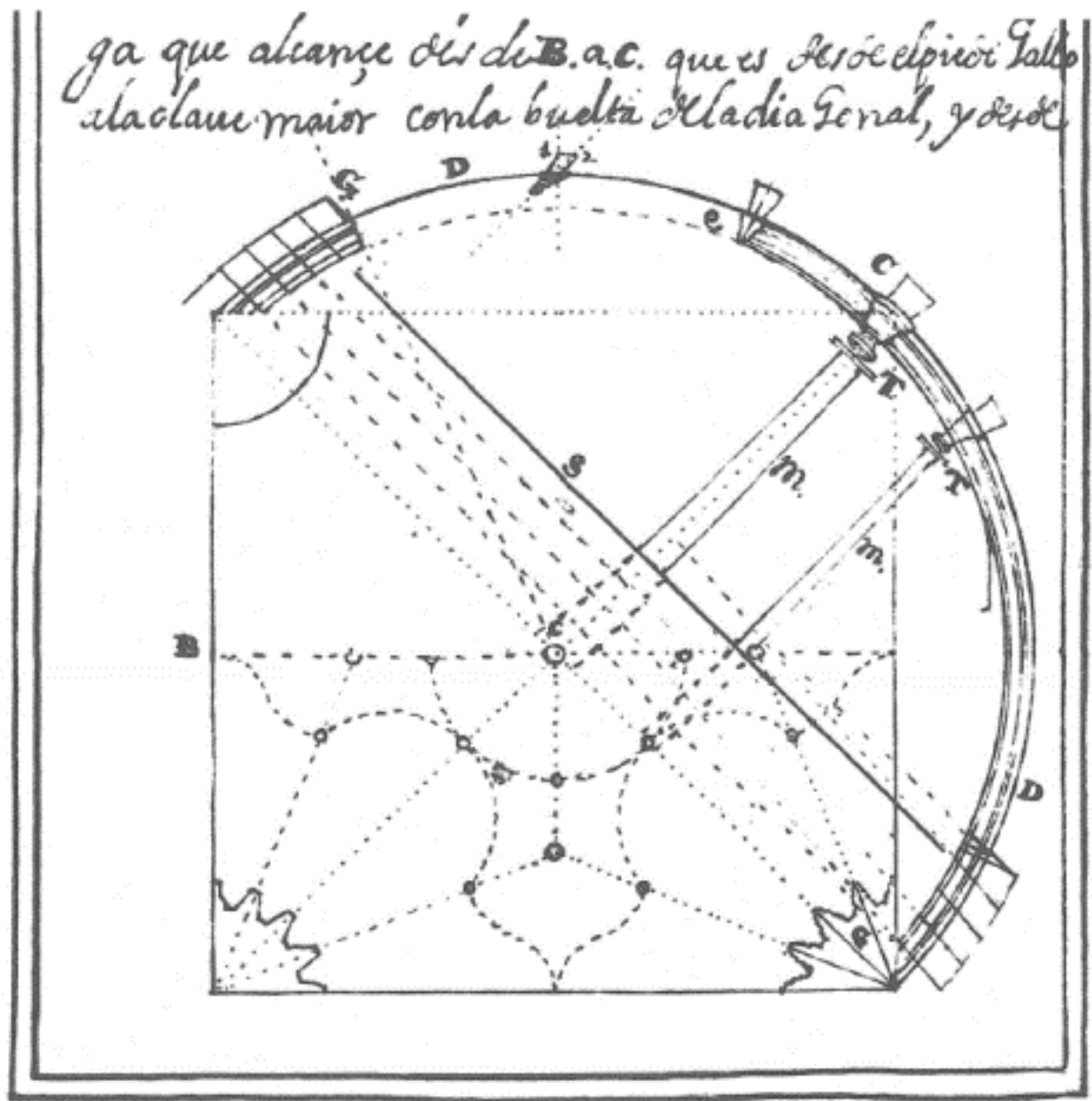

El dibujo muestra la planta de una bóveda de crucería de proporción cuadrada en la que solamente la mitad de la tracería aparece definida. Los ejes de los nervios ojivos, terceletes y combados son trazados con líneas de puntos y la situación de las claves con pequeñas circunferencias. En las esquinas aparece un esquema de lo que podría ser el último corte horizontal en planta del enjarje conformado por el contorno de las plantillas de cada uno de los nervios, que no se corresponde exactamente con la elevación del último corte del enjarje.

Abatida con respecto a la diagonal, se dibuja la elevación del nervio ojivo. Es un arco de medio punto, con su correspondiente espesor, en el que incluso se toma la molestia de dibujar las líneas paralelas que

130 Santiago Huerta Fernández, "La construcción de las bóvedas góticas según Rodrigo Gil de Hontañón, arquitecto de la catedral de Segovia", Segovia, su catedral y su arquitectura. Ensayos en homenaje a José Antonio Ruiz Hernando, (Madrid: Instituto Juan de Herrera, 2013), 118-124. 
corresponden a la molduración del nervio; y sitúa las claves en su recorrido. Las correspondientes a combados parecen ser de eje inclinado- algo no tan frecuente-, mientras que la clave central y las claves de los terceletes son verticales. En los arranques del nervio representa los enjarjes, compuestos cada uno por cinco piezas cuya altura de hiladas se corresponde entre en un lado y otro marcada por una serie de líneas de trazos paralelas. En la última pieza se encuentra la junta radial que permitirá el apoyo de la primera dovela. Es curioso que en el enjarje izquierdo esta junta inclinada aparece realizada en relación a la línea de extradós del nervio, mientras que en el enjarje derecho encontramos otros dos cortes además de éste: uno horizontal, como si en esa pieza no hubiese lecho inclinado, y otro inclinado con relación a esta línea horizontal.

Las profundidades de las piezas que componen enjarjes reales son variables, por lo que sorprende que Simón García delimite en este caso el conjunto de piezas por un arco paralelo al nervio. Lleva a malentendido, ya que da la impresión de que el enjarje no se compone de piezas horizontales que traban con el muro, sino más bien por un conjunto de dovelas de gran espesor cortadas por lechos horizontales.

Es destacable en este dibujo la información acerca del proceso constructivo de la bóveda, pues aparece en relación a la última junta horizontal del enjarje una línea gruesa que representa el lugar en el que se localizaría una plataforma horizontal de madera sobre la que se colocarían unos pies derechos localizados sobre la posición de las claves en planta para asegurar su apoyo durante la construcción. ${ }^{131}$

José Carlos Palacios ha estudiado el tratado de Alonso de Vandelvira señalando que podemos ver incluido en él un dibujo de un enjarje de una bóveda de crucería en el que aparecen representadas las plantas y alzados de las tres piezas que lo componen, ${ }^{132}$ sin olvidar que se trata de un tratado de finales del XVI en el que la arquitectura clásica es la predominante en el texto y los dibujos. Por ello se ha de ser precavido en el estudio de los ejemplos de crucería que en él aparecen, y en la valoración de la influencia

${ }^{131}$ García, Compendio de architectura y simetría de los templos conforme a la medida del cuerpo humano, fol. 25r. Allí dice: ... se ará otro segundo andamio como S. Y este tan quajado de fuertes tablones, que en ellos se pueda traçar, delinear, y montear, toda la cruceria ni mas, ni menos de lo que se ve en la planta. Esto echo y señaladas todas las claues en su lugar sobre los tablones dejar caer perpendiculos, de la buelta a ellas, esto es para las que están en los cruzeros o diagonales.

132 José Carlos Palacios, La cantería medieval: la construcción de la bóveda gótica española, (Madrid: Munilla-Lería, 2009), 107-109. 
de la nueva arquitectura en la manera en que son representados, explicados y entendidos por el autor.

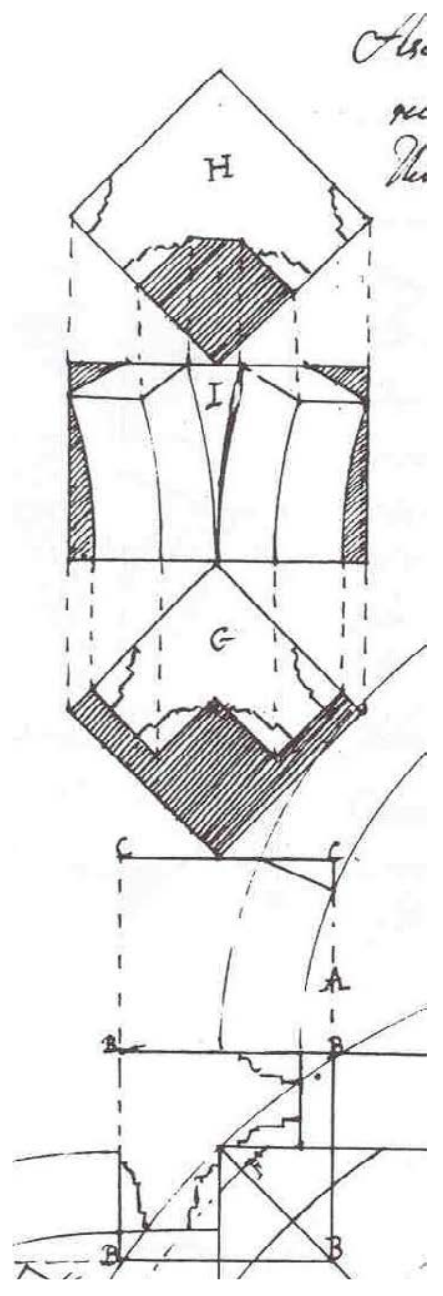

Fig. 50

Izquierda: Enjarje para arcos torales en Valndelvira (1575-1580, fol. 95r). Centro: Bóveda de crucería en Vandelvira (15751580, fol. 96v). Derecha: Enjarje para bóveda de crucería en Vandelvira (1575-1580, fol. 97r)
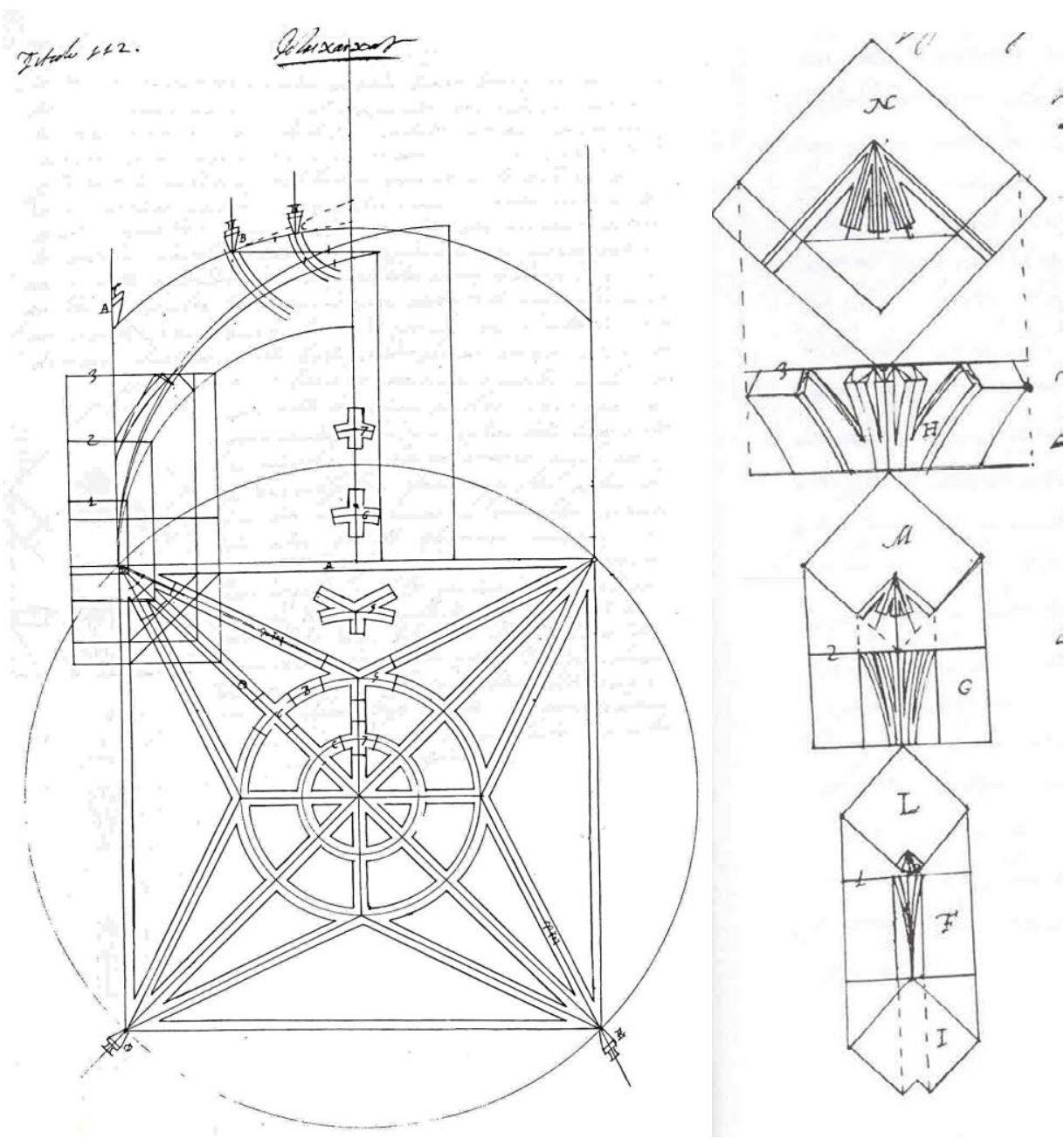

En el Fol. 94 v. se encuentra el capítulo titulado "De las xarxas" donde se refiere Vandelvira, en primer lugar, al enjarje de dos arcos formeros o perpiaños en los que se inscriben las capillas romanas que ha explicado con antelación. ${ }^{133}$ Es notable que las primeras xarxas que se detiene a explicar no tengan nervios ojivos, es decir, se trata de la reunión de los nervios formeros -o perpiaños- perimetrales de la bóveda que se ha de resolver dentro, sea cualesquiera.

A continuación, cuando se dedica, a explicar cómo se han de realizar para la capilla moderna, es decir, la de crucería, confía en que su comprensión sea más sencilla tras haber explicado el caso anterior. Además, piensa que

\footnotetext{
133 "He declarado hasta aquí las monteas de las capllas romanas de todas suertes lo más desmenuzadamente que he podido, poniendo de por sí los arcos y rincones que sobre ellos se mueven porque me pareció, según la traza es tan dificultosa de enseñar, convenía hacerlo así ya ahora declarar de la manera que se han de trazar las jarjas porque son necesarias de saber para todas suertes de capillas así romanas como modernas." Geneviève Barbé-Coquelin de Lisle, El tratado de arquitectura de Alonso de Vande/vira, (Albacete: Caja de Ahorros, 1977), 140.
} 
es necesario bastante detalle para poder comprender las jarjas de esta bóveda. ${ }^{134}$

Vandelvira muestra un enjarje de la bóveda de crucería compuesto por tres piezas en el fol. 96v, la primera y tercera pieza de igual altura, mientras que la segunda es menor, pensamos que para adaptarse su corte horizontal final al punto en el que el trasdós del nervio está en contacto con el muro. En el fol. 97r elabora un dibujo, en el que muestra unas sobre otras las plantas y alzados de las tres piezas que componen el enjarje.

Es curioso que este enjarje sea de nervios que confluyen en un punto cuando en España este tipo de solución no se da en bóvedas en esta época; es más, los únicos ejemplos que conocemos hasta este momento son los valencianos que mostraremos posteriormente. Pensamos que esto puede deberse más a un ejercicio teórico en el que Vandelvira dibuja una montea en la que los ejes de los nervios confluyen en un punto y esto le lleva a realizar la misma solución en perspectiva, que a un dibujo que manifieste el modo de hacer del momento. Quizás tenga relación con el hecho de que la bóveda es espacialmente una bóveda vaída, por lo que la única manera de que los nervios se adapten a una superficie esférica es haciéndoles confluir de este modo en un punto.

Es significativo que a pesar de que en el dibujo encontremos pruebas de cómo se han de trazar las referencias a los ejes de los nervios en planta en el lecho de las piezas -pues se puede ver perfectamente cómo se ha trasladado a cada uno de los lechos- los errores a la hora de situar el intradós de los nervios para el dibujo de su contorno son manifiestos. E ejemplo más claro puede apreciarse en la última pieza, donde Vandelvira traza una circunferencia con centro en la confluencia de los ejes para situar el intradós de los nervios, ${ }^{135}$ procedimiento incorrecto, pues el intradós del ojivo se encuentra más cerca de ese punto que el de los terceletes, como ya ha apreciado el profesor Palacios en el dibujo en el que analiza esta bóveda. ${ }^{136}$

Además Vandelvira encuadra cada una de las piezas en una especie de sólido capaz en el que, suponemos, deberían ser talladas. En la última

\footnotetext{
134 "Mucha escritura es necesaria para dar a entender la montea de esta capilla y la manera de trazar sus jarjas, mas confiado por las pasadas se dejara entender ésta no diremos de ella de un apuntamiento, por el cual serán entendidos la demás que de la forma moderna se ofrecieren." Barbé-Coquelin de Lisle, El tratado de arquitectura de Alonso de Vandelvira, 142.

${ }^{135}$ Hemos podido comprobar en el tratado de la Biblioteca ETSAM las líneas auxiliares, las marcas de punta seca, en las que se puede apreciar perfectamente esta circunferencia.

${ }^{136}$ Palacios Gonzalo, Trazas y Cortes de Cantería en el Renacimiento Español, 223: Fig 10.4.
} 
pieza traza un recuadro innecesario para la talla tomando la distancia desde el encuentro en alzado del último corte horizontal con el formero hasta el muro. Esta medida la traslada luego al dibujo en perspectiva, conformando un recuadro innecesario para la pieza.

Del resto de tratados, en los que no aparece ningún tipo de prescripción relacionada con los enjarjes, sólo podemos extraer la idea del uso de formas geométricas y reglas aritméticas sencillas para la generación de plantas o alzados.

Igualmente, es necesaria cautela si se pretende en algún momento aplicar lo que aparece en los tratados tardogóticos al estudio del gótico anterior, pues simplemente al comparar los tratados alemanes con el francés de Villard de Honnecout las diferencias son patentes.

\subsubsection{Dibujos a escala 1:1, las también llamadas monteas o dibujos constructivos}

A diferencia de los dibujos arquitectónicos en los que vemos representado en muchos casos plantas completas o alzados de edificios a escala reducida, los dibujos constructivos atienden a elementos parciales. Su función es la de representar a escala real el objeto que se desea construir, con sus espesores y juntas, actuando como guía de la ejecución y el replanteo. Sirven, por lo tanto, para el trabajo práctico de los canteros, para la toma de medidas y la elaboración de plantillas.

En la última década del siglo XII ya hay documentadas monteas, como la que representa un rosetón para la fachada de la iglesia abacial de Byland, ${ }^{137}$ encontrando siglos después bastantes ejemplos en las terrazas de catedrales, como es el caso de las de Clermont Ferrand, Narbona, Limoges o Sevilla, donde principalmente se trazaban ventanales, arbotantes, etc. ${ }^{138}$

${ }^{137}$ Schöller, "Le dessin d’Architecture à L’époque Gothique", 235.

138 Entre otros: Felix de Verneilh, "Construction des monuments ogivaux: Épures de la cathédrale de Limoges", Annales archéologiques 6, (1847), 139-144. Florence Claval, "Les Épures de la Cathedrale de Clermont-Ferrand", Bulletin Archéologique du Comité des travaux historiques et scientifiques 20-21, [1984-85, fasc. A (1988)], 185-224. Alfonso Jiménez y Francisco Pinto Puerto, "Monteas en la catedral de Sevilla", Revista de Expresión Gráfica Arquitectónica 1, (1993), 79-84. José Antonio Ruiz de la Rosa y Juan Clemente Rodríguez Estévez, "Trazas de un Arquitecto medieval. "Monteas" para la catedral de Sevilla", Revista de Arquitectura 5, (Servicio de Publicaciones de la Universidad de Navarra, 2003), 105-114. 
También hay trazados en las llamadas salas de trazas, un recinto que aparece mencionado por primera vez en un texto inglés de 1274. Las más importantes de las conservadas son las de la catedral de York, con dibujos de c. 1360-c. 1500, y la de Wells, aunque también consta la existencia de una en Estrasburgo que se utilizaba alrededor de 1490 y que fue destruida por un fuego en el siglo XVIII. Allí, los dibujos se realizaban en el suelo sobre un soporte de yeso. ${ }^{139}$

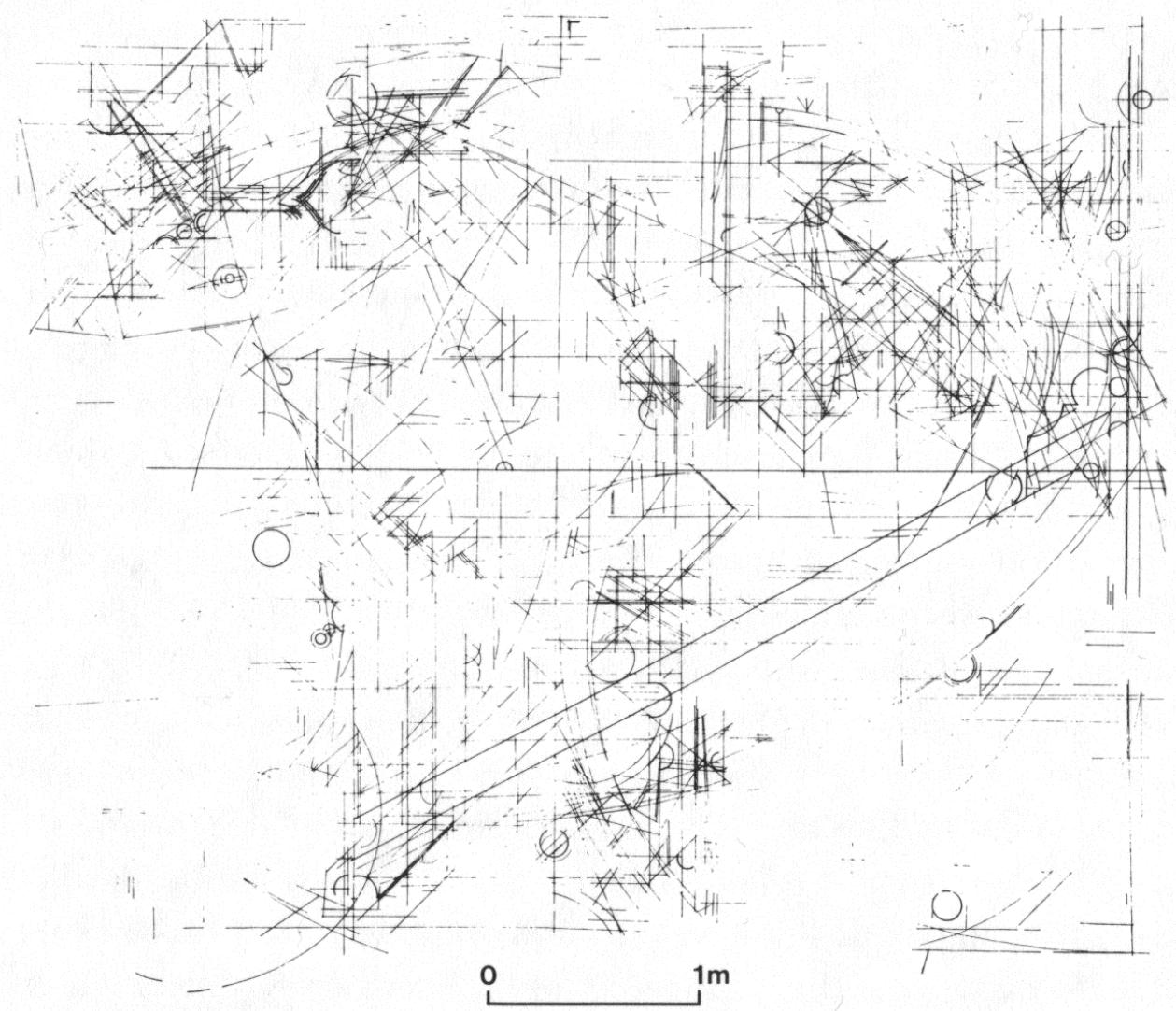

En el caso de York, la sala se encuentra separada del resto del edificio, lo que sugiere que se trataba de un lugar donde se ejercía la experimentación

139 Jonh Harvey, "Wells cathedral", The Archeological Journal, 131, (London: The Royal Archaeological Institute, 1974), 200-214. Werner Schäfke, Englische Kathedralen. Eine Reise zu den Höhepunkten englischer Architektur von 1066 bis heute, (Köln: DuMont, 1983), 180. Jonh Harvey, "The tracing floor in York Minster", Friends of York Minster, Fortieth Annual Report (York 1968), 9-13. John Harvey, "The tracing floor of York Minster, The Engineering of Medieval Cathedrals", Studies in the History of Civil Engineering. Courtenay, Lynn T. ed., (Aldershot: Ashgate, 1997), 4-9. Alexander Holton, "The Working Space of the Medieval Master Mason: the Tracing Houses of York Minster and Wells Cathedral", Proceedings of the Second International Congress on Construction History, (Cambridge: Construction History Society, 2006). Richard Morris, Cathedrals and Abbeys of England and Walles. The Building Church, 600-1540, (Londres: William Cloves \& Sons Limited, 1979).
Fig. 51

Trazados de la sala de trazas de la catedral del Wells (Schäfke, 1983, 180). 
y el diseño de manera protegida y donde no se permitía el acceso de todos los trabajadores, diferenciándola de la zona del taller. ${ }^{140}$

Fig. 52

Dibujo de la montea de la bóveda de St. Sigismund en Szydlowiek e imagen e los trazados de la parte relativa al enjarje

(Brykowska, 1992, 102: fig.2 y 105: fig. 5).

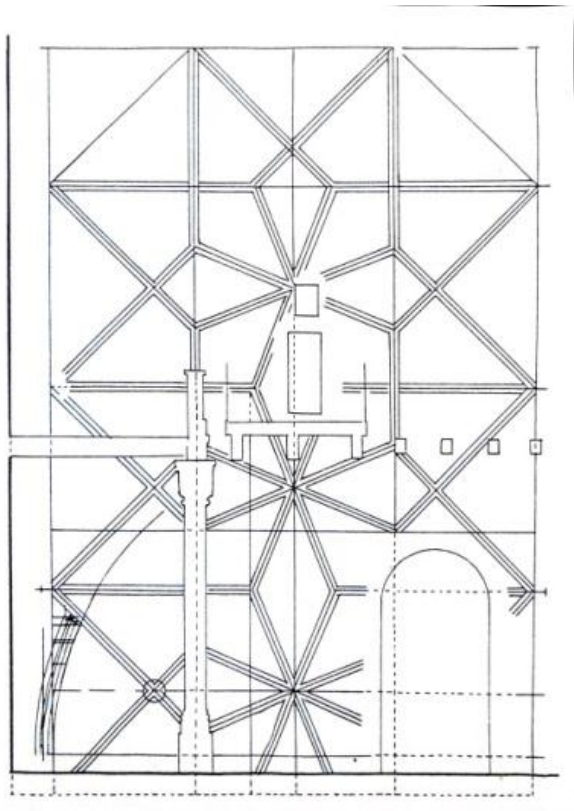

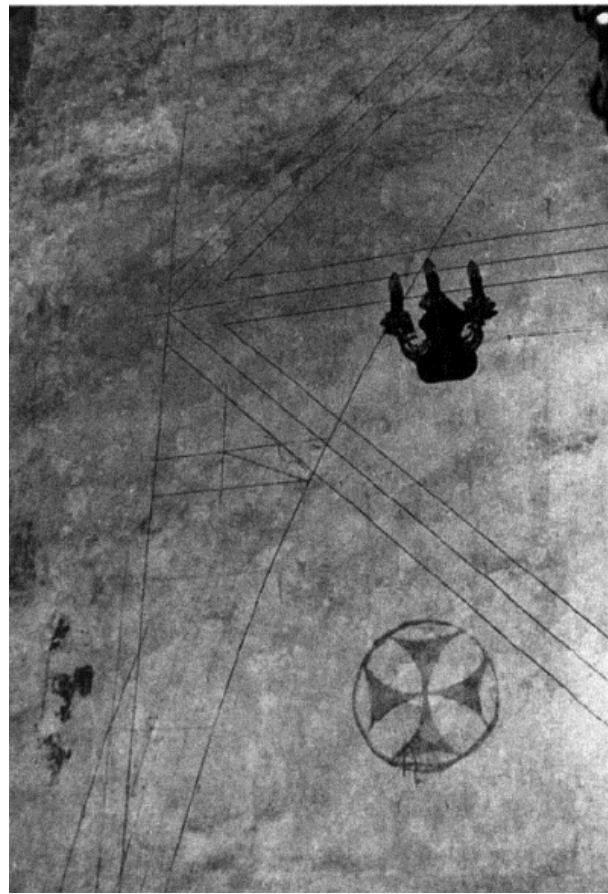

Joan Domenge sostiene que en el caso mallorquín, aunque de la catedral de Palma de Mallorca no nos quede sala de trazas, sabemos gracias a la documentación que los maestros protegían esta actividad. La realizaban en I'escriptori de la llotja (taller), que parece ser que se trataba de una estancia privada y de difícil acceso. ${ }^{141}$

Entre el gran número de trazados superpuestos que encontramos en estas salas de trazas o en los trazados de las cubiertas de catedrales hemos sido incapaces de encontrar evidencias de enjarjes.

Las únicas monteas de enjarje que conocemos hasta el momento se localizan en la iglesia de St. Sigismund en Szydlowiek, Polonia, que data de principios del siglo XVI; y otra en la catedral de Tui, más tardía. ${ }^{142}$ La de Polonia se encuentra en relación al trazado general de la planta de la

\footnotetext{
140 Holton, "The Working Space of the Medieval Master Mason: the Tracing Houses of York Minster and Wells Cathedral", 1593.

141 Joan Domenge i Mesquida, L'Obra de la Seu. El procés de construcció de la catedral de Mallorca en el tres-cents, (Palma: Institut d'Estudis Baleàrics, 1997), 168: Es comprà una estora, galfons i corretges per a aquest escriptori i es tancà amb pany i clau.

${ }^{142}$ Miguel Taín Guzmán et al., "Stonecutters' literature and construction practice in Early Modern Gothic: the tracings for a rib vault at the Cathedral of Tui in Galicia", Construction History, 27, (2012), 1-21. No analizaremos con profundidad la montea que se presenta en este artículo puesto que sólo se pueden apreciar en ella algunos cortes horizontales, no hay referencias a último en el que se da el corte radial. Además, su datación - principios del XVII- nos parece tardía para su comparación con el resto de ejemplos presentados.
} 
bóveda de la cabecera de la iglesia, en el muro norte, cerca del coro trasero, con una dimensión de 8,18 por 12,70 metros. Ha sido reproducida por Maria Brykowska junto con un estudio de la geometría de la bóveda, imágenes de la iglesia y la traza del enjarje. ${ }^{143}$

Tal y como se puede apreciar en la planta, la bóveda posee ocho enjarjes, cuatro de ellos conformados por tres nervios que convergen en un punto del muro, dos en el muro norte y dos en el sur. Los cuatro restantes se localizan en la parte poligonal de la cabecera, donde sólo dos nervios convergen en ellos.

La montea muestra la elevación de un nervio con la línea de intradós del arco que arranca tangente y en relación a la línea del muro de la planta. Se aprecian curvas paralelas al arco que seguramente representan las molduras del nervio, así como su espesor. Los enjarjes están todos compuestos por tres piezas y la altura de las hiladas es común, tal y como se puede ver en el dibujo. A partir de la línea del muro y en paralelo al suelo aparecen representados dos cortes horizontales delimitando la altura de las dos primeras piezas. Finalmente, la última pieza está determinada por un corte en el que se aprecia una zona horizontal desde el muro hasta llegar al extradós del nervio y, a partir de ahí, un lecho inclinado radial.

Pensamos que es muy probable que todos los nervios que salen del enjarje tengan la misma curvatura, lo que seguramente provocase que sólo fuese necesaria la montea de un único arco.

\subsection{Construcción}

Una vez estudiados los dibujos que hacen posible la definición de un enjarje nos planteamos el sentido de cada uno de los trazados y su uso. Qué función tiene cada línea y qué medidas y trazas se trasladan a las piezas para tallar será el propósito del análisis que llevaremos a cabo a continuación mediante el estudio combinado con las evidencias arqueológicas que han llegado hasta nosotros. Al examinar los restos de trazados en piezas de enjarjes podemos establecer conexiones con las líneas presentes en la montea y, de este modo, reconstruir el sistema de trazado y construcción del enjarje de la bóveda de crucería.

Los ejemplos recogidos en la literatura nos son abundantes, siendo la labor de Robert Willis, quien fue el primero en documentar unas piezas de enjarje en el siglo XIX, o Luc Mojon, a finales del XX, nuestro punto de partida.

\footnotetext{
${ }^{143}$ Maria Brykowska, "Quadratur des spätgotischen Gewoelbes im Chorraum der Pfarrkirche zu Szydlowiec/Polen“, Architectura 22, (1992),101-108.
}

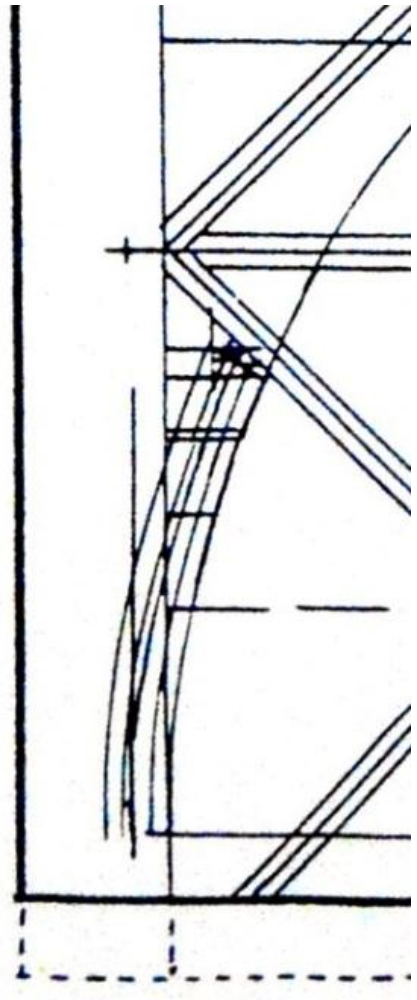

Fig. 53

Detalle del trazado del enjarje (Brykowska, 1992, 102: fig.2). 


\subsubsection{Evidencias arqueológicas y su relación con la montea}

\section{$\underline{\text { Robert Willis }}$}

Cuando Robert Willis se planteó de qué forma se podían trabajar las molduras de un enjarje en la piedra, se le ocurrieron dos explicaciones posibles. Primeramente pensó que el enjarje podría haber sido construido como un macizo y que, tras haber ejecutado los nervios en la zona superior, el resto de molduras podrían haber sido talladas hacia abajo, primero en bloque y luego en detalle. De este modo, todos los ejercicios de entrecruzamientos de molduras e interpenetraciones habrían sido resueltos por los canteros durante la ejecución in situ. ${ }^{144}$ Sin embargo, tras el estudio de una serie de piezas de enjarje que pudo examinar y documentar, desarrolló una teoría basada en procedimientos geométricos para el trazado y talla de estos elementos que él asumió como el método empleado por los maestros medievales. Su planteamiento no ha sido contradicho hasta el momento.

Fig. 54

Trazados documentados por Willis en los lechos de piezas de enjarjes (Willis, [1842] 1910, 7: fig 6 y 8: fig. 7).
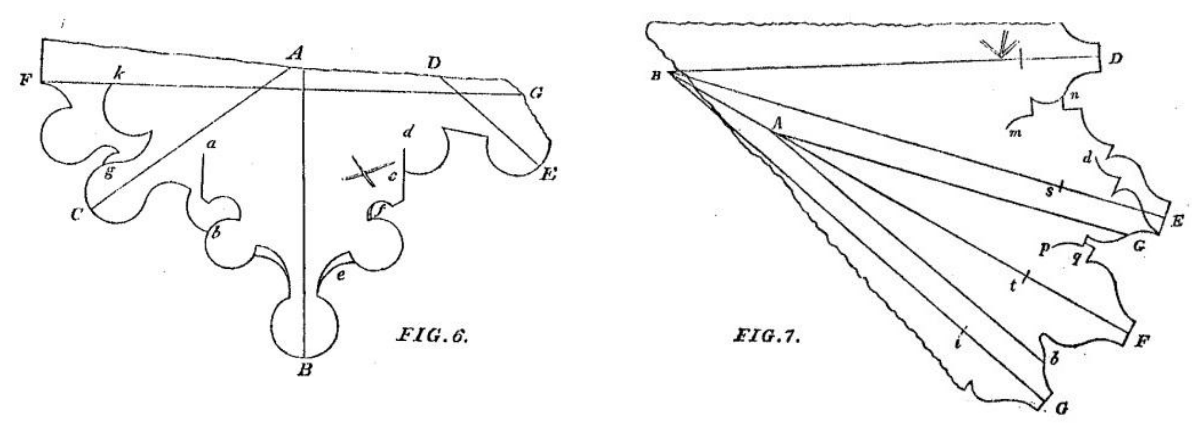

El problema al que se enfrenta todo aquel que se interese por el estudio de los enjarjes es que rara vez se encuentran en ruinas, lo que hace que el análisis de los lechos de las piezas sea en pocas ocasiones viable. Willis tuvo la suerte de poder examinar varios ejemplos muy tempranos, como los de la iglesia de Saint Saviour en Southwark durante su demolición de 1839 o los de la bóveda que cubría el extremo noroeste de la nave de la catedral de Canterbury en la parte inferior de la llamada torre de Lanfranc, cuyas piezas de enjarje habían sido cuidadosamente almacenadas tras su ruina. Willis comprobó la existencia de marcas de trazados en los lechos que permanecían allí como el primer día en que fueron realizadas. ${ }^{145}$

De Saint Saviour realizó un dibujo a escala 1/8 copiando cuidadosamente cada una de las líneas que encontró, indicando que había localizado este tipo de trazados tanto en la cara inferior como en la superior de cada una de ellas. Como se puede apreciar en su Fig. 6, aparecen trazadas unas líneas principales evidenciando los ejes que se corresponden con el trazado en planta del enjarje. Así la recta FG señala la posición del muro en

\footnotetext{
${ }^{144}$ Willis, "On the construction of the vaults of the Middle Ages", 6-7.

145 Willis, "On the construction of the vaults of the Middle Ages", 7-8.
} 
el que se sitúa el enjarje, la recta $A B$ representa el nervio perpiaño y las rectas $\mathrm{AC}$ y $\mathrm{DE}$ a los nervios ojivos, que en este caso no son simétricos con respecto al perpiaño. Además, se aprecian restos de las trazas de los perfiles de los nervios que fueron descartadas tras definir el contorno final que unificase la superposición de las molduras. Willis dice que estos contornos eran trazados con plantillas, dícese perfiles de los nervios recortados en un material delgado. Tras ser colocados en su lugar correspondiente en el lecho eran perfiladas con un instrumento afilado en la piedra. ${ }^{146}$

Los trazados de los ejes, que se localizaban tanto en la zona inferior como en la superior de la pieza, se extendían hasta los límites del lecho coordinándolos con un trazado en su dimensión vertical. De este modo, se aseguraba que el trazado de ejes del lecho inferior se correspondiese con el superior.

En Canterbury, la pieza que documentó Willis formaba parte de una hilada del enjarje que seguramente había estado compuesta por dos piezas diferentes debido a su gran dimensión. En ella podemos ver el trazado de los ejes de cuatro nervios de los siete que compondrían el enjarje. Curiosamente, además, aparecen unas marcas para dichas direcciones que fueron desestimadas seguramente porque su situación hacía inviable el trazado de la pieza. El nuevo replanteo viene señalado por unas pequeñas muescas para diferenciarlo del dibujo fallido. ${ }^{147}$

Tras esta toma de datos, Willis se dio cuenta de que los maestros trazaban en cada una de las piezas la posición en planta de los ejes de los nervios del enjarje, siempre en la misma situación en cada uno de los lechos y en cada una de las piezas, asegurando así que en el montaje de unas sobre otras los nervios se correspondiesen. ${ }^{148} Y$ sobre estos ejes se situaba la moldura de cada uno de los nervios en su posición correcta. Como veíamos en la montea polaca, si representamos un nervio en elevación en relación al plano vertical del que sale, el intradós del nervio se va alejando cada vez más de esa referencia vertical del muro según vamos avanzando en altura.

Para dibujar estos perfiles de los nervios es necesario, por lo tanto, saber la proyección o elevación de cada uno de los nervios del enjarje y los puntos en los que se sitúa su intradós de cada uno de los cortes

\footnotetext{
${ }^{146}$ Willis, "On the construction of the vaults of the Middle Ages", 7.

${ }^{147}$ Willis, "On the construction of the vaults of the Middle Ages", 8.

148 Willis, "On the construction of the vaults of the Middle Ages", 7-8.
} 
horizontales en relación a la posición del plano vertical del que sale. Estas medidas se obtienen de la montea, de donde se pueden tomar fácil y rápidamente y trasladar sobre el eje correspondiente del nervio dibujado en el lecho de la pieza. Caso especial es el del lecho de la última pieza del enjarje, donde la junta es inclinada para dar apoyo a la primera dovela del nervio, presentando una problemática especial.

Además, al trazar las molduras de todos los nervios en cada lecho, muchas veces solapadas unas con otras, los maestros podían valorar cuales debían prevalecer. Una vez los dos contornos de la pieza estaban definidos, se enlazaban en vertical sin perder de vista que cada uno de los nervios tiene una curvatura que hay que asegurar la concordancia entre unas piezas y otras.

\section{$\underline{\text { LuC Mojon }}$}

La labor de Luc Mojon en el estudio de estas evidencias arqueológicas es sobresaliente. En 1986 publicó un artículo en el que documentaba un enjarje perteneciente a la cabecera de la iglesia abacial de St. Johannsen en Suiza, de 1365-90, que fue desmontado en los años 60 con motivo de una restauración. En el tiempo que duraron los trabajos tuvo la oportunidad de analizar cada una de las piezas del enjarje. Tras limpiarlas con un cepillo salieron a la luz trazados tanto en el lecho superior como en el inferior de cada una de las piedras. ${ }^{149}$

El enjarje que documentó posee dos nervios formeros, dos ojivos y un perpiaño que son continuación del perfil de la pilastra del muro sin intermediación de ningún capitel. Además, está compuesto por cinco piezas de alturas diversas, con juntas de $6 \mathrm{~mm}$ entre ellas, conformando una altura total de $1,769 \mathrm{~m} .^{150}$

Tanto en el lecho inferior como en el superior de cada pieza se encuentran señaladas varias trazas. Una corresponde a la línea de la referencia del muro al que llegan los nervios y otra al eje del nervio perpiaño. Estas dos rectas se intersecan en un punto desde el cual hay señaladas unas líneas que forman ángulo con las anteriores determinando los ejes de los nervios diagonales. Como las dos bóvedas que llegan al enjarje corresponden a tramos con profundidades diferentes, el ángulo de estos nervios diagonales con el muro y el perpiaño es diferente en un lado y el otro.

\footnotetext{
${ }^{149}$ Luc Mojon, "Analyse eines spätgotischen Tas-de-charge", St. Johannsen Saint-Jean de Cerlier Beiträge zum Bauwesen des Mittelalters aus denBauforschungen in der ehemaligen Benediktinerabtei, 1961-1984, (Berna: Staatl. Lehrmittelverl, 1986).

150 Mojon, "Analyse eines spätgotischen Tas-de-charge", 91.
} 
A partir de la determinación de estos ejes, se dibuja sobre ellos el perfil de cada plantilla en relación a su situación en cada lecho. Estos dibujos no sólo permiten mostrar los principios de la construcción del enjarje, sino también arrojar luz sobre la geometría de la construcción medieval. ${ }^{151}$
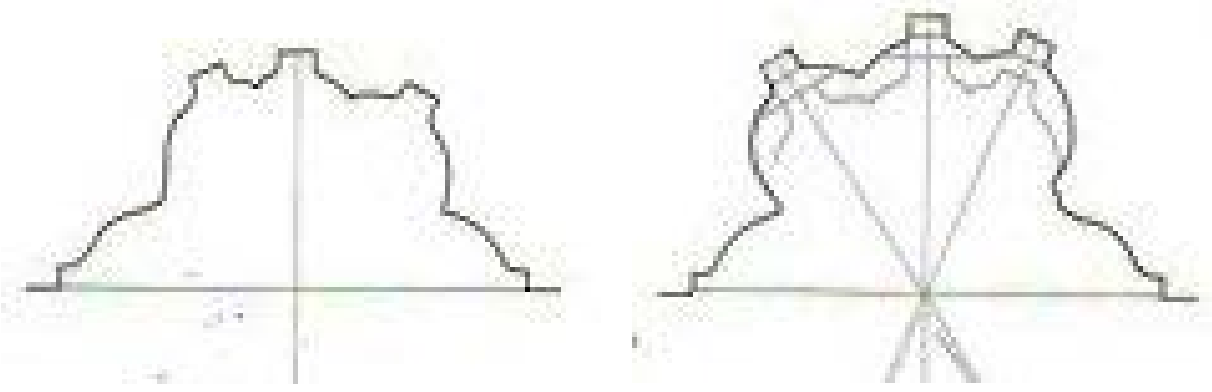

En lecho inferior de la primera pieza W1L1, que corresponde con el perfil de la pilastra y que Mojon llama das harte Lager (el plano duro), aparecen marcadas dos rectas perpendiculares, una que hace referencia al plano del muro y otra al eje del perpiaño. También un contorno completo sin rastros de trazados auxiliares donde Mojon señala que podemos reconocer una plantilla con ese perfil- a la que llama S2- que ha sido utilizada directamente en esa cara de la pieza ajustándola a los dos ejes señalados.

En la cara superior de la pieza W1L2, das weichen Lager (el plano blando), volvemos a encontrar trazada prácticamente por completo esta plantilla junto con los ejes de todos los nervios, el muro y el contorno correspondiente a ese corte. La utilización de la plantilla ayuda a controlar de manera sencilla que el ángulo que forman unos nervios con otros sea el correcto pues, como hemos señalado con antelación, no es siempre el mismo.

En el caso se esta primera pieza y en la segunda, se marca tanto en la cara superior como en la inferior esta plantilla S2 mientras que en la tercera y quinta pieza aparece marcada en el lecho inferior; y en la cuarta en el superior. ${ }^{152}$ Es la referencia perfecta para asegurarse de que al montar el enjarje no se produzcan desviaciones entre los ejes de los nervios entre unas piezas y otras. Mojon señala la peculiaridad de la utilización de este procedimiento, pues algo así no había sido recogido en ningún otro caso
Fig. 55

W1L1 y W1L2, es decir, trazados en el lecho inferior de la primera pieza (arriba y en superior (abajo) (Mojon, 1986, 96).

\footnotetext{
${ }^{151}$ Mojon, "Analyse eines spätgotischen Tas-de-charge", 89-90.

152 Mojon, "Analyse eines spätgotischen Tas-de-charge", 97, 98, 99, 100,101, 102.
} 

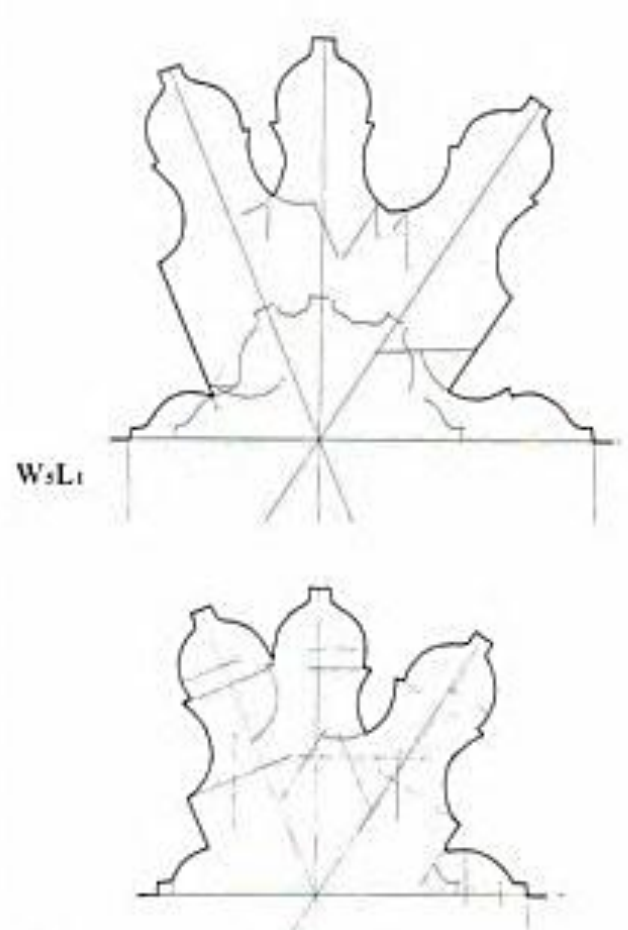

WaLt
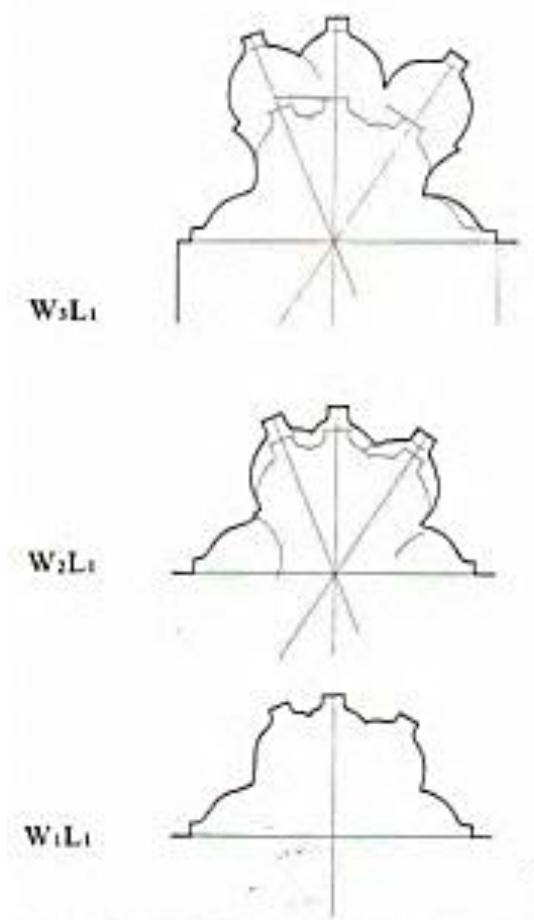
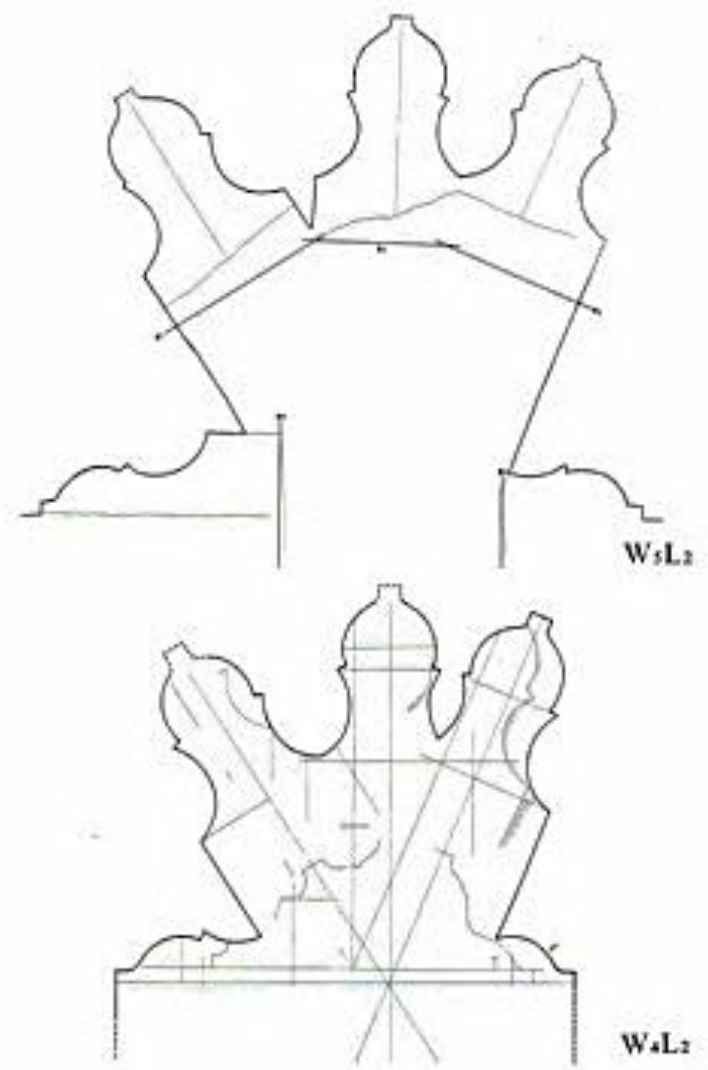

W.L.2

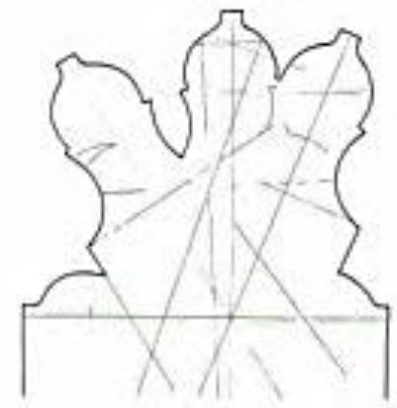

$\mathrm{W}_{3} \mathrm{~L}_{2}$

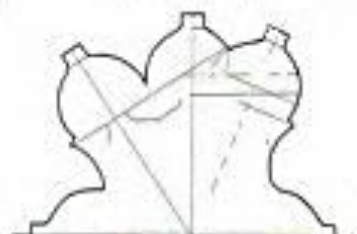

$\mathrm{W}_{2} \mathrm{~L}$,

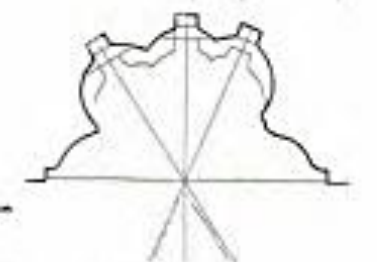

$\mathrm{W}_{1} \mathrm{~L}_{2}$
Fig. 56

Documentación de los trazados de cada uno de los lechos de las piezas del enjarje. L1 son los inferiores y L2 los superiores (Mojon, 1986, 96). con anterioridad. Esta práctica expresa cómo los maestros medievales utilizaban medios para simplificar los trabajos y controlar el proceso de construcción de la manera más sencilla posible.

El perfil de los nervios se compone de un filete en forma de $U$ en el intradós que se continúa con un baquetón cóncavo definido por una circunferencia. 


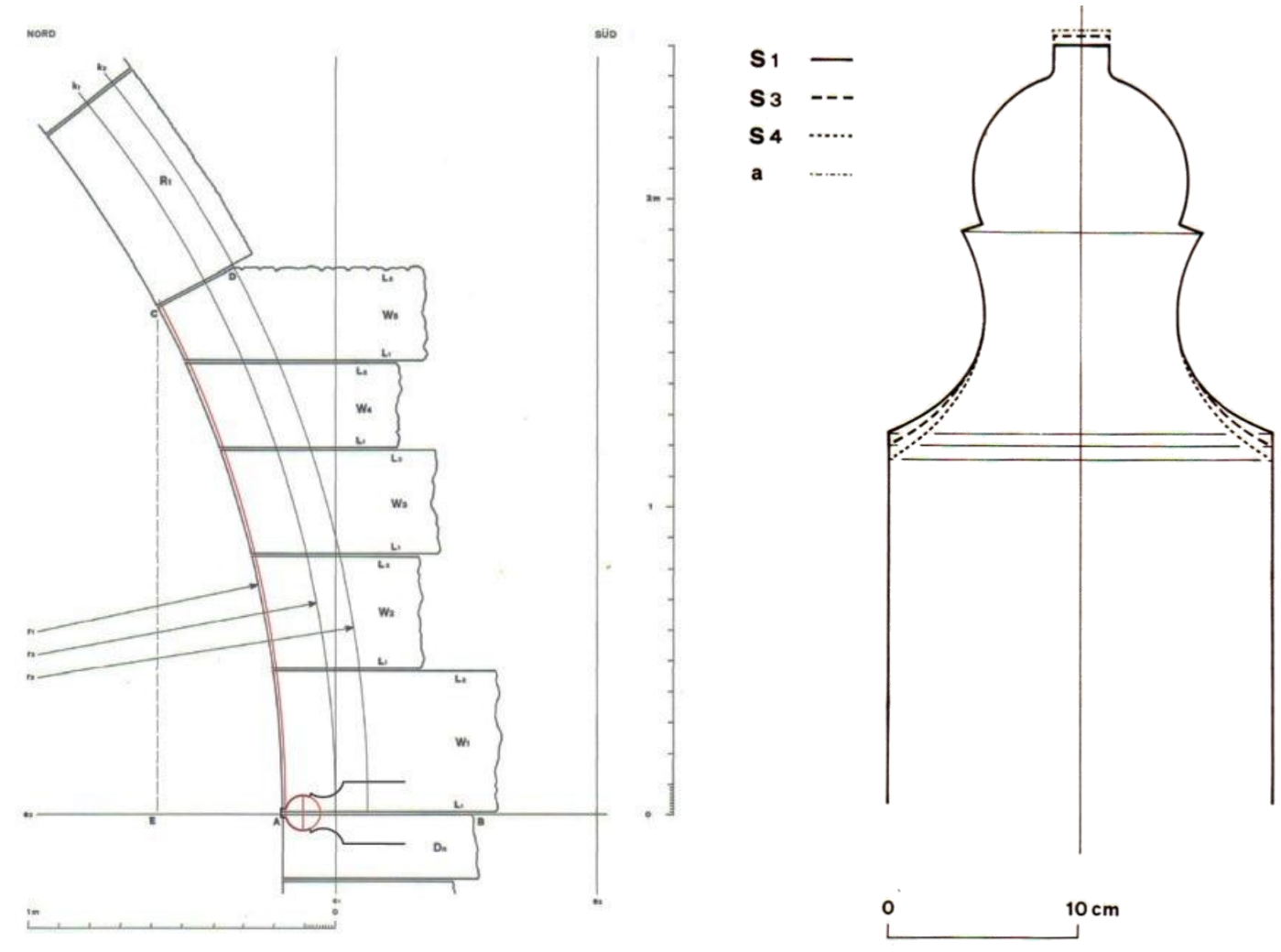

Ésta se ve interrumpida por un pequeño plano, a partir del cual se aumenta la sección del nervio mediante una concavidad.

Este perfil se hace insuficiente en los lechos horizontales debido a que el corte que se da no es radial, sino oblicuo, siendo cada vez más alargado en los lechos superiores. ${ }^{153} \mathrm{El}$ caso de este enjarje es singular, puesto que en vez de encontrarnos la deformación del perfil de manera proporcional en toda su dimensión en los cortes horizontales, encontramos con que solamente se alarga el filete de intradós de la plantilla para dar respuesta a Fig. 57

Dibujo en rojo de la curva paralela al intradós por el cambio de molduración tras el filete de intradós. Sobre Mojon (1986, 90).

Fig. 58

Plantillas deformadas superpuestas (Mojon, 1986, 95). la diferencia de dimensión. En todas, excepto en la última horizontal, se traza el resto de la plantilla sin deformar. Para tomar estas medidas de deformación del filete sería necesario dibujar en la montea una curva paralela por el punto en el que la circunferencia de la moldura corta el eje de la plantilla, tal y como se indica en la Fig. 57.

En el lecho superior de la primera pieza, así como en los de la segunda pieza y el lecho inferior de la tercera, vemos unas trazas paralelas al intradós de las plantillas, señalando el traslado de esta distancia. A partir de ahí, se trazó el resto del contorno del perfil sin deformar.

En algunos lechos encontramos también rectas perpendiculares a los ejes que se corresponden con la posición del centro de la circunferencia que 
define el baquetón del perfil. Mojon sostiene que pueden responder al hecho de que los canteros trabajasen con media plantilla y estas referencias les ayudasen a marcar el contorno completo. ${ }^{154}$ También hay otra serie de rectas paralelas que señalan el cambio en la molduración de la convexidad a la concavidad. Estas marcas son interesantes porque se trazan seguramente como simple referencia del comienzo de la zona cóncava de la plantilla, pero en ningún caso se las aplica la deformación correspondiente según la altura del corte.

Aparecen otras rectas paralelas relacionadas con el final de la parte cóncava de la plantilla en los trazados de las dos últimas juntas horizontales, pues es donde se empieza a hacer visible esta parte de la moldura del nervio. Mojon confunde estas líneas en ocasiones con trazados de la plantilla común S2. ${ }^{155}$ Además, su situación en los lechos de las piezas no se corresponde con la medida de la montea que debieran seguir. En el caso de la penúltima junta horizontal Mojon sostiene que los maestros hicieron uso de una nueva plantilla ${ }^{156}$ pero, si estudiamos el lecho W3L2 y el W4L1, la posición de estas rectas encaja con el trazado de la plantilla sin deformar.

Esto no ocurre en la última junta horizontal, donde tanto en el lecho W4L2 y W5L1 la situación de estas rectas difiere de la plantilla sin deformar. Lo curioso es que el alargamiento no se corresponde tampoco con el que debiera tener si tomamos la distancia de la montea, pues es ligeramente menor. En este trazado se puede observar claramente la utilización de una nueva plantilla, pues el trazado cóncavo del perfil por primera vez no se corresponde con el de la plantilla sin deformación. ${ }^{157}$

Nos parece oportuno también reseñar la presencia de trazados de ejes que se han descartado en dos de los lechos, el W3L2 y el W4L2. Mojon sugiere que en el caso de estas piezas, los maestros disponían de piedras de dimensiones ajustadas, lo que comportaba la necesidad de optimizar el trazado lo máximo posible, pues ante cualquier error, la pieza no cabría en el bloque. Por ello, apunta que seguramente trazasen en primer lugar el lecho superior, pues es el de mayor dimensión y el que determina si la pieza se puede ejecutar o no. Probablemente era también posible que los planos verticales fuesen inclinados en algunas partes, siempre y cuando pudiesen

\footnotetext{
${ }^{154}$ Mojon, "Analyse eines spätgotischen Tas-de-charge", 100.

${ }^{155}$ Mojon, "Analyse eines spätgotischen Tas-de-charge", 99 y 100.

${ }^{156}$ Mojon, "Analyse eines spätgotischen Tas-de-charge“, 99.

${ }^{157}$ Mojon, "Analyse eines spätgotischen Tas-de-charge", 101 y 102
} 
contener la curvatura de los arcos al tallar la unión entre el lecho superior y el inferior. ${ }^{158}$

Tras el estudio de los trazados de todas las piezas, Mojon señala que es evidente y necesario el uso de una montea en el desarrollo de los trabajos. Aunque advierte que en el caso de este enjarje es sorprendente la no sistematización del modo de elongación de las plantillas, pues en unos casos alargan el filete del perfil, en otros la parte cóncava o, en otras ocasiones, ambas. ${ }^{159}$ Cuestionamos esta apreciación, pues si bien es cierto que el procedimiento de deformación de las plantillas no responde a un procedimiento común en todo el desarrollo del enjarje, sí pensamos que tiene una cierta lógica. En todas las juntas se deforma el filete del perfil, medida que sería muy sencilla de medir de la montea ${ }^{160}$ o trazar mediante tanteo.

Somos partidarios de la idea de que sólo en el último lecho horizontal se hizo uso de la plantilla alargada del nervio porque es el único en el que se hace necesaria debido a la mayor diferencia entre el corte radial y el horizontal. Parece ser que los maestros eran conscientes de que la mayor deformación se daba en el último lecho horizontal del enjarje y que en el resto la diferencia entre el perfil alargado y el normal era tan pequeña que se hacía innecesario el trazado de una nueva moldura.

El hecho de que en ningún caso deformen el baquetón del perfil puede señalar la dificultad que encontraban a la hora de dibujar la deformación de una circunferencia, siendo por ello más sencillo simplemente alargar el filete del intradós.

\section{Otros ejemplos}

Durante el trascurso de la presente investigación hemos hallado también evidencias arqueológicas de trazados en enjarjes desmontados o en ruinas.

\footnotetext{
${ }^{158}$ Mojon, "Analyse eines spätgotischen Tas-de-charge", 101.

159 Mojon, "Analyse eines spätgotischen Tas-de-charge", 104.

160 Mojon olvida incluir en su dibujo de elevación del nervio: Mojon, "Analyse eines spätgotischen Tas-de-charge“, 90.
} 

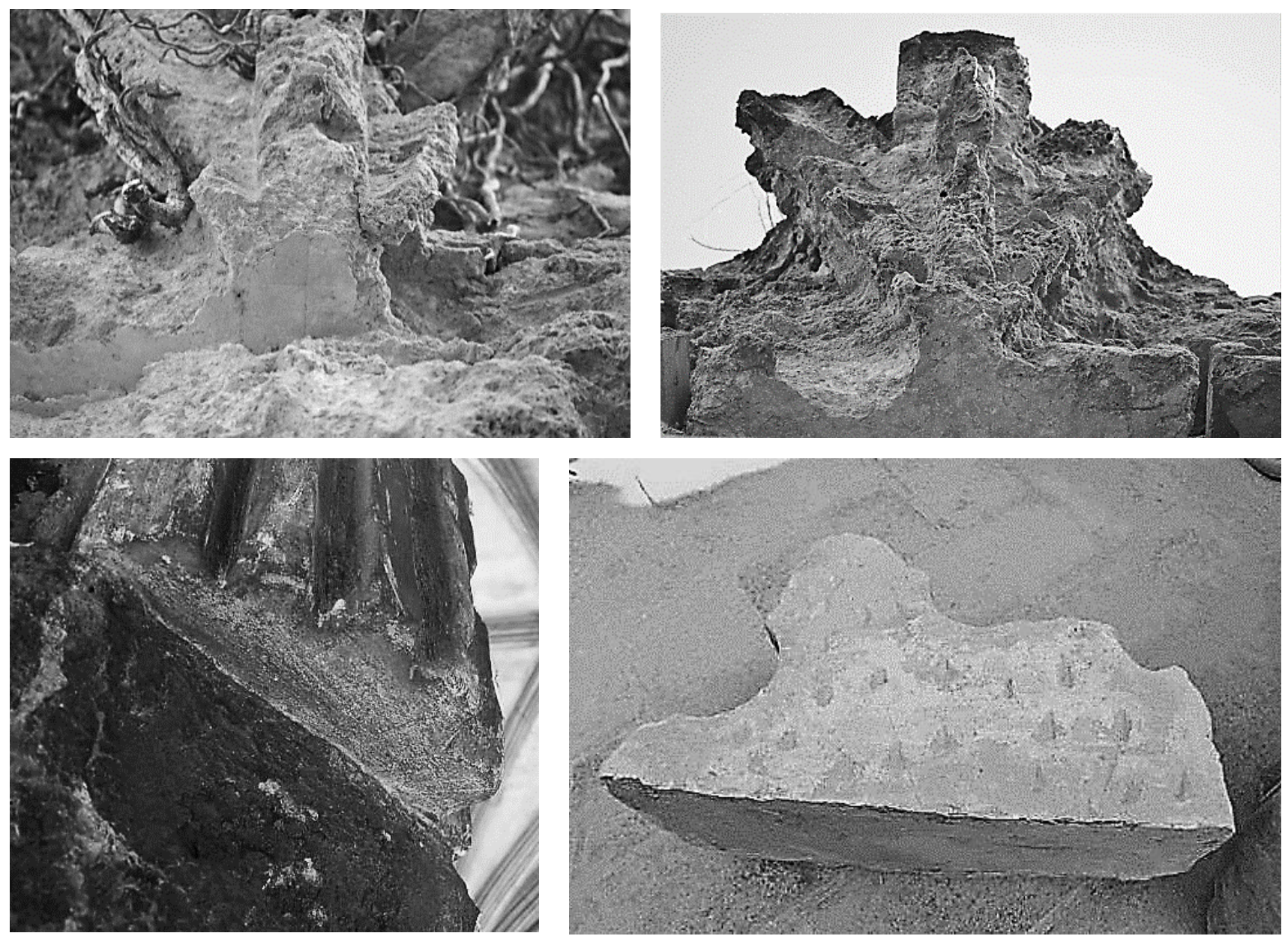

Fig. 59

Trazas documentadas en enjarjes. De arriba abajo y de izquierda a derecha: Dos enjarjes arruinados en la cartuja de Valdecristo (Altura), enjarje en la catedral de Norwich (imagen: Alberto Calderón González), enjarje de la catedral de Valencia y enjarje en refectorio de St. Viktor en Xanten (Schubert, 2007, 227: fig. 31).

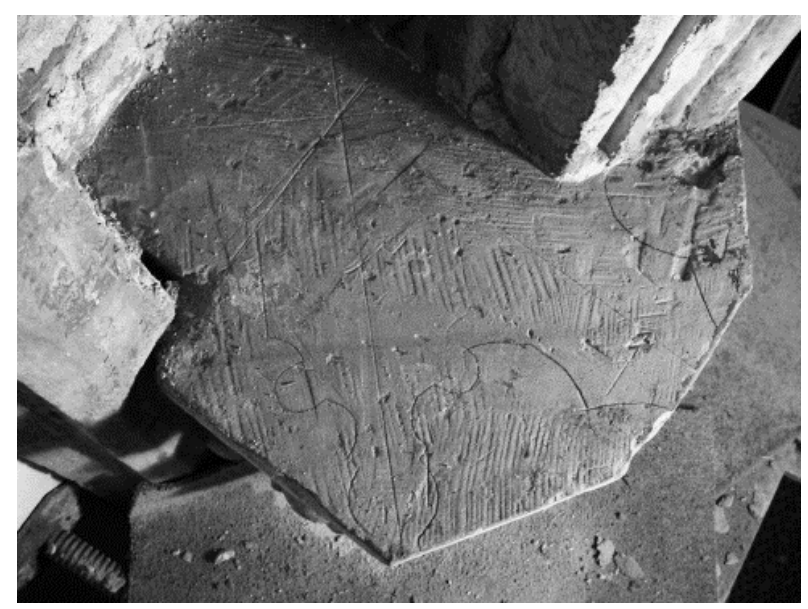

Gracias a Alberto Calderón González sabemos que en los enjarjes de las bóvedas del claustro de la catedral de Norwich de finales del siglo XIII hay restos del trazado de los ejes de los nervios en los lechos.

También en los enjarjes de la cartuja de Valdecristo de finales del siglo XIV, cerca de Valencia, hemos podido observar en diversas piezas la presencia de trazas en las que se ve, como en el caso del enjarje suizo, la presencia de una recta que hace referencia al muro y el resto de ejes de los nervios que confluyen en un punto de ella. 
En la propia Valencia y en relación a la catedral, localizamos piezas de uno o varios enjarjes en los que era evidente el trazado de ejes y en algunos casos, incluso, el de perfiles de las plantillas de los nervios. ${ }^{161}$

Finalmente, mostramos el trazado de los ejes del enjarje del refectorio de St. Viktor en Xanten (Alemania), junto con los restos de marcas del trazado de plantillas. ${ }^{162}$

Tras toda esta serie de casos distribuidos por toda Europa, pertenecientes a diferentes periodos, podemos afirmar sin lugar a dudas que el procedimiento presentado por Willis era conocido y utilizado por todo aquel constructor de bóveda de crucería que acometía la tarea de construir un enjarje. Era el modus operandi.

\subsubsection{Otras propuestas relativas al trazado}

Willis no conoce ninguna montea de enjarje, por lo que se muestra cauteloso sobre el modo de representar en elevación los nervios. A pesar de dibujar la bóveda de crucería con los nervios abatidos dice que en ningún caso pretende señalar que en el medievo se hiciese así, sino que es la única manera que ha encontrado para mostrar la mutua dependencia geométrica entre el trazado en planta y elevación de la bóveda con sus elementos singulares, los enjarjes, las claves y las dovelas. ${ }^{163}$ Tras el estudio de toda la documentación gráfica analizada no nos quedan dudas de que los maestros medievales hacían uso de este sistema de representación.

Willis está además interesado en el estudio de la curvatura de los nervios y dedica un capítulo, On the curvature of the ribs ${ }^{164}$, para explicar cómo se han de trazar, preocupado por el estudio del abanico de posibilidades que ofrece la utilización de diferentes curvaturas o la variación de los puntos de arranque en los nervios, así como la posición de altura de las claves. Desarrolla métodos para trazar arcos conociendo su punto de partida y de llegada ${ }^{165}$ o ensalza las ventajas del trabajo con arcos compuestos por dos

\footnotetext{
${ }^{161}$ Agradezco a Arturo Zaragozá Catalán y a Salvador Vila haberme facilitado esta visita y haberme permitido tomar fotografías.

162 Agradezco a Herr Schubert, Dombaumeister de Xanten haberme permitido la visita al lugar y haberme facilitado esta imagen. A Herr Knapp, Steintechniker y Steimetz de Xanten le agradezco haberme mostrado la imagen y todas sus aclaraciones con respecto a ella.

163 Willis, "On the construction of the vaults of the Middle Ages", 15, 18.

${ }^{164}$ Willis, "On the construction of the vaults of the Middle Ages", 9.

165 Willis, "On the construction of the vaults of the Middle Ages", 11.
} 
Fig. 60

Viollet-le-Duc, 1979, vol. 4: 91, fig. 48bis.

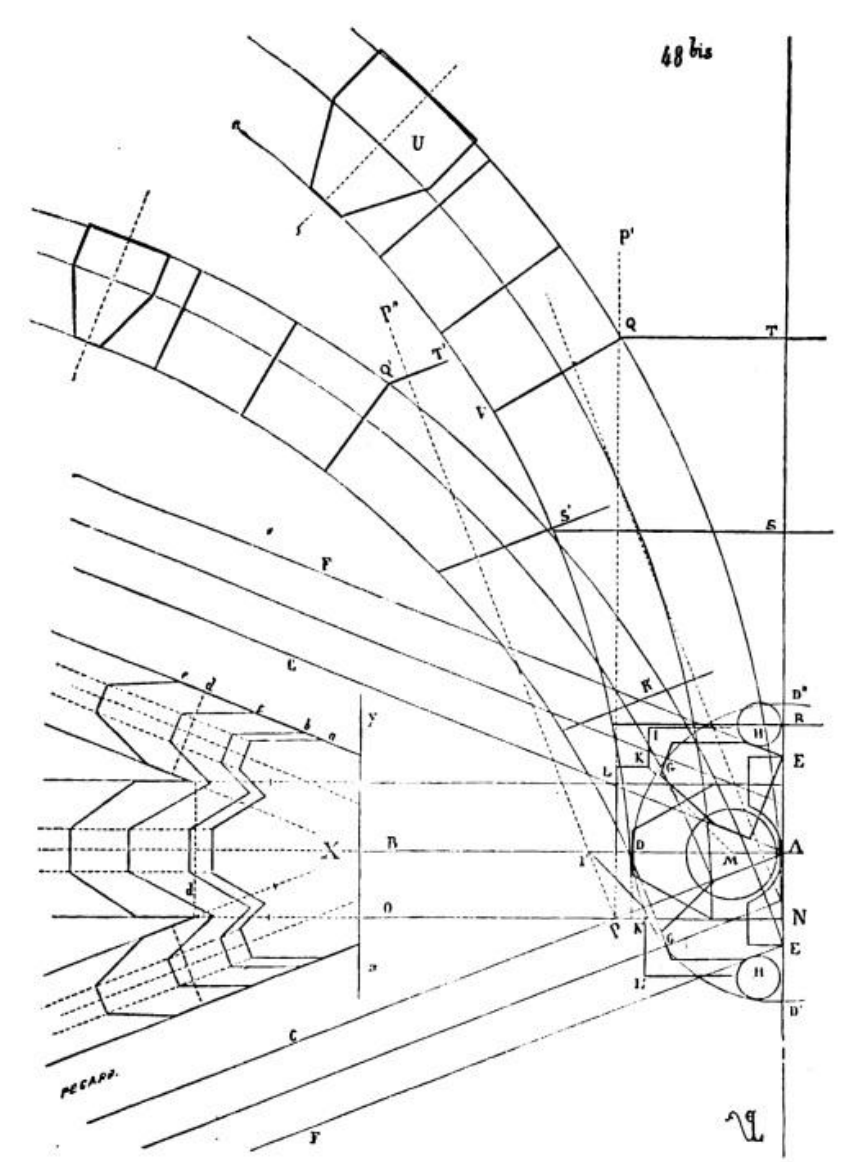

curvaturas, cosa que permite que en el enjarje todas las curvaturas sean iguales y, a partir de ese punto, las curvaturas de cada arco varíen en relación al punto al que tiene que llegar cada nervio. ${ }^{166}$

Viollet le Duc presenta el trazado de un enjarje, en el que la elevación de los nervios se traza también en relación a su planta. Plantea en este ejemplo que en el nivel de arranque de los nervios, sus intradoses, estén contenidos en la circunferencia D'DD' ', enrasada con el intradós del perpiaño. En el espacio entre los ojivos y el muro sitúa unas columnillas que no rebasan tampoco dicho contorno. ${ }^{167}$

También se interesa por el modo de determinar la posición de la junta inclinada de la pieza final del enjarje. Para ello señala en la planta el punto $P$, que es donde el canto nervio perpiaño y el ojivo se intersecan, y lo traslada a la elevación del arco perpiaño hasta cortar su extradós. ${ }^{168} \mathrm{~A}$ partir de ahí realiza la junta inclinada y la parte horizontal de esta última pieza. De ese modo además determina la altura total del enjarje dividiendo el resto

166 Willis, "On the construction of the vaults of the Middle Ages", 17.

${ }^{167}$ Eugène Viollet le Duc, Dictionaire raissoné de l'architecture française du XIe au XVle siècle, (París: B. Bance, 1979), vol 4, 90-92.

168 Viollet le Duc, Dictionaire raissoné de l'architecture française du Xle au XVIe siècle, 91. 
en piezas horizontales. Asimismo advierte que el nervio ojivo, al tener menor espesor que el perpiaño, presenta una superficie sin cubrir que nombra en el dibujo como Q'y que aportará ventajas para empezar a colocar el comienzo de la plementería. ${ }^{169}$

Este método de Viollet le Duc puede haber sido utilizado en alguna ocasión por maestros medievales pero no tenemos evidencias que lo corroboren. Probablemente estemos ante el intento de un estudioso del XIX del gótico por presentar reglas para procedimientos medievales bajo una visión mucho más teórica focalizada en la sistematización de procesos.

Enrique Rabasa Díaz apunta, además, sobre el dibujo de Viollet le Duc, que no basta sólo con garantizar que los nervios se separen a partir de cierto punto, sino también que los perfiles no queden parcialmente solapados uno sobre otro. Ilustra la explicación con un dibujo que denota la variedad de soluciones de la última pieza simplemente cortando los nervios a la altura 1 (caso a) o a la altura 2 (caso b), estando 1 y 2 en la misma vertical. Para Rabasa, hablar de procedimientos para determinar esta situación del último corte sólo nos puede remitir a ejercicios relacionados con la geometría descriptiva y no a la verdadera práctica medieval, donde la maestría y la intuición de los maestros guiarían el proceso de determinación de esta junta, al mismo tiempo que gracias a su experiencia solventarían posibles errores o tanteos sobre la marcha. ${ }^{170}$

En cuanto al trazado de la bóveda, al profesor Rabasa tampoco le quedan dudas de la utilización de la elevación de los nervios, pues es indispensable la definición de la curva de intradós para el trazado de enjarjes y claves, así como apunta a que:

Las reglas de la traza de la bóveda nervada gótica son escasas y elásticas. La proyección horizontal es una red; elevando verticalmente sus nudos -lo que llamamos claves- a las cotas adecuadas, esta red se adapta a la forma volumétrica deseada. ${ }^{171}$

169 Viollet le Duc, Dictionaire raissoné de l'architecture française du Xle au XVle siècle, 92.

170 Enrique Rabasa Díaz, "Construcción de una bóveda de crucería en el Centro de los Oficios de León”, Actas del Cuarto Congreso Nacional de Historia de la Construcción, (Madrid: Instituto Juan de Herrera, 2005), 912.

${ }^{171}$ Enrique Rabasa Díaz, "Principios y construcción de las bóvedas de crucería", Loggia, Arquitectura \& Restauración, (1996), año X, n² 20, 89.
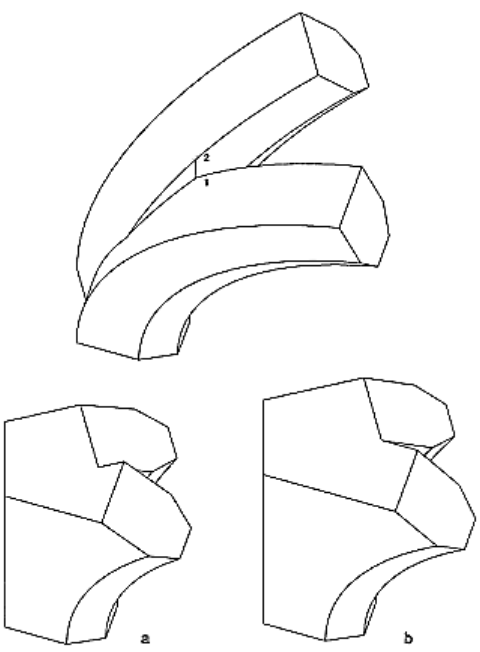

Fig. 61

Formas de solucionar la última pieza del enjarje (Rabasa, 2005, 912). 
Fig. 62

Plantillas en el Álbum de Villard de Honnecourt (XIII, fol. 32).

\subsubsection{La utilización de plantillas en enjarjes.}

Es sabido que los maestros medievales hacían uso de plantillas para la construcción. Las vidrieras de la catedral de Chartres dan fe de ello, ${ }^{172}$ así como muchos dibujos medievales; ${ }^{173}$ o su presencia en páginas del Álbum de Villard de Honnecourt, donde además, se las representa en ocasiones con marcas para facilitar su identificación con los elementos arquitectónicos. ${ }^{174}$

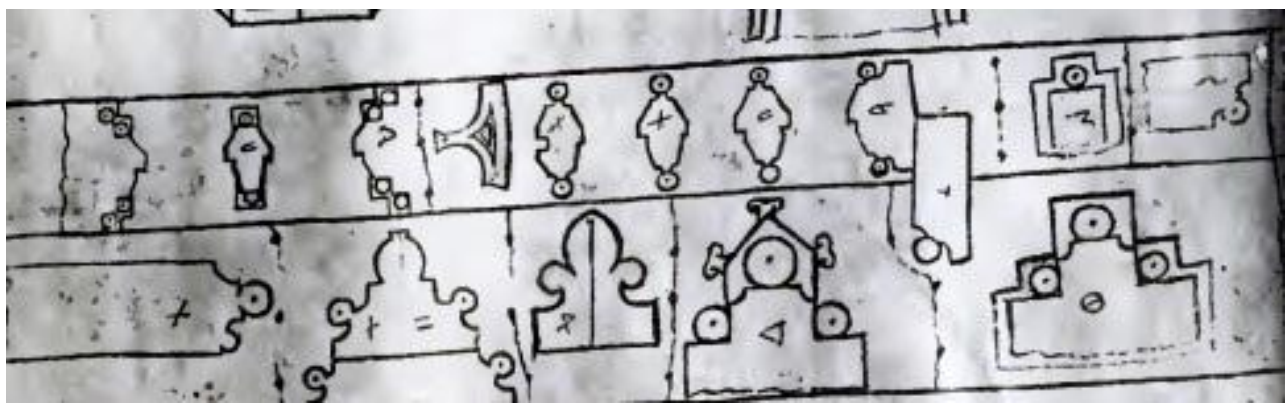

En cuanto a su aparición en la documentación, encontramos noticias ya en el siglo XIV en referencia a los trabajos de la St. Stephen's Chapel en Westminster Palace. Alli se hace alusión al hecho de que el maestro Thomas de Canterbury estuvo tres semanas antes de comenzar a trabajar con el resto de canteros ocupado in trasura super moldas operanti, es decir, realizando plantillas. ${ }^{175}$ En Mallorca también se recoge que a finales del XIV, Pere Morey se ocupaba de la elaboración de plantillas de madera para los picapedreros de Santanyí. ${ }^{176}$ Los documentos hablan en este caso de molles, mollos, contramolos i contramollos. ${ }^{177}$ Poco después, en tiempos de

172 Étienne Houvert e Yves Delaporte, Les vitraux de Chartres, (Chartres: Durand, 1926), pl. LXXXI-LXXXIV.

${ }^{173}$ El profesor Binding ha recogido y estudiado un gran número de dibujos medievales en los que la presencia de plantillas es abundante. Günther Binding, Romanischer Baubetrieb in zeitgenössischen Darstellugen, (Köln: Henry Deckner, 1972). Günther Binding, Baubetrieb im Mittelalter, (Darmstadt: Wissenshaftliche Gesellschaft, 1993). Günther Binding y Norbert Nußbaum, Der mittelalterliche Baubetrieb nördlich der Alpen in zeitgenössischen Darstellungen, (Darmstadt: Wissenschaftliche Buchgesellschaft, 1978). Günter Binding, Was ist Gotik? Eine Analyse der gotischen Kirchen in Frankreich, England und Deutschland 11401350, (Darmstadt: Wiss. Buchges, 2000).

${ }^{174}$ Lon R Shelby, "Mediaeval Masons'Templates", J.S.A.H, XXX, n 2 (1971), 145.

${ }^{175}$ Lon R Shelby, "Mediaeval Masons'Templates", 141.

176 Domenge i Mesquida, L'Obra de la Seu. El procés de construcció de la catedral de Mallorca en el tres-cents, 166.

177 Domenge i Mesquida, L'Obra de la Seu. El procés de construcció de la catedral de Mallorca en el tres-cents, 267. 
Guillem Sagrera como maestro mayor de la catedral de Palma, se habla de que se hace cargo de comprar madera para las plantillas o modelos para dar los perfiles a los canteros. ${ }^{178}$

Fuera aparte de su mención en la documentación, su utilización en piezas arquitectónicas es más que probada gracias a las evidencias arqueológicas que han llegado hasta nosotros en forma de trazados, tal y como hemos mostrado con antelación. También de manera indirecta somos conscientes de su uso mediante, como explica Enrique Rabasa, huellas de la traza directa, es decir, a través de la evidencia de su uso en piezas dónde sólo podemos explicar la existencia de partes labradas por un metódico trabajo con ellas. Rabasa muestra el ejemplo de los enjarjes de la capilla del Condestable, donde pudo comprobar in situ que las piezas están talladas por dentro, siendo esta una zona que nadie nunca verá debido a su inaccesibilidad y cuya talla hubiese sido inviable una vez colocadas las piedras. ${ }^{179}$

Una plantilla puede representar la moldura de un nervio, el perfil de un elemento, su planta; o servir para tallar varios planos en la piedra que deban ser proyectados durante la marcha de los trabajos. Shelby apunta a que en alguna situación, cuando no se disponía de plantillas para el trabajo de un determinado plano, los maestros también realizaban plantillas secundarias normalmente cortando papel. ${ }^{180}$ Tras el estudio de libros financieros, libros de fábrica y dibujos existentes, afirma que los maestros realizaban las plantillas sin la necesidad de planos; por lo que podemos decir que fueron, con antelación a los dibujos arquitectónicos, los primeros instrumentos mediante los cuales trasmitieron las formas arquitectónicas a los canteros que las ejecutaban en piedra. ${ }^{181}$

En el caso de los enjarjes, las plantillas necesarias para el trazado del contorno de los lechos son las que se refieren a la molduración de los nervios. Y además, acusan una problemática especial, como ya señalamos anteriormente: como consecuencia de cortar el recorrido del nervio por lechos horizontales, la plantilla del contorno del nervio definida por el corte

\footnotetext{
178 Joan Domenge i Mesquida, "Guillem Sagrera, maître d'oeuvre de la cathédrale de Majorque. Aspects métriques et économiques du travail de la pierre (1432-1446)", Histoire \& Mesure, XVI-3/4, (2001), 18, cita 56: "El 5 de marzo de 1446 recibe 2 libras por una plancha de nogal y el trabajo efectuado para la repara las plantillas para los arbotantes al servicio de dicha obra".

179 Enrique Rabasa Díaz, Forma y construcción en piedra: de la cantería medieval a la estereotomía del siglo XIX (Madrid: Akal, 2000), 116.

180 Lon R. Shelby, "Mediaeval Masons'Templates", 141.

181 Lon R. Shelby, "Mediaeval Masons'Templates", 142.
}

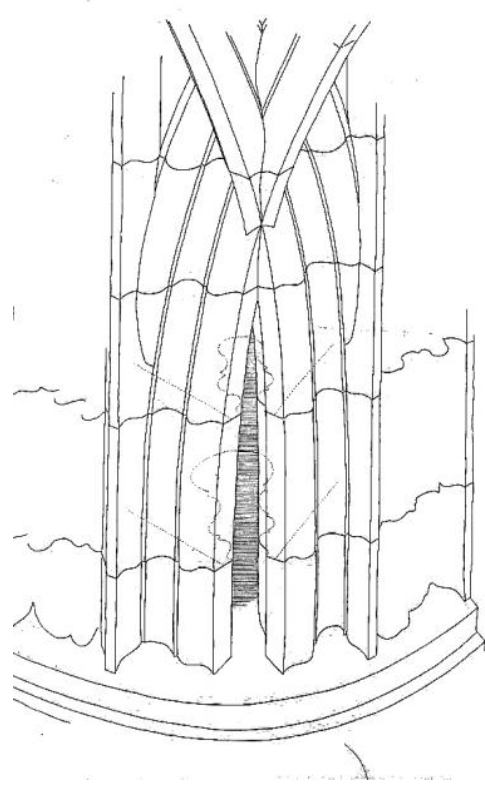

Fig. 63

Huellas de la traza directa (Rabasa, 2000, 115: fig.100). 
radial se hace insuficiente en longitud en estas secciones oblicuas. Teóricamente, los cortes horizontales requerirán una plantilla deformada que se adapte a esta nueva dimensión.

Robert Willis fue el primero que se percató de dicha singularidad. Explicó cómo ha de proceder teóricamente el cantero al enfrentarse a este cambio de dimensión: ha de medir en la elevación de cada nervio, en el lugar en el que el intradós está representado, el desplazamiento horizontal de la plantilla en cada uno de los lechos. ${ }^{182}$ Sin embargo, tras el estudio de varios ejemplos, Willis llegó a la conclusión de que los maestros también habían utilizado la misma plantilla sin deformar para todos los lechos. Esto provocaba ciertas incongruencias no demasiado agradables entre unas piezas y otras, siendo una prueba de que se permitían ciertas tolerancias o errores en la construcción. A pesar de este error fruto del uso de la misma plantilla en la ejecución, Willis consideró que las discordancias entre las piezas no eran perceptibles una vez estaban situadas y eran visualizadas a cierta distancia desde el suelo. ${ }^{183}$
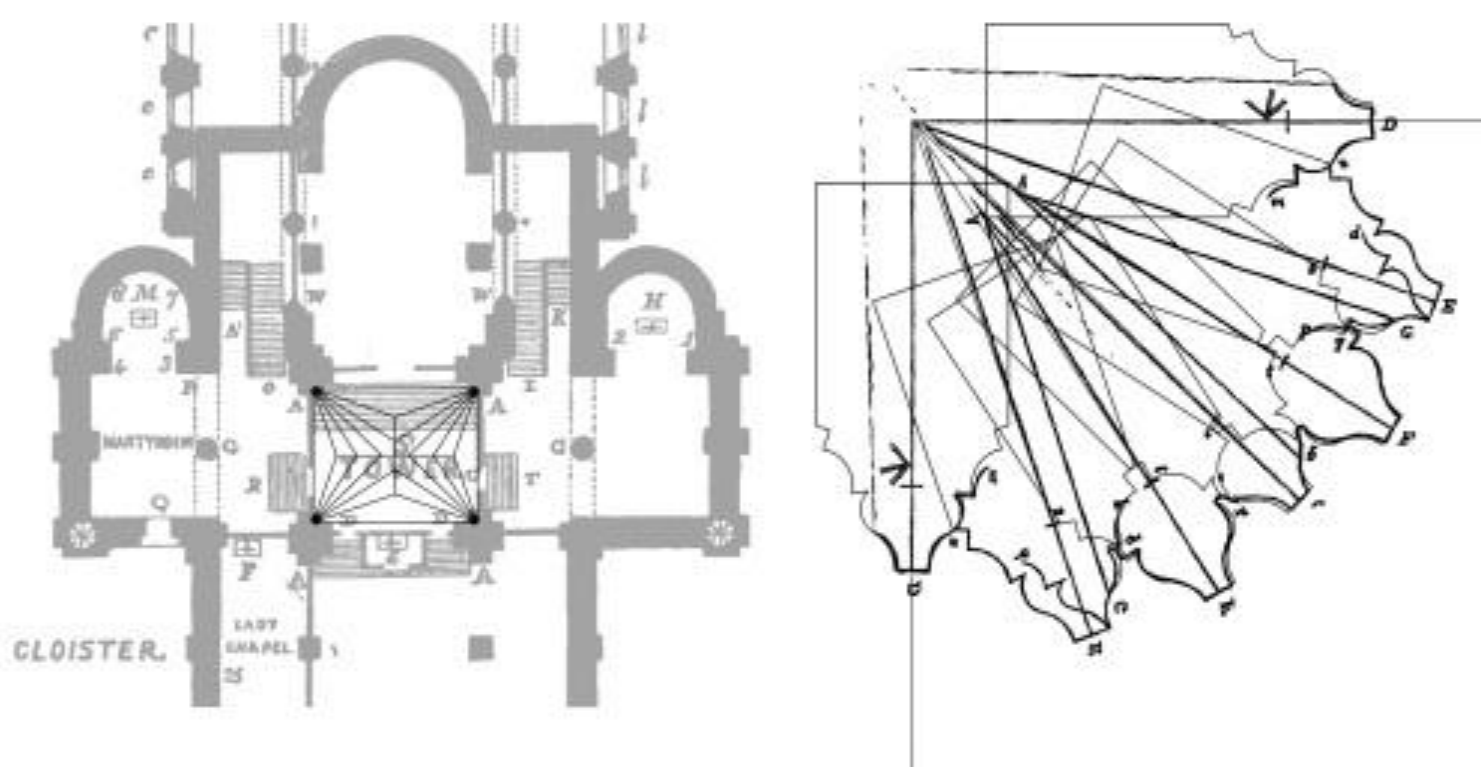

Fig. 64

Posible trazado de la bóveda en la torre de Lanfranc sobre el plano de Willis $(1845,38)$. Hipótesis del trazado de uno de los lechos de enjarje sobre Willis ([1842] 1910, 8: fig. 7).
En el ejemplo que estudió, y que hemos mostrado anteriormente, en la torre de Lanfranc en la catedral de Canterbury, sostiene que este fue el procedimiento seguido. Willis probablemente se percató de que en bóvedas con grandes luces y, por tanto, con arcos de grandes curvaturas, el uso de una única plantilla sin deformar para la construcción del enjarje era viable. Para demostrarlo, midió las piezas y presentó un croquis analizando este fenómeno. En enjarje está compuesto de hiladas de 10 pulgadas de altura y las molduras de los nervios en la sección radial tienen una longitud de 5 pulgadas y en la horizontal de 5 y media. En su Fig. 5

\footnotetext{
182 Willis, "On the construction of the vaults of the Middle Ages", 8-9.

${ }^{183}$ Willis, "On the construction of the vaults of the Middle Ages", 9.
} 
señala, por tanto, que el ángulo entre el lecho horizontal de la última pieza y el punto del intradós del arco en la sección inclinada de la parte superior de la pieza forman un ángulo de $110^{\circ} .^{184}$

Al acercarnos a este ejemplo consideramos oportuno comprobar la correspondencia de las medidas dadas por Willis con el ejemplo existente, con intención de valorar a escala real la diferencia entre la plantilla radial y la horizontal. ${ }^{185}$ Realizamos una propuesta de reconstrucción de la bóveda de la torre de Lanfranc utilizando el dibujo de la pieza de enjarje que presenta Willis y su planta. ${ }^{186}$ Tras varios tanteos se llegó a la conclusión de que probablemente los nervios que salen del enjarje tuviesen una curvatura en torno a seis metros.
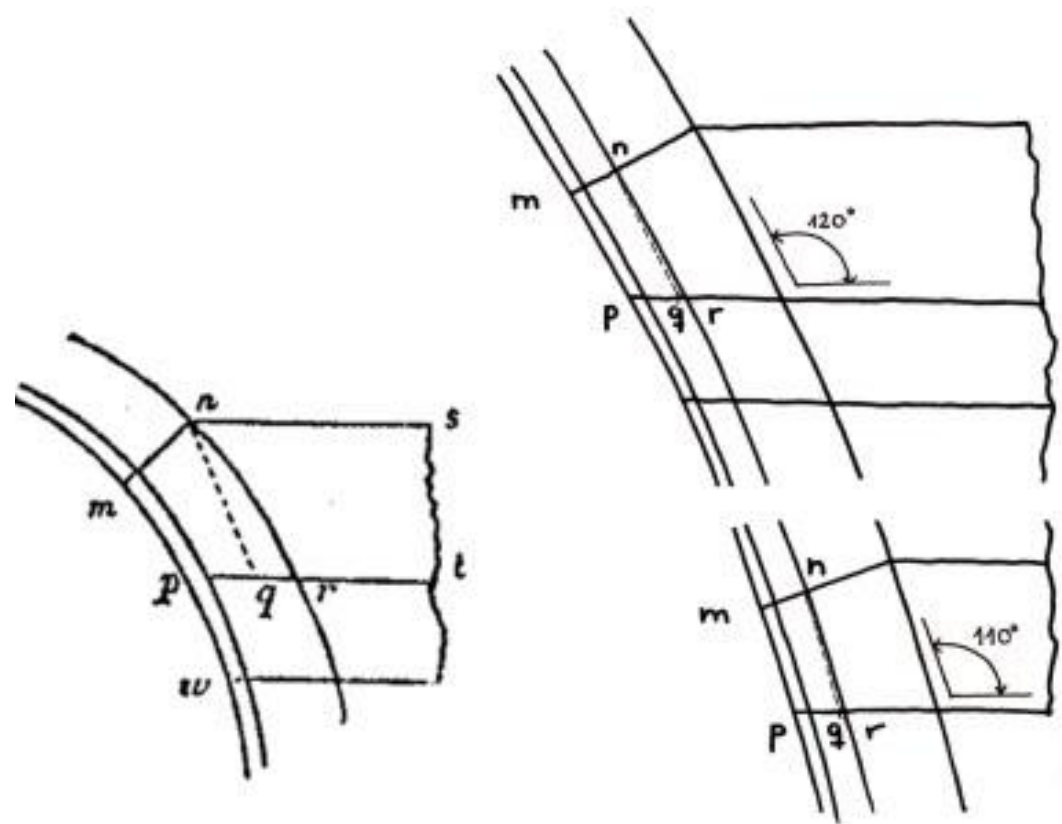

Al llevar las alturas de hilada y los tamaños de plantillas a un nervio con esta curvatura pudimos apreciar que la observación realizada por Willis era inviable. Solamente podríamos encontrar la solución en dos localizaciones diferentes del nervio, pero siempre variando alguna de las variables. En primer lugar, si nos ciñéramos al ángulo y a la altura propuesta por Willis, la longitud de la plantilla horizontal sería de 5 pulgadas y cuarto en vez de 5 pulgadas y media. En segundo lugar, si nos ajustáramos a la medida correcta de las molduras, la solución sólo sería posible si el último corte del

184 Willis, "On the construction of the vaults of the Middle Ages", 9.

${ }^{185}$ Esta revisión crítica del dibujo de Willis fue publicada en: Carmen Pérez de los Ríos y Enrique Rabasa Díaz, "Stretched templates in Gothic tas-de-charge construction", Proceedings of The First Construction History Society Conference \& Annual General Meeting, (Construction History Society, 2014), 333-342.

${ }^{186}$ Robert Willis, The architectural history of Canterbury Cathedral, (London: Longman, Pickering and Bell, 1845), 37-38.
Fig. 65

Izquierda: esquema de Willis sobre el uso de plantillas deformadas ([1842] 1910, 9: fig. 5). Derecha: análisis de las posibilidades reales sobre sus estimaciones. 


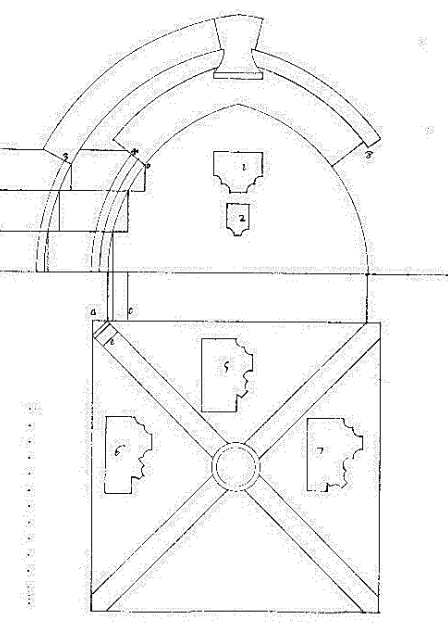

Fig. 66

Gelabert, 1653, Traza numerada 118, en fol. 133v. enjarje se encontrase cuatro hiladas más arriba de lo que señala Willis. Y, en este caso, el ángulo no sería de $110^{\circ}$, sino de $120^{\circ}$.

Es probable que durante el proceso de medición por parte de Willis de las piezas del enjarje la precisión al tomar datos de las plantillas fuera mucho mayor que al tomar el ángulo, pues llevar a cabo dicha tarea siempre comporta más error. ${ }^{187}$

\section{$\underline{L a}$ deformación en la tratadística $^{188}$}

La presencia de esta problemática en los tratados no es común, apareciendo solamente en un dibujo de una bóveda de crucería en el manuscrito de Joseph Gelabert, un tratado mallorquín del siglo XVII. ${ }^{189}$

Gelabert señala la importancia de alargar las plantillas para construir el enjarje y enseña cómo realizar la retirade (alargamiento) en cada una de las juntas horizontales. Sin embargo, admite que, debido al tamaño tan reducido de los dibujos de las plantillas en el tratado, es difícil de apreciar a simple vista en ellos el cambio de dimensión. ${ }^{190}$

Además sugiere tallar las piezas primero en cuadrado, inscritas en un bloque cuadrado que se adapte a la línea de intradós, tal y como aparece en el dibujo. A partir de ahí, las plantillas se trazarían en los lechos de las piezas.

Apunta que la deformación de la plantilla se ha de realizar partiendo de la línea de intradós del nervio hasta la línea de extradós y no de modo

\footnotetext{
187 Pérez de los Ríos y Rabasa Díaz, "Stretched templates in Gothic tas-de-charge
} construction", 337. ${ }^{188}$ Este estudio de la problemática en los tratados se lo debemos a Enrique Rabasa Díaz,
quien se ocupó de ello para el artículo "Stretched templates in Gothic tas-de-charge
construction".

189 Josep Gelabert, Verdaderes traçes de l'Art de Picapedrer,(facsimil en Palma de Mallorca: Consell Insular de Mallorca, 1977 [1653]), Traza numerada 118, en fol. 134r. Enrique Rabasa Díaz ha realizado una revisión crítica del manuscrito, con dibujos en perspectiva que permiten su mejor comprensión, así como la inclusión de la trascripción del texto y su traducción del mallorquín al castellano; sin olvidar aportaciones en partes del manuscrito faltas de una explicación gráfica. Enrique Rabasa Díaz, El manuscrito de cantería de Joseph Gelabert, (Palma de Mallorca/Madrid: Collegi Oficial d'Arquitectes de les Illes Balears /Fundación Juanelo Turriano, 2011).

190 Gelabert, Verdaderes traçes de l'Art de Picapedrer, Traza numerada 118, en fol. 133v. 

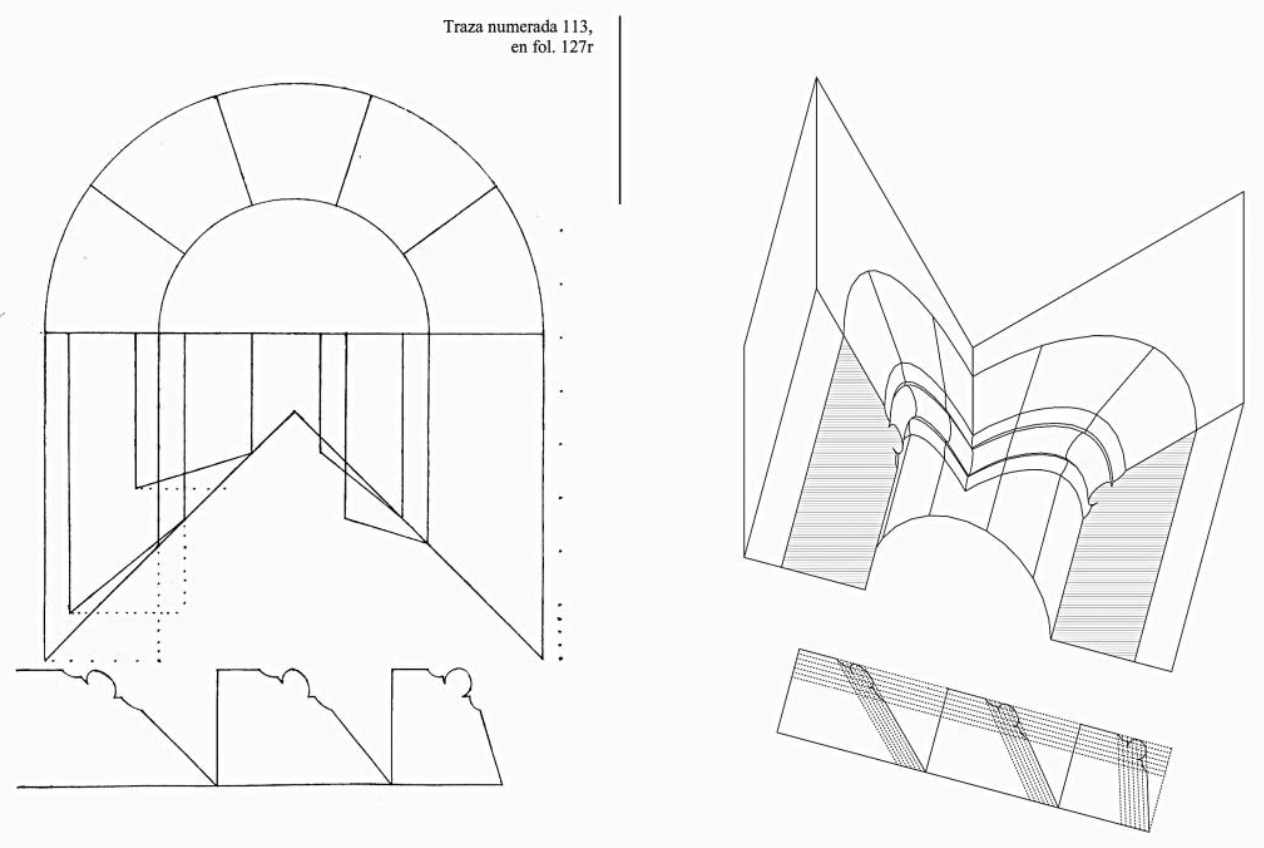

inverso. ${ }^{191}$ Parece ser que este tema le preocupa al maestro mallorquín, mostrando cómo alargar o deformar molduras en otras partes del manuscrito. El procedimiento que emplea consiste en ajustar una determinada forma a una retícula, a continuación deformar la malla y redibujar de nuevo la forma original. ${ }^{192}$ Considera que en el caso del enjarje no es necesario explicar mediante qué procedimiento se ha de obrar para el alargamiento, pues los perfiles utilizados son sencillos.

Se ha de tener en cuenta que se conocen procedimientos similares y más antiguos para alargar una forma determinada, muchos relacionados con formas ovales. Philibert de L'Orme llama a los utilizados para alargar una curva cherche ralongée, donde incluye uno en el que una vez determinadas las coordenadas $x$ - e y- de cada punto, la deformación se lleva a cabo mediante el cambio de escala en el eje x-. ${ }^{193}$ Esta expresión aparece también en el tratado de Derand, así como en otros autores, pero con un sentido más general. ${ }^{194}$

${ }^{191}$ Gelabert, Verdaderes traçes de l'Art de Picapedrer, Traza numerada 118, en fol. 133v.

192 Gelabert, Verdaderes traçes de l'Art de Picapedrer, Traza numerada 81, en fol. 94v; Traza numerada 82, en fol. 96v; Traza numerada 113, en fol. 127r. También en la Traza numerada 154 alarga una cornisa por métodos que hoy en día llamaríamos trasformación afín.

${ }^{193}$ Philibert de L'Orme, Le premier tome de l'architecture, (Paris: Féderic More. Facsimil en París: Léonce Laget, 1988, y 1648 edición en Brusellas: Pierre Mardaga, 1981 [1567]), fol.55r-55v, fol. $56 \mathrm{v}$.

${ }^{194}$ François Derand, L'Architecture des voûtes, chapitre XXIV, (Paris: Sébastien Cramoisy, 1643), 179.
Fig. 67

Izquierda: Gelabert, 1653, Traza numerada 113, en fol. 127r. Derecha: análisis de Rabasa (2011, 351).

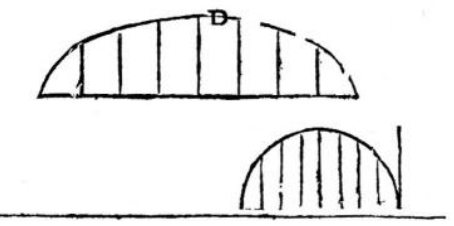

Fig. 68

Cherche ralongée (de L'Orme, 1567, fol. $56 \mathrm{v}$ ). 
Fig. 69

Deformación de la circunferencia en elipse según Durero (1525, fig. 33)
Durero emplea de manera más clara la deformación en una de las dimensiones de la malla reticulada para trasformar una circunferencia en lo que hoy llamamos elipse. Dice que este procedimiento era útil para los maestros que construían bóvedas, probablemente refiriéndose a la de arista. También aplica esta retícula a formas de la naturaleza. ${ }^{195}$

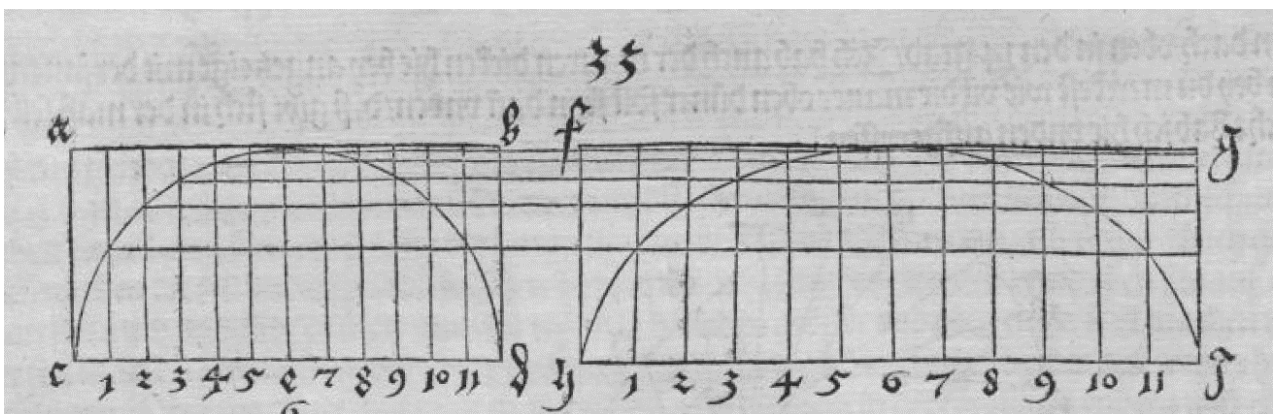

Sebastiano Serlio en su primer libro llama transporte a los cambios de escala- en un eje o dos- utilizando en teorema de Thales. ${ }^{196}$ Además, como es sabido, Serlio también muestra cómo dibujar una elipse mediante la transformación afín de dos circunferencias. ${ }^{197}$ En España, el maestro Hernán Ruiz utiliza también procedimientos similares, nombrándolos transferente. ${ }^{198}$ Sin embargo, fue Alonso de Vandelvira ${ }^{199}$ quien enseña por primera vez lo que hoy en día llamaríamos transformación de una circunferencia en elipse definida por diámetros conjugados, haciendo uso de una malla reticulada oblicua, tal y como ha explicado Rosa Senent. ${ }^{200}$

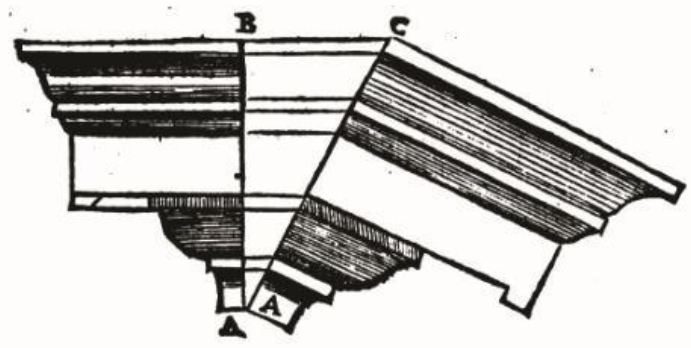

Serlio, 1545 , fol. 8 r
195 Albert Dürer, Unterweisung der Messung, (Nürnberg, 1525. Facsimile edition, Nördligen: A. Uhl, 1983), Fig.33.

${ }^{196}$ Sebastiano Serlio, II Primo libro d'Architettura, (Paris, 1545), fol. 7r- fol. 8r.

197 Serlio, II Primo libro d'Architettura, fo. 11r.

198 Hernán Ruiz, el Joven, Arquitectura, (Biblioteca de la Escuela Técnica Superior de Arquitectura de Madrid. MS R.16, ca. 1545), fol. 40v.

199 Alonso de Vandelvira, Libro de traças de cortes de piedras, (Biblioteca Nacional de Madrid MS 12.719 and Biblioteca de la Escuela T.S. de Arquitectura de Madrid MS R.10, 1575-1580. Facsimile in G. Barbe-Coquelin De Lisle, Tratado de Arquitectura de Alonso de Vande/vira, Albacete: Caja de Ahorros, 1977), fol. 126v.

200 Rosa Senent Domínguez, "Las bóvedas irregulares del tratado de Vandelvira: Estrategias góticas en cantería renacentista", Actas del Séptimo Congreso Nacional de Historia de la Construcción, (Madrid: Instituto Juan de Herrera, 2011), 1335. 
En lo referente a la bóveda de crucería, Vandelvira llama revirado a la trasformación afín del perfil de un nervio. ${ }^{201}$ Esto consiste en que su eje se mantiene vertical en condiciones dónde intuitivamente hubiera parecido más oportuno inclinarlo en relación a la curvatura del nervio. Para el mismo concepto, Rodrigo Gil de Hontañón en Simón García usa el término bulco. ${ }^{202}$ Ninguno de los dos explica cómo realizar la deformación, por lo que algunos autores has asumido que los métodos para alargar plantillas formaban parte del conocimiento de los maestros medievales.

François Derand y Amédée-François Frézier, ambos citados por Willis, explicaron cómo trazar bóvedas góticas y cómo proceder con la problemática del enjarje. Derand mantiene que el encuentro de las molduras de varios nervios entraña dificultades, por lo que propone el uso de diferentes colores o diferente modo de trazado de cada plantilla para simplificar los trabajos, lo que nos puede llevar a pensar que quizás era consciente del uso de diferentes plantillas en los diferentes lechos. Derand hace uso del ejemplo de la bóveda de terceletes cuadrada para ilustrarlo, pues sostiene que los demás tipos sólo llevan a errores y confusión. Cuando explica cómo trazar el enjarje no utiliza ningún dibujo, del mismo modo que no hace en ningún momento referencia a la necesidad de alargar las plantillas. ${ }^{203}$

Frézier, sin embargo, trata el tema de la superposición de las plantillas en los lechos, donde unos trazados se superponen y ocultan con otros. Muestra un dibujo similar a los que Willis sobre las piezas de enjarje de la catedral de Canterbury. En cuanto a la explicación del enjarje, Frézier fuerza que la intersección de dos de los nervios se realice exactamente en un plano vertical, lo que da muestras del típico modo de pensamiento de un autor del siglo XVIII y su preferencia por las configuraciones regulares. ${ }^{204}$

Utiliza también el término cerche ralongée $e^{205}$ para explicar el método para alargar las plantillas sin indicar por qué es necesario deformarlas. De

Fig. 72

Frézier, 1737-39, fig. 71, imagen 22.

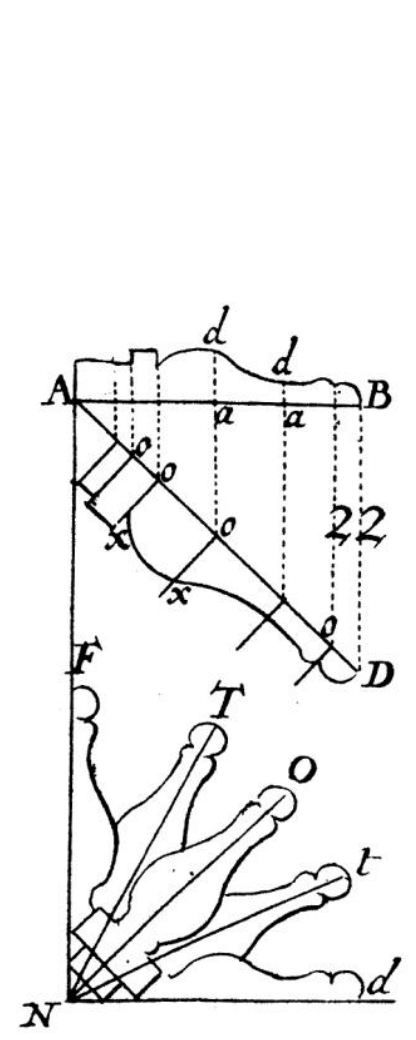

${ }^{201}$ Vandelvira, Libro de traças de cortes de piedras, fol. 96r.

202 Simón García, Compendio de architectura y simetría de los templos conforme a la medida del cuerpo humano, por Simón García, architecto natural de Salamanca, Ms. 8884, (Biblioteca Nacional de Madrid, 1681), fol. 25.

203 Derand, L'Architecture des voûtes, (Nota 6), 177-179.

${ }^{204}$ Amédée-François Frézier, La théorie et la pratique de la coupe des pierres et de bois ... ou traité de stéréotomie..., (Strasbourg/Paris: Jombert, 1737-39), 3 vol, (facsimile in Nogentle-Roy: L.A.M.E., 1980), 24-31.

${ }^{205}$ François Frézier, La théorie et la pratique de la coupe des pierres et de bois ... ou traité de stéréotomie..., 29.

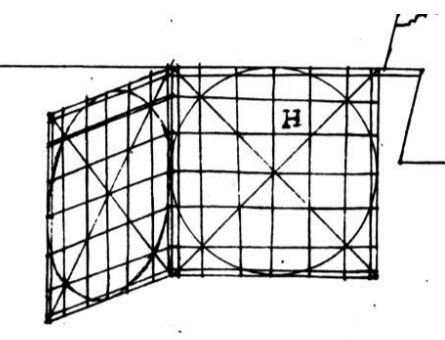

Fig. 71

Vande/vira, 1575-1580, fol. $126 \mathrm{v}$.

.


hecho, muestra un ejemplo en el que el alargamiento depende del ángulo entre la ligadura y el ojivo, sin relación aparente con los niveles del enjarje. Se diría que Frèzier tiene en la mente la necesidad de alargar las plantillas, pero no se encuentra a gusto al entrar en el tema de manera detallada.

\subsubsection{La talla y el control del trabajo ${ }^{206}$}

Una vez que en el lecho superior e inferior de cada bloque de piedra escuadrado destinado a formar parte del enjarje se han marcado los ejes de los nervios y del muro -o el del eje del pilar, etc.- y se ha trazado el contorno final que reúne los perfiles de sus plantillas -con su pertinente deformación si procede-, se comienza la talla de la pieza.

El procedimiento consiste en la coordinación entre el trazado superior e inferior en la piedra enlazando los dos contornos aparentes. ${ }^{207}$ En enjarjes en los que encontramos todos los nervios en ambos lechos, es decir, en enjarjes en los que no se producen cruzamientos de nervios o intersecciones de cierta complejidad, la búsqueda de esta correspondencia de molduras no entraña, en principio, demasiadas dificultades.
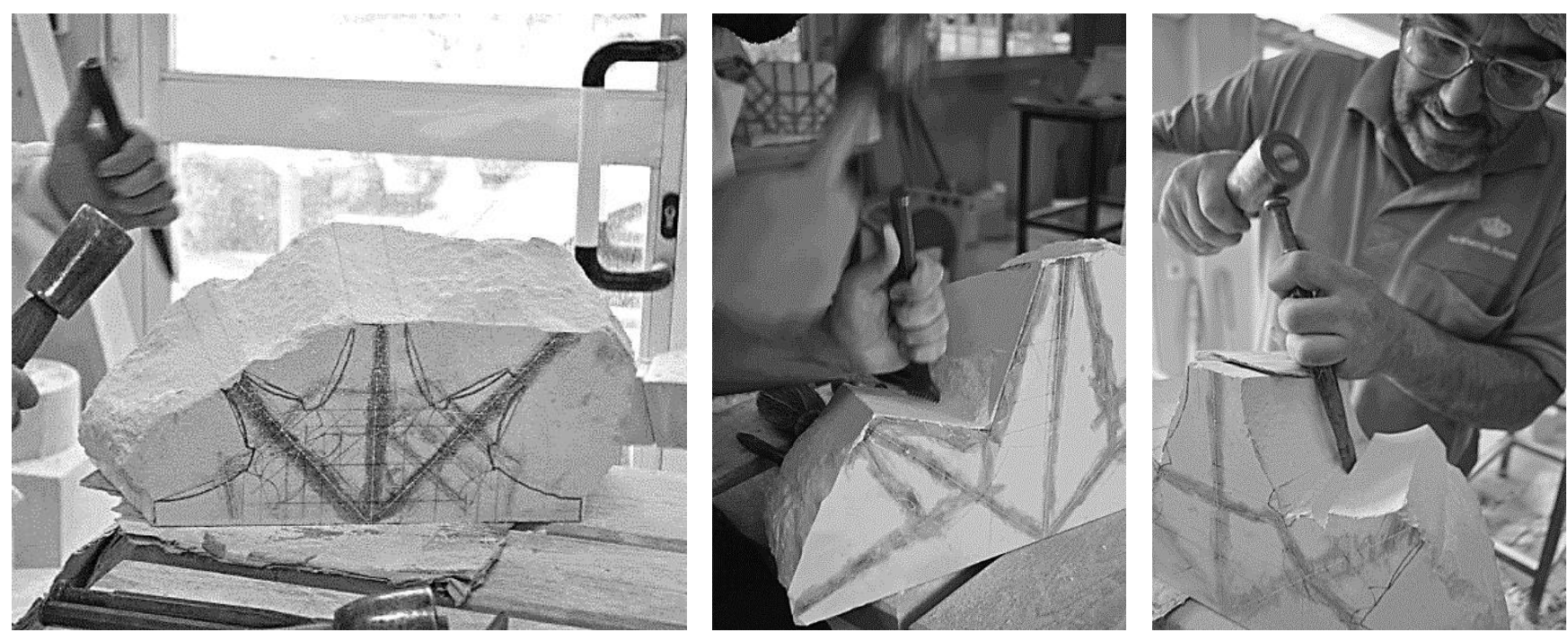

Fig. 73

Talla de una pieza del enjarje de la Lonja de Palma en el taller de la ETSAM por César Cabeza.
El trabajo de la talla se fundamenta siempre, como explica César Cabeza, en la búsqueda de referencias. A veces se determinan sobre planos tallados que formarán parte de superficies finales de la pieza, mientras que en otras el cantero deberá labrar planos auxiliares para su trazado. Esto

${ }^{206}$ Agradezco a César Cabeza, a Miguel Sobrino y Enrique Rabasa haberme introducido en el mundo de la talla en piedra, unos desde un punto de vista más práctico y otros más teórico; todos desde la generosidad y armados de la paciencia suficiente para solventar las dudas que iban surgiendo en el proceso de talla de los enjarjes llevados a cabo en el taller de cantería de la ETSAM.

${ }^{207}$ Rabasa Díaz, Forma y construcción en piedra: de la cantería medieval a la estereotomía del siglo XIX, 100 
supone, a simple vista, un esfuerzo innecesario a los ojos de los desconocedores del oficio de la cantería, pues puede parecer una pérdida de tiempo el tallar planos que desaparecerán y cuya única función es la del trazado de referencias. Sin embargo, y aunque parezca asombroso, esta práctica ahorra esfuerzo, pues guía el trabajo, y evita errores que en un futuro serían irremediables si se hubiera procedido libremente y sin control. El trabajo de talla ha de ser ordenado y la ejecución de un plano ha de ser llevada a cabo cuando el cantero tiene las aristas necesarias -las referencias- para poder acometer su talla de manera precisa y controlada. $^{208}$

Hemos visitado talleres de cantería en Alemania, donde aún existen Bauhütten $^{209}$ permanentes ligadas a grandes catedrales -como es el caso de Colonia- que necesitan la reparación y reposición continua de piezas; o iglesias como la de Soest o Xanten, donde se han de cometer importantes trabajos de reparación de elementos. ${ }^{210}$ En todas ellas hemos comprobado que el trabajo de talla se realiza de este modo. Incluso, los canteros tienen una frase para ilustrar la importancia de la determinación de dichas referencias: Die Flächen und die Kanten sind die Steinmetz Verwandten. ${ }^{211}$

En el caso de la labra del enjarje, en primer lugar, el cantero acometerá las primeras referencias posibles, que son las que coordinan los intradoses de los nervios en el lecho superior e inferior de la pieza mediante un plano que une los dos trazados. De este modo, se comenzará a comprender la situación y dirección de cada nervio. Además, para facilitar su labra se habrá tenido que desbastar la piedra entre un nervio y otro, por lo que también se empezará a percibir el tamaño de la pieza. Hay que tener en cuenta que estos planos rectos no son la superficie final del intradós, pues ésta viene definida por la curvatura del nervio.

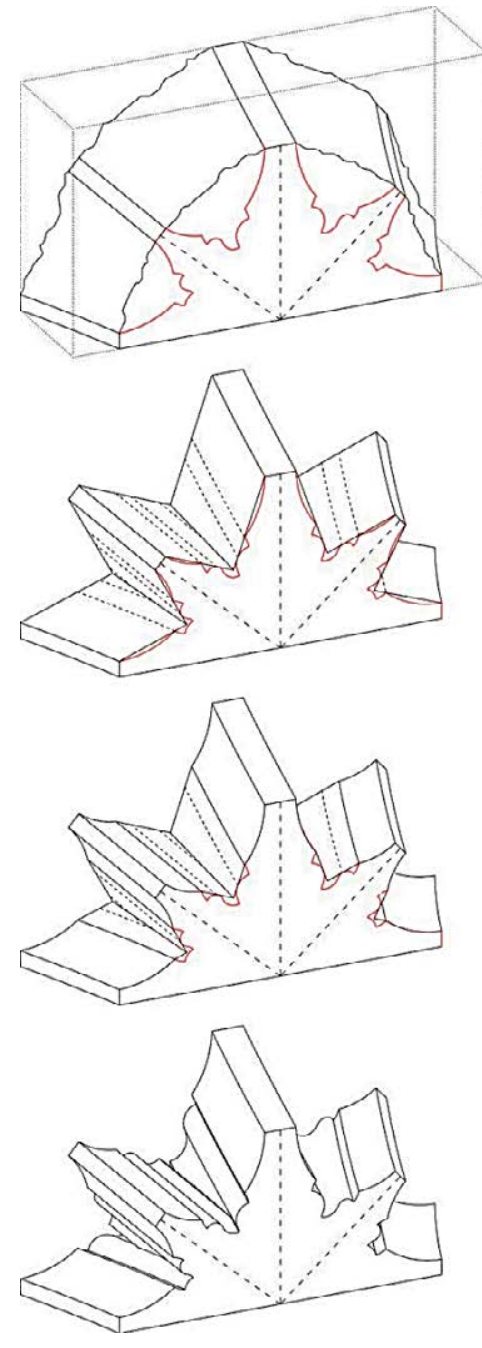

Fig. 74

Proceso de talla para una pieza del enjarje de la Lonja de Palma.

${ }^{208} \mathrm{Si}$ bien es cierto que en el caso de ciertas intersecciones o detalles, como explicaremos más adelante, la pericia, la práctica y el saber hacer permiten al cantero tallar ciertos elementos con mayor libertad.

${ }^{209}$ Talleres de cantería en alemán. En esta web se pueden ver los talleres permanentes o puntuales en Europa http://www.dombaumeisterev.de.

${ }^{210}$ Agradezco al profesor Norbert Nußbaum el haberme posibilitado y gestionado dichas visitas, así como a los Dombaumeister del Kölner Dom, Xanten y Soest el haberme permitido conocer su trabajo y mostrarme su labor.

211 En castellano: "Los planos y las aristas son los parientes de los canteros". Me lo comentó un cantero que trabaja en el taller de cantería de la catedral de Friburgo para explicarme cómo se ha de proceder en la talla. Me dijo que era la única regla que un cantero no ha de olvidar. 
En la cara superior de la pieza, al encontrarse el nervio más alejado del eje vertical del enjarje - del muro o del pilar, etc.-, el contorno de la plantilla será mayor que en la cara inferior, donde se encuentra más próximo. Esto provoca que se produzcan encuentros entre las molduras de los nervios al encontrarse unas con otras en la parte inferior. Para ejecutar su talla sería muy complejo comenzar a labrar sus perfiles directamente y conduciría a errores, por lo que el proceso se ha de llevar a cabo de lo general a lo particular.

De este modo, el cantero trazará un contorno que englobe la moldura del nervio en los lechos procurando en la medida de lo posible su paso por puntos estratégicos de la misma, es decir, por aristas o quiebros del perfil. De este modo, podrá comenzar a tallar este sólido capaz en el que se contendrá el perfil del nervio y que le permitirá visualizar los encuentros entre unos nervios y otros de manera general. El procedimiento es el mismo que con el intradós del nervio. Se irán tallando planos que unan este contorno contenedor del perfil del lecho superior e inferior de la piedra.

Una vez ejecutados estos planos, se talla la concavidad de intradós del nervio, pues ya puede ser trazada sobre el plano del sólido capaz y controlar su talla. Para asegurarse de que la curvatura del intradós es correcta se utiliza una plantilla llamada cercha con la curvatura tomada de la montea. Apoyándola en los trazados de intradós de los lechos se comprueba que el plano se ajuste perfectamente a ella.

A continuación se trazan en los planos del sólido capaz de los nervios las líneas que coordinan los puntos estratégicos de la moldura del contorno superior e inferior a las que hacíamos referencia anteriormente. Estos trazados no son rectos, sino curvas paralelas al intradós del nervio por dichos puntos ${ }^{212}$ que nos permitirán acometer la talla del perfil del nervio de manera ordenada y controlada. Por ejemplo, si la primera recta define una arista del perfil y entre ella y la arista del intradós del nervio hay un plano cóncavo, se labrará esta superficie de manera precisa y eficaz, pues se conocen todos sus bordes, todas las referencias necesarias para la talla: la arista del intradós del nervio, la curva trazada sobre el sólido capaz y el perfil cóncavo de la plantilla presente en los lechos de la pieza, con su pertinente alargamiento o no.

\footnotetext{
212 Generalmente, a pesar de que no es correcto, se puede utilizar la misma curva de intradós, pues el error cometido es inapreciable. Sin embargo, Enrique Rabasa durante su primera experiencia en el Centro de los Oficios de León apunta que los operarios realizaron curvas con radios diversos para el trazado de las molduras en el enjarje. Enrique Rabasa Díaz, "Principios y construcción de las bóvedas de crucería", Loggia, Arquitectura \& Restauración, (1996), año X, n 20, 86-97. Enrique Rabasa Díaz, Guía práctica de la estereotomía de la piedra, (León: Editorial de los Oficios, 2007), 92.
} 
En orden, comenzando por los planos más cercanos al intradós, se continúa la talla. Se van solucionando desde fuera hacia el rincón el encuentro de nervios dos a dos. En algunas ocasiones no se tiene el trazado en el lecho inferior una parte de la moldura del nervio, puesto que muere en la moldura del nervio contiguo. Para tu talla, se requerirán elementos auxiliares y la maestría del cantero, que mediante su destreza en la estimación del lugar del encuentro, será capaz de resolverlo.

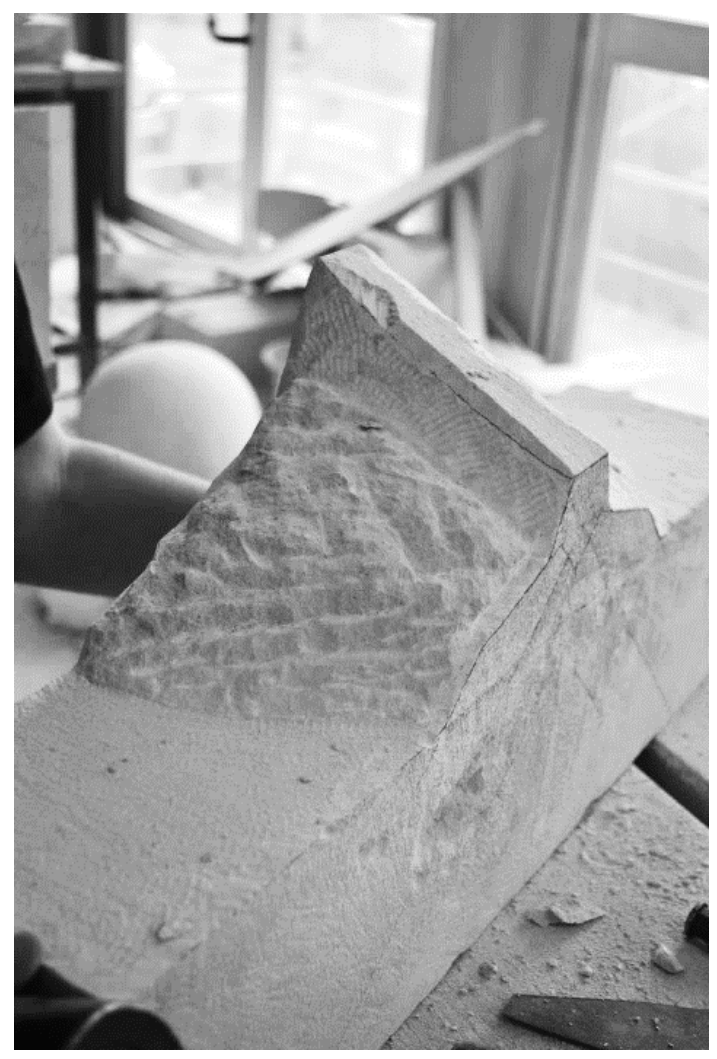

Enrique Rabasa apunta que para la ejecución del primer enjarje que realizó en el Centro de Oficios de León los canteros hicieron uso de gramiles especiales y contraplantillas para comprobar la redondez de las molduras. $^{213}$

\subsubsection{La puesta en obra}

Los enjarjes de la bóveda de crucería se construyen a la vez que el muro, trabando con él y asegurando su perfecta y estable transición con los nervios. Esto quiere decir que se llevan a cabo antes que la colocación de claves y nervios, conteniendo sin embargo toda la información referente a ellos. En los enjarjes ya están definidas sus curvaturas, su altura de arranque, su perfil, su dirección, etc. Los enjarjes contienen el ADN de la bóveda.
Fig. 75

Trazado de la curvatura de intradós del nervio para su talla.

${ }^{213}$ Rabasa Díaz, "Principios y construcción de las bóvedas de crucería", 92. 
Fig. 76

Retundido entre las piezas de un enjarje en St. Florentinus en Niederhaslach.

Alexander Kobe.
Hay que tener en cuenta, además, que los medios auxiliares para elevar estas piezas del enjarje han de ser capaces de elevar piedras de gran tamaño. Muchas veces pensamos en el esfuerzo de elevar alguna clave de bóveda de dimensiones audaces siendo, sin embargo, el tamaño de las piezas de los enjarjes mucho más sobresaliente.

Además, una vez colocadas las piezas del enjarje unas sobre otras, hay ocasiones en las que se hace necesario realizar un repaso, principalmente en las juntas, llamado retundido, para mejorar visualmente la transición entre ellas y eliminar pequeños errores de la talla.

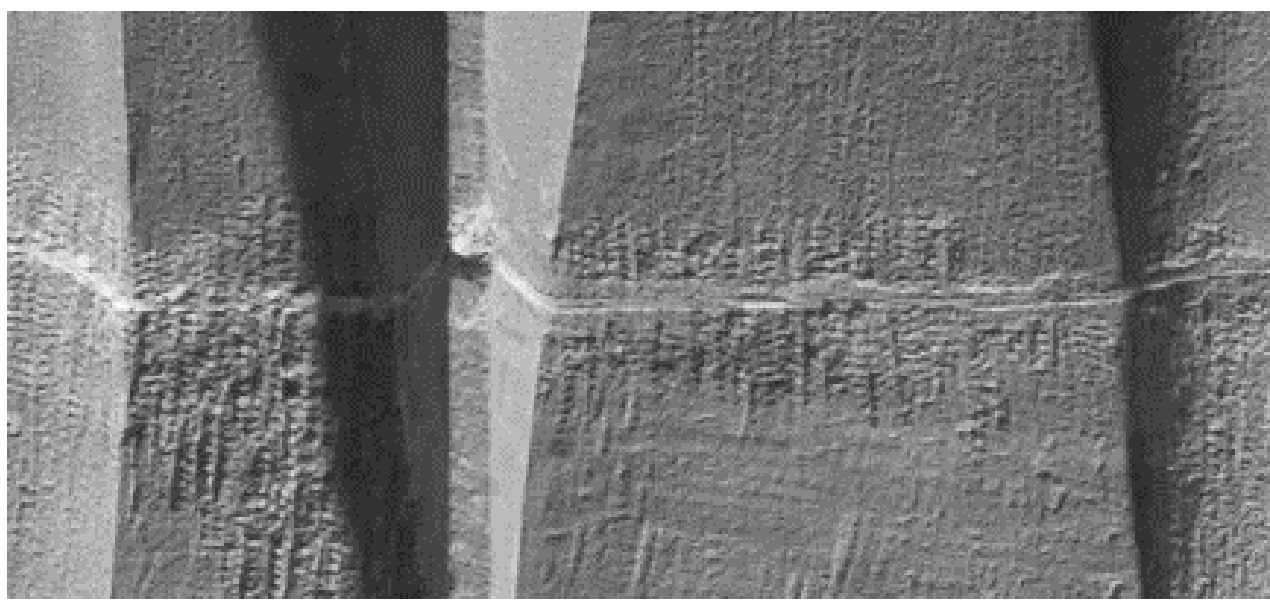

Entonces se procede a la construcción del resto de la bóveda. Para llevar a cabo esta tarea, según aparece en el manuscrito atribuido a Rodrigo Gil en el Compendio de Simón García, se coloca una plataforma de madera a la altura del final del enjarje para trazar la bóveda y apoyar unos pies derechos de madera en los que colocar las claves. Una vez conocidos los nudos de la bóveda se colocan las cimbras de los arcos que permiten su unión y se colocan las dovelas de los nervios. ${ }^{214}$

John Fitchen, a pesar de que elabora unos dibujos en los que representa estructuras de madera más próximas a nuestros tiempos que al medievo, realiza interesantes reflexiones acerca de las cimbras de las bóvedas de crucería. Señala la problemática del hecho de que los nervios al llegar a la parte baja del enjarje no mantienen completo su perfil, lo que hace imposible pensar en una cimbra completa para cada uno desde su arranque por problemas de espacio. Por ello propone, al igual de Rodrigo

${ }^{214}$ García, Compendio de architectura y simetría de los templos conforme a la medida del cuerpo humano, por Simón García, architecto natural de Salamanca. Año 1681, fol. 25r 


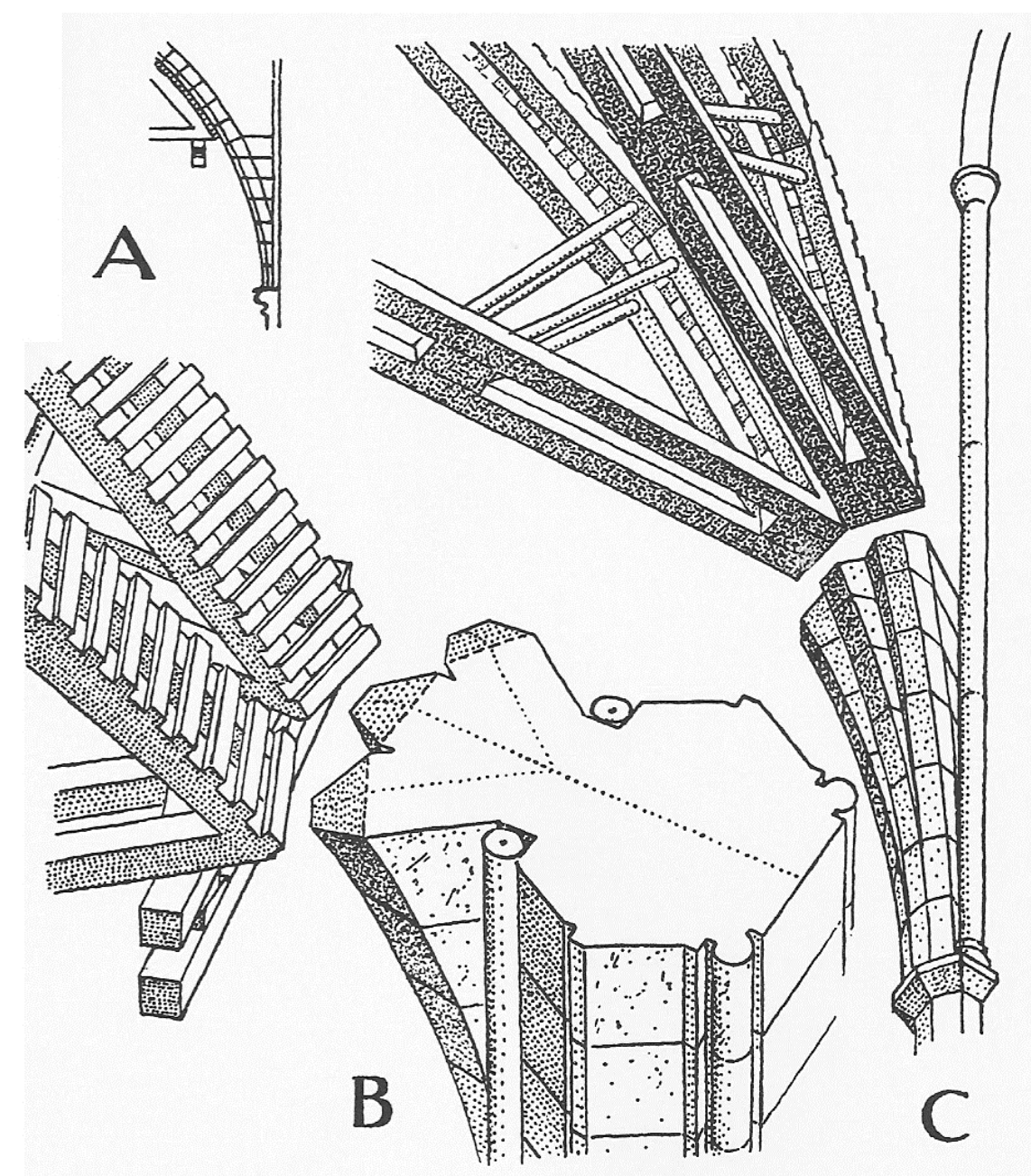

50. Convergence of the Rib Frames at the Top of the Tas-de-Charge
Fig. 77

Fitchen, 1961, fig. 50.

Gil, que la estructura de madera para los arcos comience cuando el enjarje ya ha terminado, pues los nervios están libres y su sección está completa. ${ }^{215}$

En todos los ejemplos en los que hemos podido estudiar mediante levantamiento topográfico las curvas de intradós de los nervios hemos constatado un quiebro tras el enjarje. En la mayoría de los casos tanto el enjarje como el nervio permanecen con la mima curvatura, pero no se produce una perfecta continuidad entre unos y otros. Esto nos da pie a pensar que el dibujo atribuido a Rodrigo Gil y las apreciaciones de Fitchen están en lo cierto, pues este quiebro sólo es explicable por la situación de las cimbras para los arcos una vez finalizado el enjarje y a partir de él.

Es imposible asegurar una concordancia perfecta entre el enjarje -en el que la curvatura del nervio es precisa -y el arco- donde también lo es gracias a

\footnotetext{
215 John Fitchen, The construction of gothic cathedrals: a study of medieval vault erection, (Chicago: University of Chicago Press, 1981), 136-138.
} 
la cimbra que sostiene las dovelas-, pero no entre ambos elementos. En muchos casos estamos hablando de un error prácticamente inapreciable y que sólo puede ser estudiado tras un exhaustivo análisis mediante una toma de datos muy densa en el intradós del nervio marcando las juntas de las piezas.

Hay que tener en cuenta también que muchas veces y debido a muchos factores -la planta de la bóveda, los huecos que se ejecutan bajo el formero, el número de nervios y su posición, el arranque de nervios a diferentes alturas, etc.-, los encuentros entre el enjarje y el muro o la resolución de las primeras hiladas de plementería presentan problemáticas singulares. Por ejemplo, es ciertamente corriente encontrar nervios formeros que arrancan a mayor altura que el resto debido a que han de acoger un ventanal. La superficie creada entre ellos y el ojivo presenta dificultades debido a que posee cierta torsión. ${ }^{216}$

También es común que, como decíamos en capítulos anteriores, el enjarje esté resuelto con cortes inclinados que provocan la aparición de piezas especiales; o que se haga uso de piezas de transición con el comienzo de la plementería. Por supuesto, en ambos casos deberán ser planificadas, trazadas y talladas del mismo modo que el enjarje. Hemos podido medir y analizar algunos ejemplos con los que pretendemos ilustrar esta problemática. En el desarrollo de la investigación no hemos encontrado modo de clasificar estas soluciones, pues cada una responde a un ejercicio particular y a la solución de una situación única. Eso sí, en su diseño y proyecto queda plasmada la gran capacidad técnica de los maestros medievales, pues en muchos casos su concepción es de gran complejidad. Las hemos denominado piezas especiales o piezas de transición pero, ¿No podríamos decir que son parte del enjarje, que son enjarje? Quizás en este sentido habría que revisar también su definición.

${ }^{216}$ Willis, "On the construction of the vaults of the Middle Ages", 4-5. 


\section{PROYECTO}

\subsection{Dying mouldings, interpenetraciones, intersecciones y maclas}

Las mejores oportunidades en arquitectura aparecen como consecuencia de lo que el proyectista considera normalmente en un primer momento un gran problema o desventaja. ${ }^{217}$

Por ello, ante la dificultad a veces producida de la reunión de los nervios en el enjarje -debida a diversos factores- los constructores medievales desarrollaron nuevos modos de solucionar los encuentros entre los nervios en el arranque mediante la experimentación con un sistema constructivo que conocían y manejaban con destreza, llevando a cabo un cambio en la concepción en el diseño arquitectónico.

Pretendemos en esta investigación realizar un breve repaso de los primeros experimentos relacionados con el modo de relacionarse los nervios entre sí en los enjarjes para ilustrar el contexto y origen de las soluciones realizadas por Guillem Sagrera a principios del siglo XV, pues es necesario conocer las experiencias anteriores para poder valorar su contribución.

Parece ser que muchas de las primeras pruebas se dan en primer lugar en Inglaterra y algunas zonas de Francia, así como en la frontera con Alemania, o en el caso singular de la catedral de Praga. Para algunas soluciones hemos detectado propuestas similares y prácticamente contemporáneas en diferentes partes de Europa. Consideramos, sin embargo, la influencia entre unas y otras ciertamente improbable. La sintaxis gótica y su sistema constructivo permiten una libertad y flexibilidad que, desde etapas muy tempranas, favorece la aparición de estas pruebas y variaciones en diferentes localizaciones, asociadas, en un primer momento, a la necesidad de resolver un problema constructivo y que acaban por ser motivos formales específicos de un modo de entender la modernidad del momento.

La obra de Sagrera supone el uso de este nuevo modo de diseñar enjarjes de manera diferenciadora, en la que el proyecto del edificio es generado por la idea que se quiere llevar a cabo en el enjarje. No estamos hablando únicamente de un edificio, sino de una obra, pues sí que hay construcciones anteriores al maestro en las que el diseño parte también de la innovación en el arranque de los nervios, pero Sagrera lo personaliza en su figura convirtiéndolo en su firma. Hasta ahora no conocemos ningún

\footnotetext{
217 Luis Moreno Mansilla me hizo consciente de esta apreciación.
} 
arquitecto anterior a él que lo utilice con su intensidad e identificación personal.

Para la comprensión del cambio de mentalidad y el surgimiento de la innovación en los arranques realizaremos un recorrido desde las dying mouldings explicando todas sus variantes, hasta hablar de ejemplos tempranos de molduras que se intersecan. Comentaremos también el concepto de macla y lo que diversos autores han escrito al respecto.

\subsubsection{Dying mouldings}

En el siglo XIII nos encontramos con una manera nueva de entender la resolución del encuentro de las molduras de los nervios en el enjarje, lo que Virginia Jansen ha denominado dying mouldings ${ }^{218}$ y que anteriormente Robert Willis ya había intuido dentro de la clasificación de impost que presenta en el capítulo III de Remarks on the Architecture of the Middle Ages. ${ }^{219}$

Antes de que se convirtiera en un recurso común dentro de lo que hoy designamos como arquitectura tardogótica, el dying mouldings ya se daba en áreas de Inglaterra y Francia en el siglo XIII:220

Sometimes paired with hollow chamfer mouldings, these features [dying mouldings] are symptomatic of the re-evaluation of relationships in the second half of the thirteenth century which transformed the preceding Gothic styles into those of Late Gothic. ${ }^{221}$

En el Decorated Style los perfiles de los nervios que configuran los arcos formeros que dan paso desde la nave central a las laterales en las catedrales inglesas son voluminosos y de molduras complejas. Esto genera ciertos problemas al resolver el encuentro de estos grandes arcos que han de descansar en un elemento que les unifique y permita su coordinación con el pilar inferior o columna. Mientras que en Francia se deciden por reducir la dimensión de los perfiles, en Inglaterra los

\footnotetext{
${ }^{218}$ Virginia Jansen, "Dying Mouldings, Vertical Springer Blocks, and Hollow Chamfers in Thirteenth- Century Architecture", Journal of the British Archaeological Association, CXXXV, (1982), 35. La profesora Jansen, además, en la nota al pie de página número 2 expone el estado de la cuestión en referencia a este término.

${ }^{219}$ Ver página 22. Robert Willis, Remarks on the Architecture of the Middle Ages, especially of Italy, (Cambridge: Pitt Press, 1835), capítulo III: 28-33.

220 Jansen, "Dying Mouldings...", 47.

221 Jansen, "Dying Mouldings...", 49.
} 
arquitectos proponen nuevas soluciones, sacando partido a esta dificultad de reunión, pues provocan, entre otras cosas, oquedades entre sus molduras al juntarse o encuentros difíciles de resolver. ${ }^{222}$

La respuesta a este problema técnico se da mediante una solución práctica que poco después acaba convirtiéndose en un recurso formal. Resuelven la unión de los nervios a través de su desvanecimiento o penetración en el muro, sin intermediación de ningún elemento, es decir, sin capiteles ábacos, etc., que articulen la junta. Esto no debe der confundido con molduras que nacen unas de otras o que se interrumpen debido a que se reúnen en un espacio muy reducido, pues las dying mouldings parten de una decisión clara de proyecto en la que se opta por una solución formal determinada y consciente a un problema constructivo.

Igualmente, presentan la ventaja de favorecer la continuidad visual y espacial de los elementos, enfatizándolos y diferenciándolos. Hay que tener en cuenta que su aparición se da en un momento en el que el lenguaje gótico está perfectamente articulado, siendo esta nueva concepción reflejo de una nueva búsqueda formal, de un cambio en la función y relación de la sintaxis gótica. ${ }^{223}$

La profesora Jansen ha localizado, datado y analizado los primeros ejemplos en las décadas centrales del siglo XIII en diversas áreas de Inglaterra y Francia. ${ }^{224}$ De este modo ha identificado diversas soluciones que se basan en este principio. A pesar de que ella las diferencia mediante epígrafes diferentes a los que presentaremos a continuación, nos basaremos en su investigación para el desarrollo de los diversos casos.

\footnotetext{
222 Norbert Nußbaum y Sabine Lepsky, Das gothische Gewölbe, Überkreuzte Bogenanfänger: 171-172.

${ }^{223}$ Jansen, "Dying Mouldings, ...", 38.

${ }^{224}$ Especial interés tiene la tabla que Jansen ha elaborado con todos los ejemplos y sus dataciones: Jansen, "Dying Mouldings...", 50-54.
} 

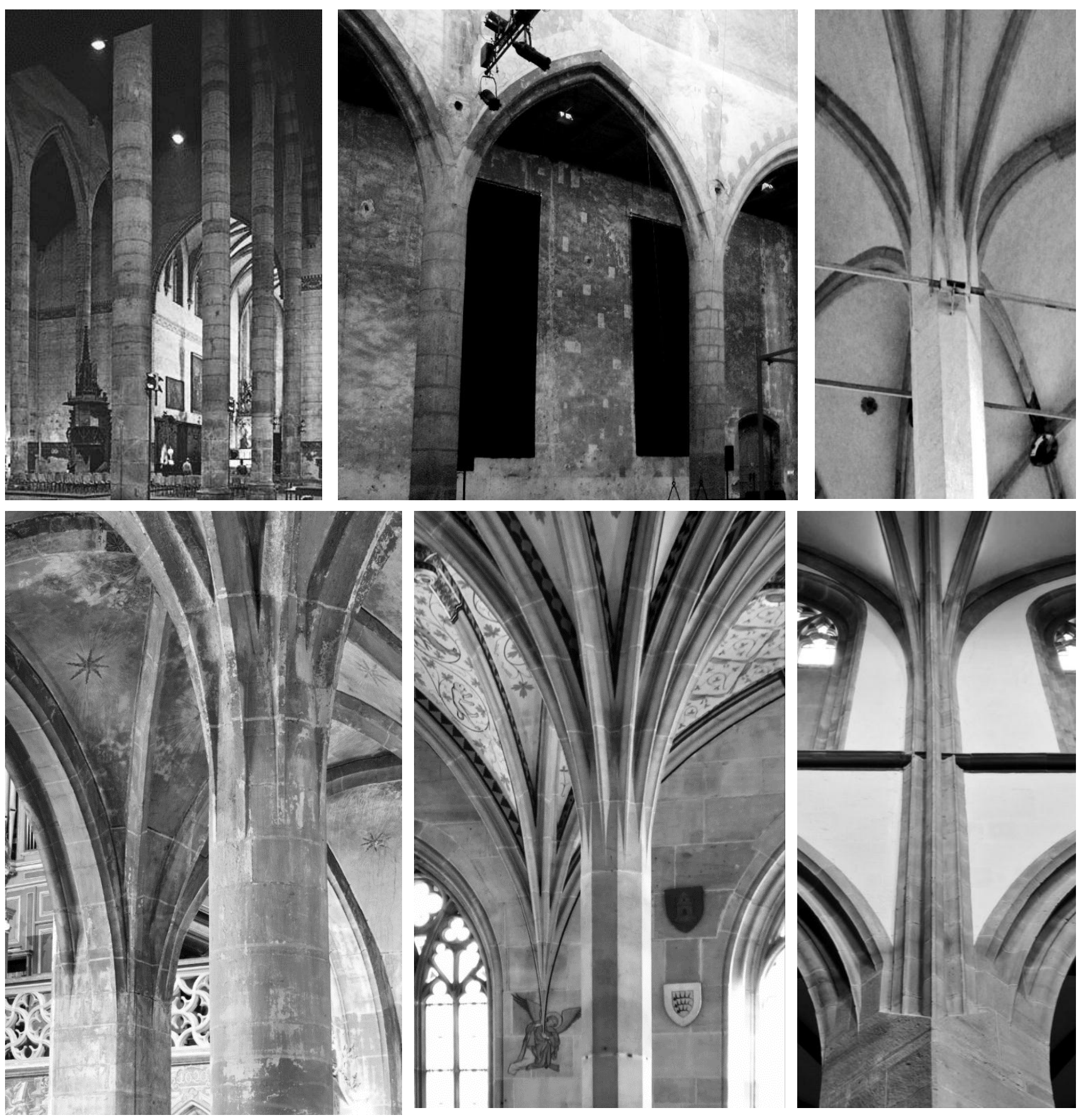

Fig. 78

Molduras de nervios que emergen directamente de los soportes

Enjarjes en los que las molduras emergen directamente de los soportes. De arriba abajo y de izquierda a derecha: iglesia de los dominicos en Colmar (imagen: www.crdp-strasbourg.fr), Dominicos en Guebwiller (imagen: Roger Joseph en flickr), Imbach en Austria (imagen: Josef lex en flickr), Saint Pierre le Jeune en Estrasburgo, Refectorio de la abadía de Bebenhausen e iglesia de St. Florentinus en Niederhaslach.

Son resultado de la eliminación de los capiteles favoreciendo la penetración directa de los nervios en los soportes. Este es un factor importante para la aparición de dying mouldings, pero no es su causa. $^{225}$

\footnotetext{
225 Jansen, "Dying Mouldings...", 36.
} 
Aparecen, en algunos casos, en relación con la arquitectura de las órdenes mendicantes, quienes buscan probablemente en este tipo de estrategia la identificación con los valores de humildad y sencillez. Ejemplos relevantes encontramos en el este de Francia, en la frontera con Alemania, como es el caso de la iglesia de los dominicanos en Colmar (1292-c. 1340) y la de Guebwiller (c. 1306).

En Austria, Nußbaum y Lepsky señalan la iglesia dominicana de Imbach (hacia 1269) como un ejemplo temprano de nervios que salen directamente de un pilar octogonal. Desarrollan la cuestión de los nervios que salen del muro sin capitel, Anschießende Rippen, haciendo un repaso a los casos en Inglaterra, Francia y Alemania. ${ }^{226}$

También hemos localizado soluciones similares en la iglesia de Saint Florentinus en Niederhaslach (principios del XIV), con enjarjes extremadamente interesantes por su complejidad, calidad e idea de proyecto. Los nervios de las bóvedas de la nave principal surgen de un corte inclinado en el pilar cuadrado -girado $45^{\circ}$ con respecto al eje esteoeste-, del que además arrancan de manera directa los nervios que separan la nave central con las laterales. Los de las naves laterales también emergen directamente del pilar y de pilastras situadas en el muro. ${ }^{227}$ En la iglesia de Saint Pierre le Jeune en Estrasburgo (primera mitad siglo XIV), los nervios de la nave salen directamente de pilares cuadrados achaflanados $y$, en el lado sur, brotan sin capitel de tres pilares cilíndricos. En la Frauenkirche en Esslingen (principios del XIV) la solución es curiosa, pues el pilar no presenta estrías, que sí aparecen de manera fluida cuando comienza a convertirse su moldura en nervios que brotan directamente.

El refectorio de la abadía de Bebenhausen (1335) ${ }^{228}$ es un ejemplo sobresaliente, en el que se resuelve una estancia a partir de la idea de realizar enjarjes en el perímetro de nervios que confluyan en un punto y con tres pilares octogonales en el centro de los que los nervios emergen de manera continua. La iglesia de Marie zur Wiese en Soest es especialmente interesante por la continuación de las molduras de los nervios conformando los pilares y pilastras (principios del XIV) de manera fluida y elegante.

Tampoco hay que olvidar, en la segunda mitad del siglo XIV, las molduras de los nervios que continúan conformando el pilar en la sacristía de la

\footnotetext{
${ }^{226}$ Nußbaum y Lepsky, Das gothische Gewölbe, 172-174.

${ }^{227}$ Agradezco a Alexander Kobe, quien se encarga del estudio de esta iglesia en su tesis doctoral, haberme mostrado estos ejemplos, así como su datación.

228 Jürgen Michler, "Studien zum Bebenhäuser Sommerrefektorium", Jahrbuch der Staatlichen Kunstsammlungen, no 35, (1998), 44.
}

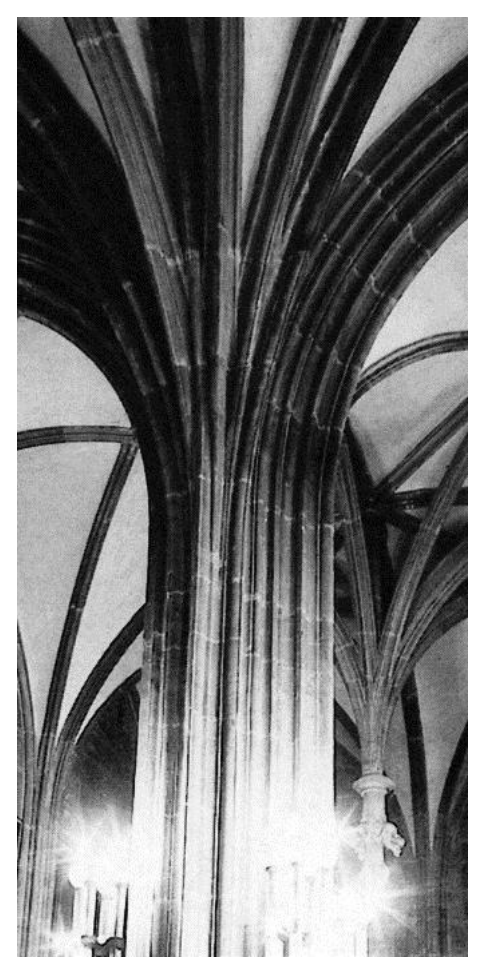

Fig. 79

Sacristía de la catedral de Praga (Schurr, 2003). 
Fig. 80

Marie zur Wiese en Soest. Imagen: Westfälische Dombauhütte, (c) Achim Bunz.

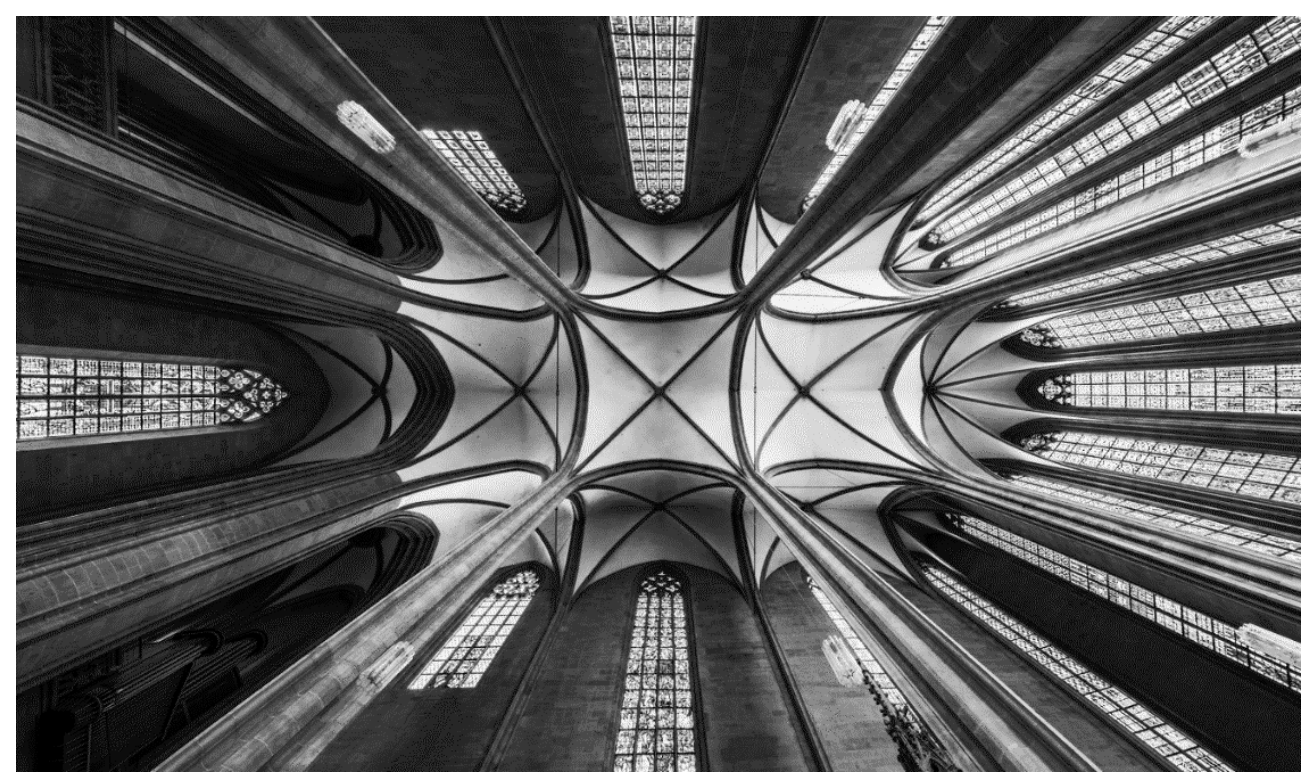

catedral de Praga o en la Capilla de St. Wenceslas en el mismo edificio. También en los enjarjes de la girola -a pesar de le existencia de una mínima decoración a modo de capitel-se puede apreciar esta idea de continuidad.

Aunque este hecho de que los nervios emerjan directamente del muro no es algo novedoso, pues esta idea está presente en ejemplos más tempranos. Por ejemplo, en el monasterio de Poblet o en el refectorio de Fontfroid donde, a pesar de parecer un enjarje, se trata de nervios separados. También nervios que continúan el soporte se pueden localizar en el dormitorio del monasterio de Fountains en Inglaterra o en el vestíbulo de la sala capitular de la catedral de Chester de principios del XIII. ${ }^{229}$

También Jansen muestra los interesantes ejemplos de la estancia en Lambeth Palace Chapel en Londres o en la abadía de Beaulieu, donde en los enjarjes los nervios perpiaños tienen el punto de tangencia por encima del arranque, llegando al capitel como arcos ultrasemicirculares. ${ }^{230}$ En el refectorio de la abadía hay además un interesante encuentro entre los nervios que llegan al pilar, pues la suma de sus intradoses configura un polígono que se difumina para dar continuidad con un pilar circular.

Un caso particular lo representan los enjarjes del claustro de la catedral de Lincoln (1296), ${ }^{231}$ pues salen directamente del muro pero con la especial

${ }^{229}$ Nikolaus Pevsner y Pricilla Metcalf, The Cathedrals of England. Southern England,. (London: Viking, 1985).

230 Jansen, Dying Mouldings..., 43.

231 Jenny Alexander, "Lincoln Cathedral Cloister", Journal of the British Archaeological Association, 159, (2006), 227. 

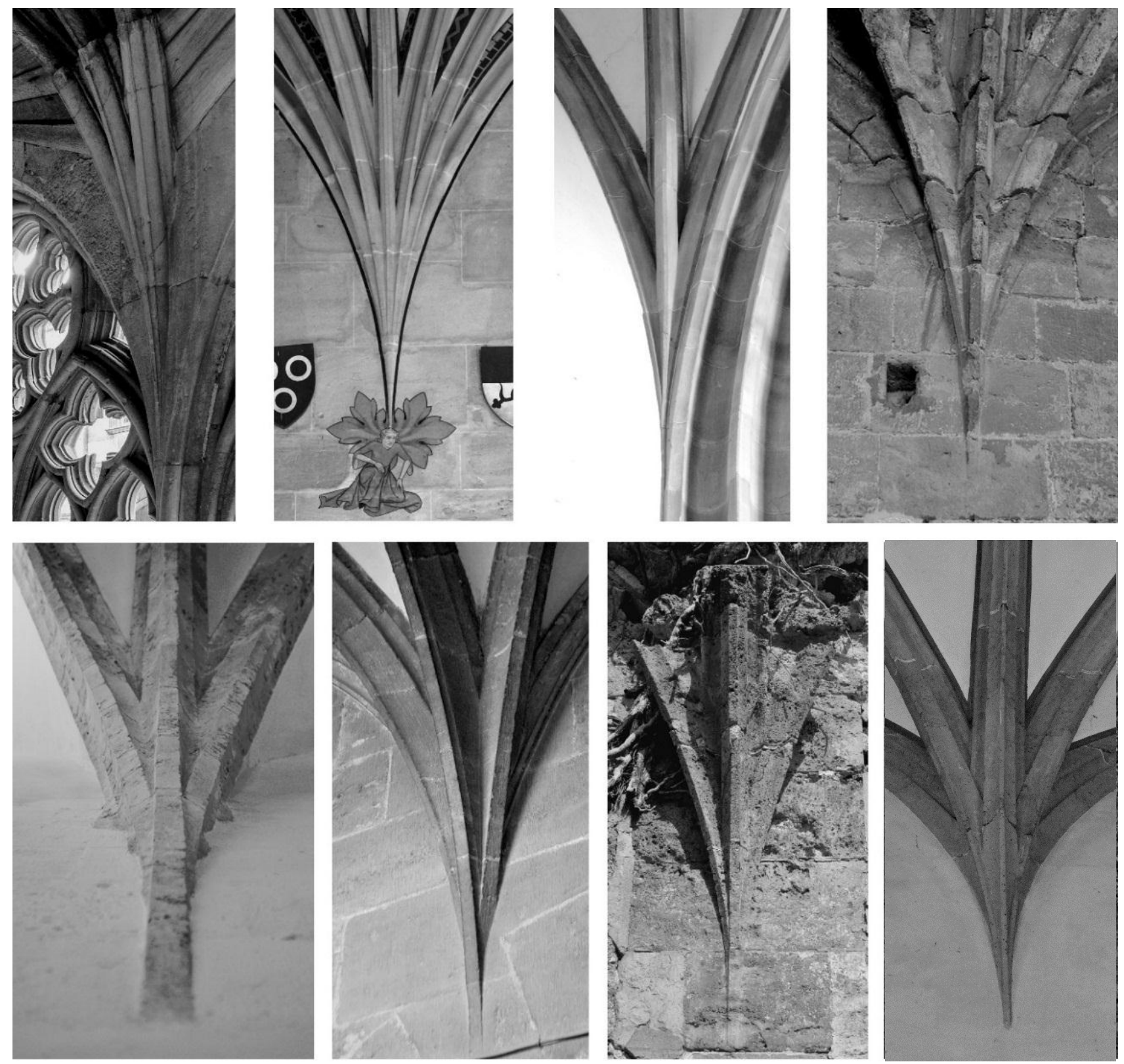

característica de que los nervios confluyen en un punto. Linda Monckton ha señalado el importante rol de la reconstrucción en el siglo XIV en Inglaterra de muchos claustros de catedrales en los que, debido a que la dimensión de sus bóvedas no planteaba grandes dificultades estructurales, se convirtieron en espacios ideales para desarrollar y experimentar nuevas ideas, lugares en los que se podía llevar a cabo la aventura de pasar de la "micro" a la "macro" arquitectura. ${ }^{232}$ Es singular, por tanto, encontrar este tipo de enjarjes de nervios que confluyen en un punto también en el claustro de la catedral de Mainz (1400-1410), el claustro de la Cartuja de Valdecristo de principios del XV o el claustro de la Trinidad en Valencia de finales del XIV. A pesar de no ser un claustro, en

Fig. 81

Enjarjes cuyos nervios confluyen en un punto. De arriba abajo y de izquierda a derecha: Catedral de Lincoln, abadía de Bebenhausen, Saint Florentinus en Niederhaslach, claustro de la catedral de Narbona, sala capitular de Perpiñán monasterio de La Trinidad en Valencia, Cartuja de Valdecristo en Altura, claustro de la catedral de Mainz.

${ }^{232}$ Linda Monckton, "Experimental Architecture? Vaulting and West Country Cloisters in the Late Middle Ages", Medieval Achaeology, Volumen 159, Issue 1, (2006), 250, 227-228. 


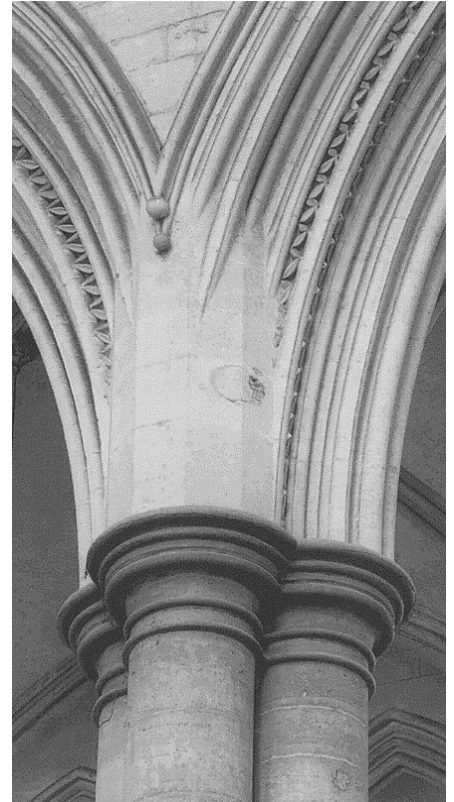

Fig. 82

Enjarje en el transepto de la catedral de Salisbury (Draper, 2003
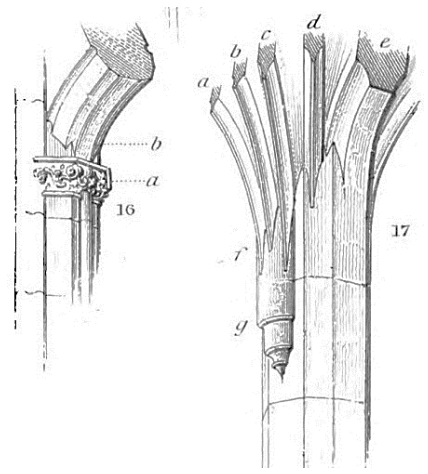

Fig. 83

Willis, 1835, lámina 3. el corredor que rodea la cabecera de la catedral de San Martín de Colmar (mediados del XIV) también encontramos este tipo de solución en una escala similar.

En el trascoro de la catedral de Lincoln también se realiza a menor escala este tipo de enjarje de nervios que convergen. ${ }^{233}$ Estos son los primeros ejemplos que hemos encontrado al respecto, cuya problemática analizaremos con profundidad posteriormente a partir de mediciones.

\section{Molduras de nervios que salen de elementos prismáticos tras el capitel}

Otra forma de resolver el encuentro, cuando las molduras de los nervios que confluyen son demasiado grandes, es la introducción, más allá del capitel, de un elemento prismático o cilíndrico que permita cortar el desarrollo de los perfiles y unificarlos, así como evitar incómodas o irresolubles oquedades entre las molduras.

Es curioso ver que ya Robert Willis apunta en este sentido cuando pretende clasificar o clarificar posibles soluciones para el encuentro entre los pilares y los nervios. Él denomina este recurso double impost y consiste en la introducción de este elemento prismático tras el capitel o la ménsula que permite resolver estos encuentros de molduras. ${ }^{234}$

En la década de 1230 este tipo de solución apareció por primera vez en dos lugares diferentes: el transepto de la catedral de Salisbury y la cabecera de la catedral de Rouen. Lo interesante de ambos ejemplos es la decisión de utilizar esta nueva forma de realizar los enjarjes en partes fundamentales de edificios de importante magnitud, haciendo patente la fuerza y desarrollo de esta novedosa idea. ${ }^{235}$

El coro de Salisbury se finaliza en 1246 con la utilización de esta solución de manera visible y continuada, dando muestra del uso deliberado de este recurso. Hay penetraciones de molduras en la catedral anteriores a estas, como las que se sitúan en el presbiterio (c. 1225-30), pero allí no fueron ejecutadas para ser vistas, sino para solucionar problemas de uniones entre molduras. ${ }^{236}$ Norbert Nußbaum y Sabine Lepsky muestran al respecto

\footnotetext{
233 Hugh's choir data de c. 1200. Se completa en 1210. En 1239 se refuerzan los pilares debido a un fallo estructural. La fachada del trascoro data de 1256-1320. Peter Meyer, English Cathedrals, (London: Thames and Hudson. 1961, 43.

${ }^{234}$ Robert Willis, Remarks on the Architecture of the Middle Ages, especially of Italy, (Cambridge: Pitt Press, 1835), capítulo III: 31-33 y lámina III: fig. 16 y fig. 17.

235 Jansen, Dying Mouldings..., 38.

236 Jansen, Dying Mouldings..., 39.
} 
el ejemplo del coro de la catedral de Exeter. En la parte en la que las intersecciones han de ser vistas, es decir la cara de los arcos formeros situados en el tránsito de la nave mayor a las laterales, se coloca en el encuentro de las molduras una pequeña ménsula decorativa. Sin embargo, en el encuentro que da a las naves laterales, que no es tan visible, se dan cruces e interpenetraciones de molduras. ${ }^{237}$

En Salisbury se eleva tras el capitel, en las zonas donde las oquedades de la moldura podrían ocasionar encuentros no deseables, prismas verticales, que también Draper ha señalado. ${ }^{238}$

En la catedral de Rouen (c. 1230-40) se realiza la solución en el mismo lugar, en la arcada de la nave principal. ${ }^{239}$ En este caso se continúa el cilindro del pilar tras el capitel para propiciar el encuentro con las molduras de los arcos e interrumpir su recorrido para evitar oquedades entre molduras.

De especial interés para nuestra investigación es la difusión -aparte de la que tendrá en Inglaterra a partir de entonces- de este modo de hacer en el sur de Francia, con ejemplos tan destacables como la arcada en el transepto de St. Nazaire en Carcasonne (finales del XIII), las capillas laterales norte y la arcada de la nave de la catedral de Toulouse (las primeras anteriores a 1286 y la segunda anterior a 1317), el deambulatorio y las capillas de la cabecera de la catedral de Rodez (finales del XIII, principios del XIV), la arquería de la nave de la catedral de Narbona (principios del XIV), la arcada de la nave de la catedral de Rodez (c. 132540), etc. ${ }^{240}$ Así como en la parte debida al primer proyecto de la catedral de San Juan el Nuevo de Perpiñán (se inicia a principios del XIV), ${ }^{241}$ los enjarjes de la cabecera de la catedral de Gerona, los enjarjes de la nave de la iglesia de la Chaise-Dieu (mediados del XIV) ${ }^{242}$ o los enjarjes de las bóvedas de la

${ }^{237}$ Nußbaum y Lepsky, Das gothische Gewölbe, 171.

238 Peter Draper, The formation of English Gothic. Architecture and Identity,(New Haven and London: The Paul Mellon Centre for Studies in British Art by Yale University Press, 2006), 76.

239 Jansen, "Dying Mouldings...", 50: nota al pie 38

240 Dataciones en: Jansen, "Dying Mouldings... ", 53-54.

${ }^{241}$ Ponsich, "La cathédrale Saint-Jean de Perpignan", 140.

242 El 3 de mayo de 1344, Clemente VI, dos años antes de ser nombrado papa, anuncia la reconstrucción de la Chaise Dieu. En 1350 la obra está acabada. En Anne Courtillé, Auvergne, Bourbonnais, Velay Gothiques. Les édifices religieux, (Paris: Picard, 2002), 155

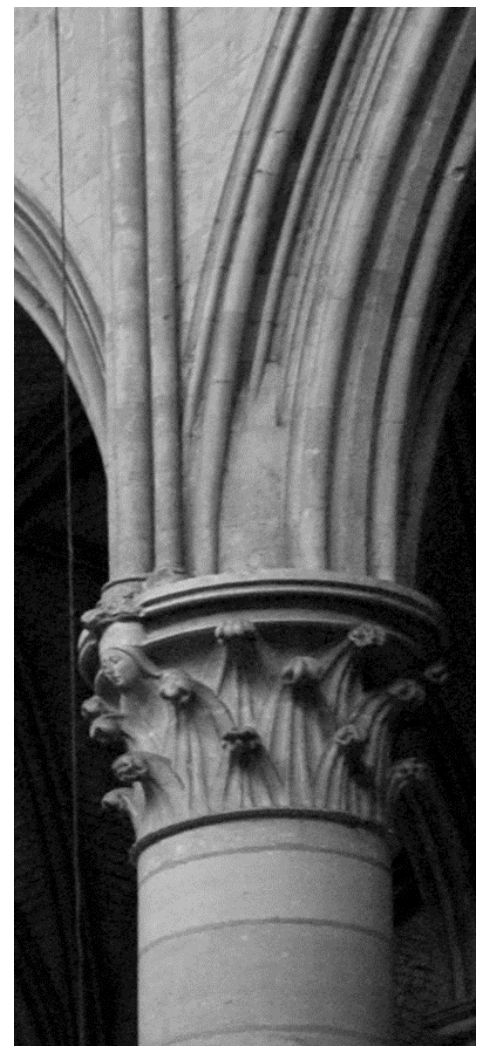

Fig. 84

Arcada de la nave principal de la catedral de Rouen. 

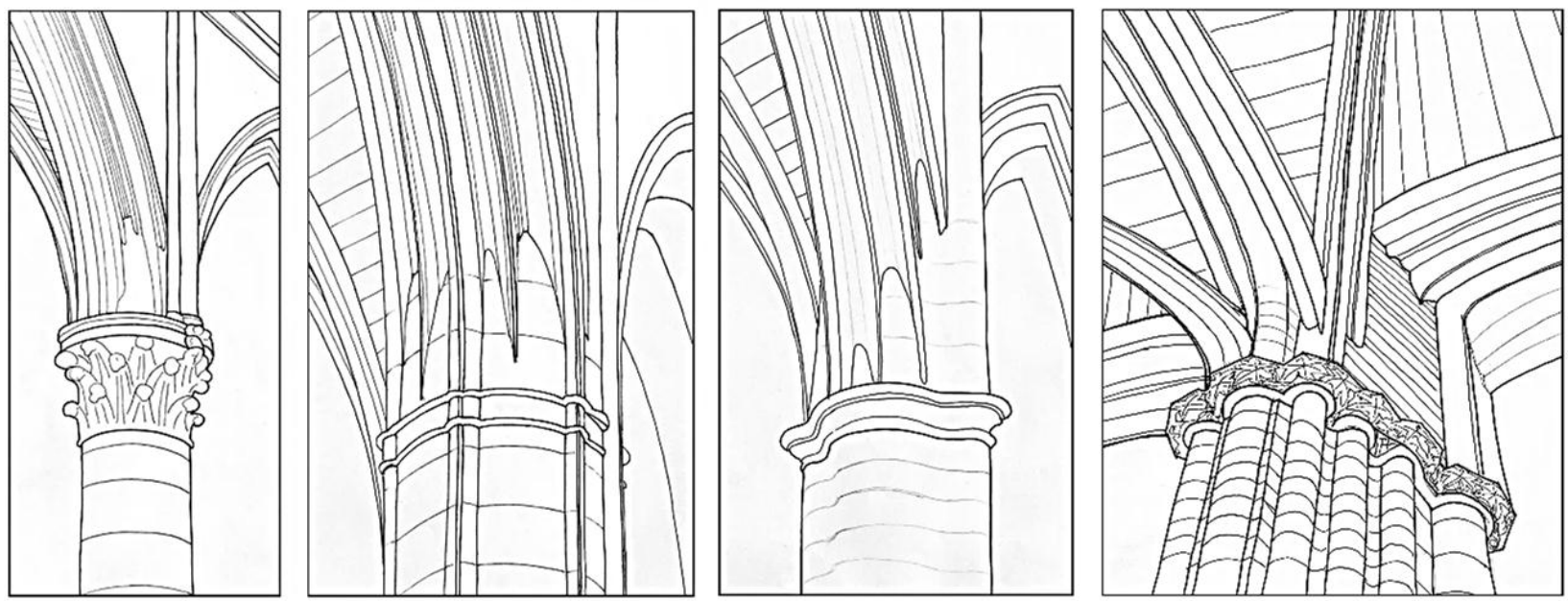

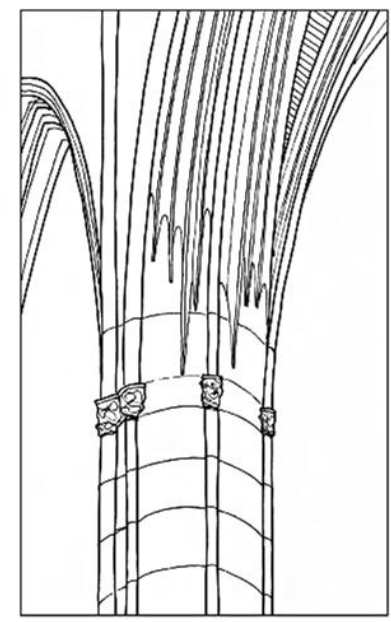

Fig. 85

De izquierda a derecha y de arriba abajo: catedral de Rouen, catedral de Narbona. Catedral de Rodez, catedral de Gerona, Toulouse, Carcasonne, catedral de Perpiñán, Chaise-Dieu y catedral de Palma de Mallorca.
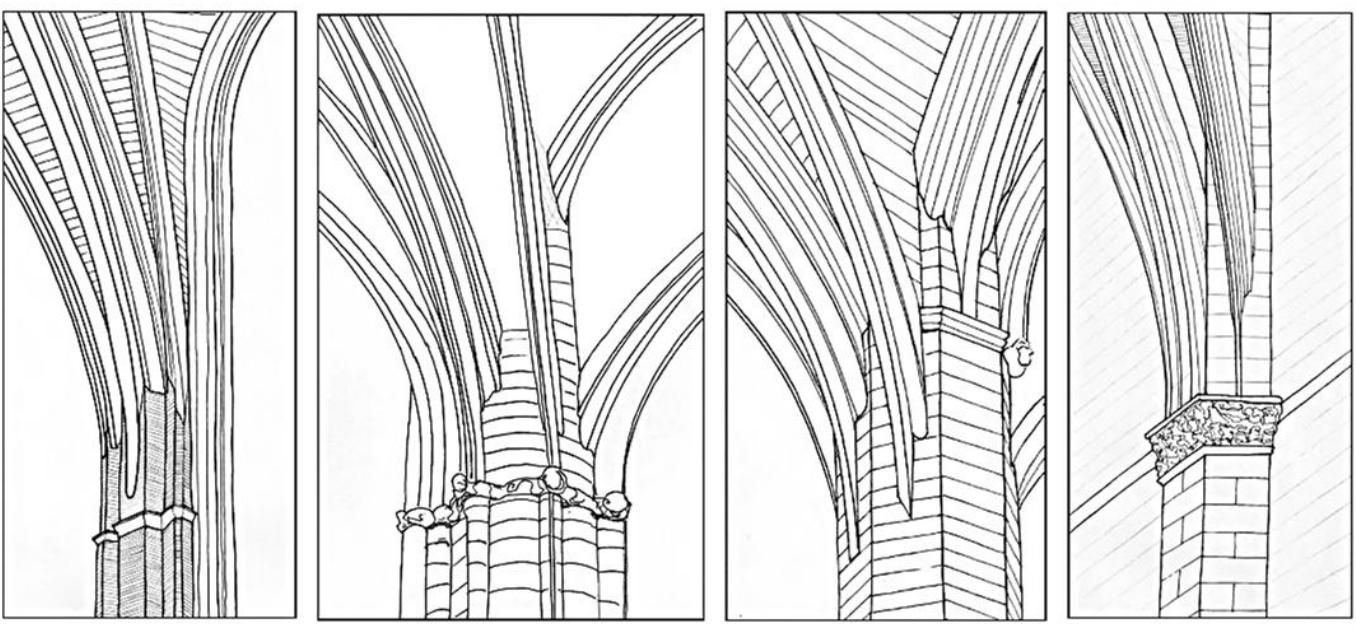

nave principal de la catedral de Palma de Mallorca (el primer tramo se eleva a finales del XIV). ${ }^{243}$

También es interesante la utilización de un elemento de transición entre el capitel y las líneas verticales de las molduras con que llegan los nervios, que Viollet-le-Duc denomina congé. ${ }^{244}$ Suele consistir en un plano inclinado, pocas veces visible desde abajo por el observador, que va desde el borde del capitel hacia el centro del pilar. Jansen muestra una imagen de este tipo de intersección en un enjarje del presbiterio de la catedral de Westminster. ${ }^{245}$

\footnotetext{
${ }^{243}$ Joan Domenge i Mesquida, L'Obra de la Seu. El procés de construcció de la catedral de
} Mallorca en el tres-cents, (Palma: Institut d'Estudis Baleàrics, 1997), figura 16.

${ }^{244}$ Eugène Viollet le Duc, Dictionnaire raisonné de l'architecture française du Xle au XVle

245 Jansen, "Dying Mouldings...", Plate XX. A.

\author{
siècle, (París: B. Bance, 1979), III: 509-512; VIII: 441, 444
}


Molduras de nervios que se reducen en el enjarje: ogives terminées en fuseau

Virginia Jansen también hace referencia a las soluciones en las que las molduras de los nervios acaban en forma de huso, motivo común en la arquitectura cisterciense de finales del siglo XII y principios del XIII, como en la sala capitular de Fontfroid, la sala capitular de Santes Creus, en el monasterio de Sylvanès, ${ }^{246}$ en la sala capitular de Flaran / Gers (11801210), en la de Escaladieu (primera mitad del siglo XIII) ${ }^{247}$ o en la abadía de Villelonge.

\section{Hollow Chamfer mouldings: molduras cóncavas.}

Jansen ha llamado la atención acerca de la utilización de molduras cóncavas, que aparecen a mediados del siglo XIII, en relación con el dying mouldings.

Un ejemplo de especial interés aparece en los años 70 del siglo XIII en el triforio norte de la catedral de Chester. Allí encontramos tanto una molduración cóncava para la parte vertical de soporte como para las basas de las columnitas. Los efectos visuales resultado de la talla de este tipo de molduras cuando se producen encuentros o intersecciones son claramente un acierto en combinación con el dying mouldings, pues realzan el carácter lineal de los elementos y permiten la visualización del juego de molduras de manera limpia y clara.

En la segunda mitad del XIII se utilizan de manera común en la arquitectura inglesa. Se pueden ver en la catedral de Chester, Salisbury, Christchurch Priory, Wymering, etc. ${ }^{248}$ Este tipo de moldura será muy frecuente tiempo después en Centroeuropa y Francia.

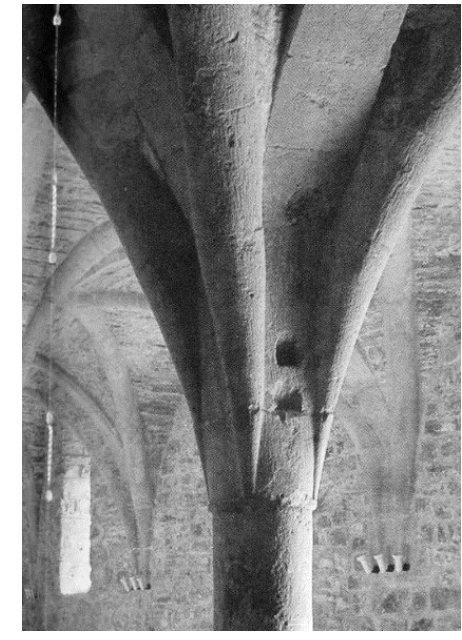

Fig. 86

Abadía de Sylvanès (Chastel, 1993).

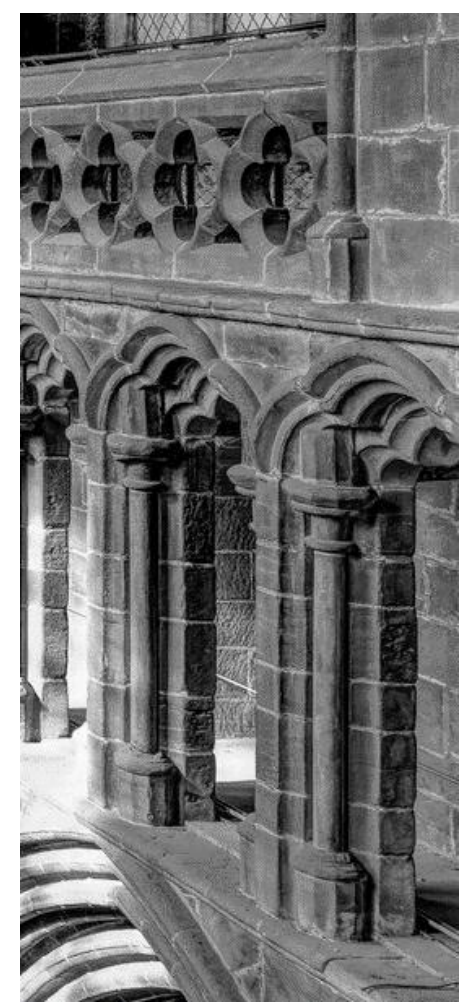

Fig. 87

Catedral de Chester. Imagen: Ajhaysom_flickr.

\footnotetext{
246 Jansen, „Dying Mouldings...", 41.

${ }^{247}$ Nußbaum y Lepsky, Das gothische Gewölbe, 106-107.

248 Jansen, "Dying Mouldings...", 46.
} 


\subsubsection{Intersecciones: molduras que desaparecen y aparecen}

Fig. 88

Arcos en que se resuelven intersecciones de molduras en Bolton (Knowles 1959) y en la catedral de Wells (Jansen, 2000).
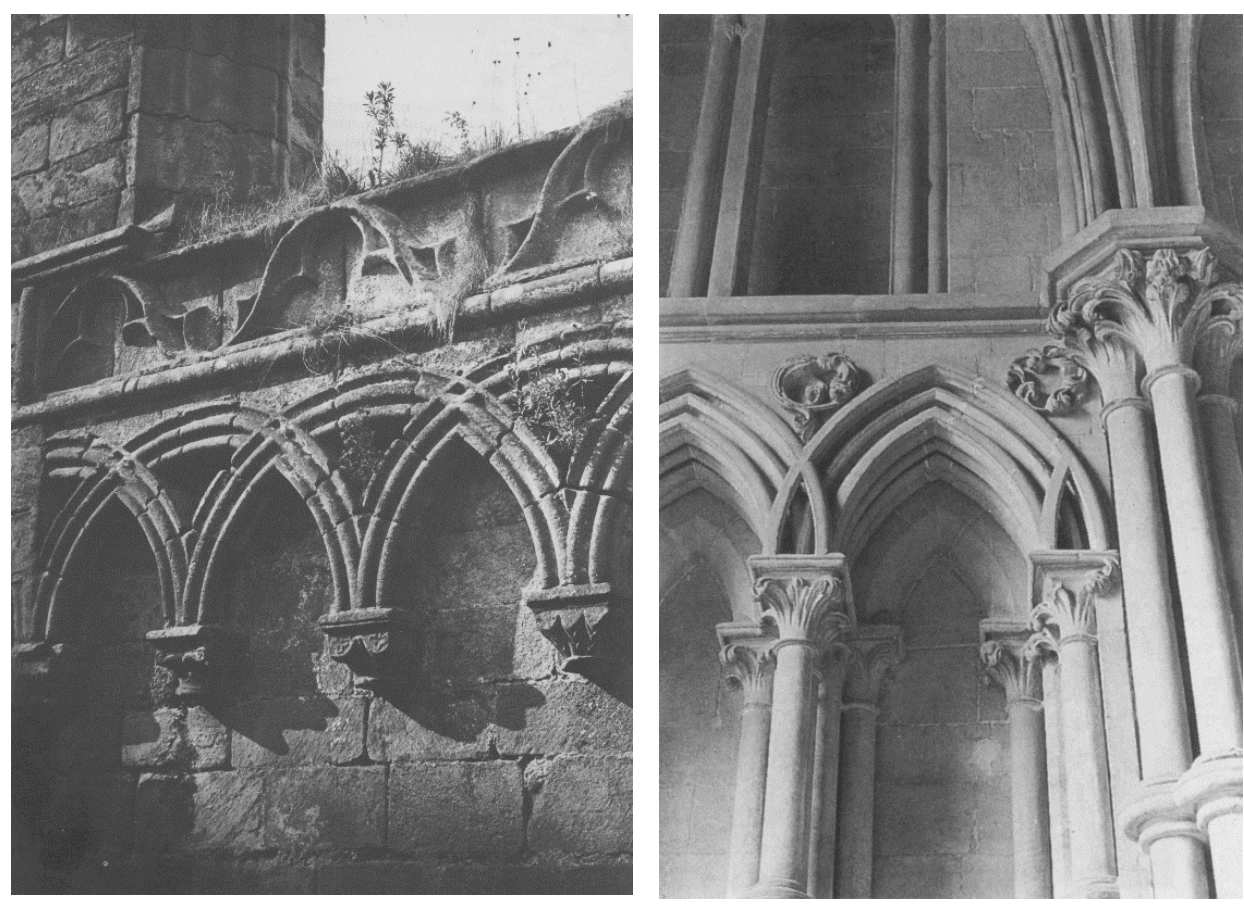

A pesar de que en muchos casos encontremos ejemplos tempranos en los que se producen intersecciones de molduras en los enjarjes como resultado de la dificultad de la reunión de los nervios y no como la expresión de una decisión deliberada, pretendemos mostrar algunos ejemplos en los que la intersección de molduras es una opción por la que se inclinan los maestros de manera deliberada.

\section{$\underline{\text { Intersecciones lineales }}$}

La intersección entre molduras ha estado presente entre elementos en la arquitectura gótica desde un estadio muy temprano. En Inglaterra, el uso de arcos que se interpenetran en una dirección es un motivo recurrente en la arquitectura del XII y de principios del XIII, como por ejemplo los localizados en la catedral de Wells ${ }^{249}$ o los situados en la zona norte del presbiterio de Bolton. ${ }^{250}$

\footnotetext{
${ }^{249}$ Virginia Jansen, "Attested but Opaque: The Early Gothic East End of St Werburgh's", Medieval Archeology, Art and Architecture at Chester. The British Archeological Association Conference Transactions XXII, (Leeds: British Archeological Association and Maney publishing, 2000), 61.

250 David Knowles, Bare Ruined Choirs. The Dissolution of the English Monasteries, (Cambridge: Cambridge University Press, 1959), 311.
} 


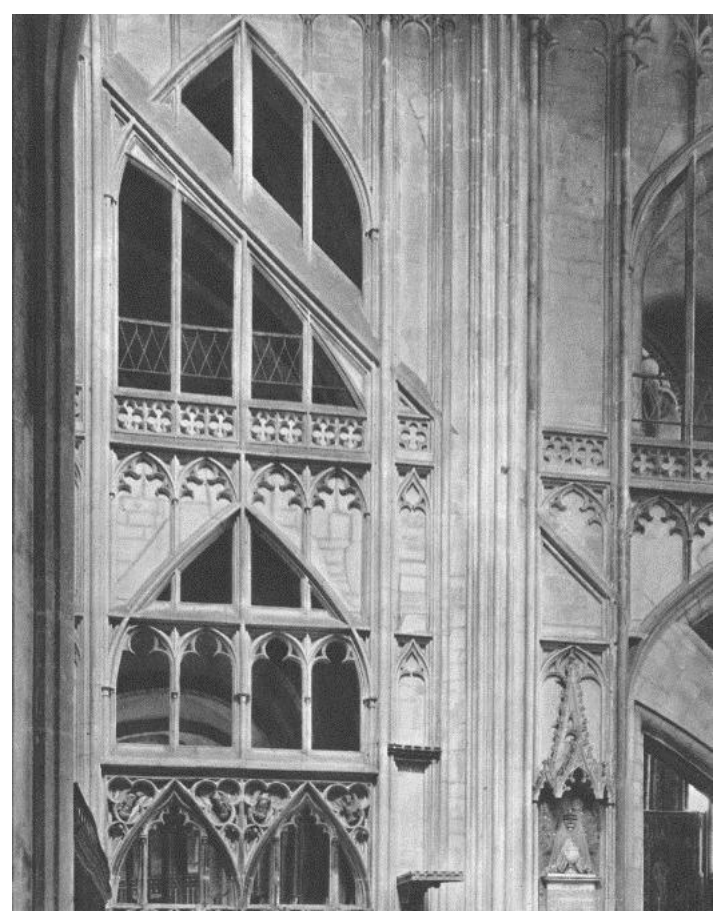

En esos ejemplos se puede apreciar como las molduras que conforman el arco aparecen y desaparecen unas en otras resolviéndose intersecciones, en algunos casos, de considerable complejidad.

También encontramos este tipo de encuentros entre elementos de manera perpendicular u oblicua, siendo el caso más espectacular el de la moldura que corta de manera inclinada la fachada interior de la catedral de Gloucester de principios del XIV. ${ }^{251}$

Es destacable, por su relación con los enjarjes anteriormente estudiados, la intersección que se produce bajo el triforio de la catedral de Rouen (1230s), donde la moldura de la cornisa bajo las ventanas interseca las pilastrillas que suben de los pilares, desapareciendo y apareciendo entre ellas.

Un ejemplo de especial interés lo localizamos también en la iglesia de Saint Florentinus en Niederhaslach, donde se produce una intersección de este tipo, con la peculiaridad de que la pilastra es asimétrica y los restos de moldura tallados en sus concavidades son diferentes. También en la cabecera de la iglesia de Maria zur Wiese de Soest de principios del XIV encontramos restos de una cornisa tras la intersección con un elemento vertical.

En la catedral de Praga se localizan también intersecciones de molduras en la zona del triforio. Y lo que es más interesante para nuestra investigación
Fig. 89

Intersección de molduras a gran escala en la catedral de Gloucester (Meyer, 1961)

\footnotetext{
${ }^{251}$ Peter Meyer, English Cathedrals, 35. Meyer la fecha entre 1331 y 1337.
} 
Fig. 91

Intersecciones lineales de molduras en el sistema de contrarrestos de la catedral de Praga (Plicka, 1953), en el arbotante de Le Mont-Saint-Michel (Besnard, 1951), cabecera de la catedral de Praga y Saint Florentinus en Niederhaslach.

Fig. 90

Intersecciones de molduras en la catedral de Mallorca atribuibles a Guillem Sagrera.
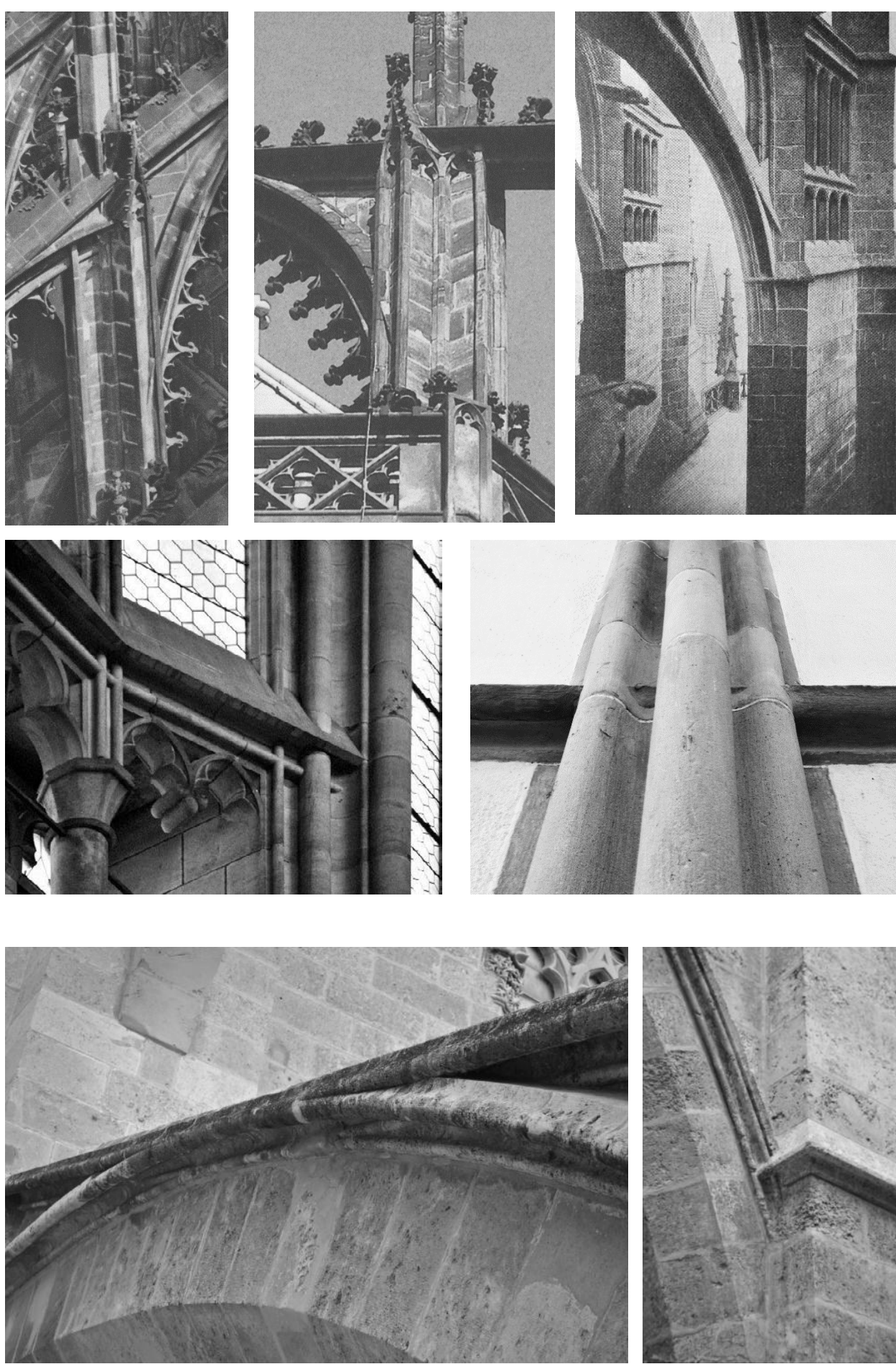

- pues Sagrera realiza intersecciones en los arbotantes de la catedral de Palma de Mallorca- en los contrafuertes y arbotantes de la cabecera. Hasta este momento no hemos localizado ejemplos anteriores a éste en los que se den intersecciones entre molduras en estos elementos estructurales exteriores. Con posterioridad, merecen ser citados los de la abadía del Mont Saint Michel (de finales del XIV). ${ }^{252}$

252 Besnard (Ch.-H.), Le Mont Saint Michel, (Paris: Henri Laurens, 1951). 


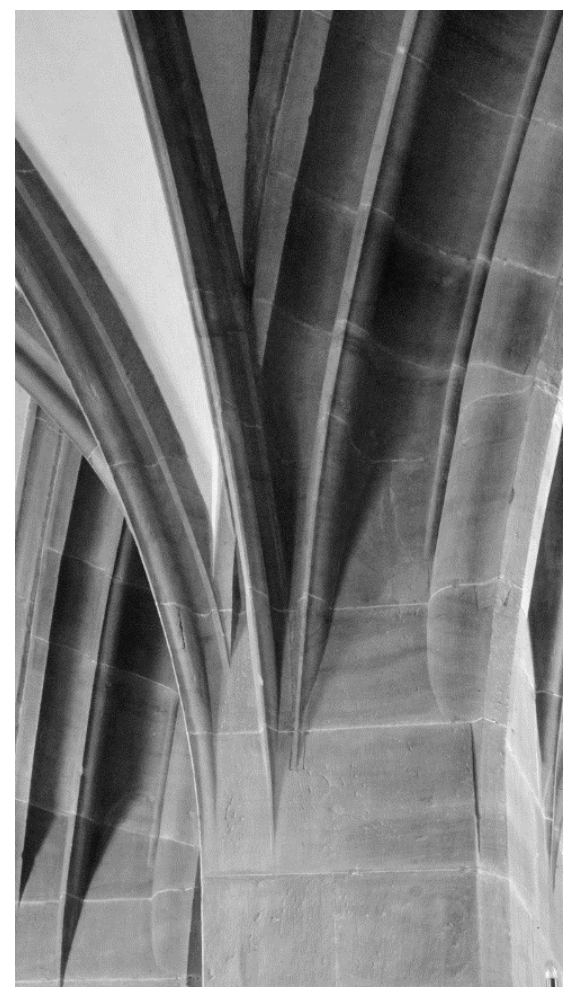

Intersecciones en el espacio

Molduras que se intersecan

El cruzamiento de molduras en tres dimensiones, es decir, entre los nervios en el enjarje presenta más dificultades que los encuentros contenidos en un plano. Nußbaum y Lepsky han detectado un ejemplo muy temprano en el enjarje del baldaquino para la tumba de Giles de Bridport (†1262) en la catedral de Salisbury. En ella se puede apreciar como el intradós del nervio ojivo desaparece en la moldura del nervio perpiaño para aparecer poco después antes de apoyar en el capitel. ${ }^{253}$

También encontramos cruces de molduras realizadas deliberadamente en los arcos torales del cimborrio de la catedral de Canterbury, cuya construcción comienza en $1378,{ }^{254}$ o en España, en el claustro viejo de la catedral de Burgos donde se utilizan en toda una panda de manera sistemática en la segunda mitad del siglo XIII. ${ }^{255}$

${ }^{253}$ Nußbaum y Lepsky, Das gothische Gewölbe, 172.

${ }^{254}$ Meyer, English Cathedrals, 17.

255 Agradezco a Alberto Calderón González haberme mostrado este enjarje. Para su datación: Henrik Karge, Die Kathedrale von Burgos und die Spanische Architektur des 13 Jahrhunderts: Granzosische Hochgotik in Kastilien und León, (Berlin: Gebr Mann, 1989), 177
Fig. 92

Intersecciones de molduras en enjarjes: Saint Florentinus en Niederhaslach, claustro de la catedral de Burgos, Saint Pierre de Montpellier. 

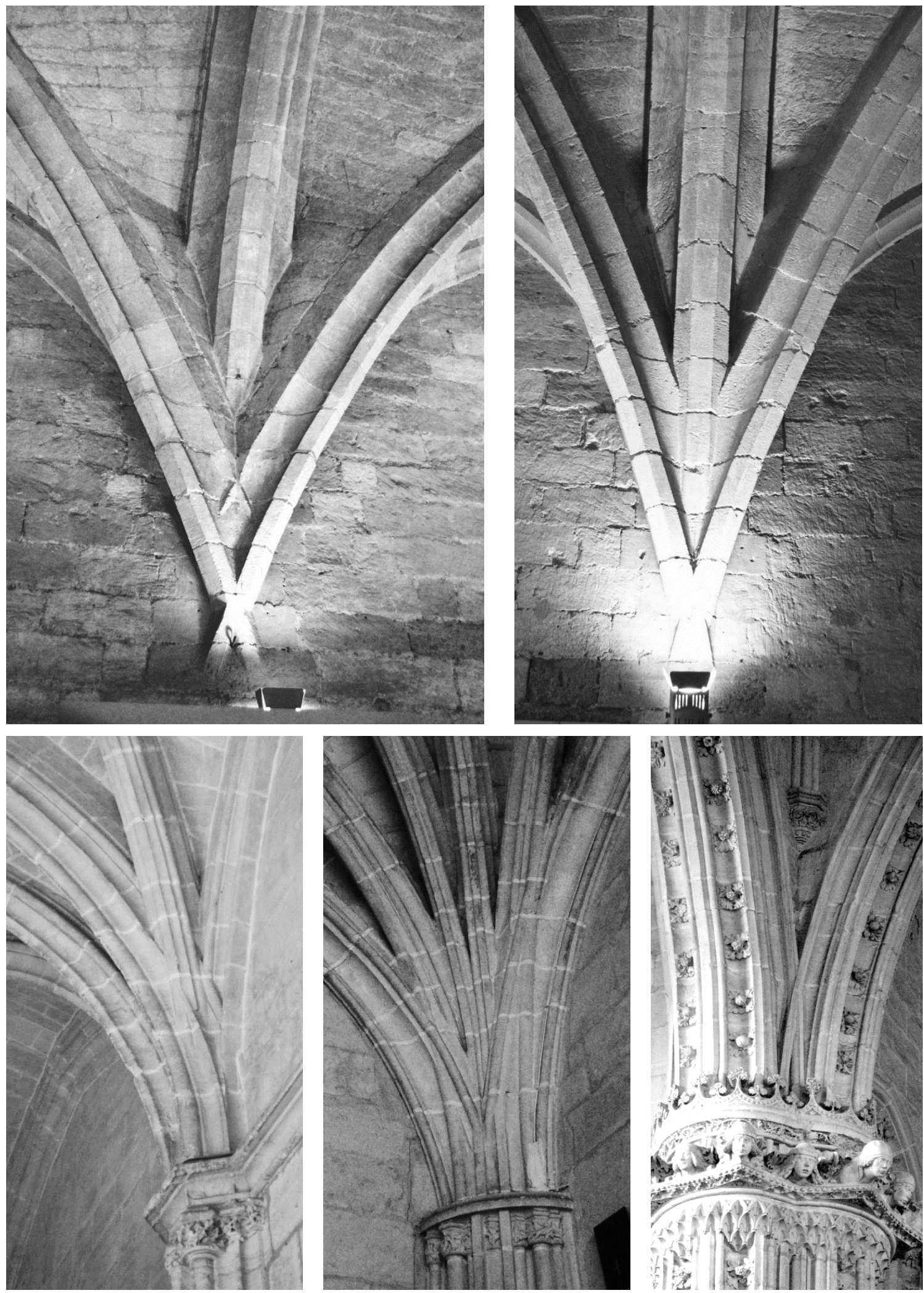

Fig. 93

Ejemplos de cruces de molduras en enjarjes: arriba, sala de Teología del Palacio de los Papas en Aviñón, abajo: claustro de la catedral de Segovia y San Juan de los Reyes en Toledo.
Este tipo de soluciones son frecuentes, por tanto, en Inglaterra, Francia o Centroeuropa. Destacamos los enjarjes de Saint Pierre en Montpellier 
(1364-1372), ${ }^{256}$ la sala de teología del Palacio de los Papas de Aviñón, ${ }^{257}$ los enjarjes del claustro de la Chaise-Dieu (mediados del XIV). 258 También hay ejemplos interesantes en el Mont Saint Michel a mediados del XV, ${ }^{259}$ en la colégiale de Saint Didier en Aviñón, en la iglesia de Saint Florentinus de Niederhaslach ${ }^{260}$ o en el claustro de la catedral de Narbona de finales del $\mathrm{XIV} .^{261}$

En España encontramos significativos ejemplos a partir de la segunda mitad del XV como el de la capilla de Álvaro de Luna o de Santiago en la catedral de Toledo, la capilla Real de Granada; o los asociados al taller de Juan Guas, realizados con gran desenvoltura, por ejemplo, en el claustro de la catedral de Segovia, el claustro del monasterio de El Paular, San Juan de los Reyes en Toledo, etc.

En el Levante cabe destacar el claustro y la zona inferior de los arcos torales del cimborrio de la catedral de Barcelona, la sala capitular de la catedral de Palma, el monasterio de la Trinidad, ${ }^{262}$ la Lonja de Valencia, etc.

${ }^{256}$ En abril de 1365 se traza el portal. Los trabajos en la catedral comienzan en 1364 y estaba terminada en 1372. François Robin, Midi Gothique. De Béziers à Avignon, (Paris: Picard, 1999).

${ }^{257}$ Robin, Midi Gothique. De Béziers à Avignon. La iglesia se consagra en 1359. Hay un cruce de molduras en el enjarje que recuerda al de la catedral de Montpellier.

258 El 3 de mayo de 1344, Clemente VI, dos años antes de ser nombrado papa, anuncia la reconstrucción de la Chaise Dieu. En 1350 la obra está acabada. Anne Courtillé, Auvergne, Bourbonnais, Velay Gothiques. Les édifices religieux, (Paris: Picard, 2002), 155. Del claustro sólo queda la galería norte y oeste. Las claves de las bóvedas indican que la galería norte fue construida entre 1378-1420. La galería oeste, puede datarse entre 1390-1417. Courtillé, Auvergne, Bourbonnais, Velay Gothiques. Les édifices religieux, 174.

259 La cripta se comienza en 1446 y es acabada en 1450. Ch. Besnard, Ch, Le Mont SaintMichel, (Paris : Henri Laurens, 1951), XX.

260 Kobe, Die Stiftskirche St. Florentinus in Niederhaslach im Kontext der Architektur und Skulptur des 14. Jahrhunderts am Oberrhein.

${ }^{261}$ Victor Mortet, Notes historiques et archéologiques sur la Cathédrale, le cloître et le palais Archiépiscopal de Narbonne, XIII-XVI siècles, (Toulouse: Édouard Privat, 1899).

262 Arturo Zaragozá Catalán, Real Monasterio de la Trinidad, Monumentos de la Comunidad Valenciana, T. X, (Valencia, 1995), 140-149; Mercedes Gómez Ferrer, La cantería valenciana en la primera mitad del XV: El maestro Antoni Dalmau y sus vinculaciones con el área mediterránea, Anuario del Departamento de Historia y Teoría del Arte, Vols IX-X, (Madrid, 1997-1998), 91-105; Arturo Zaragozá Catalán y Mercedes Gómez Ferrer, Pere Compte arquitecto, (Valencia: Ajuntament de València y Generalitat Valenciana, 2007); Mercedes Gómez Ferrer y Arturo Zaragozá Catalán, Lenguajes, fábricas y oficios en la arquitectura valenciana del tránsito entre la Edad Media y la Edad Moderna. (1450-1550), Artigrama, núm.

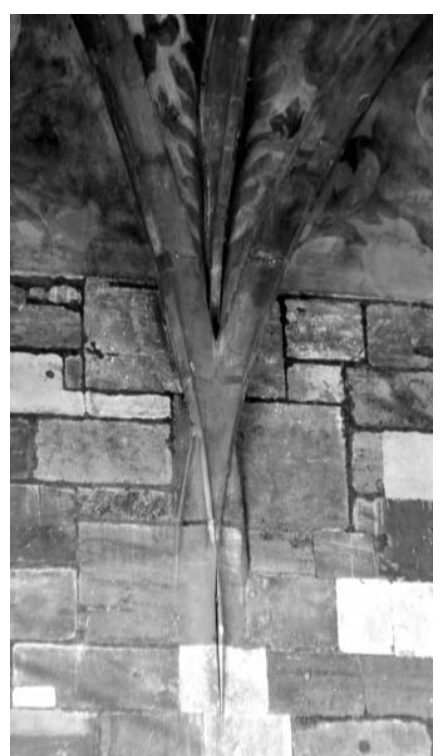

Fig. 94

Nervios que se intersecan en los enjarjes de la bóveda del puente de Praga. 
Fig. 95

Enjarjes de nervios que se cruzan en el claustro de la catedral de Narbona.
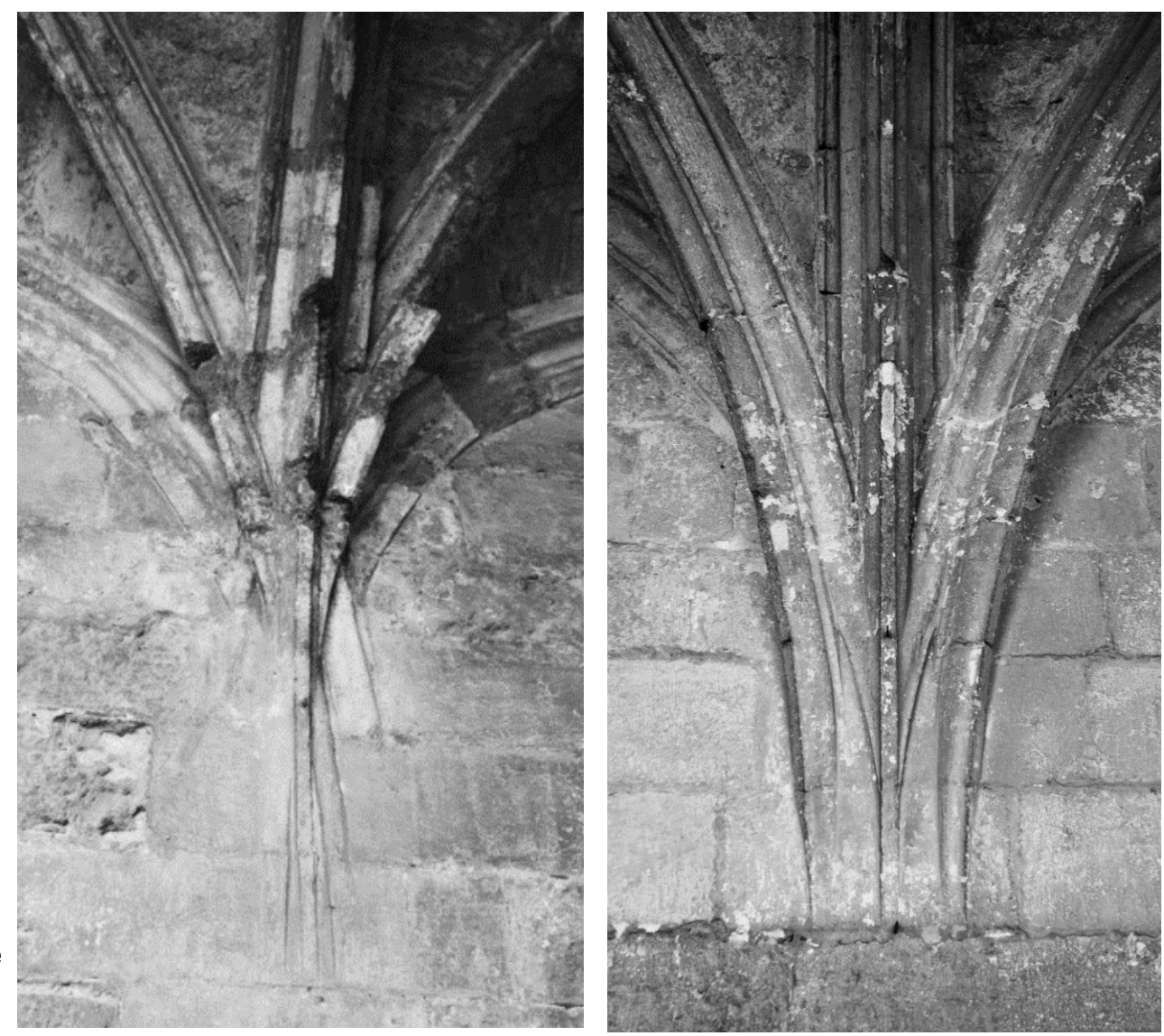

Nervios que se intersecan

La primera intersección de nervios que desaparecen y aparecen la hemos encontrado en Saint Mary, Beverley (1330-40), ${ }^{263}$ fruto de la necesidad de resolver una nave en la que los apoyos se encontraban a diferente distancia desde el centro de la bóveda en un lado y otro.

El enjarje en la torre del puente de Praga, asociado a la factura de los Parler, de finales del XIV, puede que sea uno de los primeros ejemplos de este tipo llevados a cabo con voluntad de proyecto, junto con los enjarjes de la torre sur de la catedral de San Esteban de Viena o los localizados en la torres de la catedral de Basilea en el primer tercio del siglo XV; a falta de un

23, (2008), 149-184; Mercedes Gómez-Ferrer, El maestro de la catedral de Valencia Antoni Dalmau (act. 1435-1453), (s/f).

263 Nikolaus Pevsner, The Buildings of England. Yorkshire: York and the East Riding (London: William Clowes \& Sons, Limited, 1972), 182: "When the N arcade was built, three bays of the chancel aisle were made into a superb chapel with luscious tierceron-star vaulting. It means by the necessity of its supports that the corresponding arcade piers are totally different on their $\mathrm{N}$ and their $\mathrm{S}$ sides. The difficulty was partly solved by a brilliant intersecting of ribs, a device familiar in the C 15 and early C16 in Germany and France but here anticipated about 1330 or $1340 . "$ 
exhaustivo trabajo de localización y datación de enjarjes cuyo alcance es inabarcable para el presente trabajo. ${ }^{264}$

Puede que un enjarje situado en el claustro de la catedral de Narbona (finales del XIV), junto con un enjarje del claustro de la Chaise-Dieu (mediados del XIV), sean los más tempranos ejemplos situados en Francia, al menos que conozcamos hasta el momento, para poco tiempo después, eclosionar en la obra de Guillem Sagrera, al que se le atribuye la Sala Capitular de la catedral de San Juan el Nuevo de Perpiñán, es autor de la Lonja de Palma en Mallorca, maestro mayor de la catedral de Palma y director de la reforma de Castelnuovo Nápoles donde construye la gran Sala o Sala dei Baroni.
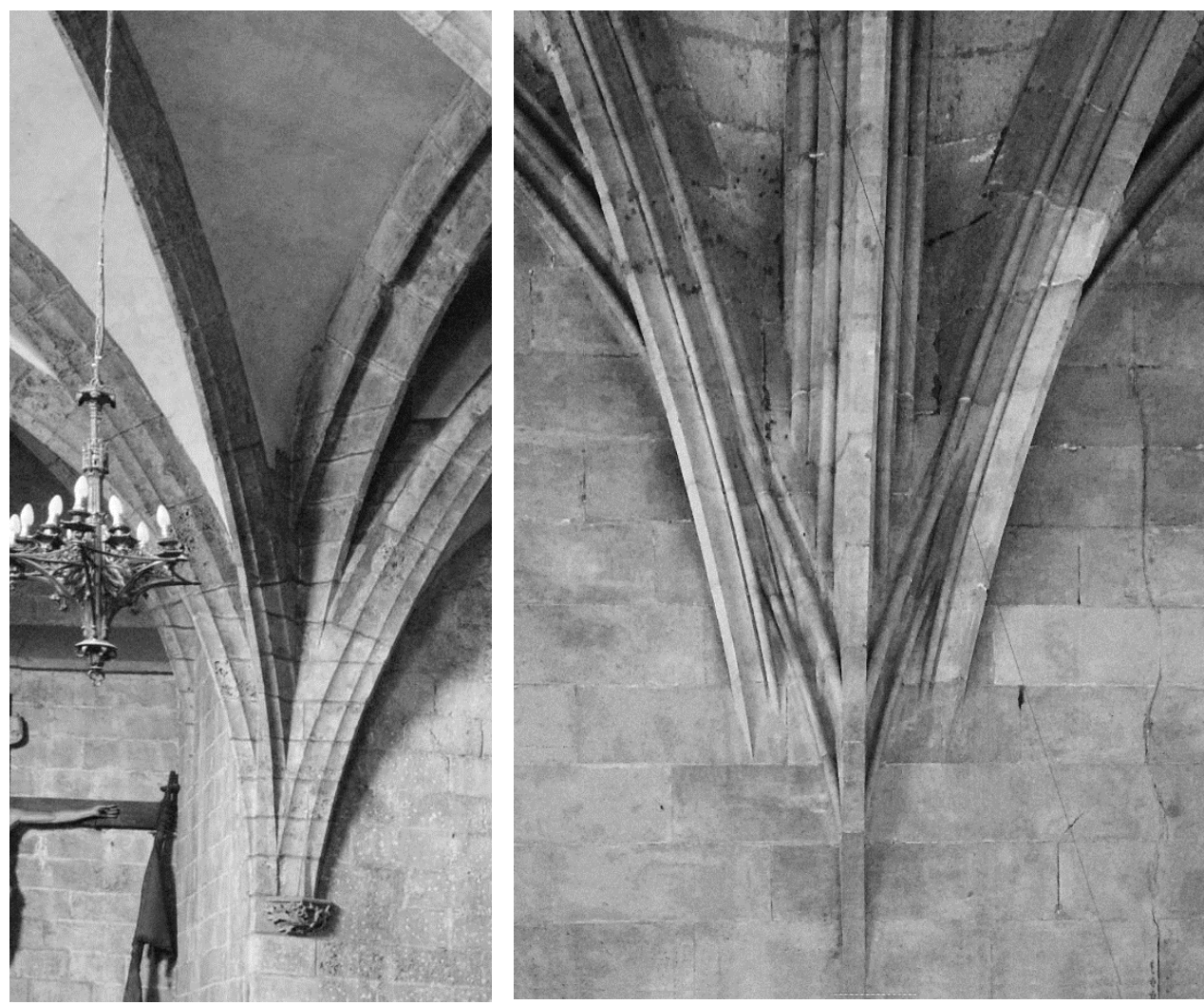

Fig. 96

Enjarjes con nervios que se cruzan en la obra de Guillem Sagrera.

\subsubsection{Interpenetraciones y maclas}

Robert Willis señaló que el mecanismo de la interpenetración de elementos era una característica diferencial de la arquitectura tardogótica francesa. No sólo como fruto de la concurrencia entre elementos colindantes, sino de manera premeditada mediante la introducción de piezas en el conjunto que dieran lugar a estas intersecciones, junto con la variación de las alturas.

\footnotetext{
${ }^{264}$ Agradezco a Nicolás Menéndez González haberme mostrado estos ejemplos y su ayuda con la datación.
} 
Esta última permite mediante un procedimiento sencillo dar lugar a resultados de gran complejidad. ${ }^{265}$

Willis era consciente de la existencia de motivos con interpenetraciones en Alemania o Centroeuropa pero encontraba entre éstas y las francesas fundamentales diferencias. Willis sostiene que las germanas son fruto de la vecindad entre elementos -comparándolas con ejemplos ingleses llevados a un mayor exceso-, mientras que en el flamboyant las interferencias entre elementos son provocadas deliberadamente en una anhelada búsqueda por la intersección:

...the interferences are produced not merely between neighbouring architectural members, but by placing two coexisting members of the same kind in the same place, and by making their forms or their relative position different, so to produce the desired intricacy effect. ${ }^{266}$

Fig. 97

Willis, 1842, 82: fig. 2, 83: fig. 6 , 84: fig. 7.
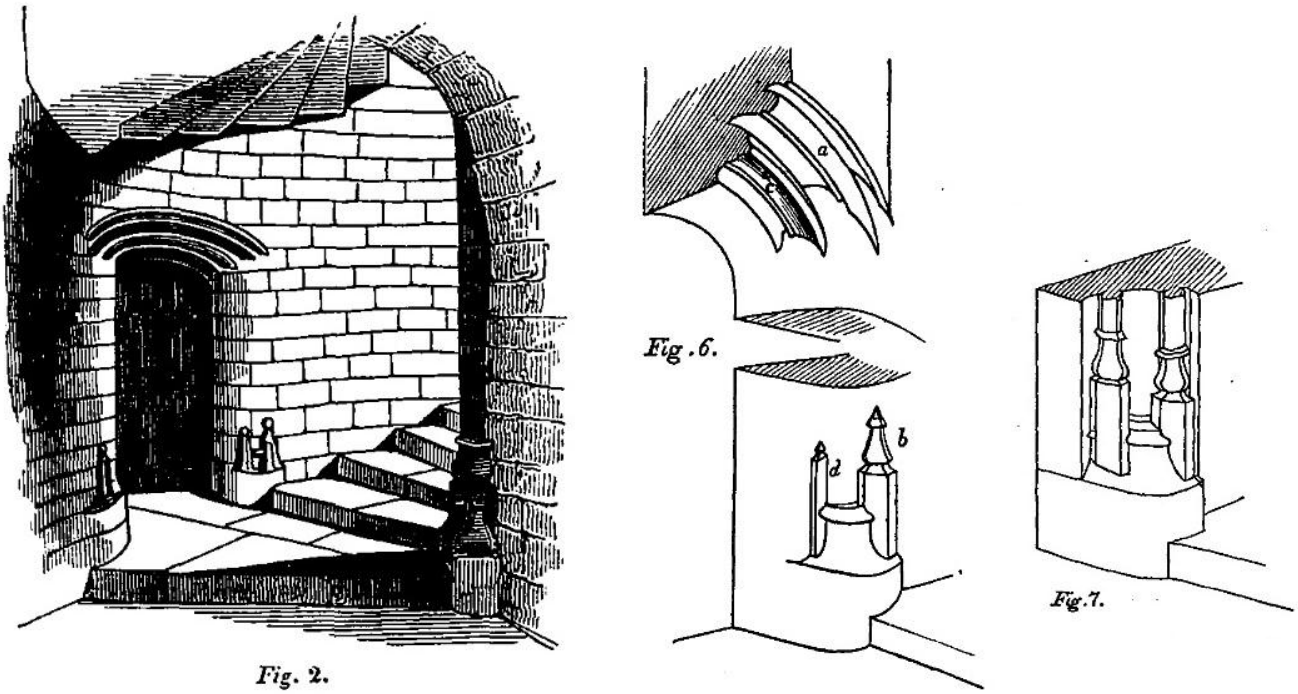

Para llegar a estos motivos se puede recurrir a diversas estrategias, pudiendo ser resultado del giro de unos elementos con respecto a otros o de la variación entre las alturas. Para ilustrar estas ideas Willis presenta varios ejemplos. En el primero se centra en explicar la decoración que enmarca una puerta y cómo ciertas molduras desaparecen y vuelven a aparecer de manera deliberada. También muestra cómo hubiera sido esta

265 Robert Willis, "On the Characteristic Interpenetrations of the Flamboyant Style", Transactions of the Institute of British Architects, (London: RIBA, 1842), volumen1, II: 81-87.

${ }^{266}$ Robert Willis, On the Characteristic Interpenetrations of the Flamboyant Style, 87 


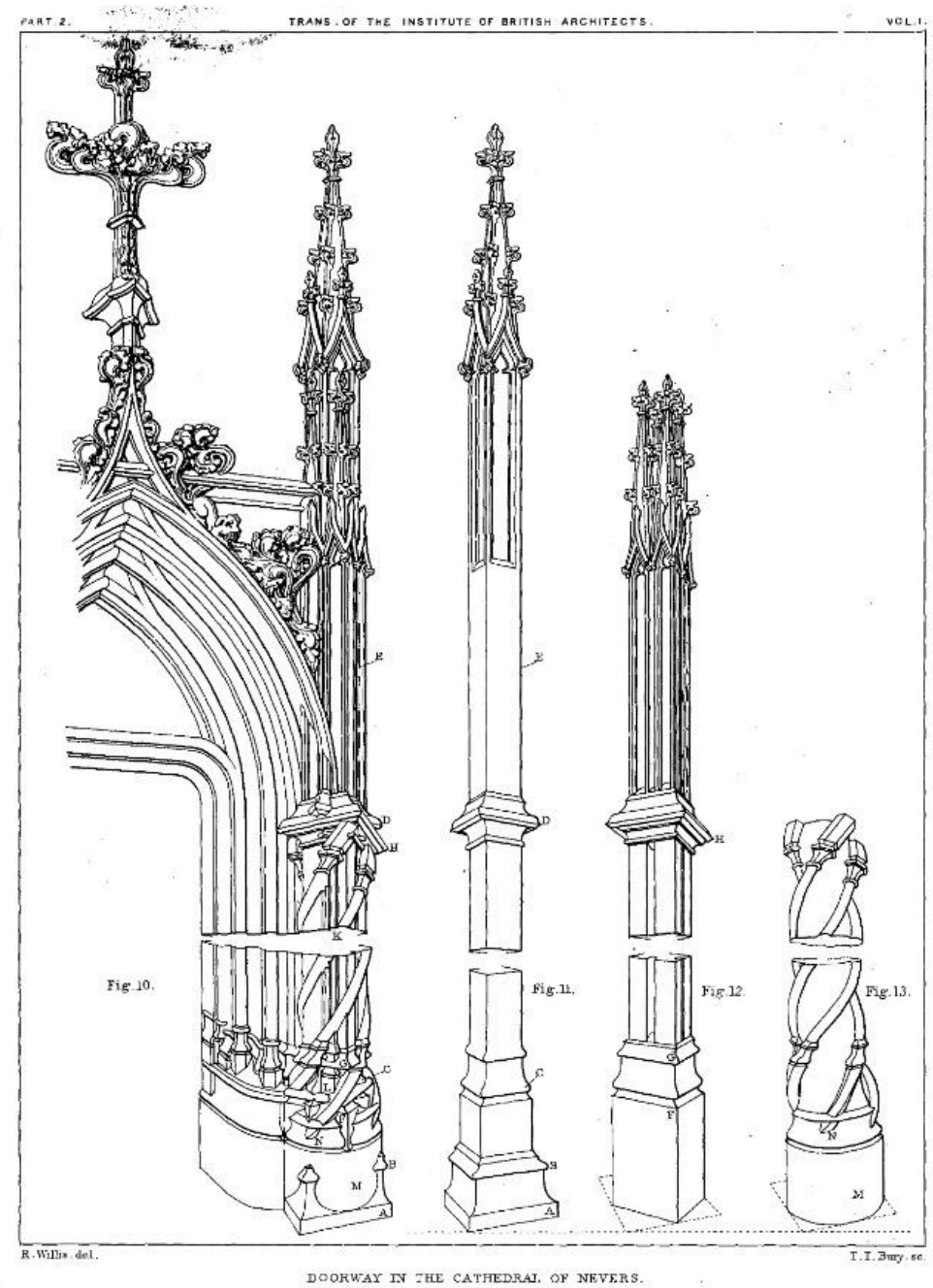

Fig. 98

Willis, 1842, 85.

entrada con la moldura continua y sin interrupciones, señalando la diferencia entre ambas opciones. ${ }^{267}$

De especial relevancia es el modo de representar el análisis que realiza acerca de la portada de la catedral de Nevers, tema sobre el que han profundizado recientemente Elena Pliego de Andrés y Alberto Sanjurjo Álvarez. ${ }^{268}$ Willis muestra en una perspectiva la puerta y, a continuación, uno de los pilares que enmarcan el acceso dividido en los tres elementos superpuestos que lo generan. Estos son: un pilar cuadrangular rematado en pináculo, otro pilar cuadrangular estriado al medio rematado por dos pináculos y rotado $45^{\circ}$ con respecto al anterior; y finalmente un pilar

${ }^{267}$ Robert Willis, On the Characteristic Interpenetrations of the Flamboyant Style, 82-84; fig. 1 , fig. 6 y fig. 7.

268 Elena Pliego de Andrés y Alberto Sanjurjo Álvarez, "Robert Willis' Contribution to Understanding the Gothic Flamboyant Style", Proceedings of the First National Conference on Construction History, (Cambridge: 2014), 343-353. 
Fig. 99

Choisy, 1899, tomo II, 353. cilíndrico caracterizado por una serie de molduras que recorren su superficie dándole un aspecto entorchado. ${ }^{269}$

August Choisy, en el tomo II de su Histoire de l'Architecture, también aborda, aunque de manera más escueta, la intersección entre elementos, en este caso en los enjarjes. Al tratar de explicar cómo se relacionan formalmente los pilares y las bóvedas se detiene a explicar el fenómeno de la supresión del capitel, que da lugar a que los nervios nazcan directamente y a que se produzcan entrecruzamientos e interpenetraciones entre ellos. ${ }^{270}$
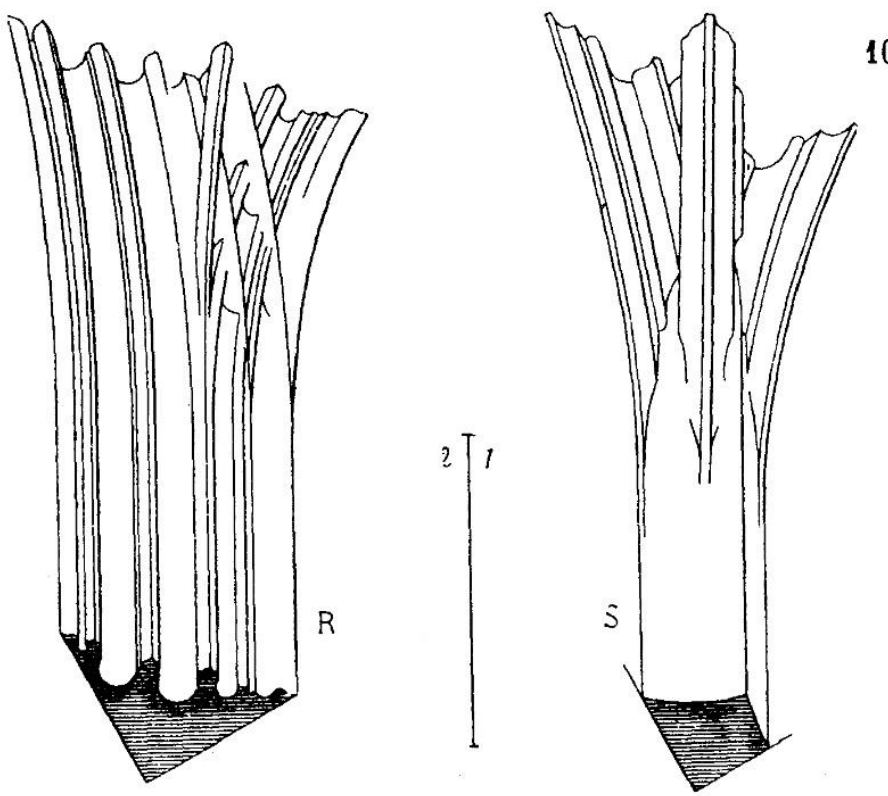

10

Dice que es a partir del siglo XV cuando se comienzan a realizar estas soluciones y que son posibles dos posibilidades. La primera, en la que los nervios se entrecruzan los unos con los otros y se continúan verticalmente por el pilar hasta la base y, la segunda, en la que las molduras de los nervios mueren por penetración en soporte.

Es curioso que anteriormente pero de manera menos sistemática Viollet-leDuc muestre en el tomo IX de su Dictionnaire Raisonné de l'Architecture Française du Xle au XVIe siècle unos dibujos similares, ilustrando cómo ha sido resuelto un enjarje en el que los nervios mueren en el pilar cilíndrico y otro en el que las molduras de los nervios se intersecan y cruzan para configurar en su recorrido vertical el contorno del pilar. ${ }^{271}$

${ }^{269}$ Robert Willis, "On the Characteristic Interpenetrations of the Flamboyant Style", 85; fig.10, fig. 11 y fig. 13 .

${ }^{270}$ Auguste Choisy, Histoire de l'architecture, tomo II, (París: Gauthier-Villars. 1899), 352-353.

${ }^{271}$ Eugène Viollet-le-Duc, Dictionnaire Raisonné de l'Architecture Française du XIe au XVIe siècle, (París: B. Bance, 1868), tomo 9: 539-543. 

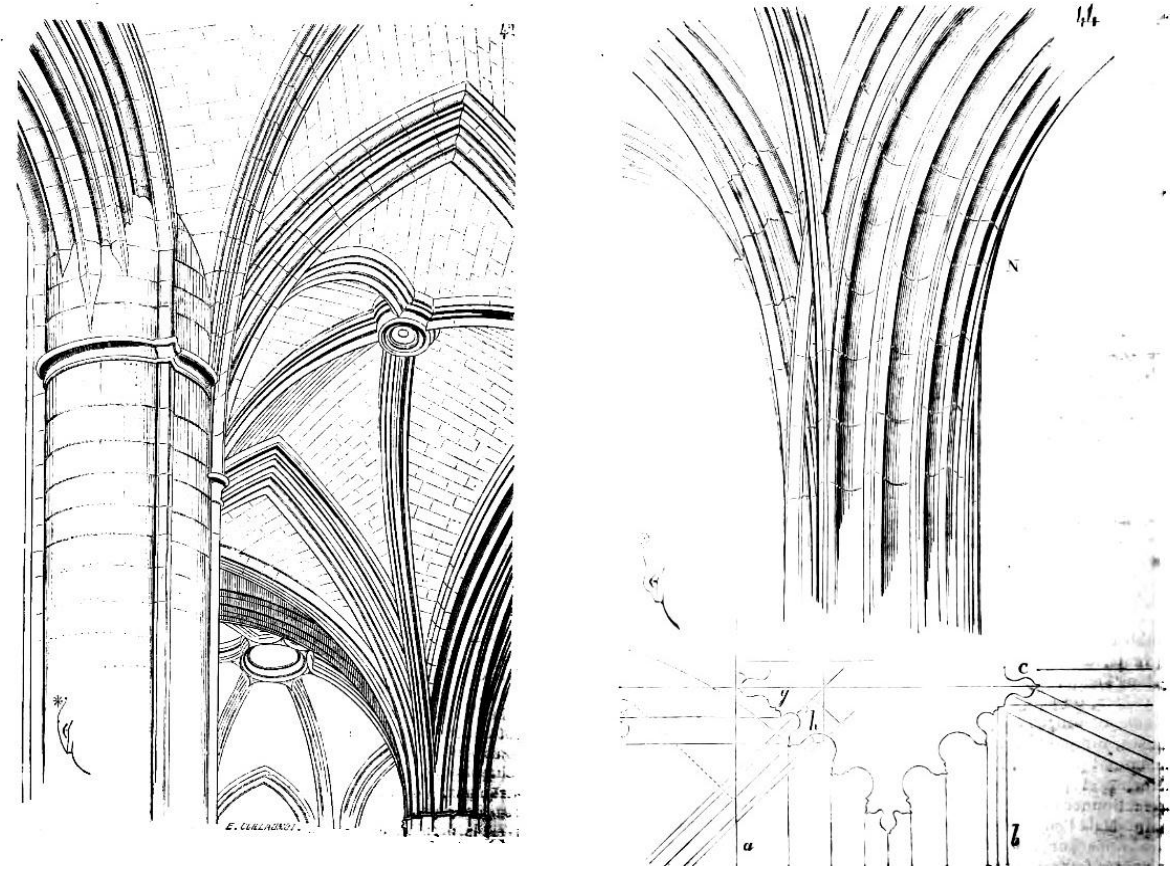

Fig. 100

Viollet-le-Duc, 1868, tomo 9, 552 y 554.

Ya en los años setenta del siglo XX. Alexandre Cirici desarrolló una terminología ingeniosa y novedosa para referirse a estas intersecciones entre elementos, que remite a otras disciplinas científicas. ${ }^{272}$ Para ello utiliza términos como macla, propio de la geología, ${ }^{273}$ e imbricación, que alude a superposiciones de elementos. ${ }^{274}$

Con estas dos palabras describe el fenómeno de las intersecciones y cortes entre molduras, en los que las formas se imbrican y se realizan las maclas, motivo frecuentemente utilizado en la arquitectura gótica catalana y en el que destaca, según Cirici, la figura de Guillem Sagrera. ${ }^{275}$ Llama la atención sobre el gran número de maclas e intersecciones de gran interés en la Lonja de Palma, bien en el zócalo escarpado exterior que se interseca con los pináculos, las columnas torsas, los nervios de las bóvedas al interior, etc.; o las bases de las torres en Castelnuovo en Nápoles, entre otros muchos ejemplos. ${ }^{276}$

272 Alexandre Cirici, Arquitectura gótica catalana, (Barcelona: Lumen, 1973), 324-333 y 392395.

${ }^{273}$ Real Academia Española, s.v. "macla. (Del fr. macle). 1. f. Geol. Asociación de dos o más cristales gemelos, orientados simétricamente respecto a un eje o un plano."

${ }^{274}$ Real Academia Española, S.v. “imbricar.1. tr. Disponer una serie de cosas iguales de manera que queden superpuestas parcialmente, como las escamas de los peces."

${ }^{275}$ Cirici, Arquitectura gótica catalana, 324.

${ }^{276}$ Cirici, Arquitectura gótica catalana, 324 - 332. 
Las imbricaciones, las caracteriza al hablar de su papel en el juego de trasparencias y superposiciones entre las partes convexas y cóncavas, unas determinadas por la luz y otras por la sombra. ${ }^{277}$ Las imágenes presentadas en el libro son ilustrativas del mensaje que Cirici quiere trasmitir y fundamentales para la comprensión de este juego geométrico entre volúmenes.

Más recientemente Enrique Rabasa ha centrado parte de su investigación en el concepto de macla en relación y como fruto del trabajo con plantillas en el gótico, siendo punto de partida fundamental para la presente investigación. En 2011 presentó un primer texto en el que llama la atención sobre dos lugares de especial interés en los que la reunión de los perfiles de los nervios da lugar a interpenetraciones: las claves y los enjarjes de la bóveda gótica; así como elementos decorativos fruto de encuentros de molduras en puertas, cornisas, etc. ${ }^{278}$ Todos ellos son tallados gracias al empleo de plantillas trazadas en los lechos horizontales de las piezas, que permiten controlar los perfiles y sus encuentros durante la ejecución.

Rabasa señala que algunas de estas intersecciones pueden ser casuales, mientras otras son resultado de una intención deliberada. En este sentido nos parece especialmente inspirador el término anticipación, con el que caracteriza el fenómeno de la previsión de resultados mediante el trabajo con plantillas. ${ }^{279}$ El profesor Rabasa ha podido documentar la existencia de perfiles de elementos que aparecen y desaparecen a lo largo de su recorrido -a veces a cotas muy separadas y difícilmente relacionables a simple vista- dando testimonio del control exhaustivo en empleo sistemático de la proyección horizontal.

Apunta a que intersecciones y maclas hablarían, por tanto, de la voluntad de mostrar el dominio de una técnica, un cierto orgullo de una artesanía intelectual en pleno progreso. ${ }^{280}$

En su último artículo junto con Ana López Mozo llama también la atención sobre la complejidad de la resolución de los rincones, lugares en los que se encuentran también las molduras y que presentan particularidades de

\footnotetext{
277 Cirici, Arquitectura gótica catalana, 396.

278 Enrique Rabasa Díaz, "Plantillas y maclas", La arquitectura castellana entre Europa y América, (Madrid: Silex ediciones, 2011).

279 Rabasa Díaz, "Plantillas y maclas", 438

${ }^{280}$ Rabasa Díaz, "Plantillas y maclas", 440.
} 
especial interés. ${ }^{281}$ Así como la resolución de esquinas cuyas molduras se continúan y cuyo procedimiento de talla no tendría que ver con las cornisas clásicas. Entre otras muchas cosas, también inciden en la reunión de los nervios en las claves, especialmente en los casos en los que la inexistencia de cilindros centrales da lugar a nervios que se intersecan y pasan unos sobre otros -lo que denominan cruce de nervios pasantes-, mostrando además la posibilidad de que esto no ocurra y se produzcan formas extrañas. $^{282}$

Seguramente este fenómeno de la interpenetración de elementos o molduras habrá sido señalado por otros autores, pero sería un ejercicio que desbordaría los límites de la presente investigación el pretender reunirlos a todos.

${ }^{281}$ Enrique Rabasa Díaz, y Ana López Mozo, "Configuraciones formales del gótico tardío en relación con las técnicas de labra", Sevilla, 1514. Arquitectos tardogóticos en la encrucijada, (Sevilla: Universidad de Sevilla (en prensa) 2015).

282 Rabasa Díaz, y Ana López Mozo, "Configuraciones formales del gótico tardío en relación con las técnicas de labra". 



\subsection{Análisis de casos}

La obra de Sagrera supone una gran novedad en términos de lugar y tiempo, especialmente si estudiamos su obra en relación al gran desarrollo que tendrán este tipo de soluciones posteriormente en Centroeuropa. En España, encontrar enjarjes similares a los del mallorquín es difícil, incluso podríamos decir, imposible. Destacan tres ejemplos en Valencia y sus alrededores que analizaremos a continuación y en los que hemos podido comprobar como tres enjarjes que a primera vista son muy similares responden, sin embargo, a tres diseños diferentes.

Que Sagrera haga uso de estas soluciones tecnológicas con gran habilidad y maestría sin referencias claras ha despertado el interés de historiadores, quienes no han dudado en ir en búsqueda de su origen en los que desconocemos su paradero. Entre otros, se apunta que pudo llegar a Dijon, lo que explicaría la relación entre la supuesta obra escultórica de Sagrera y la de Claus Sluter. Joan Domenge i Mesquida ha localizado ejemplos de enjarjes anteriores a Sagrera y que comparten ciertas características con él en el sur de Francia. Entre otros, en el Palacio de los Papas de Aviñón o en el claustro de la catedral de Narbona, los cuales hemos medido y analizado con motivo de esta investigación y que mostraremos a continuación. ${ }^{283} \mathrm{En}$ Aviñón, el comienzo de los enjarjes revela variaciones sobre el trabajo con plantillas en los lechos de las piezas en uno de los primeros ejemplos de cruzamientos de molduras, mientras que en Narbona somos testigos de una de las primeras pruebas de experimentación con enjarjes, con tres soluciones consecutivas y diferentes que no son fruto de irregularidades en planta.

En el estudio de los casos de Valencia, Aviñón y Narbona advertimos que al tratarse de bóvedas cuatripartitas el esfuerzo está puesto en el diseño de los enjarjes. Esto motivó nuestro interés por comprobar si el caso opuesto era posible, si la configuración de la bóveda puede dar lugar a un determinado comienzo de los nervios. Por ello, y porque la capilla del Condestable de la catedral de Burgos representa unos de los pocos casos de enjarjes en los que se producen cruces de nervios en España, se decidió medir y analizar; decidiendo que formara también parte de este compendio de ejemplos que nos ayudan a acercarnos al proyecto de enjarjes.

\footnotetext{
283 Joan Domenge i Mesquida, "Guillem Sagrera", Gli ultimi indipendenti. Architetti del gotico en el Mediterraneo tra XV e XVI secolo, (Palermo: Edizioni Caracol, 2007), 58-93; Joan Domenge i Mesquida, "Guillem Sagrera et lo modern de son temps", Revue de I'art, n 1664, (2009), 77-90.
} 


\subsubsection{Enjarjes parecidos con diseños diferentes: el caso valenciano ${ }^{284}$}

Contemporáneamente a la obra de Guillem Sagrera, en Valencia y sus alrededores, se construyen tres ejemplos diferentes con enjarjes de nervios que emergen de un punto. Con tan pocos precedentes, es sorprendente localizar en un área tan pequeña estos ejemplos similares. La gran calidad de su ejecución, la dificultad de clara atribución de dichas obras a uno o varios autores, y el hecho de tratarse de fábricas de gran importancia y envergadura, suscitan gran interés. Se encuentran en este episodio el gran claustro de la cartuja de Valdecristo (Altura), el refectorio del monasterio de Santa María de la Valldigna (Tavernes de la Valldigna) y el claustro del monasterio de la Trinidad en Valencia.

Diseñar un enjarje de estas características no es algo mecánico ni su resultado es fortuito, sino fruto de una voluntad clara. Mediante el análisis geométrico y constructivo de cada uno de estos casos valencianos pretendemos arrojar luz sobre el modo de concepción de los mismos y contrastar si en los tres casos se siguen las mismas reglas; comprobaremos que, a pesar de las similitudes, nos encontramos con tres soluciones diferentes en la ejecución práctica y el detalle.

\section{Metodología}

Se han realizado mediciones en el claustro del monasterio de la Trinidad, en los restos de la cartuja de Valdecristo y en el refectorio de Santa María de Valldigna con una estación total Leica FlexLine TS02. Se han tomado datos de la planta del edificio, las curvas de los arcos, con mayor densidad en la zona del enjarje, puntos siguiendo las juntas de las piezas, desplomes y perfiles de los nervios.

Obtenida la nube de puntos, los enjarjes ha sido modelados mediante Rhinoceros v.4. En el proceso hay que coordinar las curvas de los arcos y las hiladas horizontales, intentando que ambas difieran lo menos posible una vez se haya extruido el perfil del arco. El perfil ha de ser dibujado con gran fidelidad en el caso de los enjarjes, ya que a la más mínima variación,

\footnotetext{
${ }^{284}$ Esta investigación se llevó a cabo junto a Arturo Zaragozá Catalán, dando lugar a dos contribuciones: Carmen Pérez de los Ríos y Arturo Zaragozá Catalán, "Bóvedas de crucería con enjarjes de nervios convergentes que emergen del muro en el área valenciana, Ss. XIV - XV", Octavo Congreso Nacional de Historia de la Construcción, (Madrid: Instituto Juan de Herrera, 2013). vol. 2: 833-842. Arturo Zaragozá Catalán y Carmen Pérez de los Ríos, "Bóvedas de crucería con enjarjes de nervios convergentes que emergen del muro en el área valenciana. SS. XIV-XV", Bóvedas valencianas. Arquitecturas ideales, reales y virtuales en época medieval y moderna, (Valencia: Universidad Politécnica de Valencia 2013). Le debo a Arturo haberme mostrado estos ejemplos, así como encargarse de compilar y escribir el contexto histórico de cada uno de ellos. Además, fue él quien gestionó la visita a los edificios, pudiendo así llevarse a cabo la medición con la estación de las bóvedas.
} 


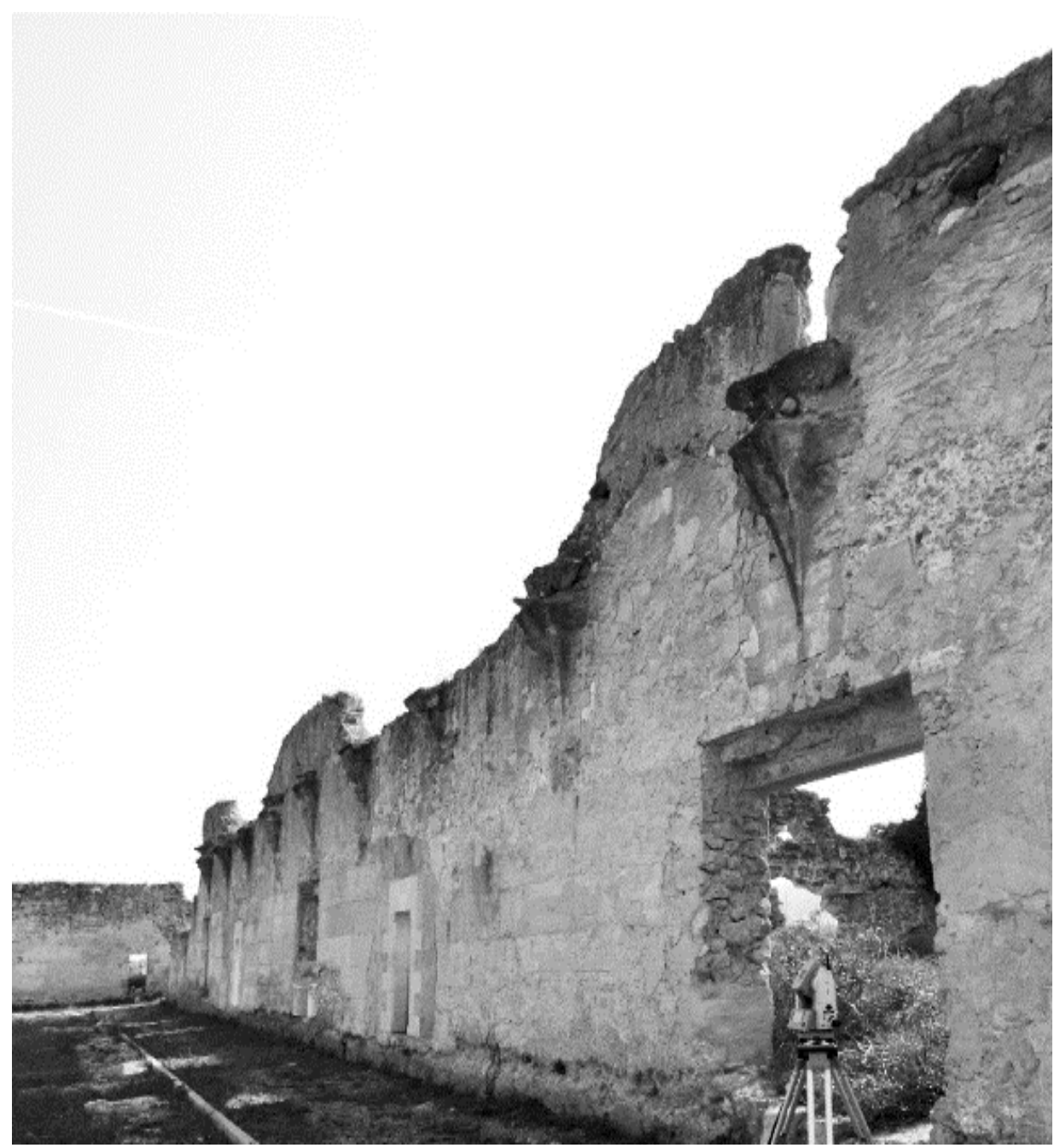

el resultado varía enormemente.

\section{Introducción a los edificios}

\section{Claustro de la cartuja de Valdecristo}

La cartuja de Valdecristo fue fundada por el infante Martín de Aragón en 1385. Entre las motivaciones para la fundación de la cartuja debe recordarse el conocido patrocinio de esta orden por parte de las casas reales y la alta nobleza en los siglos XIV y XV. ${ }^{285}$

La cartuja sigue la disposición habitual de las casas de la orden. Un amplísimo claustro cuadrado de 260 por 260 pies valencianos ${ }^{286}-78,4 \mathrm{~m}$ por 78,4 m- de lado da acceso a las veinticuatro celdas de generosa dimensión. Estaba cubierto mediante bóvedas de crucería simple, con los

\footnotetext{
${ }^{285}$ Amadeo Serra Desfilis y Juan Matilde Miquel, "La capilla de San Martín en la cartuja de Valldecrist: construcción, devoción y magnificencia”, Ars Longa, (2009), no. 1, 18: 65-90.

${ }^{286}$ el pie valenciano es de $30,2 \mathrm{~cm}$.
}

Fig. 101

Vista del claustro de la Cartuja de Valdecristo, donde se aprecia el estado de ruina en el que han permanecido los muros con los enjarjes. 


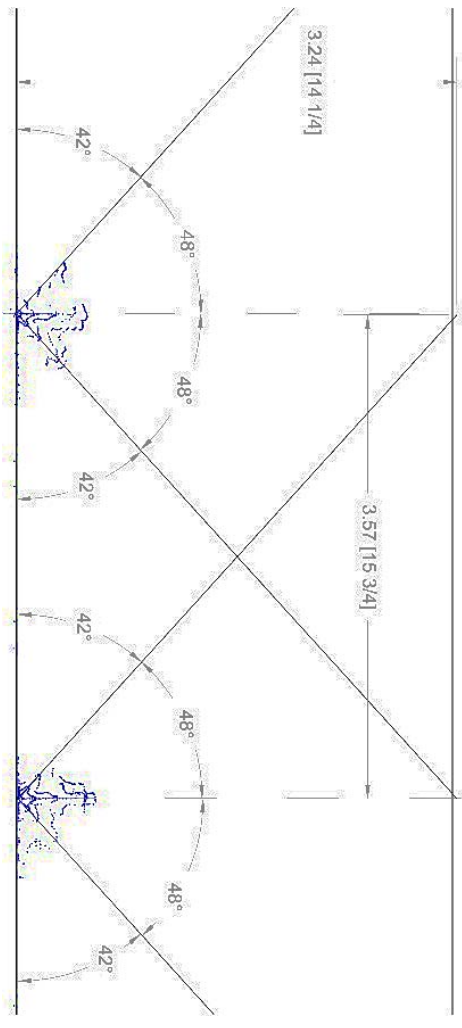

Fig. 102

Izquierda: detalle de los dos enjarjes medidos.

Fig. 103

Derecha: planta del claustro de la cartuja de Valdecristo.

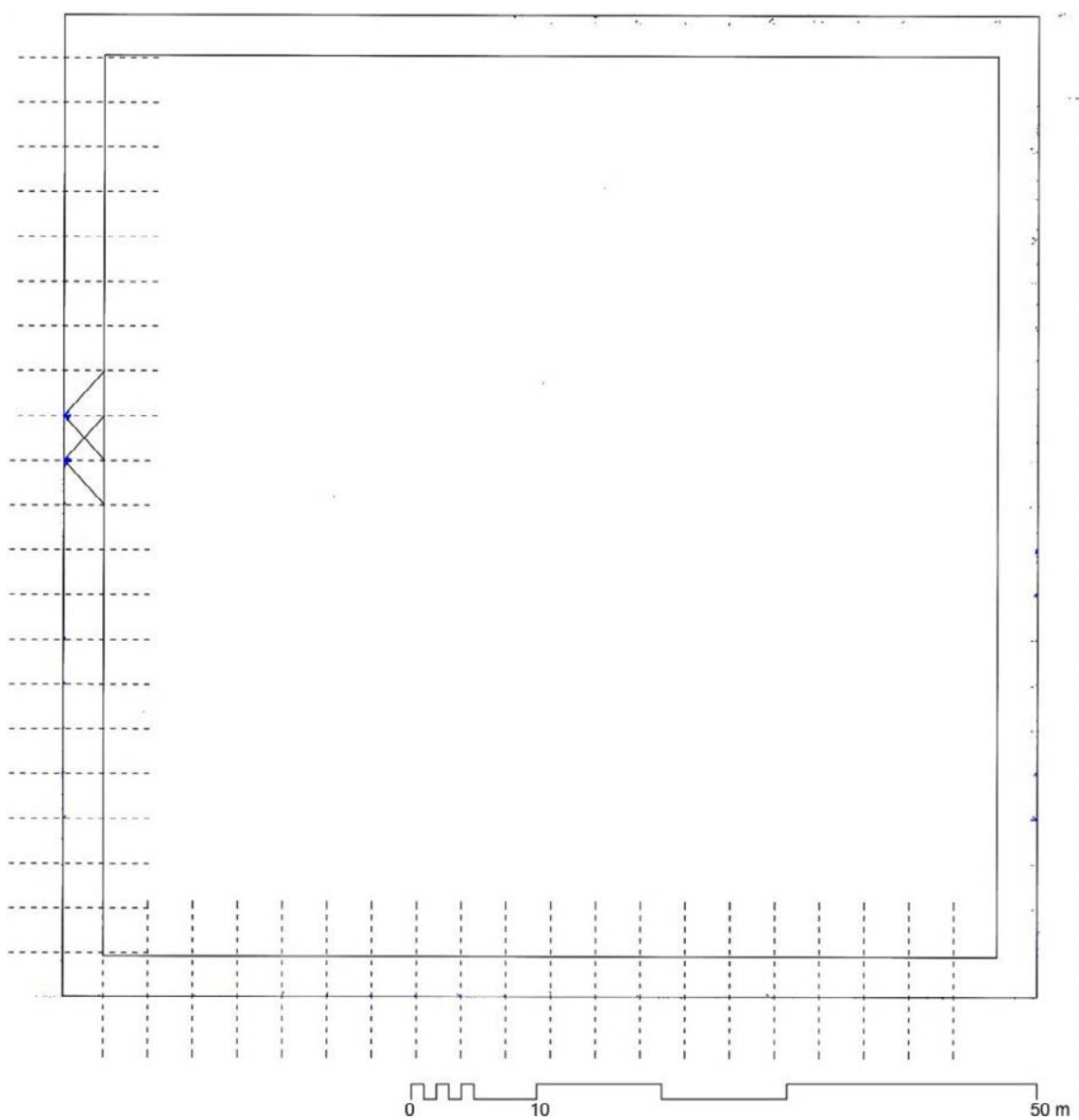

arranques y las claves de piedra caliza. ${ }^{287}$ Los muros son de tapia y las bóvedas tabicadas. Las innovaciones técnicas experimentadas en Valdecristo, como son las bóvedas tabicadas y los enjarjes cabe atribuirlos al monje conrer (mayordomo o cillerero) Bernat Çafabrega, amigo personal del futuro rey Martín I y seguramente, como él, aficionado (o profesional) de la arquitectura. Hay noticia de que en el año 1400 ya se había cerrado una parte del claustro con las bóvedas de crucería. ${ }^{288}$

La mayoría de los enjarjes del claustro se encuentran en un estado de conservación lamentable. Todos son iguales, con un nervio perpiaño y dos ojivos cuya directriz parece converger en un punto. No quedan restos de

${ }^{287}$ Encontramos una dovela entre los restos allí existentes. En un primer momento pensamos que pudiera ser de yeso, pues en esa zona no es un material extraño para la solución de bóvedas. Ver Rafael Marín Sánchez, Uso estructural de prefabricados de yeso en la arquitectura levantina de los siglos XV y XVI, (Universidad Politécnica de Valencia, 2014), tesis doctoral. Gracias al análisis en el laboratorio de la ETSAM llevado a cabo por David Sanz Arauz, hemos podido comprobar que se trata de una piedra muy ligera y porosa que permite a simple vista llevar a confusión.

288 D. Girona i Llagostera, Epistolari del rey En Marti d'Aragó (1396-1410), Revista de la Asociación Artística Arqueológica Barcelonesa, (1906-11), no. 56-58: 187-309. Arturo Zaragozá Catalán y Javier Ibañez Fernández, "Materiales, técnicas y significados en torno a la arquitectura de la Corona de Aragón en Tiempos del Compromiso de Caspe (1410-1412)", Artigrama, (2011), no. 26: 21-102. 


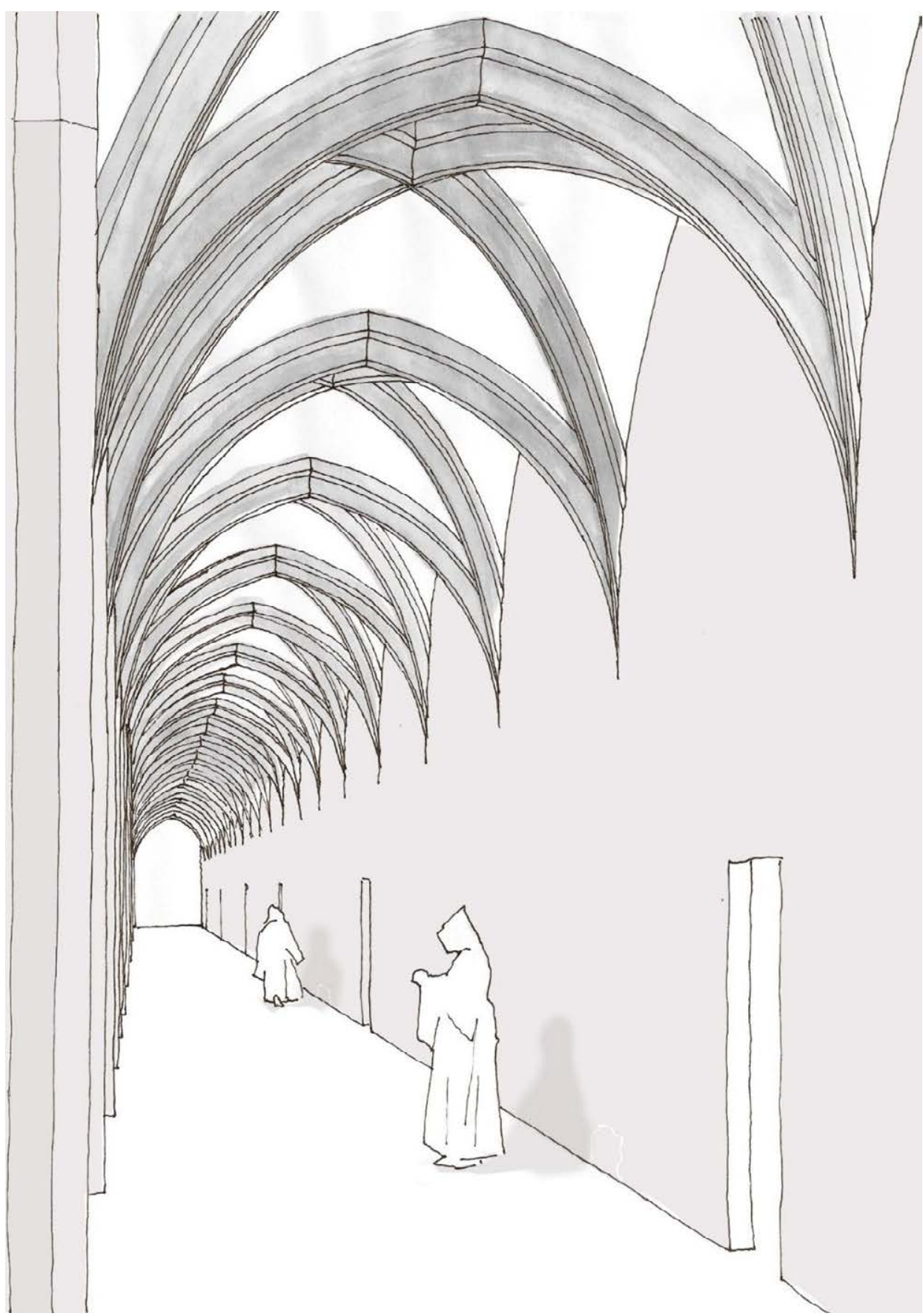

los enjarjes situados en los rincones ni en las esquinas, que hubiesen presentado una solución diferente. Todo el muro que daba fachada al patio ha desaparecido. El claustro estaba conformado por pandas con 22 bóvedas cuatripartitas, todas rectangulares, con una dimensión de 10 pies valencianos y un palmo, de ancho, por 12 pies de largo. Los arcos perpiaños, con 6 pies de radio, eran apuntados; mientras que los ojivos eran semicircunferencias de 8 pies de radio. La posición de la clave de los ojivos quedaría aproximadamente $40 \mathrm{~cm}$ por encima de la clave de los perpiaños. No existen nervios formeros y, en cuanto a la plementería, como hemos apuntado anteriormente, aún son visibles restos de ladrillo tabicado.
Fig. 104

Reconstrucción del claustro de la cartuja de Valdecristo. 


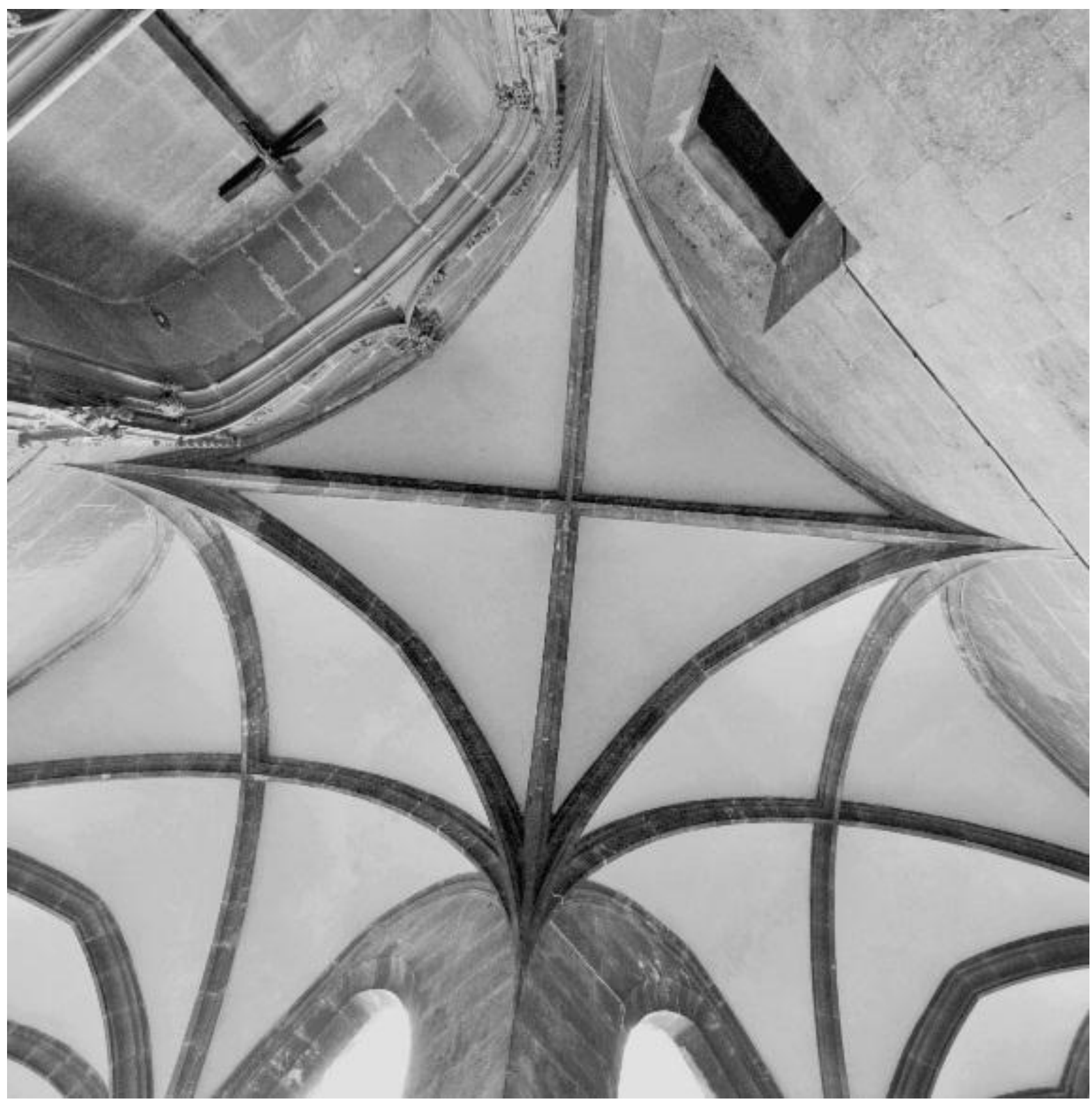

Fig. 105

Claustro del monasterio de La Trinidad en Valencia.
El real monasterio de clarisas de la Santísima Trinidad de Valencia es un edificio de notable importancia histórica. Fue fundado por la reina María de Castilla, consorte del rey Alfonso el Magnánimo de Aragón y regente del reino durante la larga ausencia de su marido en Italia. Se comenzaron las obras, con una solemne ceremonia, el 9 de julio de 1445. Las crónicas del monasterio hacen suponer que debió de construirse primero la iglesia y el sepulcro de la reina, que se sitúa en el muro en el que confluye el lado del evangelio de la cabecera de la iglesia con la nave sur del claustro. ${ }^{289}$

${ }^{289}$ Arturo Zaragozá Catalán, "Real Monasterio de la Trinidad (Valencia). Monumentos de la Comunidad Valenciana. Catálogo de Monumentos y Conjuntos declarados e incoados", Valencia, Arquitectura Religiosa (Valencia: Generalitat Valenciana 1995), 140-149. 
El monasterio se ordena alrededor de un claustro de planta rectangular de dos pisos. El claustro bajo está abovedado y formado ocho tramos en su lado mayor y siete en el menor. La galería inferior, construida con cantería de excelente labra, se cubre con bóvedas de crucería simple con nervios de piedra que arrancan limpiamente del muro, sin impostas. La plementería, que está encalada, debe de ser de ladrillo.

El interés arquitectónico del monasterio de La Trinidad no radica únicamente en la reconocida belleza del conjunto sino, especialmente, en la vanguardista experimentación técnica y formal realizada en sus fábricas. Las distintas piezas del conjunto monástico muestran el discurrir, sin graves cesuras, de la estereotomía medieval a la moderna. Entre sus muros se tienden arcos en esviaje, bóvedas aristadas, arcos en rincón de claustro, decendas de cava, o bóvedas de arista y esquifadas.

En este contexto la personalidad de los maestros que trabajaron con admirable sentido de continuidad en la obra del monasterio, así como la datación de las diferentes partes de la obra es, historiográficamente, de gran interés. Lamentablemente la construcción del monasterio no ha sido explorada archivísticamente y, de momento, únicamente cabe recurrir a utilizar fuentes indirectas y plantear los problemas existentes. La primera noticia que conocemos sobre un maestro de obras en el monasterio la recoge el libro de bienhechores, que se custodia en el propio archivo del monasterio y en el que figuran las personas que contribuyeron entre 1446 y 1449 para la fábrica, y se hicieron acreedores a las correspondientes indulgencias. Figura en primer lugar la reina, seguida de otras muchas personas conocidas de la sociedad valenciana de este momento. En esta relación aparecen NanthoniDalmau, Pedrapiquer, MESTRE DE LA OBRA y JuanetDalmaufill del MESTRE DE LA OBRA. ${ }^{290}$

Antoni Dalmau (1435-1453) fue un fino escultor y un prestigioso maestro de obras, siendo maestro también de obras de la Seo. Los ocho años que median entre el comienzo de la obra de la Trinidad y la muerte del maestro Dalmau hacen pensar que éste únicamente pudiera realizar las trazas generales del conjunto monástico e iniciar la iglesia y el claustro. Los arranques de las bóvedas de claustro son obra asociada al sepulcro de la reina María, con lo que se puede pensar en la atribución de los enjarjes de los arcos de las bóvedas del claustro a Antoni Dalmau, quien seguramente fue el artífice de la tumba. La obra de este maestro en la Trinidad puede

\footnotetext{
290 Arturo Zaragozá Catalán," Real Monasterio de la Trinidad (Valencia). Monumentos de la Comunidad Valenciana. Catálogo de Monumentos y Conjuntos declarados e incoados", Valencia, Arquitectura Religiosa (Valencia: Generalitat Valenciana 1995), 140-149.
} 


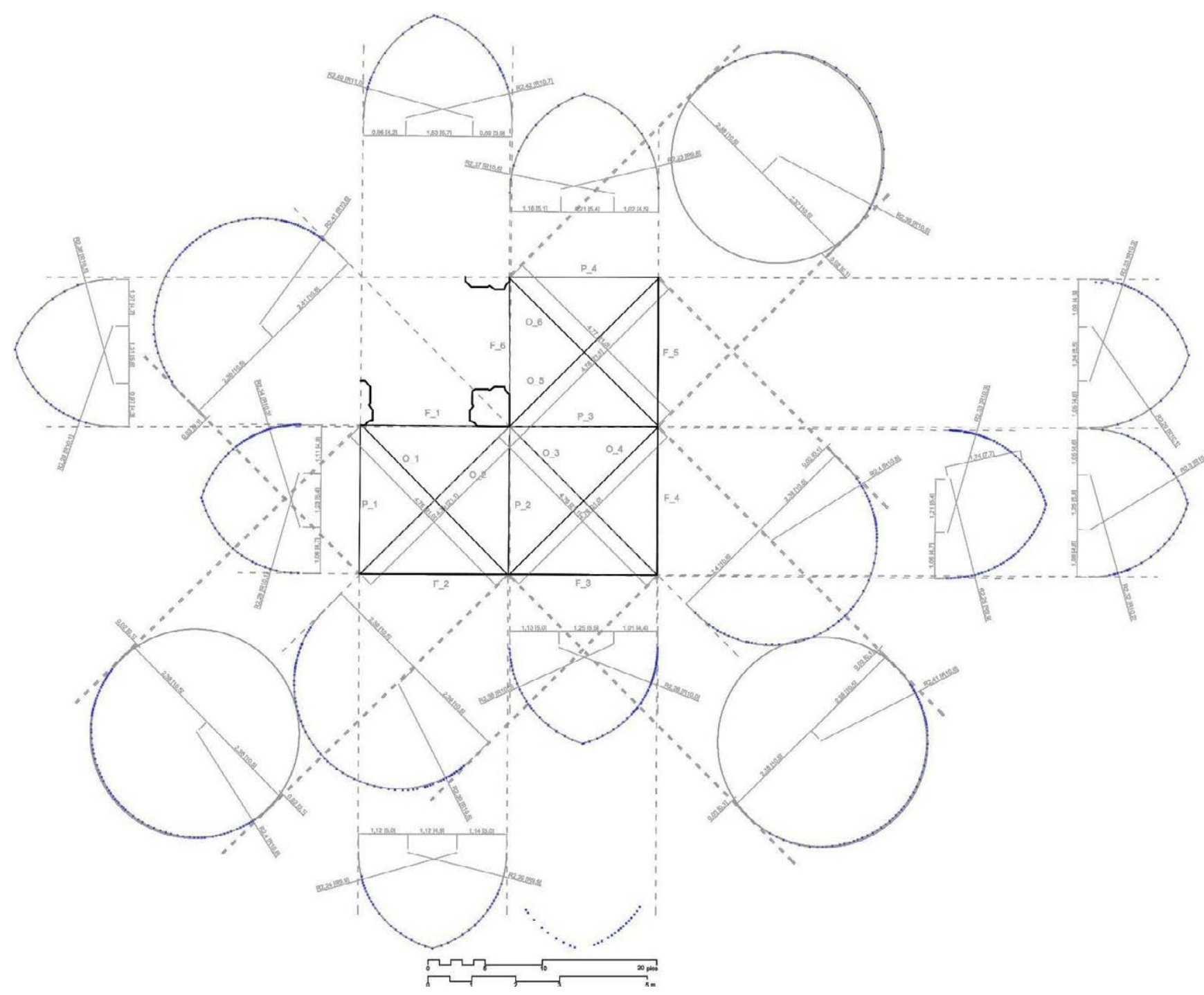

Fig. 106

Análisis de puntos de arranque y curvatura de los arcos en las tres bóvedas medidas en el monasterio de La Trinidad. datarse entre 1445 y $1453 .^{291}$

El claustro es de planta rectangular, de 9 por 10 pandas, compuesto por bóvedas de planta cuadrada cuatripartitas de 15 por 15 palmos. ${ }^{292}$ Se han medido las tres bóvedas de la esquina sureste. Los arcos perpiaños son apuntados y arrancan tangentes al muro. En la esquina, su eje coincide con el quiebro y todos tienen la misma dimensión y radio. El radio de los formeros es muy similar y todos arrancan del punto en el que el eje del perpiaño encuentra el muro. En La Trinidad hay tres tipos diferentes de enjarjes, los que salen directamente del muro, con cinco nervios convergentes; los de la esquina, de la que se salen siete nervios; y los de los rincones, donde se encuentran un ojivo y dos formeros.

A la vista parece un trabajo muy cuidado y perfecto. La ejecución no acusa algunos pequeños e imperceptibles ajustes. En efecto, los arcos ojivos no

${ }^{291}$ Arturo Zaragozá Catalán y Mercedes Gómez Ferrer, Pere Compte arquitecto, (Valencia: Ajuntament de València y Generalitat Valenciana, 2007).

292 el palmo valenciano es de 22,65 cm. 
son semicircunferencias perfectas, pues, aunque el radio del nervio en el enjarje y en la parte central del arco- es decir, en el conjunto de dovelas continuación del enjarje- es siempre la misma, se producen ajustes en el encuentro del enjarje con el resto del arco. Esto es debido a que la longitud del arco en planta no es siempre igual. Los ojivos que van a muro arrancan de un punto situado a cierta distancia del arranque de perpiaños y formeros, mientras que en el rincón arrancan precisamente del rincón y, en la esquina, de la esquina. Como consecuencia, los ojivos que van de muro a muro son más cortos que los que van de muro a esquina, o de esquina a rincón, que serían los mayores. También influye en este ajuste de los arcos el hecho de que las alturas de las hiladas no se mantienen, es decir, que unos arcos arrancan ligeramente más altos que otros.

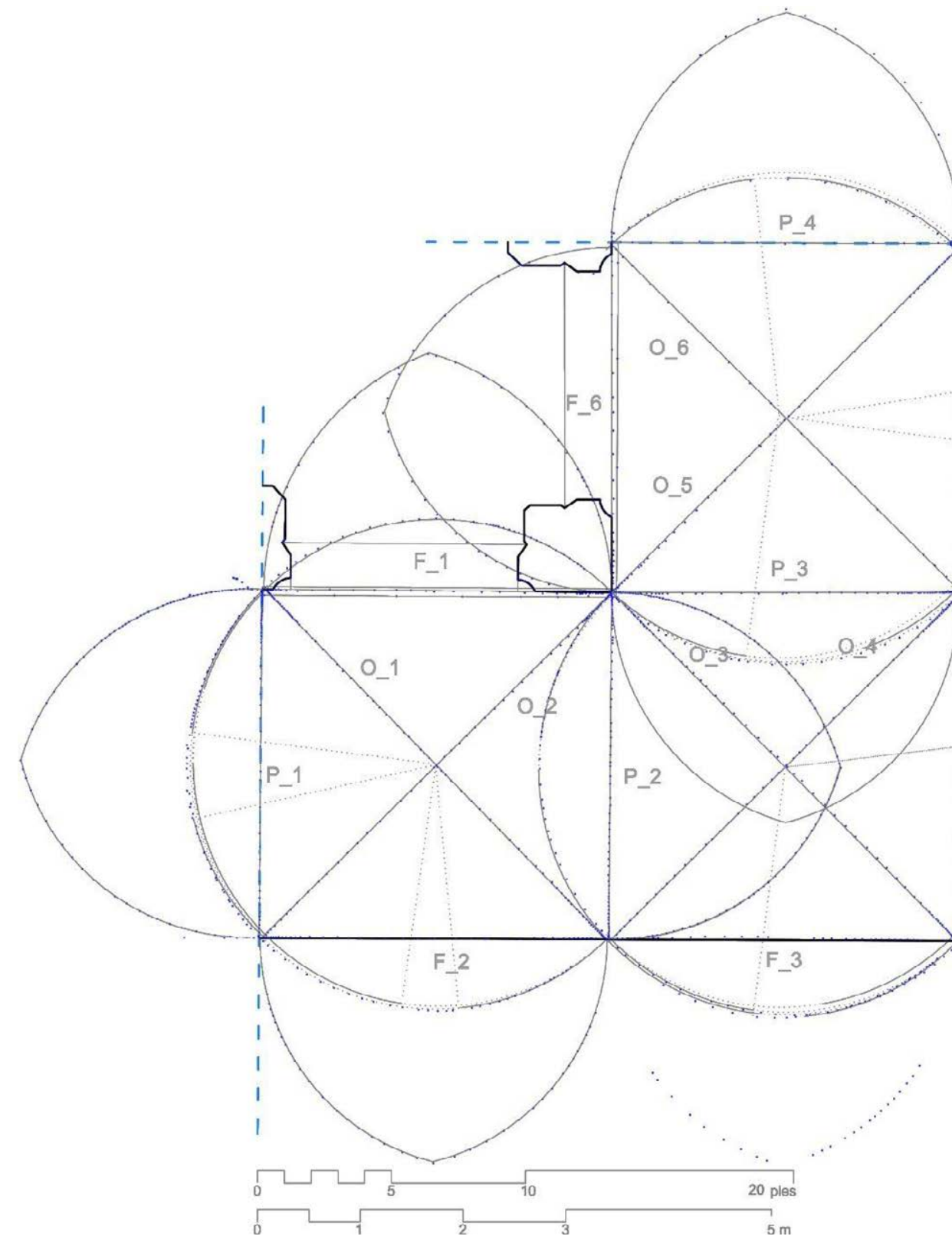

Esta estrategia muy sencilla de ajuste mediante un pequeño quiebro a partir del enjarje es imperceptible a la vista y permite resolver y solucionar
Fig. 107

Ajustes en los arcos tras el enjarje en el monasterio de La Trinidad. 


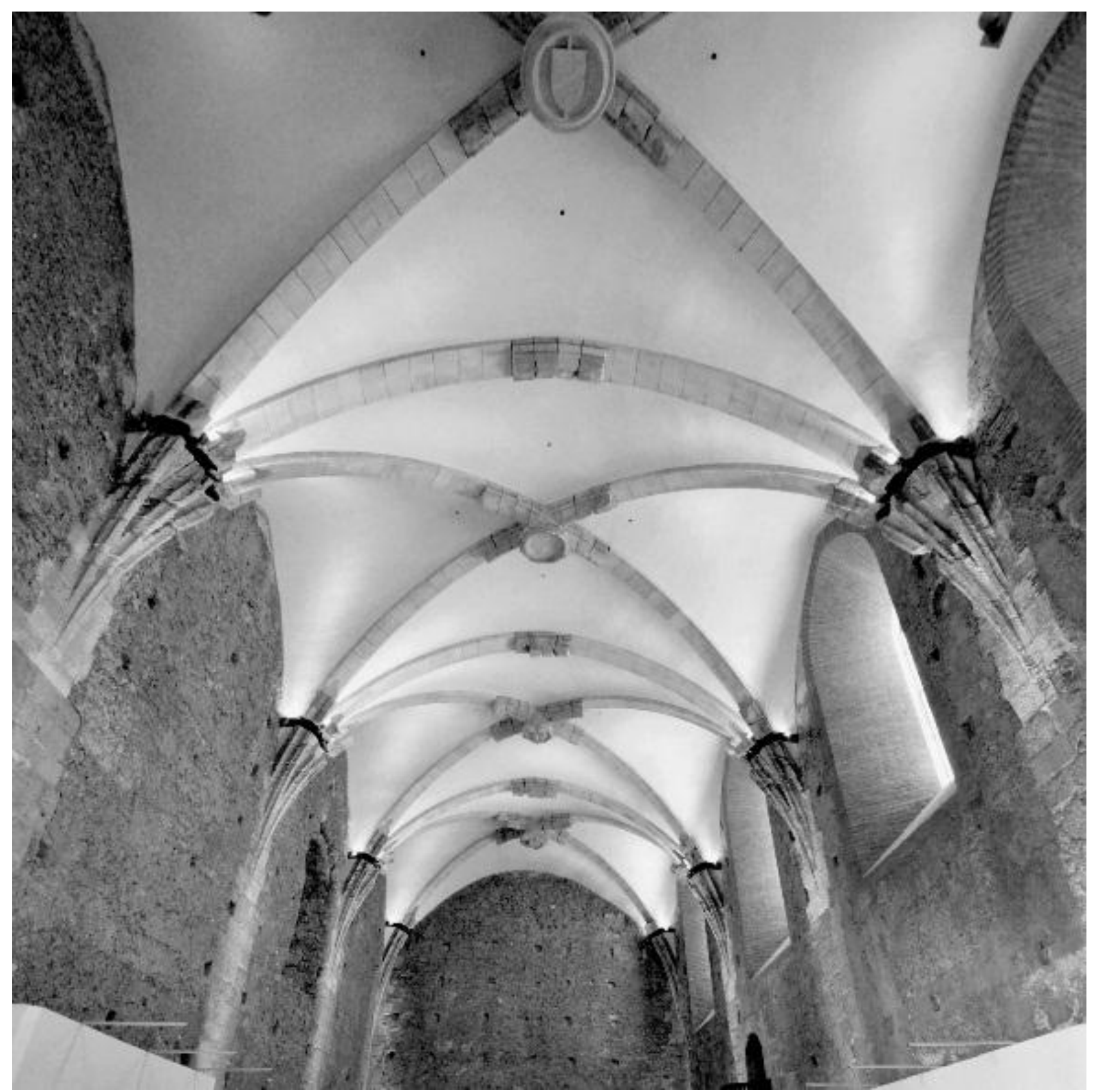

pequeños ajustes constructivos de manera sencilla y práctica.

Fig. 108

Refectorio de Santa María de la Valldigna.
Refectorio de Santa María de la Valldigna

El monasterio de Santa María de Valldigna fue fundado por el rey de Aragón Jaime II El Justo en 1298. Tiene una larguísima historia de destrucciones y renovaciones. Adquirido por la Generalitat Valenciana, está actualmente en proceso de estudio y de restauración. El refectorio, que tenía las bóvedas hundidas, ha sido reconstruido aprovechando que se mantenían en su lugar los enjarjes en los muros y en el suelo parte de las dovelas y de las claves. Estas últimas llevaban los escudos de Aragón y de Castilla y León, 

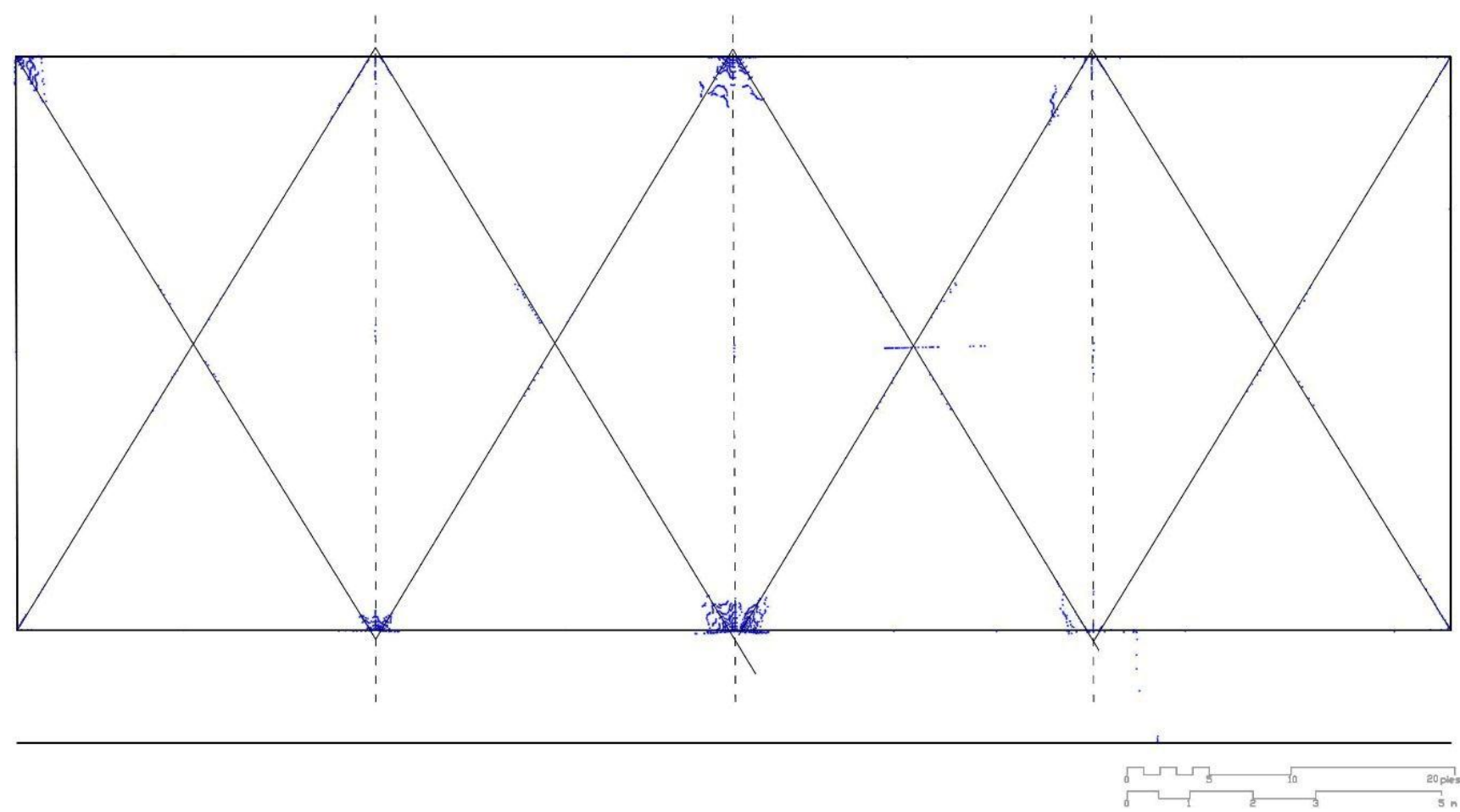

hecho que abonó la atribución de su construcción al abad Juan de Aragón $(1460-1475){ }^{293}$

No obstante, otras noticias documentales, señalan que hacia 1448 se trabajaba en la renovación del refectorio. ${ }^{294}$ Los escudos que ostenta la sala coinciden también con los de la reina María de Castilla, consorte del rey de Fig. 109

Planta esquemática con los puntos medidos en el monasterio de Santa María de la Valldigna. Aragón Alfonso el Magnánimo, por lo que podría adelantarse la datación del inicio de la construcción en unos años. En cualquier caso, la escalerilla de la tribuna del lector, que asciende por el grueso del muro de tapia, es un muestrario de estereotomía moderna realizada en piedra. Esta tribuna y otros detalles, junto con las fechas que suministran los documentos y la heráldica remite al momento central y a las características de la obra de Francesc Baldomar. De hecho, el carácter monumental del refectorio podría ser una obra de patronato real en el que interviniera el maestro de las obras reales en ese momento. ${ }^{295}$

El refectorio es de planta rectangular y está cubierto por cuatro bóvedas cuatripartitas. La proporción en planta del lado largo es de dos veces y

\footnotetext{
293 J. Toledo Girau, "El monasterio de Valldigna y sus abades comendatarios", Boletín de la Sociedad Castellonense de Cultura, (Castellón de la Plana, 1946); José Manuel Martínez García, Guía del monasterio de Santa María de Valldigna, (Simat de Valldigna, 1998).

${ }^{294}$ Ma Desamparados Cabanes Pecourt, Monasterios Valencianos, (Valencia: Universidad de Valencia 1974).

295 Arturo Zaragozá Catalán, Arquitectura Gótica Valenciana, (Valencia: Generalitat Valenciana. 2000).
} 

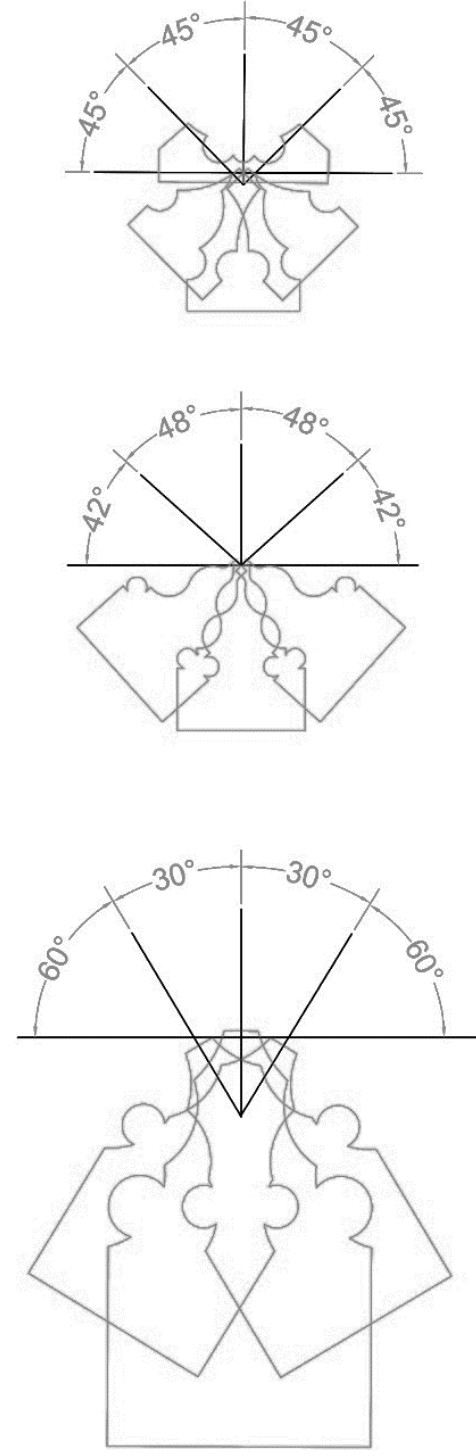

Fig. 110

Ángulos entre los ejes de los nervios y posición de las plantillas en su arranque. Trinidad, Valdecristo y Valldigna. medio el corto, es decir, 100 por 40 palmos (22,7 por 9,12 m). En Valldigna hay seis enjarjes iguales en los muros de mayor longitud, de los que sale un perpiaño y dos nervios ojivos; y dos iguales en las esquinas, de las que sólo sale el nervio ojivo. No hay nervios formeros.

\section{$\underline{\text { Tres enjarjes similares, tres diseños diferentes }}$}

Los tres edificios se caracterizan por la utilización de una solución muy concreta y poco común en el comienzo de las bóvedas. Éstas son cuatripartitas, no presentando gran dificultad técnica, por lo que los esfuerzos formales y de diseño se centran en el enjarje, con unos nervios que parecen brotar como en ramillete del muro, de manera sencilla confluyendo en un punto. A pesar de que en un primer momento los tres casos puedan parecer iguales, cuando se estudia con precisión su geometría y sus detalles, las diferencias son notables.

Diseño en planta

Valdecristo y Valldigna están resueltos con bóvedas de planta rectangular, mientras que en La Trinidad las bóvedas son cuadradas. En este claustro, los nervios ojivos forman un ángulo de $45^{\circ}$ con formeros y perpiaños, encontrándose el punto de confluencia de sus ejes con los del perpiaño dentro del muro. En Valdecristo, los ojivos forman un ángulo de $42^{\circ}$ con los formeros y de $48^{\circ}$ con los perpiaños y todos confluyen en un punto que se sitúa precisamente en el contacto con el muro. Por el contrario, en Valldigna y, al tratarse de bóvedas rectangulares con mayor diferencia entre el lado mayor y menor que en Valdecristo, los ángulos se acentúan. Los ojivos forman $60^{\circ}$ con el muro y $30^{\circ}$ con el perpiaño. En este caso la confluencia de los ejes también se realiza dentro del muro.

Caso particular presenta el enjarje de la esquina de la Trinidad, donde todos los nervios confluyen precisamente en la esquina. Es decir, se deja atrás todo el orden seguido en el claustro; las intersecciones de los ejes de los nervios ya no se localizan dentro del muro, sino que se llevan al punto de quiebro de la línea del muro. Todos los nervios forman un ángulo de $45^{\circ}$ entre sí.

Arranque de los nervios

El lugar de arranque de cada uno de los nervios del enjarje es un aspecto problemático a estudiar a la hora de abordar su diseño, ya que puede coincidir o no con algún punto notable, como la confluencia de ejes, el contacto con el muro, etc., y se ha comprobado que a la más mínima 

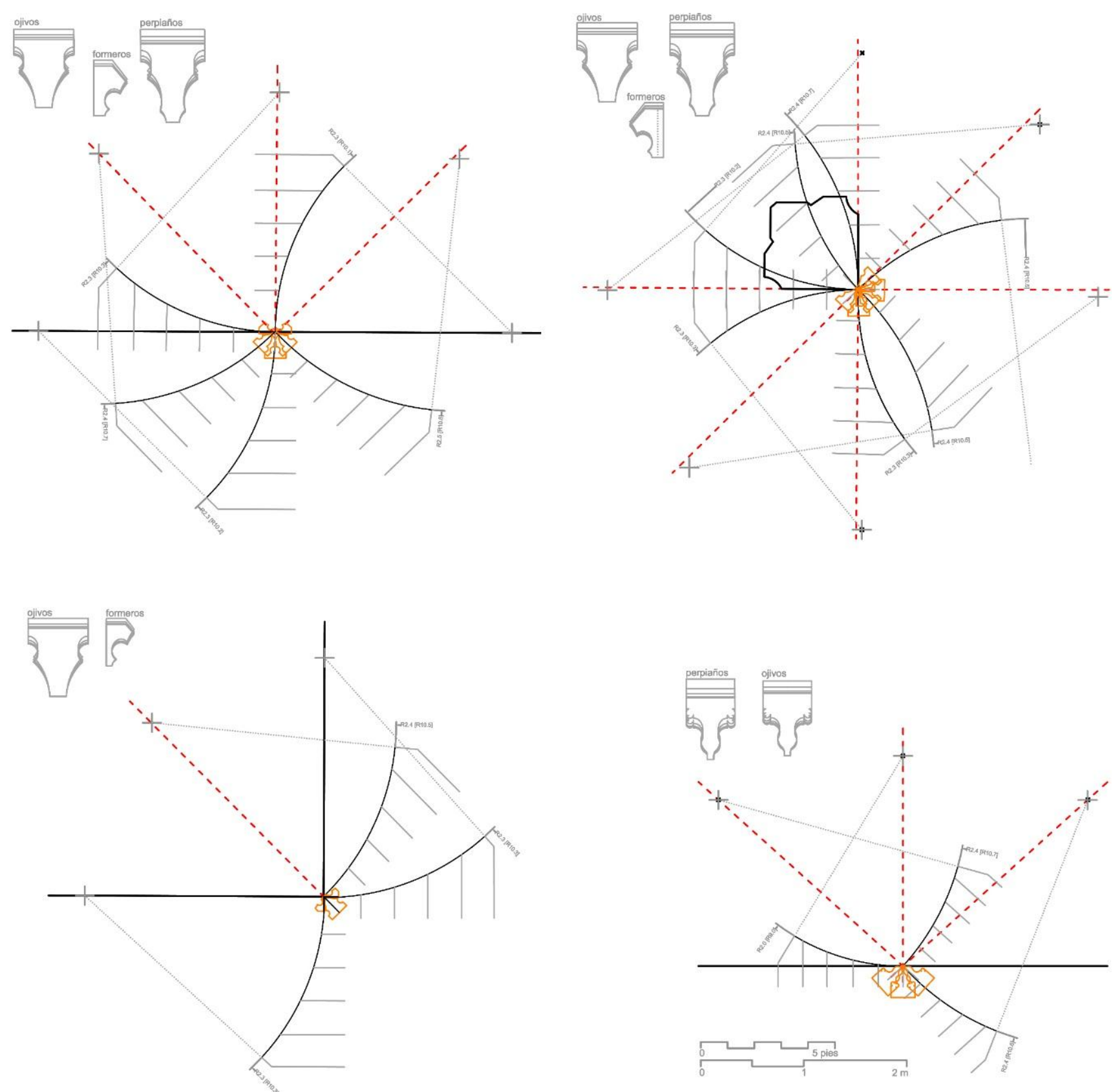

variación de su posición, el resultado formal del enjarje no es el deseado. Por lo tanto, de su precisión depende el obtener un enjarje con una forma más o menos armoniosa, o con intersecciones más o menos complicadas de labrar, etc.

En este sentido, el enjarje de Valdecristo es de gran claridad conceptual. Todos los nervios salen del mismo punto y del mismo nivel situado en la Fig. 111 Posibles monteas para los enjarjes del monasterio de La Trinidad: enjarje del muro, enjarje de la esquina y enjarje del rincón. Abajo a la derecha posible montea para el enjarje base de la primera pieza del enjarje. Sin embargo, el enjarje del muro de la del claustro de Valdecristo. Trinidad presenta una mayor complejidad. Los perpiaños salen del contacto de su eje con el muro en la base del enjarje. Los formeros también salen con esa misma referencia, el eje de perpiaño con el muro, pero en la mitad de la primera pieza. Esto es bastante singular, ya que normalmente los maestros aprovechan las juntas del enjarje para situar las plantillas y, como parece lo más lógico, localizar también en ellas los arranques de los 
Fig. 112

Modelado de los enjarjes tras las hipótesis geométricas y cotejo con los puntos tomados. Arriba: monasterio de La Trinidad. Abajo a la izquierda: claustro de Valdecristo. Abajo a la derecha: Refectorio de Valldigna.

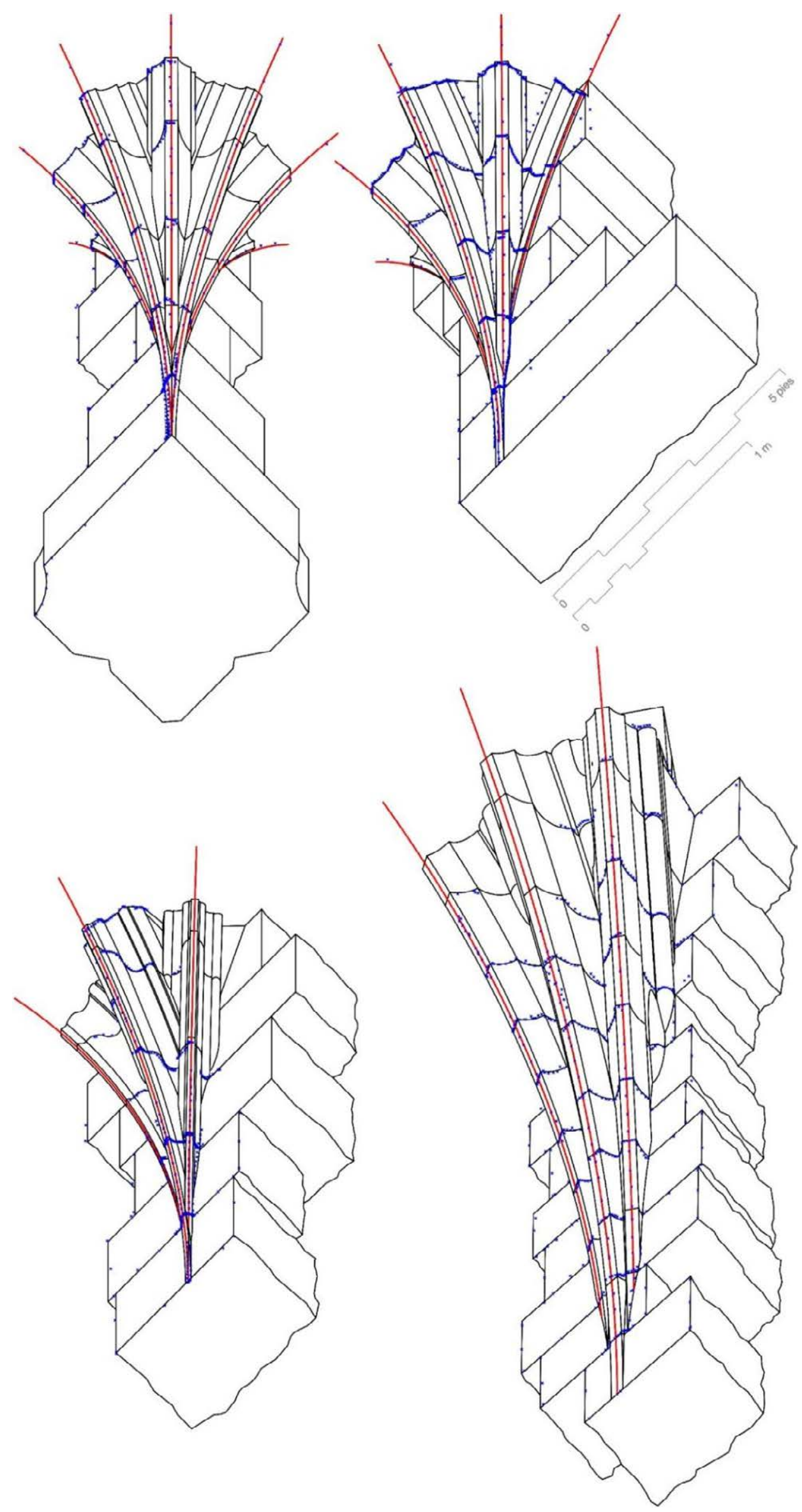



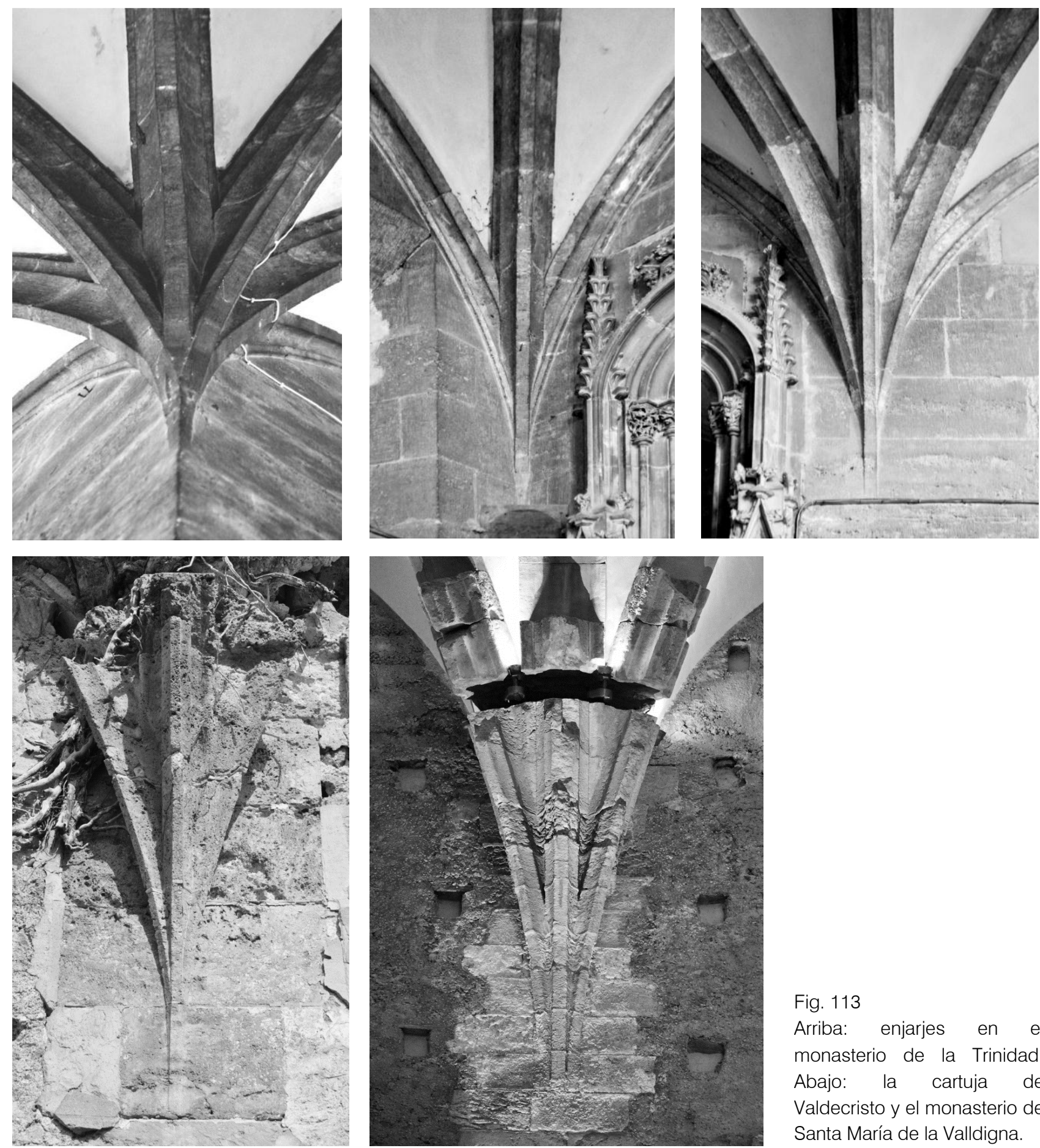

Fig. 113

Arriba: enjarjes en el monasterio de la Trinidad. Abajo: la cartuja de Valdecristo y el monasterio de Santa María de la Valldigna.

$\operatorname{arcos}$

Situar estos comienzos en la posición intermedia de una pieza no es habitual. Por otra parte, de ese nivel salen también los ojivos, lo que nos lleva a imaginar la posible realización de una maqueta con mayor número de cortes que el enjarje ejecutado en piedra, de la que fuesen tomando medidas.

La posición de la plantilla de los ojivos tampoco es la que podría esperarse: no se sitúa en la concurrencia de los ejes de los ojivos, ni en el contacto de 

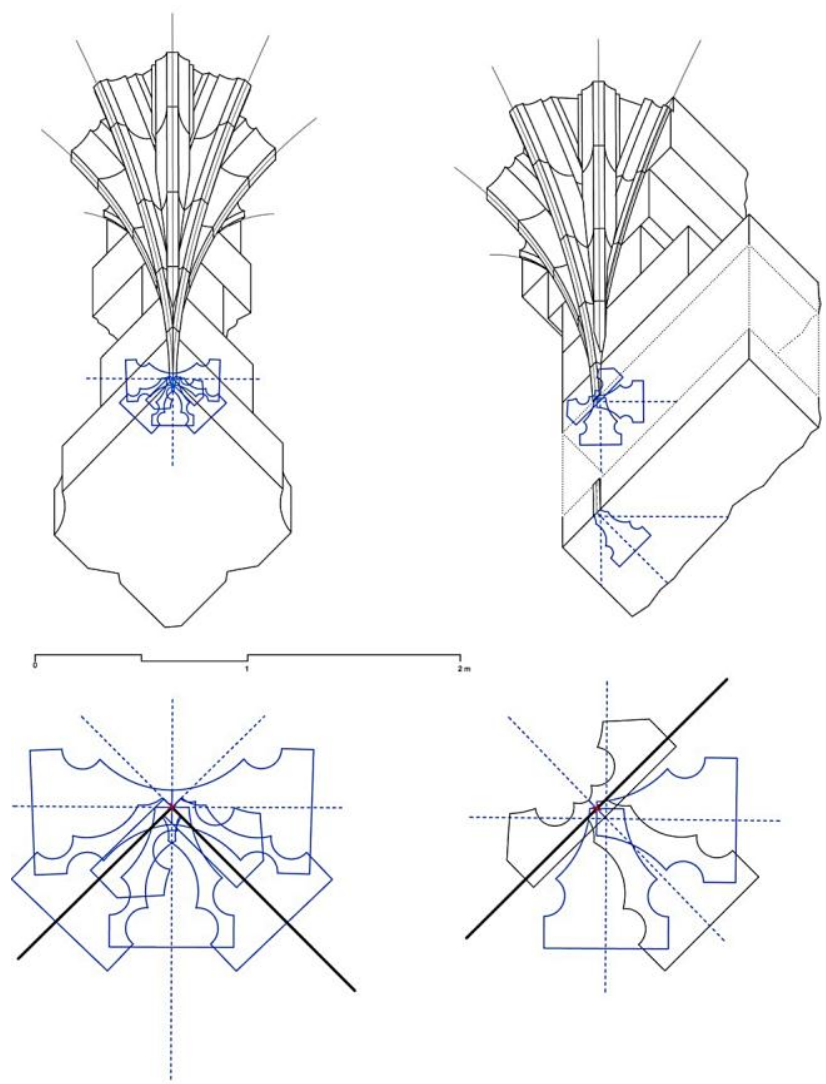
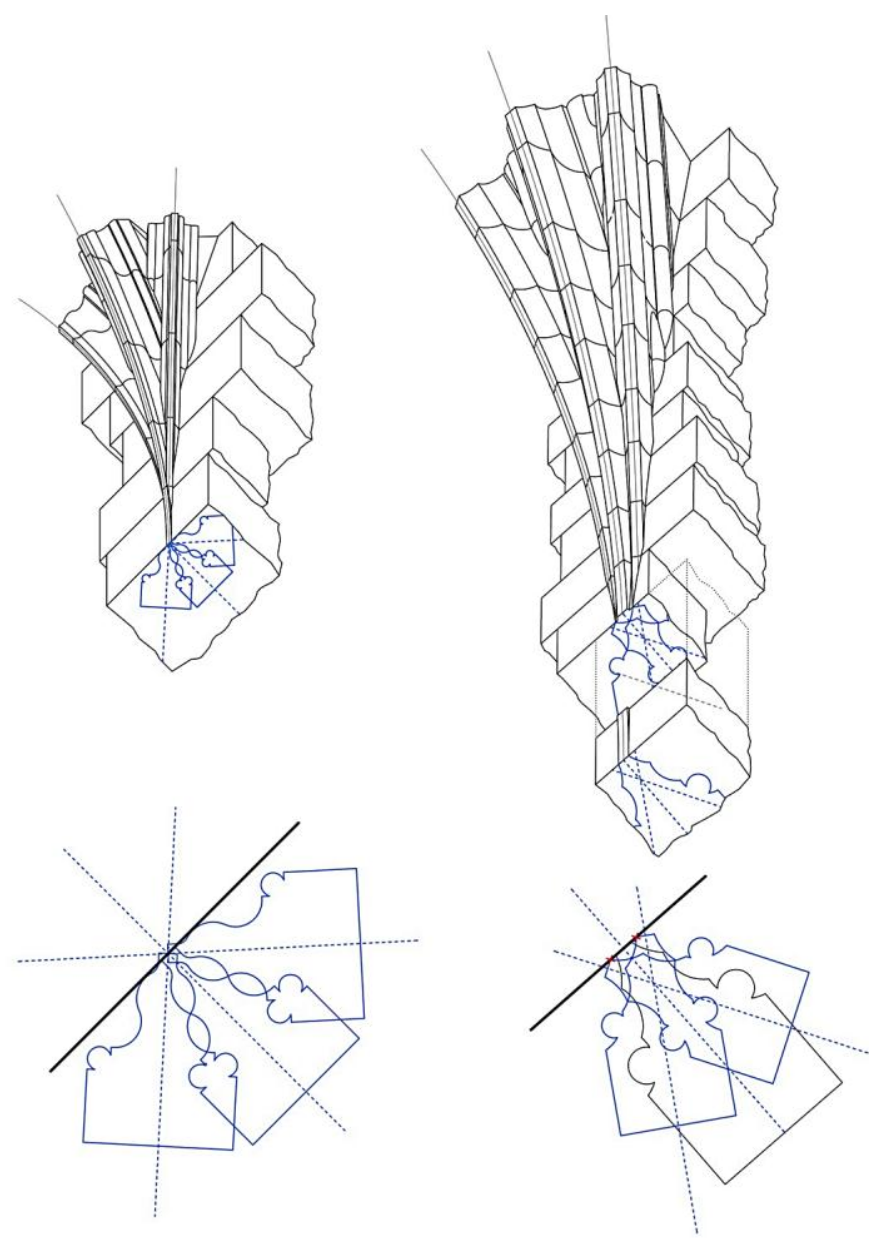

Fig. 114

Situación del arranque de las plantillas en cada uno de los casos. los mismos con el muro. La estrategia seguida es compleja, ya que se desplaza la plantilla en el eje del ojivo hasta que la línea de su intradós coincide con el cruce formado por el eje del perpiaño y el muro. Detrás de esta decisión puede encontrarse el deseo del maestro cantero de que los nervios ojivos aparezcan en la segunda pieza del enjarje de modo que no lleguen a tocar el intradós del perpiaño; y su intersección con él y el muro forme un triángulo muy esbelto que llega hasta la junta. Se han probado otras posibilidades, pero desplazando la plantilla simplemente $1 \mathrm{~cm}$ el resultado de la intersección no es el mismo. En el enjarje de la esquina de La Trinidad, sin embargo todos los nervios nacen de la base de la primera pieza, del punto de la esquina. En este caso, si se hubiesen elevado los arranques de los ojivos no parecería que todos los nervios van a un punto y el resultado hubiese sido extraño.

En el refectorio de Valldigna el nervio perpiaño arranca de la base del enjarje, desde el punto de contacto del eje con el muro, mientras que los ojivos arrancan a partir de la primera junta, entre la primera y la segunda pieza. En vez de disponer la línea de intradós de la plantilla en relación con el punto de convergencia de los ejes de los ojivos dentro del muro o en el contacto de los mismos con el muro, se desplaza la plantilla por el eje del ojivo hasta que ese borde del intradós hace contacto con la línea del muro. 

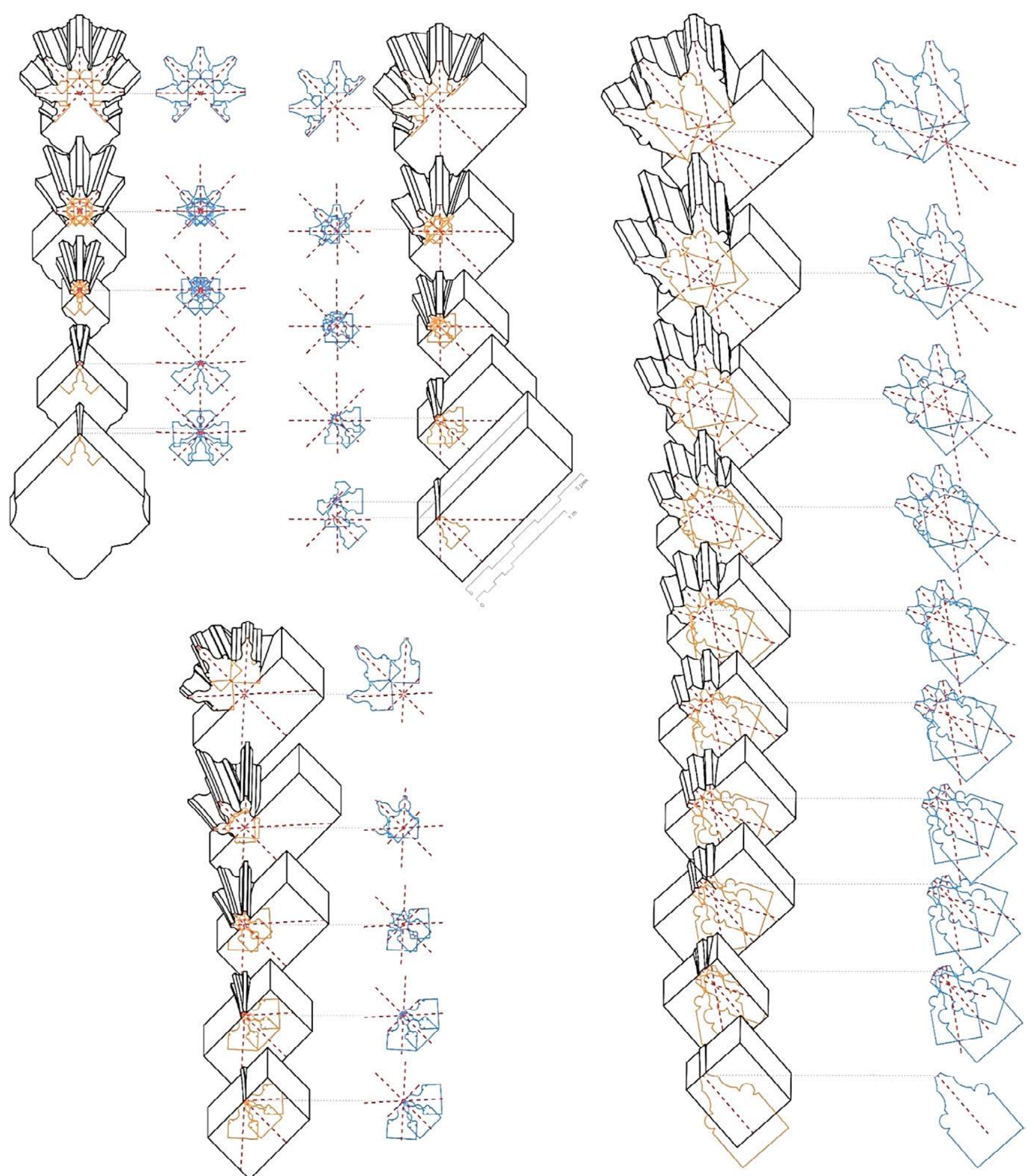

Perfiles

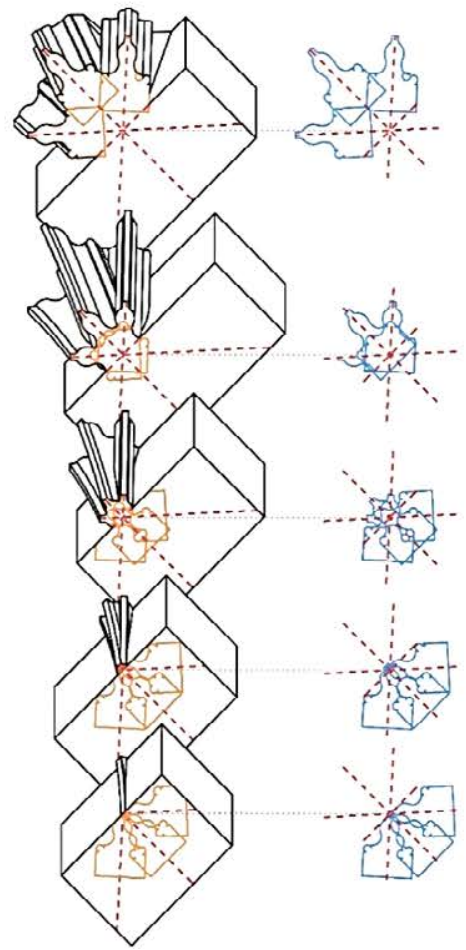

Fig. 115

El trazado, el tamaño y proporción de los perfiles de los tres edificios son

Situación de las plantillas y ejes de los nervios en cada uno de los lechos. Arriba a la izquierda, enjarje de la esquina y enjarje del muro en el monasterio de La Trinidad. Derecha: enjarje de Valldigna. Abajo a la izquierda: enjarje en Valdecristo. todos los arcos tienen el mismo perfil, con un filete estrecho $(3 \mathrm{~cm})$ en el intradós, un juego de curva y contracurva y un baquetón al final. La Trinidad presenta un perfil que prescinde de baquetones y se compone a base de concavidades; los perfiles son diferentes según cada nervio, el perpiaño está compuesto de tres concavidades, el ojivo de dos, y el formero tiene 
también dos, con la peculiaridad de que el final de la moldura acaba con una pequeña inclinación. Valldigna es una mezcla entre estos dos edificios, con un comienzo de moldura con dos concavidades y luego un baquetón. El perfil de ojivos y perpiaños es similar, aunque uno es mayor que el otro.

Trabajo por niveles

Para construir un enjarje se realiza primeramente una montea, en la que quedan definidas la curvas de los arcos, de dónde arrancan y los niveles en que será ejecutado. De esa montea también se pueden extraer medidas para elaborar las plantillas de los perfiles de los nervios según niveles. En un enjarje, al no cortar el nervio radialmente como en el resto del arco, las plantillas deben sufrir deformaciones, que van siendo mayores en las juntas superiores. A continuación, se empiezan a trabajar las piezas, colocando las plantillas correspondientes a cada lecho, situándolas más alejadas del muro y sus referencias iniciales según se va ascendiendo. Este trabajo por niveles es necesario para controlar qué nervios aparecen en cada nivel o, todo lo contrario, para suprimir parte de la moldura evitando así resultados formales indeseados. En los enjarjes valencianos hay partes de molduras eliminados debido a que su presencia haría confusa la precepción del conjunto y, por otro lado, hay partes de molduras que permanecen y cuya presencia no está justificada.

En los tres edificios se eliminan restos de ojivos en la primera pieza de los enjarjes ya que, si se siguiese el trabajo con plantillas de manera exhaustiva, aparecerían partes de estos nervios en el intradós de los perpiaños. En el enjarje de la esquina de La Trinidad que hemos medido quedan estos restos. Puede tratarse del primer enjarje de esquina que se ejecuta en el claustro, ya que en el resto se suprimen.

En el enjarje de Valdecristo, además, se suprime una parte de la moldura del nervio perpiaño que pasaría a través del ojivo y se encontraría con el muro. Es eliminada, presumiblemente, para propiciar una intersección más clara entre los ojivos y el muro. Y para también evitar resolver complejas intersecciones de molduras en el proceso de labra. Esto no pasa, sin embargo, en Valldigna, donde sí que aparece un resto de la moldura del perpiaño encontrándose con el muro tras atravesar el nervio ojivo. Ocurre precisamente en el sexto nivel del enjarje y supone la ejecución por parte del cantero de una intersección compleja, ya que este resto es parte del baquetón de la moldura del perpiaño e interseca la segunda concavidad del ojivo y parte de su baquetón.

El uso de plantillas deformadas es necesario dependiendo de la altura del nivel y el tamaño de la bóveda. Sería posible no realizar plantillas para los primeros niveles de los enjarjes estudiados, hasta que se produce el primer cambio en el perfil, es decir, cuando aparece la segunda concavidad. El ejemplo de Valldigna, con un enjarje de gran tamaño y unas bóvedas muy 

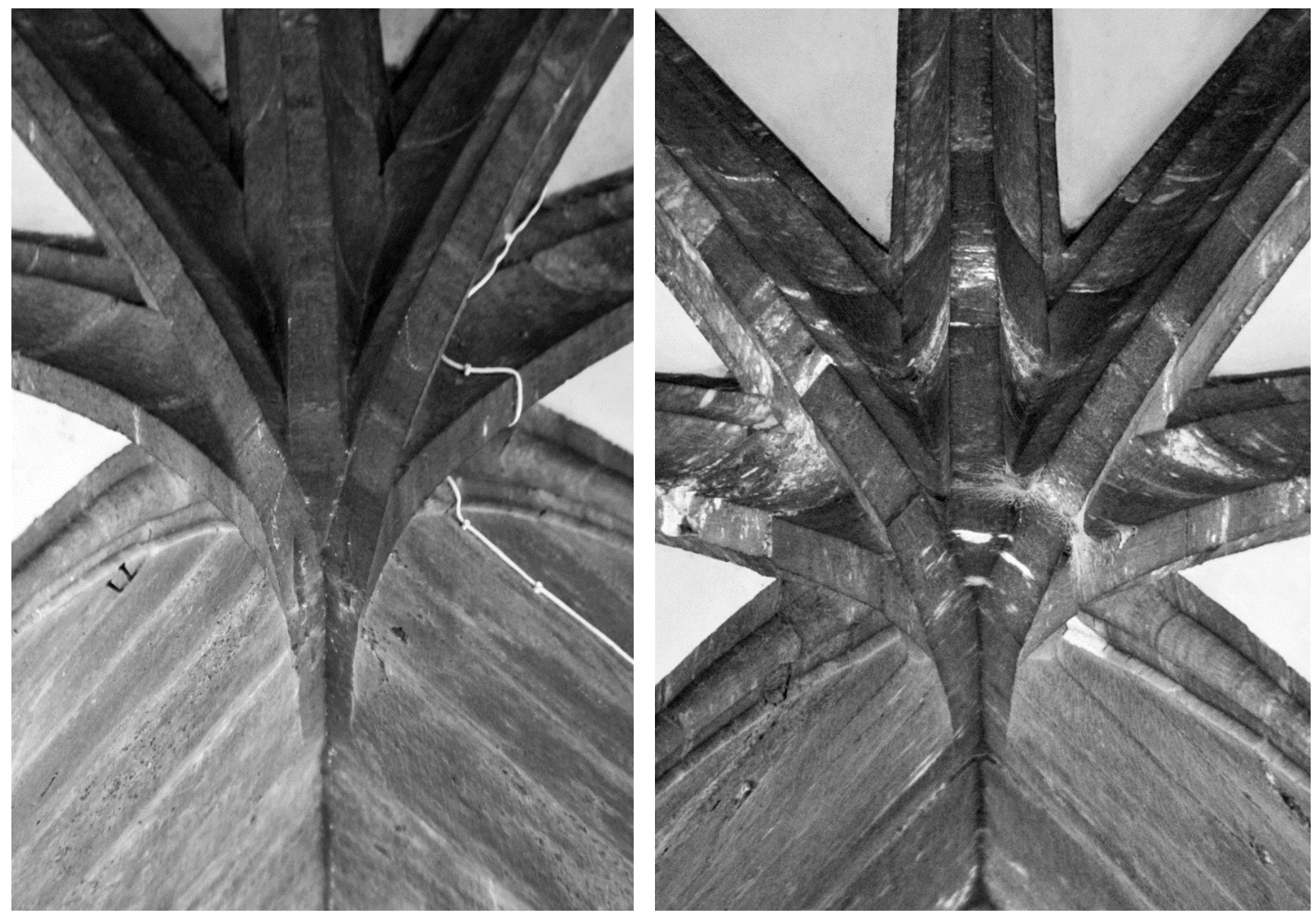

grandes, podría propiciar incluso el uso de la plantilla sin deformar en algún nivel superior más.

\section{Altura de hiladas}

Los enjarjes de La Trinidad están compuestos por 5 piezas, con una altura de hiladas variable en el muro pero bastante homogénea en la esquina. Los tres tipos de enjarje de este claustro no se corresponden en altura. En Valdecristo, los enjarjes del muro están también compuestos de 5 piezas, con alturas de hiladas homogéneas. El caso de Valldigna es el que presenta más peculiaridades, ya que todos los enjarjes tienen la misma altura de hiladas, pero no son homogéneas. Prácticamente todas las piezas del enjarje tienen la misma altura, menos las piezas 5,7 y 8 , de altura menor.

Soluciones para la última pieza

La última pieza del enjarje es aquella en la que se talla en la parte superior los nervios la inclinación precisa para recibir las primeras dovelas del arco. Lo más común es disponer en esos planos inclinados la plantilla completa, y a partir de su línea de trasdós cortar en horizontal. El enjarje de Valldigna presenta una solución especial, con un antecedente similar realizado por Guillem Sagrera en Mallorca. Es posible que quien proyectara el refectorio de Valldigna conociese la solución de Sagrera, pues forzarse a terminar el

Fig. 116

A la izquierda, restos de molduras en el enjarje de la esquina del monasterio de La Trinidad. A la derecha, resto de las esquinas sin ellos.

Abajo: Solución para la última pieza en Valldigna.

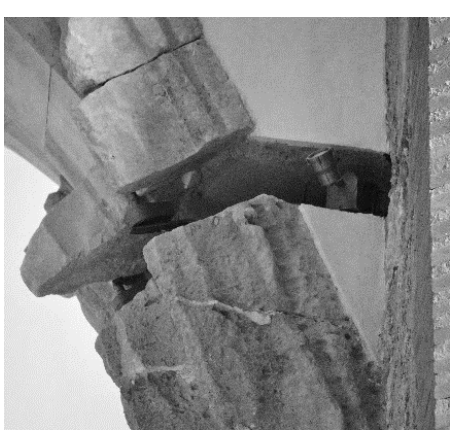




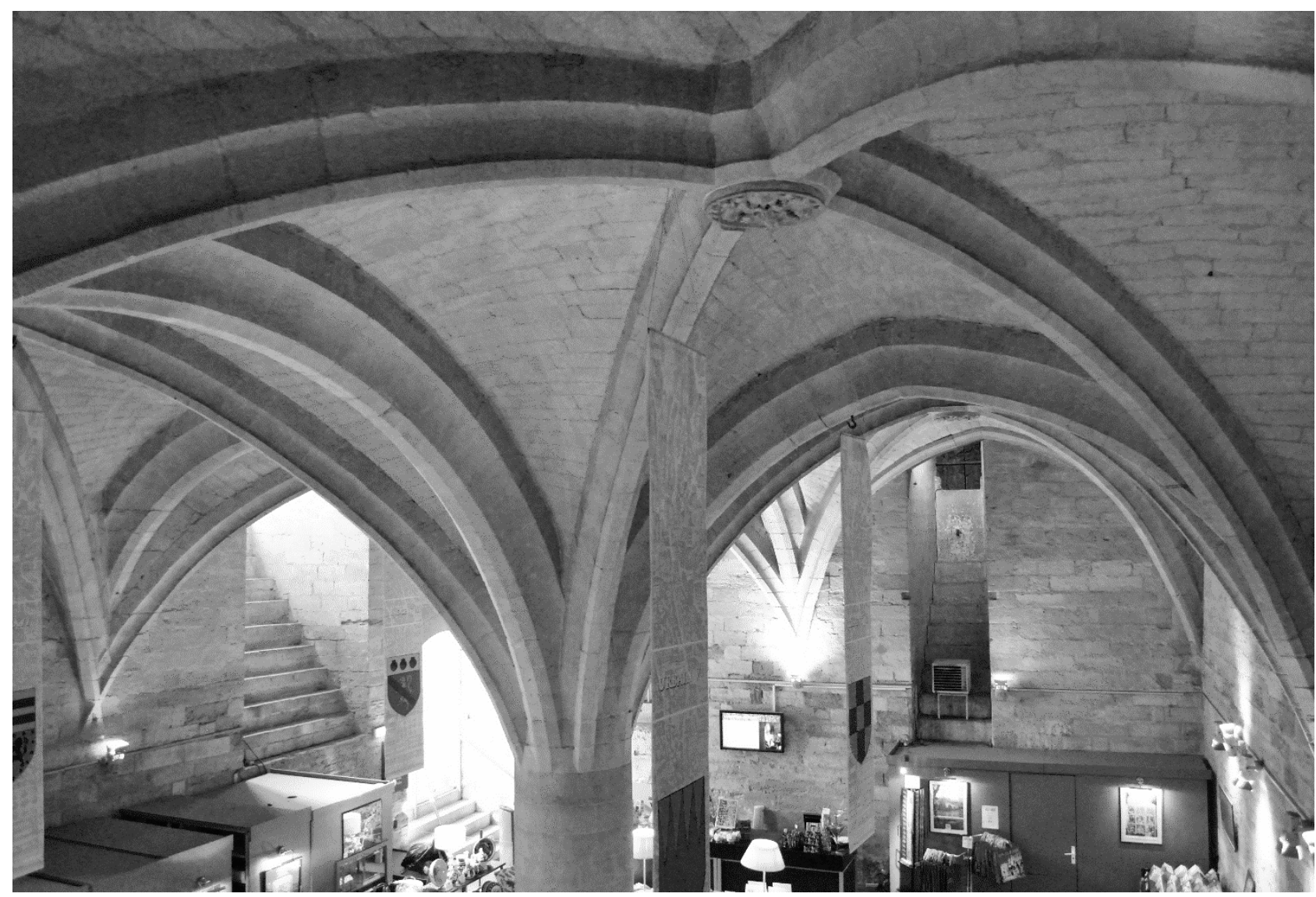

Fig. 117

Sala de Teología del Palacio de los Papas de Aviñón. enjarje de esta manera acarrea más complicaciones que hacerlo de un modo más convencional. ${ }^{296}$

3.2.2. Variaciones sobre el trabajo con plantillas en uno de los primeros cruzamientos de molduras: la Sala de Teología del Palacio de los Papas en Aviñón

Un paso importante en el desarrollo del diseño de enjarjes lo encontramos en la Sala de Teología del palacio de los Papas en Aviñón. En ella hay soluciones distintas de enjarjes en cada uno de los dos lados, en ambos casos con intersecciones de nervios con perfiles sencillos, que evidentemente no son casuales, sino muy meditadas. Es el primer ejemplo en el que aparentemente se cruzan los nervios, o al menos las molduras de sus perfiles, como precisaremos más adelante.

En estos ejemplos y otros posteriores surgen dos cuestiones a contestar: hasta qué punto manda el diseño de la bóveda o el del enjarje; y hasta qué punto los pequeños detalles a los que la intersección de los nervios da lugar son previstos con antelación, es decir, el tipo de control o previsión del resultado. 


\section{Metodología}

Se ha realizado la medición de la sala de teología del Palacio de los Papas de Aviñón con una estación total Leica FlexLine TS02. Se han tomado datos de la planta del edificio, las curvas de los arcos, con mayor densidad en la zona del enjarje, puntos siguiendo las juntas de las piezas de los enjarjes, desplomes y perfiles de los nervios.

La medición del enjarje presenta dificultades debido a que en ocasiones las juntas están muy deterioradas o hay dificultad para poder verlas por completo. En el caso de la sala de teología, las piezas se encuentran bastante bien conservadas, a excepción de los enjarjes del muro norte; además puede apreciarse en estos que alguna pieza del enjarje está ligeramente desplazada con respecto a la anterior, probablemente debido a imprecisiones durante la puesta en obra.

Obtenida la nube de puntos, los enjarjes ha sido modelados mediante Rhinoceros v.4. En el proceso hay que trabajar conjuntamente con las curvas de los arcos y las hiladas horizontales, intentando que ambas se ajusten lo más posible al modelo 3D del enjarje una vez se haya extruido el perfil del arco. Mediante el modelado hemos cotejado las hipótesis geométricas enunciadas.

\section{Sala de Teología del Palacio de los Papas}

La Sala de Teología del Palacio de los Papas de Aviñón fue edificada en tiempos del papado de Clemente VI por el arquitecto Jean de Louvres, quien estaba al cargo de la ampliación del palacio y de las obras para la realización de la nueva "Grande Audience". Bajo ella se sitúa la sala de teología, permitiendo salvar el gran desnivel de terreno que existe con el exterior. Los trabajos en la sala comenzaron en 1344, y en un año las obras en la sala habían acabado. A pesar de ello, parece ser que en 1346 se realizaron nuevos trabajos que tendrían como finalidad un nuevo acondicionamiento del sitio. ${ }^{297}$

297 S. Gagnièrey J. Granier, Les Fouilles de la Salle de Théologie au Palais des Papes d'Avignon, (Avignon: Aubanel, 1969), 4; Dominique Vingtain, Avignon: Le Palais des Papes, (Saint-Léger-Vauban: Zodiaque, 1998), 202, Dominique Vingtain, "Rapide aperçu du développement chronologique du Palais des Papes au XIVe siècle", Monument de l'Histoire. Construire, reconstruire le Palais des Papes XIV-XX siècle, (Avignon, 2002): 23-28; Philippe Bernardi, "Un chantier médiéva"I, Monument de l'Histoire. Construire, reconstruire le Palais des Papes (XIVe-XXe siècle), (Avignon, 2002): 47-53; Dautrey, "Les chantiers de 1344-1345 à travers leurs comptes", Monument de l'Histoire. Costruire, reconstruire le Palais des Papes Papes (XIVe-XXe siècle), (Avignon, 2002): 41-46. 
La sala está concebida en pies de Aviñón, con una planta rectangular de 47 por 34 pies y medio (15,5 por 11,4 metros) o 63 por 46 palmos. El espacio está cubierto por cuatro bóvedas cuatripartitas rectangulares cuyos nervios descansan directamente en los muros perimetrales y en un consistente pilar cilíndrico situado en el centro de la sala de 3 pies de diámetro.

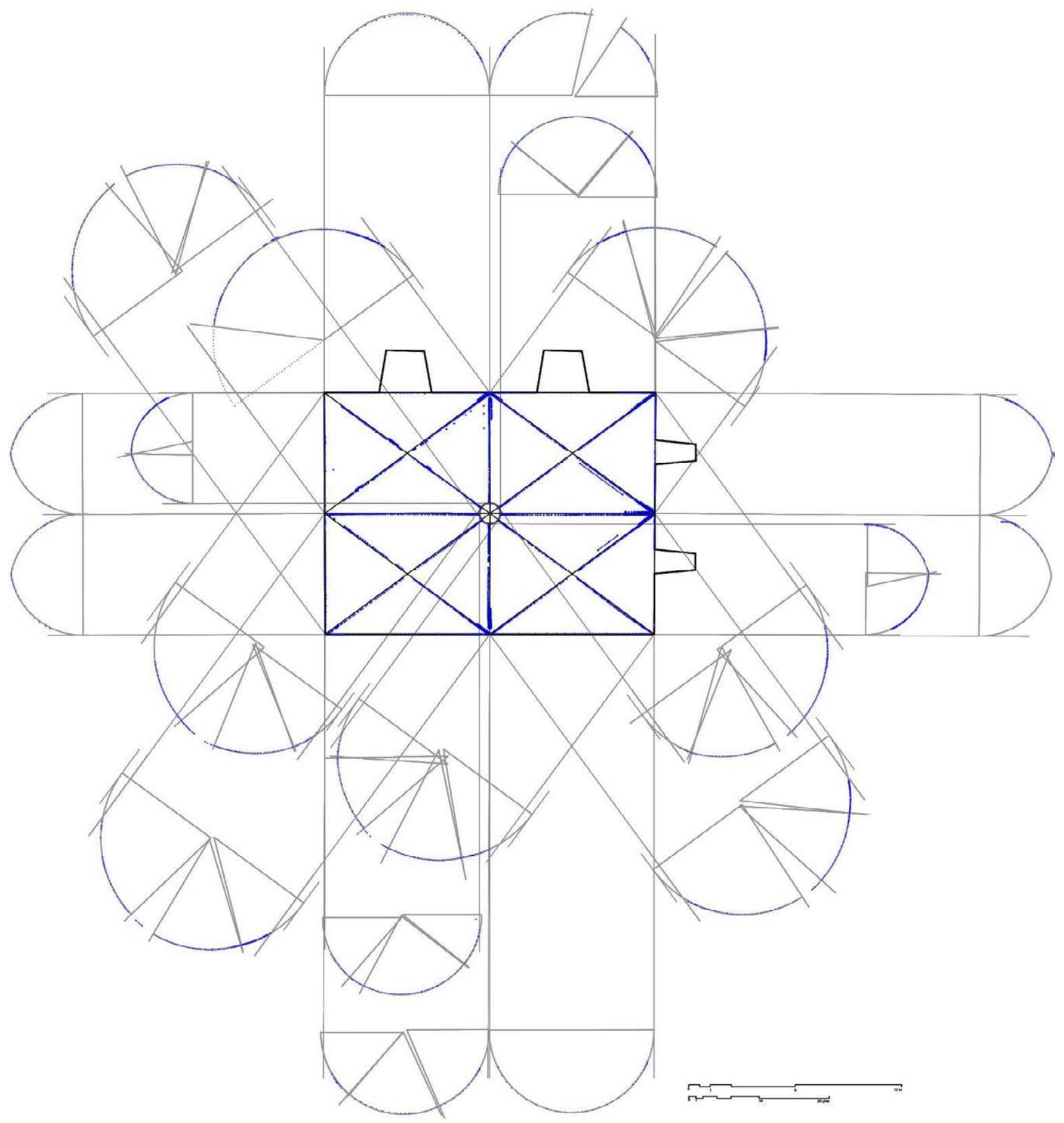

Fig. 118

Análisis de la geometría de la planta y de las curvas de los arcos.
La configuración en planta de los ejes de los nervios es muy ordenada. Los nervios perpiaños dividen la sala en cuatro partes, cruzándose sus ejes en el centro del pilar central. Los ejes de los ojivos unen las esquinas de los rectángulos definidos por los perpiaños. De este modo, nos encontramos con un diseño en planta de los enjarjes, tanto para el lado mayor de la sala como para el menor, en el que las líneas directrices de los nervios convergen, en planta, en un punto situado precisamente en el muro. 
Tras el análisis de la curvatura de los nervios, se ha podido comprobar que se produce el mismo fenómeno que en el monasterio de La Trinidad en Valencia. Los arcos no son semicircunferencias perfectas, pues, aunque la curva en el enjarje y en las partes del arco hasta la clave son siempre las mismas, se producen ajustes en el encuentro del enjarje con el resto del arco. Estos ajustes son consecuencia de la diferencia de longitudes de los arcos ojivos en planta.

Los ojivos que van del centro de un muro al centro del otro muro son más largos en planta que los que van del rincón al pilar central, debido a que el grosor de este aconseja no llevar el arranque hasta el centro de la planta. Además, el arranque de todos los ojivos se produce aproximadamente a la misma altura, lo que obliga también a estos ajustes. Gracias a estos ajustes en la transición entre arco y enjarje, se utiliza la misma curvatura en ojivos (16 pies de radio) tanto en los arranques como en las porciones de arco que van hasta las claves. Es lógico pensar que se construyese el enjarje con la curva prevista y a continuación se colocase la cimbra hasta la clave de la bóveda con la misma curvatura pero con tolerancias para coordinar ambos intradós. Hay que tener en cuenta que estos ajustes no son fruto de deformaciones de los arcos debidos a movimientos en los muros, pues los desplomes son despreciables. Han sido medidos en los cuatro muros y son del orden de $1 \mathrm{~cm}$.

Además, los ojivos no emergen tangentes al muro, sino que su punto de tangencia se encuentra dentro del mismo, a un pie y un cuarto del borde del muro en el lado largo y un pie y medio en el corto. Por lo tanto, la altura a la que salen los nervios del muro con respecto al centro de la circunferencia es un poco mayor a dos pies. En el caso de los ojivos que salen del pilar, su punto de tangencia se encuentra a un poco menos de un pie del borde. Estos arcos además presentan la particularidad de que centro del arco de la zona del enjarje del pilar se encuentra más alto que el del resto del arco hasta el rincón. Esto se debe a la voluntad de hacer que todos los arcos que salen del pilar central salgan a la misma altura, tanto ojivos como perpiaños.

En cuanto a los perpiaños, hay dos tipos diferentes: los que van desde el pilar al lado largo de la sala formados por arcos apuntados y los que van del pilar al lado corto, que son semicircunferencias. Los primeros están compuestos por arcos de 9 pies de radio y sus curvas directrices son tangentes tanto al pilar como al muro. Esto no ocurre con los otros perpiaños. Al igual que ocurría con los ojivos, se producen ajustes en el contacto de la zona del enjarje y el resto del arco. Comparten la misma curvatura, 11 pies y medio, pero en este caso, al no haber claves, la discontinuidad se sitúa entre los arranques y el resto del arco formado por las dovelas. Además, no salen tangentes al muro, sino que sus puntos de tangencia se localizan aproximadamente 2 pies y medio por debajo de su 

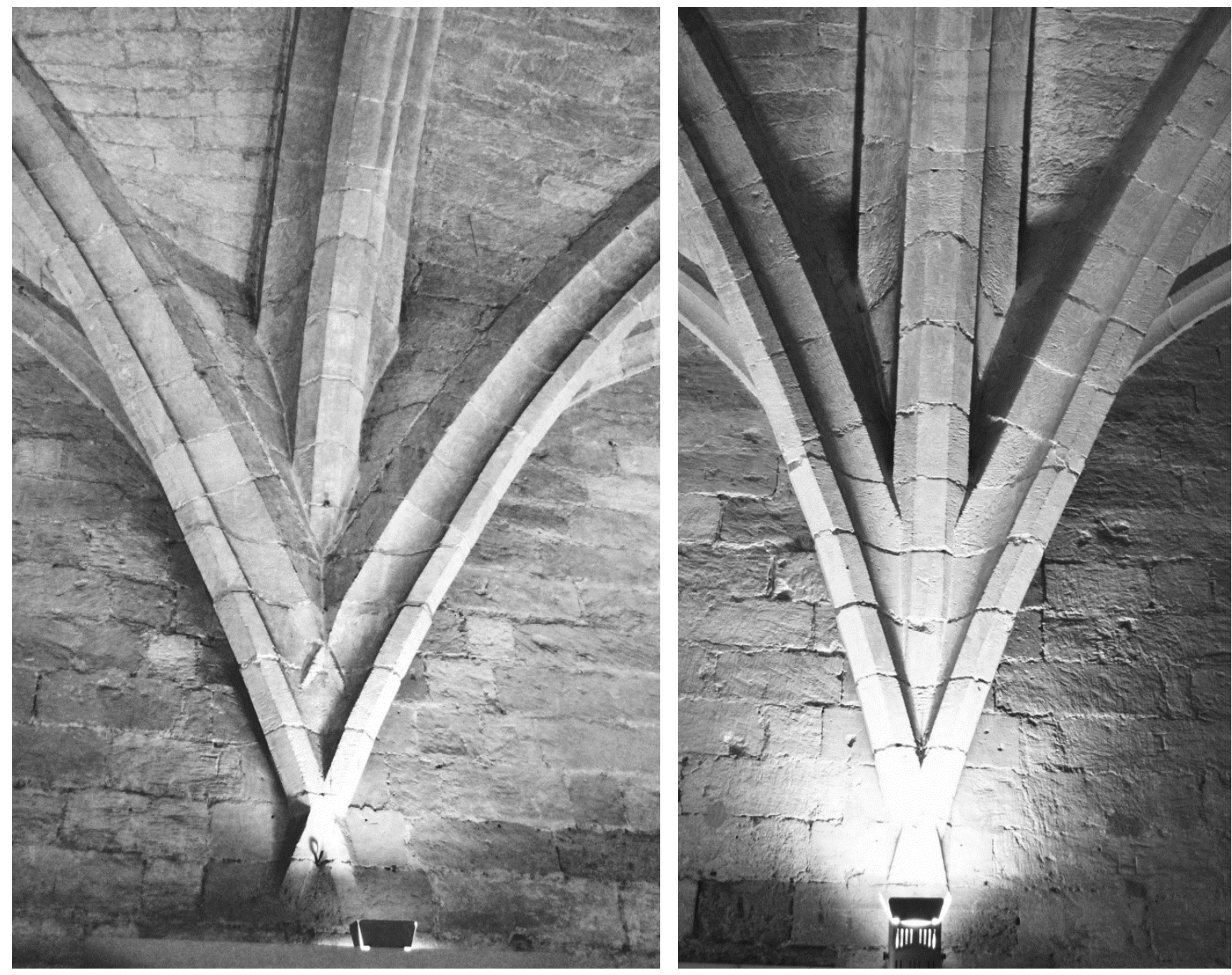

Fig. 119

Enjarjes en la sala de teología del Palacio de los Papas en Aviñón. A la izquierda, el del lado largo de la sala; a la izquierda, el del lado corto arranque y a $1 / 3$ de pie dentro del muro.

En los arcos formeros también encontramos diferencias entre los que se sitúan en el lado largo, con semicircunferencias de 12 pies de radio, y los del lado corto, formados por arcos apuntados de 10 y medio pie de radio. Todos emergen tangentes, tanto desde los rincones, como desde los puntos centrales de los muros.

La altura de las hiladas de la sala ronda los $20 \mathrm{~cm}$, sin tener en cuenta la altura de la junta; es decir aproximadamente tres cuartos de palmo de Aviñón. Se produce continuidad de hiladas entre los enjarjes del muro sur y el pilar central; y entre los del muro este y el rincón sureste. No han sido medidas las hiladas del muro norte y el oeste. El hecho de que la esquina sureste comparta la altura de hilada con el muro este y no el sur, puede solucionarse gracias a la presencia del hueco en el muro sur más próximo a él, en el que es probable que se cambie la altura de hilada.

\section{Los enjaries}



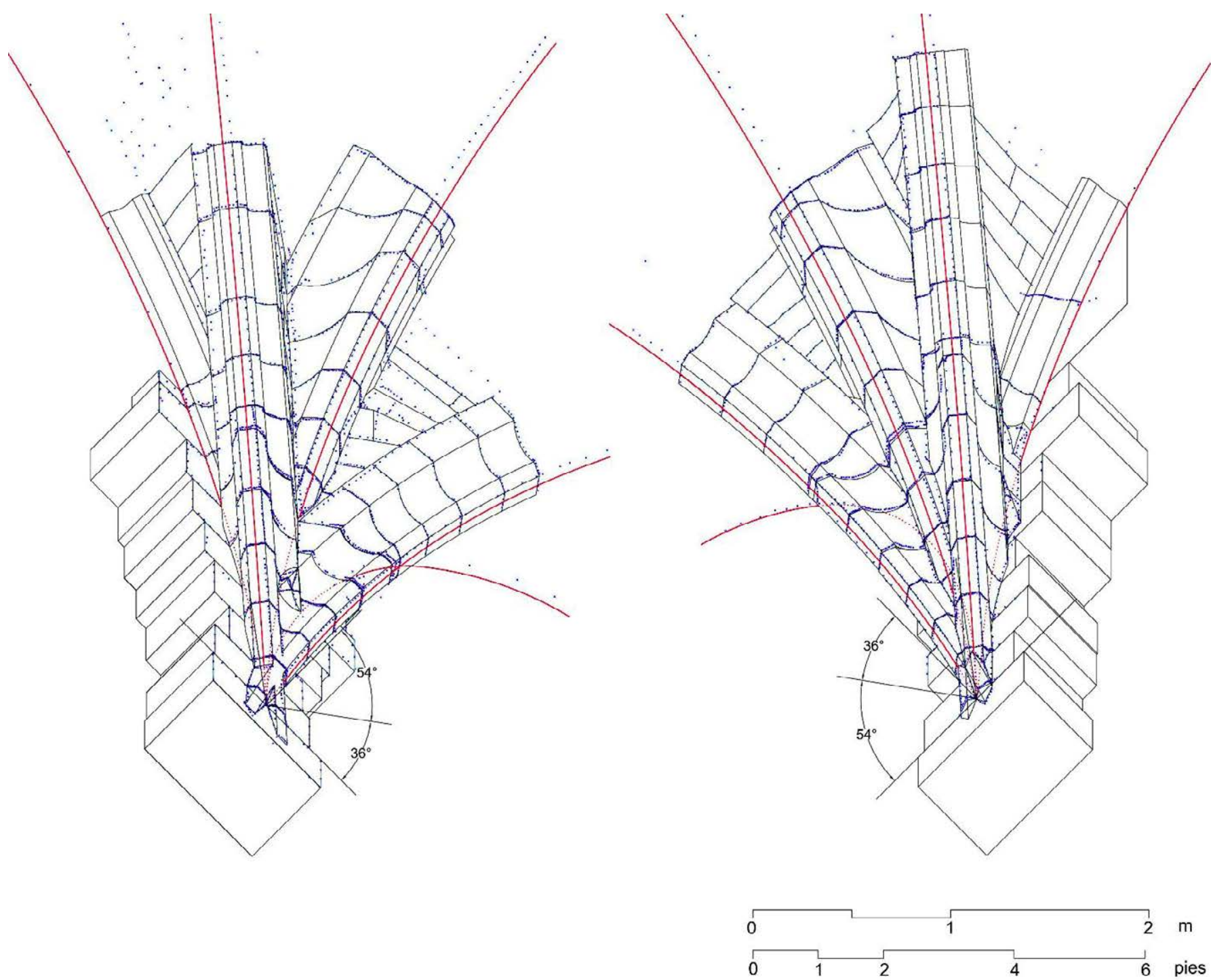

Como ha señalado ya Dominique Vingtain, la solución de los enjarjes en el muro, sin capitel que los sustente, es algo único en el edificio. ${ }^{298}$ Además, su comienzo, con el marcado cruce de molduras, es una aportación fundamental debido a que el primer ejemplo gótico de estas características.

La sala tiene dos tipos de enjarjes, los que se encuentran en los lados cortos y los de los lados largos de la sala. El resultado final de estos elementos viene marcado por una serie de decisiones proyectuales, geométricas y constructivas que analizaremos a continuación.

Diseño en planta y arranque de los nervios

Como hemos señalado con anterioridad, las directrices de los nervios de los enjarjes situados en los paramentos convergen en planta en un único punto del muro. La diferencia formal entre los dos tipos de enjarjes de la sala, el del lado mayor y el menor, es consecuencia de la forma rectangular

Fig. 120

Análisis de la geometría de los enjarjes con los puntos medidos en azul. A la izquierda el del lado largo, a la derecha, el del lado corto.

\footnotetext{
298 Vingtain, Avignon: Le Palais des Papes, 203.
} 
de las bóvedas. En el lado menor de la sala, los ojivos forman un ángulo de $54^{\circ}$ con los formeros y de $36^{\circ}$ con el perpiaño. Mientras, en el lado mayor, los ojivos forman un ángulo de $36^{\circ}$ con los formeros y de $54^{\circ} \mathrm{con}$ el perpiaño.

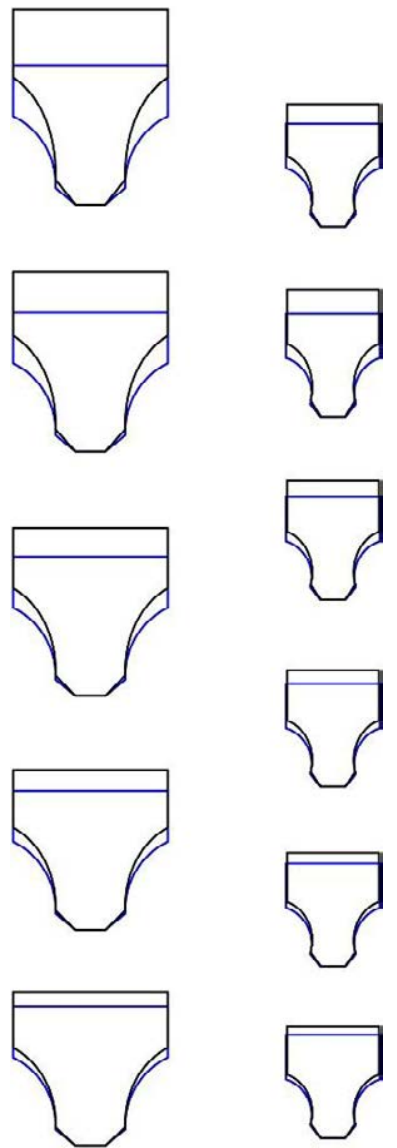

Fig. 121

Montea para el enjarje del lado largo y plantillas por niveles con la comparación entre la plantilla deformada necesaria en azul y el perfil del corte radial en negro.

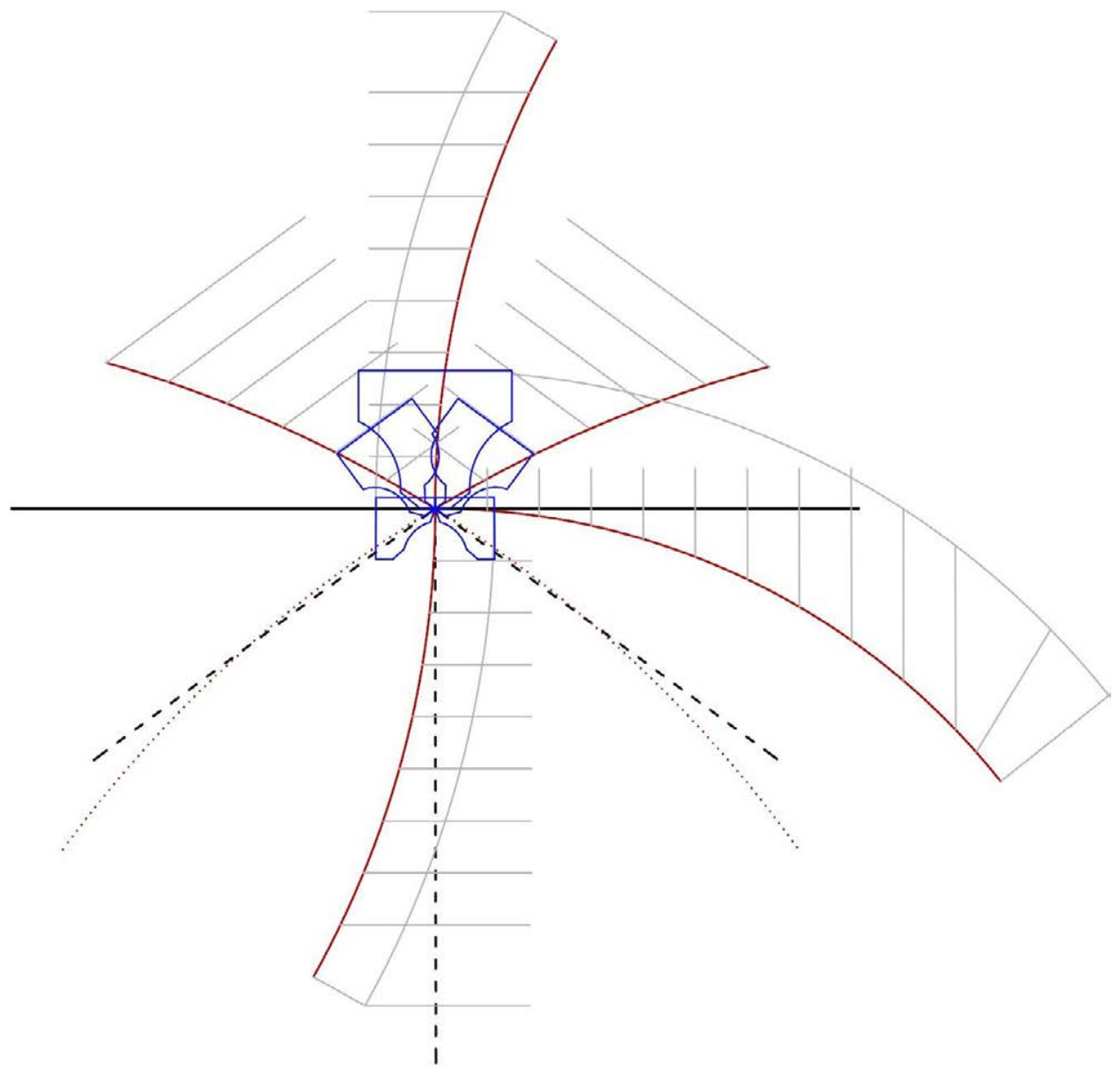

El lugar de arranque de cada uno de los nervios del enjarje es un aspecto fundamental a estudiar a la hora de abordar su diseño, ya que puede coincidir o no con algún punto notable, como la confluencia de ejes, el contacto con el muro, etc., y se ha comprobado que a la más mínima variación de su posición, el resultado formal del enjarje puede no ser el deseado. Por lo tanto, de su precisión depende el obtener un enjarje con una forma más o menos armoniosa, o con intersecciones más o menos complicadas de labrar, etc.

En este caso, puede parecer a simple vista que el perpiaño de los enjarjes de los lados mayores sale del muro más alto que el perpiaño de los lados menores; pero no es así. Tras el análisis de los puntos medidos y de las curvas, hemos podido comprobar cómo todos los nervios salen a la vez del muro desde mismo punto en ambos enjarjes, siendo los formeros los únicos en salir tangentes. Todos emergen de la junta situada sobre la primera pieza.

El diseño en planta y la decisión de salida de los nervios de ambos enjarjes es en cierto modo "conservador", pues no se produce, como ocurrirá en otros casos, salida de nervios a diferentes alturas, confluencia de ejes 

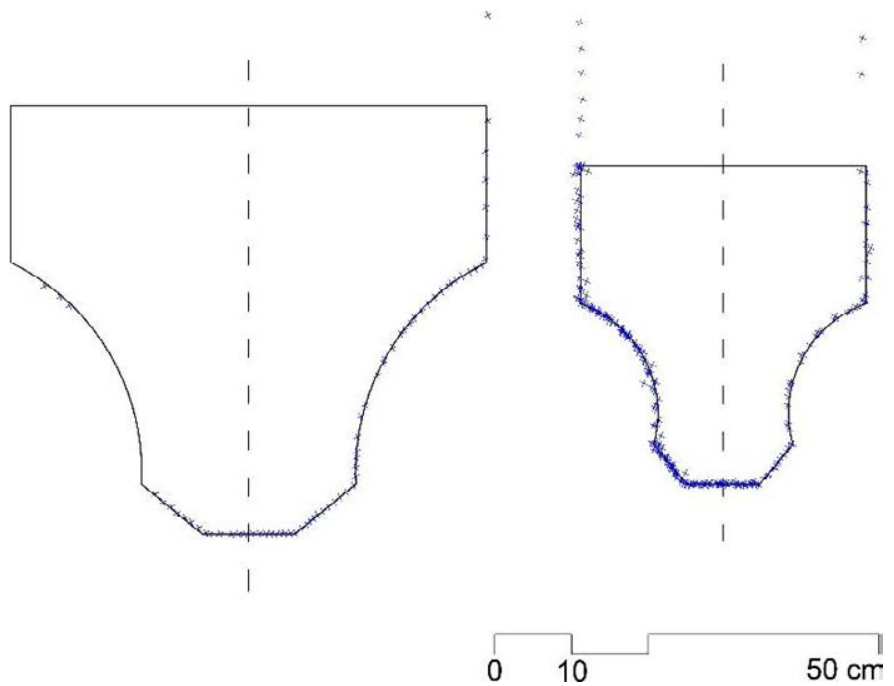

dentro del muro, etc. Cabe preguntarnos qué hace que estos enjarjes parezcan enjarjes de nervios que se cruzan o, al menos, que podamos hablar de una solución nueva. La respuesta viene dada por los perfiles utilizados, tanto por su tamaño y moldura; como por la decisión de no suprimir parte de ella tras la confluencia de los nervios ojivos. Los nervios perpiaños miden dos palmos y medio de ancho por dos palmos y un cuarto de alto (62 por $56 \mathrm{~cm}$ ) y los ojivos un palmo y dos tercios de alto por un palmo y medio de ancho (37 por $41 \mathrm{~cm}$ ). Como se puede apreciar, la proporción de los nervios perpiaños es ciertamente singular, puesto que son más anchos que altos. En cuanto al perfil de ambos nervios, nos encontramos con una moldura muy sencilla formada por un plano de intradós de $10 \mathrm{~cm}$ en el caso de ojivos y $12 \mathrm{~cm}$ en el de perpiaños seguido de otro plano recto formando chaflán, de $7 \mathrm{~cm}$ en el caso de ojivos y $10 \mathrm{~cm}$ en perpiaños. Esta es la porción de moldura que sobrepasará la intersección de los intradós de los nervios ojivos y dará lugar a lo que Vingtain ha llamado terminación en queue d'aronde. La moldura de los perfiles sigue con un plano cóncavo y finaliza en vertical. ${ }^{299}$

Algunas descripciones no dudan en denominar a este tipo de enjarjes como enjarjes de nervios cruzados. Como se ha podido comprobar, las directrices de los nervios no se cruzan -convergen en planta en el muro-, sólo lo hacen sus molduras. Por ello debemos matizar que estamos ante enjarjes de molduras cruzadas.

\section{Despiece}

El problema constructivo generado por la reunión de los diversos nervios de una bóveda de crucería en el apoyo, pasará por diferentes etapas durante la evolución del gótico. En un primer momento, encontramos soluciones mediante dovelas separadas. Poco después, se unifican los
Fig. 122

Perfiles de los nervios. 
nervios en piezas únicas, por niveles, despiezando el comienzo de la bóveda mediante cortes horizontales. Se pasa así de la reunión física de los nervios a la concepción abstracta del movimiento del perfil del nervio en el espacio, materializado por el uso de la plantilla, que controla la ejecución del tas-de-charge y hace posible algunos cruces o intersecciones de las molduras de los nervios.
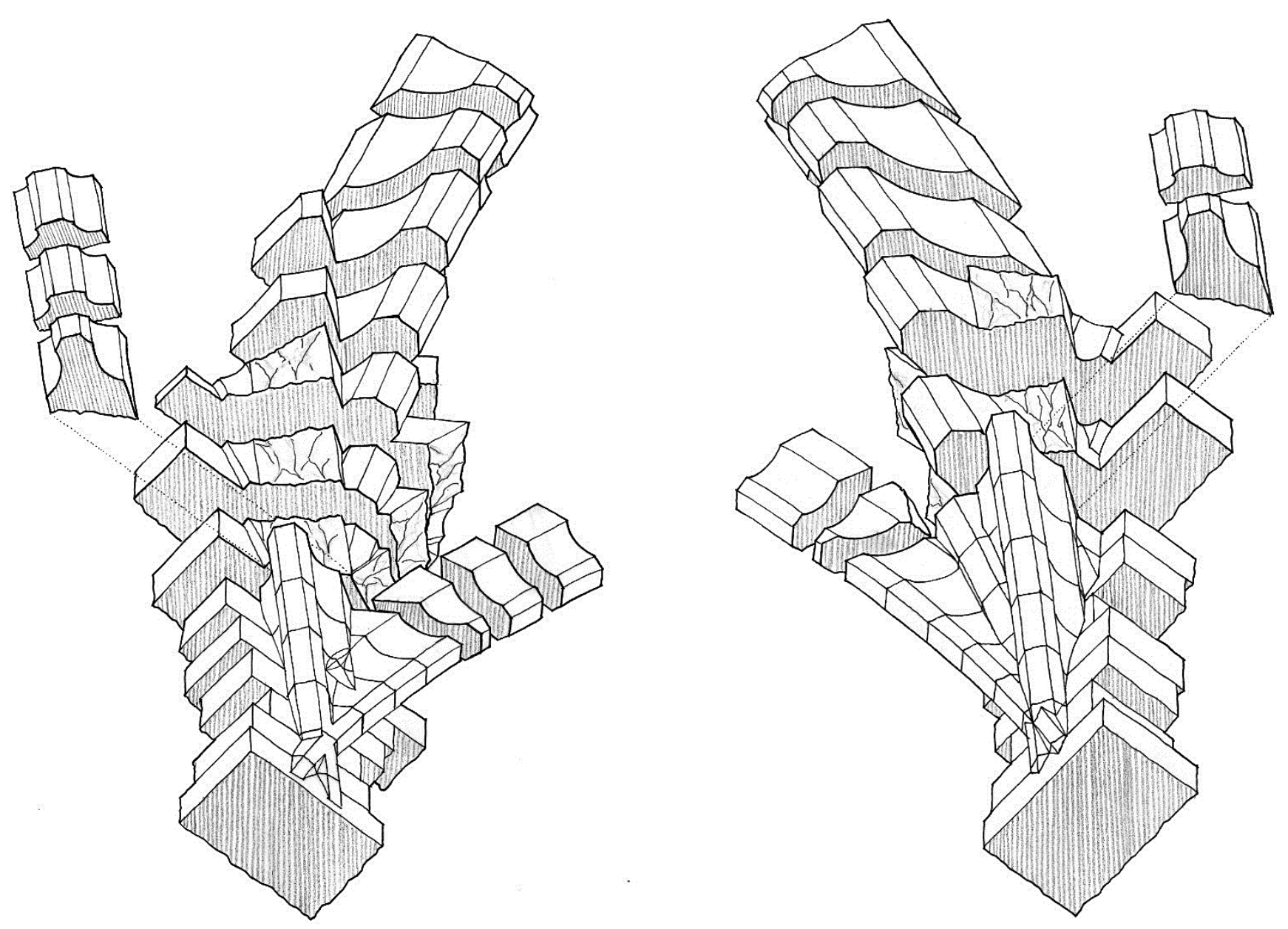

Fig. 123

Despiece de los enjarjes. A la izquierda, el del lado largo; a la derecha, el del lado corto.
En el momento en el que son realizados los enjarjes de la Sala de Teología ya se tenía sobrada experiencia en la construcción de enjarjes. Lo común era realizar una serie de piezas de lechos horizontales trabados con el muro, con una pieza final en la que el lecho inferior era horizontal y el superior inclinado siguiendo la dirección radial de las juntas de las dovelas que se apoyarían a continuación en el enjarje. El despiece de los enjarjes de la sala es ciertamente sorprendente, ya que este orden no se respeta. Ambos enjarjes están compuestos por 6 piezas con lechos horizontales al comienzo. Pero, en el momento en que debiera aparecer la última pieza con lechos inclinados en los ojivos, nos encontramos con dovelas sueltas. Es decir, la última pieza del enjarje para los ojivos tiene lecho horizontal y se colocan a continuación unas extrañas dovelas con un lecho horizontal en la parte inferior e inclinado en la superior. A partir de ahí se comienzan a colocar dovelas en los ojivos. Sin embargo, los perpiaños continúan hacia arriba con piezas con lechos horizontales. En este momento se nos plantea 
la duda de si es correcto denominar a esta parte continuación del enjarje, pues en el del lado largo es fácil suponer que estas piezas horizontales del perpiaño traban con el muro, mientras que en el enjarje del lado corto es difícil de asegurar en ciertos lugares, dando la sensación de ser piezas independientes.

Además, en ambos casos, antes de aparecer la junta inclinada con la dirección radial del arco en los perpiaños, nos encontramos con una pieza de transición. Es una dovela cuyo lecho inferior es el último horizontal y el superior es inclinado, pero no con la dirección radial del arco, sino con una inclinación intermedia para que el salto entre el plano horizontal y el inclinado no sea tan brusco. Si se hubiese realizado directamente la última pieza con un lecho inferior horizontal y el superior con la inclinación radial del arco nos encontraríamos con un elemento con un intradós de recorrido muy corto y un trasdós muy largo, siendo una pieza muy delicada.

En cuanto a los formeros, los encuentros de los nervios con el resto son muy diferentes en los enjarjes de lado corto y del largo. En el lado mayor, puede parecer que las dos primeras piezas, con lechos horizontales, están conectadas con partes del ojivo. Pero se trataría de una solución extraña, puesto que las partes del ojivo con las que se unirían serían las ya anteriormente mencionadas dovelas sueltas. Además, el encuentro entre los nervios formeros y ojivos presenta restos de mortero, por lo que es probable que se trate realmente de una junta entre ellos y nos encontremos ante piezas independientes. Es difícil de asegurar cualquiera de las hipótesis.

La plementería de los enjarjes presenta también diversas soluciones de despieces. En el enjarje del lado corto, las hiladas son claramente curvas, mientras que en el largo no. Además, en el enjarje largo del lado este, se realizan dos soluciones de despiece de plementería diferentes para el encuentro del perpiaño y el ojivo en la parte de la derecha y en la de la izquierda. La parte siniestra, se realiza mediante lechos horizontales que se elevan en vertical, mientras que en la otra esto sólo ocurre en las tres primeras juntas y, a partir de ahí, las juntas empiezan a inclinarse.

Trabajo por niveles

Para tallar las piezas de un enjarje se realiza primeramente una montea, en la que quedan definidas la curvas de los arcos, de dónde arrancan y los niveles en que será ejecutado. De esa montea también se pueden extraer medidas para elaborar las plantillas de los perfiles de los nervios según niveles. Este trabajo por niveles es necesario para controlar qué nervios aparecen en cada nivel o, todo lo contrario, para suprimir parte de la 

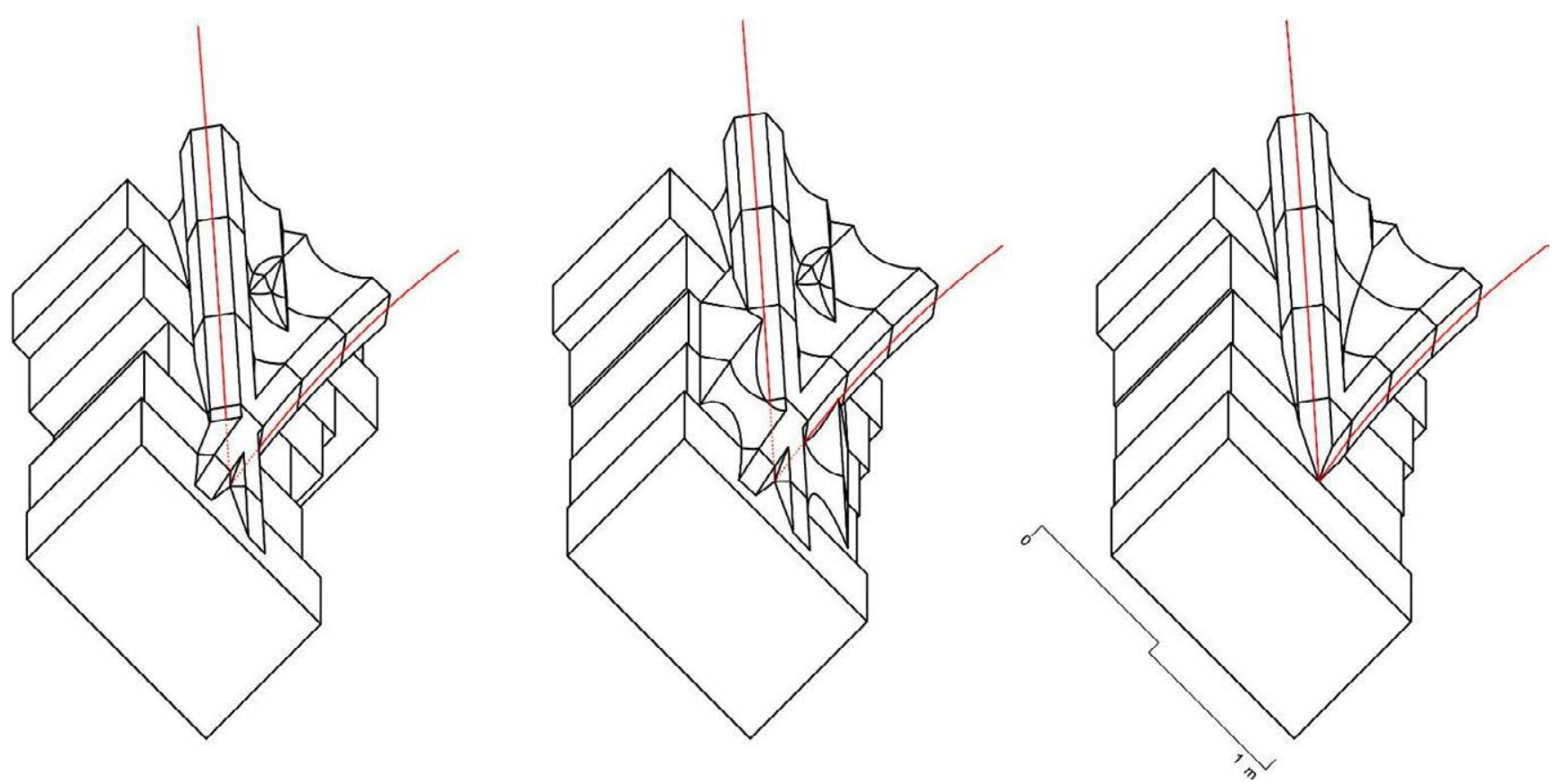

Fig. 124

Modificación del trabajo con plantillas en el comienzo de los enjarjes para favorecer una mejor comprensión de la intersección entre molduras. A la izquierda, solución existente; en medio, solución directa fruto del trabajo exhaustivo con plantillas; a la derecha, solución en la que todos los nervios emergen de un punto. moldura evitando así resultados formales indeseados.

En el caso de los enjarjes de la Sala de Teología hemos podido comprobar cómo se lleva a cabo este trabajo por niveles, principalmente en dos situaciones: el comienzo del enjarje y la zona de contacto de formeros y ojivos en los enjarjes del lado corto de la sala.

En el comienzo de ambos enjarjes se trabaja con plantillas en la primera junta. Allí se sitúan las plantillas de los ojivos que serán talladas hasta hacerlas desaparecer en el plano del muro en la primera pieza, como hemos indicado anteriormente hablando del arranque de los nervios. En los lechos superiores, la parte de la moldura del ojivo que pasa sobre el otro se eliminará, pues quizás acarrearía ciertas dificultades de talla. Para solucionar el encuentro entre la parte del ojivo que cruza y el muro, se eleva una línea más o menos vertical a partir de la arista formada entre el plano de chaflán del perfil y la parte cóncava en su contacto con el muro. Esta línea llega al otro ojivo y se resuelve la transición entre esta nueva arista y el encuentro de los ojivos en la parte central mediante dos planos triangulares, más marcados en el enjarje del lado corto que en el del largo. Este resultado final no es fruto del trabajo con plantillas, sino de la decisión de ajustar este comienzo del enjarje, de manera libre por parte de los canteros, a un resultado formal más claro en el que esas dos porciones de ojivo que se cruzan sean los elementos protagonistas.

Ha sido fundamental poder constatar la utilización de plantillas no deformadas en lechos horizontales en el enjarje del lado corto, 


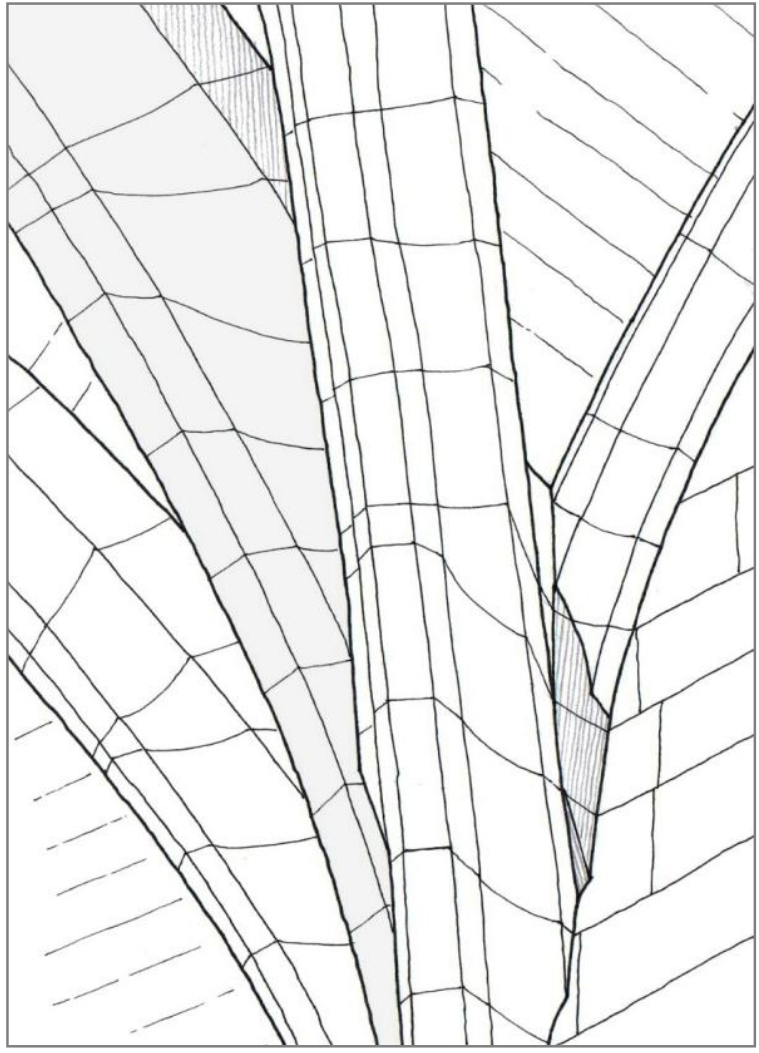

concretamente en el lecho sexto. El uso de plantillas deformadas es necesario dependiendo de la altura del nivel y el tamaño de la bóveda. En muchos de los enjarjes que hemos estudiado con anterioridad sería posible no utilizar plantillas deformadas para los primeros niveles hasta que se produce el primer cambio en la moldura del perfil, pero es prácticamente imposible llegar a esta aseveración, puesto que la diferencia en los primeros lechos, en muchos casos, entre las plantillas deformadas y sin deformar es muy pequeña.

En la sala de teología se localiza el uso de una plantilla sin deformar en una porción del nervio perpiaño que atraviesa el ojivo y aparece en contacto con el muro. Tras tomar puntos de esa parte de la junta con la estación total y trabajar con el modelo 3D, pudimos comprobar como la plantilla deformada no encajaba con el corte horizontal en esa localización. Sin embargo, al situar la plantilla original, sin deformar, no cabía duda de que se trataba de la solución correcta, pues la diferencia entre la situación del punto de la arista en el perfil entre una y otra era de $6 \mathrm{~cm}$, medida nada despreciable.
Fig.125.

Constatación mediante medición topográfica del uso de plantillas sin deformar en un lecho del enjarje. En azul la plantilla no deformada que se adapta perfectamente al contorno de la pieza. En naranja, la plantilla deformada correspondiente al corte cuya arista se distancia $6 \mathrm{~cm}$ de la existente. 
Fig. 126

Claustro de la catedral de Narbona. Panda sur.

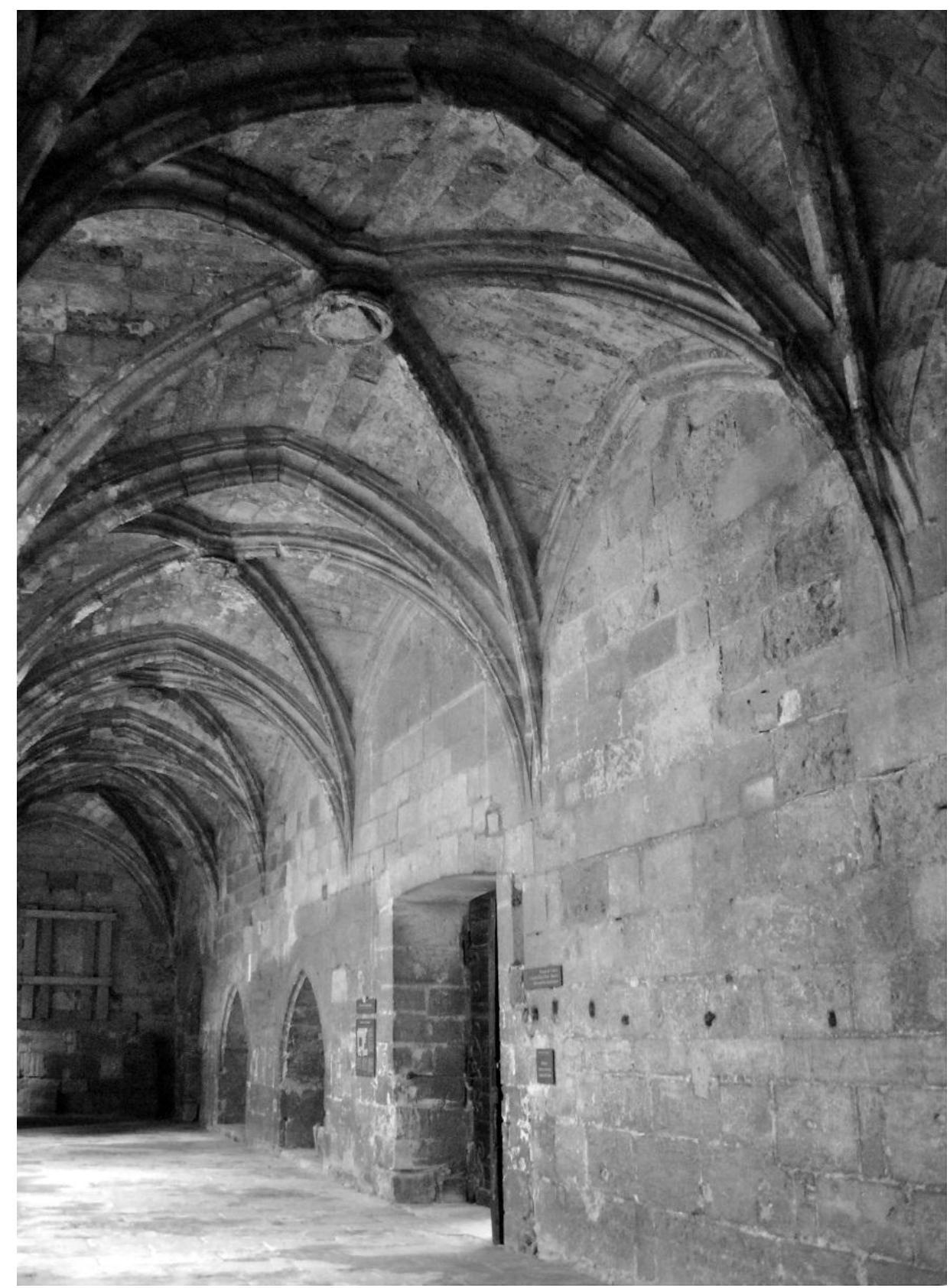

3.2.3. El enjarje como experimentación: tres diseños diferentes para una panda en el claustro de la catedral de Narbona. ${ }^{300}$

El claustro de la catedral de Narbona es un ejemplo especialmente relevante en la evolución del diseño de enjarjes. Narbonne dice que existe una noticia documental referente al claustro a mediados del siglo XIV, donde se acuerda la división de unos terrenos con motivo de su construcción. Sostiene que las obras se comienzan por la zona situada en

${ }^{300}$ Este trabajo se ha realizado junto a Rosa Senent Domínguez, tanto la toma de datos y medición, como el análisis de los mismos. 


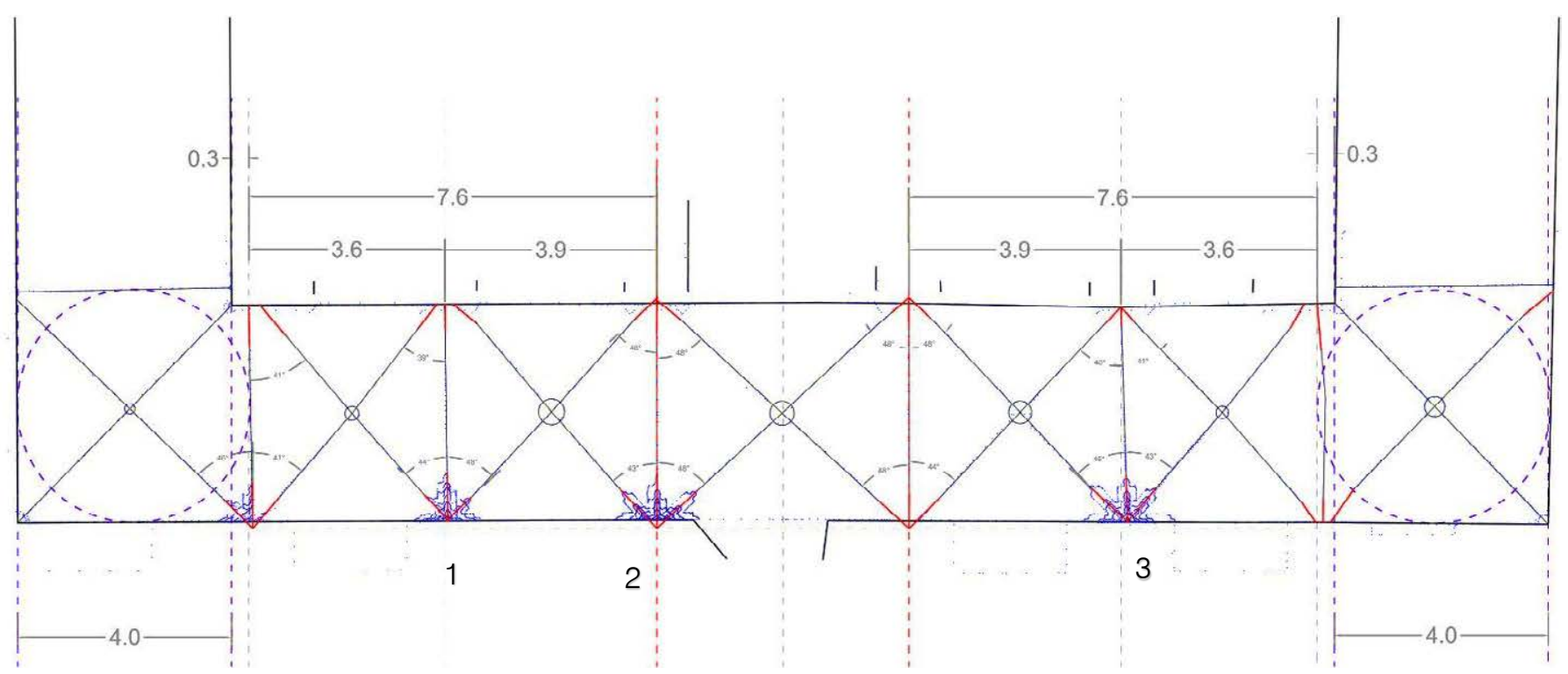

relación con el palacio arzobispal y se alargan en el tiempo hasta principios del siglo XV.

Fig. 127

Análisis de la planta tras los datos

Es especialmente emocionante el hecho de presenciar en primicia un juego de experimentación proyectual. Todo el claustro está resuelto con un enjarje en el que los nervios ojivos salen directamente del muro separados del nervio perpiaño, de manera que se permite el cruzamiento de los nervios formeros para su confluencia en el centro con el perpiaño (2).

Sin embargo, en la panda situada al sur se localizan dos variaciones de este diseño. La primera, se sitúa en el segundo enjarje del muro tras atravesar la puerta, hacia la derecha (3). La segunda, en el mismo muro, también en el segundo enjarje tras atravesar la puerta pero, en este caso, hacia la izquierda (1).

En el 1 los nervios formeros y perpiaños convergen, pero los ojivos se cruzan entre sí antes de llegar al muro, mientras que en el 3 los nervios convergen en un punto en el plano del muro.

Se llevó a cabo una medición del recinto, de las bóvedas y de los enjarjes para poder valorar si estos comienzos de las bóvedas eran resultado de ajustes en planta o realmente su diseño era fruto de variaciones intencionadas del orden establecido.

Realizamos un levantamiento topográfico recogiendo puntos de la planta, de los intradós de los nervios de todas las bóvedas de la panda, de los perfiles de los nervios y de los enjarjes.

${ }^{301}$ M. Louis Narbonne, La cathédrale Saint-Just de Narbonne, (Narbonne: F. Caillard, 1901). entamiento topográfico. En el enjarje 1 se cruzan los nervios ojivos; el 2 es el que se repite en todo el claustro, con el cruce de formeros y ojivos; en el 3 los nervios convergen. (n) 

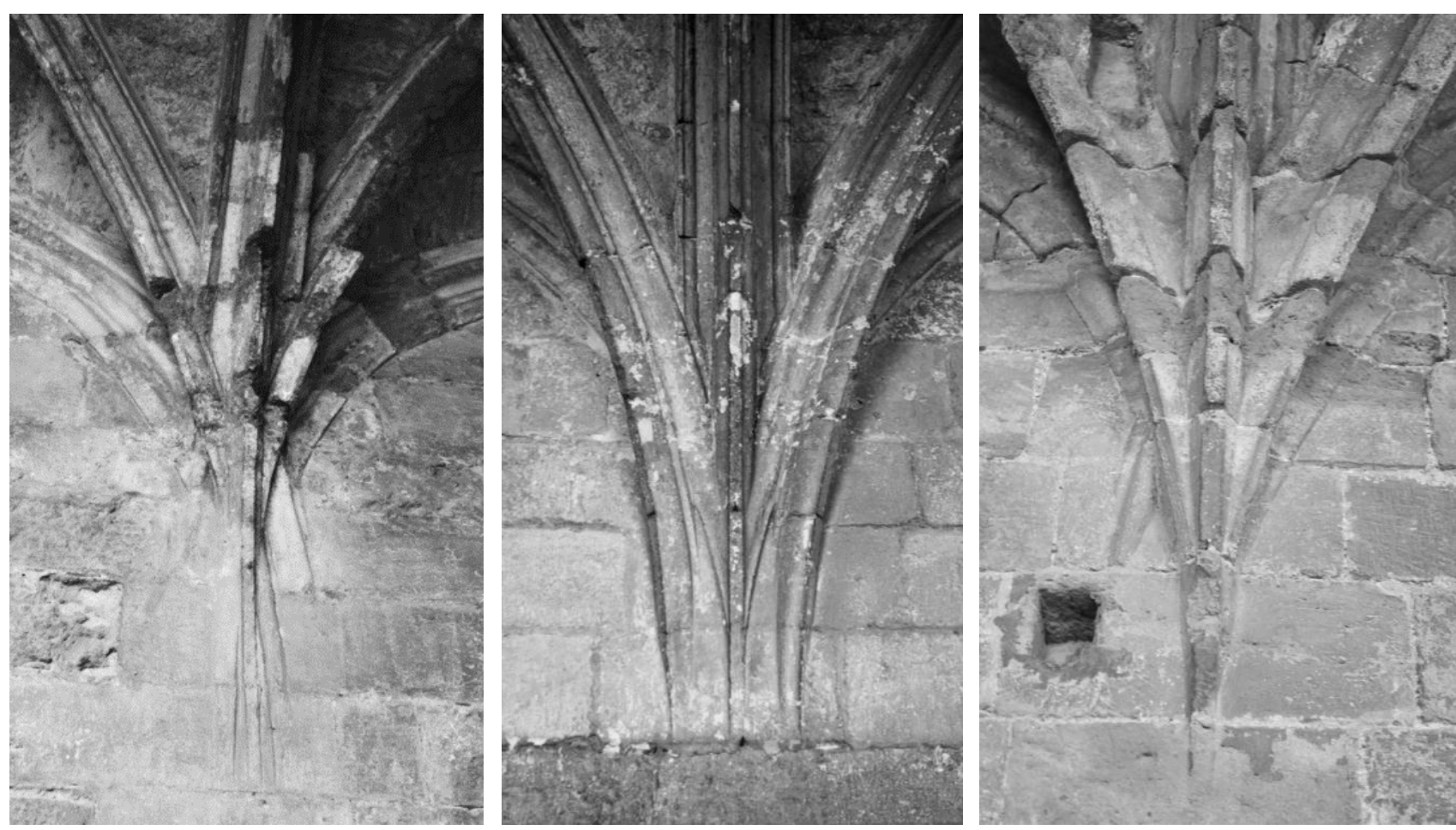

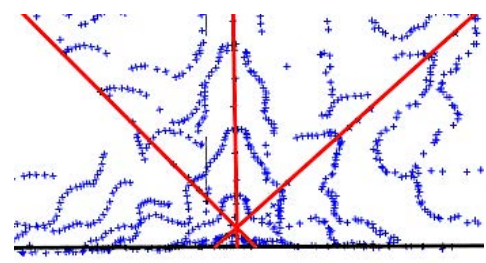

1

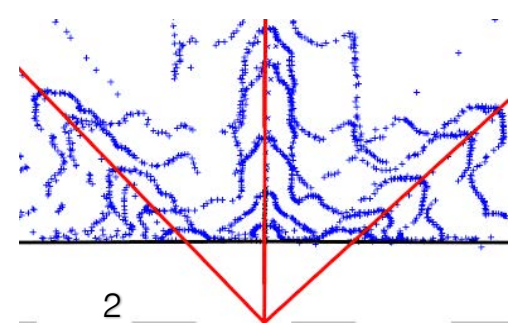

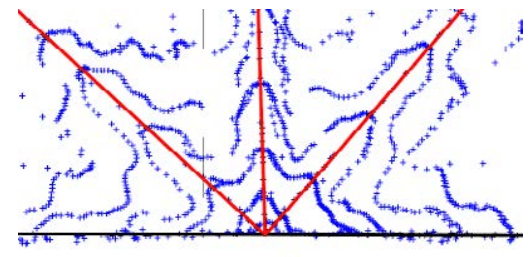

3
Fig. 128

Enjarje en el que los nervios ojivos se cruzan (1), enjarje que se repite en el claustro (2) y enjarje de nervios convergentes (3).
Tras analizar la planta pudimos comprobar que los enjarjes no respondían a ajustes geométricos debidos a irregularidades, incluso los ángulos de los nervios no afectaban a la solución final. El esquema presentaba unos tramos a ambos lados del acceso que se disponían de manera simétrica. Los enjarjes son resultado de una modificación deliberada de los ejes de los nervios en ese punto, no así en el resto de la bóveda.

Se producen las variaciones mediante una estrategia sencilla: la localización en planta del punto de confluencia de los ejes de los nervios con respecto al muro y su situación de arranque. En el caso que se repite en todo el claustro (2) los ejes de los nervios convergen en un punto dentro del muro a pesar de que su salida se produzca tangente con respecto a este. De esta manera, los formeros pueden converger con el perpiaño y cruzarse con los ojivos.

En el caso del enjarje 3, los ejes de los nervios convergen en un punto, siendo significativo el hecho de que aparezca un resto de moldura de un nervio en uno de los laterales. Seguramente sea prueba de que el momento en el que estos enjarjes fueron realizados este tipo de soluciones no eran habituales y los canteros tenían dudas a la hora de la talla sobre el resultado final que tendría su trabajo con plantillas. 
Finalmente, en el enjarje 1, todos los nervios se cruzan. Esto es posible al localizar el cruce de los ejes de los ojivos fuera del muro, de manera que ambos emergen del muro y se cruzan entre sí y con el perpiaño. Además, los formeros siguen convergiendo con el perpiaño, lo que conlleva su cruce con los ojivos.

\subsubsection{La bóveda traza el enjarje: la capilla del Condestable en la catedral de Burgos}

Los enjarjes de la capilla del Condestable de la catedral de Burgos constituyen un ejemplo sin precedentes dentro la arquitectura castellana de finales del $X V$, pues hasta ese momento no se había realizado ninguna bóveda en la que sus nervios saliesen separados y a continuación se cruzasen. Es una solución tecnológica sin antecedentes resuelta con una maestría y calidad difícilmente igualables. Entre las bóvedas de este tipo en Castilla, puede que estemos ante los enjarjes con mejor factura a pesar de ser los pioneros. ${ }^{302}$

Debido al escaso número de ejemplos en el actual territorio español pensamos llevar a cabo un estudio comparativo de los mismos. Se ha realizado la toma de datos mediante estación total de algunos de ellos pero, debido a la limitación de tiempo, hemos decidido acometer dicha tarea en futuras investigaciones e ilustrar mediante el estudio de la capilla del Condestable la problemática de esta solución técnica; si bien es cierto que cada bóveda viene marcada por condicionantes distintos y las decisiones en cuanto a su trazado y ejecución son fruto de dicha diversidad. ${ }^{303}$

\section{Metodología}

Se ha llevado a cabo una medición con la estación total Leica FlexLine TS02. Se han tomado puntos de la planta de la capilla, así como de la cornisa a partir de la cual se empiezan a construir las trompas que permiten la transición hacia el octógono en el que se inscribe la bóveda. También se han medido las partes superiores de los capiteles, los desplomes de los muros, superficies de plementería -completas en unos casos y en otros partes de la cáscara que nos permitiese comprender la volumetría de la bóveda-, el despiece de una de las trompas, los perfiles de los nervios en varias localizaciones y los intradós de los arcos. En este último caso,

\footnotetext{
302 No sabemos si hubo ejemplos anteriores con este tipo de solución para el enjarje, pues, o no han llegado hasta nuestros tiempos, o desconocemos en el momento de redacción del presente trabajo su existencia.

${ }^{303}$ Ver página 35
} 


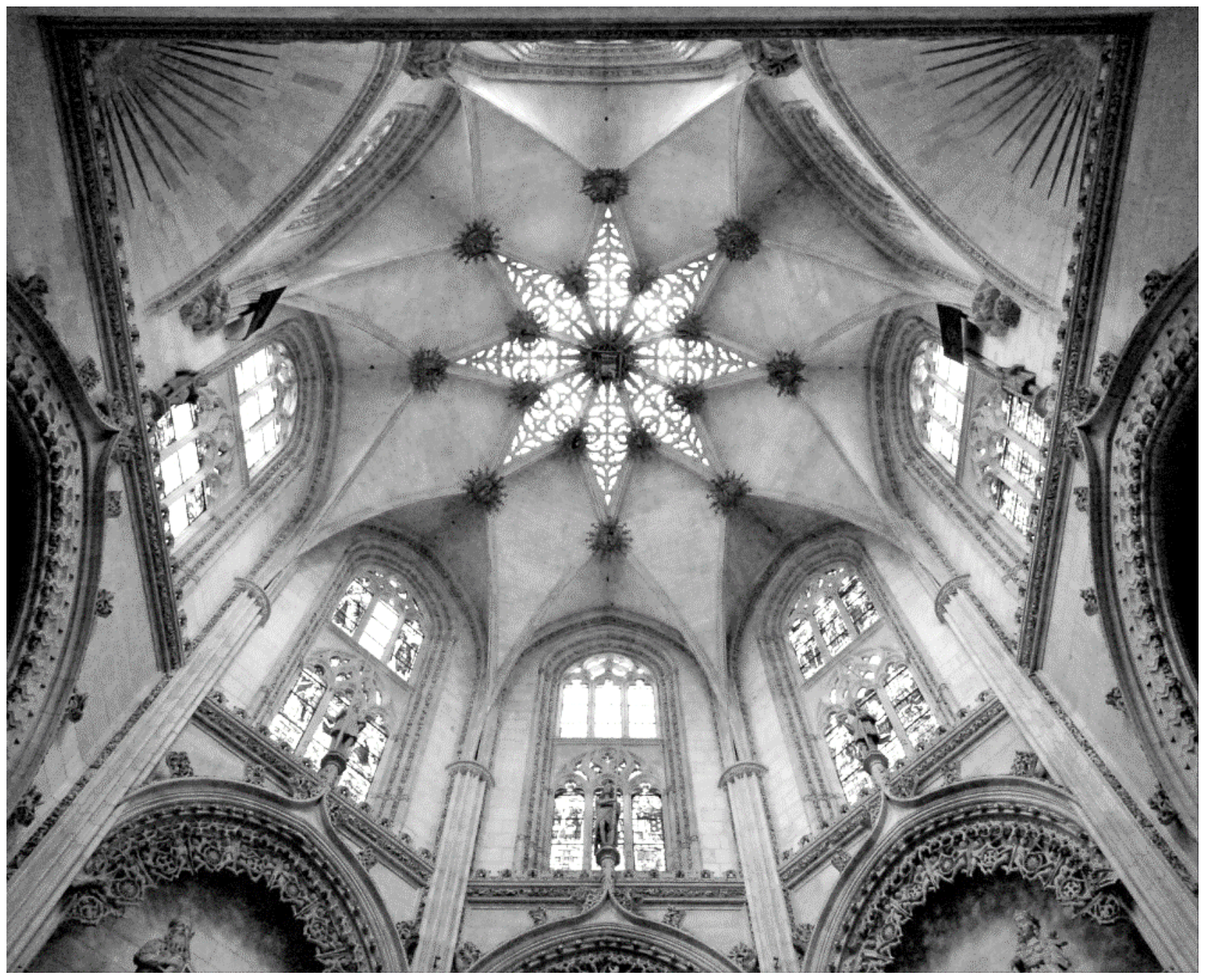

Fig. 129

Capilla del Condestable en la catedral de Burgos. tuvimos que enfrentarnos a algunas dificultades. La medición de los formeros, los terceletes y los arcos que conforman la estrella en planta no presentó mayores problemas, mientras que para los arcos que se unen en el centro sí. No se pueden tomar puntos en su intradós debido a la existencia de decoración, por lo que tomamos algunos puntos entre ella y realizamos la medición en el contacto del nervio con la plementería. De este modo, mediante una paralela a esa curva apoyándonos en los puntos que pudimos medir del intradós, pudimos definir estos arcos. Tampoco se pudieron tomar puntos de las claves, pues sobre ellas hay superpuestas torteras de madera.

Para poder acometer el análisis de los enjarjes, se tomó un gran volumen de puntos- más de 7 por pieza- en el intradós de todos los terceletes de la bóveda. A simple vista no apreciamos gran diferencia entre unos y otros, lo que nos llevó a realizar una medición exhaustiva de las juntas solamente en uno de ellos, el que se encuentra entre el lado norte y el chaflán noreste de la capilla. Su situación era ventajosa, pues podíamos llevar a término mayor número de estacionamientos y sus juntas se apreciaban mejor que en el resto. 


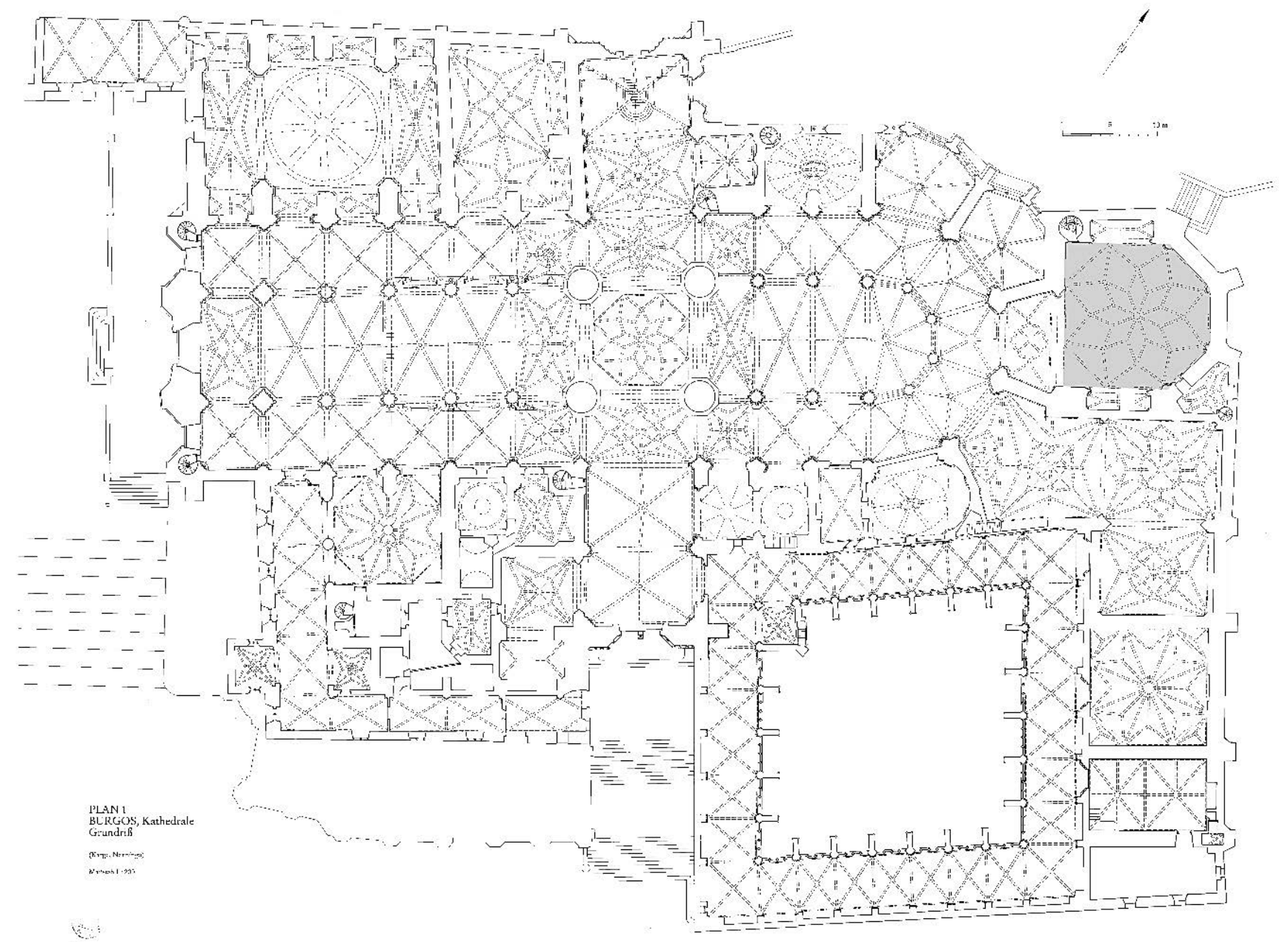

Se tomaron puntos en los lechos horizontales y juntas verticales de cada una de las piezas además del comienzo de la plementería para comprender y analizar mejor el final del enjarje.

La nube de puntos resultado del levantamiento topográfico se ha procesado mediante programas CAD. En AutoCAD hemos realizado el análisis de la planta, los perfiles de los nervios, así como el abatimiento y estudio de todos los arcos de la bóveda. Con Rhinoceros v.4 se ha modelado el enjarje basándonos en los datos obtenidos del análisis anterior.

\section{Diseño en planta de la bóveda}

Durante la presente investigación hemos trabajado principalmente con bóvedas de planta cuadrada o rectangular resueltas mediante nervios ojivos que se cruzan en el centro del tramo en una clave, representando esta bóveda de planta octogonal y diseño estrellado un caso especial dentro de la tesis. En ella podemos analizar un fenómeno que en el resto podría llevar a muy diversas especulaciones: la decisión del lugar en el que se cortan los nervios del enjarje en el diseño en planta.

Fig. 130

Planta de la catedral de Burgos sombreada la situación de la gran bóveda de la capilla del Condestable junto con las trompas que permiten el paso de los rincones al octógono. (Karge, 1989). 

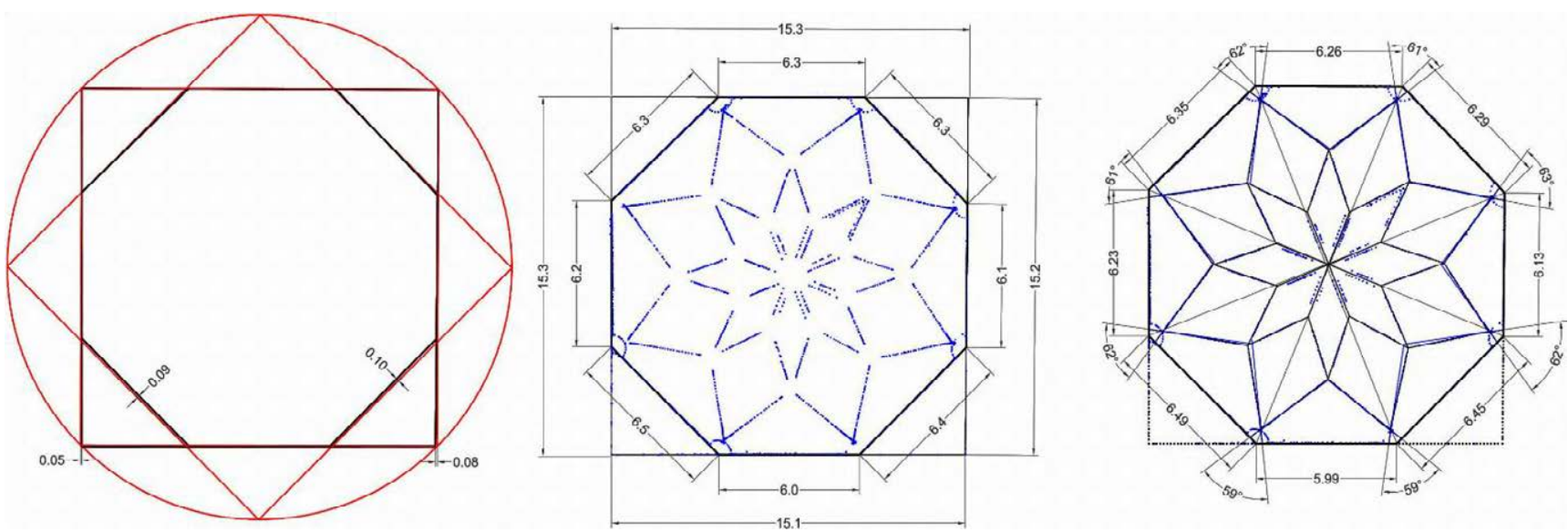

Fig. 131

Análisis de la planta de la bóveda señalando las irregularidades que la separan de un diseño regular.
La situación de este punto de encuentro en planta en este tipo de enjarjes es crucial. Como explicamos con antelación, los enjarjes en los que los nervios nacen separados y se cruzan en su recorrido para de nuevo separarse pueden resolverse mediante dos soluciones constructivas diferentes. La primera, formando parte el cruce de los nervios del propio enjarje, es decir, resolviendo la intersección en las piezas con lechos horizontales que traban con el muro. $\mathrm{O}$, por el contrario, ese cruce puede encontrarse en una posición muy elevada o alejada del muro que impida esta solución y se opte porque el cruce de los nervios forme ya parte de las piezas con lechos inclinados radiales. Es decir, el cruce de los nervios se convierte en una pieza independiente del enjarje.

Por ello, esta determinación en planta es fundamental pues, si se encuentra cerca del arranque, seguramente el cruce pueda resolverse en el enjarje, mientras que si se localiza muy separado las posibilidades de que no sea así aumentan. La pregunta que surge en estos momentos al enfrentarnos al análisis en planta del enjarje es ¿La voluntad de diseñar el enjarje en una forma concreta es prioritaria y condiciona de alguna manera el diseño de la bóveda, o, por el contrario, el enjarje es un detalle que debe responder a las condiciones de un trazado general?

Pequeñas irregularidades

Existe una pequeña diferencia entre la planta octogonal de la capilla construida y lo que sería el trazado ideal de la misma. Al medir el contorno se hizo patente que el lado de la capilla que está en contacto con la catedral es ligeramente más pequeño que el resto. Si contenemos el octógono en un cuadrado cuyos lados son paralelos y perpendiculares a la cabecera de la catedral, se aprecia que el lado situado al oeste mide 15,10 m, mientras los demás rondan los 15,30 m. Esta diferencia de unos $20 \mathrm{~cm}$ es importante a tener en cuenta, pues puede hablar de las limitaciones de espacio en esta parte debidas a la inserción de la capilla en la cabecera.

Si estudiamos los lados del octógono, por tanto, tampoco son todos iguales. Los tres lados situados al este miden lo mismo, 6,3 m, los norte y sur alrededor de 6,2 m, los noroeste y suroeste son los más largos con 6,5 m, y el localizado al oeste $6 \mathrm{~m}$. 
También se produce un fenómeno que hemos advertido en otros levantamientos realizados y que consiste en el cambio de dirección en planta de los ejes de los nervios una vez termina su recorrido en el enjarje. Es decir, los ejes de los terceletes en el enjarje siguen una dirección que se quiebra al comenzar la parte del nervio compuesta por dovelas. La diferencia entre la dirección del enjarje y del resto no difiere en más de $4^{\circ}$ en el lugar más desfavorable, representado por los dos nervios que salen de los enjarjes del lado oeste en dirección hacia el este y que probablemente esté relacionado con la menor dimensión de este lado del octógono.

El ángulo que forman los ejes de los nervios en el enjarje es más o menos el mismo en todos los casos, del mismo modo que el formado por los nervios tras el quiebro. Dicho ángulo- pero invertido- se mantiene hasta llegar a las claves. Sólo encontramos un caso en que esto no se cumple: en el chaflán entre el lado oeste y sur. Alí las claves están ligeramente más separadas y el ángulo que forman los nervios es mayor. Desconocemos la causa, pero es probable que sea consecuencia de los ajustes que se debieron llevar a cabo para hacer inapreciables las pequeñas irregularidades de los lados del octógono.

Trazado de la planta

Abordamos, en un primer momento, el estudio del trazado de la planta mediante rectas que contuviesen los ejes de los terceletes que salen de los rincones del octógono, siendo imposible dar con una respuesta satisfactoria. Debido a estas dificultades decidimos tantear el trazado mediante otros procedimientos e hicimos uso de circunferencias. El resultado fue sorprendente pues, si trazamos una circunferencia en el centro de la bóveda cuyo recorrido una las claves del interior de la estrella y la copiamos hacia un lado y otro del octógono, los centros de estas circunferencias encajan con bastante precisión con la situación de las claves del exterior de la estrella, a las que llegan los terceletes.

Sin embargo, las tres circunferencias consecutivas no llegan a los lados del octógono, lo que nos causaba ciertas dudas. Decidimos hacer uso en ese momento de las circunferencias de los capiteles, que curiosamente tienen un radio que se corresponde con la distancia desde una esquina del octógono a la intersección entre su eje y su circunferencia inscrita. Si dividimos esta pequeña circunferencia por la mitad en lados enfrentados del octógono el resultado es esa distancia que estábamos buscando, lo que faltaba a las tres circunferencias mencionadas para llegar al octógono 
En este punto acudimos al profesor Robert Bork para plantearle nuestras hipótesis y dudas. ${ }^{304}$ Él clarificó estas intuiciones y propuso realizar el proceso de concepción del trazado de la bóveda de modo inverso, es decir:

1. Se traza el octógono principal y los ejes que unen sus vértices.

2. Se dibuja la circunferencia inscrita al octógono. Así se localizan los puntos en los que se sitúan los cruces de los terceletes, que coinciden con la intersección de la circunferencia inscrita y los ejes que unen las esquinas del octógono.

3. Se trazan las circunferencias con centro en los vértices del octógono que pasan por el punto de cruce de los terceletes y, por tanto, son tangentes a la circunferencia inscrita. Curiosamente el radio de estas circunferencias coincide con el radio de los capiteles de los enjarjes.

4. Se divide el radio de dos de estas circunferencias de vértices enfrentados por la mitad y desde dicho punto se traza una paralela al lado del octógono.

5. La distancia entre dos paralelas al lado de las antes mencionadas se divide en tres partes y se trazan tres circunferencias de igual radio. La central define la situación de la clave central y las claves de los lados interiores de la estrella. Las laterales señalan en sus centros las posiciones de las claves de las puntas exteriores de la estrella.

6. Se trazan ocho circunferencias con "polo" en el centro y en relación con las mediatrices de los lados del octógono.

7. A partir de este momento, el trazado podría continuar con el dibujo de los terceletes que parten de los puntos de intersección que habíamos definido en el paso 2 y que llegan a los centros de las circunferencias.

8. También se trazaría la estrella partiendo de los centros de las circunferencias y llegando a las intersecciones entre la circunferencia central y los ejes que unen las esquinas del octógono.

9. Así como los nervios centrales que unen las claves y se cruzan en el centro de la bóveda.

\footnotetext{
${ }^{304}$ Robert Bork es catedrático en la School of Arts \&Art History de la Universidad de lowa y es especialista en el estudio de la arquitectura gótica, especialmente en los trazados de los dibujos arquitectónicos. Le agradezco su generosidad y su ayuda; siempre está disponible para la discusión científica.
} 

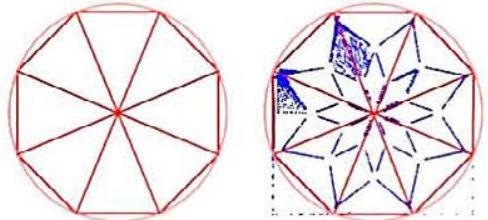

2. circumference intrados octagon
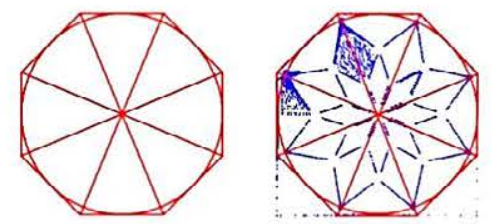
3. circumferences between octagon and big circumference
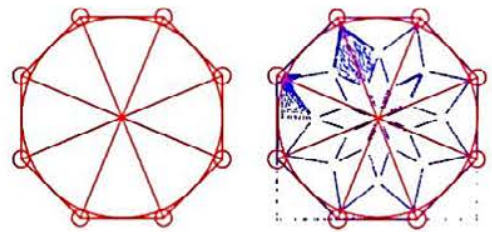

4. circumferences half small circunf. to define width of the side
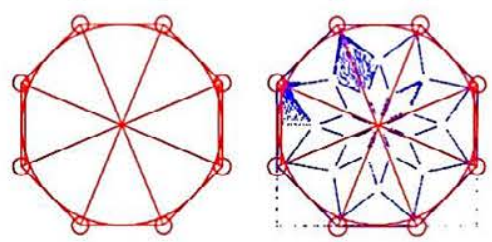

5. widht divided in three, so three circumferences
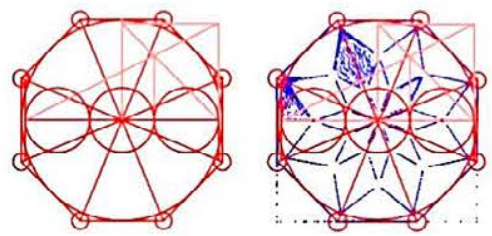

6. circumferences in all directions
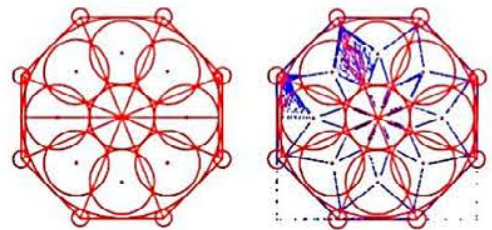

7. first lines from center circumferences to intersection axes-big circumf.
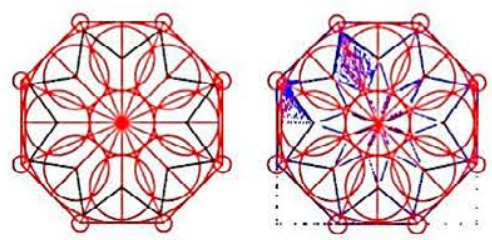

8. second lines from center

circumferences to intersection axes-central circumf.
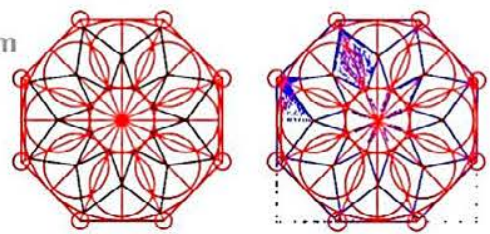

9. third lines connecting the middle
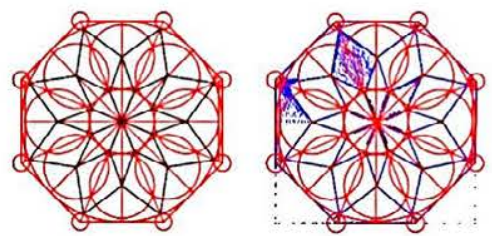

theorical drawing on the measured points

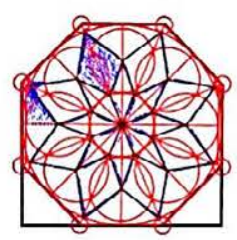

Fig. 132

Posibles pasos a seguir para el trazado de la planta. A la izquierda de manera teórica y a la derecha su cotejo con los puntos medidos. Estos dibujos son fruto del trabajo coordinado con el profesor Robert Bork. 
Seguramente el arquitecto que se enfrentó al diseño de esta bóveda partió de la premisa de realizar un enjarje en el que los nervios salieran separados y se cruzaran en su desarrollo. Pudiendo haber sido el proyecto de este elemento el que determinase la geometría del resto planteamos la hipótesis de que en este caso se da la estrategia contraria. Su definición depende del trazado general de la bóveda, pues un proceso sencillo permite determinar el lugar en el que los nervios se cruzan y su trazado.

Fig. 133

Planta de la bóveda con los puntos medidos en azul.

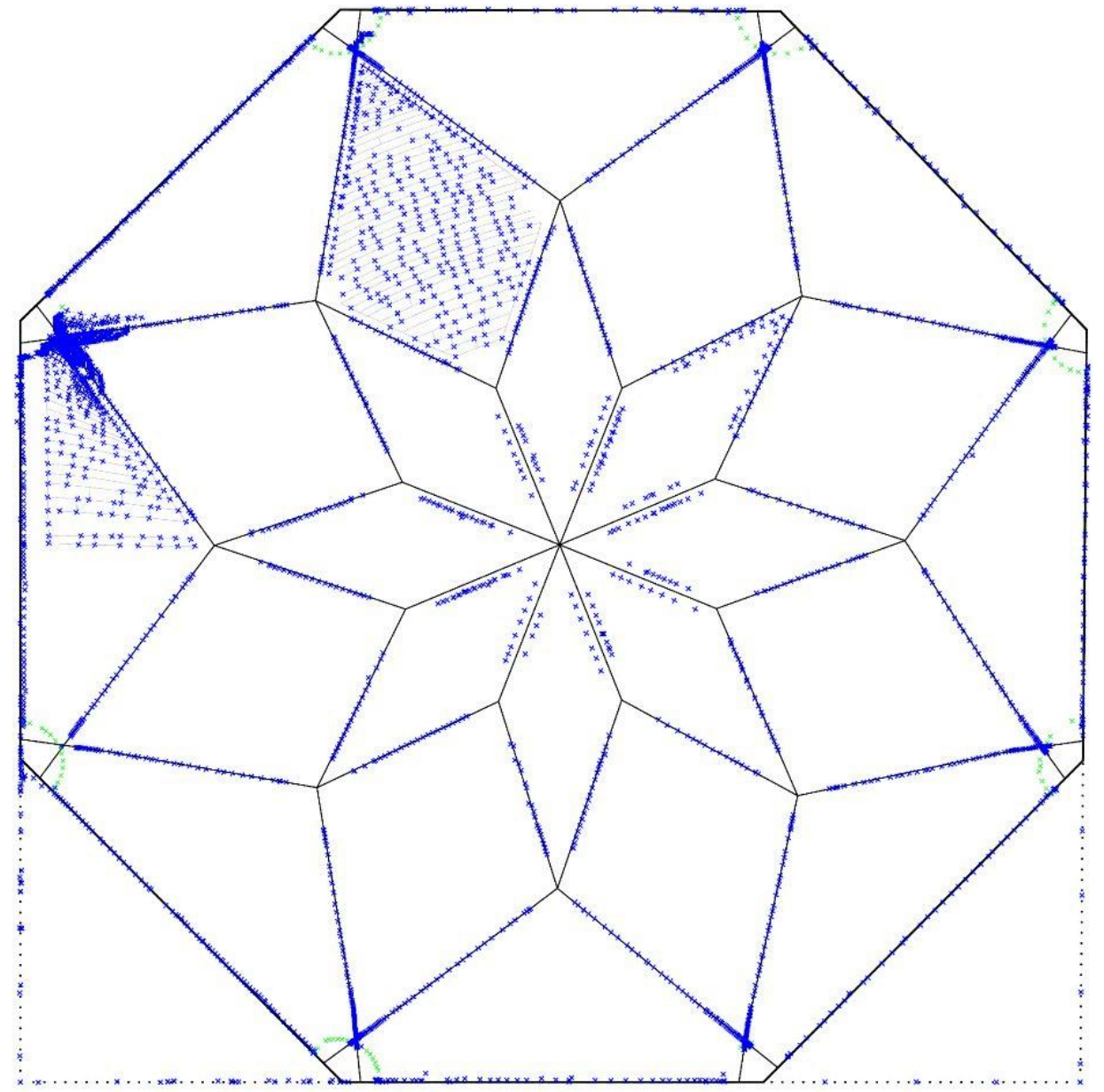

\section{0}

El control y la definición volumétrica de la bóveda

En la presente investigación nos hemos enfrentado principalmente al estudio de bóvedas cuatripartitas conformadas por dos ojivos cuyo control volumétrico no presenta mayores dificultades. Generalmente los ojivos son arcos de circunferencia que se cruzan en el centro, por lo que su trazado en elevación suele corresponderse con media circunferencia y la altura de la única clave de la bóveda se sitúa en la intersección de ambos, coincidiendo con su punto más elevado donde su tangente es horizontal.

Estudiar esta bóveda de la capilla del Condestable de planta centralizada, con trazado estrellado y diecisiete claves constituye, en este marco, un caso de especial interés y dificultad. Nos hemos enfrentado por primera vez 

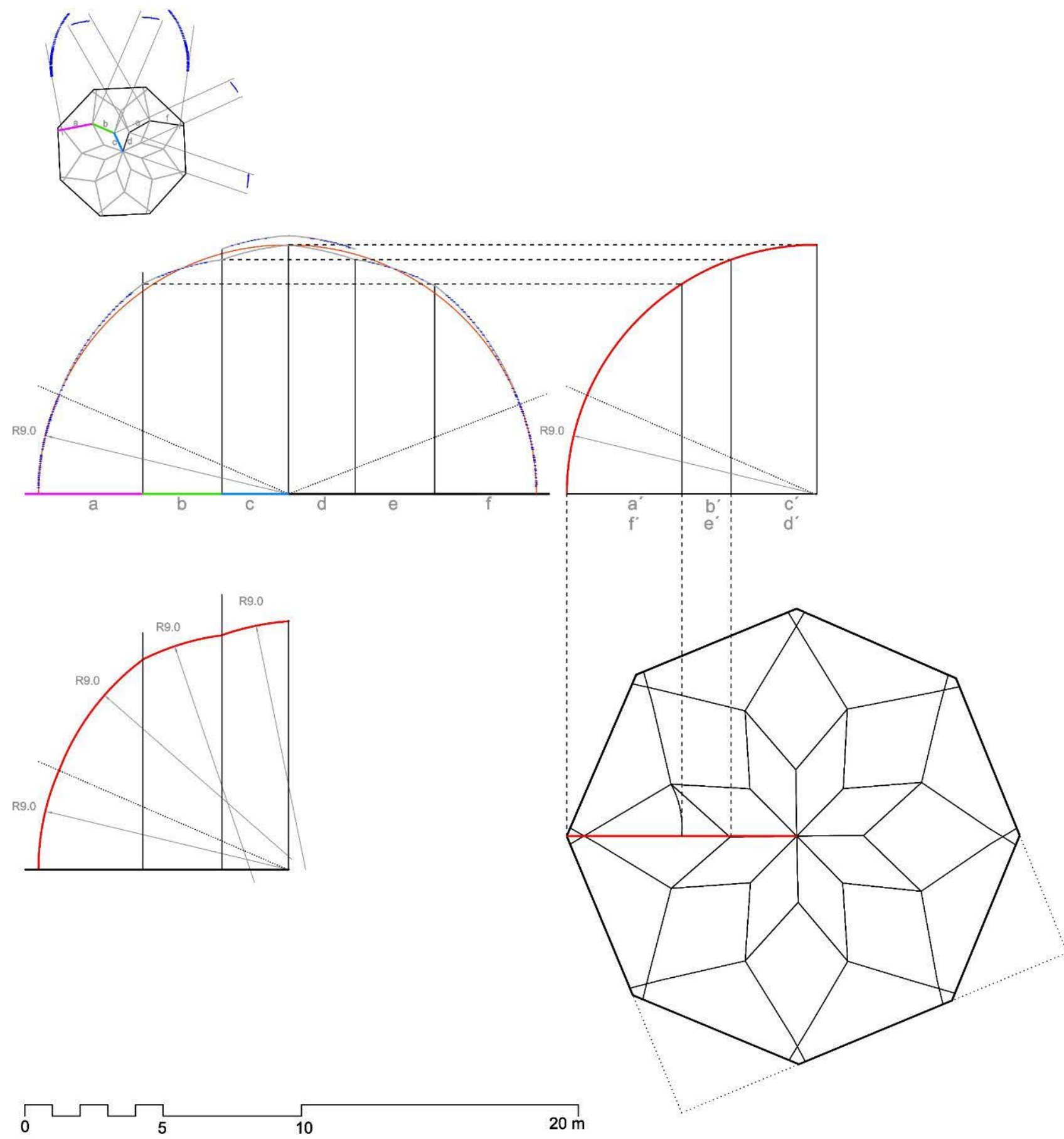

a la problemática del análisis de la volumetría de una bóveda de cierta complejidad a partir de su trazado de planta.

Fig. 134

Análisis de la sección de uno de los arcos en su recorrido entre

Para analizar en el programa de CAD la curvatura de los puntos de los nervios ojivos medidos en bóvedas cuatripartitas el procedimiento es dos rincones pasando por la clave central. sencillo: abatimos los puntos de cada uno de ellos sobre su correspondiente eje en planta, que coincide con las diagonales del cuadrado o del rectángulo. De este modo, podemos proponer hipótesis de arcos que se ajusten a la medición realizada y analizar cómo es el contacto con el muro- o pilar, capitel, etc- al dibujar también su situación en el abatimiento. 

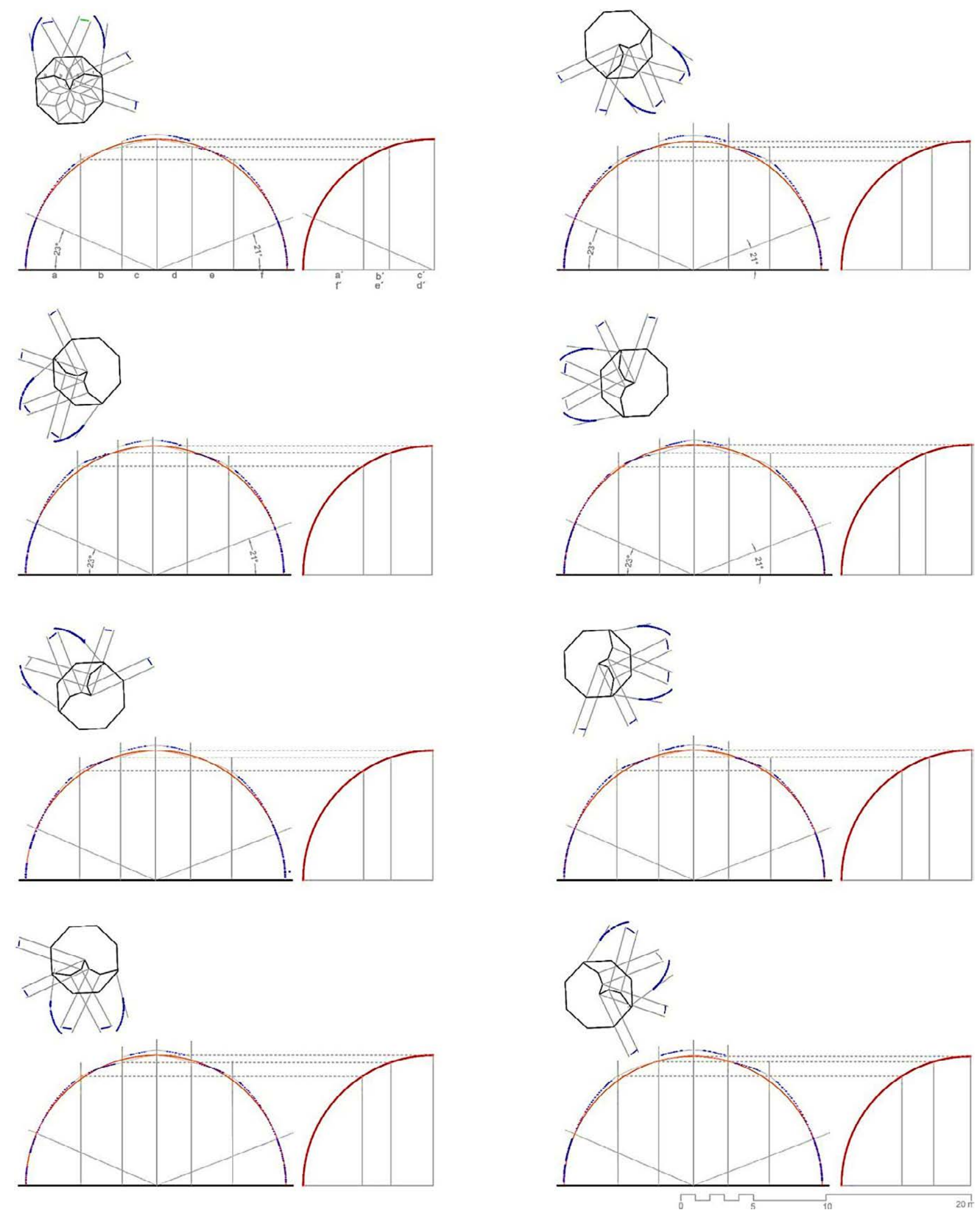

Fig. 135

Análisis de todas las secciones de la bóveda según la hipótesis presentada.
Sin embargo, en esta bóveda de la capilla del Condestable, no hay ojivos, es decir, no hay nervios que salgan de una esquina y mueran en la otra. El problema espacial es muy diferente al de la bóveda de crucería sencilla, por lo que nos planteamos cómo controlar este espacio centralizado sin recurrir a una circunferencia que coordine dos esquinas pasando por el centro; en definitiva, cómo pudo haberse afrontado el control volumétrico de esta bóveda. 
Tras algunos tanteos, decidimos valorar el resultado de trazar un recorrido quebrado desde un rincón al opuesto, pasando por un tercelete, un nervio de la estrella y el que llega a la clave central; y sus correspondientes al otro lado. Abatimos los arcos de cada uno de los tramos sobre su eje y, casi de manera inmediata, se hizo patente la necesidad de situar todos los segmentos con sus elevaciones de manera consecutiva conformando el segmento integrado por los tramos a (desde el arranque del tercelete), $b, c$ $y d, e, f$.

El resultado pareció, en un primer momento, decepcionante, pues esperábamos encontrar un perfil de puntos que se ajustase a una semicircunferencia y habíamos obtenido, sin embargo, una sección con muchas discontinuidades. Realizamos el mismo ejercicio para todos los posibles recorridos en la planta de la bóveda como el que habíamos planteado para poder así valorar si este resultado era compartido por el resto. En efecto, todas las secciones eran similares y si superponíamos unas sobre otras, la coincidencia era clara. Además, habíamos marcado la zona del final del enjarje y también en ese punto se producía un pequeño quiebro en el recorrido del arco. A partir de él se vuelve más vertical

Para estimar la desviación del perfil de los puntos abatidos con relación a la hipotética semicircunferencia, trazamos esta última haciendo centro en el lugar correspondiente a la clave central y con diámetro definido por el arranque de los terceletes, de los que sale además con tangente vertical. A partir de ahora la designaremos como circunferencia de radio $r$, con unos 9 metros. El resultado de la superposición de ambos trazados reveló algo inesperado: los puntos en la zona del enjarje coincidían, con un error mínimo -no más de 2 centímetros en los puntos más desfavorables- con la circunferencia $r$; y la cota de la clave central también se encontraba en el punto de tangente horizontal del arco, es decir, en su punto más alto. Los enjarjes tienen una altura de unos 3 metros y medio y cubren un ángulo desde el centro del arco de unos $21^{\circ}$.

La cuestión aún por resolver seguía siendo la situación de las otras dos claves hasta llegar a la central, pues su posición de distanciaba mucho de la circunferencia trazada. Para ello, indagamos la manera de encontrar un procedimiento que ligase la planta con el arco $r$ y la determinación en él de la altura de dichas claves, pues era clara la importancia de la situación de esos puntos para el trazado de la elevación.

Volvimos de nuevo a la planta de la bóveda y planteamos la posibilidad de que la posición de estos puntos no estuviese relacionada con el recorrido quebrado, sino con el eje que va desde la esquina del octógono hasta el centro de la bóveda, en el que se podría haber utilizado la circunferencia. Ésta se localizaría entre el vértice del octógono y su centro, con su comienzo tangente en el rincón. Su centro no se correspondería con el del 
centro de la bóveda, pues el radio es mayor porque es fruto de la suma se segmentos a (desde el arranque del tercelete), b y c.

Pensar en la utilización de este procedimiento podría relacionarse con la idea de controlar el volumen a través de una curva sin la necesidad de que se adapte a una media esfera, permitiendo establecer una secuencia de alturas de puntos relevantes con criterio. Hablaría de procedimientos sencillos para controlar el espacio en los que el resultado final ha de ser coherente, sin ánimo de adaptarse a formas ideales. Además, en este caso, ¿por qué no utilizarlo para la cota de estos nudos si las claves de la parte interior de la estrella también se localizan en ese eje? Las únicas distancias que habría que trasladar serían las relacionadas con las claves de la parte exterior de la estrella a la que se dirigen los terceletes.

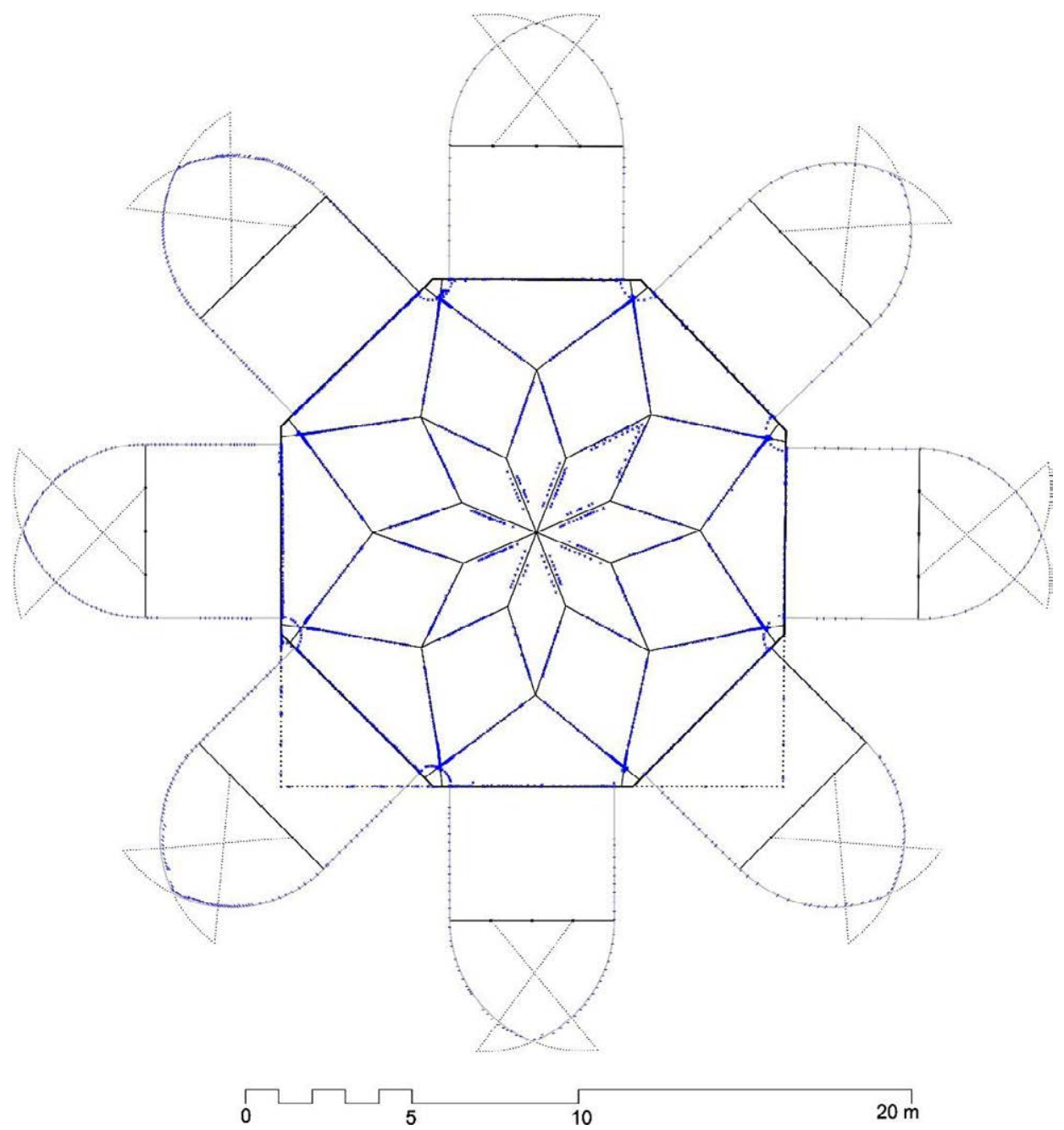

Si estas distancias desde el vértice del octógono hasta las claves en esta planta las llevamos a la circunferencia anteriormente trazada y dibujamos rectas verticales a partir de ellas hasta cortarla, obtenemos la altura de las claves de la bóveda.

Una vez que teníamos situados dichos puntos en el recorrido quebrado probamos a superponer arcos de circunferencia $r$ en el resto de puntos medidos de la sección, pudiendo advertir la clara correspondencia entre

Fig. 136

Análisis de los nervios formeros. 
ellos y la curva. Además, el perfil de los nervios en toda la bóveda es el mismo, por lo que nos parece coherente el hecho de que su curvatura también. Esto hubiera facilitado los trabajos de talla, pues todas las dovelas serían iguales. No estamos refiriéndonos a un proceso de estandarización, sino de inteligencia constructiva. ${ }^{305}$

Por lo tanto, el procedimiento es sencillo. Primero se despliega el recorrido quebrado de la planta de la bóveda -la suma de segmentos del tercelete, lado de la estrella y nervio que va a la clave central- con el que se determina el radio $r$ que servirá para la curvatura del arranque de los nervios en el enjarje y la altura de la bóveda. En la planta se traza eje que va desde los vértices del octógono al centro de la bóveda y en él se miden las distancias desde el rincón hasta la traslación por giro de la primera clave sobre el eje y hasta la segunda clave. Estas distancias se llevan a la circunferencia $r$ anteriormente trazada partiendo del arranque del arco y se elevan en vertical hasta cortarlo. De este modo se determinan las alturas de las claves. Se trasladan estas alturas a sus puntos correspondientes en el recorrido quebrado desplegado y se trazan los arcos de radio $r$ que unen esos puntos de la bóveda. La volumetría resultante poco tiene que ver con una esfera, pero sí con una idea volumétrica.

Los nervios formeros arrancan una vez ha finalizado el recorrido en el enjarje de los terceletes, localizándose su clave ligeramente más elevada que la clave a la que éstos acometen, unos 15 centímetros. Su trazado es sencillo. Se divide su luz en cuatro partes y se trazan circunferencias de radio $3 / 4$ de la luz que arrancan con tangente vertical de los extremos conformando un arco apuntado.

Prinzipalbogen, métodos de control volumétrico de la bóveda de crucería 306

Tras analizar la bóveda de la capilla del Condestable puede que se tenga la tentación de hablar de la aplicación del método llamado Prinzipalbogen para la generación de su volumetría; y más aún si hablamos de una autoría con apellido "Colonia".

El trabajo realizado en esta bóveda no es más que un sistema sencillo y eficaz de control espacial de un trazado en planta que no podemos valorar en relación con Alemania o España, pues para poder hablar de la utilización de un único arco para el trazado de bóvedas sería necesario realizar el análisis de un gran número de ellas y que se probase el uso de esta

\footnotetext{
305 Sobre estandarización: Dieter Kimpel, "Le développement de la teille en serie dans I'architecture médiévale et son rôle dans I'histoire économique ", Bulletin Monumental, CXXXV, n³, (1977), 195-222; Dieter Kimpel y Robert Suckale, L'Architecture gothique en France 1130-1270, (Paris: Flammarion, 1990), 36 y 220-221.
}

${ }^{306}$ Agradezco a Elena Pliego de Andrés sus correcciones y ayuda en esta parte. 

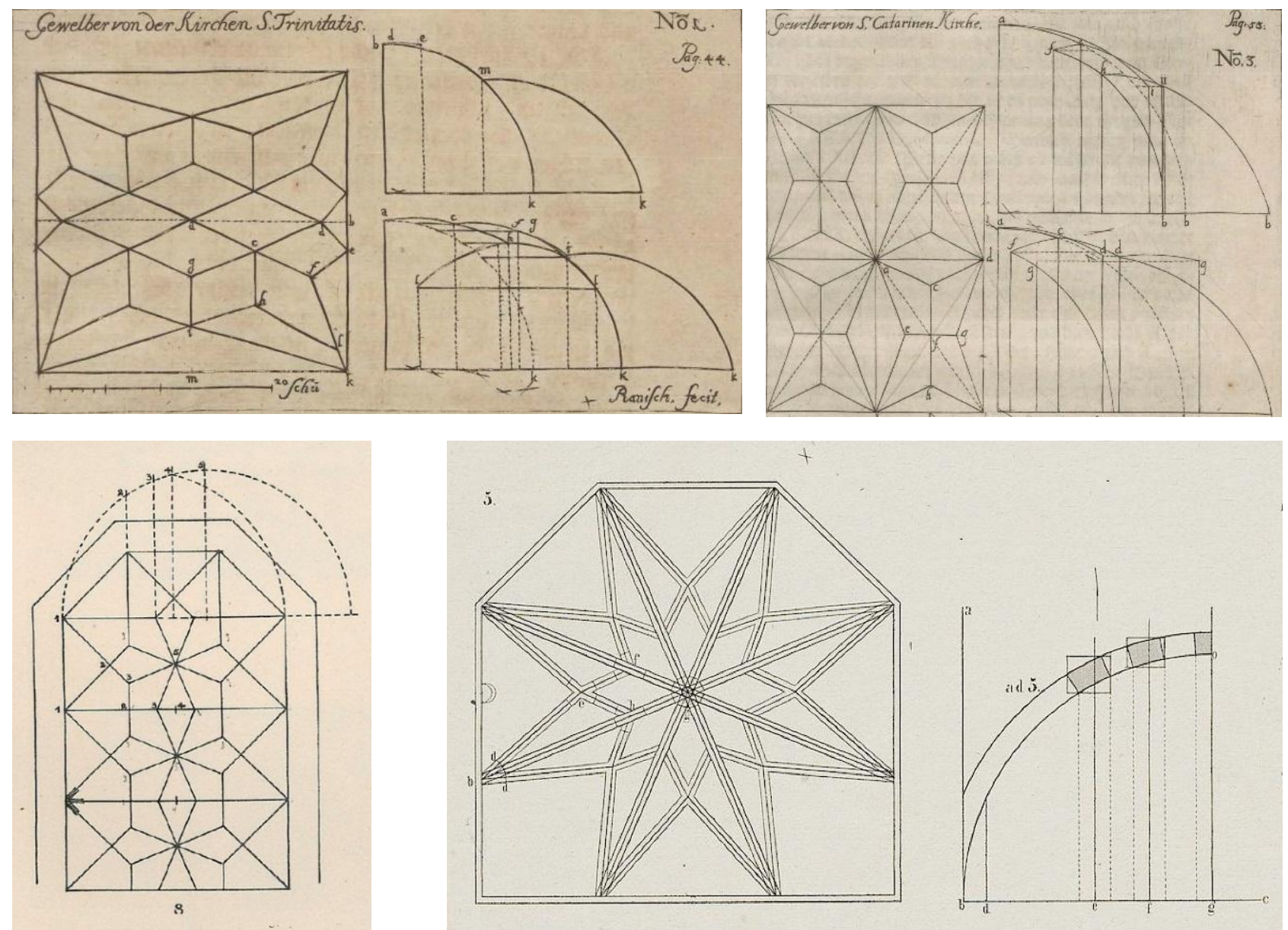

Fig. 137

Arriba Ranisch (1695, 89 y 119), abajo a la izquierda Meckel (1933, 21: fig. 8); abajo a la derecha Hoffstadt (184063, lámina XIV. A, 5). estrategia. ${ }^{307}$ Hemos desarrollado la hipótesis de que en este caso se trabaja así, pero seguramente sean muchas las bóvedas en las que la utilización de diferentes curvaturas $u$ otros procedimientos de control volumétrico hayan sido los elegidos.

Norbert Nußbaum y Sabine Lepsky, en el capítulo titulado Der Prinzipalbogen en Das gotische Gewolbe, abogan por la prudencia. No niegan la existencia de métodos de trazado con un único arco en manuscritos medievales del gótico tardío alemán, ${ }^{308}$ pero incitan a la reflexión cuestionando en qué medida esta práctica era aplicada realmente

307 Ana López Mozo et al. Han estudiado dos bóvedas de similar trazado en planta, una resuelta con arcos que tienen la misma curvatura mientras que en la otra se utilizan varias curvas diferentes. Ana López Mozo et al., "Asymetrical vaults in Late European Gothic: Basel and Bebenhausen as case studies", Proceedings of the 5th International Congress on Construction History, (Chicago, 2015).

308 Nussbaum y Lepsky, Das gotische Gewölbe, 179-180. Se refieren a su presencia en tratados principalmente de finales del XVI. Señalan que la distribución de arcos "nach der Reiung" que aparece en el manuscrito de Lorenz Lechler seguramente haga referencia a este procedimiento. También aparece en el WG. 


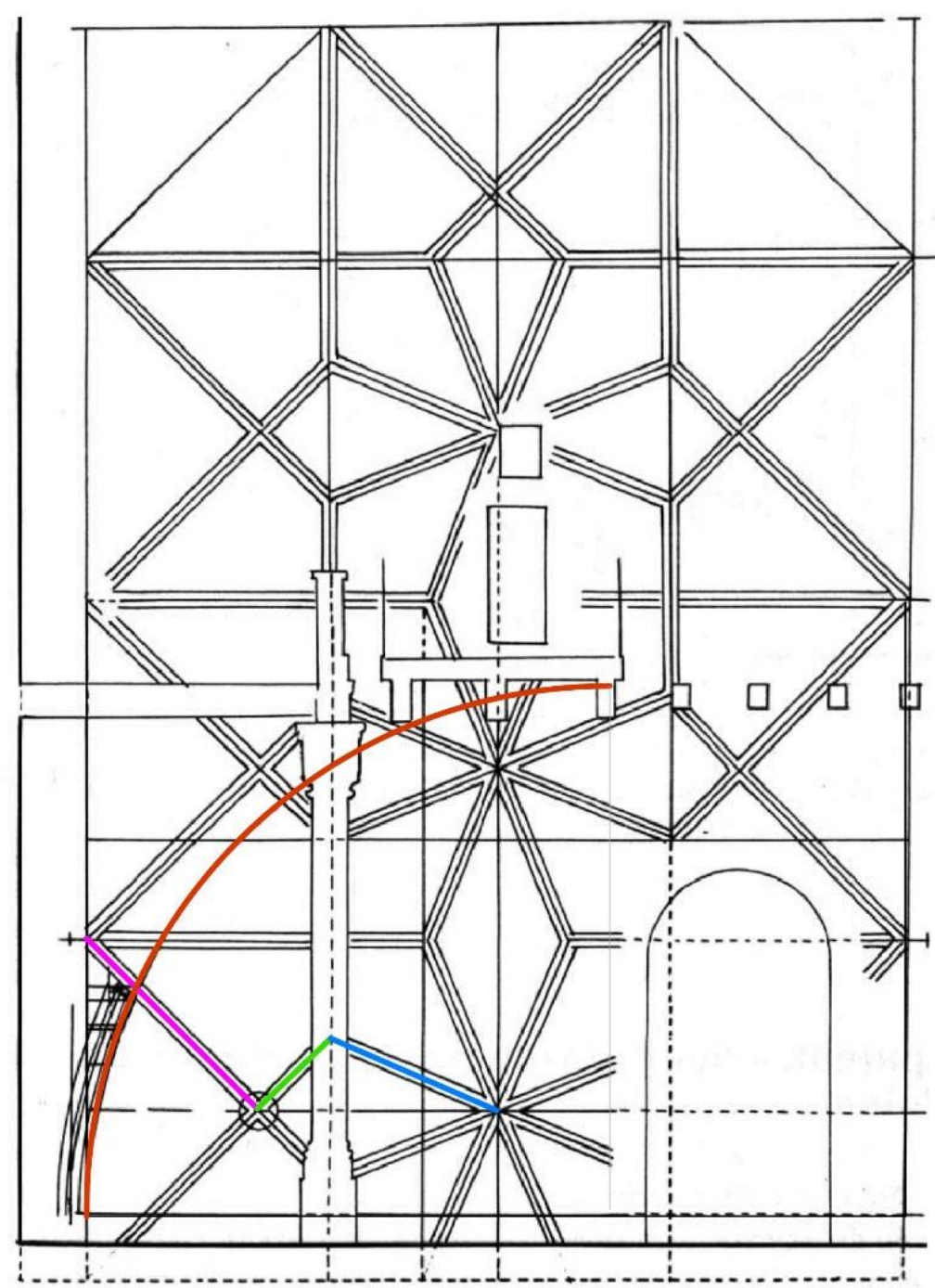

en la construcción real, ${ }^{309} \mathrm{O}$ incluso si era un procedimiento conocido en épocas anteriores u otros lugares. ${ }^{310}$ Y señalan, además, que la difusión del Prinzipalbogen no ha sido probada fuera del ámbito germánico. ${ }^{311}$

También indican que mediciones llevadas a cabo han demostrado el trabajo con dos o más radios, contradiciendo, por tanto, la utilización sistemática de este principio. ${ }^{312}$ Eso no impide que su utilización no se haya podido probar en algunas bóvedas- muy pocas- siendo asombroso la constatación de su uso en la montea de la iglesia de St. Sigismund en

\section{Fig. 138}

Cálculo del radio del nervio a partir de la suma de segmentos quebrados en un único eje. Trazado sobre Brykowska, 1992, 102: fig. 2.

\footnotetext{
309 Nussbaum y Lepsky, Das gotische Gewölbe, 180.

${ }^{310}$ Nussbaum y Lepsky, Das gotische Gewölbe, 177.

${ }^{311}$ Nussbaum y Lepsky, Das gotische Gewölbe, 181.

312 Nussbaum y Lepsky, Das gotische Gewölbe, 180.
} 
Polonia que mostramos anteriormente, ${ }^{313}$ pues contiene la única montea de enjarje medieval que conocemos como ya han señalado Nußbaum y Lepsky. ${ }^{314}$

Parece ser que esta idea del control volumétrico de la bóveda mediante la utilización de una única curvatura parte de una idea concebida en el siglo XVII por Bartel Ranisch, quien en su publicación Beschreibung aller Kirchengebaüde der Stadt Danzig, en la que estudia las bóvedas de las iglesias de dicha ciudad, presenta una serie de dibujos de elevaciones de bóvedas trazados mediante la utilización de un único arco. ${ }^{315}$ Según el tipo de bóveda, Ranisch aborda la utilización de este arco único de una manera u otra, proponiendo un método para las bóvedas que se "adaptan" espacialmente a un tramo longitudinal y otro para las bóvedas más centralizadas o estrelladas. La idea en ambos casos es poder controlar la volumetría de la bóveda mediante un arco que permita fijar su altura máxima -el nudo en el punto medio del tramo para bóvedas longitudinales o en el centro de la bóveda para centralizadas- y de este modo situar la cota del resto de claves jerárquicamente desde ese punto apoyándose en dicho arco. Y, del mismo modo, que esa misma curvatura sirva para resolver lo que ocurre entre los nudos, es decir, los nervios de la bóveda.

Esta teoría fue retomada por Hoffstadt (1840), ${ }^{316}$ Ungewitter (1859), ${ }^{317}$ Meckel (1933), ${ }^{318}$ y más recientemente por Müller, ${ }^{319}$ quien en su texto de 1990 realiza una clasificación de tres posibles maneras de configurar los arcos de la bóveda, siendo dos de ellas explicaciones de Ranisch, Hoffstadt y Meckel. Las últimas y más conocidas revisiones sobre el

${ }^{313}$ Maria Brykowska, "Quadratur des spätgotischen Gewoelbes im Chorraum der Pfarrkirche zu Szydlowiec/Polen“, Architectura 22, (1992),101-108.

${ }^{314}$ Nussbaum y Lepsky, Das gotische Gewölbe, 180.

315 Bartel Ranisch, Beschreibung aller Kirchengebäude der Stadt Danzig, (Danzig, 1695). Elena Pliego de Andrés está desarrollando en estos momentos una investigación sobre el trabajo de Ranisch. En Elena Pliego de Andrés, "La geometría de las bóvedas estrelladas en el gótico tardío alemán", Actas del séptimo congreso nacional de historia de la construcción, (Madrid, 2011), la autora realiza un recorrido desde Ranisch hasta posteriores interpretaciones del término Prinzipalbogen por otros autores posteriores.

${ }^{316}$ Friedrich Hoffstadt, Gothisches ABC Buch: das ist Grundregeln des gothischen Styls für Künstler und Werkleute, (Frankfurt a. M.: Schmerber, 1840-63).

${ }^{317}$ G. G Ungewitter, Lehrbuch der gotischen Constructionen, (Leipzig: Weigel, 1859-1864); G. G Ungewitter, K. Mohrmann, Lehrbuch der gotischen Constructionen, (Leipzig: Weigel, 1890).

${ }^{318}$ C.A. Meckel, „Die Konstruktion der Figurierten Gewölbe in der deutschen Spätgotik en Architektura", Jahrbuch für Geschichte der Baukunst (1933), 1: 107-114.

${ }^{319}$ Werner Müller, Grundlagen gotischer Bautechnik, (Munich, 1990). 
Prinzipalbogen han sido llevadas a cabo por Nussbaum y Lepsky (1999); ;20 y Wendland (2008) $)^{321}$ en Alemania. En España, Elena Pliego ha realizado una aproximación al tema durante su investigación centrada en Ungewitter. ${ }^{322}$ Tampoco hay que olvidar, sin embargo, que en algunas ocasiones el término Prinzipalbogen ha sido objeto de usos inapropiados debido a su incomprensión.

Es curioso comprobar cómo para Hoffstadt, Ungewitter o Meckel el modo de proceder para desarrollar la volumetría de la bóveda mediante un arco único es diferente que lo presentado por Ranisch. Müller analizó un ejemplo de cada uno de los autores en el apartado III de su clasificación. ${ }^{323}$

Müller presenta el trazado de una bóveda contenida en el artículo de Meckel Die Konstruktion der Figurierten Gewölbe in der deutschen Spätgotik para ilustrar el procedimiento en el caso de una bóveda longitudinal. ${ }^{324}$ En él se muestra cómo determinar el radio mediante la adición consecutiva en un eje horizontal de los segmentos de un recorrido quebrado de los nervios desde el enjarje hasta el nudo central, cuyo resultado genera radios de mayor curvatura

El caso de la bóveda de St Sigismund corresponde a este procedimiento, dando testimonio de su uso a principios del siglo XVI en una construcción real.

Para la bóveda estrellada, Müller hace uso de un ejemplo de Hoffstadt, del Gothisches ABC Buch: das ist Grundregeln des gothischen Styls für Künstler und Werkleute, anterior al de Meckel. ${ }^{325}$ Se trata en este caso de una bóveda con el trazado de una estrella de ocho puntas en la que para determinar el radio se toma el recorrido desde uno de los terceletes que emerge de la punta de la estrella pasando por otro segmento que va desde la clave entre este tercelete y el contiguo hasta el nervio trazado desde la siguiente punta

\footnotetext{
320 Nussbaum y Lepsky, Das gotische Gewölbe. Eine Geschichte seiner Form und Konstruktion, (Darmstadt: Wissenschaftliche Buchgesellschaft, 1999).

${ }^{321}$ David Wendland, Lassaulx und der Gewölbebau mit selbsttragenden Mauerschichten, (Petersberg: Michael Imhof Verlag, 2008).

322 Pliego de Andrés, "La geometría de las bóvedas estrelladas en el gótico tardío alemán".

${ }^{323}$ Müller, Grundlagen gotischer Bautechnik, 155-157

${ }^{324}$ Meckel, „Die Konstruktion der Figurierten Gewölbe in der deutschen Spätgotik en Architektura", 21, 8.

${ }^{325}$ Hoffstadt, Gothisches ABC Buch: das ist Grundregeln des gothischen Styls für Künstler und Werkleute, lámina XIV. A, 5.
} 
al centro; y finalmente hasta el centro. Sumando todos los segmentos en horizontal de manera consecutiva se traza el radio.

En estos ejemplos, el perfil de la bóveda no se ajusta ni en el primer caso a un cañón ni en el segundo a una esfera. Es más, la altura que se obtiene para la bóveda es mayor que mediante el trazado propuesto por Ranisch, pues esta cota la limitaba desde un principio a la mitad del tramo o a la mitad de diámetro de la diagonal y, aquí, al tratarse de la adición de segmentos del recorrido en planta, siempre se obtienen radios mayores.

Parece ser que Ungewitter advirtió tal efecto. Según recoge Elena Pliego, éste explica en primer lugar el modo de la obtención del Prinzipalbogen basándose en Ranisch y, a continuación, cuando se refiere al método que había desarrollado ya Hoffstadt, propone que para fijar la altura total de la bóveda se determine mediante el método de Ranisch, de manera que el centro del arco del Prinzipalbogen hallado de la segunda manera quede por debajo de la línea de imposta. ${ }^{326}$

Se ha decidido mostrar estos ejemplos referentes a la determinación de la curvatura de los radios de la bóveda y la altura de las claves debido, en cierto modo, a su parecido con la hipótesis planteada para la capilla del Condestable.

No se planteó la solución para la bóveda basada en estos métodos, pero comparte con ellos la búsqueda de una estrategia global que permita hacer frente a la resolución de la volumetría de la bóveda de manera sencilla y controlada.

La idea del posible uso de un arco para la localización de nudos fundamentales de la bóveda a partir de claros trazados bidimensionales parece viable en el caso del Condestable, sin la necesidad de que deba ser denominado Prinzipalbogen o tenga que enmarcarse de manera cerrada en ninguno de estos procedimientos.

\section{$\underline{\text { Perfiles de los nervios }}$}

Todos los nervios de la bóveda, a excepción de los formeros, comparten el mismo perfil, pudiéndose inscribir más o menos en un rectángulo de iguales dimensiones. El ancho del nervio es de 23 centímetros, mientras que la medida del canto -37 centímetros- se corresponde con su dimensión vertical hasta el encuentro con la plementería, por lo que no se trata del tamaño real del nervio, que será mayor. Esta dimensión a partir del contacto con la plementería es imposible de estimar debido a que el trasdós de la bóveda no es visitable.

\footnotetext{
${ }^{326}$ Pliego de Andrés, "La geometría de las bóvedas estrelladas en el gótico tardío alemán",
} 1154. 

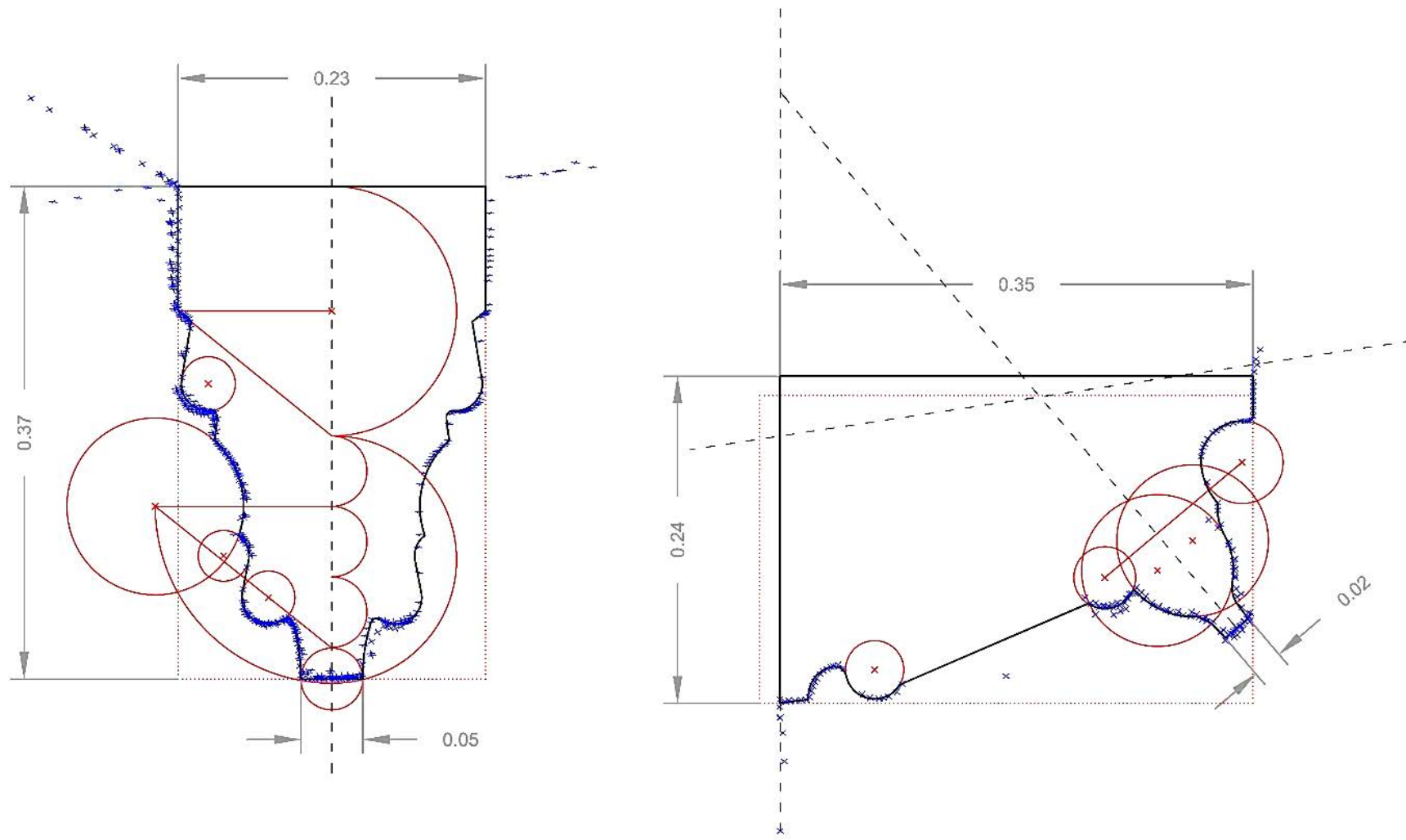

Para el trazado del perfil de los nervios hemos tomado puntos con la estación de dos terceletes, dos nervios de la estrella y dos nervios que se dirigen al centro de la bóveda. Una vez superpuestos verificamos que coinciden y ese volumen de puntos nos ha permitido realizar una hipótesis

Fig. 139

Perfiles de los nervios. A la izquierda, el de los terceletes y a la derecha el de los formeros. del trazado. Las propuestas sobre la geometría del perfil son resultado de la necesidad de establecer reglas que permitan trazar con la mayor precisión posible el contorno del nervio, siendo conscientes de las limitaciones que tiene llevar a cabo tal empresa mediante los puntos tomados con la estación. Para un dibujo exacto del perfil sería necesario tomar los datos directamente con un medidor de perfiles, lo que es únicamente posible si se dispone de una estructura de andamios que permita llegar hasta ellos.

El perfil de los nervios terceletes, de la estrella y de los nervios centrales está compuesto de un filete central de unos 5 centímetros flanqueado por dos baquetones que, tras dos concavidades, dan paso de nuevo a dos baquetones que mediante un pequeño quiebro acaban conformando el espesor total del nervio que avanza en vertical hasta la plementería. En el caso de los nervios formeros, el perfil presenta la particularidad de componerse de dos partes conectadas por una franja de decoración escultórica que no hemos reproducido en nuestro dibujo. Cerca de los terceletes se localiza una molduración similar al perfil de un nervio.

\section{El enjarje}

Los enjarjes de la capilla del Condestable son ocho y, en principio, son todos iguales. Están compuestos por dos nervios terceletes que nacen separados de una base cónica y que, en el trascurso de su recorrido se 


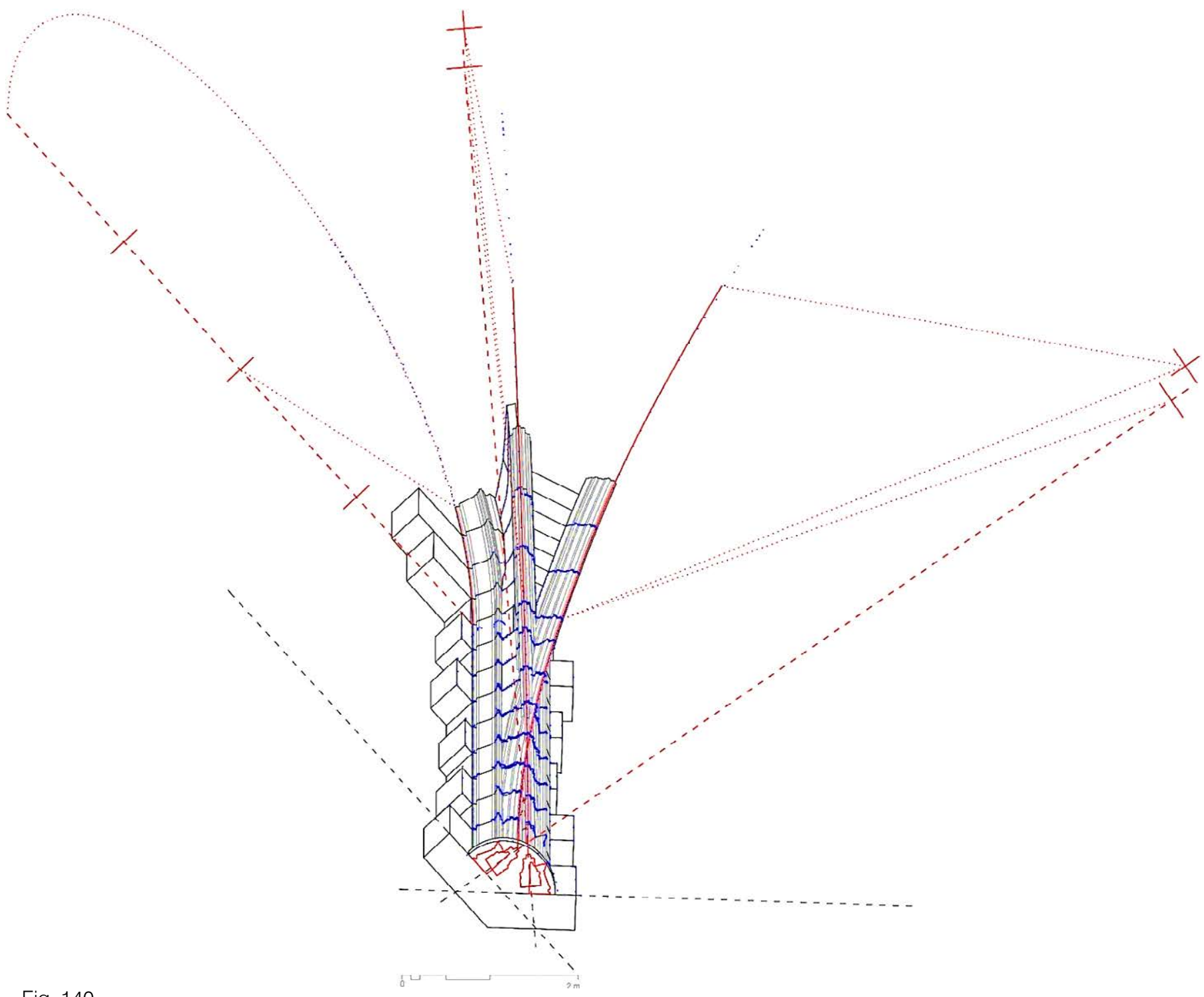

Fig. 140

Análisis geométrico del enjarje y de sus piezas en relación a los puntos tomados. cruzan de manera simétrica para, a continuación, separarse. Están flanqueados por nervios formeros peraltados a ambos lados.

El arranque de estos arcos formeros se realiza a partir del final de una pieza especial situada a continuación de la junta inclinada de los terceletes que recibe las primeras dovelas. Hasta ese punto los formeros son meras molduras verticales que enmarcan el recorrido de los otros nervios. Forman también parte del enjarje aunque su última pieza con lecho inclinado se localiza a mayor altura que el corte inclinado del resto. Además el comienzo de la curvatura de estos nervios viene significado por un elemento decorativo, un capitel situado en la pieza inferior.

Los arcos formeros se encuentran peraltados para poder dar cabida en los muros a los grandes ventanales que iluminan la capilla. Es necesario que no interfieran con el cruce de los terceletes. Si los formeros hubiesen arrancado a una cota similar a la de los terceletes la solución habría sido inviable debido a la difícil coordinación del extradós de ambos nervios. La solución existente es clara, elegante y permite que las claves de los formeros queden prácticamente a la misma altura que las claves a las que 


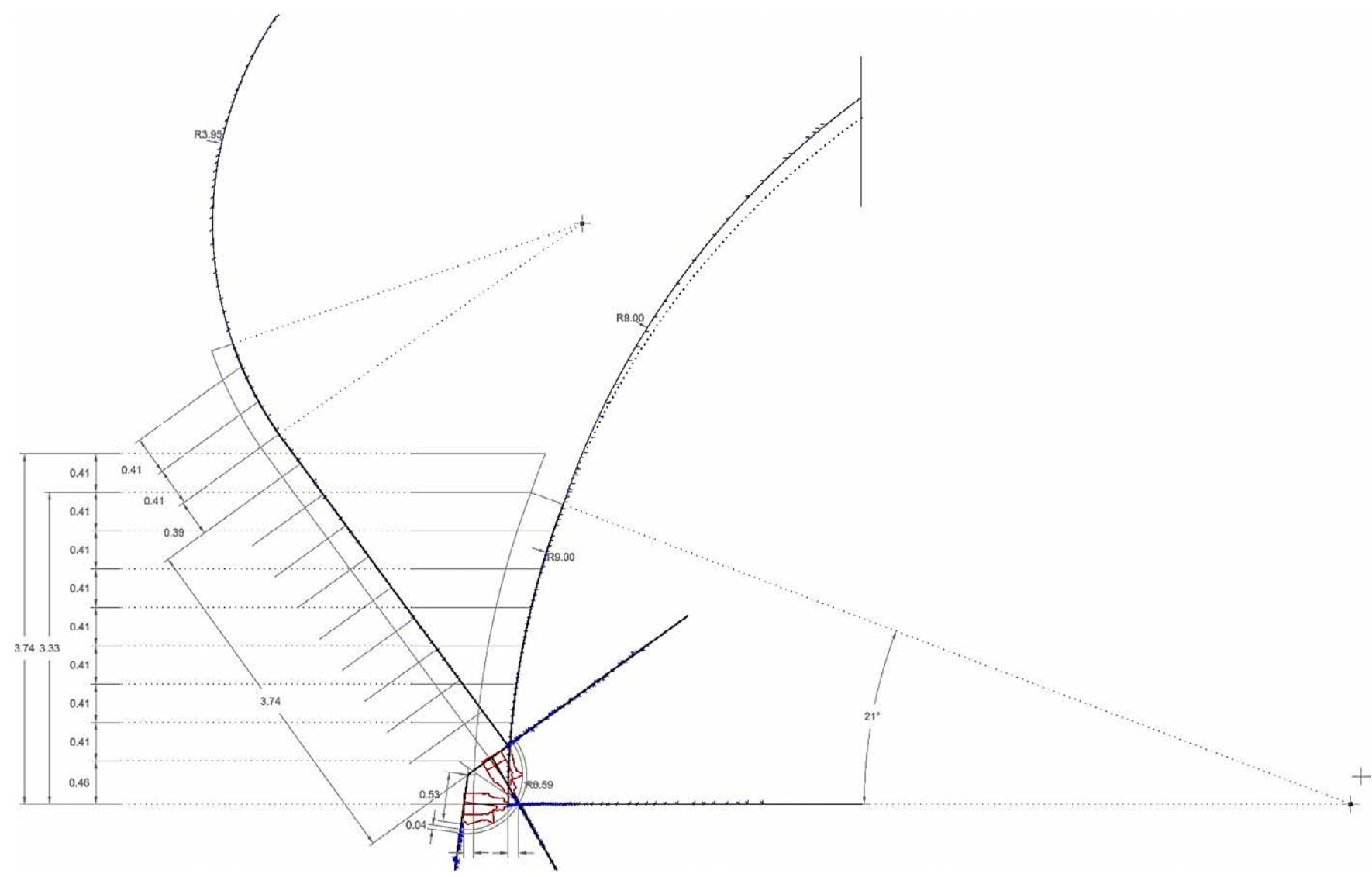

llegan los terceletes. Esto permite ejecutar la plementería con hiladas horizontales hasta llegar a una altura de 1,85 metros. A partir de ahí, la superficie va tomando inclinación desde el muro hacia el nervio con una cierta concavidad.

En su arranque en planta, los nervios terceletes se encuentran separados unos 12 centímetros. Es difícil valorar su situación en este punto, pero proponemos la hipótesis de que simplemente el canto del nervio medido hasta la plementería se sitúa en la mitad de segmento de su eje entre el corte con la base circular del capitel, que además coincide con el cruce en planta de los nervios y la línea del muro. De este modo, también es sencillo pensar que la distancia desde el final medido del nervio y el muro nos pueda hablar de la dimensión real del perfil, pues habría que sumarle unos 10 centímetros que seguramente fueran necesarios para la cola del nervio en la unión con la plementería.

Los formeros se situan en relación al muro y el intradós del filete del pequeño perfil que se encuentra cercano a los terceletes está contenido dentro de una circunferencia paralela a la del capitel.

La geometría de los arcos, como hemos visto con anterioridad, viene marcada por el diseño en planta y volumétrico general de la bóveda. La bóveda traza el enjarje. Aun así, ciertas decisiones de diseño son tomadas para éste; la primera, y más importante, el hecho de que el cruce de los
Fig. 141

Posible montea para el enjarje de la capilla. 
Fig. 142

Análisis de las piezas que componen el enjarje.

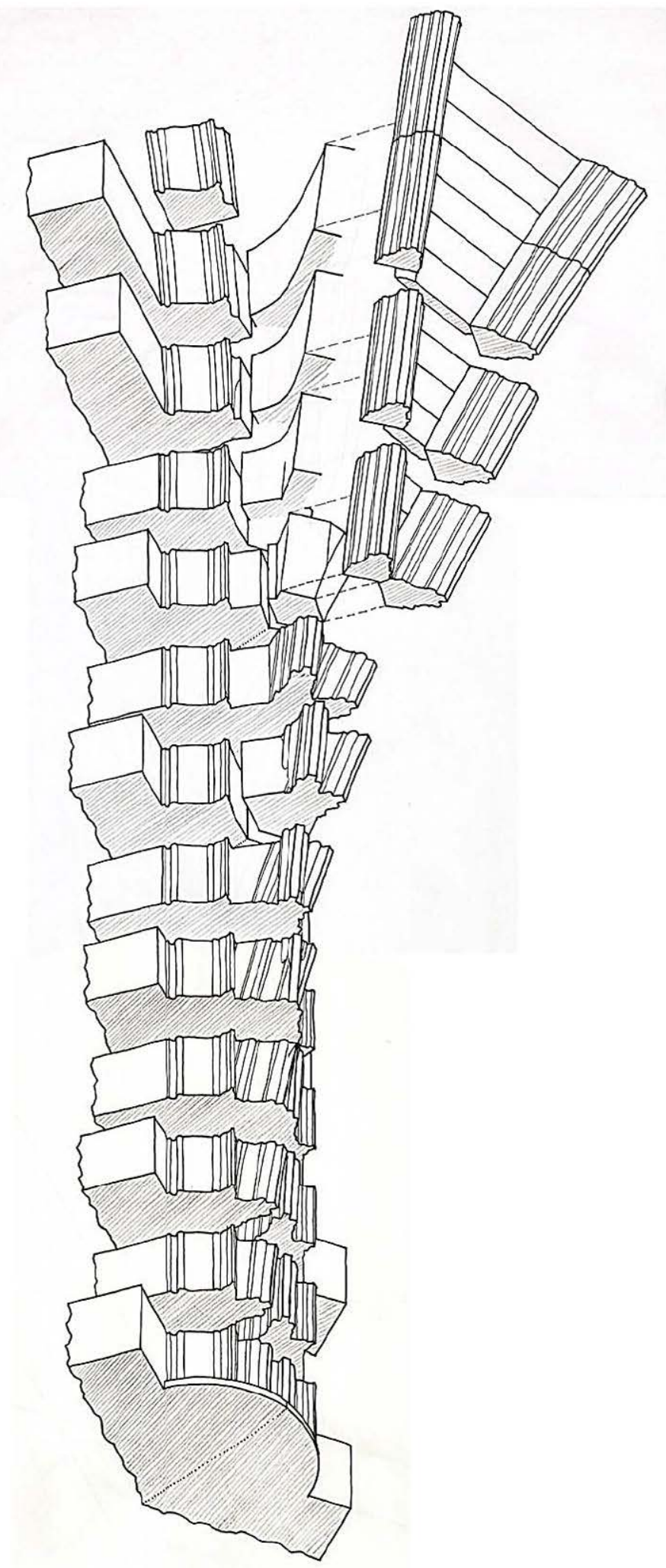

nervios se resuelva dentro de las piezas con lechos horizontales que traban con el muro. Dicha solución en este caso no acarrea el problema de que este punto se encuentre muy alejado del muro debido a la gran curvatura de los nervios, que en el recorrido del enjarje son bastante verticales. 
Todos los nervios, además, arrancan de un cono cuya base es la circunferencia en la que se enmarcan los formeros. Tiene una parte cilíndrica de unos 5 centímetros elevándose a partir del capitel y a continuación se desarrolla el cono al cual hemos dado una inclinación "a estima", pues esa zona es imposible de medir al no ser visible desde el suelo. ${ }^{327}$

La altura desde la base hasta el lecho en el que se localiza el plano inclinado de los terceletes es de 3,74 metros. Hasta esa altura el enjarje está compuesto por 9 piezas con una altura cada una de unos 41 centímetros, siendo la primera un poco más alta- 46 centímetros- debido al peralte del cilindro de base del cono. Por lo tanto, incluso en esta primera pieza, si descartamos esta base y tenemos en cuenta el lugar del arranque de los nervios, volvemos a tener una altura de 41 centímetros.

La siguiente hilada, la que funciona a modo de transición entre los terceletes y el arranque de los formeros tiene una altura menor, de 39 centímetros. Además, es la única en la que con la estación y con los prismáticos hemos podido comprobar la existencia de una junta vertical, de modo que se compone por tres piezas. Una central, a la que llamamos pieza especial, y dos piezas laterales en las que nos volvemos a encontrar el perfil vertical del formero con el capitel situado en la parte superior que anuncia el arranque del arco formero.

La pieza especial pasa desapercibida. Fuimos conscientes de su existencia gracias a la medición de las juntas de la plementería entre los terceletes. De este modo advertimos que la primera junta estaba exactamente a la misma cota que el lecho de la pieza. Además, debido al reducido espacio que quedaba entre la junta vertical que dividía las piezas y los terceletes, la solución de este espacio mediante varios elementos nos parecía difícil y problemática, lo que nos daba mayor seguridad al plantear la existencia de esta pieza especial de transición. Es una pieza cuyo frente contiene las dos superficies de trasdós de los nervios terceletes, pues ha de asegurar el contacto con las primeras dovelas.

El aparejo continúa con dos piezas horizontales para los formeros, también de 41 centímetros de altura. Tras la medición y estudio del elemento, planteamos la posibilidad de que la primera dovela de los formeros sea la pieza de transición entre los lechos horizontales e inclinados, pero es difícil asegurarlo debido a la dificultad para la toma de puntos es esa localización. De este aspecto, quedamos a la espera de futuras investigaciones.

\footnotetext{
327 Sabemos que el enjarje arranca así gracias a una fotografía que nos ha facilitado Enrique Rabasa, quien realizó una visita a la Capilla durante las últimas obras de restauración en las que se había colocado una enorme estructura de andamios.
} 
No sabemos si la altura de las piezas del enjarje viene determinada por la altura de las piedras de las que se disponía para la obra, si fue resultado de dividir una cierta altura en partes iguales, si corresponde con un pie y medio castellano, etc. Lo que sí podemos asegurar es que su situación es muy ventajosa para el control de la talla en situaciones complejas, como es el cruce de los nervios.

Las tres primeras hiladas del enjarje seguramente estén solucionadas por dos piezas cada una de ellas. Enrique Rabasa, durante la visita al lugar pudo meter la mano por el hueco entre los dos ojivos y comprobar que la parte interior del perfil estaba perfectamente labrada, lo que muestra claramente el trabajo con plantillas y prueba que no pudo ser labrado in situ. ${ }^{328}$ También, por ello, sería muy difícil pensar que hubiesen sido realizadas en una única pieza, pues la labra de la zona interna sería muy difícil de ejecutar y las piezas serían de dimensiones muy considerables. Por lo tanto, estas piezas son bastante singulares, ya que en ellas no existe ninguna vinculación entre los nervios, y son, de algún modo, perfiles de nervios aislados que se cortan por planos horizontales.

Entre la cuarta y la quinta pieza es cuando entran en contacto los perfiles y se resuelve el cruce de los nervios. Es curioso que prácticamente en el cruce se sitúe una junta. Esto facilita bastante el trabajo de coordinación de los perfiles en el momento de la labra y evita errores de ejecución, permitiendo mayor control de la dirección de los nervios.

La sexta pieza presenta la particularidad de que la parte central es solucionada como cualquier encuentro de nervios en un enjarje corrientepues se trata de la moldura de dos nervios que se aproximan- mientras que en los laterales avanza un plano vertical hacia el frente, desde la moldura del formero y en relación al espesor del nervio, en el que la moldura de un ojivo interseca al opuesto. Esto había comenzado a ocurrir en la pieza inferior, pero en esta se produce una intersección de mayor complejidad.

Esta especie de muro vertical lateral continúa hasta la pieza especial, siendo la primera pieza del comienzo de la plementería la que soluciona su tránsito hacia una superficie curva. Por lo tanto, hay que pensar que estas primeras piezas de plementería laterales del enjarje, que unen el trasdós del tercelete con el formero, son fruto de un diseño en planta, no son consecuencia de la adición de elementos para conformar una superficie. Son piezas enterizas tan planificadas y talladas, con unas medidas establecidas, como el resto.

\footnotetext{
${ }^{328}$ Enrique Rabasa Díaz, "Plomo y nivel: hábitos y pensamiento espacial en la construcción gótica", La piedra postrera. Simposium Internacional sobre la catedral de Sevilla en el contexto del gótico final, (Sevilla, 2007), 71.
} 
La séptima pieza del enjarje no presenta dificultades especiales en su talla y diseño, pues los perfiles de los nervios no entran en conflicto. Valoramos en este caso la idea de una posible junta vertical en su contacto con la moldura del formero que facilitaría la resolución de la hilada por tres piezas, facilitando el trabajo al trabajar con piezas más pequeñas que serían más fáciles de tallar, elevar y situar.

En la octava pieza se produce el apoyo de las primeras dovelas de los terceletes, en los planos inclinados de la pieza que permiten dicha transición. Es destacable en este enjarje que este corte radial de la última pieza se realiza en la montea en relación al extradós del nervio, lo que hemos denominado como "solución general" para el final de la última pieza de los enjarjes.

En el taller de cantería de la Escuela de Arquitectura de Madrid hemos realizado la montea, trazado de piezas y talla del enjarje de la capilla del Condestable a escala $1 / 2$ respetando la misma altura de hilada, curvatura de nervios y diseño general; a excepción de las molduras que debieron ser ligeramente simplificadas para hacer posible su talla. ${ }^{329}$

${ }^{329}$ Ver página 202. 



\section{ARQUEOLOGÍA EXPERIMENTAL}

\subsection{Experiencias de construcción de enjarjes de Enrique Rabasa Díaz}

Enrique Rabasa Díaz ha desarrollado dos experiencias de construcción de enjarjes en colaboración con el Centro de Oficios de León reproduciendo los detalles y procedimientos conocidos sobre la construcción de las bóvedas de crucería góticas. La primera, que ha sido publicada en varios textos, consistió en el trazado, talla y montaje de una bóveda de crucería a partir del dibujo de la bóveda de cinco claves contenida en el tratado de Hernán Ruiz. ${ }^{330}$

Durante el proceso se enfrentó a diversos problemas, como por ejemplo el trazado del perfil de las molduras, el tamaño que debía tener la bóveda en relación a ellos, su sistema de contrarrestos o la información necesaria en el trazado de la montea para el trazado de las piezas. Para la definición de los enjarjes y las claves, los puntos que entrañan mayor dificultad pues en ellos se reúnen los nervios, se vio en la necesidad no sólo de trazar la elevación de la línea de intradós de los nervios, sino también su extradós, definiendo así su espesor. ${ }^{331}$ Los enjarjes eran de nervios independientes, formados por dos formeros, dos ojivos y un perpiaño cuyos ejes confluían en un punto, no así sus intradoses.
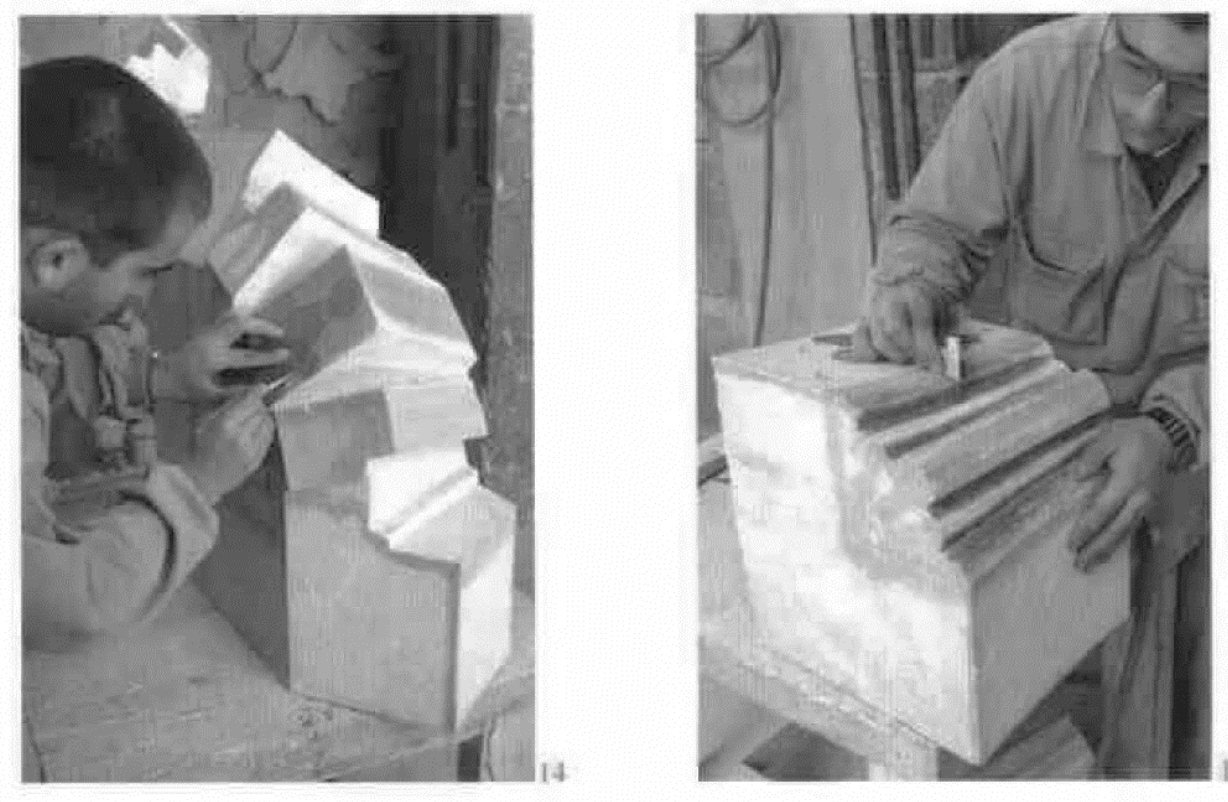

Fig. 143

Talla de la pieza de enjarje y comprobación de las molduras (Rabasa, 1996, 93).

\footnotetext{
${ }^{330}$ Enrique Rabasa Díaz, "Construcción de una bóveda de crucería en el Centro de los Oficios de León", Actas del Cuarto Congreso Nacional de Historia de la Construcción, (Madrid: Instituto Juan de Herrera, 2005), 909-917. Enrique Rabasa Díaz, Guía práctica de la estereotomía de la piedra, (León: Editorial de los Oficios, 2007). Rabasa Díaz, "Principios y construcción de las bóvedas de crucería".

${ }^{331}$ Rabasa Díaz, "Principios y construcción de las bóvedas de crucería", 91.
} 
Durante el proceso de trabajo y definición de las piezas hizo uso de programas de CAD que le permitiesen prever la apariencia final de cada elemento y poder así explicar mejor a los operarios su tarea, sin dejar de puntualizar que esta información es de utilidad para nosotros, diseñadores sin experiencia y tallistas que nunca nos hemos enfrentado al problema. ${ }^{332}$ Los maestros medievales no necesitaban estos recursos, del mismo modo que tampoco hacían uso de recursos propios de la geometría descriptiva que encontramos a menudo en tratados posteriores en relación con la bóveda nervada.

Fig. 144

Enjarje llevado a cabo por Rabasa en 2010 (Rabasa Díaz y Pérez de los Ríos, 2014, 107: fig.

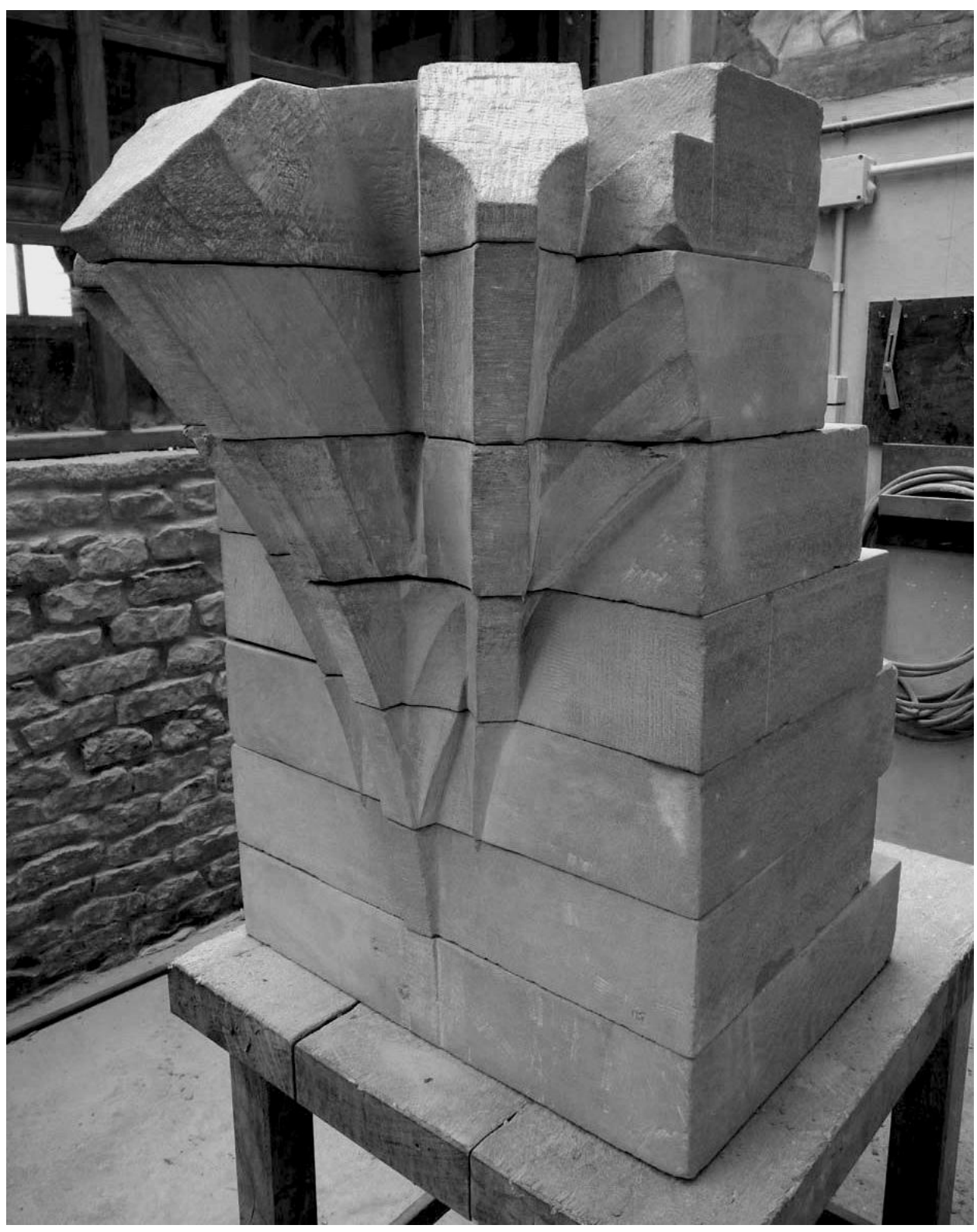

La segunda experiencia a cargo del profesor Rabasa tuvo lugar en 2010. En este caso los canteros debían tallar un enjarje que guardaba ciertas

\footnotetext{
332 Rabasa Díaz, "Principios y construcción de las bóvedas de crucería", 91.
} 
similitudes con unos de la Lonja de Palma de Mallorca. ${ }^{333}$ Formuló el diseño de la geometría del enjarje y la molduración de los nervios decidiendo no mostrar ninguna solución previa a los participantes a la espera de valorar el resultado del trabajo haciendo uso simplemente de los trazados de la montea a escala real y las plantillas de los nervios. Había siete piezas para siete canteros, quienes acabaron el trabajo en tres días. ${ }^{334}$

Los nervios formeros y el perpiaño estaban compuestos por unas plantillas con doble concavidad, mientras que los ojivos solamente tenían una. Todos arrancaban directamente del muro, produciéndose un cruce entre los ojivos y formeros, los cuales morían en el perpiaño. La definición de la deformación de los perfiles de los nervios en los cortes horizontales se tomó de la montea y se realizaron plantillas deformadas para los lechos en los que se consideraron necesarios.

La supervisión de los trabajos era necesaria para evitar errores pues, aunque los canteros tenían experiencia en la talla, nunca se habían enfrentado a un ejercicio de estas características. Las dificultades en el proceso aparecían cuando un nervio moría en otro, pues las referencias del contorno del perfil sólo se encontraban en uno de los lechos, mientras que en el otro se situaban alejadas del borde. El resultado no fue perfecto pero sí satisfactorio. Los errores no eran significativos al observarse el enjarje a cierta distancia. ${ }^{335}$

\subsection{Experiencias en el taller de cantería de la ETSAM}

A partir de las experiencias llevadas a cabo por Enrique Rabasa, al comenzar la presente investigación y puesto que el profesor Rabasa dirige el taller de cantería de la Escuela Superior de Madrid, se nos propuso seguir experimentando con el diseño y ejecución de enjarjes.

Durante cuatro años hemos realizado cuatro enjarjes, cada uno abordando una problemática distinta que nos permitiese experimentar y comprender mejor diferentes aspectos de su trazado y construcción. La talla de las piezas no ha correspondido en este caso a manos experimentadas, sino a estudiantes que acuden semestralmente al taller a cursar una asignatura de libre elección del Plan 96 de la carrera de arquitecto llamada Taller de cantería, así como más recientemente la asignatura del Taller experimental

\footnotetext{
${ }^{333}$ Enrique Rabasa Díaz y Carmen Pérez de los Ríos, "Late Gothic as an expression of procedure", Traces of Making. Entwurfsprinzipien von spätgotischen Gewölben, (Petersberg: Michael Imhof, 2014), 102-111.

${ }^{334}$ Rabasa Díaz y Pérez de los Ríos, "Late Gothic as an expression of procedure", 107.

${ }^{335}$ Rabasa Díaz y Pérez de los Ríos, "Late Gothic as an expression of procedure", 108.
} 


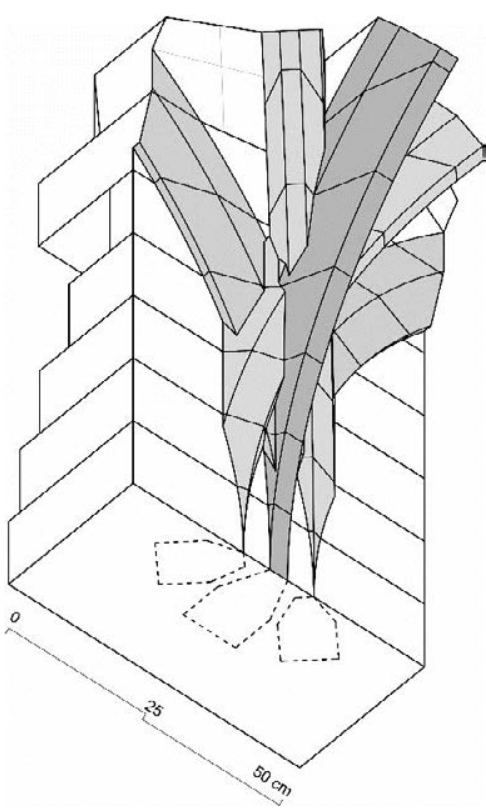

Fig. 145

Modelo del enjarje similar a uno de los del claustro de la catedral de Narbona.
Fig. 146

Montea llevada a cabo en el taller de la ETSAM por los estudiantes.

Fig. 147

Montea del enjarje. del Plan 2010, denominada Historia de la construcción. Han trabajado sin ningún tipo de conocimiento previo pero con mucha ilusión y dedicación. ${ }^{336}$ Tampoco el desarrollo de los enjarjes hubiera podido ser llevado a cabo sin la ayuda, consejo y magisterio de Miguel Sobrino González, escultor y cantero, y de César Cabeza, cantero de Patrimonio Nacional. Ellos nos han guiado en la ejecución de las piezas y el uso de las herramientas, aportando siempre ideas y ofreciendo soluciones a los problemas de ejecución de las piezas a los que nos enfrentábamos cada día. También, en los últimos enjarjes realizados han sido fundamentales las observaciones de Ana López Mozo y la ayuda de Miguel Alonso Rodríguez.

Nuestra intención durante el desarrollo de los trabajos en el taller ha sido poner en práctica los procedimientos medievales que conocemos y que hemos explicado anteriormente. Al dibujar cada uno de los enjarjes a escala 1:1, enfrentándonos en cada caso a un ejercicio diferente, pretendimos comprobar cuántas referencias eran necesarios para el trazado posterior de las piedras y qué información nos puede aportar la montea o no. También la conveniencia, o no, del trabajo con plantillas deformadas.

Consideramos pertinente dar una breve explicación del desarrollo de cada uno de los enjarjes ejecutados, mostrando las decisiones tomadas en su resolución.
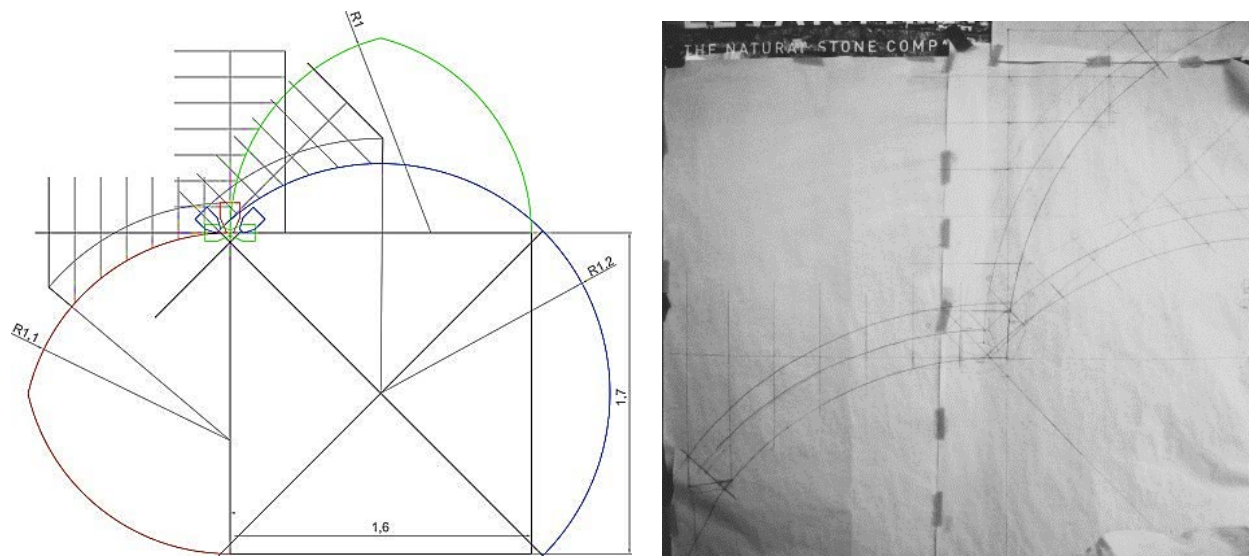

\subsubsection{Enjarje similar a uno en el claustro de la catedral de Narbona}

En primer lugar, decidimos continuar con una experiencia similar a la llevada a cabo por Enrique Rabasa en León realizando un enjarje de nervios cruzados que saliesen directamente del muro. Para ello, se decidió tomar como referencia un enjarje situado en el claustro de la catedral de Narbona

\footnotetext{
${ }^{336}$ La lista de alumnos que ha participado en el desarrollo de los enjarjes se puede consultar en los agradecimientos de la tesis. Sin ellos, este trabajo hubiera sido imposible e inabarcable.
} 
en el que los nervios formeros se cruzan con lo ojivos; y éstos, a su vez, con el perpiaño.

Se diseñaron unos perfiles sencillos, sin relación con los del enjarje real, para facilitar el proceso de talla a los alumnos, y se elaboró un modelo 3D procurando llegar a un resultado similar al del enjarje francés. ${ }^{337}$ Se decidió, por tanto, una dimensión de la bóveda de 1,63 por 1,73 metros, mucho menor que la original debido a la limitación del tamaño de las piedras de las que se disponía en el taller, en este caso disponíamos de piedra de Novelda. Al ser una bóveda más pequeña, el enjarje tenía también menos desarrollo en altura y una curvatura pequeña en los arcos, compuesto por 7 piezas.

Tras el proyecto y diseño del enjarje se comenzó el trabajo en el taller. En primer lugar se dibujó la montea del enjarje sobre un soporte de papel de 2 por 2 metros situado en la pared. Al tratarse de una bóveda de dimensión reducida comenzamos trazando su planta, correspondiente con un cuarto de la bóveda. En primer lugar dibujamos una recta que representase el muro y el eje de los nervios formeros. A continuación, el eje del nervio perpiaño que se sitúa perpendicularmente al muro y, a partir de ahí, los ejes de los nervios ojivos que se cruzan a $45^{\circ}$ sobre el perpiaño a cierta distancia del muro.

Una vez definidos los ejes de los nervios, trazamos sus plantillas con el intradós ubicado en su punto de arranque. Es decir, la del perpiaño se localizó enrasada con el muro, la de los formeros, que se cruzan, saliendo desde el eje del perpiaño; y las de los ojivos dentro del muro, en el lugar en que, una vez desplazadas por el eje del nervio, su arista de intradós quedaba enrasada con el muro.

A partir de ahí, se midió desde el intradós de cada plantilla sobre el eje de los nervios el radio de cada uno de los arcos para localizar sus centros y poder así dibujar sus elevaciones abatidas sobre ellos. Localizando en los centros de los arcos un clavo y ayudados por una cuerda, trazamos enrasados con los perfiles los arcos de intradós de cada uno de los nervios abatidos, así como sus extradoses; y un arco paralelo más que se correspondía con la moldura del nervio. En este caso era muy sencilla y estaba compuesta únicamente por un plano en chaflán.

Tal y como vimos anteriormente en la montea de Polonia, sólo nos quedaba por trazar la situación del muro en relación con las elevaciones de los nervios y la definición de las piezas que compondrían el enjarje. Para

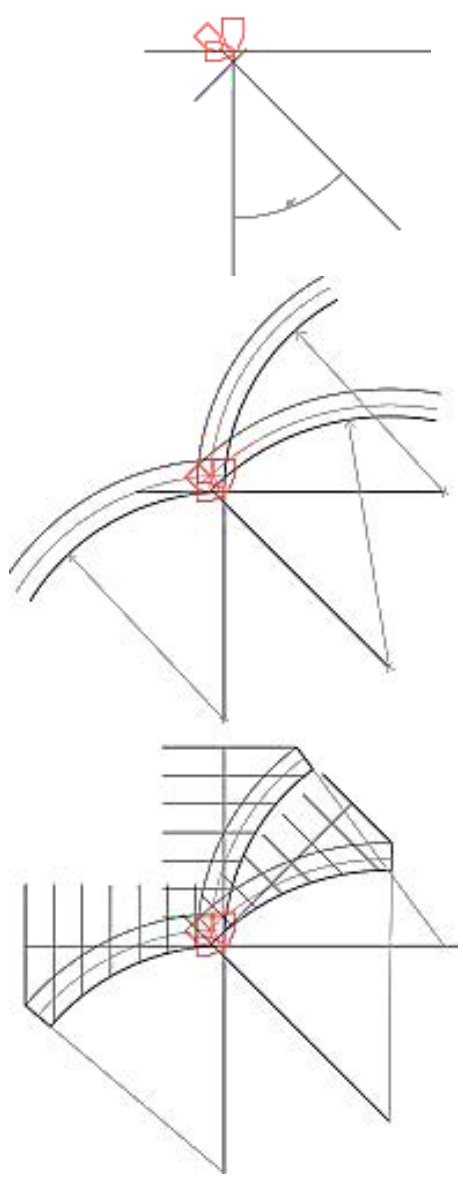

Fig. 148

Proceso de trazado de la montea.

\footnotetext{
${ }^{337}$ En esos momentos no habíamos realizado aún un levantamiento topográfico de Narbona.
} 

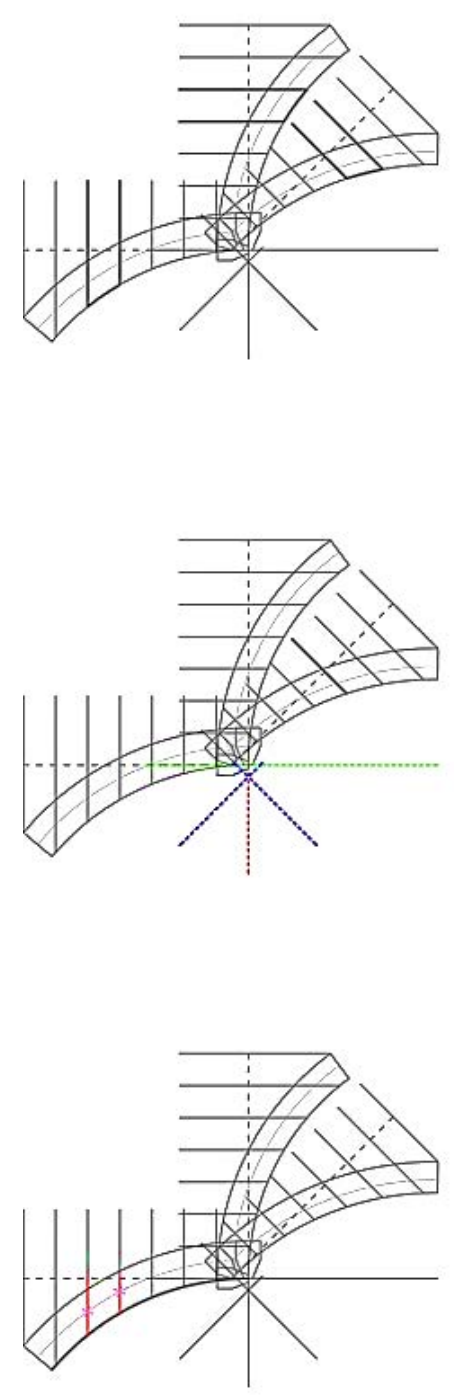

Fig. 149

Proceso de trazado en las piedras de cada una de las piezas tomando medidas y referencias de la montea.
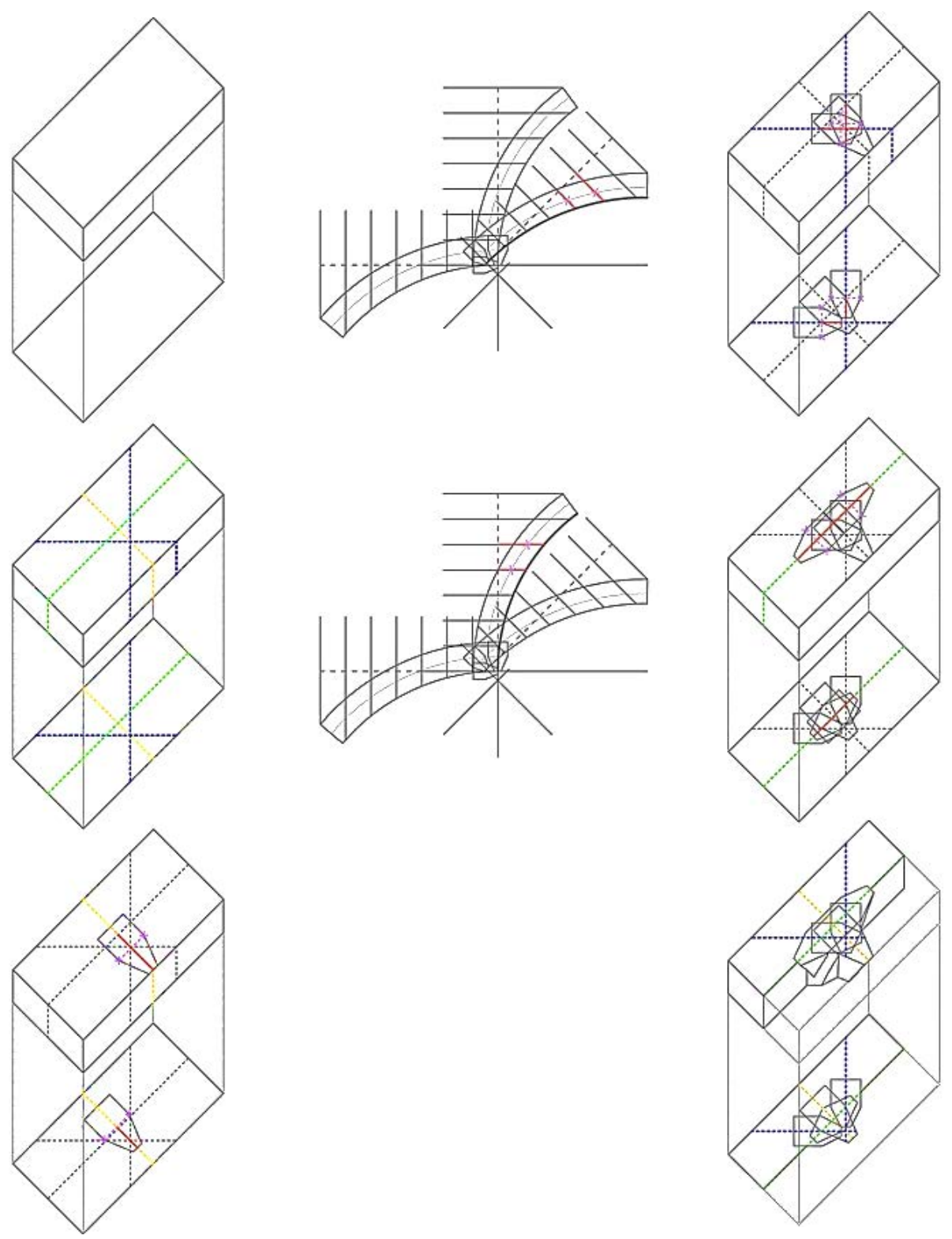

representar el muro, se llevó una perpendicular al eje en planta de cada nervio desde su punto de intersección con el muro.

Las piedras de las que disponíamos en el taller tenían 14 centímetros de alto, por lo que en cada una de las elevaciones de los nervios fuimos trazando rectas paralelas a los ejes de la planta hasta concretar 7 piezas. En la última, para definir el plano inclinado que debía recibir la primera dovela del arco, trazamos una recta radial desde el punto en el que el último corte horizontal intersecaba a la circunferencia del trasdós del arco.

Este dibujo fue suficiente para trazar las referencias necesarias en cada una de las piezas de piedra, para lo que hicimos uso de regla, escuadra, lápices, marcadores de punta seca y hojas o hierbas. Las piedras de las que disponíamos estaban escuadradas, con un largo de 60, un ancho de 30 y una altura de 14 centímetros. Las cinco primeras piezas cabían perfectamente en estas dimensiones, mientras que para la sexta y séptima tuvimos que realizar un despiece especial añadiendo otros bloques debido a su mayor tamaño. 
El procedimiento de traza en todas las piezas fue el mismo. En primer lugar, marcamos en el plano superior de la piedra una línea que la dividiera longitudinalmente en dos partes, que fuera paralela al eje menor y perpendicular al mayor del bloque. En él situaríamos el eje del nervio perpiaño. Perpendicularmente a este trazo, dibujamos el eje del muro, en este caso paralelo al lado mayor de la piedra. En él se localizaban también los ejes de los formeros. Para optimizar la dimensión del bloque lo máximo posible, situamos la línea del muro con referencia al borde de la pieza. Allí llevamos la medida de lo que se aleja del muro el intradós del arco perpiaño en el lecho superior.

Una vez situadas estas referencias, trazamos los ejes de los ojivos, que forman $45^{\circ}$ con el perpiaño y los formeros -que no se cortan en la intersección de éstos dos, sino alejados del muro- sobre el eje del perpiaño unos 7 centímetros.

Una vez marcado el plano superior, trazamos líneas perpendiculares a la arista en los planos verticales del bloque que nos sirvieran para controlar que el próximo trazado en la cara inferior de la pieza tuviese correspondencia con la superior. Como ya explicamos anteriormente, los ejes en planta son iguales en todas las piezas, por lo que hay que vigilar que sea así; del mismo modo que hay que asegurar que la planta trazada en la cara superior e inferior de la pieza- con los ángulos que forman los nervios- se corresponde. Por tanto, trazamos los mismos ejes en esta cara inferior que en la parte superior.

Así llegó el momento de comenzar a trazar los perfiles de los nervios en ambas caras. Comenzamos por los perpiaños en la superior. Como para trazar la línea del muro habíamos tomado la referencia de la distancia desde éste al intradós del nervio, teníamos ya determinada la posición del perfil. En ese borde dibujamos el filete de intradós centrado en el eje.

Decidimos probar a no realizar plantillas alargadas para cada lecho horizontal, sino tomar las medidas del perfil deformado en cada uno de los cortes directamente de la montea y dibujar nosotros sus perfiles. La moldura era muy sencilla, lo que nos permitía poder llevar a cabo esta prueba. Probablemente en los primeros cortes horizontales podríamos haber prescindido de alargar la plantilla, pues la diferencia en los dos primeros lechos con la plantilla sin deformar no llega si quiera a los 3 milímetros, pero nuestra inexperiencia nos llevó a llevar las medidas en todos los lechos de manera sistemática para asegurar la correcta marcha del trazado. Ahora, tras la experiencia adquirida, seguramente tomaríamos
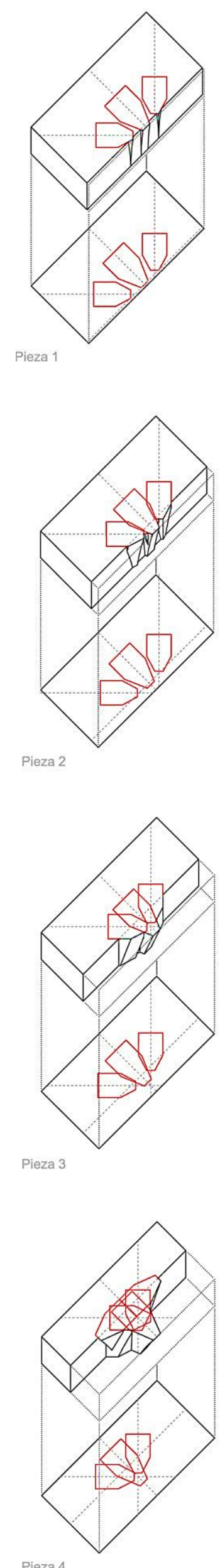


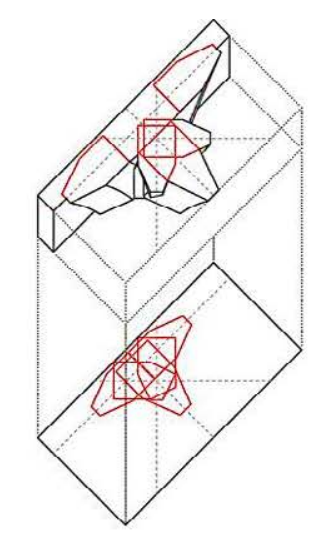

Pieza 5
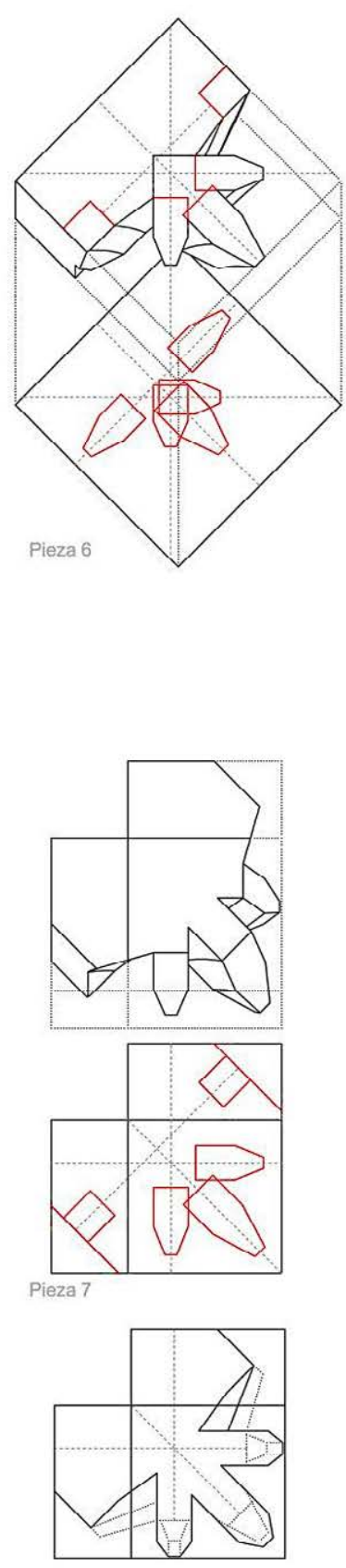

Fig. 150

Situación de las plantillas en los lechos de las piezas. solamente medidas para alargar las plantillas en los dos o tres últimos lechos de este enjarje.

Para alargar la plantilla del perpiaño medimos en la montea del nervio, en el corte correspondiente, la distancia desde el intradós hasta el punto en el que se produce el chaflán de la moldura- que habíamos determinado mediante el arco paralelo al intradós- y trasladamos esta medida a una recta paralela a la de intradós. La dimensión del perfil del nervio en sentido transversal no se ve afectada, por lo que el ancho se mantiene constante y puede ser trazado sin problemas. Una vez esos puntos estaban determinados se redibujó el contorno del perfil, apreciándose que en los lechos superiores el alargamiento de la plantilla era sobresaliente.

En el plano inferior, para localizar la situación del perfil del perpiaño, medimos en la montea la distancia entre el intradós del nervio y la referencia del muro en su correspondiente corte. Así la trazamos, a partir del eje del muro de la piedra, quedando alejada una cierta distancia del borde de la piedra.

Realizamos el mismo ejercicio con los ojivos y los formeros, tomando las referencias en sus correspondientes elevaciones y cortes. La localización de las plantillas de los ojivos presentó dificultades, pues algunos alumnos cometían el error de trasladar la distancia desde el muro hasta el intradós del arco en un lugar erróneo en el eje del ojivo en la piedra. Medían a partir del cruce de los ejes de los ojivos y no desde la referencia del muro. También se realizó el mismo procedimiento para medir el alargamiento de las plantillas tomando las medidas de la montea.

Cuando todos los perfiles estaban dibujados procedimos a repasarlos con un marcador de punta seca para definir el contorno final de la pieza en el lecho inferior y superior; distinguiendo qué perfiles de nervios prevalecían como borde y cuáles eran desestimados. Sobre esta marca frotamos hierbas u hojas y volvimos a repasar con el marcador para resaltar una línea blanca sobre el fondo verde. Este procedimiento nos lo mostró César Cabeza, pues forma parte del saber hacer de los canteros, y facilita que las marcas y trazados no desaparezcan. Si hubiéramos dejado solamente las líneas del grafito, tras mover y rozar la piedra varias veces, hubieran desaparecido.

Debido a que un alumno diferente realizaba cada pieza, el dibujo de las plantillas en el lecho superior de la pieza que debía corresponder con el lecho inferior de la siguiente- y viceversa- no eran perfectamente iguales. Además acarreaba un trabajo de control del trazado por nuestra parte exagerado, pues cometer un error en el traslado de datos se antojaba 

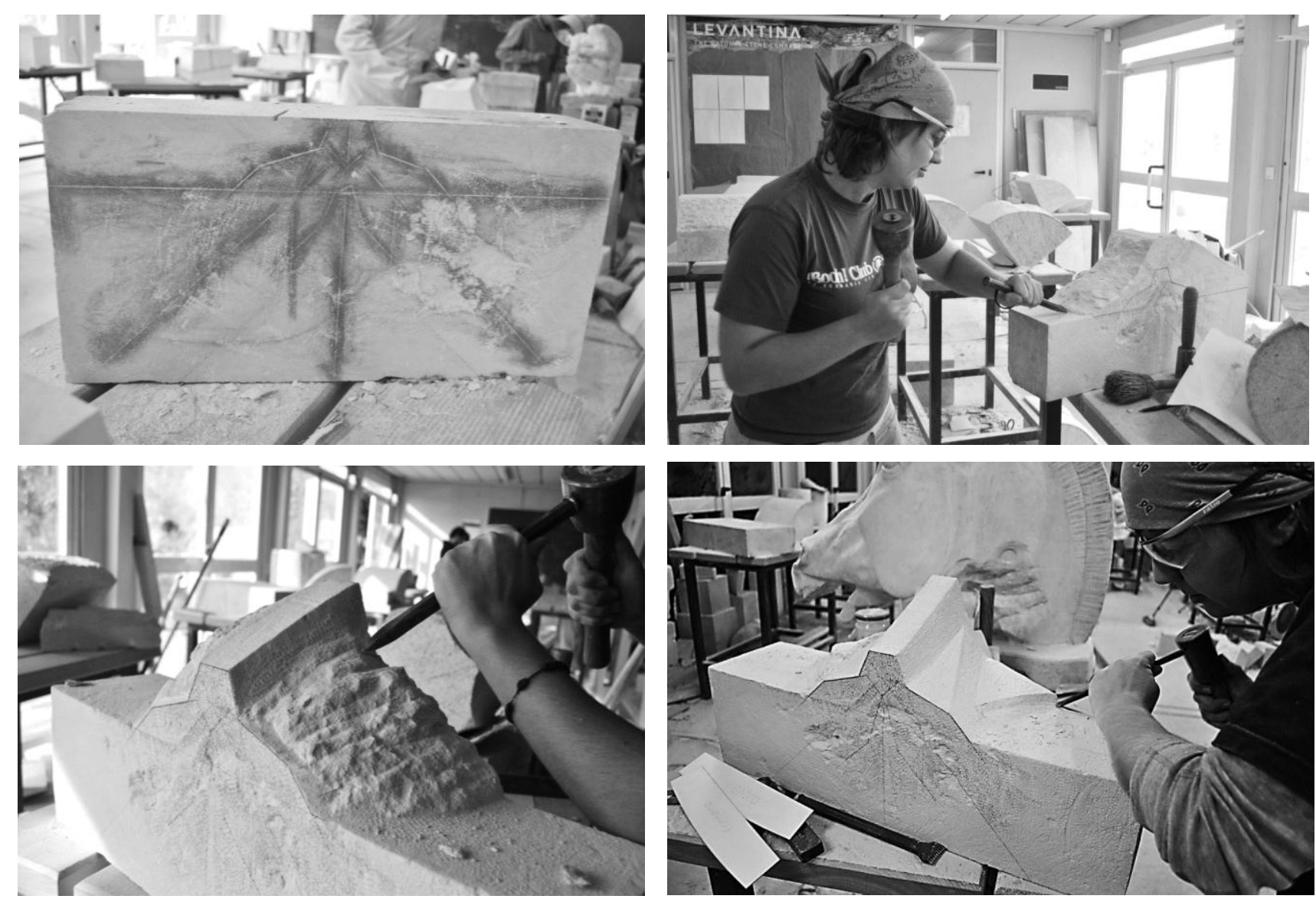

frecuente. Esto provocó que, al colocar finalmente las piezas, una sobre otra, la correspondencia no fuera completamente perfecta.

Fig. 151

Proceso de talla de una de las piezas.

El proceso de talla de las piezas fue revelador. No es frecuente que un cantero hoy en día se enfrente a la labra de un enjarje, pues tras el colapso de una bóveda no se suelen ven afectados, convirtiéndolos en elementos inexistentes -o muy infrecuentes- en las labores de los talleres de cantería. Por tanto no sólo para mí, inexperta en esos momentos en el mundo de la talla, sino también para César Cabeza y Miguel Sobrino fue, en cierto modo, un reto. ${ }^{338} \mathrm{El}$ debate que se creó en el taller, amparado en su oficio y conocimiento, acerca de las operaciones que pensábamos más viables para la resolución de problemas fructificó en el procedimiento que hemos explicado anteriormente y que hemos utilizado de manera sistemática en el desarrollo de los siguientes ejercicios del taller.

La primera pieza del enjarje fue muy sencilla de solucionar. En ella los nervios salían directamente del muro y aún no se producían encuentros

${ }^{338}$ Enrique Rabasa ya había desarrollado dos enjarjes anteriormente. Me dio libertad a la hora de desarrollar este trabajo, dejándome encargada de su dirección como parte de mi investigación. Fue siempre solícito en la resolución de las dudas que se me planteaban y participó en las discusiones que se generaban durante el desarrollo de la talla. 
entre ellos. Los perfiles a tallar estaban definidos tanto en el lecho superior como en el inferior.

La segunda pieza presentaba más dificultad, pues a mitad de altura surgían los nervios formeros del lateral del nervio perpiaño y se intersecaban con el intradós de los ojivos. Por lo tanto, el contorno de las plantillas de estos formeros sólo estaba presente en el lecho superior. César Cabeza propuso resolver este encuentro mediante el desalabeo del plano, una técnica muy común en la cantería, principalmente para la escuadría de piezas. Mediante el uso de una regla situada en cada lecho en relación a la posición de la recta que pasaba por el punto de la arista que queríamos trazar y situando la vista -cerrando uno de los ojos- de modo que quedasen perfectamente en correspondencia las reglas, podíamos trazar la unión de dichos puntos para localizar el lugar en el que ese nervio desaparecía en la moldura del contiguo.

Lo mismo ocurrió con el formero en la siguiente pieza pero de manera inversa, es decir, la moldura aparecía en la cara de abajo y el nervio desaparecía en los otros a mitad de la pieza.

En la cuarta pieza la intersección entre nervios cobró mayor relevancia, pues en las dos piezas anteriores, a pesar de tener que realizar la ejecución lo más precisa posible, el volumen de nervio formero era muy pequeño y favorecía que los errores que se pudieran cometer no fuesen demasiado apreciables. Sin embargo, en esta pieza la intersección debía ser resuelta limpiamente. El encuentro entre ojivos y perpiaño no presentaba complicaciones, mientras que de los planos verticales del canto de los ojivos emergían los nervios formeros. Por lo tanto, su plantilla estaba presente solo en el lecho superior de la pieza. Este encuentro se solucionó de manera relativamente sencilla debido a que el plano del ojivo del que salía el formero era vertical. Además, como el formero es paralelo al plano del muro era sencillo trazar su curvatura y controlar frontalmente su desarrollo para determinar su intersección con el ojivo. Esta pieza fue ejecutada por Eva, una alumna que fue capaz de realizar su pieza de enjarje en un semestre. En cuatro meses pasó de dibujar la montea, a trazar la piedra y a tallar por completo la piedra.

La quinta pieza también presentaba intersección entre nervios, siendo en este caso los ojivos los que emergen a ambos lados del perpiaño. Este encuentro es más complejo que el anterior porque se produce entre planos que no son verticales o frontales. Aquí se disponía del perfil del ojivo en el contorno superior, pero no en el inferior, pues quedaba dentro de la pieza. La labra se comenzó mediante la resolución de los planos conocidos, es decir, el intradós del formero y el perpiaño, así como el plano lateral del formero y la primera mitad del perpiaño. 
Había, en ese momento que localizar los puntos que definían el encuentro del plano de intradós del ojivo con el perpiaño. Para dicha tarea, César nos ayudó a desalabear el plano. También elaboramos una especie de baive ${ }^{\beta 39}$ para poder controlar la curvatura del nervio en relación con el plano horizontal superior del enjarje. Estaba hecho de cartón, lo que nos permitía ir cortándola según nos íbamos aproximando al plano. Fue un recurso que inventamos para poder tallar el encuentro de la manera más precisa posible, pero no tenemos pruebas del uso de este tipo de baiveles en la talla medieval de enjarjes. Poco después de utilizar este artefacto, lo localizamos en el Livre III de I'Architecture de Philibert de L'Orme, quien lo denomina buveau. Dice que se parece a la escuadra, pero que a diferencia de ella, sus brazos son articulados. Las ventajas de cada uno, claramente, son diferentes, pues la escuadra, cuyas extremidades forman un ángulo recto, es fija, mientras en el baivel, tiene una curvatura en relación al objeto que se quiere realizar. Dice que a veces los dos extremos son curvos, a veces uno curvo y otro recto; o incluso se combinan recta y curva en el mismo extremo, según la necesidad. ${ }^{340}$

Para Vandelvira, el baibel es un instrumento que aparentemente no se representa como articulado y que sirve para tallar la curvatura del intradós

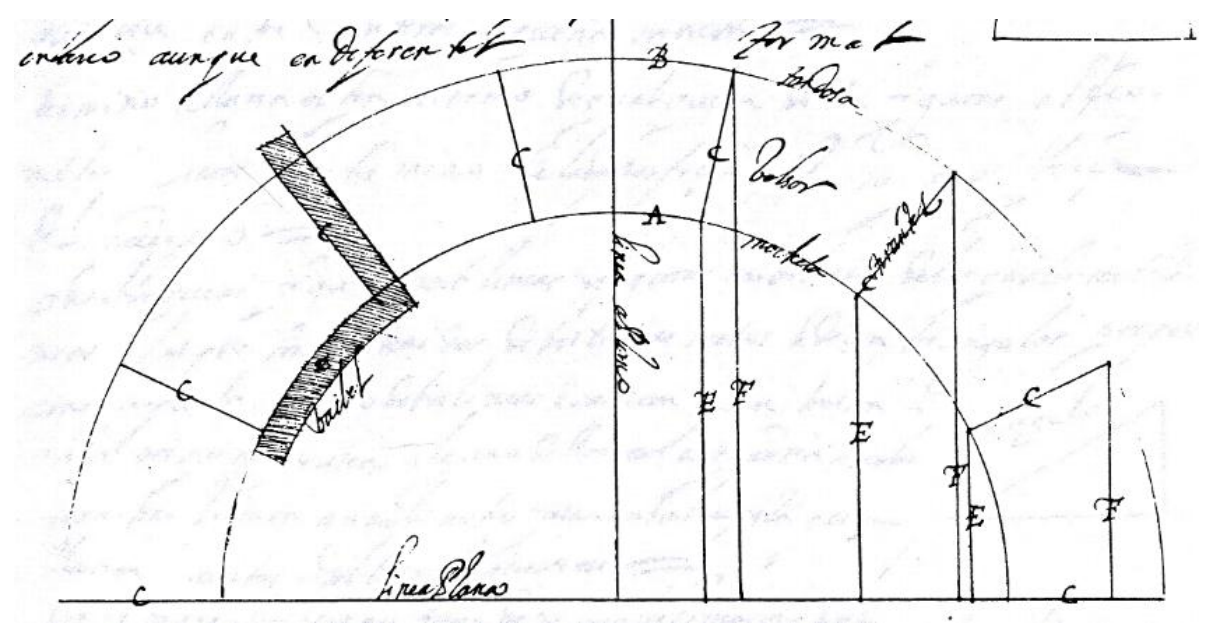

Fig. 152

Baivel (A) en el tratado de Philibert de L'Orme (1567, libre III, fol. $54 \mathrm{v}$.).

Fig. 153

Baivel en el tratado de Vandelvira (1575-1580, fol. 4v.).

\footnotetext{
${ }^{339}$ En el tratado de Alonso de Vandelvira se recoge la palabra baibel, así como en el de Philibert de L'Orme, que la llama buveau. Vandelvira, Libro de las traças y cortes de piedra, fol. 4v. Philbert de L'Orme, Le premier tome de l'architecture, (Paris: Féderic More. (facsimil en París: Léonce Laget, 1988, y 1648 edición en Brusellas: Pierre Mardaga, 1981, 1567), livre III, fol. $54 \mathrm{v}$.

${ }^{340}$ Philbert de L'Orme, Le premier tome de l'architecture, livre III, fol. 54v y 55r. Imagen fol. $56 v$.
} 

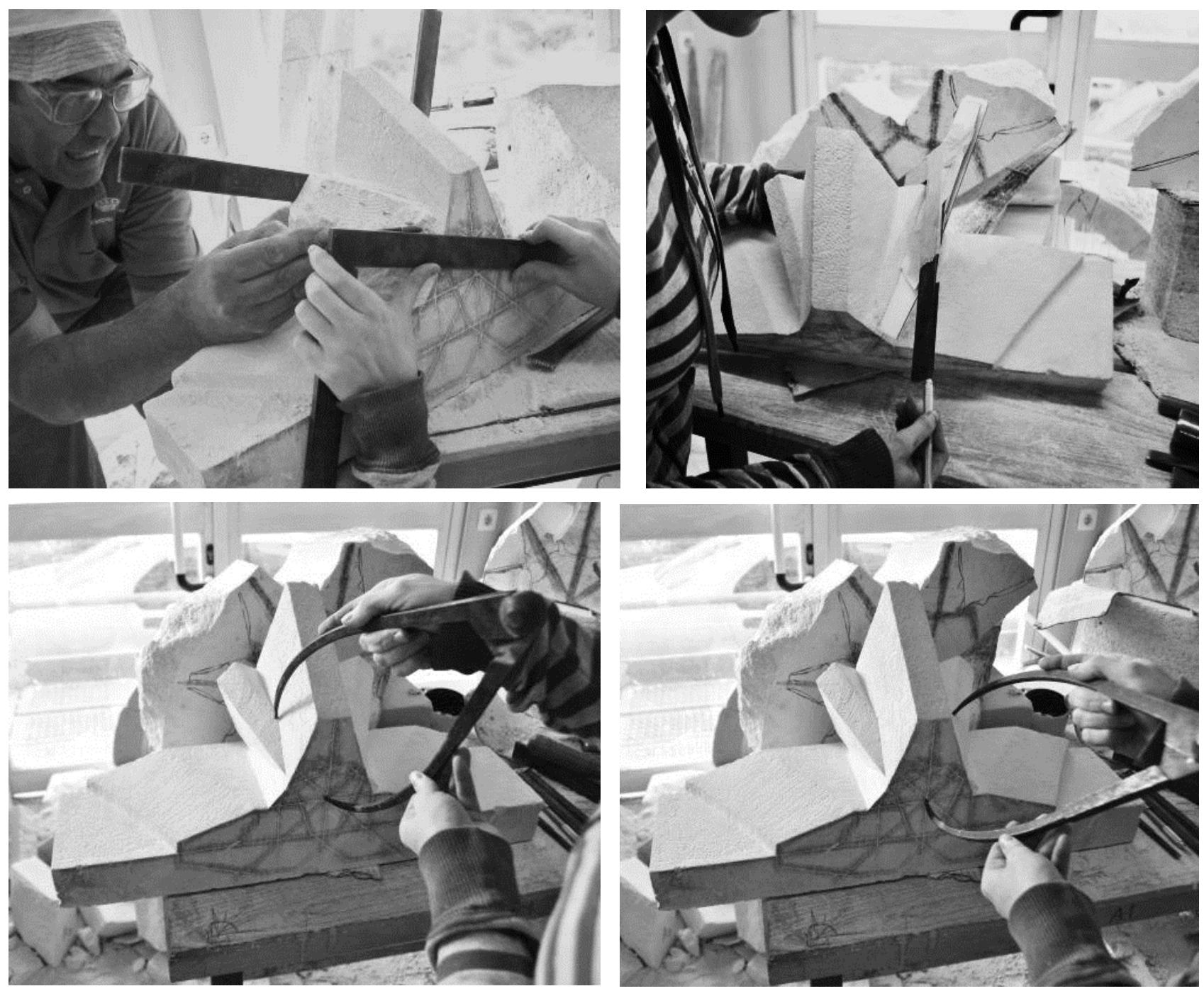

Fig. 154

Procedimientos llevados a cabo para la talla de las piezas. Arriba a la izquierda César Cabeza determina intersecciones mediante el desalabeo de planos. Arriba a la derecha, fabricación de un baivel para la talla de intersección de la moldura de un nervio en otro. Abajo, bajo indicación de Miguel Sobrino, traslado de puntos determinados en una mitad de la pieza en su simétrica con un compás de medida. de las dovelas, que llama bolsor. ${ }^{341}$ José Carlos Palacios Gonzalo ha analizado los dibujos del tratado, presentando axonometrías en las que se apoya en el uso del baivel, en este caso articulado. ${ }^{342}$

Una vez resuelto el encuentro en uno de los lados de la pieza del enjarje, y cuando nos disponíamos a realizar el mismo procedimiento en el otro lado, Miguel Sobrino nos advirtió de que podíamos ahorrar mucho trabajo si trabajábamos con compases de medida para trasladar la medida de los puntos que habíamos obtenido en el lado acabado en el simétrico aún por resolver. Así lo hicimos y el resultado fue óptimo. Tampoco hay evidencias de

341 "Está este arco repartido en siete partes que cada una de ellas llaman bolsor o dovela, la cual tiene mocheta que es la parte cóncava señalada con la A. y la tardosa que es la parte convexa señalada con la B. y tirantez que es las líneas C.C. De una de las cuales líneas C. y de la mocheta se causa la figura D. que se llama baivel, con el cual se labra el bolsor." Geneviève Barbé-Coquelin de Lisle, El tratado de arquitectura de Alonso de Vandelvira, (Albacete: Caja de Ahorros, 1977), 42.

342 José Carlos Palacios Gonzalo, Trazas y Cortes de Cantería en el Renacimiento Español, (Madrid : Munilla-Lería, 2003). 
la resolución de enjarjes de este modo, pero sí de que estas herramientas eran comunes en los talleres de cantería, lo que nos hace pensar que un proceder así fuera más que posible.

La sexta pieza tuvo que ser dividida en dos debido a que no disponíamos en el taller de piedras de ese tamaño. En ella ya no hay intersecciones complejas de nervios, por lo que se solucionó por el procedimiento general.

La última pieza, la séptima presenta la particularidad de que en la parte superior aparecen los nervios cortados radialmente para poder recibir las primeras dovelas. Por ello, en ese plano horizontal no se trazan las plantillas deformadas, sino simplemente el ancho del perfil. Lo primero que se ha de tallar es un prisma vertical contenedor de los nervios cuyo límite viene marcado en el lecho superior por la proyección vertical del intradós de cada nervio. Habrá que llevar sobre la piedra las medidas a y b en el caso del perpiaño y las c y d en el caso de los ojivos. Este prisma sirve para poder trazar en su lateral el ángulo de inclinación del corte $\alpha$ y, tras eliminar la piedra sobrante, dibujar en él el contorno de la plantilla sin deformar. De este modo, tendremos trazados los perfiles de los nervios en el lecho inferior y en los lechos inclinados, y podremos acometer su talla.
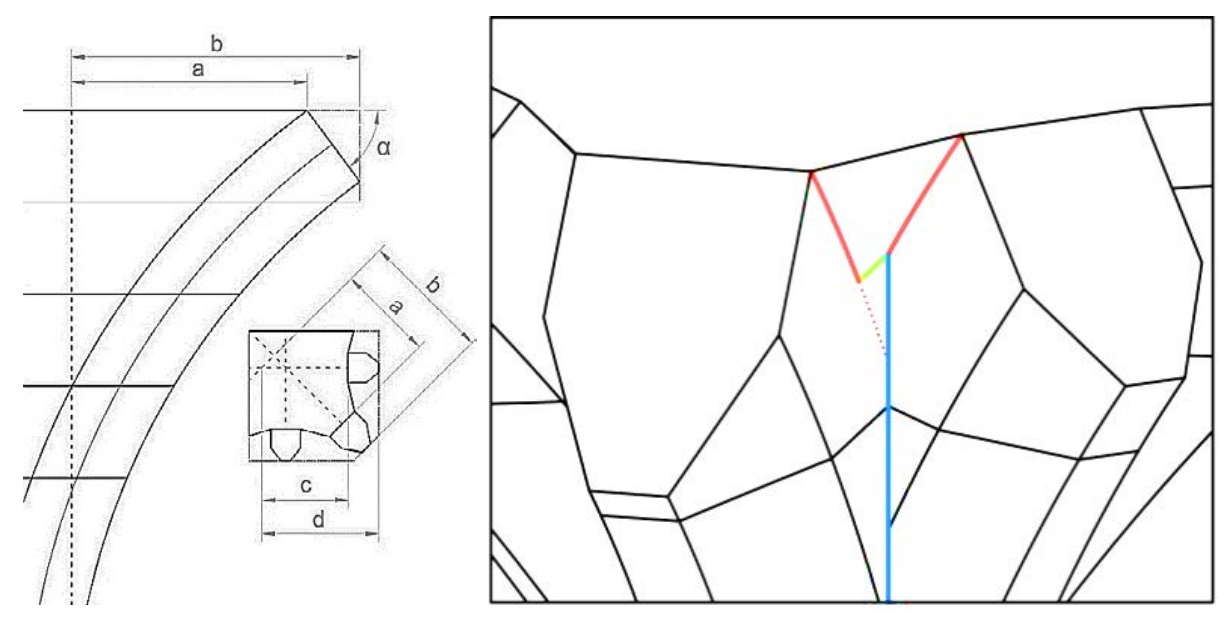

Fig. 155

Solución de los encuentros entre los estradós de los nervios al final del enjarje.

En esta última pieza, además, hay que resolver la transición entre los extradoses de nervios contiguos, pues están separados en el lecho superior, no así en el inferior. Este ejercicio requiere habilidad y conocimiento previo, pues se genera una superficie alabeada que hay que definir correctamente y que sin instrucción lleva a error. 
Para ello, es fundamental tener en cuenta que la intersección entre los cantos de los nervios en el lecho inferior resulta en la talla de una recta perpendicular al plano del lecho, pues los dos cantos de los nervios son planos verticales que se cortan en ella. Y se podrá ejecutar hasta llegar al último de los extradoses que participan en el encuentro. A partir de ahí, para solucionar en encuentro con el extradós de nervio que ha permanecido más abajo, se ejecuta un plano definido por esta línea vertical y una recta horizontal (en verde) que conecta los dos extradós.

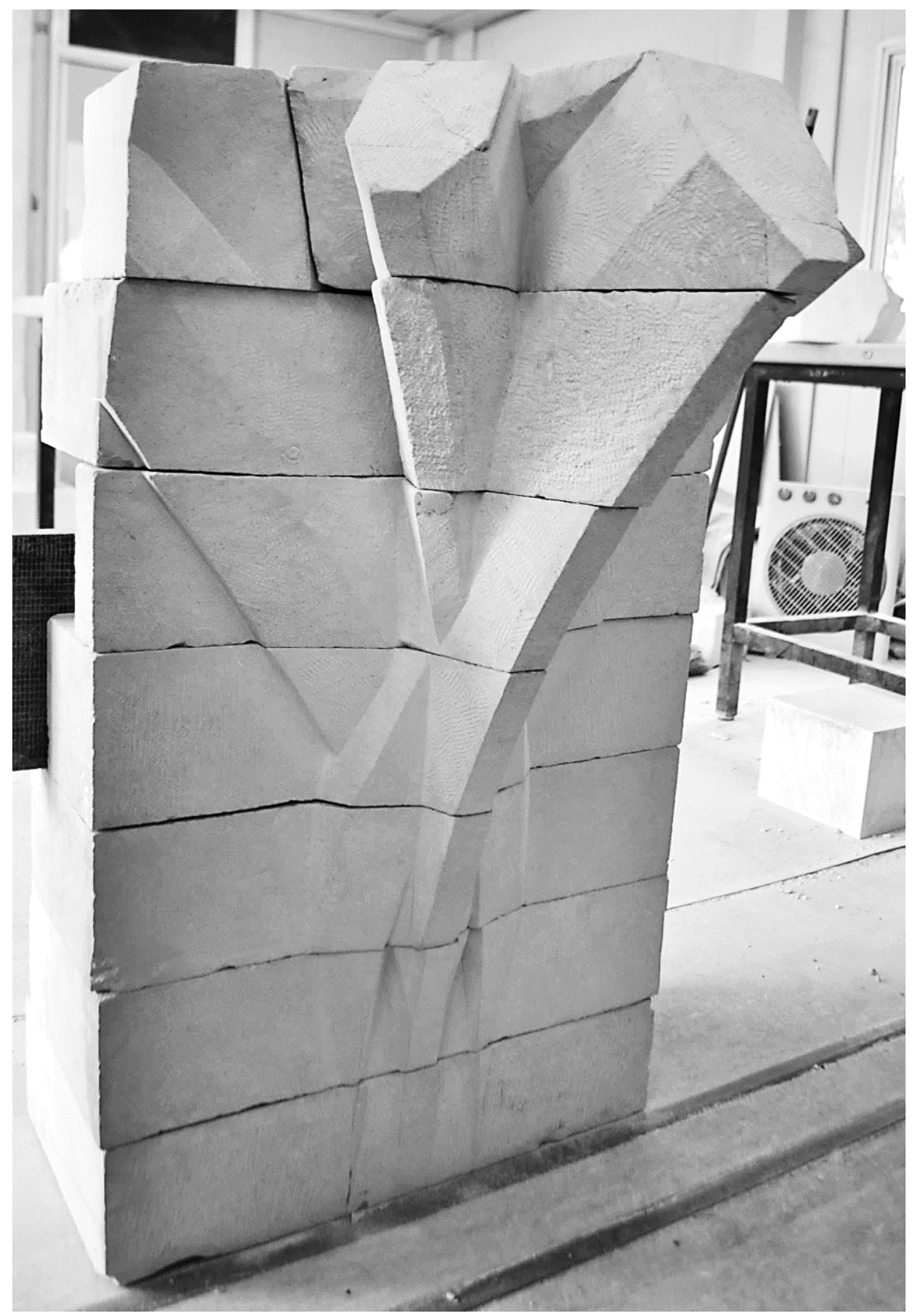

Enjarje tallado y construido en el taller de la ETSAM

Una vez solucionado este pequeño plano, se acometerá la transición entre la parte restante entre ambos extradoses mediante un plano alabeado definido por dos rectas horizontales: la recta que une en el lecho superior 
de la piedra los extradoses de los nervios y la recta horizontal que habíamos definido entre ambos a partir del encuentro de la vertical con el extradós del nervio superior hasta llegar al inferior. El contorno vertical viene definido por los trasdoses de ambos arcos, que aunque son curvas, debido a su pequeña longitud las podremos equiparar con rectas. Así tallaremos un plano controlado mediante la colocación de una recta que una las referencias horizontales superior e inferior cuyo resultado es una superficie reglada. Una vez acabada, si procede, podremos mejorarla tallando la curvatura de los extradoses y la daremos un acabado más cercano a una superficie alabeada

\subsubsection{Enjarje de la Lonja de Palma de Mallorca}

Con el segundo ejercicio pretendíamos enfrentarnos a una nueva problemática realizando un enjarje que partiera de un pilar, en este caso, entorchado, del que los nervios brotaban directamente. Tomamos como modelo los de la Lonja de Palma de Mallorca, aunque en ese momento aún no habíamos analizado los datos topográficos de las curvas de los nervios, sí teníamos las medidas de la planta. ${ }^{343}$

Con antelación, Enrique Rabasa había tallado con los alumnos en el taller de cantería unas piezas de pilar entorchado ajustándose a las dimensiones de unas piedras disponibles. Tomando como punto de partida esa dimensión para el pilar entorchado, guiándonos por la proporción rectangular de las bóvedas de Palma y utilizando unos perfiles simplificados de los originales, propusimos un modelo que se aproximara lo más posible al real. Lo único que no pudimos respetar en este caso fue la altura de juntas, pues nos debíamos ceñir a las piedras de las que
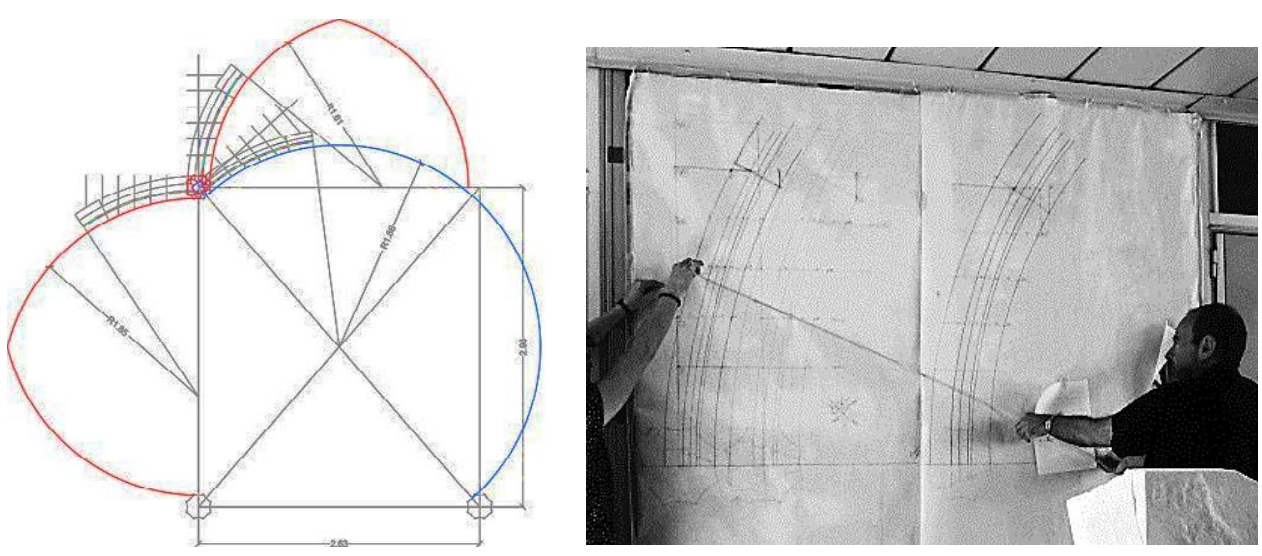

Fig. 157

Montea del enjarje.

Fig. 158

Montea llevada a cabo por los alumnos en el taller de la ETSAM.

\footnotetext{
${ }^{343}$ Enjarje de la Lonja de Palma: ver página 330
} 

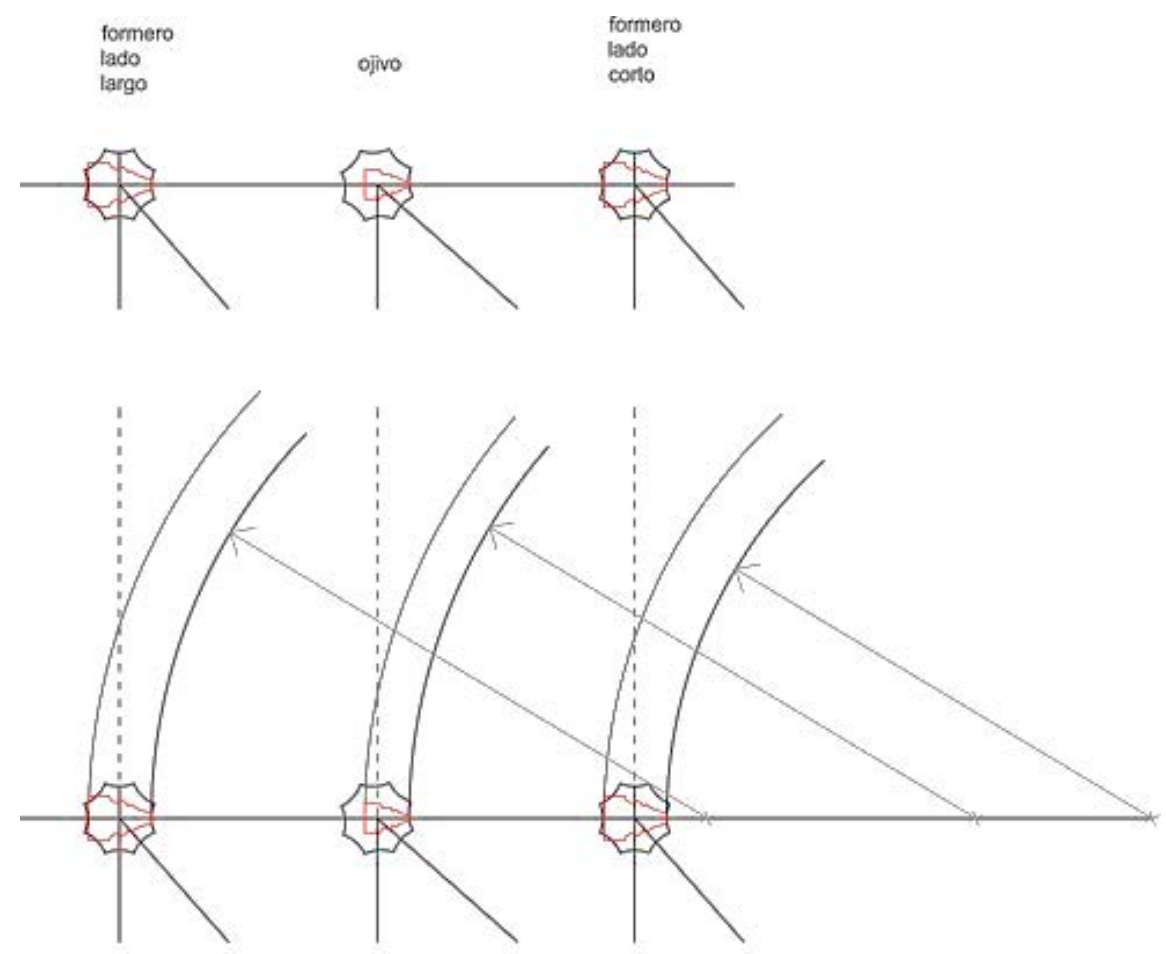

Fig. 160

Proceso de trazado de la montea.

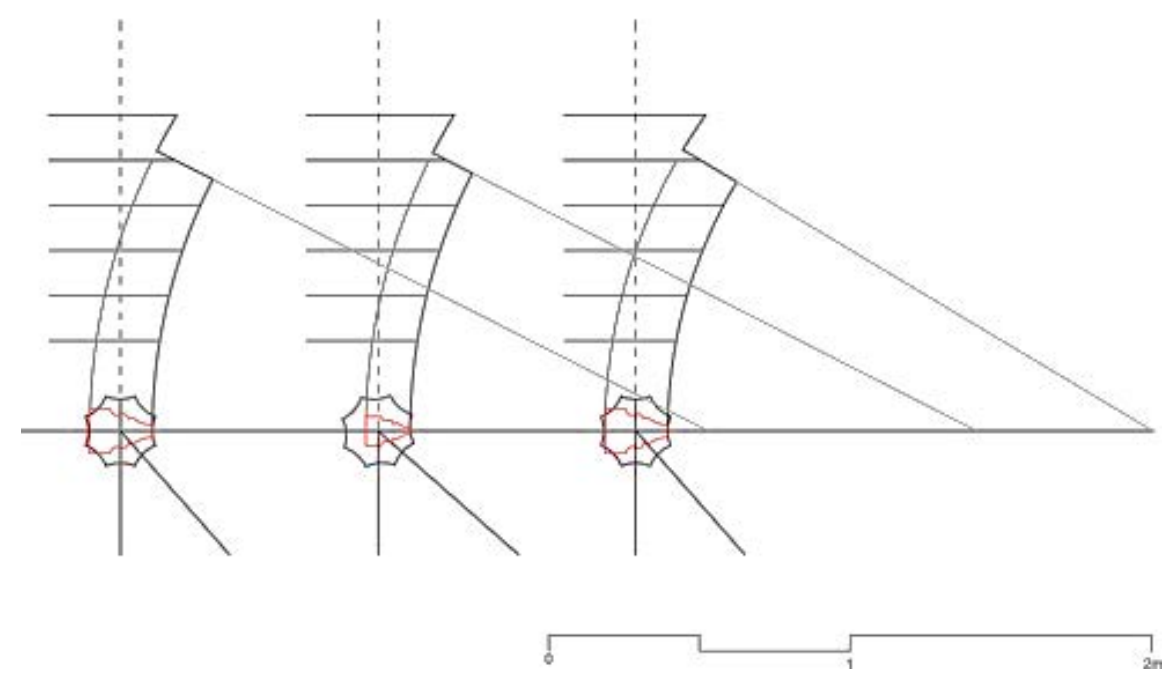

disponíamos en el taller. Sin embargo, sí que seguimos la regla de Palma haciendo que las piezas del enjarje tuvieran la mitad de altura que las del pilar entorchado para así simplificar el control de la talla gracias a un mayor control en el desarrollo en altura. La piedra utilizada fue una caliza de Cabra (Córdoba) muy dura en todas las piezas excepto en la primera y segunda, que se utilizó piedra de Novelda.

Del enjarje nacen ocho nervios, 4 perpiaños -2 pertenecientes a un arco apuntado de mayor luz y otros 2 a otro de menor-y cuatro ojivos iguales. Eso sí, con la particularidad de que los ángulos entre ojivos y perpiaños no forman $45^{\circ}$, sino $49^{\circ}$ y $51^{\circ}$, pues en el pilar confluyen cuatro bóvedas de planta rectangular.

La dimensión de las bóvedas era mayor que la del enjarje anterior, de 3 por 2,6 metros, lo que hacía imposible, por problemas de espacio, dibujar en el muro del taller la planta del entorchado con las elevaciones de los 
nervios. Sin embargo, al tratarse de nervios que salen de un pilar, nos dimos cuenta que era posible dibujar cada nervio independientemente de los otros apoyándonos siempre en la planta del entorchado. De él, además, partían nervios con tres curvaturas diferentes, por lo que debíamos dibujar la elevación de tres arcos: los ojivos y los que llamamos perpiaños cortos y perpiaños largos.

Dibujamos sobre un soporte de papel de 2 por 2 metros una recta horizontal que nos sirviese de referencia y que sería después de gran utilidad para trazar paralelas para cortes horizontales del enjarje. En ella dibujamos tres veces el contorno del pilar y, sobre su centro, una recta perpendicular a la horizontal que señalara el eje del entorchado.

Alineadas con la situación del arranque de los arcos en el pilar y en relación con el punto medio de la concavidad del entorchado situada en el eje horizontal, se dibujaron las molduras de los perfiles. En una de las plantas se dibujó la plantilla para los ojivos, en otra la de los perpiaños largos y en otra la de los perpiaños cortos, ambas iguales, pero a las que les corresponderían elevaciones de arcos diferentes.

Desde el intradós de los perfiles medimos en la horizontal el radio de cada uno de los nervios y, una vez localizados sus centros, trazamos las diferentes curvas de intradós y de extradós ayudados por una cuerda. También referencias a las molduras, que no fueron utilizadas posteriormente y de las que podríamos haber prescindido.

Mediante paralelas al eje horizontal fuimos definiendo la altura de las piezas del enjarje. La primera tendría 30 centímetros de alto, mientras el resto 15, hasta llegar a conformar 5 piezas más una pieza especial. Esta es consecuencia de que el último corte inclinado del enjarje no se encuentra en relación a la intersección del último plano horizontal y el extradós del nervio, tema comentado anteriormente en la clasificación de enjarjes y que se tratará con mayor profundidad en el texto referente a la Lonja de Palma. ${ }^{344}$

De esta montea pudimos obtener la información necesaria para el trazado de las piezas y determinar de manera muy rápida y sencilla los puntos en los que el intradós de los nervios en cada hilada se distanciaban del eje del

\footnotetext{
${ }^{344}$ Ver página 28 y página 328.
} 

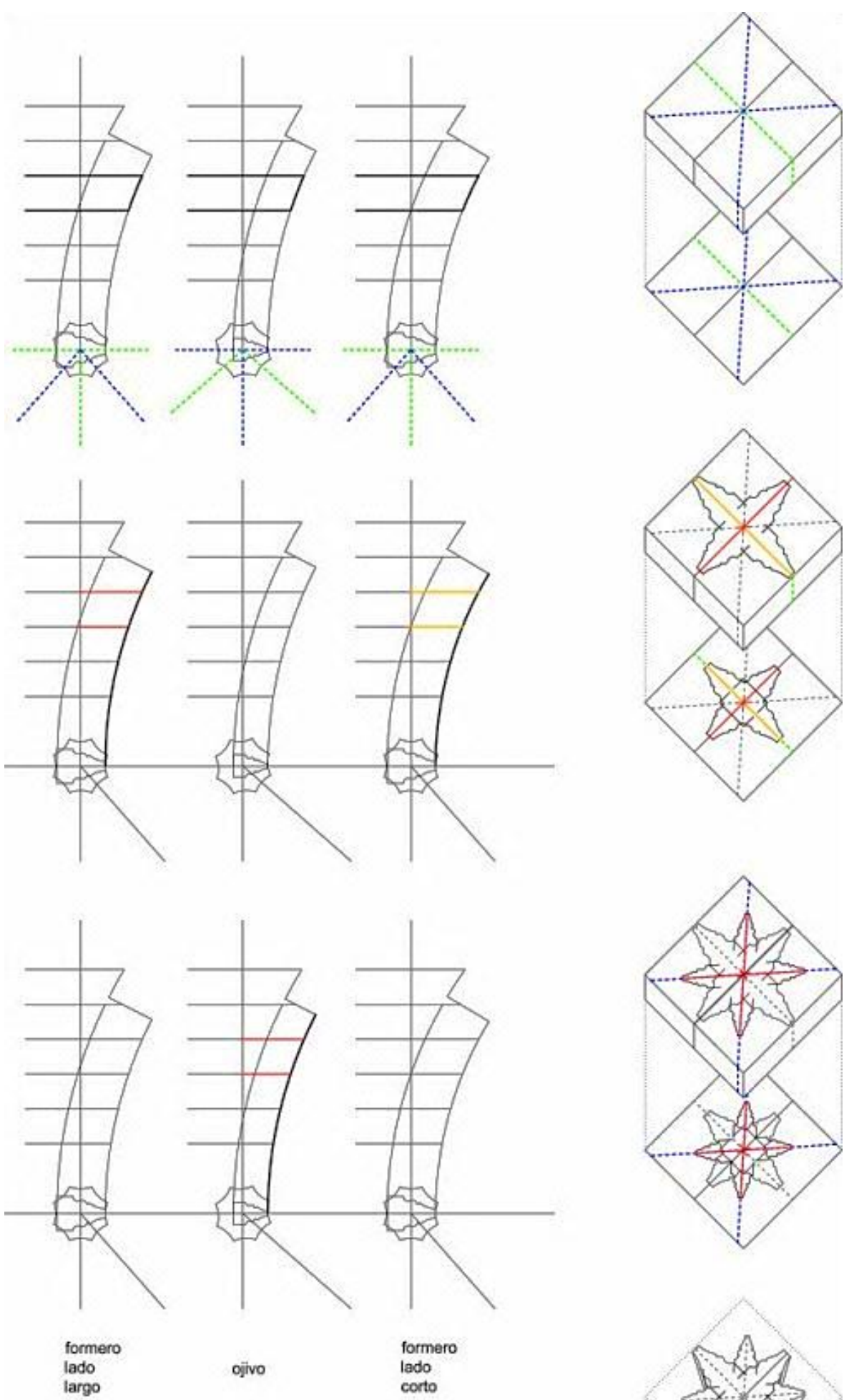

Fig. 161

Toma de referencia de la montea para el trazado de los contornos de los lechos de las piezas.

pilar, a diferencia del ejemplo anterior en el que no existía esa configuración centrada y siempre medíamos lo que se distanciaban los nervios del muro. 
La primera pieza del enjarje, cuya base viene determinada aún por el contorno del pilar entorchado y en la que comienzan a emerger los nervios de la bóveda, se trazó y talló sobre una pieza de 30 por 40 por 40 centímetros. La segunda pieza, sobre una piedra escuadrada de 40 por 40 por 15 centímetros. El resto de las hiladas por dos piezas 30 por 60 por 15 centímetros que se iban contrapeando según se iban colocando unas sobre otras.

Para marcar, por ejemplo, las dos piezas de la cuarta hilada situamos las dos piedras juntas de modo que en su unión se localizara uno de los ejes del perpiaño, en este caso el del lado largo. El corte entre una pieza y otra se sitúa en medio del intradós del perfil, pues realizarlos entre la unión de nervios es inviable. Sería extremadamente dificultoso resolver dicho encuentro. ${ }^{345}$

En sentido perpendicular a la junta, en la mitad de la misma, trazamos el eje del otro nervio perpiaño, el del lado corto. De esta manera, en su intersección queda determinado el centro del pilar entorchado, es decir, el eje vertical con el que controlaremos la posición de los nervios en cada uno de los cortes. A partir de este momento, siendo cuidadosos a la hora de controlar los ángulos que forman los ojivos con los perpiaños- pues son de $49^{\circ}$ y de $41^{\circ}$ - trazamos sus ejes, que también pasan por el eje. Como en el enjarje anterior, dibujamos las referencias de los ejes en los planos laterales verticales de la piedra y trazamos la misma planta en la cara inferior.

Una vez determinadas todas las direcciones de los nervios, emprendimos el trabajo de trazado de sus perfiles en los diversos lechos. En el caso de esta pieza, comenzamos trazando los perpiaños. Para ello, tomamos de la montea la distancia desde el eje del entorchado hasta el intradós del nervio en el corte -una diferente para cada perpiaño- y la trasladamos a la piedra a partir del eje. A continuación, realizamos el mismo ejercicio con los ojivos.

Al enfrentarnos a este segundo enjarje intentamos, en un principio, reproducir el método anteriormente utilizado para trazar el contorno de las plantillas, es decir, alargar las plantillas tomando las medidas de la montea. Pero su perfil es bastante más complejo, con baquetones y concavidades. Los alumnos debían deformar mediante tanteos las curvas del perfil, lo que hacía imposible que dos plantillas que debieran tener la misma deformación fueran iguales, pues cada alumno trazaría el contorno a su parecer.

\footnotetext{
${ }^{345}$ Se ha comprobado durante el estudio del ejemplo de Palma, que se recurre a esta solución, como explicaremos más adelante. Sobre la Lonja de Palma, a partir de la página 291.
} 


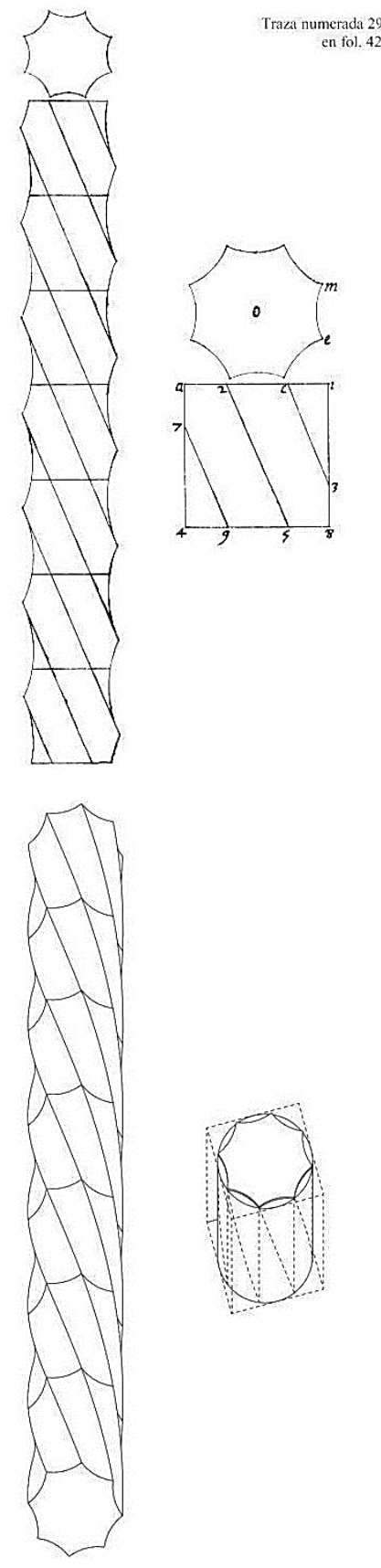

Fig. 162

Arriba: entorchado en el tratado de Gelabert (1653, Traza numerada 29, fol. 41v.). Abajo: análisis del dibujo por Rabasa (2011, 105).
Esto acarrearía incongruencias entre las piezas una vez montadas, pues la moldura de la parte superior de una pieza no encajaría perfectamente con la de la parte inferior de la siguiente. Ya lo habíamos comprobado con el enjarje anterior, por lo que César Cabeza nos sugirió la elaboración de plantillas. También tras, la experiencia de la construcción de baiveles para el enjarje anterior, produjimos baiveles fijos para algunas de las piezas

A partir del modelo de CAD- aunque también lo podríamos haber realizado a partir de la montea- obtuvimos las plantillas correspondientes a cada uno de los lechos horizontales y las llevamos a un soporte metálico para luego recortarlas. En el taller hemos trabajado con plantillas también de cartón o cartulina, siendo las metálicas las que mejor resultado han dado debido a que no se deforman o rompen. Los baiveles los elaboramos de cartónpluma, material que no ha dado demasiado buen resultado debido a su fácil rotura, pero que proporcionaba la suficiente rigidez para las comprobaciones.

Se produjo una media plantilla de nervio diferente para cada lecho. El hecho de realizar solo la mitad tenía ventajas, pues era más fácil de situar y trazar en relación al eje de simetría, evitando que se produjeran errores debido a su movimiento durante el trazado. De este modo, se delinearon las plantillas situándolas en relación a su intradós, que ya habíamos determinado. Y como en el caso anterior, se repasaron los contornos de la unión de los perfiles de los diferentes nervios determinando el perfil final de la pieza de enjarje en su plano superior e inferior con un marcador de punta seca y con hierba.

La talla de la primera de las piezas nos planteó muchas dudas. En la parte inferior estaba presente solamente el perfil del pilar entorchado, mientras que en la superior ya aparecían todos los nervios, pues su nacimiento se tendría que localizar en las concavidades del pilar.

El resto de piezas de tambor del entorchado habían sido resueltas en el taller por Enrique Rabasa basándose en el manuscrito de Joseph Gelabert, quien muestra como trazar las aristas del pilar entorchado para un bloque cuya altura es igual al diámetro en el que se inscribe la planta. Después de la explicación, sin embargo, dice Gelabert que en la práctica sería necesario solamente dibujar la planta, tallar un cilindro vertical en el que quedase inscrita y, como la plantilla tiene 8 aristas y la hace girar un octavo, trazar la unión en el cilindro de cada arista superior con su consecutiva en 

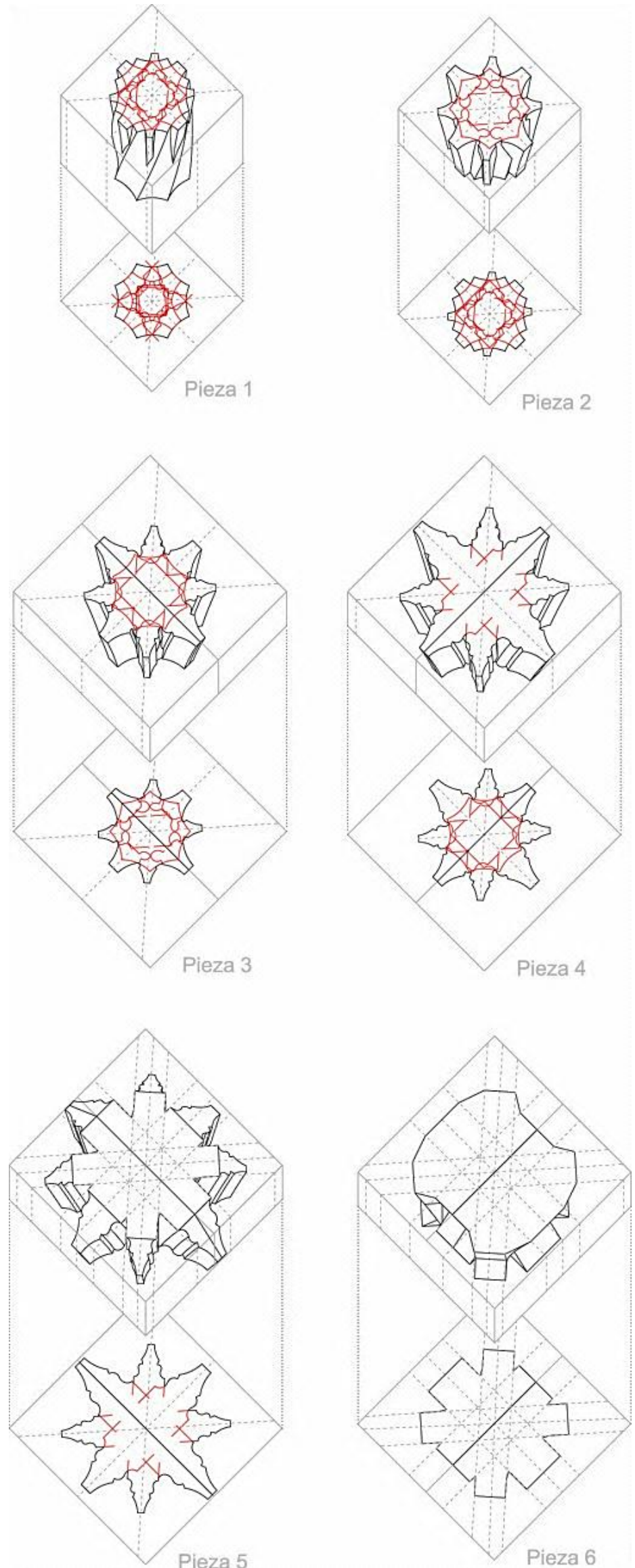

Fig. 163

Situación de las plantillas y ejes de los nervios en cada una de las piezas.

el lecho inferior. ${ }^{346}$ Rabasa apunta a que aunque Gelabert no lo señala, sería necesario utilizar una banda plana que se adaptase al cilindro para trazar 
las aristas. ${ }^{347}$

Con este conocimiento nos enfrentamos a la resolución de la primera pieza, con la dificultad de no poder tallar un cilindro completo, pues el trazado de las plantillas de los nervios en el lecho superior superaba la circunferencia circunscrita de la plantilla del entorchado. Enrique Rabasa propuso la talla de dos cilindros, uno que contuviese la plantilla del pilar en la parte inferior y que llegase hasta mitad de altura; y otro cuyo diámetro fuese tangente a las aristas de intradós de los nervios de la cara superior hasta llegar, desde arriba, a la mitad de la pieza, pues más o menos allí se localizaría su nacimiento.

Primero se talló el cilindro de mayor diámetro, inscrito en un octógono. Tras realizar la labra de cada una de las caras del prisma, se ejecutó la curvatura del cilindro de manera controlada. A continuación, se procedió a la talla del cilindro pequeño. Para ello se podría volver a inscribir la circunferencia en un polígono y acometer de nuevo la labra del elemento prismático que llegase hasta mitad de la pieza; y luego solucionar las partes curvas.

En ese momento se replanteó la situación de los nervios mediante rectas perpendiculares al lecho superior desde las aristas de la plantilla que recorrían verticalmente el cilindro grande. En los espacios que quedaban en el cilindro entre los nervios se terminó de resolver el cilindro pequeño de manera que se pudieran coordinar los perfiles superior e inferior del pilar. Una vez finalizado el plano, se trazó con un folio que se adaptaba a él la arista del entorchado uniendo, como explicamos anteriormente, la arista de la cara inferior con la consecutiva en la superior.

De esta manera se comenzó a tallar la concavidad del entorchado en la primera mitad de la pieza para, a continuación, solucionar la otra mitad superior. En este segundo estadio había que tallar la intersección de las concavidades del pilar y los arranques de los nervios. El intradós de los nervios se podía ir controlando con los baiveles fijos para ese lecho que habíamos confeccionado en cartón pluma a partir de la montea. Y la concavidad del entorchado con una contraplantilla que se ajustaba a ambos lados a las aristas y que tenía la curvatura de la concavidad.

La segunda pieza también presentaba múltiples encuentros entre el pilar entorchado y los nervios, pero con la ventaja de que los intradoses de todos los nervios estaban presentes tanto en el lecho inferior como en el inferior. Eso facilitó el comienzo del trabajo, pues permitió solucionar dichos planos y permitió comenzar a controlar el tamaño y forma de la pieza. A partir de ahí, se comenzaron a tallar cada una de los senos entre los nervios en los

\footnotetext{
${ }^{346}$ Gelabert, Verdaderes traçes de l'Art de Picapedrer, traza numerada 29, fol. 41v.

${ }^{347}$ Rabasa Díaz, El manuscrito de cantería de Joseph Gelabert, 104-105.
} 
que había que solucionar el encuentro con la moldura del pilar entorchado, que moría ahí, no estando presente en el lecho superior de la pieza.

Para calcular dichos encuentros fuimos trabajando mediante visuales relacionando la arista del perfil del entorchado en el lecho superior en inferior a la vez que íbamos tallando los perfiles de los nervios, que podían ser tallados sin problemas porque teníamos su perfil perfectamente definido en ambos planos.

La talla de las piezas 3 y 4 no presentó dificultades debido a que las intersecciones entre nervios que aparecían eran las comunes de cualquier enjarje. Simplemente había que realizar la transición entre los contornos superiores e inferiores de cada uno de los nervios.

La quinta pieza, la que presentaba los planos inclinados se talló del mismo modo que hemos descrito en el caso del primer enjarje. Se realizó un prima rectangular que contuviese los nervios y en el que trazar el ángulo de inclinación de los planos superiores y, cuando estuvo acabado, se trazó en

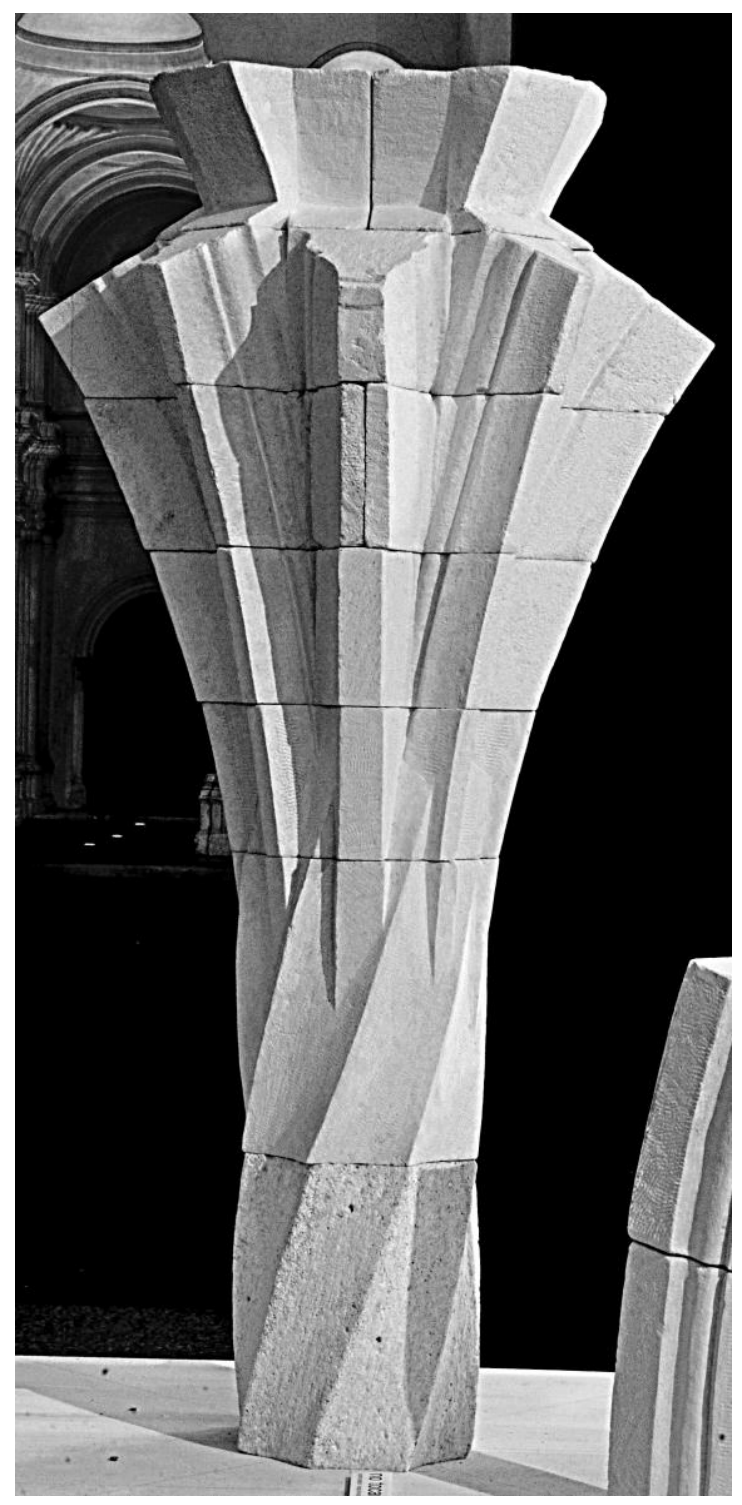

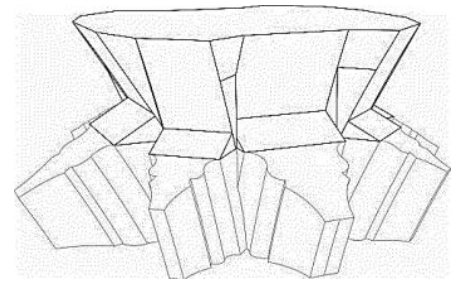

Fig. 164

Última pieza con los cortes inclinados en los perfiles de los nervios para el apoyo de las dovelas y pieza especial con el "tacón de Mallorca" sobre ella.
Fig. 165

Resultado final del enjarje. 
él el perfil del nervio en su corte radial. Hay que tener en cuenta que en el caso de este enjarje, el corte horizontal que define el lecho superior de esta pieza no está coordinado con el extradós el nervio, sino que queda por debajo. Esto hace que no se pueda trazar en ese plano inclinado el perfil completo del nervio y provoca la aparición de la siguiente pieza para asegurar que la primera dovela pueda apoyar completamente su testa.

La sexta pieza, por tanto, es una pieza especial que permite completar, como decíamos, el perfil del nervio. Para su trazado dibujamos en ambos lechos las direcciones de los nervios y su ancho. De la montea tomamos las distancias en el plano inferior en la que quedaban cortados los planos inclinados de cada uno de los nervios y las trasladamos al lecho. En el plano superior, las distancias de cada uno de los extradoses.

La talla de esta pieza fue muy delicada, pues la piedra era muy dura y las partes que debían resultar con un ángulo agudo eran muy frágiles y se rompieron en más de una ocasión. El control geométrico tampoco fue sencillo, pues para ejecutar el hueco para el extradós de los nervios perpiaños cortos había que profundizar en el sólido. Para la talla de los planos en los que tendrían que encajar posteriormente las dovelas fue fundamental el uso de contraplantillas con su perfil, que pudimos elaborar a partir de la montea. La ejecución en primer lugar de dichas referencias facilitó la resolución del encuentro entre los nervios.

\subsubsection{Enjarje de la capilla del Condestable}

Con este enjarje quisimos experimentar con una bóveda de gran luz en la que los nervios parten de un ángulo- pues salen del rincón de una planta ochavada -y, tras arrancar separados, se cruzan en un punto que aún es parte del enjarje. ${ }^{348}$

Además, habíamos tenido la posibilidad de realizar un levantamiento topográfico, analizarlo y realizar un modelo del original. Al disponer de las piedras suficientes en el taller, una arenisca relativamente blanda, decidimos llevarlo a cabo a escala 1:2 con el mismo sistema de juntas que el real, la misma geometría, pero con perfiles simplificados realizados a partir de los existentes. En este caso el enjarje no tendría una altura de 4

${ }^{348}$ Ver página 35. 

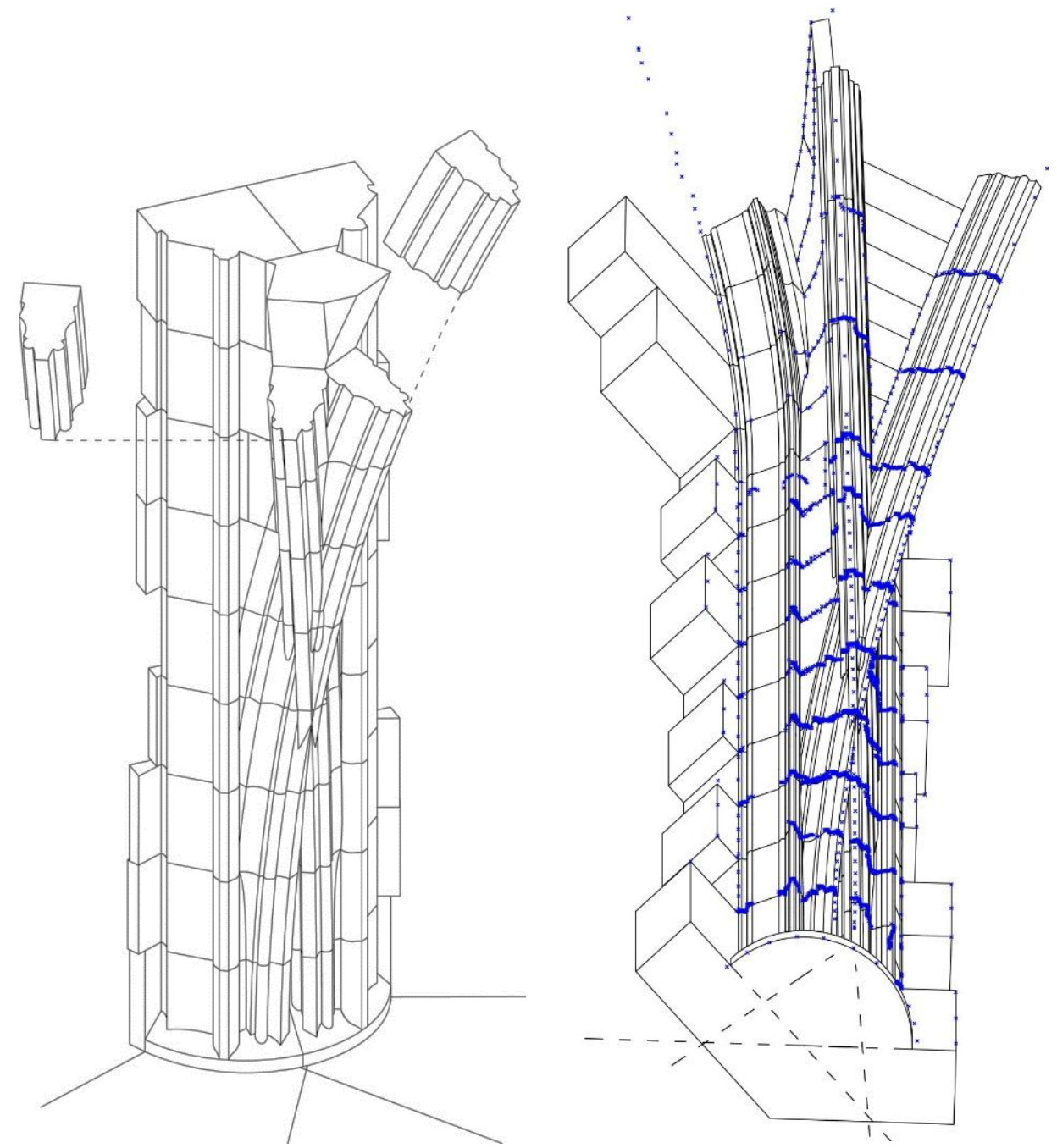

Fig. 166

Modelo del enjarje de la capilla del Condestable para su talla en el taller de la ETSAM tras la reducción a la mitad del original, que había sido medido y analizado (a la derecha). metros, sino de 2, y estaría compuesto de 8 hiladas más una, una pieza especial. $^{349}$

Los dos nervios que salen en el enjarje y que se cruzan de manera simétrica con respecto a un eje tienen la misma curvatura, por lo que era necesario solamente definir la elevación de uno de ellos. El problema venía dado por el radio del arco, de 4,75 metros, imposible de trazar en el muro del taller. Para ello, dispusimos un soporte de papel de 3 por 1 metros en un suelo con un despiece que nos sirviese para alinear el dibujo y poder situar fuera del papel el centro del arco de la manera más precisa posible.

En primer lugar, dibujamos la planta del enjarje. Trazamos el eje de uno de los nervios en la horizontal, para que su elevación pudiese ser contenida en el desarrollo vertical del papel y, controlando el ángulo que forman los dos nervios, trazamos el eje en planta del otro. A partir de la intersección de sus ejes, medimos la distancia hasta el intradós de su moldura en el arranque y dibujamos los perfiles en planta. También la situación del muro quebrado 
Fig. 167

Trazado de la montea por los alumnos del taller. en rincón, que nos sirvió para localizar la posición en la planta de los nervios formeros, que en todo el desarrollo del enjarje son simples molduras verticales. Desde el rincón del muro se puede trazar una circunferencia que para por el intradós de los formeros y define la base del enjarje, pues en la

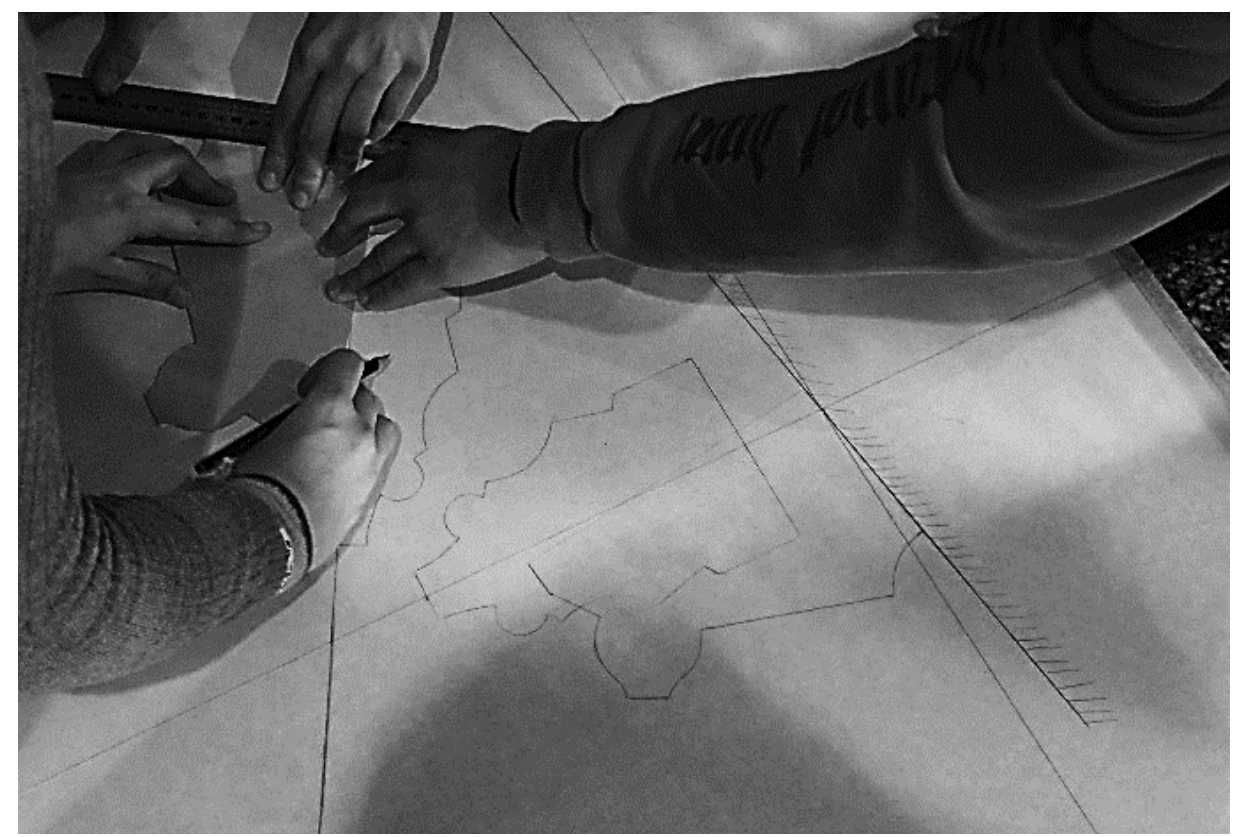

primera pieza los nervios arrancan de un elemento cónico cuya base está delimitada por dicha curva.

Una vez que la planta estuvo trazada, continuamos la montea realizando la elevación del nervio que habíamos dejado preparado. Para localizar el centro del intradós del arco situamos el eje del nervio en relación a una línea del pavimento del suelo y medimos el radio. Haciendo uso de una cuerda trazamos la curva, tanto de intradós como de extradós.

Mediante el dibujo de líneas paralelas al eje del nervio -la primera a 25 centímetros y el resto a 22 centímetros- definimos en elevación las 8 piezas que conforman el enjarje y la pieza especial que lo corona. En la octava pieza trazamos en relación a la intersección del corte horizontal y el extradós del nervio el plano inclinado radial en el que se apoya la primera dovela.

Para ejecutar el enjarje dispusimos de piedras de 30 por 25 por 25 centímetros. En primer lugar los alumnos tuvieron que reducir en todas, excepto en las que usaríamos para la primera hilada, la altura de las piedras de 25 a 22 centímetros. 

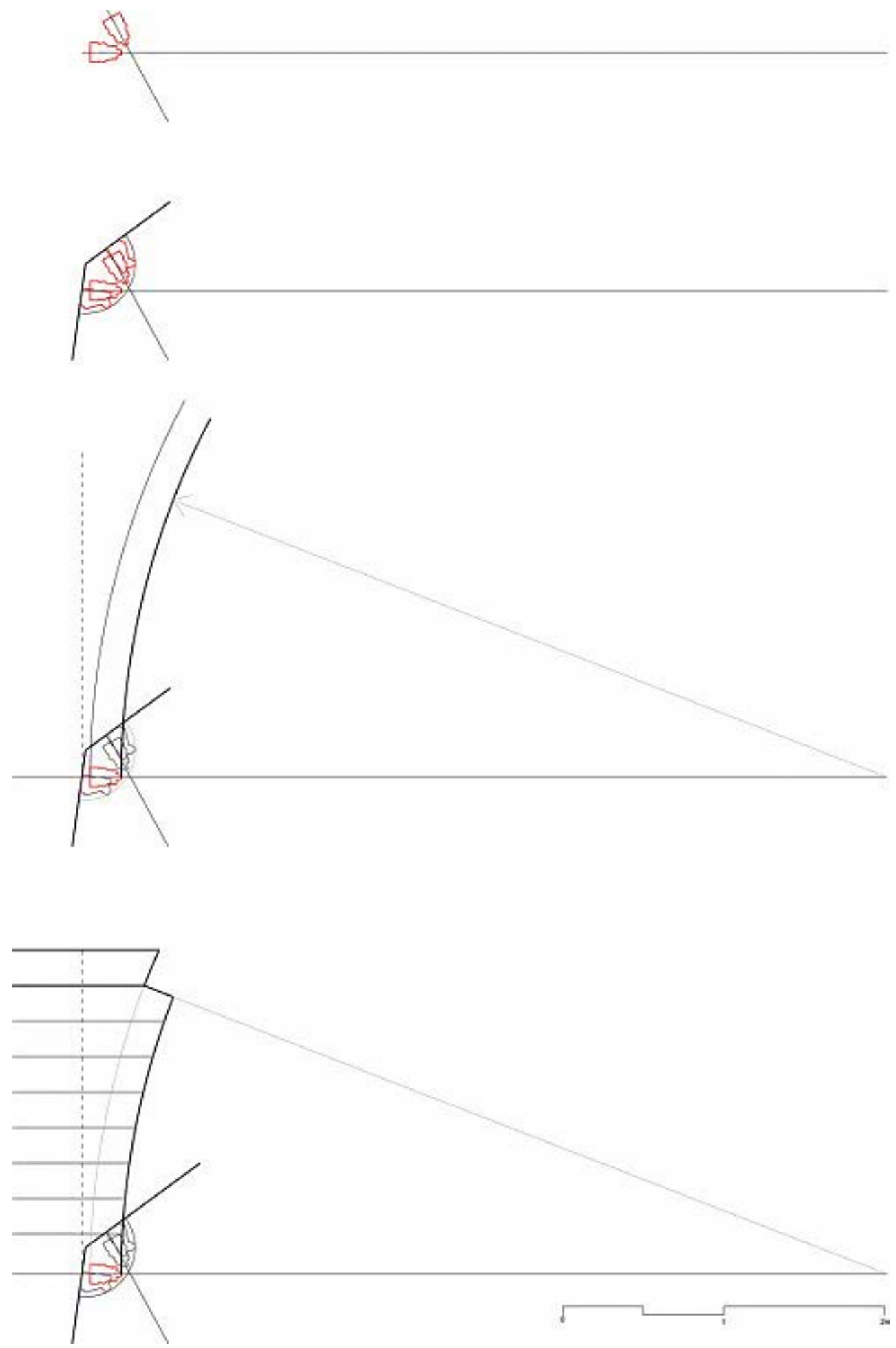

Fig. 168

Pasos para trazar la montea.

Las dos primeras hiladas, en las que los nervios aún se encuentran separados, se realizaron en dos piezas diferenciadas respectivamente. Para el trazado de muchas de las piezas, y debido a que disponíamos de piedras relativamente pequeñas, les dimos a los alumnos instrucciones acotadas de la situación de los ejes del muro y de los nervios en relación con las piedras que disponían para que las dibujasen correctamente. No era posible trasladar todo el dibujo de la planta tal y como habíamos hecho con los enjarjes anteriores por motivos de espacio. 
Fig. 170

Izquierda:

proporcionadas a los alumnos para el trazado en las piedras debido a la reducida dimensión de las piedras que disponíamos.

Fig. 169

Derecha: imagen tomada por Enrique Rabasa del arranque de los nervios de la capilla del Condestable tomada durante las obras de restauración.
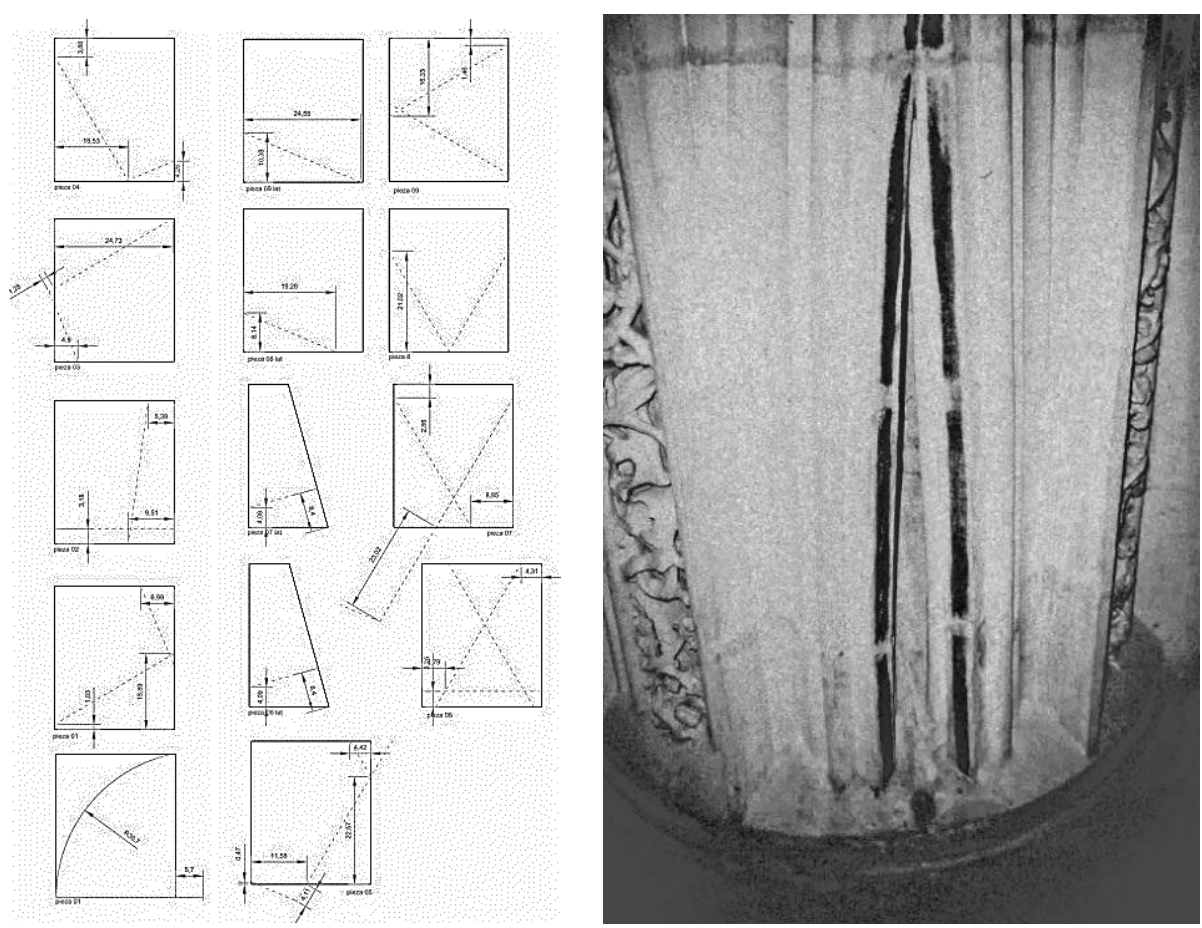

Enrique Rabasa tuvo la oportunidad hace unos años de visitar las obras de restauración de la capilla y tomó algunas fotografías. Nos facilitó una en la que se puede ver cómo los nervios arrancan de un elemento cónico, por lo que decidimos reproducirlo también en el taller. Por tanto, además del trazado de los nervios en el plano superior e inferior, trazamos en el lateral de la piedra el perfil del cono y, en el lecho inferior, su base. Durante el proceso de talla, el encuentro entre unos y otros no presentó demasiadas dificultades a pesar de no tener los perfiles de los nervios en el plano inferior para coordinarlos con el plano superior.

Al tratarse del comienzo del arco que sale con tangente vertical en la parte inferior y al trabajar con una curvatura tan grande, casi podíamos asemejar la curvatura del arco perpiaño a una recta vertical, lo que facilitaba el control del encuentro con el cono. Podíamos tallar desde arriba las molduras de los nervios en vertical y desde la base, una vez que estuvo tallado el pequeño cilindro de la base del cono, la inclinación del cono, ayudándonos de una contraplantilla con dicho ángulo o la propia saltarregla. Avanzando desde ambos lados se llegaba a solucionar el encuentro.

La segunda hilada también se realizó mediante dos piezas simétricas. En este caso, su ejecución no presentó problemas debido a que teníamos en ambos lechos el perfil de los nervios y simplemente había que coordinarlos.

Las piezas 3, 4 y 5 se resolvieron pegando dos piedras de las anteriores, por lo que disponíamos de un bloque de 30 por 50 por 25 centímetros. Esto hizo posible que en estos casos los alumnos sí pudiesen trazar sobre 

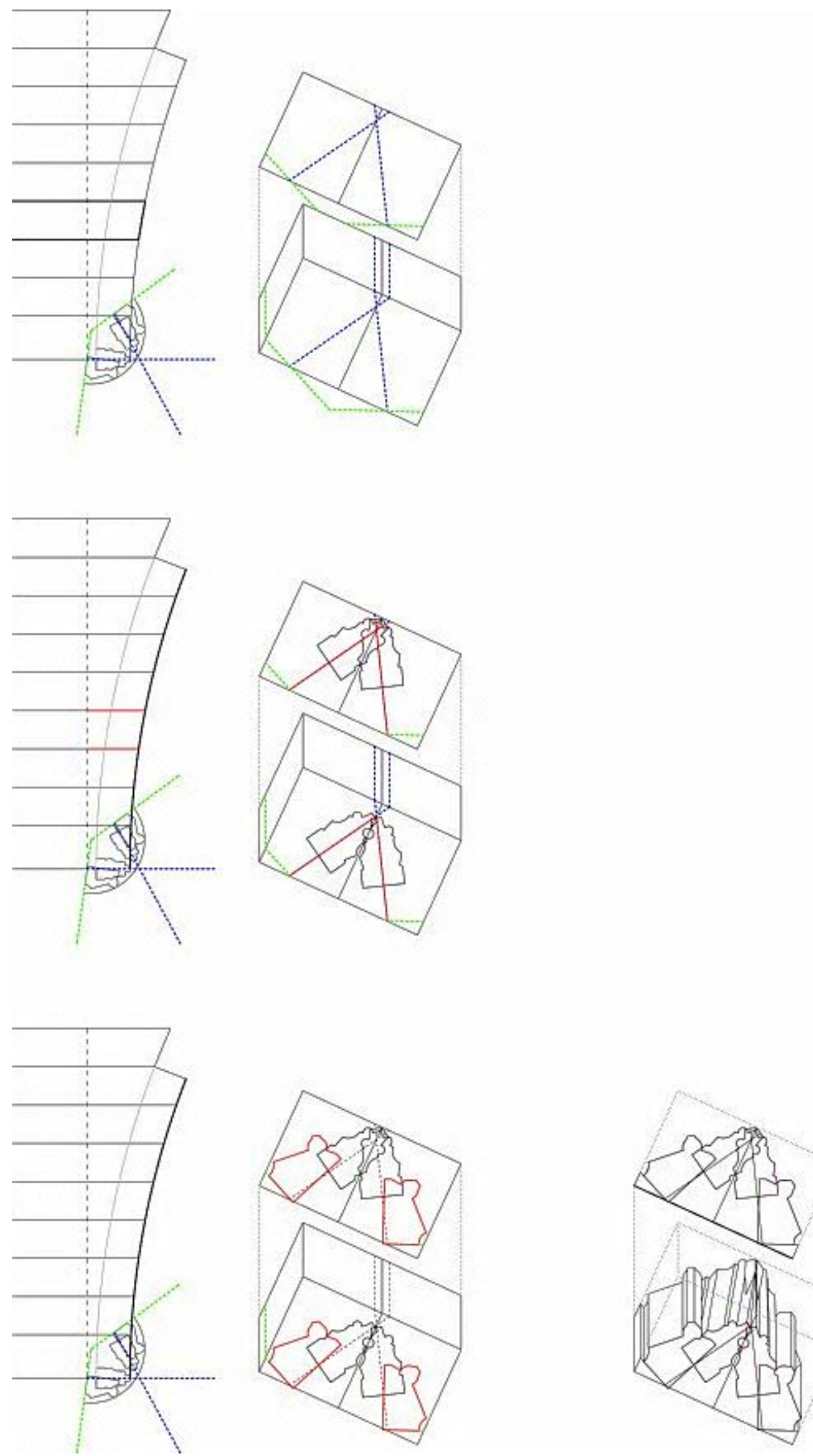

Fig. 171

Proceso de trazado de las platillas y los ejes de los nervios en las piezas tomando los datos de la montea.

los lechos los ejes de los nervios en planta a partir de la montea. Además, la junta de unión de las piezas facilitaba el trabajo, pues hacía las veces de eje. Una vez trazados las líneas de los nervios en la parte superior de la 

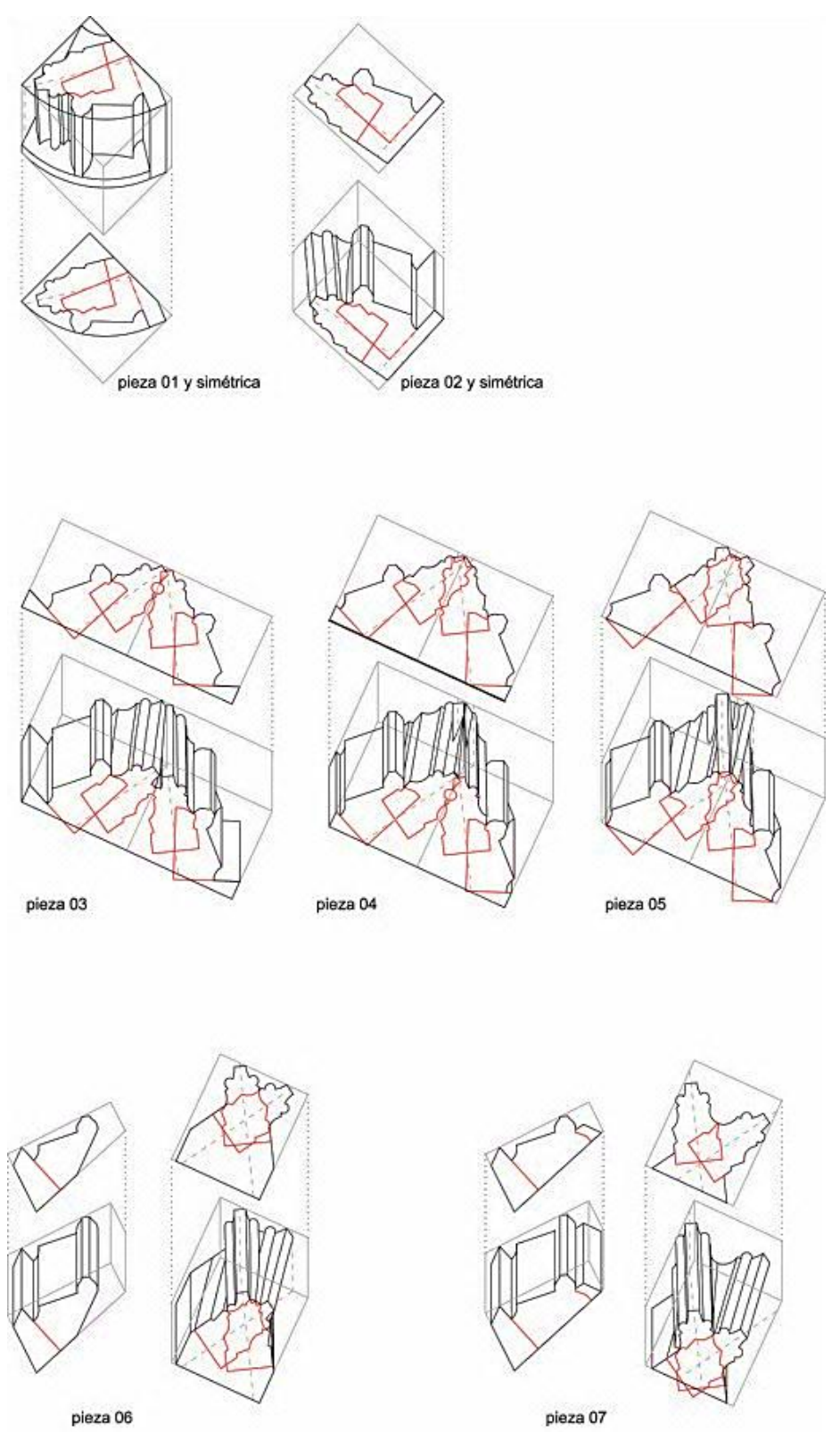

Fig. 172

Descripción de cada una de las piezas del enjarje con la situación de las plantillas en los lechos.
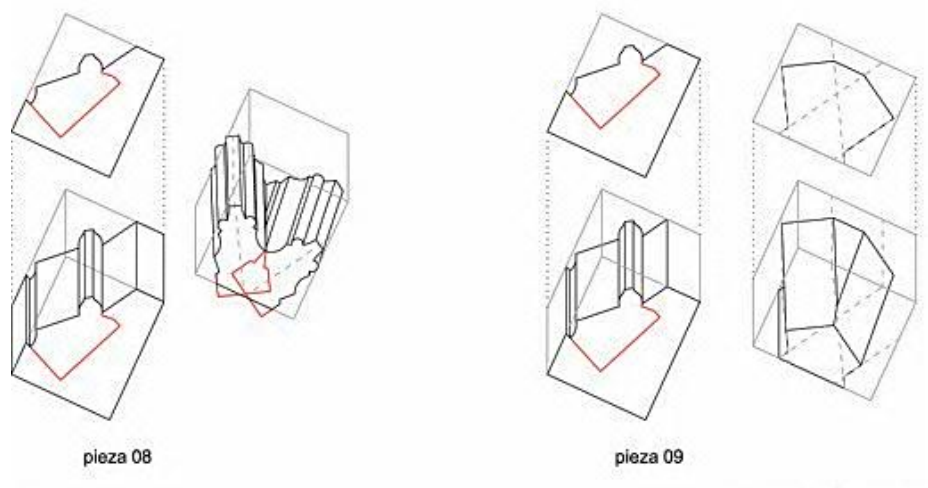

piedra se llevaron las referencias por los bordes laterales para facilitar el trazado de la cara inferior. También se dibujaron las referencias al muro porque eran necesarias para la localización de la plantilla de los formeros. 

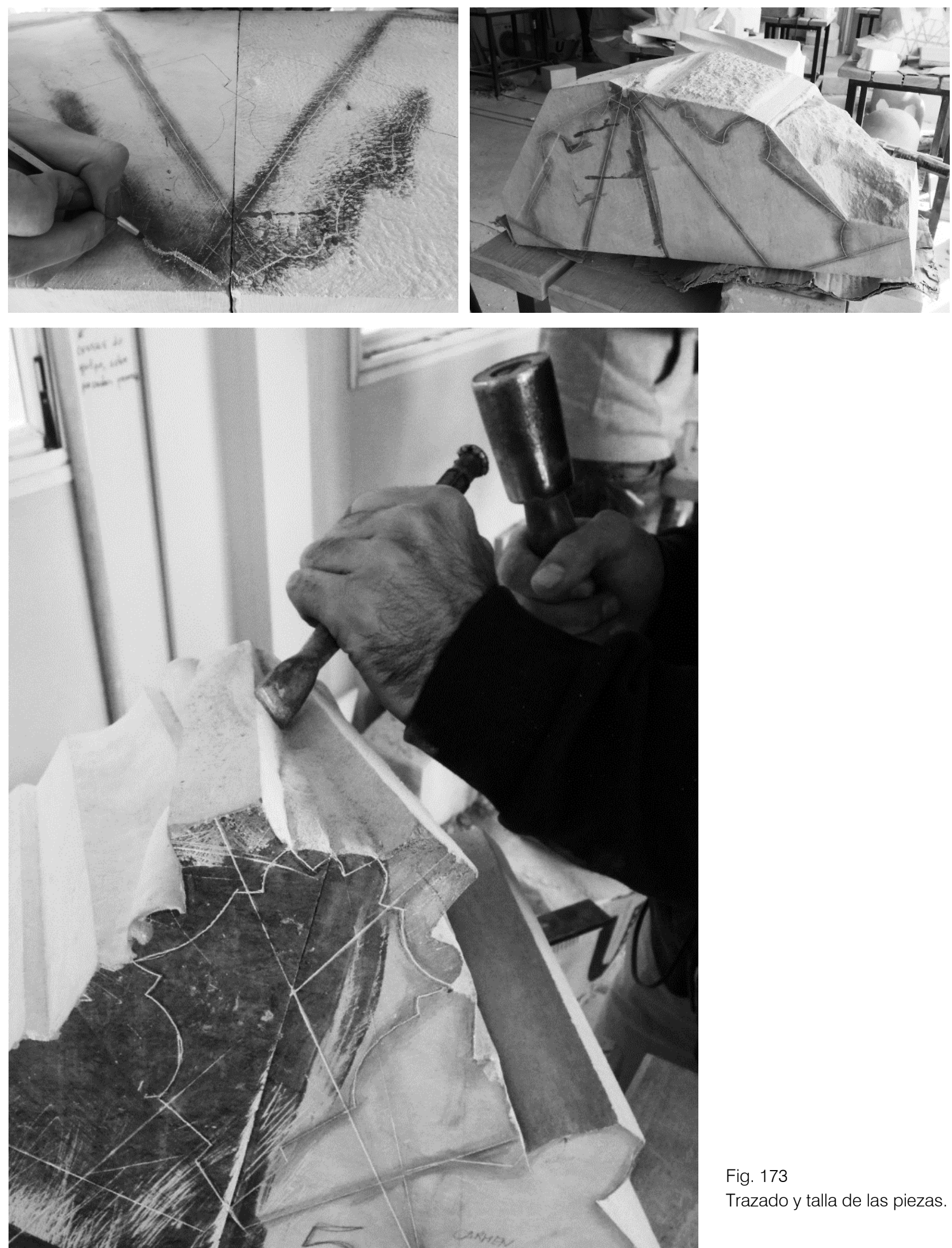

Fig. 173

Trazado y talla de las piezas.

A continuación, se trazaron los contornos de las plantillas en los lechos. En este ejercicio hemos probado a utilizar siempre la misma plantilla sin deformar para trazar los contornos de los nervios en todos los cortes excepto en el último, pues en él la elongación del perfil era más 
Fig. 174

Resultado final del enjarje del Condestable.

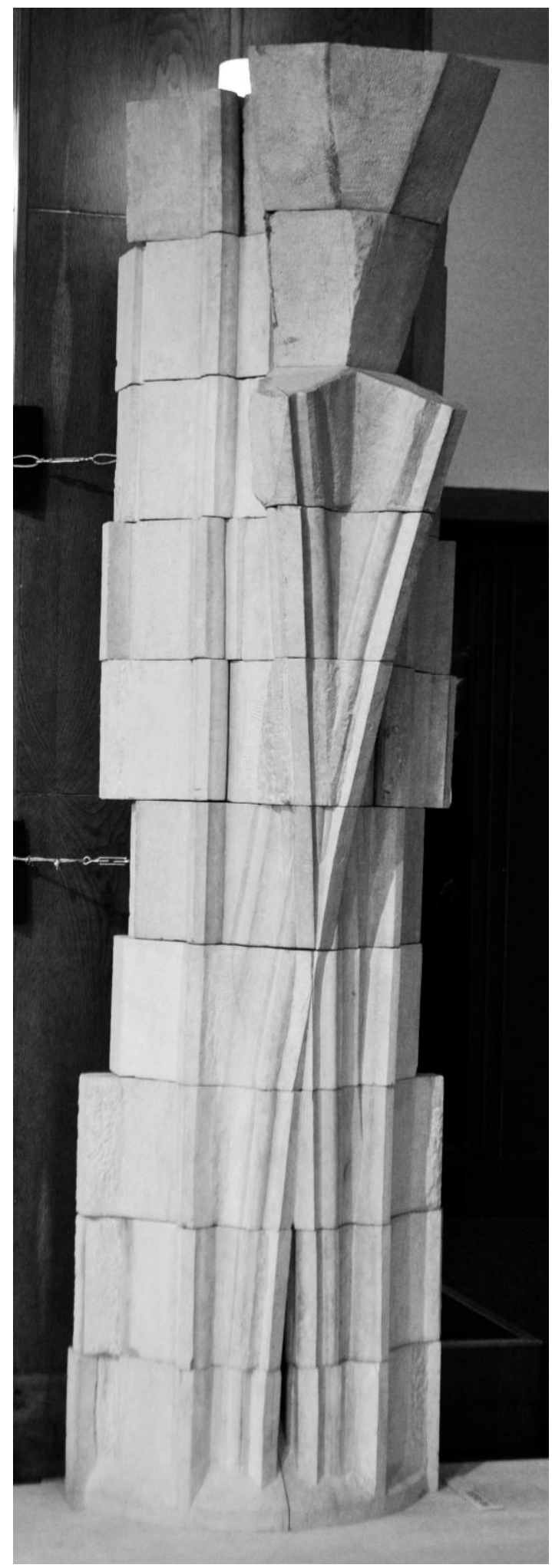

pronunciada y se hubiera percibido el error una vez tallado y montado el enjarje.

Por lo tanto, para esta cuarta pieza, medimos en la montea la situación del intradós del arco en el lecho inferior y superior con respecto al muro y trasladamos la distancia a la piedra. Y, para trazar el contorno de los perfiles utilizamos la plantilla original. A continuación, y en relación con la línea del muro, trazamos los perfiles de los formeros, cuya situación no varía en todo el enjarje. Una vez trazadas todas las molduras, se realizó el repaso con el 
marcador de punta seca y la hierba de los contornos finales superiores e inferiores.

La talla de la tercera pieza no presentó ninguna dificultad especial, mientras que en la cuarta y en la quinta había que resolver el cruce de los nervios y el encuentro entre molduras que mueren en otras. Para solucionar las aristas de cruce de los nervios en el centro de la cuarta pieza tallamos un plano auxiliar definido por las dos aristas de los intradoses de los terceletes que aparecían en el lecho inferior y las dos que aparecían en el superior. Una vez que estuvo resuelto, trazamos en ese plano rectas que unían las aristas superior e inferior de cada nervio definiendo así el cruce. La resolución de los encuentros de los intradoses en la parte inferior de la pieza fue sencilla, mientras que en la parte superior llevó más trabajo. Allí el intradós de cada nervio moría en la primera concavidad del perfil de otro. Para solucionar esta intersección hicimos uso de una saltarregla para controlar el ángulo del nervio en relación al plano horizontal superior hasta alcanzar la moldura cóncava, que resolvimos usado como referencias el baquetón del nervio y las rectas del cruce que habíamos trazado anteriormente.

En la sexta pieza también tuvimos que solucionar encuentros entre molduras. No sabemos si se debió a que fue ejecutada por un alumno especialmente diestro, Álvaro, o si el hecho de que en este caso ya se podían coordinar directamente los intradoses de ambos nervios facilitaba los trabajos, pero la realidad es que su talla presentó menos dudas. Ana López, además, hizo uso durante el replanteo de lápices de colores para repasar los contornos de los nervios y así, coloreando un tercelete de rojo y otro de azul, logró aclarar a los alumnos la correspondencia de las molduras de un nervio y otro en cada lecho tras el cruce. Muchas veces se nos presentaban dudas a este respecto.

Las piezas número 7 y 8 , a diferencia de las anteriores, se resolvieron mediante una pieza central que contuviese a los nervios y dos pequeñas piezas laterales a los lados en las que se tallaron los formeros. Su talla tampoco presentó complicaciones especiales.

La novena y la décima -o pieza especial- se solucionaron también con una pieza central, pero en este caso con dos piezas de mayor dimensión en la parte trasera. Todas las piezas laterales fueron muy sencillas de realizar debido a que en ellas sólo aparece el perfil del formero y durante todo el desarrollo del enjarje se mantiene vertical, puesto que el nervio toma curvatura tras él para da cabida a las ventanas que iluminan la capilla.

La pieza especial es singular, pues como en el caso de Palma, hay que tallarla para asegurar el apoyo de trasdós de la primara dovela. Su parte frontal se ve entre los nervios, haciéndonos pensar que es parte de la 
plementería. Para trazarla en la piedra también se miden desde el eje del muro las distancias al extradós del arco.

Nos hubiera gustado haber realizado todas las piezas en piedras suficientemente grandes para no tener que realizar despieces diferentes al original, pero también hubiera planteado el problema del peso y manipulación por parte de los alumnos.

\subsubsection{Enjarje bajo la escalera de la Sala dei Baroni}

Este ha sido, sin lugar a dudas, el ejercicio más complejo de los que hemos llevado a cabo. Se trata de un enjarje situado en una bóveda cuatripartita formada por arcos carpaneles bajo la escalera que da acceso a la Sala dei Baroni del Castelnuovo en Nápoles. Haciendo esquina con esa bóveda se sitúa un pasaje con una bóveda de cañón en cuya embocadura hay también un potente arco carpanel.

El nudo que estudiamos se localiza en la esquina entre ambas bóvedas, donde se produce la intersección entre las molduras de ese gran arco carpanel y el perpiaño y ojivo de la bóveda de crucería. El resultado del encuentro es un ejercicio de gran calidad y complejidad que hemos tenido la oportunidad de medir y analizar. ${ }^{350}$

Fig. 175

Modelo para realizar en el taller de la ETSAM a mitad de escala del original medido y analizado.
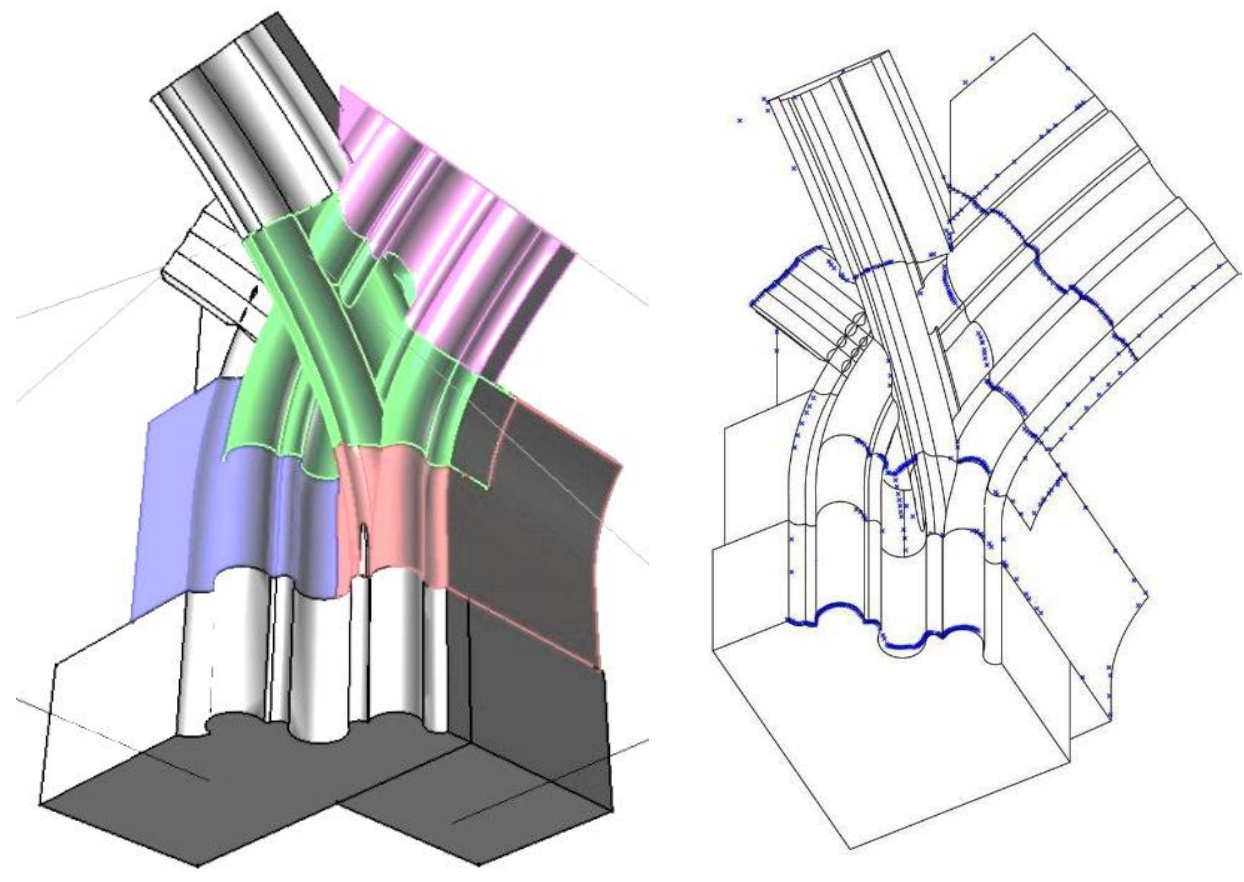
Una vez estudiada su geometría y su despiece planteamos realizar dicho enjarje en el taller a mitad de escala y con el mismo sistema de juntas que el original. Variamos la moldura de los nervios, puesto que era necesario simplificarlos para hacer factible su talla y elegimos una arenisca calcárea blanda, llamada piedra de Novelda, para su ejecución.

El tamaño de la montea del enjarje era mucho menor que la del resto, pues la bóveda es pequeña y los radios de los arcos que conforman el enjarje rondan el metro. Para la realización utilizamos un soporte de papel de 2 por 1 metro, que colocamos en el muro del taller tras realizar el trazado en el suelo, pues era más cómodo para controlar la ejecución con precisión de las curvas y localizar los centros de la segunda curvatura de los arcos.

En primer lugar dibujamos la planta de la esquina, trazando la gran moldura del arco de embocadura. También trazamos los ejes del ojivo y el perpiaño de la bóveda de crucería y continuamos la dirección de su muro que se corresponde con el espesor del arco de embocadura de la bóveda de cañón. Sobre esas referencias dibujamos el contorno de las molduras del ojivo y el perpiaño. El intradós del perpiaño se localiza en la intersección de su eje con la moldura de arco de embocadura, mientras que la posición del intradós del ojivo viene determinada por la geometría general de la bóveda de crucería. En el resto de rincones los intradoses de los nervios parecen confluir.

Llevando la distancia del radio de los arcos sobre sus ejes en planta, situamos los centros sobre los que trazar las curvas de intradós y de extradós ayudados por una cuerda. Este momento fue decisivo, pues debido a que los arcos son carpaneles -es decir, compuestos por dos arcos de diferente radio-, tuvimos que localizar también los centros de los radios de mayor curvatura que no se encuentran en esos ejes. Aunque en bóvedas rebajadas, donde la utilización de este tipo de arcos es normal y el enjarje suele estar resuelto con el de menor curvatura y su final se corresponde con el cambio de arco, ${ }^{351}$ en este caso de Nápoles no ocurre así. El intradós de los nervios en las últimas piezas del enjarje está resuelto con la curvatura del arco mayor, produciéndose incluso dentro de la misma pieza la tangencia entre ambas curvas.

Es despiece del enjarje también presenta peculiaridades, pues la primera hilada está solucionada por dos piezas que dejan en su encuentro un hueco para poder situar la siguiente hilada compuesta por una pieza de gran tamaño que contiene el encuentro de molduras. A continuación, en el lado de la bóveda de crucería hay una pieza con la salida del ojivo y en el
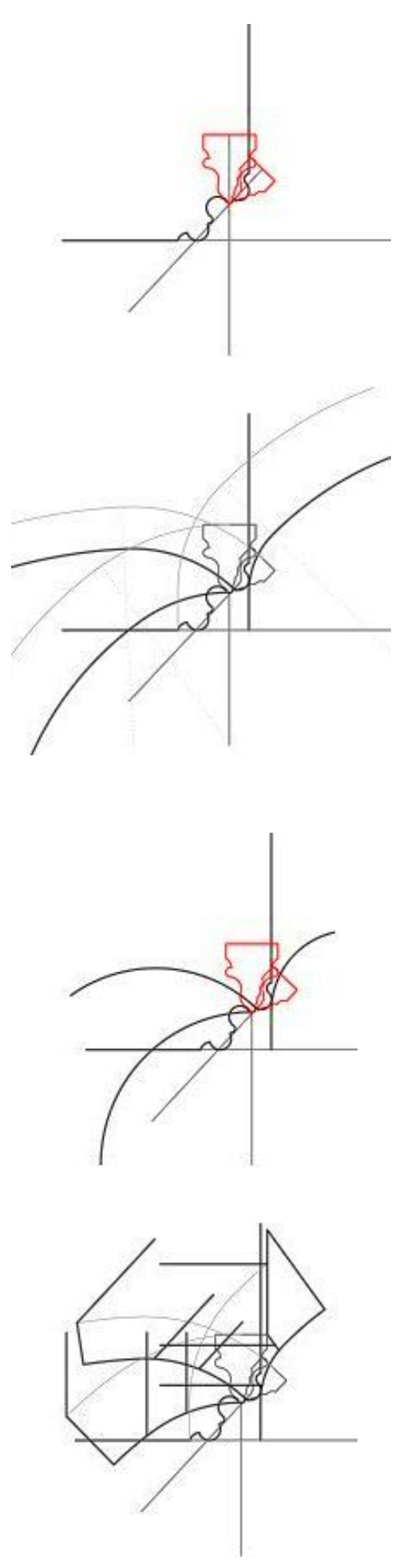

Fig. 176

Pasos a seguir para trazar la montea.

\footnotetext{
351 Rafael Martín Talaverano, "Bóvedas de crucería rebajadas hispanas: geometría, estructura y construcción”, (tesis doctoral, 2014), entre otras: 273, 535-536, 586-587.
} 